
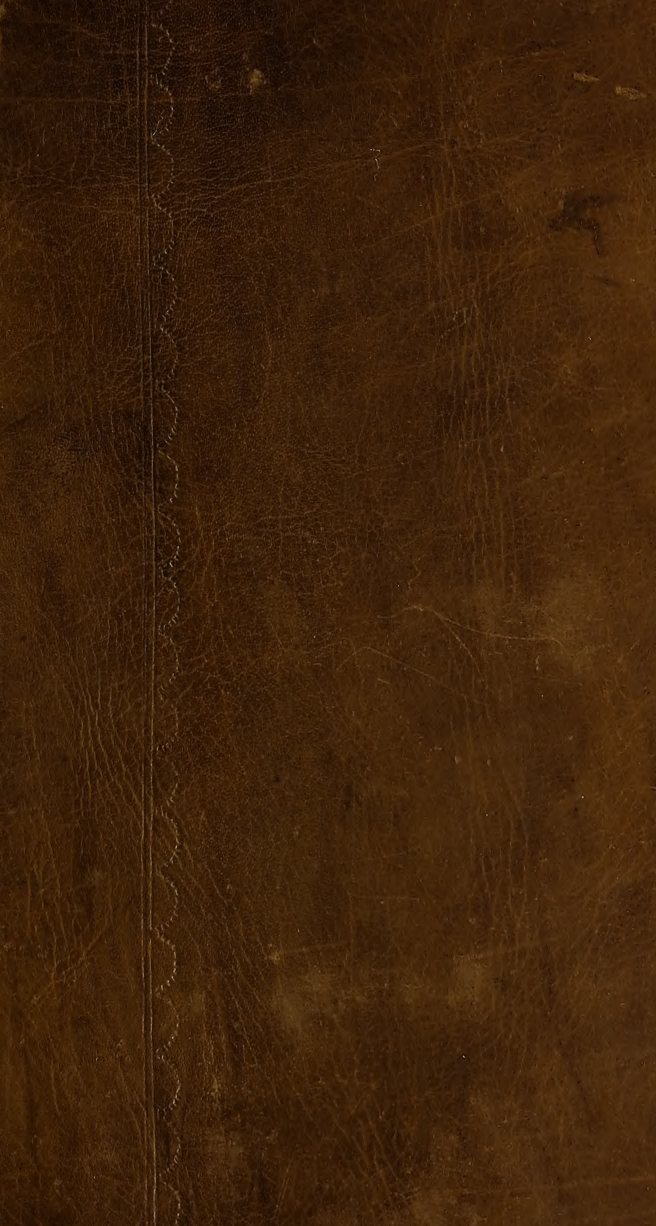

-

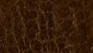


$5 x$

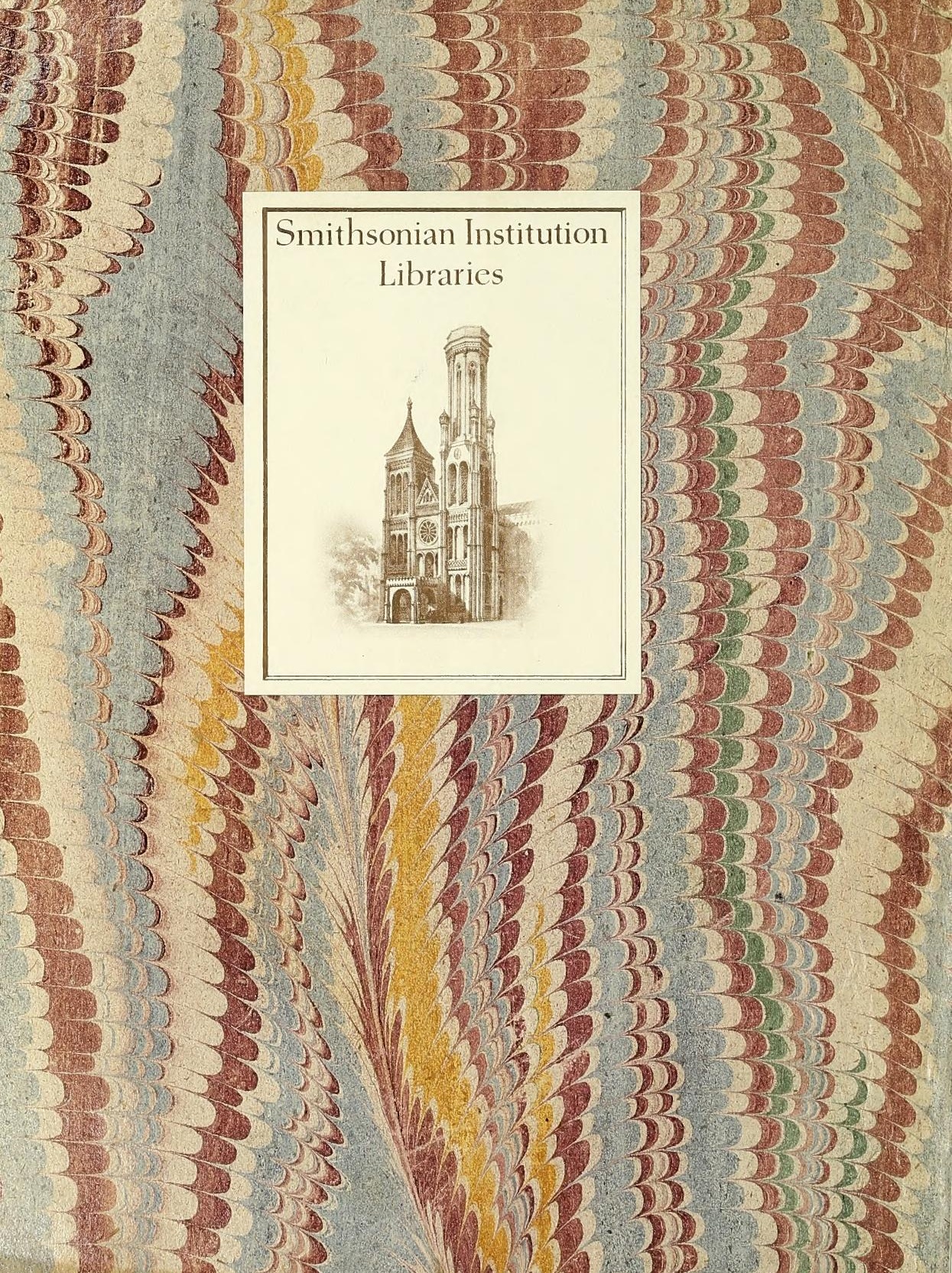




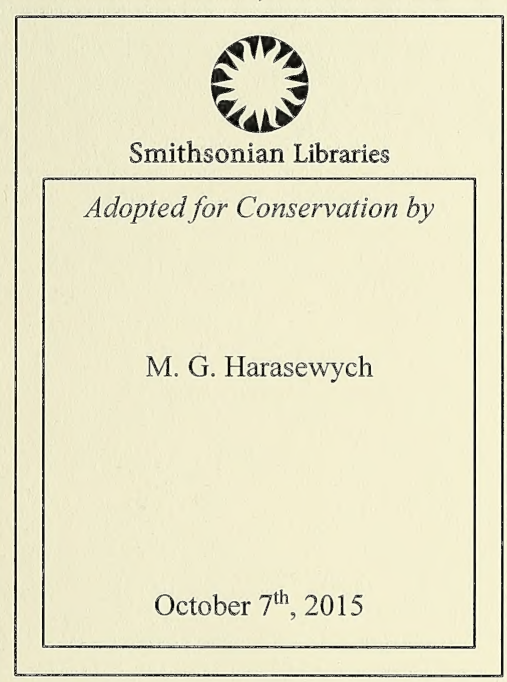






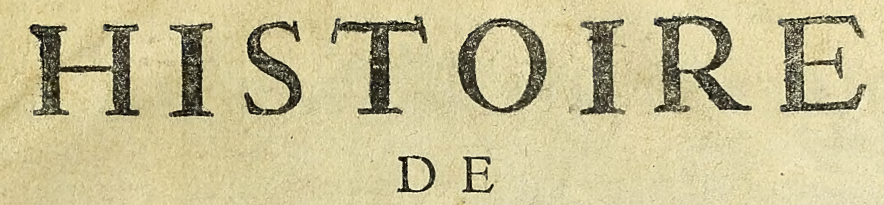

\section{L'ISLE ESPA GNOLE O U D E}

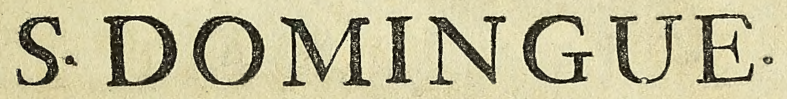

ECRITE PARTICULIEREMENTSUR des Memoires Manufcrits du P. Jean-Baptiste IE Pers, Jefuite, Mifionnaire d̀ Saint Domingue, of fur les Pieces Originales, qui fe confervent au Dépôt de la Marine.

Par le P. Prerre-François-Xavier de Charlevorx, de la Compagnie de Jefus.

\section{TO M E P R E M I E R.}

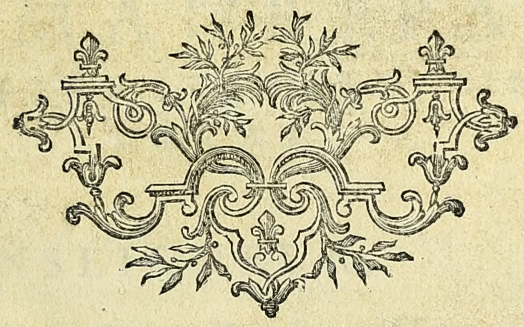

\section{A P A R IS,}

Chez Hippolyte-Louis Guerin, ruëS. Jacques, vis-à-vis S. Yves, à S. Thomas d'Aquin.

$$
\text { M. D C C. X X X. }
$$

AVEC APPROBATION ET PRIVILEGE DU RO\% 



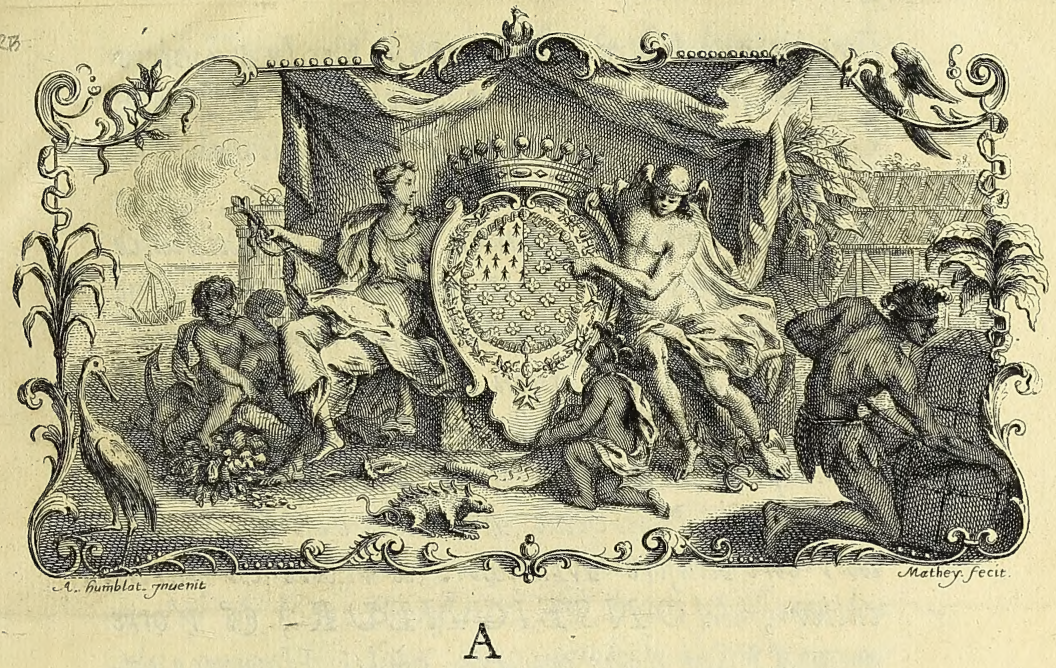

MONSEIGNEUR

L E C O M T E

DE M A U R P A ,

$M$ I N IS T R E E T S E C R E T A I R E D' E T A T.

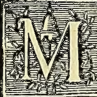

O NSE I G N E UR,

L'Hiftoire de Saint Domingue Vous appar. tient par toutes fortes d'endroits, छ l'on feroit 
furpris que Votre Nom ne fut pas la premiere chose, quion y apperçuit. C'eft à VOTRE $G R A N D E \cup R$, que je finis redervable de ce quielle contient de plus interreßant, EO la Colonie Françoise, dont on y verra la naißance E le progries, étoit bien peu de chofe, lorfque Fen Monfeigneur le Chancelier Votre Ayeul, prit en main le Timon de la Marine Si depuis ce têms-là elle eft devenuë le plis riche, EG le plus bel Etablißement, que notre Nation ait dans le Nowrean Monde, cieft lOnvrage de Votre Illuftre Maifon: le Votre en particulier, MONSEIGNEVR, G Votre coup d'Eßai dans un àge, oì les Hommes ordinaires ne fravent pas encore fe gouverner euxmêmes, c'efl'd'y avoir parfaitement rétabli l'ordre $E^{\circ}$ la tranquillité, E $\mathscr{E}^{\circ}$ de l'avoir mife en état de ne plus rien craindre, ni au-dedans, ni au-dehors. Et que ne Je promet-elle pas pour lavenir d'un fi beureux début, E de la conftante application d'un tel. Minifire, à qui elle fgait qu'elle eft chere ES précienfe?

Mais comment les Colonies, qui Vous font confiées, ne proppereroient - elles pas entre wos mains, tandis que votre premier $\sigma^{\circ}$ principal Objet , est d'y étendre partont le. Culte dist 
rurai Diew, Es que c'eft fur le fondement inébranlable de la Religion, que Vous y ćtábliffe's l'Autborité du Grand Roy, qui Vous on a chargé ? C'eft une juftice, MONSEI. $G N E \cup R$, que vous doivent cenx, qui Sçavent comme nous, ce qui fe paße dans ces Contrées éloignées, EG en même têms un Tribut de Reconnoiffance, que je Vous rends au nom de mes Freres, qui font répandus dans toutes les parties de l'Amérique Francoife. Nous apprenons d'eux tous les jours quils ne fyauroient faire un pas, fans rencontrer des traces de Vos Bienfaits, EF lewrs foubaits les plus empresfés font de pouvoir publier partout que, fi leurs Travawx Apoftoliques ont dans tous les lieux commis à Votre Miniftere des fucces, quils n'auroient jamais ofé efperer, c'eft encore plus à Votre Zéle Eo à Vos Attentions, quils en font redervables, qu'à leurs foins $G$ à leurs fatigues.

Ainfr, MONSEIGNEUR, en Vous préfentant ce Fruit de mes veilles, $E \vec{\sigma}$ de celles d'un de mes Confreres, qui m'aroit dérancé, EO m'a beancoup fervi dans ce Travail, je Vous fais Hommage de ce que je tiens de Vous: je m'acquitie pour ceux, qui m'y ont engagé,

$$
\text { a is) }
$$




\begin{abstract}
vj
d'un devoir, que l'Equité $\sigma^{2}$ la gratitude leur imposent, $\varepsilon^{\circ}$ je profite d'une occafion filong. têms défirée de faire connoitre le fincere Eे refpectueux Attachement avec lequel je fuis:
\end{abstract}

\title{
M ONSEIGNEUR,
}

De Votre Grandeur,

Le très-humble \& très-obéiffant Serviteur, PIERRE-FR ANÇOIS-XAVIER D CHARLEVOIX, D, L, C. D, J. 


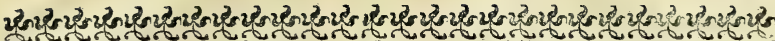

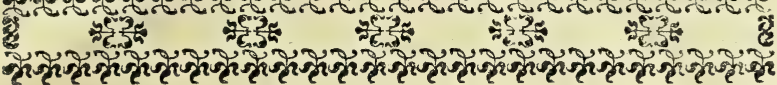
A VER TISSEMENT.

L y a plufieurs années, que le Pere JeanBaptifte le Pers, Jefuite Vvalon, avec qui j'avois eu de grandes liaifons d'amitié à Paris, lorfqu'il y faifoit fes Etudes de Theologie, m'envoya des Mémoires pour écrire l'Hiftoire de l'Ifle de S. Domingue, où depuis vingt-cinq ans il travaille à la Vigne du Seigneur avec un zéle, que le Ciel a favorifé de fes plus abondantes Bénédictions. Trois mille Negres adultes, $\&$ un plus grand nombre encore d'Enfans baptifés de fa main, \& neuf ou dix Eglifes bâties par fes foins dans les dépendances du Cap François \& du Portde Paix, en font la preuve. Comme ces Mémoires fe trouverent imparfaits, une partie en ayant été égarée par la négligence de ceux, à qui l'Autheur les avoit addreffés pour me les rendre ; je ne me preffai point de les examiner; \& cependant je fus obligé de partir pour l'Italie, où je reftai trois ans. Je ne doutois point que le P. le Pers, me voyant hors d'état de faire ce qu'il avoit fouhaité de moi, n'en eût chargé quelque autre; mais je fus fort furpris, lorfque de retour à Paris, après une fi longue abfence, j’y retrouvai fes Mémoires, dont il avoit réparé les bréches, \& des Lettres fort pref- 
fantes de fa part, pour m'engager à ne plus diffé. rer de les mettre en œuvre.

Dans la vérité, ces empreffemens me firent - quelque peine. Tout en arrivant de l'Amérique, \& avant que de partir pour Rome, javois annoncé le Journal du Voyage, que je venois de faire par Ordre du Roi, avec une Hiftoire générale des Découvertes \& des Etabliffemens des François dans l'A mérique Septentrionnale, dont javois parcouru la meilleure partie; \& je me croyois obligé d'employer les premiers momens du loifir, dont je commençois à joüir, à remplir l'engagement, que j'avois avec le Public ; mais ce n'étoit pourtant pas encore-là ce qui caufoit ma plus grande répugnance, pour ce que mon Confrere \& mon ancien Ami defiroit de-moi : elle avoit un autre principe, dont je n'ofois pas trop mouvrir à lui. C'eft que véritablement liidée, que je m’étois formée, \& que je ne m’étois pas encore donné le loifir de bien développer, d'une Hiftore particuliere de l'lfle de $\mathbf{S}$. Domingue, ne me préfentoit rien de fort interreffant, \& il me fâchoit d'êcre obligé d'y facrifier un têms, que javois deftiné à des Ouvrages, qui me paroiffoient devoir être plus du goût du Public: quoique j'en jugeafle peut-être ainfi, parce qu'ils étoient beaucoup du mien. Enfin, la complaifance \& l'amitié l'emporterent fur toute autre confidération; je quittai tout pour me livrer à ce qu'exigeoit de moi une perfonne, à qui je ne pouvois rien refurer. 


\section{AVERTISSEMENT.}

Je commençai donc à parcourir les Mémoires, fur lefquels je devois travailler, \& j’avouë que cette premiere lecture me fit bien changer de fentiment par rapport à mon fujet. Je compris même que je ferois bien plus embarraffé de fon abondance, que je n'avois appréhendé de l'être de fa ftérilité. Et en effet, les deux parties, qui divifent naturellement cette Hiftoire, pouroient fournir chacune la matiere d'un Ouvrage très-curieux, \& d'une étenduë raifonnable. Car enfin, l'une renferme ce qui s'eft paffé de plus merveilleux à la Découverte du Nouveau Monde, le plus grand Evenement de ces derniers Siecles; $\&$ non feulement un Autheur peut, fans craindre qu'on ne l'accufe de s'être écarté, mais doit même, s'il ne veut pas s'expofer aux reproches de n'avoir pas rempli tout fon fujet, y raconter, ou du moins y indiquer par quels moyens, \& par quels dégrés les Efpagnols fe font formé dans l'Amérique un Empire, auffi vafte, \& plus riche que celui des premiers Céfars. L'autre comprend toute l'Hiftoire de la plus puiffante de nos Colonies, \& de celle de toutes les Indes Occidentales, dont la naiffance \& les progrès font marqués par des traits plus capables de plaire, $\&$ d'inftruire.

Etant donc ainfi raffuré fur le fond de mon Ouvrage, je ne penfai plus qu'à tenir la parole. que j’avois donnée, \& je me difpofai à commencer. Mais en examinant de plus près mes Ma Tome I. 
teriaux, je m'apperçus que javois entrepris un bien plus grand travail, que je n'avois penfé d'abord.Effectivement, quelque perfuadé que je fuffe; que le $P$. le Pers avoit puifé dans les meilleures fources, je ne me crus pourtant pas difpenfé de les confulter, furtout dans la premiere Partie, pour laquelle je pouvois craindre, qu'il n'eût pas eu tous les fecours, dont il avoit befoin. Cette recherche ayant juftifié mes foupçons, j'écrivis au Miffonnaire, \& lui propofai mes doutes; ils lui pa* rurent raifonnables, \& il me laiffa une liberté entiere de faire à fes Ecrits tous les changemens, que je jugerois néceffaires : liberté, don j’ai ufé fort fobrement, \& jamais que dans le cas d'une évidente néceffrté. Mais on concevra aifément que cette difcretion même, bien loin de diminuer mon travail, n'a fait que l'augmenter.

Pour ce qui eft de la fecende Partie, fur laquelle nous n'avons encore d'imprimé, que quelques morceaux détachés, fort fuperficiels, \&c fur lefquels on ne doic pas même beaucoup compter; je me flattois encore, que je n'y aurois qu'à fuivre aveuglément mon Guide, ne voyant point d'authorité, que je puffe oppofer à celle d'un Homme d'efprit, lequel eft depuis vingt-cing ans fur les lieux, où il a pû confulter plufieurs de ceux, qui ont vû́ la Colonie dans fon enfance. Je n'étois pourtant pas tout-à-fait fans inquiétude, je fentois dans mes Memoires des vuides, qui me fairoient peine : je ne voyois pas 
affés de liaifon entre la plûpart des faits, \& l'attente des Lecteurs ne me fembloit pas devoir être fatisfaite fur plufieurs articles. Je trouvois bien en cela une preuve convainquante de la fincerité de mon Autheur, qui fe contentant de dire les chofes, dont il fe croyoit bien informé, n’avoit pas jugé qu'il lui fût permis de fuppléer d'imagination à ce qu'il ne fçavoit pas, ainfi que font tous les jours tant d'autres: mais il falloit pourtant y fuppléer, des vuides ne fe pouvant gueres pardonner dans une Hiftoire auffi récente que celle-ci. La difficulté étoit d'avoir dequoi les remplir.

Dans cette perplexité, je pris la liberté de m'addreffer à M. le Comte de Maurepas, lequel eut la bonté de permettre qu'on me communiquât les Pieces, qui font au Dépôt de la Marine. Ce Dépôt, que depuis quelques années on a partagé en deux, contient tous les Plans, qui dépendent de la Marine; toutes les Lettres de nos Rois, des Miniftres, des Gouverneurs, des Intendans, \& autres Perfonnes en place; les Relations, les Inftructions, les Procès verbaux, \& généralement tout ce qui émane de la Cour, \& tout ce qu'on y addreffe, qui a rapport à ce Département. Les Plans, \& les Memoires relatifs aux Plans, font confiés à la garde du. Chevalier de la Blandiniere, Capitaine de Vaiffeau, Officier de mérite, \& actuellement chargé d'une Négociation importante. Tout le refte eft fous 
$x i j$ AVERTISSEMENT.

la direction de $M$. de Clairambault, Genealogifte des Ordres de Sa Majefté, lequel a commencé cette prodigieufe Collection fous le $\mathrm{Mi}$ niftere de M. Colbert, \& y a établi un ordre, qu'on ne peut fe laffer d'admirer. Mais ce bel ordre n'empêche pas qu'il n'en coûte infiniment pour profiter d'un tel fecours. En effet, l'exactitude fi néceffaire dans un pareil Receuil y a produit une abondance bien onéreufe à ceux, qui font obligés d'en parcourir les Pieces; parce que fouvent ce qu'ils cherchent fe trouve enveloppé dans un grand nombre de chofes, qui leur font tout-à-fait inutiles. Auffi ceux, qui ont été témoins des fatigues, que jai euës à effuyer, pour profiter de la grace, qu'on m'avoit faite; font-ils convenus quil falloit un grand amour de la vérité, pour me les rendre fupportables: mais j’en avois reconnu la néceffité.

Une Hiftoire de la nature de celle ci, reçoit fon principal agrément d'un détail, qui fe foûtient par la nouveauté des faits, \& qui interreffe un trop grand nombre de Particuliers de tous Etats, pour ne pas picquer la curiofité du Public : mais fi les Memoires, qu'on tire de ceux, qui ont été témoins, ou prefque contemporains des évenemens, dont ce détail eft compofé, font pour ainfi parler, le Corps de l'Hiftoire; on peut diro que les Pieces, que jai trouvées au Dépôt de la Marine, en font comme l'Ame, puifque c'eft par elles qu'on découvre les refforts cachés des mou- 
vemens, que ceux mêmes, qui les ont vûs de plus près, ne comprenoient pas toûjours. $U_{\mathbf{n}}$ autre avantage, qui réfulte de la confrontation de ces deux fortes de monumens ; c'eft qu'en les rapprochant ainfi, on les peut corriger les uns par les autres. Car il ne faut pas s'imaginer que tout ce qui eft au Dépôt de la Marine, foit également décifif. On y trouve bien des Ecrits, qu'il faut lire avec une grande précaution, \& ce n'elt pas même toûjours une chofe fort aifée, que d'y démêler la vérité des artifices, dont l'interêt, la paffion, la malignité, l'envie de fupplanter un Rival, ou de fe faire valoir, \& la néceffité de fe difculper, ont cherché à l'embroüiller. Le meilleur moyen pour y réuffir, eft de leur oppofer les fuffrages non fulpects d'un Public définterreffé, incorruptible, fans paffion, \& qui ne fait grace à perfonne aux dépens de la Verité.

Mais ce Public n'eft pas exactement inftruit de tout; d'ailleurs, il n'eft pas auffi aifé, qu'on le penfe, d'en receüillir les véritables fuffrages, \& de les diftinguer de certaines Traditions vulgaires, qui fe forment de bruits incertains, où préfident ordinairement la précipitation, les préjugés, la malignité d'un petit Peuple, toûjours difpofé à fe foulever contre la féverité des Loix, $\&$ facile à fe prévenir contre ceux, qui veulent en maintenir la Sainteté, conferver l'ordre, \& reprimer les abus; fource de jugemens iniques, dont cette Hiftoire nous fournira plus d'un exemple. 
Or fi quelque chofe peut fervir de regle pour faire ce difcernement, ce font quantité d'Actes contenus auReceüil,où l'on m'a permis de puifer : car,outre qu'il s'y en trouve d'une authenticité, fi j’ofe ainfi m'exprimer, que rien ne peut affoiblir ; on peut encore juger par le parti, que le Prince \& fes Miniftres ont pris, après une difcuffion exacte, \& une mûre délibération, à quoi il faut s'en tenir fur les faits les plus conteftés. Ou fi la Juftice du Souverain, \& la Sageffe de fon Confeil ont été furprifes, la force de la Verité trouve une reffource dans un témoignage univerfel, qui reclame, \& porte avec foi un caractere d'évidence, lequel diffipe jufqu'à l'ombre même de l'erreur.

Ces réflexions repréfentées au Miffionnaire de Saint Domingue le convainquirent de nouveau que, s'il eft avantageux d'avoir long-têms demeuré dans une Colonie, quand on en veut écrire l'Hiftoire, cela ne fuffit pas; \& il connut d'abord tout le prix des Memoires, dont javois fortifié les fiens. De mon côté j'étois perfuadé, que des Materiaux fi précieux, \& fi complets, feroient beaucoup mieux entre fes mains, qu'entre les miennes, n’y eût-il que parce qu'il étoit encore plus en état que moi d'appliquer le correctif aux endroits des uns \& des autres, qui en auroient befoin. De cette forte, s'il n'avoit pas la fatisfaction d'avoir fourni toute la matiere d'un Ouvrage, qu'il a extrêmement à cœur, \& pour lequel il s'eft donné bien des foins, le Public 
lui feroit redevable de la forme, en quoi peu de perfonnes étoient plus capables de réuffir que lui, fil l'on en juge par le tour, qu'il a donné à fes Memoires, \& par le tile, dans lequel ils font écrits.

De cette maniere nous aurions partagé le Travail, ainfi qu'il l'avoit prétendu, avec cette différence, que s'étant flatté d'abord d'en avoir préparé toute la matiere, \& fa modeftie lui faifant regarder, comme fort au-deffus de lui, d'y ajoûter la forme; après s'être rendu juftice fur le premier Article, il confentiroit qu'on la lui rendît fur le fecond. Mais on me fit obferver qu'inutilement je ferois cette propofition à un Miffionnaire du caractere du P. le Pers, \& qui chargé d'un nombreux Troupeau, n'a pas beaucoup de têms à donner à de pareilles occupations, fort au-deffous de celles, qui font propres de fon Miniftere. Il fallut donc me charger de tout le travail, \& je m'y fuis livré avec toute l'application, que demandoient le mérite de mon Sujet, $\&$ la confiance, dont on m'avoit honoré.

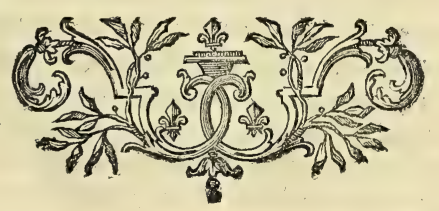


XVj

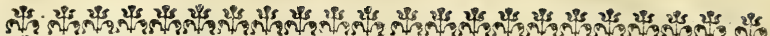

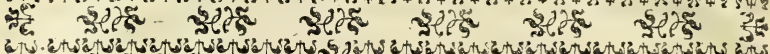

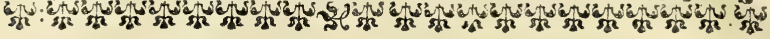

\section{T A B L E \\ DES SOM M A I R S D U TOME PREMIER.}

\section{I V R E P R E M I E R.}

$\mathrm{D}$ Ivifion des Antilles. Origine de ce nom. Ifle Efpagnole, of Jes differens noms: Ja fituation, \&o fon étendue. Ses environs. Obfervations fur les Cotes de l'Ifle Efpagnole, た fur les Marées. De la Brife. Des Pluyes. Différence des climats \&o Jes caufes. Caufes de la fraîcheur ó de la clarté des nuits. Des Rofées \& des Brouillards. Différence des Saifons. Incommodités du Climat de notre Ifle. De la différence des Terroirs. De la maniere, dont les Arbres jettent leurs racines. Des Rivieres. Des Lacs. Du Lac Xaragua. De l'Etang du Cul-de-Sac, \& de l'Etang Salé, felon Oviedo of felon divers Auteurs, qui paroiffent lui être contraires. Des Mines, Minieres, \& Carrieres. Des Tempêtes de ces Mers. Des Poiffons. Des Cancres. Des Crabes \& du Soldat. Sar. gafJes, Prairies Marines, Tortuës. Des Pilotes, du Remora, des Dorades, \& des Bonites. Des Galeres. Du Lamentin. Des Crocodiles. De l'Ivana. Des Canards, des Oyes, des Pintades, des Paons, fo des Failans. Des Tourterelles, des Picvers, des Roffignols, ¿o des Linottes. Des Grands Goziers, des Perroquets, du Flamand, du Colibry, des Mouches luifantes. Des Infectes venimeux, de l'Efcarbot Rhinoceros. Des Chiques er des Poux de bois. Des Quadrupedes. Nombre or figure des Habitans. Leur complexion, \&o leur caractere. Leur Tradition, Conjectures fur leur Drigine. Leurs Danfes or leurs Chanfons. Tambours an 


\section{DES SOM M A I R E S. xvij}

fon anquil ils danfoient. Fुen de Batos. Yvrefe de Tabac. Origine du mot de Tabac. Differens noms que cette Plante a eus en France. Moeurs des Infulaires. Origine du mal de Naples. De leur Mariage. Des Obfeques. Lewrs occupations. Leur maniere de fe difpofer à chercher de lor. Leur maniere de cultiver la Terre, $\leftarrow$ de faire du feu. Leurs Canots ou Pirogues. Leur Gouvernement. Supplice des Voleurs. DéfinterrefJement $\sigma \sigma$ hofpitalité. Ordre de la fucceffion anx Principantés. Leurs Guers nes. Leur nourriture. Leurs Maifons. Leur Langue, leur Religion, \& leurs Divinités. Zemés, Divinités jubalternes. Fourberie an fujet des Zemés. Proceffion folemnelle en l'honneur des Dicux. Des Prêtres of Medecins. Danger qu'ils couroient quand un Malade mouroit. Leur maniere de traitter les Malades. Zeurs différentes opinions. Cavernes facrées. Origine des Femmes. Divifion de l'Ifle, telle qu'elle éroit au têms de fa découverte. Quel éroit chriftophle Colomb. Sentimens des Anciens fur l'exifrence d'un Nowrean Monde. Conjectures de Colomb. Colomb fait fon Plan, or le propofe à diver/es Puiffances. Supercherie qu'or lai fait en Portugal. Il envoye fon Frere en Angleterre, ko s'en va en Efpagne. Barthelemi Colomb en Angleterre, Chriftophle Colomb arrive en Efpagne. Ses premieres tentatives aupres des IRois Catholiques. Son projet eft rejetté. Ce qu'on lui oppofe. Lenteur qu'il eut à effuyer de la Cour d'Efpagne. Il fe difpofe à paffer en France. Derniers efforts-aupres de la Reine. Elle accepte les conditions propofées par colomb. Quelles furent ces conditions. Le Traitté eft figné du Roi oo de la Reine, mais an nom de la feule Couronne de Cafille. Embarquement de colomb. Il arrive aux Canaries. Mutinerie des Equipages. Conduite de Colomb en cette occafion. Propofition hardie quil fait à Jes gens. Indices de la Terre. Colomb la décowvre le premier. Il ef falué Amiral 'o vice-Roi. Colomb defcend à terre, бo prend poffeffion de l'Ifle Guanahani au nom de la Couronne de Caftille. Etonnement réciproque des Sawvages és des Européens. Découverte de l'Ifle Haysi. Une Caravelle quitte Colomb. Colomb arrive à l'Ifle Hayti.

Tome I. 


\section{xviij T A B L E}

\section{I V R E S E C O N D.}

I

Sle de la Tortuë. I'Ifle Hayti, nommée Ifle Efpagnole. Les Infulaires fe défient diabord des Efpagnols, of fe familiarifent enfuite avec eux. L'Amiral continuë la Décowverte de l'Ifle. La Capitane fe brije contre un éceivil. Conduite du Roi de Marien à cette occafion. Les Européens reçoivent de l'Or pour les plus viles Marchandifes. L'Amiral fonge à bâtir une Fortereffe à Puerto Real. Il vifite le Roi de Maricn, es la réception que ce Prince lui fait L'Amiral reçoit des avis de la Pinta. Il laifje trente-huit Ilommes dans Puerto Real. Il part pour l'Efprgne. Il découvre toute la Côte du Nord. La Pinta rejoint l'Amiral. Suite de la. découverte de la Côte de lifle. Ce qui fe paffa dans la Baye de Samana. I'Amiral fait route pour l'Elpagne, Er il effuye une grande Tempête. Ce quilui arrive aux Açorres é en Portugal. Honneurs. qu'il reçoit du Roi de Portugal. Son arrivée en EJpagne. La Pinta arrive en même têms que lui, aprés en avoir été feparé par la premiere Tempête. Réception qu'on lui fait à Palos. Pourquoil Amérique porte le nom d'Inde Occidentale. Colomb fe rend à Barcelone: honneurs quil reçoit fur la route. Son entrée à Barcelonne. Son Audience du Roi đo de la Reine. Nouveaux honneurs quil reçoit. Ligne de Démarcation. Les Privileges de l'Amiral font confirmés. Baptême des premiers Indiens. On fait un grand Armement pour les Indes. Départ de la Flotte. Découverte de plufieurs des petites Antilles. La Dominique, la Deffeada, Marie Galante, la Gua. deloupe, Montferrat, Antigoa, Saint Chrifophle. Colomb trowve fa. Colonie ruinée of tous Jes gens morts. Difcours du Frere de Goacanaric à l'Amiral. Conduite de Colomb à l'égard du Roi de Ma. rien. Il lui rend vifite. Il cherche un liew commode pour y faire un Etabliffement. Il bâtit une Ville fous le nom d'Ifabelle. Il envoye vifuter les Mines de Cibao. Caractere d'ojeda. Defcription de Cibao. Confpiration découverte \& punie. I'Amiral va lui-même. à Cibao. Il y batit une Forterefe. Murinerie dans Ifábelle. L'A. miral part pour de nowvelles Décowvertes. Son retour à Ifabelle, 


\section{DES SOM M A I E S. xix}

oin il trouve fon Frere D. Barthélemit. Les Gens de Guerre fe comportent mal, \& ce qui en arrive. Belle action, \& mawvaife conduite de D. Pedro Margarit. Il repafe en Elpagne, es y fait de grandes plaintes contre les Colombs. $L^{\top}$ Amiral fair fon Frere $A d e^{\prime}-$ Laniade. Stratagéme d'ojedo, pour fe faifir de la perfonne de Caonabo. Fierté du Cucique, prifonnier, és fa mort. L'Amiral reçoit du fecours d'Ejpagne. Il marche contre une nombreufe Armée d'Indiens, of la met en déroute. Mort de Goacanaric. Tribut impofé ä toute l'Ifle. Déféfpoir des Indiens, ơ les fuites qu'il ewt. Le Roi \& la Reine envoyent un Commiffaire dans les Indes. Conduite de ce Commiffaire. Toute la colonie fe déclare contre les Colombs. Conduite de l'A miral à cette occafion. Il fe difpofe à pasfer en Efpagne. Découverte des Mines de Saint Chrifiophle. Dépari de l'Amiral pour l'Espagne. Ce qui lui arrive à la Guadeloupe. Sor arrivée en Efpagne. Sa réccption à la Cour. Reglement pour l'Etabliffement des Indes, tant pour le fpirituel que le temporel. Avis pernicieux de colomb pour peupler les Indes. Les fouls Sujets de la Couronne de Caftille ont droit d'aller aux Indes. L'Armement ordonné pour le troifiéme Voyage de Colomb fe fait lentement. I'aA: miral ordonne de placer ailleurs la Colonie d'Ifabelle. Avanture d'un jeune Efpagnol avec une Dame Indienne. Fondation de San. Domingo, Voyage de l'Adélantade à Xaragua. Limites de ce Royaume. Réception des Efpagnols à Xaragua. Behechio fe foumet an Tribut. Révolte de Guarionex. Prije de ce Cacique. L'Adélantade va recevoir le premier Tribut du Roi de Xaragua.

\section{LIVRE TROISIE'ME.}

$\mathrm{R}$ Evolte de l'Alcaide Major. Il fait foulever les Indiens. Enireprifes hardies de ce Rebelle. Progrès de la Révolie. Entreviè de Roldan avec D. Barthélemi fans fuccés. Celwi-ci reģit du fecours d'Ejpagne. Fuite de Guarionex. L'Adélantade marche contre lui, e' fait la guerre aux cigwayos, chés qui il s'étoit retiré. Les Indiens font défaits. Prife de Majobanex. Belle aetion d'un Seigneur Indien. Supplice de Mayobanex. Ce qui avoit fi fort 
retardé le troifiéme Voyage de l'Amiral. Il part d'Efpagne. Il fait un grand détour, Er pourquoi. Il découvre l'Ifle dela Trinité. Il apperçoit la Terre Ferme fans la reconnoitre pour telle. Froid ex. trdordinaire que les E fpagnols reffentent fous la Zone Torride. Imaginations de Colomb. Decouverte de la Péche des Perles. Il arriz: a San-Domingo. Progrés de la Révolte de l'Alcaïde Major. L'Alcaide Major débauche plufieurs Efpagnols nowvellement débarqués. L'Amiral effaye de les gagner. Negociation de Ballefter avec Roldan, fans fruit. L'Amiral entre en defiance de Carvajal. Il ne lailfe pas de fe fervir de lui pour négocier avec Roldan. Lettre de l'Amiral à Roldan. Quel en fut le fucces. Embarras de l'Amiral. Déclaration de l'Amiral, portant amnifie pour les Rebelles. Il écrit anx Rois Catholiques tonte la fuite de cette affaire. Roldan écrit de fon coié, of trouve de l'appui à la Cour. Entrevüë de Roldan avec l'Amiral, fans fruit. Carvajal conclut un accommodement avec les Rebelles. Nouveaux incidens qui le rompert. Nowv l accord conclu ơ execuré. L'Amiral balance s'il n'ira pas en EJpagne. Il rend compte awx Rois Catholiques de tout ce qui regarde les Séditieux. Origine des Départemens des Indiens. Ojeda é Amerique Vefpuce partent pour les Indes. Infidelité d'Americ Vefpuce. Succes de ce Voyage. Conduite d'ojeda avec l'Amiral. Mowrement à Grenade contre les Colombs. La Reine sirrite contre l. Amiral, oo le dépo fe de la Vice-Royanté. Prétexte qu'on prend pour le rappeller. François de Bovadilla envojé Gouverneur Général dans les Indes. Son arrivée à San-Domingo. Il force la Citadelle: Conduite de colomb à certe nouvelle. Il je met à la difcretion de Bovadilla, qui lui fait mettre les fers aux pieds, anfli bien qu' fon Frere $D$ : Diegue. Il engage fon Frere $D$. Barthelemi à fe rendre Prifonnier. Conduite irréguliere du Commandeur. Chefs d'accufation contre les Prifonniers. Ies Réponfes de l'Amiral. Bovadilla fe réfout à l'envoyer en Efpagne. L'Amiral arrive en E/pagne. Réception de l'A miral à la Cour. Andience particuliere ob. tenue de la Reine par l'Amiral, אo ce qui s'y pafje. Nouvelle propofition de l'Amiral à la Reine. Conduite de Bovadilla dans fon Gourernement. Il rend les Infulaires efclaves: Grain d'Or exsraordire. Bovadilla rézoqué, Ovando envoye à fa place; for 


\section{E S S O M M A I R E S. Xxî}

caractere. On change beaucoup d'Habitans de lijle Efpagnole. Infructions données à Ovando. Attention de la Cour pour la converfion des Indiens. Ovando arrive à l'Ifle Efpagnole. Sa corduite à l'égard de tout le monde. Le travail des Mines ceffe en. tierement. Reglement pour les nouvelles Villes. Lettres de Ferdinand à l'Amiral. Il part de 'Cadix. Il n'eft pas reçu à l'Ifle Efpagnole, \&o pourquoi. Nanfrage de la Flotte. Ie plus petit Navire, où étoit tout le bien de l'Amiral, fe fauve. Découverte de Rodrigue de Baftidas dans le Continent. Second Voyage d'Americ Vefpuce avec Ojeda. La Ville de San-Domingo renverfée par louragan. On oblige les Indiens à travailler aux Mines en les payant. Ovando fonge à établir Puerto di Plata. Action cruelle d'un Efpagnol. La Province de Higuey prend les armes. Belle action d'un Indien, qui fe bat contre deux Efpagnols. Les Indiens font défaits, er on leur donne la Paix. San-Domingo re. bâti dans une fitwation moins avantageufe. Situation de cette Ville. Son Port. Qualités de fon Terroir, é de fon Climat. - Maladies anfquelles on y eft fujet. Mines dans la Ville; Pluyes abondantes.

\section{LIVRE QUATRIE'ME.}

T Ouveaux Ordres donnés an Grand Commandeur, conformes 1 à ce quil avoit repréfenté. Les Départemens d'Indiens ét ablis. Bonnes qualités d'Ovando. Mefures que prend_la cour pour policer les Indiens. Etat oì $\int e$ trowvoit alors la Province de Xaragua. Ovando s'y tranfporte. La réception qu'on lui fait. Il fe perfuade que la Reine de Xaragua a formé de mawvais de feins contre les E/pagnols. De quelle maniere Ovando fe rend Maûre de la Reine de Xaragua, Eo ce qu'elle devint. Horrible maffacre des Habitans de Xaragua: Révolte de quelques Provinces affoupie fur le champ. Etat de liIfle Efpagnole en 1504 . Nouvelles Découvers tes de Chriftophle Colomb. Il découvre la Province de Honduras, It prend le change, ơ manque la Découverte du Mexique. Il dé. couvre Portobelo, 'o pliffieurs autres Ports. Il fonge à s'en rerroum- 


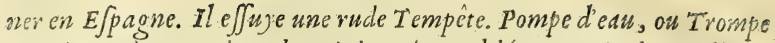
Morine. Il entre dans la Riviere de Bethléem, puis dans celle de Veragua. Montagnes deSaint Chriftophle. Mines d'Urira. Bourgade batie jur le Veragua, o brûlée par les Indiens. Colomb arrive à la Famaïque. Précaution qu'il prend pour ne point s'attirer les InJulaires. Un EJpagnol \& un Genois entreprennent de traverfer en Canot à l'Ifle Eppagnole. Ils y arrivent apres bien des rifques. Emburras oì fe trouve l'Amiral. Soulevement contre lui. Les Séditieux fe retirent. Ils font plufieurs tentatives pour paffer à l'Ifle Ejpagnole, mais fans fruit. Violences qu' ils exercent fur les Infulaires. Conduite toute oppofee de l'A miral. Stratagême dont il ufe pour avoir des vivres. Il reçoit des nouvelles de l'Ifle Efpagnole. Manvaifes manieres du Grand Commandeur à fon égard. Il tente inutilement de fe réunir avec les Porras. L'Adélantade les défait. Les Rebelles $\int e$ fostmettent. L'Amiral arrive à San-Domingo. Conduite haute du Gouverneur avec lui. Son arrivée en Efpagne; il apprend la mort de la Reine. Caractere de cette Princelfe. L'. Amiral fait d'inutiles efforis pour être rétabli dans fa Charge de Vice-Roi. Apologue, dont il fe fert pour fermer la bouche à fes envieux. On cherche à l'amufer, Will s'addrefse au Roi Philippe d'Autriche. Mort de Colomb és fon caractere. Ses défauts. Nouvelle Révolte dans le Higuey. Efquibel marche contre les Indiens. Effets du défe poir des Indiens. La prife du Cacique met fin à la Guerre. Les Indiens font plius maltraittés que jamais. Richeffes immenfes, qui fortent de l'Ifle EJpagnole. Départemens donnés aux Seigneurs de la Cour. Entreprife odieufe du Grand Commandeur pour angmenter les revenus du Roi. Cannes de Sucre plantées dans l'Ejpagnole. Nine de Cuivre. Reglement pour les Mariages. Habitans des Lucayes tranfportés ì IIfle Efpagnole, ¿o avec quel fuccès. Violences commifes en cetre occufion. La Juflice do les Finances font ôtées aux Gowverneurs Generaux. D. Diegue Colomb époufe la Niéce du Duc d'Albe, Eo rentre dans fes droits fur le Gowvernement des Indes. La Charge de Vice-Roi eft fupprimée. Caufes du rappel d'Ovando. Ce qu'ors penfa d'Ovando à fon rappel. Départ de l'A Amiral, es fon arrivée à San-Domingo. Il fe browille d'abord avec le Miniftre. La Colosie de l'Epagnole prend une nowvelle face. Owragans, co leurs of 


\section{E S S O M M A I R E S. xxiij}

fets. Sources de la décadence de l'Ifle Efpagnole. Etabliffement dans l'Ifle des Perles. Il dure pen, of quelles en furent les fuites, Defcription de Portoric. Ponce de Leon pafje dans cette 1fle, Er y trowve des Mines d'Or. Il efl fait Gouvernewr de l'Ifle. Révolte des Indiens de Fortoric. Comment ils s'affurent que les Efpagnols ne fone pas immortels. Plufieurs Efpagnols fon: maffacrés. Hi ftoire d'un chien fumeux. Ce quíporte les Indiens à Je Joumettre. Etabliffement dans la famaique, dans la caftille d'or, \& dans la nowvelle Andaloufie. Mécontentemens donnés à l'Amiral, ơ quelles en furent les fources. Sa conduite pen politique. L'Audierce Royale établie à San-Domingo. Les Negres introduits dans lifle Eppagnole. Arrivée des Peres Dominiquains. Leur zéle, of le fucces quil ent. Avantures dojeda. Sa mort \& fon caractere. Ce qui arriva à fes gens après fon départ de Saint Sebaftien. Rerscontre d'Encifo \& de Pizirre. Ils retournent tous enfemble à Saint Sebaftien. Ils trouvent cette Ville brûlée: extrêmité où eft réduite la Colonie. Caractere de Vafco Nugnezde Balboa. De quelle maniere il pafje en Terre. Ferme. La Colonie paffe de l'auire coté du Fleuve Darien. Fondation de. Sainte Marie l'Ancienne du Darien. Encifo dépouillé du Commandement; forme du Gouvernement établi à Saint Marie. La nouvelle Colonie accepte Nicue fJa pour Gouverneur, to l'envoje chercher. Avantures de Nicueffa. Sa mauvaife conduite. Sa. mort. On rejette fes malheurs, do ceux d'ojeda fur l'Amiral. I. peu de fondement de cette accufation.

\section{LIVRE CINQUIEME.}

Réation d'Evêchés dans l'Ifle Efpagnole. Les Infulaires prefque entierement exterminés. Sermon d'un Pere Dominiquain, ó les fuites quil eut. On exarine au Cinfeil la Caufe des Indiens. Ordonnance en faveur des Indiens. Préparatifs pour la Conquête de. Cuba. Préparatifs des Infulaires pour fe défendre. Diew des E/pagnols felon les Indiens. Ils le jettent à la Mer, croyant Je garartir par lá de linvafion des Caftillans. Défaite e fupplice d un Caciques or pourquoi il ne veut pas être baptifé à la mort. Toute lifle fs 
Sowmet. Croyance des Indiens de Cuba.D. Barthélemi Colomb eft eme voyé à lifle Efpagnole, es pourquoi. Las Cafas travaille à la con. verfion des Penples de Cuba. Ponce de Leon cherche la Fontaine de Jouvence. Sur quoi il fe fondoit. Il découvre la Floride par hazard. En quoicette découverte fut préjudiciable à l'Ifle E ppagnole. Les Départemens d'Indiens confirmés de nouveau. Les PP. Dominiquains demandent la permijfion de faire une Miffion dans le Continent de l. Amérique. Ils commencent la Miffion avec Jucces. Trabifon faite aux Indiens par les Efpagnols. Elle retombe fur les PP. Dominiquains. L'Audience Roýale refufe de rendre juftice aux In. diens, qui maffacrent les deux Miffionnaires. Ceux de l'Efpagnole feconvertiffent. Le Roiy envoye des Difributeurs d'Indiens. L'Amiral repafJe en Efpagne. Mort de D. Barthélemi. Nowveau Diftributeur des Indiens, mort en arrivant, Ev non fans foupçon de poifon. Alliance des Espagnols avec les Indiens. D. Barthélemi de Las Cafas dans l' Ifle Efpagnole. Son caractere. Ilpafe en Efpagre pour y plaider la Caule des Indiens. Mort du Roy Ferdinand. Le Cardiral Ximenés cherche les mojens de remedier aux abus des Indes. Il envoye des PP. Hyeronymites à l'Ifle Efpagnole en qualité de CommifJaires. Reglement arrêté entre Las CaJas, or Rubios. Ce qu'on oppofe à ce Reglement. Inftructions données aux Commiffaires. Reglement touchant les Mines. Les Commiffaires ont un plein pouvoir touchant l'execution de ce Plan. Adminiftrateur nommé pour

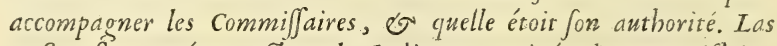
Cafas eft nommé Protecteur des Indiens. Arrivée des Commiffaires aux Indes, of leur conduite. Arrivée de l'Adminiftrateur, of la conduite qu'il tint. Les Commiffaires ne paroiffent pas difpo fés à remettre les Indiens en liberté. Las cafas fe broiillle avec eux, do repaffe en Efpagne. Raifons pourquoi les Commiffaires ne touchent point awx Départemens. Nowvelle mortalité parmi les Indiens : un des Commiffaires paffe en EJpagne. Las Cafas \& Z Zazo reçoivent quelque mortification de la Cour. On envoye des Negres aux Indes. Les Commiffaires \& l'A dminiftrateur font révoqués. Zuazo eff rappellé, ó Figueroa envoyé à fa place. Ordre donné à cet Adminiftrateur. Conduite des PP. de Saint Ferôme avant leur rappel. La petite Verole défole les grandes Antilles. Les Fourmis font un terrible dégat dans 


\section{DES SO M M A I R E. XXY}

les Ifes. Comment on fit mourir ces Infectes. Arrivée du nouvel Adminifirateur. Départ des PP. de Saint Ferôme. Las Cafas follicite l'envoy des Laboureurs dans lés Ifles. Il propole le Plan d'une Colonie. Entreprife hardie de Las Calas. Funte extraordinaire pour examiner la Caule des Indiens. Cripublic contre la déliberation de la Funte. Las Ca as répond à tout ce qu'on lui objecte d'une maniere à contenter tout le monde. Il obtient tout ce quil jouhaite. Ce quife

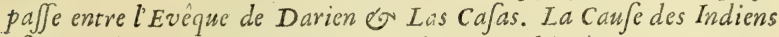
eft difcutée en préfence du Roi. Difcours de l'Evêque du Darien. Réponfe de Las Cajas. Difcours d'un Pere Francifquain. Sentiment de l'Amiral. On ne conclut rien, ¿o pourquoi. Etat floriffant de l'ifle de Cuba. Velajquez's rend indépendant de l.Amiral. Déconverte de l'Yucatan. Pointe ou Cap de Cotoche. Ce qui fe paffe à Campeche; or à Potonchan. Retour de Fernandez à l'Ifle de Cuba. Velafquez fait un nouvel Armement pour continuer les découvertes. Caractere de Grijalva. Son départ. Il arrive à l'Ifle de Cozumel. Culie de la Croix dans i rucaian, \&o fon origine. Grijalva ef bleffé à Potonchan, or découvre la nowvelle E pagne. Il entre dans la Riviere deT abafco; étonnement des Indiens. Grijalva prend poffeffion

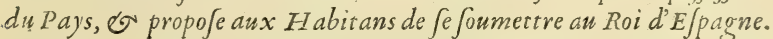
Réponje des Indiens. Entrevî̀ du General es du Cacique de Tabafco. Pourquoi Grijalva ne fair point d'Etab́liffement dans ce liew la. Premiere connoiffance de Motezuma. Grijalva envoye demander de nouveaux ordres à Velalquez, qui s'emporte mal-à-propos contre lui. Grijalva continuë la découverte de la nouvelle Espagne. Il retourne à l'Ifle-de Cuba : réception que lui fait Velafquez. Fernand Cortez nommé Capitaine General de la Flotte deftinée à la Conquête de la nouvelle E Ppagne. Quel il étoit. Ses Avantures. Son Caractere. Velafquez obtient plufieurs graces de la Cour. Ses difgraces. Conduite de Cortez à fon éoard. Velafquez râche en vain d'oter à Cortez le Commandemeat de la Flotte. Cortez fe hate de partir. Etat de la Flotte. Elle met à la voile. Velafquez manque un Navire de Cortez, qui alloit en Efpagne. Confeil établi dans larmée. Cortez le démet entre fes mains du Generalat. Le Con/eil le choifit de nouveau pour Capitaine General. Fondation de la VeraCruz. Cortezreçoit du fecours, or apprend des nowvelles de Cuba, たo Tome I. 
XXYi

envö̈e des dépéches en Cour. Velafquez fait un grand Armemoss. contre Cortez, do le confie à Narvaez.

\section{I V R E SIX I E'ME.}

Acique Chrétien, nommé Henry, donné en commande. Le Cacique Henry eft maltraité par fon Mairre. Il nen peut. avoir juftice. Il fe retire do forme un parti, avec lequelil je canconne dans les Montagnes de Baoruco. Les EJgagnols Jont d fairs en plufieurs rencontres. Il difcipline Jes Troupes, or fe tient fur la $d$ fenfive. Sa moderation dans fes Victoires. Sa vigilince, for de quelle maniere il govverne fa République; fes.mefures pour mertre fa pere. fonne en fureté. La terreur de fon nom je répand partout, do les. gfets qu'elle produit. Un P. Francifquain va tratter avec le cacique. De quelle maniere il eft reçù dis Indiens. Ce qui fe paffe entre Ini oo le cacique. Il n'ubtient rien: extrêmité où la Colonie je trouve réduite. Vojage do Av nture d'un Navire. Anglois. Etat de l'Ifle Efpagnole en cetre année; $\sigma \sigma$ del Ifle de Cuba.L'Amival retourne aux Indes : mauviife conduite de Figneroa. Nouveaux Reglemens. Conduite de l'Amiral à Jon arrivée. Expédition de Luc Va quez d'Ail. lon dans la Fluride. Quel en fut le Jucces. Las Cafas repaffe aux In: des. Diux Dominiquiins maff crés à li Core de Cumana. Embar. ras de Las Cafas. Il s'oppofe envain à une expédition contre les Indiens. de Cumana. Succés de cetre expédition. Difficultés qu'on fait à Las Cafas pour fon entreprife. Il entre en accommodement avec I.Audience Royale. Il retourne à l'Ifle Efpagnole, ó pourquoi. Les Indiens pendant fon abfence arraquent la nouvelle Tolede. Les Efpagnols font obligés de fe fauver. Mort de Soto. L'Ifle de Cubagua évacuée. De quelle maniere Las Cafas apprend cetre Révolution. Il: fe fait Dominiquain. Les Indiens de Cumana font punis of foumis: Les Negres fe multiplient dans l'I fle Ejpagnole. Ils fe révoltent. Ils font défaits or punis. Muvvais fervice rendu à l'Amiral par Pafjas monté. Il eft rappellé en ESpagne, Goit connoitre fon innocence. Nouveaux Reglimens pour les Indiens. Balboa s'empare de toute. Irautborité dans la Province du Darien. Il envoge demander du for 


\section{E S S O M M A I R E S. xxvij}

cours à l'Amiral. Il fait la guerre aux Indiens avec fuccès. Premiers indices de la Mer du Sud, e du Perou Balboa reçoit de fâcheufes nowvelles de Caftille. Il décowvre la Mer du Sud. Il en prend poffeffion. Il retourne à Sainte Marie. D. Pedrarias Davila, Gouverneur de la Province du Darien. Son arrivée à Sainte Marie. Sa réception. Il fait faire le Procés à Balboa. Sa mawvaile foi en écri. vant au Roi. Et at ois fe trowve la Colonie. Balboa ef ñommé Adélantade de la Mer du Sud. Pedrarias lui fait couper la tête. Cruautés exercées par Predarias dans la Caftille d'Or. Sainte Marie l'Ancienne tranfportée à Panama. Il Jonge tout de bon à la découverte. du Perow. Affociation entre Pizurre, "Almagro, do Fernand de Luques, pour lu Conquete du Perou. Etabliffement de l' Ifle Marguerite ơ de Sainte Marihe. Mort de PafJamonté, \&o de l'Amiral D. Diegue. Etat de fa famille. L'Ifle Efpagnole fe dépeuple. Audience Royale du Mexique, diftrict de celle de San-Dominoo. Union des deux Evêchés de l Ifle Espagnolt. Nouvel Evêque de San-Dumingo: fa conduiie. On tâche irutilement de gagner lés Indiens révoliés. On ne.réuffit pas mienx par la force. Nuuvelles tentatives pour furprondre le Cacique. On entre en accommodement. Ce qui le fait rompre. Colonie envoyée dans le Venezuela. La Ville de Coro batie par fean d'Ampués. L'Empereur cede cette Province à des Allemands. Conditions de part eo d'autre. Divers Reglemens. Arrivée des Allemands à Coro. Leur mauvaife conduite er leur crucuté. Mort du Comm ndant, \&o diffiparion de la Troupe. Un Gouvirneur Efpagnol envoyé dans cette Province y commet de grands exces. On examine de nouve un l'aff ire de la liberté des Indiens. Délibération prife fur cela, fans effet. Abus,qui s'étoient glifés parmi les Navigateurs Efpagnols dans les Indes. Embarras du Prefident. Remede qu'il propole pour corriger ces abus. Réponfe aux objections concre ce projet. Il eft fans effit. Nowvelles Mines déconverres. La Guerre recommence avec les Indins. Un Commiffizire arrive de la part de l'Empereur pour la finir. On déllbere Jur le parri qu'on doit prendre. 2uel fut le réfultat de cette délibération. Marche de Barrio Nuevo pour chercher le Cacique. Courage de ce General à furmonter de grandes difficultés. Il déconvre le lien de la retraite du Cucique. Le cacique ervoje lui faire un compliment. Il arrive chés le Cacique. 


\section{xxviij TABLE DES SOMMAIRES.}

Son Difcours au Cacique. La Réponfe du Cacique. Conditions du Traité. Il eft ratifié par les Indiens. Accident, qui penfe rallumer la guerre; défiances du Cacique, \&o furquoi elles étoient fondées. Elles font levées, or la paix publiée. Le Pere de Las CaJas va trowver le Cacique. Ses Travaux Apoftoliques parmi les Indiens. Nouvel Eta. bliffement du coté de Monte Chrifto. D. Henry va à San-Domingo. De quelle maniere le Traitté fait avec lui eft exécuté. Décadence de la Colonie Efpagnole. L'Audience Royale fait monter la Monnoye, Gr l'Empereur le trowve manvais. D. Louis Colomb pafse à l'Espagnole en qualité de Capiraine General. Extinction de cette Famille. San-Domingo érig"éen Métropole. Quelle fut l'occafion, qui engagea Las CaJas à écrive Jon Livre de la Tyrannie des EJpagnols. Grand Commerce de lifle Ejpagnole. Prife de San-Domingo. Le Commerce défendu avec les Etrangers aux Habitans de l'ifle Efpagnole. Déperiffement entier de la Colonie.

Fin de la Table des Sommaires. 




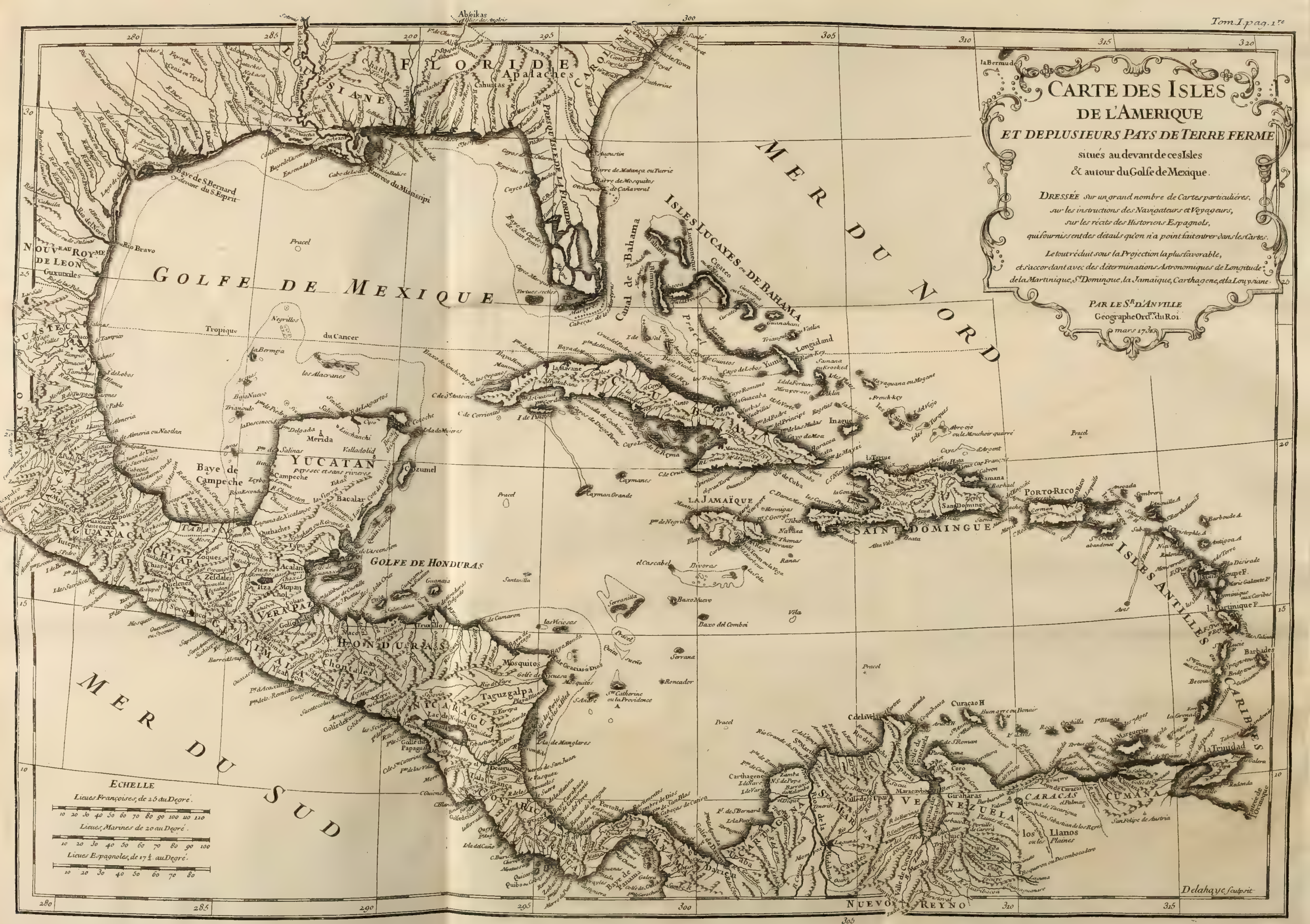


2

$v$

है 


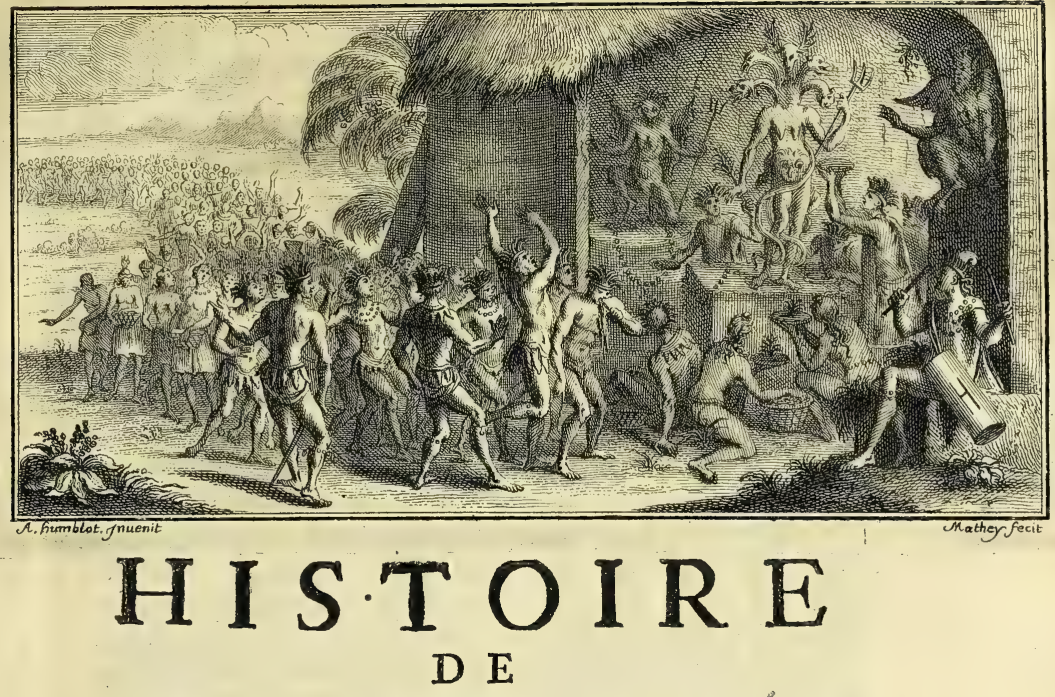

\section{L'ISLE ESPAGNOLE \\ O U D E}

\section{S. DOMINGUE. \\ PREMIERE PARTIE.}

L I V R E PRE M I E R.

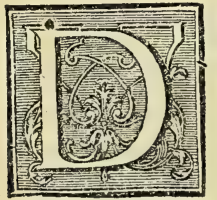

A s s cette partie de la mer du Nord qui Divifion eft renfermée entre les 8. \& les 28. degrés des Antillese d'élevation de Pole, \& s'étend en longitude depuis les 293. jufqu'aux 3 I 6 . degrés, on trouve une quantité prodigieufe d'Inles de toutes grandeurs qui portent communément le nom d'Antilles, \& forment le plus nombreux Archipel, que nous connoißtions dans l'Ocean. On les divife Tom. $I$. 
quelquefois en grandes \& petites Antilles : le nombre des grandes fe reduit à cinq, qui font, la Trinité, S. Jean de Portoric, l'Expagnole, ou S. Domingue, Cuba, \& la Jamaique. Celui des petites eft infini. Les vents, qui dans ces mers fouflent prefque toûjours de la partie de l'Eft, ont donné lieu à une autre divifion, qui eft beaucoup plus en ufage, fur tout parmiles Efpagnols, quoiqu'on ne foit pas bien d'accord fur le partage. Selon cette divifion, les Inles, qui font plus à l'Orient, fe nomment les Ifles du vent, \& les autres, les Ifles de deffous le vent. Ou pour me fervir des termes Caftillans à l'exemple de tous nos anciens auteurs; celles-ci font les Ifles de Sotto vento, \& les autres, les Ines de Barlo vento. Quelques anciennes cartes ne comprennent fous le nom des premieres que celles, dont eft comporée une chaine de petites Inles qui font fort prés de la terre ferme entre l'embouchure du grand fleuve Orenoque, \& l'en. trée du lac Maracaibo, \& du nombre defquelles font $\mathrm{Cu}_{\text {- }}$ bagua, autrefois l'Inle des perles, \& Curaçao ou Coraçol: mais aujourd'hui il paroît que les Inles de Sotto vento commencent à lline de Sainte Croix, \& que toutes celles, qui font à fon Orient \& à fon Midy, paffent fous le nom de $\mathbb{B}$ arlo vento. On auroit, ce femble, été mieux fondé à divifer les Antilles fuivant le caractere de leurs habitans naturels, dont les uns étoient les Caraibes, ou Cannibales, peuple feroce \& antropophage; \& les autres, qui n'avoient point de nom particulier, étoient extrêmement doux \& pacifiques, \& avoient en horreur l'ufage de manger la chair humaine. Cette difference partageoit naturellement ce grand Archipel en deux portions affés égales; mais la chofe ne merite pas qu'on s'y arrête plus long-tems.

Origine de Le nom d'Antille, que j'ai dit être general à toutes ces se nom. Itles, a exercé plus d'un écrivain, \& donné lieu à bien des fables. Le Miniftre Rochefort le fait venir de la particule Grecque àvi, le P. du Tertre de la Latine ante. Comme qui diroit, felon le premier, Ines oppofées au Continent, \& felon le fecond, Ifles, qu'on rencontre avant que d'arriver 


\section{DE S. DOMINGUE, IIV. I.}

a la terre ferme. Antoine Herrera, un des plus exacts \& des plus judicieux écrivains, qui ayent parlé du nouveau monde, croit avec plus de fondement que ce nom a été donné aux premieres Ifles, qu’on a découvertes dans l'Amérique, à caufe d'une Ifle imaginaire, qui fe trouvoit marquée fur d'anciennes cartes fous ce même nom, \& qui le devoit peutêtre à la fameufe Thulé des Poëtes. Les Géographes Portugais plaçoient l'Antille environ à deux cens lieuës des Açorres vers l'Occident, \& ils l'appelloient encore l'Ine des fept villes. Ce qu'il ya eu de plus facheux, c'eft qu'un affés grand nombre de particuliers de cette nation, \& peut-être auffi quelques Caftillans fe font ruinés, ou ont peri en cherchant cette Ifle. Ce qui les engageoit dans cette recherche étoit une vieille tradition populaire, que dans le têms de l'invafion des Efpagnes par les Maures fept Evêques s'étoient embarqués avec quantité de Chrétiens pour fuir la perfécution des Mahometans, \& qu’après avoir long-têms erré au gré des ondes \& des vents, ils avoient pris terre dans un port de l'Antille, qu'ils s'y étoient établis, après avoir mis le feu à leurs navires, \& que chaque Evêque y avoit bati une ville. Des auteurs Portugais ajoûtent que vers le milieu du quinziéme fiecle, dans le têms que l'Infant D. Henry Comte de Vifeo mettoit toute fa nation en mouvement pour chercher un nouveau chemin aux Indes, un navire de Portugal fut jetté par la tempête fur les côtes de l'Antille, que le Comte de Vifeo layant fçu, voulut y renvoyer le Pilote; mais que celui-ci n'ofant entreprendre un fi long voyage, d'autant plus qu'il n'avoit pas obfervé fort exactement la route quili avoit tenuë à fon retour en Portugal, \& craignant qu'on ne le fit embarquer malgré lui, fortit du royaume. Cependant quelques fabuleux que ces recits ayent paru à Herrera, cet auteur n'a pas laiffé de croire, \& il a cru fans doute avec fondement, que le nom de l'Antille imaginaire avoit été donné aux Ines, que Chriftophle Colomb découvrit, par la raifon qu'elles fe trouvoient fituées à peu près au même endroit, où celle-là avoit été placée parles Géographes. 
The Efpa- Quoi qu'il en foit parmi toutes les Antilles une feule at:

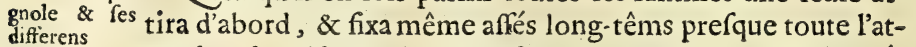
noms. $\quad$ tention des Efpagnols, \& c'eft celle, dont j'ai entrepris d'écrire l'hiftoire. Elle n'eft pas la plus grande, mais elle eft fans contredit la plus riche de toutes: nulle autre ne pouvoit mettre les premiers conquérans de l'Amérique en état de s'établir folidement au delà des mers, \& l'on peut dire qu'elle a enfanté toutes les Colonies Efpagnoles du nouveau monde. Ses premiers habitans la nommoient Quifqueia \& Haïti. Le premier de ces deux noms fignifie une grande terre, \& le fecond, une terre montagneufe, mais elle a perdu l'un \& l'autre en changeant de maîtres. Si l'on en croit Dom Pierre Martyr d'Anglerie, cette Ifle fut d'abord peuplée par des Sauvages venus de la Martinique, autrement dite Matinino, lefquels furpris de fa grandeur, crurent que c'étoit la plus grande terre du monde, \& la nommeren Quifqueia, du mot Quifquey, qui en leurlangue fignifioit, Tout: puis ayant aperçu de longues chaînes de montagnes, qui occupent prefque tout le milieu de l'Ihe, \& dont plufieurs la traverfent d'un bout à l'autre, ils l'apellerent $H$ aitit; c'eft-â-dire, pays rude \& montueux. Enfin comme parmices montagnes ils en eurent vâ d'affés femblables à celles de leur Inle, dont le nom dans leur langue naturelle, étoit Cipangi, ils lui donnerent celui de Cipanga. Mais je crois devoir avertir ici, que j'ai trouvé quelquefois Pierre Martyr d'Anglerie peu exąt dans ce qu'il a ecrit du nouveau monde. Son hiftoire n'eft qu'une fuite de lettres qu'il écrivoit à differentes perfonnes, \& il paroît qu'il les écrivoit fur les premiers bruits, qui couroient à la Cour d'Efpagne, où il étoit dans le têms des découvertes de Chriftophle Colomb.

Sa fituation

Au refte il eft furprenant qu'on foit encore aujourd'hui fi \& fon étendue. peu d'accord fur la firuation d'une Ine, que toutes les nations de l'Europe ont fréquentée depuis deux fiecles plus

xe P. Pierre qu'aucune autre de l'Amérique. Un Miffionaire, qui y travaille Boutinjefuite depuis vingt-cinq ans, \& qui a eu un très-grand foin d'obferver toutes les Eclipres, prétend avoir totijours conftam- 


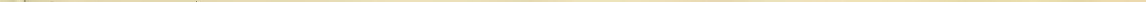




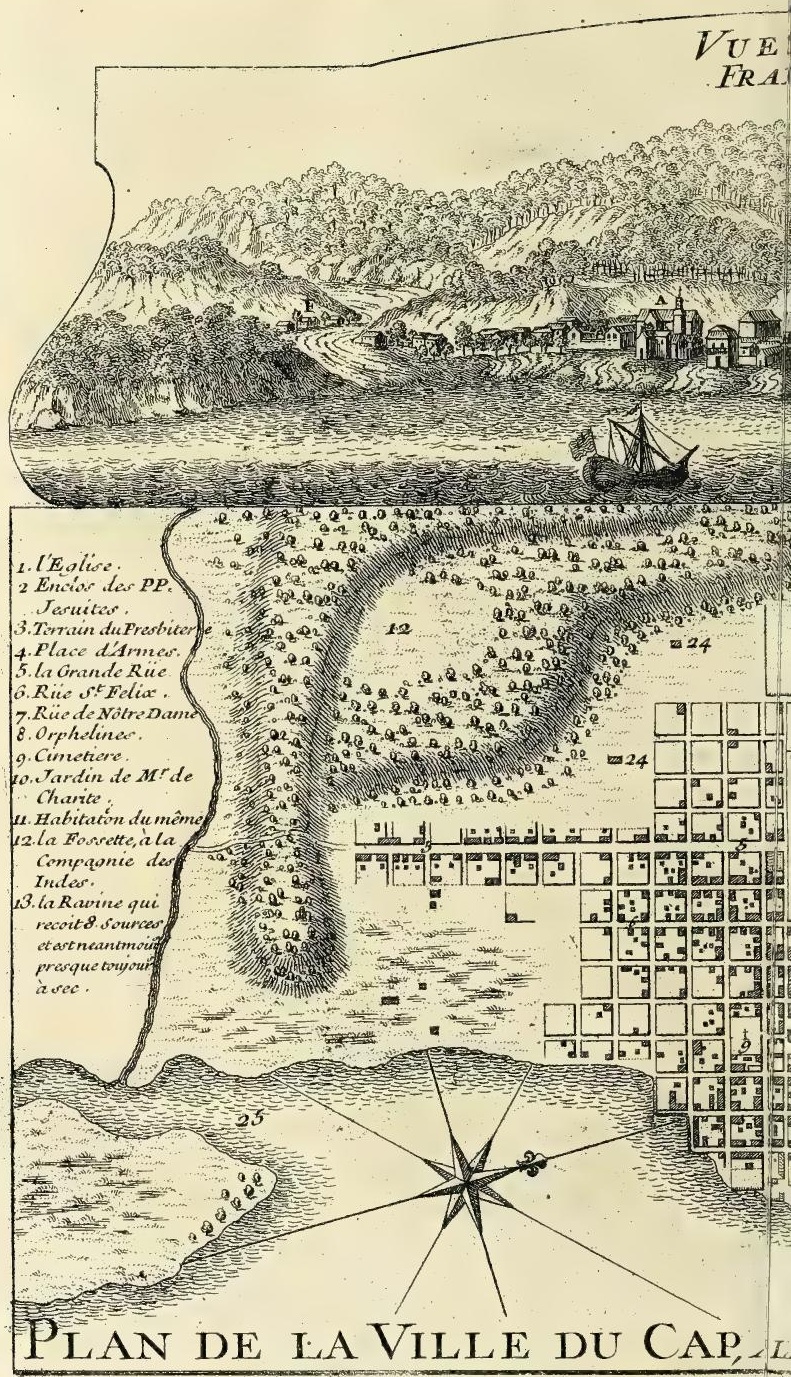




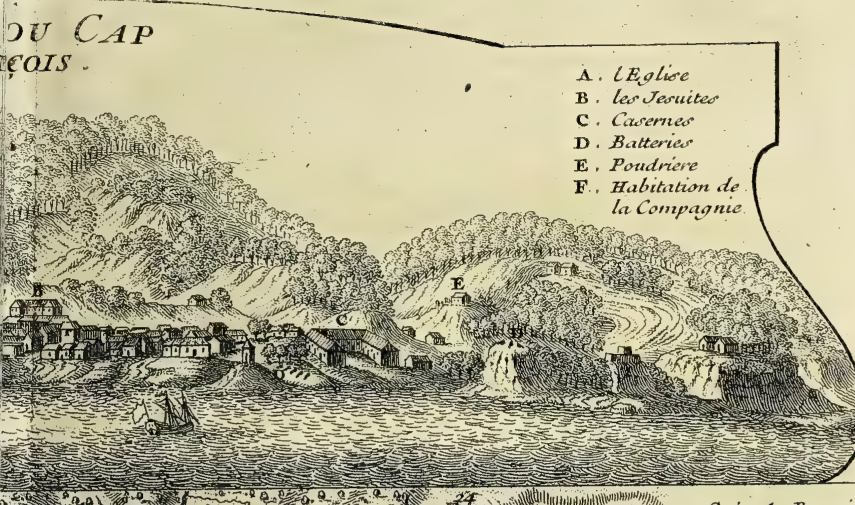

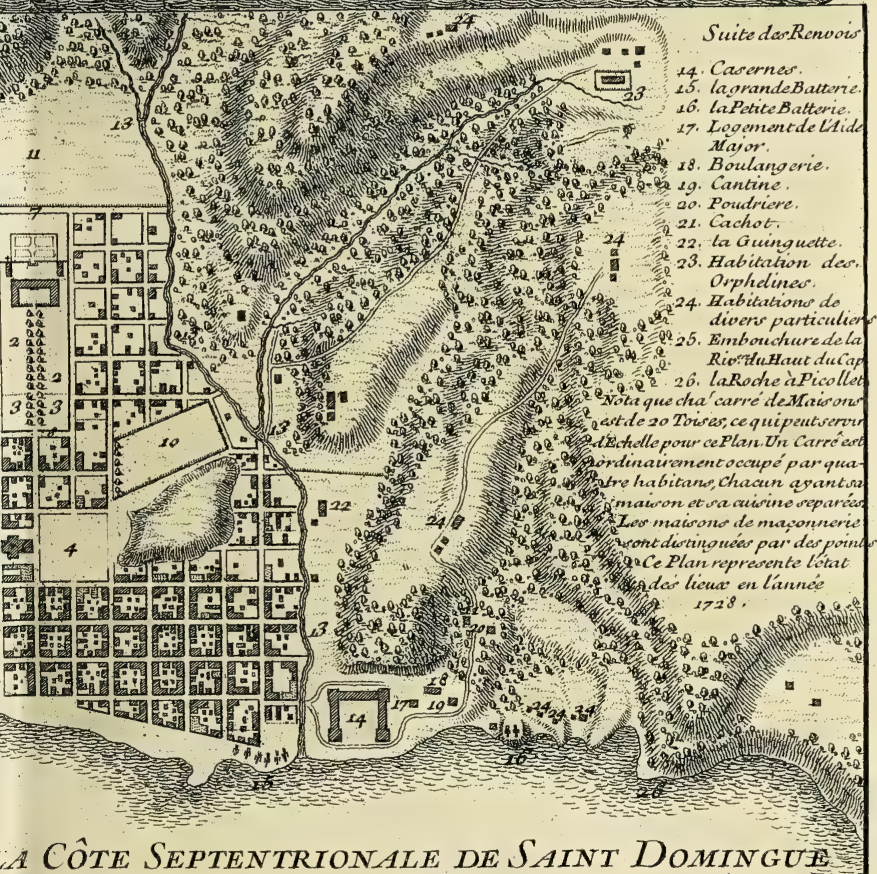





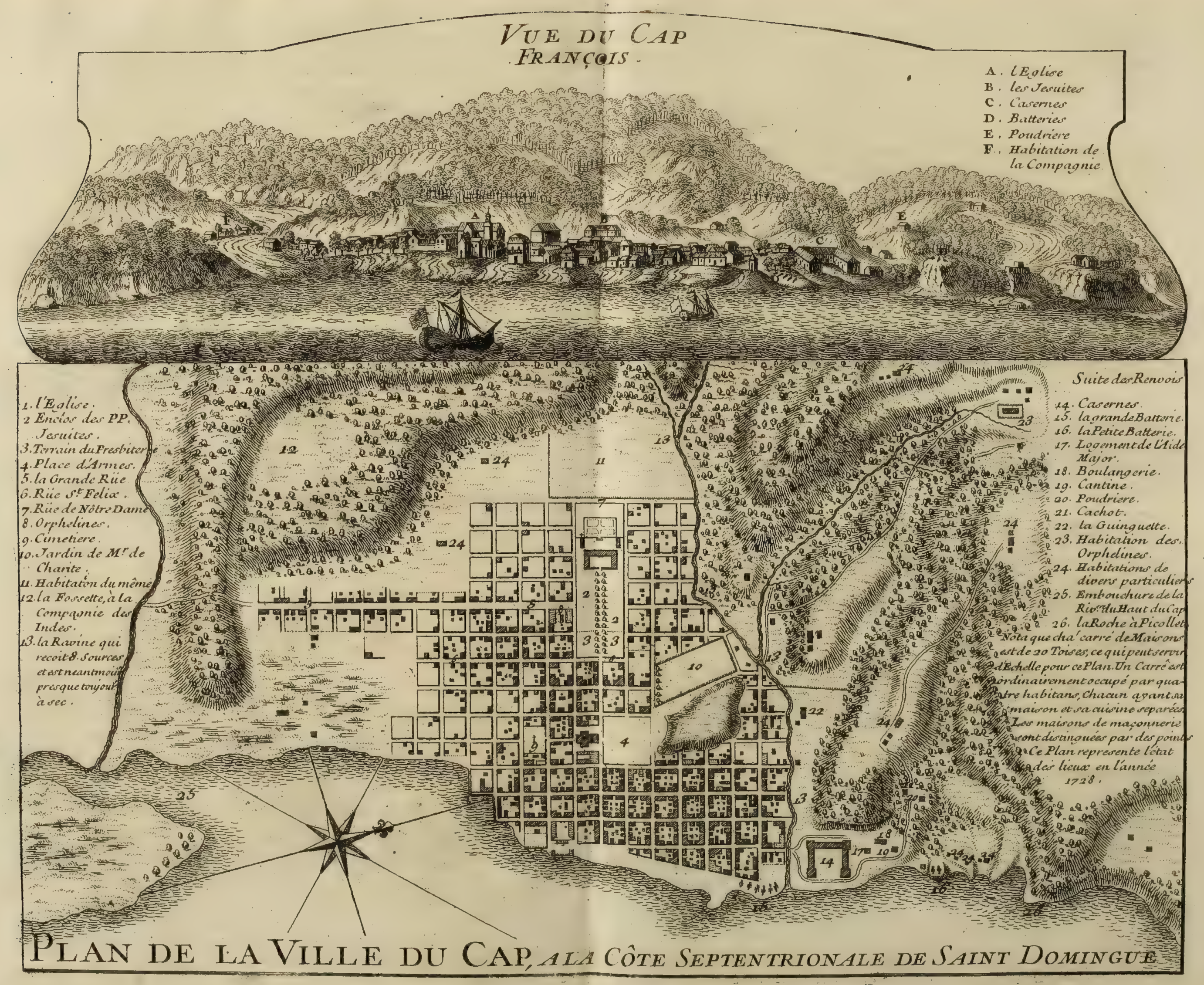





\section{DE S. DOminguE, LIV. I.}

ment trouvé 4 . heures $43^{\circ}$. \& $5 \mathrm{r}^{\prime \prime}$. de difference entre le meridien de l'Obfervatoire de Paris \& celui dı Cap François, d'où il s'enfuivroit que ce Port eft au $308^{\circ}$. degré de longitude. D'un autre côté fuivant l'obfervation, que le P. Feuillée a faite à la Caye S. Loüis des Satellites de Jupiter,ce Port eft au 304. degré, \& la difference de longitude entre la Caye S. Loüis \& le Cap François n'eft felon M. Frezier que d'un degré \& environ 55. minutes. Pour ce qui regarde la latitude, il paroit certain que la pointe de $S$. Loüis auprès du Port de Paix , qui eft l'endroit de l'Ifle le plus Septentrionnal , eft par les 20 . degrés deux ou trois minutes d'élévation de Pole, fur quoi il faut réformer les Cartes Hollandoifes, dont l'erreur en ce point a été caufe de plufieurs naufrages fur le Mouchoir quarré, écueil, dont nous parlerons bientôt. Quant à fon étenduë, fa longueur eft d'environ I 60 . lieuës du Levant au Couchant; fa largeur moyenne du Nord au Sud eft eftimée de trente, \& elle en a environ 350 . de circuit; ceux qui lui en donnent 600 . font le tourdes anfes.

La fituation de cette Ifle par raport aux autres Antilles ne Ses environs. pouvoit être plus avantageufe, elle en eft prefque environ. née, \& l'on diroit qu'elle a été placée au centre de ce grand Archipel pour lui donner la loi. Les trois autres grandes Antilles de Sottovento paroiffent fur tout difpofées de maniere à faire fentir fa fuperiorité, \& leur dépendance ; car elle a comme trois pointes avancées, à chacune defquelles répond une de ces trois Ines. Le Cap Tiburon, qui la termine au Sud-Oueft, n'eft qu'à 30 . lieuës de la Jamaïque: entre celui de l'Erpade, qui eft fa pointe Orientale, \& Portoric, il n'y en a que 18 . \& 12. feulement du Cap ou Mole S. Nicolas, qui regarde le Nord-Oneft, à l'llfe de Cuba. Outre cela on trouve autour de l'Efpagnole plufieurs petites Ifles, qui en font comme des annexes, \& dont elle peut encore tirer de grands avantages. Les plus confiderables font la Saona, la Beata, Sainte Catherine, Altavela, l'Ifle à Vaches, la Gonave \& la Tortuë; fans compter la Navazza \& la Mona, dont la premiere eft à dix lieuës dus 


\section{6}

\section{I $S$ T $\bigcirc$ I $R$ E}

Cap Tiburon vers la Jamaïque, \& la feconde d moitié chemin du Cap de l'Efpade à l'Ine de Portoric.

Mais la nature n'a pas moins pourvû à la fureté de notre Ine, qu’à fa dignité \& à fa commodité. On voit tout au tour quantité de rochers qui en rendent l'abord affés difficile; la bande du Nord eft fur tout bordée d'écueils \& de petites Ines fort baffes,entre lefquelles il n'y auroit pas de prudence à s'engager, avant que de les avoir bien connuës. On a cru longtêms que celui de ces écueils, que les Efpagnols nomment $\mathcal{A}$ brojo, \& les François le Mouchoir quarré, étoit le plus reculé de tous à l'Orient; mais aux dépens d'un aflés grand nombre de navires, on a reconnu qu'il y avoit encore d'autres brifans au Sud-Ef, ce qui joint aux obfervations fur lefquelles on a reculé l'Ine de 20 . minutes vers le Sud, en a rendu l'atterrage beaucoup plus fùr. A l'Ouef du Mouchoir quarré, \& prefque fur la même ligne font tout de fuite plufieurs grouppes de perites Ifles affés baffes, entre lefquelles il n'y a de paffage que pour des chaloupes, \& quelquefois même pour des canots. Les unes font nommées Inles Turques, \& les autres font connuës fous le nom de Caïques. Mais elles ne font pas toutes auffi inhabitables, qu'on le croit communément, \& il y en a même dont les côtes font fort faines, du moins en quelques endroits. J'en ai rangé une tout un jour de fort près fur un navire de 400 . tonneaux, \& elle me parut avoir en plufieurs endroits des terres affés élevées, \& d'une bonne nature. Les Inles Turques, qui font les plus Orientales, portent encore le nom d'Amanas, \& elles ont des falines naturelles, dont les Anglois de la Bermude \& de la Jamaïque tirent un grand profit.

Obfervations Les Lucayes font après les Caïques, \& il n'y a entre les furles côtesde unes \& les autres, qu'un débouquement affés étroit. C'eft le le \& fur les paffage de tous les navires, qui fortent du Cap François poü marées. retourner en France. Les plus Occidentales des Lucayes ne font féparées de la Floride, que par un canal, qui n'a nulle part pius de 20 . lieuës de largeur, \& auquel l'Ine de Bahama la deraiere de toutes a donné fon nom. Ces Ifles font aujourd'hui 


\section{DE S. DOMINGUE, LIV. I.}

inhabitées, fil l'on en excepte celle de la Providence, oû les Anglois ont un affés petit établiffement. La plûpart même n'ont jamais eu d'habitans fixes, \& font peu fertiles; mais on y voit une quantité prodigieufe de gibier à plumes, leurs côtes font auffi beaucoup plus poiffonneufes que celles des grandes Ifles, celles de la nôtre fur tout, le font très-peu, fi ce n'eft aux embouchures des rivieres, \& par tout où monte Ia marée, c'eft-à dire, l'éfpace d'un quart de lieuë au plus. Sur quoi il eft bon d'obferver en paffant que le flux ne monte jamais en aucun endroit des Antilles plus haut de trois pieds.

A juger du climat de cette Ine par fa fituation, on pourroit croire que les chaleurs y font exceffives pendant les fix mois de l'année, que le Soleil demeure entre la ligne équinoctiale \& notre Tropique; \& cela feroit fans doute, fans un vent d'Orient, que l'on appelle Brife, aparemment parce qu'il brife les rayons perpendiculaires du Soleil, \& en ralentit la grande ardeur. On le nomme aufi vent Alifé du vieux mot François $\mathscr{A}$ lis, qui vouloit dire, uni. Effectivement il n'eft point de vent plus égal, ni qui fouffle plus uniment que celui-là. Cette étymologie eft fi naturelle, qu'il eft étonnant qu'on ne s'en foit point encore avifé. Mais de tous ceux, qui ont entrepris d'expliquer la nature de ce vent, perfonne à mon avis n’a mieux rencontré que le P. Jofeph de Acofta Jefuite dans fon Hiftoire naturelle \&s morale des Indes. Cet auteur commence par obferver qu'un effet permanent, univerfel \& qui n'eft point accidentel, doit avoir une caufe, qui foit permanente, univerfelle, \& naturelle. Or, ajoûte-t-il, la Brife regne toûjours dans la Zone torride, aux endroits, où la mer eft affés large, pour donner aux vents la liberté de foufler : voilà un effet permanent, univerfel, \& qui n'eft point accidentel; il a donc une caufe permanente, univerfelle, \& qui lui eft propre; cette caufe n'eft autre, felon lui, que le mouvement diurne, qui agite les globes celeftes d'Orient en Occident; \& ce mouvement il l'attribuë au premier mobile; mais il

De la Brife. 
ne faut pas incidenter fur ce fentiment, qui ne fait rien au fonds du fyftême, que cet auteur apuye fur ces deux principes.

Le premier, que le mouvement, dont il s'agit, paffe jufqu'aux élémens, tandis qu'il ne trouve pas une réfiftance capable de l'arrêter, telle qu'il la rencontre dans le globe de la terre. Il ne la trouve certainement pas dans la region fuperieure de l'air, qui fuit fon impreffion, ce qui eft démontré parles Cometes; à plus forte raifon ne la trouve t-il pas dans les élémens fuperieurs, qui font encore plus aifés à mouvoir. Le fecond principe du P. de Acofta eft que ce mouvement diurne doit être plus rapide fous la ligne Equinoxiale, que par tout ailleurs, \& s'affoiblir à mefure qu'il s'en éloigne, puifque fon centre eft directement fous cette ligne. Or tout cela eft parfaitement conforme à l'expérience, \& à la bonne Phyfique, $\mathrm{y}$ ayant, dans les opinions mêmes, qui ne mettent point la terre au centre du monde, une difference, qui n'eft pas affés grande, pour former fur cela une difficulté confiderable. Paffé le Tropique ce mouvement de circulation n'eft prefque plus fenfible dans la region de l'air, que nous habitons, \& alors les vapeurs dela terre, que la Brife avoit entraînées avec elle, heurtant contre celles, que le Soleil attire fous des climats plus froids, \& dont le feul mouvement fenfible eft celui, que leur donne cet aftre en les attirant, y trouvent une réfiftance, qui les refléchit, auffibien que l'air, qui les entraîne, comme il arrive en mer, quand deux courans oppofés fe rencontrent \& fe choquent. Et voilà pourquoi entre les 26 . \& les 36 . degrés de latitude les vents fouflent pour l'ordinaire de la partie de l'Oueft; moins reguliérement néanmoins que la Brife entre les Tropiques, parcequ'ils n'ont pas une caufe auffi forte, ni qui leur foit auffi propre. Ils font auffi bien plus fujets à devenir orageux, parce que fous ces climats l'air eft beaucoup plus fufceptible de tous les divers mouvemens, que peuvent produire les caufes accidentelles. Enfuite plus on aproche des Poles, \& moins il y a de regles certaines pour les vents; 


\section{E S. D o м I $N$ G U E L I $\mathrm{I}$.}

auffi voit-on qu'ils y font très-variables, foit fur tèrre, foit fur mer. Il y a même des pays entre les Tropiques, où ces variations fe font fentir; mais on en voit d'abord la raifon, c'eft que la mer y eft moins libre, car il ne faut qu'une terre un peu haute, ou une chaîne de montagnes, pour replier la Brife fur elle-même \& en faire un vent d'Oueft, ou bien la détourner vers le Nord, ou vers le Sud.

Il faut cependant convenir que fi la Brife n'avoit point d'autre caufe, que celle, dont je viens de parler, elle n'auroit pas autant de force, qu'elle en a : mais il n'y a point de doute qu'elle ne foit aidée par la chaleur du Soleil, qui venant à paroître fur l'horifon, raréfie l'air \& l'oblige de fluer vers l'Occident, où il en rencontre un, que la fraicheur de la nuit.y a condenfé. Et voilà en même têms de quoi répondre à ceux, qui objecteroient contre l'opinion du P.de Acofta la difcontinuation d'un vent caufé par un mouvement continuel \& de foi toûjours égal; car on leur dira, ce mouve. ment n'eft pas affés fenfible par lui-même pour produire ces fortes Brifes, que nous fentons, \& quand l'attraetion du Soleil, qui le fortifioit, vient à ceffer, il n'eft pas en état de réfifter à plufieurs caufes accidentelles, qui le détruifent. Les petites variations, qui s'y remarquent, comme par exemple, qu'il prend tantôt un peu du Nord, \& tantôt un peu du Sud, s'expliqueront ailément par les principes, que je viens de pofer. Je reviens à notre Ifle.

Le vent d'Orient ne fe fait gueres fentir fur fes côtés, que yers les neuf ou dix heures du matin, parce que jufques-là lair n'eft pas fuffifamment dilaté par la chaleur du Soleil, pour produire un mouvement fenfible. Auffi les matinées y fontelles fort pefantes, quand la Brife tarde un peu trop. Elle croît à mefure que le Soleil monte fur l'horifon, \& décroît à mefure qu'il defcend: elle tombe enfin tout-à-fait avec lui, mais le long des terres feulement, \& non en pleine mer. Or voici la raifon de cette difference. Après le courcher du Soleil l'air de la mer fe condenfe plûtôt que celui de la terre, qui demeure plus long-têms raréfié à caufe des exhaTom. I. 
laifons chaudes, que la terre échauffée produit continuellement. D'où il arrive que l'air de terre refluë néceffairement fur celui de mer, \& c'eft ce qu'on appelle ordinairement vent de terre. Il fe fait fentir la nuit, \& continuë jufqu'à ce que l'air de la mer commençant à fe rarefier par la chaleur du Soleil, refluë à fon tour vers la terre, où l'air s'eft enfin condenfé par la fraicheur de la nuit, ce qui forme un petit vent prefque infenfible, dont bien des gens ne s'apperçoivent pas, lequel foufle de la mer vers la terre une heure ou deux avant le lever de la Brife. La nature de ce vent ainfi developpée, on explique aifément tous fes effets. Par exemple, pourquoi dans l'Amérique il eft plus fort en Eté qu'en Hyver, \& fous la Canicule, que fous toute autre conftellation. C'eft qu'alors le Soleil agit avec plus de force fur l'air : en quoi l'on ne peut fe laffer d'admirer la fageffe \& la bonté du Créateur, d'avoir fait fervir les plus grandes ardeurs du Soleil au rafraichiffement de l'air dans les pays, où il en eft plus embràfé.

Des Pluyes. Les pluyes contribuent auffi beaucoup à temperer le climat de notre Ifle. Elles y font fréquentes, fur tout dans les plus grandes chaleurs, \& l'on a obfervé que dans la plûpart des pays renfermés fous la Zone torride, les pluyes augmentent à mefure, que le Soleil avance vers le Zenith. Quelques perfonnes ont prétendu qu'il y a des femaines, pendant lefquelles il tombe autant de poulces cubiques de pluye dans la feule Ine, qui fait le fijet de cet Ouvrage, quili en tombe en toute une année à Paris, ce que M. Mariot fait monter à I 8 . l'un portant l'autre. Mais ces pluyes fi abondantes en rafraichiffant l'air caufent une humidité, qui produit de facheux effets La viande s'y conferve à peine 24. heures fans fe corrompre; il y faut enterrer les morts peu d'heures après qu'ils ont expiré; la plûpart des fruits murs fe pourriffent, dès qu'ils tont ceüillis, \& ceux même, qu'on ceüille avant leur maturité, ne durent pas long-têms fans fe gater; le pain, s'il n'eft fait comme du bifcuit, fe moifit en deux ou trois jours; les vins ordinaires. 


\section{De S. DOMINGUe, LIv. I. It}

y tournent \& s'aigriffent en peu de têms; le fer s'y roüille du foir au matin; \& l'on-a bien de la peine à conferver le ris, le maï, \&\& les feves d'une année à l'autre pour les femer.

Une des chofes qui furprend davantage dans cette Ine, c'eft la varieté de climats, qu’on y trouve, \& rien ne fait des climats $\&$ mieux voir combien la nature \& les qualités du terroir mettent de difference dans l'air. De deux cantons, qui fe touchent, l'un eft continuellement inondé de pluyes, \& l'autre n'en a prefque jamais. Les nuages s'arrêtent tout court au moment, qu'ils arrivent fur fes confins; il s'en détache feulement quelquefois de petites vapeurs, qui répandent quelques gouttes de pluye, \& fe diffipent d'abord. Il eft moins furprenant que cette difference fe rencontre entre la côte du Nord \& celle du Sud, quoique leurs diftances foient en quelques endroits affés peu confiderables. En effet, fi tandis qu'à la fin de Novembre la côte du Sud, \& même celle de l'Oueft fouffrent de grandes fechereffes, celle du Nord eft arrofée de pluyes continuelles, plus ou moins toutefois, felon que les pays Septentrionaux ont eu l'Hyver plus ou moins rude; c'eft que les vents, qui ont porté dan ses climats éloignés du Soleil les frimats \& les neges, ne pouvant caufer que des pluyes dans un climat plus chaud, s'y refolvent en eaux, \& fe déchargent d'abord, deforte qu'il n'y a ordinairement que les premieres terres, qui en profitent; \& que les Ifles du vent, dont la plus Septentrionale eft au $17^{\circ}$. degré, ne s'en reffentent prefque point. Il eft même rare que dans les autres elles aillent au delà des premieres montagnes. Il eft vrai que le mois d'Avril paffé, les terres, qui font demeurées à fec pendant tout l'Hyver, font inondées à leur tour, \& tandis qu'à la côte du Nord il fe paffe cinq ou fix femaines de fuite, fans qu'il y tombe une goutte d'eau, par tout ailleurs ce font des déluges de pluyes accompagnées d'orages $\&$ de tonnerres. La caufe de ceci eft la Brife, qui foufle alors avec beaucoup de force, \&r chaffe les nuées à mefure qu'elles fe forment; car ces 
nuées ainfi chaffées vont crever dans les montagnes. Par la même taifon il y a des cantons, où il ne pleut prefque jamais; la Brife y ayant un plus libre accès, il faut, pour qu'il y pleuve, que lorage foit exceffivement gros, \& qu'il foit pouffé par un vent d'Oueft, ou de Sud affés fort, pour faire ceder celui d'Eft. Il y a de ces vents de Sud extrêmement impetueux, mais ils ne durent point. Il paroit que ce font des Brifes réflechies par des vents plus forts, qui les rencontrent fur mer.

Caufes de la fraicheur \& de la clarté des nuits.

Le tonnere fe fait rarement entendre depuis le mois de Novembre jufqu'en Avril, parce que le Soleil ne demeure pas alors affés long-têms fur l'horifon, pour enflammer les exhalaifons de la terre. Car quoi que l'élevation de cet aftre foit là plus grande à l'Equinoxe de Mars, qu'elle n'eft à $\mathrm{Pa}$. ris au folftice d'Eté, les jours néanmoins y font plus courts de 4 . heures \& davantage, \& en tout têms cet aftre tombant perpendiculairement pendant fix mois, le crepufcule n'y fçauroit être fort long. Les nuits ne font pourtant jamais fi noires, qu'on ne voye affés pour fe conduire, à moins que le ciel ne foit couvert; \& il y a deux raifons de cela. L'une, que les planettes étant plus élevées fur l'horifon, envoyent une plus grande quantité de rayons, \& qu'elles y font plus perpendiculaires. L'autre, que l'air y eft plus pur \& plus ferein, les vapeurs, dont il fe charge, fe refolvant plûtôt en pluyes \& en rofées, que dans les pays froids. C'eft encore par cette raifon qu'il n'eft point rare d'y voir des étoilles en plein midy vers le Zenith, \& d'y lire des caracteres même affés menus à la clarté de la Lune, dont les rayons ont fouvent affés de force pour produire de Axcsen-ciel.

Des Rofées Dès que les pluyes ont ceffé dans un endroit, les ro2 des Brouil- fées y deviennent très-abondantes, \& l'on en voit d'abord
lards. la raifon. Le Soleil élevant dans ce pays plus de vapeurs pendant le jour, que fous un climat plus froid, \& les nuits plus longues y ayant plus de têms pour les condenfer, il faut qu'elles fe déchargent enfin d'une maniexe ou d'une 


\section{DE S. DOMINGUE, LIV. I. I 3}

gutre; \& fans cela toutes les plantes fécheroient fur pied. D'un autre côté les broüillards n'y font pas fi communs, ou font plûtôt diffipés, le Soleil par fa maniere de s'élever perpendiculairement acquérant bientôt affés de force pour les réfoudre en rofées: auffi eft il rare qu'on paffe un jour fans voir ce bel aftre. Parła même raifon peu de perfonnes fe plaignent du ferein : il n'en eft pas de même de la fraicheur de la nuit, à laquelle plufieurs attribuent une bonne partie de leurs maladies. Cette grande fraicheur fe fait fur tout fentir, quand le têms eft calme, \& le ciel pur, ce qui eft très ordinaire dans les provinces Méditerranées. La plûpart du têms il n'y fait pas un foufle de vent le matin, les rofées y font très-fortes, \& les plaines en font toutes blanches : quelques-uns ont même affùré qu'ils en ont vû de gelées. Il eft au moins certain que le froid y eft quelquefois affés picquant, \& qu’on eft obligé de s'aprocher du feu, ou de chercher le Soleil. On en fera moins furpris, fi on fait réflexion que ces plaines étant environnées de montagnes très-hautes, le Soleil s'y couche plûtôt, \& s'y leve plus tard quailleurs; par confequent les nuits y font toûjours rrès-longues.

Cependant de ce peu de conformité, qui fe rencon- Difference tre dans l'air entre les differentes parties d'une même Inle, des Saifons. il arrive que fes habitans ne conviennent point de ce qu'ils doivent appeller l'Hyver \& l'Eté. Ceux qui font à l'Oueft \& au Sud, \& dans le milieu des terres, prennent pour l' $\mathrm{Hy}$ ver le têms des orages, c'ett-à-dire, depuis Avril jufqu'en Novembre. On fe conforme davantage à notre maniere de compter les faifons fur la côte du Nord, mais nulle part on ne connoît communément ni Printêms, ni Automne. Ceux pourtant, qui obfervent les chofes de plus près, partagent ainfil'année. L'Hyver, felon eux, commence au mois de Novembre, \& finit en Février. Alors les nuits \& les matinées font fraiches \& même un peu froides, les plantes reçoivent peu d'accroiffement, \& les herbes prennent peu. de nourrituxe, quoi que ce foit le têms des grandes pluyes. 
Cela caufe fouvent des mortalités parmi les befúaux. Ie Printêms fuit, \& dure jufqu'au mois de May : la nature femble renaître alors ; les prairies font revêtuës d'une herbe nouvelle; la féve monte aux arbres; les plantes font parées de leurs fleurs, \& l'air en eft tout embaumé. La féchereffe, qui fuit, \& fait difparoître tous ces agrémens, ne reprefente que trop bien l'Eté, car c'eft un Eré de la Zone torride. Il dure jufqu'à la fin d'Août. Enfin les orages, qui après quelque interruption recommencent de nouveata à fondre fur ces quartiers, depuis le décours de la Lune d'Août: jufqu'au mois de Novembre, mettent affés de reffemblance entre cette faifon \& notre Automne.

Incommo.

De tout ce que je viens de dire il réfulte qu'il faut être dités du cli-
mat de notre Inle.

bien fort \& bien fage, ou être naturalifé à ce climat, pour
y vivre longtêms. Aunfi voit-on peu d'Europeans, qui au bout de quelques années de fejour dans notre Ifle ne s'aperçoivent d'une grande diminution de leurs forces. La cha. leur mine infenfiblement par fa continuation les corps les plus robuftes, qui n'y font pas accoûtumés, \& y détruit peu-à-peu ce que les Medecins appellent l'humide radical, n'y ayant point d'Hyver pendant lequel la nature puife réparer fes forces perduës par une violente tranfpiration. Delà vient que toute la vivacité de la couleur du vifage fe ternit, qu'on fent dans l'eftomach un grande diminution de la chaleur naturelle; que le fang, qu'on fe fait tirer, même par précaution, eft tout livide; qu'une faignée faite indifcretement fuffit pour caufer une hydropifie; que quand on eft échauffé, on n'a point cette avidité, que nous fentons pour les rafraichiffemens, quau contraire on recherche avec empreffement tout ce qui échauffe; qu'on y vieillit de bonne heure; \& que les enfans nés de parens, qui font venus d'Europe, y font moins formés, moins forts, \& qu'il en meurt beaucoup. Mais tout cela vient auffi en partie du peu de foin qu'on a de fe ménager, $\&$ de l'excès, foit de la débauche, foit du travail : d'ailleurs à mefure que les Creols s'éloignent de leur origine Européane, on les voir 


\section{DE S. Domingue, Liv. T. Is}

beaucoup moins fujets à ces inconveniens. Les anciens Infulaires fe portoient fort bien, \& vivoient long-têms; les Negres y font forts, \& joüffent d'une fanté inalterable. auff bien que les Efpagnols, qui y font établis depuis deux fiecles : il n'eft point rare d'en voir, qui vivent jufqu'à 120. ans. Enfin, fi l'on y vieillit plûtôt qu'ailleurs, on y demeure plus long-têms vieux fans reflentir les incommodités de l'extrême vieilleffe.

J'ai dit que la difference des climats, qu'on éprouve dans notre Inle venoit, du moins en partie, de la diverfité de fon terroir, il s'y en voit effectivement de toutes les fortes \& de toutes les couleurs. Celui, dont on fait plus de cas, eft d'un noir tanné \& mêlé d'un peu de fable, qui fert à le rendre leger, mouvant \& poreux, mais il n'en eft point, ou il en eft peu, dont on ne puife tirer quelque avantage. La moitié de l'Inle eft en montagnes, mais la plûpart fe peuvent cultiver jufqu'à la cime, il n'y en a de fteriles, que quelques-unes, qui font efcarpées, \& d'une hauteur extraordinaire, comme celles qu'on trouve vers le Cap Tiburon; d'où l'on découvre celles de Sainte Marthe, qui en font é loignées de 180 . lieuës. Il y en a fur les côtes qui fervent de digues aux fureurs de la mer, \& malheur aux navires, qu'un coup de vent jetteroit fur ces côtes fans rivages, où Yon ne voit que des rocs fourcilleux, qui s'élevent tout droit, \& que pour cette raifon on appelle côtes de fer. Telle eft en particulier celle, dont l'extremité Orientale aboutit au Cap François, qui en a pris fon nom, \& l'Occidentale, au Port de l'Acul.

Dans quelques endroits, dès qu'on a creufé quelques pieds on trouve le tuf, en d'autres l'argile, ou la terre glaife, ou niere dont les de la terre à pot, ou enfin un lit de fable; mais fouvent leurs racines. auffi la bonne terre a beaucoup de profondeur; \& ce qui furprendra peut-être d'abord, c'eft que ce dernier terrein eft fouvent le plus dégarni d'arbres. Il y a pourtant une raifon fenfible de cela: c'eft la fechereffe, laquelle dure trois ou quatre mois de fuite dans les trois quarts de l'Inle, \& empêche

De la difference des terroirs. 
ces terres de pouvoir fournir aux arbres un fuc fuffifant pour les nourrir; au lieu que dans les autres les pluyes \& les rofées étant arrêtées par les fonds durs, dont j'ai parlé; entretiennent le peu de bonne terre, qui les couvre dans l'humidité nécelfaire pour cette production. Les habitans habiles ne laiffent pourtant pas de préferer toûjours les terres les plus profondes aux autres, par la raifon qu'elles ne font pas fitôt épuifées. Aurefte, qu’on ne concluë point de ce que je viens de dire du peu de profondeur de la plûpart des terres de ce pays, qu'elles ne peuvent porter que des arbres fort petits : elles en portent des plus hauts $\&$ des plus forts, \& c'eft ici une des merveilles de noftre Ifle. Car les racines des arbres, quelques qu'ils foient, n'y font jamais enfoncées plus de deux pieds en terre, \& la plûpart ne vont pas même à beaucoup près à cette profondeur, mais elles s'étendent en fuperficie plus ou moins, fuivantle poids qu'elles ont à foutenir : il faut excepter le Caffier, qui pouffe fes racines à peu près comme nos arbres font en Europe, mais il eft venu d'ailleurs. On prétend que Chriftophle Colomb entretenant un jour la Reine Ifabelle de Caftille de plufieurs particularités des pays,qu'il avoit découverts, cette Princeffe n'eut pas plûtôt entendu ce qui regardoit l'article, dont nous venons de parler, qu'elle lui dit d'un air chagrin: « J'ai grand'peur qu'il n'en foit des hommes, qui naî$\rightarrow$ tront dans ce pays-là, comme des arbres, \& qu'ils ne 2) manquent de folidité, de conftance, \& de fincerité. so Mais Colomb auroit pû lui répondre que les arbres regagnoient par l'étenduë horizontale, ou par le nombre de leurs racines, ce qu'ils perdoient en profondeur, \& qu'aparemment il y auroit auffi pour les habitans de l'Ifle un équivalent, qui les dédommageroit d'un côté de ce dont ils manqueroient de l'autre.

L'arbre, dont les racines s'étendent plus loin, eft le Figuier. Il les poufle au delà de 70. pieds. Les Palmiers au contraire les ont fort courtes, mais en récompenfe elles font en fi grand nombre, qu'encore que cet arbre ait ordinai- 


\section{DE S. Domingue, Liv. I.}

rement plus de 100. pieds de haut, il n'en eft pas plus fujet que les autres à être abatu par les vents. Au refte fi ce peu de profondeur des racines n'avoit lieu que dans les endroits, où l'on rencontre d'abord le tuf, ou le roc, ou d'autres obftacles femblables, on pourroit fe perfuader que c'en eft là l'unique raifon: mais c'eft la même chofe partout. Il il faut doncen chercher une autre caufe, \& je la trouve dans ce que jai dit de l'extrême féchereffe de la terre, au-delà d'une certaine profondeur, où les pluyes les plus continuelles ne pénétrent pas fuffifamment, le Soleil ne leur en donnant point le têms. Ainfiles arbres, qui ont befoin d'humidité, \& qui n'en trouvent qu'à la fuperficie, où elle manque rarement, n'en reçût-elle que des rofées, qui font toûjours très abondantes, font prendre à leurs racines le cours horizontal, au lieu du perpendiculaire; mais pour l'ordinaire ces terreins, ainfi que je l'ai deja remarqué, ne font pas les mieux boifés.

Notre Inle eft arrofée d'un nombre prodigieux de rivie-Des Rivicres. res., mais la plûpart ne font que des torrens \& des ruiffeaux, dont plufieurs font extrêmement rapides. Les eaux en font partout fort faines \& même falutaires, mais fi vives \& fi fraiches, qu'il n'en faut boire quavec difcretion, \& qu'il eft dangereux de s'y baigner. On affüre qu'il y en a environ une quinzaine, qui ne font pas moins larges, que la Charente l'eft à Rochefort; $\&$ dans ce nombre les fix principales ne font pas comprifes. Ces fix font l'ozama, dont l'embouchure forme le Port de San Domingo; la Neyva, qui n'a de confiderable que la quantité de bouches, par où elle fe décharge dans la Mer, \& qui a même cela d'incommode, qu'elle change fouvent de lit; le Macoris, qui eft le plus naviguable de tous les fleuves de l'Inle, \& le plus poiffonneux, mais qui ne vient pas de fort loin. L'Yaqué, ou riviere de Monte Chrifo, à la fource duquel on a trouvé une belle mine d'or, \& qui charie partout des grains de ce précieux metal avec fon fable. L'Yuna, qui eft extrêmement rapide, \& à la fource duquel il y a une très-abondante mine

Tome $I$. 
Ce mot pa- de cuivre; \& l'Hattibonite, vulgairement Artibonite, qui eft femble centr de la plus longue \& la plus large de toutes. De ces fix rivieres, Hato Budeno les trois premieres ont leur décharge au Sud, les deux fuiou Hato Bo- vantes au Nord \& la derniere à l'Oueft.
nico.

Des Lacs.

Les anciens Auteurs nous ont parlé de deux Lacs, que

Du Lac Xa- je ne dois pas oublier ici. L'un eft connu dans leurs ouvraragua de lE-ges fous le nom de Lac de Xaragua, \& il n'eft pas aifé tang du Cul- d'accorder ce qu'ils en difent avec celles de nos Cartes \& l'Etang falé. nos Relations modernes, qui ont été faites avec plus de \& divers Au- foin. Oviedo, qui l'a vifité en Is I5. affure qu'il a is. lieuës teurs, qui paroiffent lui être contraixes. de long, qu'en quelques endroits il en a trois de large, en d'autres deux feulement, \& quelquefois moins d'une; qu'il reçoit plufieurs rivieres, \& que partout, excepté à la décharge de ces rivieres, il eft falé comme la Mer, aveclaquelle on ne fçauroit douter qu'il ne communique; qu'on y pefche de toutes fortes de poiffons de Mer, à l'exception des Baleines, \& de quelques autres de la premiere grandeur; qu'on y trouve furtout quantité de Turbots \& \& de Requins, \& que les poiffons de riviere n'y manquent point. D'un autre côté le P. le Pers dit qu'un Ifthme affés long le fepare en deux parties inégales, \& D. Pierre Martyr d'Anglerie femble parler de deux Lacs au lieu d'un.

M. Butet aujourd'hui Lieutenant de Roy, \& Commandant à Bayaha, dans un Journal, qui m'eft tombé entre les mains, $\&$ qui, outre le plan de San-Domingo, m'a fourni une notice très-exacte de l'état prefent de la Colonie Efpagnole de Saint Domingue, qu'il a toute parcouruë en 1716 . \& en I717. M. Butet, dis-je, éclaircit ce point de Geographie d'une maniere, qui fait voir que D. Pierre Martyr d'Anglerie \& le P. le Pers, quoi qu'ils n'ayent point été fur les lieux, ont parlé de ce Lac plus correctement qu'Oviedo, qui n'en a écrit qu'après l'avoir vû. Suivant ce Journal, le Cul-de-Sac, Bourgade Françoife fituée à une lieuë de la $\mathrm{Mer}$, dans un enfoncement affés profond, qui fe trouve prefque au milieu de la Côte Occidentale de l'Ifte, \& oì I'on croit qu'étoit l'ancienne Xaragua, capitale d'un Royau: 
me de même nom; le Cul-de-Sac, dis-je, donne fon nom à une efpece de $\mathrm{Lac}$, ou d'Etang de figure irreguliere . qui n'a que quatre lieuës dans fa plus grande longueur. qui en a une \& demie dans fa plus grande largeur, \& beaucoup moins en plufieurs endroits; qui court Nord - Oueft \& Sud-Eft, \& dont l'eau eft douce , mais d'un goût très fade.

A l'Eft de cet Etang il y a une Plaine, qui eft connuë fous le nom de Plaine des Verrettes, dont la longueur, qui eft de quatre lieuës, eft bornée des deux côtez par des Montagnes; \& la largeur, qui eft de trois feulement , fépare l'Etang, dont je viens de parler, d'avec un autre plus grand, que les Efpagnols nomment Riquille, \& les François l'Etang falé. Ce fecond Etang a huit lieuës de long Eft-SudEft, \& Oueft-Nord-Oueft, \& il eft à l'Eft de la Plaine des Verrettes: il a deux lieuës dans fa plus grande largeur; fes eaux ne font guéres que faumatres, \& M. Butet, après les avoir bien obfervées par trois differentes fois pendant qua. tre ou cinq heures, ne s'eft point apperçû qu'elles montaffent, ni defcendiffent, non plus que celles de l'Etang du Cul-de-Sac. Il a auffi vû dans l'une \& dans l'autre quantité de Caymans, mais point de Requins, ni aucun autre poiffon de Mer; d'où il conclut que l'opinion commune , fuivant laquelle l'Etang falé communique à la Mer, eft fans fondement, \& que l'acreté de fes eaux vient uniquement des mines de fel, qui font en abondance dans les Montagnes voifines.

Outre ces deux Etangs, à une lieuë de ce dernier, il y a un petit Lac d'une lieuë de circuit, lequel y regorge dans les grandes eaux par des ravines, qui occupent tout l'entredeux. Ce petit $\mathrm{Lac}$ eft, dit M. Butet, entre les Montagnes de la Beata, qui font connuës dàns les Livres Efpagnols fous le nom de Montagnes du Baoruco, \& dont une des extrêmitez fe termine à la Côte du Sud, vis-à-vis la petire Ifle Beata. Or nous verrons dans la fuite de cette Hifroire que le Cacique Henry, qui fit pendant treize ans une fi 
rude guerre aux Efpagnols, s'étoit cantonné dans ces Montagnes, \& re retiroit quelquefois au milieu d'une Lagune, qui ne fçauroit être que le Lac Xaragua, où par conféquent il y avoit terreins habitables. Ce qui étant fuppofé, il ne me paroît pas impoffible de concilier Oviedo, dont l'autho. rité eft après tout d'un grand poids, quand il parle comme témoin oculaire, avec les Auteurs, qui lui paroiffent oppofez , \& le Journal de M. Butet, qui femble le contredire.

Effectivement en joignant les deux lieuës de largeur de l'Etang falé, qui fort à peu près Nord \& Sud, avec le petit Lac des Montagnes de la Beata, \& la demie lieuë de diftance, qu'il y a de l'un à l'autre, nous avons les trois lieuës. de la plus grande largeur, qu'Oviedo donne au Lac Xaragua: puis fuppofant que dans les trois lieuës de la Plaine des Ve. rettes, qui font la féparation de l'Etang du Cul de Sac, ou de l'Etang falé, il fe rencontre dans les grandes eaux une fuite de marécages, qui peut paffer pour une continuation d'Etang, nous n'aurons guéres moins des 18 . lieuës, que le même Oviedo donne de longueur à fon Lac, qu'il vifita. peut être dans le têms de quelque inondation. Il fe peut faire auffi queces Etangs ayent eu autrefois de Requins \& des Turbots; (on ne fçauroit au moins nier qu'on n'y ait trouvé de Lamentins dans le commencement); \& que tous ces poiffons ayent été exterminez avec le têms, ce qui feroit encore une preuve, que l'Etang falé ne communique point avec la.Mer. D'ailleurs le terrein de la Plaine de Verettes. eft fort inégal : on y voit, felon M. Butet, de petites Collines, \& de petites Savanes. Quand bien même ces Savanes ne feroient pas inondées aujourd'hur, elles ont pû l'être autrefois; on voit tous les jours des exemples de changemens. plus confiderables \& en beaucoup moins de têms, qu'il ne. s'en eft écoulé depuis la découverte de l'Ine Efpagnole. Enfin il me paroit plus naturel d'expliquer ainf la chore, que de foupçonner un Auteur tel qu'Oviedo, d'avoir vû ce qui n'étoit point, \& tous les Auteurs, qui ont écrit après lui de l'avoir fuivi à l'aveugle, \& fans examiner. 


\section{DE S. Domingue, LIV. I. * * 9}

L'autre lac dont les Hiftoriens Caftillans ont fait mention, eft fur la cime d'une très-haute montagne. Dom Nicolas Ovando grand Commandeur d'Alcantara étant Gouverneur general des. Indes, voulut faire vifiter ce Lac, dont on difoit des chofes merveilleufes, \& il donna cette commiffion à deux hommes de réfolution, dont l'un fe nommoit Pierre de Lumbreros, \& l'autre Rodrigue de Mefcia. La montagne, où eft fituéle Lac, eft fi roide d'un côté, qu'il ne leur fut pas poffible d'y monter par là, il leur fallut prendre l'autre côté, qui étoit le plus long de beaucoup, \& qui n'eft pas encore fort aifé. Aufí Mefcia, \&les Infulaires, qu'on leur avoit donnés pour les accompagner, ne purent jamais aller jufqu'au bout. $\mathrm{Ce}$ ne fut pourtant pas la feule laffitude, qui les arrêta, mais un fort grand bruit, qui les effraya à un point, qu'on ne fçauroit croire; cependant Lumbreros, quoiqu'extrêmement fatigué \& tranfi de froid, continua à marcher par des détours, qui le harrafferent beaucoup. Le froid augmentoit, \& le bruit devenoit toûjours plus terrible : Lumbreros fe repofa un peu, après quoi aïant fait un dernier effort, il arriva au fommet de la montagne. Il y aperçut une maniere de lagune, qui lui parut avoir un trait d'arbaletre de large, \& trois fois autant de long : c'eft tout ce qu'il en put dire. Il n'en approcha pas de plus près, que de douze à quinze pas, \& il n'eut point l'affûrance de le regarder plus longtêms que l'efpace d'un Miferere; le bruit, qui lui fembloit croître toûjours; l'ayant fi fort épouvanté, qu’il ne fçavoit plus où il en étoit. Oviedo, à qui Lumbreros avoit raconté lui-même fon avanture, ajoûte qu'on n'a jamais rien $f c ̧ \iota$ de plus pofitif touchant ce Lac, quoi qu'on ait bien fait des contes à ce fujet. C'eft du pied de cette même montagne, que fort une jolie riviere, qui fe nomme Niza.o. Et il y en a une autre, qui paroît fortit du lac, \& que Lumbreros cottoya quelque têms, après que fes compagnons l'eurent quitté; elle fe nomme Pani.

Il n'eft point d'Ille au monde où l'on ait jufqu'ici trou- Des Mines, $\mathrm{C}$ ij 
Minieres, \& vé de fi belles, ni de fi abondantes mines d'or: que Carticres, celle-ci. Nous verrons dans la fuite qu'on y en a aufi découvert d'argent, de cuivre $\&$ de fer. On y voit. en. core des minieres de talc, de criftal de roche, d'antimoine, d'Etain de glace, de fouffre \& de charbon de terre. Des carrieres d'un marbre blanc \& jafpé , \& de bien de differentes fortes de pierres. Les plas communes font des pierres à feu, parmi lefquelles il y en a de blanches comme ducriftal, taillées en pointes de diamant, qui coupent le verre, \& ont beaucoup d'éclat. On y rencontre auffi des pierres ponces, des pierres à rafoir, \& ce qu'on appelle des pierres aux yeux, en Latin umbilicus marinus, lefquelles ont la vertu de chaffer des yeux les ordures, qui y font, entrées. Il y a des falines naturelles en plufieurs endroits le long des côtes, \& il y a du fel mineral dans une montagne voifine du lac Xaragua, lequel eft plus dur \& plus corrofif que le fel marin \& dont les breckes fe réparent, dit-on, en un an. Oviedo ajoûte que toute la montagne eft d'un fel fort bon, aufi luifant que le criftal, \& qui n'eft point inferieur à celui de Catalogne. Si à tant d'avantages l'on joint ce dont tous les auteurs conviennent de la prodigieufe multiplication des animaux utiles, qu'on y a tranfportés, \& qui eft telle, qu'on y a donné un mouton pour un réal, une vache pour un caftillan, \& le plus beau cheval pour trois ou quatre : fi l'on fait attention à la quantité \& à la diverfité des marchandifes précieu. fes, que cette Inle feroit encore en état de fournir, fi les hommes n'y manquoient pas, \& dont nous parierons dans l'occafion : enfin que nul pays au monde ne produit des fruits plus délicieux, \& de plus d'efpeces differentes, foit en arbres, en arbriffeaux, ou en legumes, on conviendra quil n’y a pas beaucoup d'exageration dans les éloges, que lui ont donnés les Efpagnols, \& fur tour Oviedo, qui y a parfé la meilleure partie de fa vie.

Des Tem- La mer des Inles eft ordinairement plus tranquille que les pétes de ces nôtres: on en peut voir la raifon dans ce que jai dit des 
DE S. DOMINGUE, LIV. I. $2 X$ vents qui y régnent. Mais femblables à certaines perfonnes difficiles à émouvoir, \& dont les emportemens font auffi furieux, quils font rares, quand elle s'irrite, elle eft terrible. Elle franchit fes bornes, inonde tout le pays, emporte tout ce qui lui fait obftacle, \& laiffe fur tout fon paffage de triftes effets de fa fureur. C'eft après ces tempêtes connuës fous les noms de coups de Sud, de Nords, \& d'ouragans, que fes rivages fe trouvent remplis de coquillages; qui furpaffent beaucoup en luftre \& en beauté tout ce que nos mers d'Europe fourniffent en ce genre. Les plus curieux font le Lambis, le Burgot, le Pourpre, la Porcelaine, les Cornets, les Pommes de mer, \& d'autres femblables bijoux.'

J'ai dit que les côtes de notre Inle n'étoient pas fort poiffonneufes, mais il ne faut pas aller bien loin au large pour y pêcher d'excellens poiflons, \& en quantité. Les plus communs font les Rayes, les Congres, les Anges, les Mulets; les Marfoüins, les Bonites, les Dorades, les Pilotes, les Lamentins, \& les Crocodiles. On y prend auffi partout des Limaçons \& des Ecreviffes de mer, des Moules', des Crabes, \& des Cancres en quantité. On y a trouvé des Perles en plufieurs endroits; les rivages y font couvers de co. quillages de toutes les fortes; l'Ambre gris y eft rare, toutefois il y a quelque têms qu'après une grande tempête des Matelots Anglois en ramafierent environ une livre fur une des Cayes, dont j'ai parlé. On n'y voit point du tout de Coral, à moins qu'on ne veüille donner ce nom à ces Madrepores ou Panaches de mer, lefquels repréfentent fi bien un éventail.

On pêche:dans ces parages deux fortes de Cancres; la Des Caneres: premiere fe nomme Agama, \& il s'en prend beaucoup dans les filets ou feines, qu'on jette à la mer. Cer animal a environ 7 . poulces de long fur 4 . de large. Son cerapoufte ou fa coque eft de figure quarrée, veluë, chagrinée, un pers enflée, marquetée de plufieurs couleurs, terminée en bas par des pointes dentelées, ornée de poils. Ses yeux éloignés lun de l'autre de deux poulces font de la grofleur d'un poiss d'un noir luifant, enchaffés dans deux orbicules arrondis un. C. iij 
peu faillants. Son front eft plat, \& l'on y voit à droit \& d gauche deux larges plaques crénelées, remplies de poils, furmontées de deux autres, toutes quatre mouvantes en divers fens par lemoyen de deux jointures. Du milieu de ces plaques fortent deux cornes, \& quatre pointures, dont le bout eft fendu en pincettes \& velu. La gueule de l'animal eft en deffous dans un foffette ovale, couverte de plufieurs barbillons mobiles, qui ont differentes articulations.

La feconde efpece de Cancre eft le Pagurus des Anciens. Il s'en trouve beaucoup fur les falaifes, ou fur les rochers efcarpés, fur lefquels il grimpe. Il fréquente aufli les hauts fonds, les endroits, où il y a des Madrepores, des Pana ches, des Lithophitons, fur tout dans le voifinage des Inles Caraïbes. L'écaille de ce Cancre eft prefque ronde, le fond en eft rouffeâtrè, \& elle eft toute parfemée de piquants , aufi-bien que fes bords. Le mufeau de l'animal eft armé de cornes peu faillantes, fes yeux font enfoncés dans des cavités, couchés de travers, \& défendus de plufieurs pointes en guife de paupieres. Il fort de fes narines de longs filets pliants \& mobiles en divers fens. Sa gueule eft comme celle des Crabes, aufquels il reffemble encore par le plaftron. Ses deux bras font fort grêles, \& fes mordans médiocres, eu égard au refte du corps. Les quatre autres pieds, qu'il a de chaque côté rangés fous le ventre, font groffiers, \& ont chacun une articulation, $\&$ un ardillon noirâtre à leur extremité. Sa chair eft coriaffe, d'un gout fauvageon; \& il n'y a gueres que les pauvres, qui en mangent.

Des Crabes Les Crabes, qu'on trouve en quantité fur les côtes de Q du Soldat. toutes les Antilles, font une des plus riches mannes dont la nature ait pourvû leurs habitans. On en diftingue furtour: de trois fortes; ceux de mer, ceux de montagnes, \& ceux de rivieres. Les premiers font les plus communs. Ils ne fe tiennent point à la mer, mais ils vont s'y rafraîchir de têms en têms, \& c'eft fur fes bords qu'on les trouve pour l'ordinaire. Nos Efclaves les appellent leurs poulets, \& ils leur font effectivement d'une grande reffource pour la vie.. Les 


\section{DE S. D OMINGUE, LIV. I. 23}

feconds font rouges, \& s'arrêtent dans les lieux fecs; ils font encore plus eftimés que les premiers. Mais ceux de rivieres font les meilleurs de tous, \& il n'eft point de bonne table, où ils ne puiffent faire honneur. Ce qu'on appelle soldat eft, auffi-bien que les Crabes, une efpece d'Ecreviffe, ou de ce qu'on appelle cancellus marinus. On le trouve par tout le long de la mer, \& il eft bon à manger. Son nom vient de ce qu'il eft armé par tout le corps, excepté à l'extremité d'en bas, où il eft nud, \& où il paroît être d'une fenfibilité extrême; auffi fe fourre-t-il, dès qu'il eft né, dans la premiere coque, qu'il rencontre, mais pour l'en faire déloger, il ne faut qu'en approcher le feu.

Pour peu 'qu'on ait navigué dans cet Archipel, on a dû y apercevoir ces prairies naturelles couvertes d'une herbe Praires maappellée Sargaffe. Il y en a, qui paroiffent fur la fuperficie tuës.

de la mer, mais le grand nombre eft au fond de l'eau, \& fur les côtes. C'eft là qu'entrautres animaux marins fe tiennent des Tortuës en très grande quantité. Il y en a de deux efpeces. Celles, qu'on appelle Tortuës franches, recherchenr les paturages gras \& bien fournies d'herbes. Les autres, quon connoit fous le nom de Caret, \& dont la dépoüille eft cette écaille de Tortuë fi eftimée, reftent pour Fordinaire dans des endroits pierreux, couverts feulement d'un peu de mouffe.

Parmi les poiffons particuliers à ces mers on remarque Des Pilotes, le Pilote, ainfi nommé, parce que, quand il rencontre un du Remora. navire, il nage toûjours devant, jufqu'à ce qu'il l'air con- des Dorades, duit dans un port. C'eft un affés petit poiffon, je n'en ai tes. pur rien fçavoir de plus, ni du Remora, lequel doit fon nom à une erreur populaire, dont tout le fondement eft que ce petit animal s'attache aux vaiffeaux, il s'attache auff aux grands poiffons, pour fe metre à l'abri de la grande agitation des flots pendant la tempête. On connoit préfentement affés les Dorades \& les Bonites, ou poiffons volans, \& tout le monde eft inftruit de la chaffe que les premieres donment aux fecondes. On fçait auff que par une double merveille 
la Bonite vole, \& nele peut faire, que fes aîles; ou pour parler plus jufte, fes â̂lerons ne foient moüillés. Mais bien des gens ignorent peut-être que ces pauvres anirnaux également pourfuivis dans l'air \& dans l'eau, n'évitent fouvent la gueule des Dorades, que pour être la proye de certains oifeaux, qui ne leur font pas une guerre moins cruelle, deforte que la liberté, qu'ils ont de paffer d'un élément à l'antre, ne fert qu'à multiplier leurs ennemis.

Des Galeres. Rien n'eft plus joli qu'une autre efpece de poiffon, qu'on nomme Galeres. Ce n'eft au fond qu'un infecte, dont la peau enflée \& pleine de vent, qu'il poufe hors de l'eau paroît ornée de toutes les couleurs, \& lui fert comme de voile, ou plûtôt, eft caufe qu'il eft poufié de cốté \& d'autre au gré du vent. Mais il faut fe contenter de le regarder. On n'y touche pas impunément. Pour peu qu'on mette la main deffus, elle eft infectée d'une certaine gluë mordicante, qui caufe les plus vives douleurs. On a, dit-on, obferyé que cette douleur croît à mefure que le Soleil monte fur l'horifon. Mais quoiqu'Ariftote ait avancé la même chofe des Etoiles de mer, dont les environs des Antilles font auffi extrêmement peuplés, il paroît que ce fait n'eft pas encore affés verifié pour l'affûrer. Outre la Dorade, dont je viens de parler, le Perroquet de mer, \& d'autres poiffons connus fous le nom de Poiffons de Roche, ont des couleurs d'or \& d'azur fi éclatantes, que leurs écailles paroiffent comme autant de pierres précieufes. Le Herifon, le Crapeau de mer, \& une efpece de petit Cochon marin affés fingulier, font encore des productions de ces mêmes mers, \& n'ont gueres d'autre ufage, que d'orner les cabinets des curieux.

DuLamentin. On trouve dans le feul Lamentin, fi on en croit quelques auteurs, la plûpart des chofes, que la Fable a mifes fur le compte de la Sirene \& du Dauphin. Mais il faut avoir pour cela des yeux, qui voyent les objets bien differemment des autres. Je ne fçache point que le Lamentin ait jamais chanté, on dit feulement que quand on le tire à terre, il jette des 


\section{DE S. DOM I GUE, L. I . I. 25}

des larmes \& fe plaint, \& c'eft de là qu'eft venu le nom que lui ont donné les François. Quant à fa figure, elle n'a certainement rien de joli, ni même, qui approche de celle qu'on fuppofe au Dauphin, avec lequel toute la reffemblance, qu'il peut avoir, c'eft qu'il paroît affés ami de l'homme. Les Efpagnols l'ont nommé Manat $i$ à caufe de deux nageoires qu'il a fous les épaules, lefquelles aprochent un peu de la figure d'une main, \& dont il fe fert également pour nager \& pour porter fes petits. Le premier, qui s'eft imaginé que ce poiffon pouvoit bien être la Sirene des Anciens, fut Chriftophle Colomb, lequel donnoit volontiers dans tout le merveilleux, qui pouvoit rendre fes découvertes plus celebres. Mais cette imagination n'a point fait de fortune. La femelle du Lamentin met bas \& allaite fon petit à la façon des Vaches, ce qui l'a fait nommer Vache marine par quelques-uns. La figure de la tête de cet animal y a auffi contribué ; car il l'a faite à peu près comme celle d'un Bœuf, mais il a le mufeau plus enfoncé, le menton plus charnu, \& les yeux petits. Sa couleur eft minime, \& il s'en trouve de 20. pieds de long fur 10. de large vers les épaules: cette largeur va toûjours en diminuant vers la queuë. Sa chair a le goût de celle du Veau, quand elle eft fraiche, \& de celle du Thon, quand elle eft falée; mais elle eft plus exquife, \& fe conferve plus long-têms. La graiffe, qu'on en tire, eft auffi très-bonne \& ne rancit point. Sa peau eft un très bon cuir, \& on en fait des fouliers. Il s'engendre dans la tête de ces animaux des pierres, qui font fouveraines pour la colique \& pour la pierre. On ne tuë gueres les grands qu'à terre, lorfqu'ils vont paître le long de la mer \& des rivieres, les petits fe prennent dans des filets. Ce poiffon s'aprivoife, dit-on, fort aifément, furquoi Gomara raconte un fait arrivé, dit-il, dans notre Ine, auquel on donnera telle croyance, qu'on voudra. Le voici. Un Cacique nourriffoit un Lamentin dans un petit lac, ou étang des Gonaives, où effectivement ce poiffon eft plus commun, qu'en aucun autre endroit. Il l'avoit même rendu fi familier, qu'en l'appellant il le faifoit Tom. $I$. 
venir, lui chargeoit fur le dos tout ce qu'il vouloit, \& le Lamentin le portoit à l'autre bord. Un Efpagnol s'avifa de l'appeller un jour, \& le bleffa d'un coup de fufil, ce quile rendit plus circonfpect, \& depuis ce têms-là il n'aprochoit point, qu'il n'eut bien examiné, fi celui, qui l'appelloit, étoit Indien ou non, ce qu'il reconnoiffoit à la barbe. Enfin il difparut tout à fait après une grande cruë d'eau, qui felon les apparences l'entraina à la mer, avec laquelle le Lac, où il étoit, communique. Herrera raconte une hiftoire affés femblable, \& qui eft peut-être pour le fonds la même, que Gomara aura déguifé à fon ordinaire, quoique l'une ne foit pas plus croyable que l'autre. Le Iamentin d'Herrera venoit à terre, dès qu'on l'appelloit, mangeoit ce qu'on lui donnoit à la main, \& fuivoit ceux, qui le nourriffoient ainfi, jufques dans les maifons, il joüoit avec les enfans, \& paroiffoit prendre beaucoup de plaifir à la Mufique. Il fouffroit qu'on montât fứr fon dos, \& paffoit, dit-on, jufqu'à dix hommes à la fois d'un bord du Lac à l'autre.

Des Croco- Les Crocodiles, que les Amériquains nomme Caymans, diles. n'ont rien de moins fingulier que les Lamentins. A la verité on ne les aprivoife point aux Inles, comme on fait, diton, à la Chine, mais ils y ont, comme par tout ailleurs, un inftinct admirable pour aller chercher leur proye, jufques dans les forêts, où ils dreffent des embuches d'une maniere fort adroite aux Cochons marons, \& à d'autres animaux, qu’ils furprennent prefque toûjours. Des Chaffeurs même y ont été pris. On dit que ceux de Cuba font trèsalertes \& gagnent les hommes à la courfe. Pour cela ils picquent leur queuë en terre, puis s'élancent d'une grande viteffe. Il eft vrai que c'eft toûjours en ligne droite, de forte qu'il fuffit pour leur échaper de courir en ferpentant. Ceux de notre Inle quittent rarement les rivieres, où ils fe tiennent en embufcade à certains paffages, \& aux abreuvoirs. Ils ne s'attaquent pour l'ordinaire aux hommes, que quand ils en ont été bleffés, ou qu'on les a irrités de quelque maniere que ce foit; mais ils ne font aucun quartier 


\section{De S. Domingue, LIv. I.}

aux autres animaux, qu'ils faififient toûjours par le mufeau pour leur ôter la refpiration. Ils les entrainent enfuite au fond de l'eau, où ils les laiffent pourrir, avant que d'en faire leur curée. Ils aiment les odeurs fortes, \&cils en ont euxmême une, qui aproche de celle du mufc. Les Corneilles du pays font très friandés de leurs œufs, qu’elles éventent fous le fable, où cet amphibie les cache, \& où la feule chaleur les fait éclore, comme il arrive à ceux des Tortuës. On prétend qu'il y a des Caymans de 25 . pieds de long, \& il n'eft point rare d'en voir de la groffeur d'un Bouf ordinaire. Quand on a à paffer un Lac, ou une riviere, \& que l'on craint d'y trouver de ces animaux, dont la rencontre n'eft jamais fort agréable, on n'a qu'à jetter fur l'eau des veffies enflées, les Caymans courent après, \& n'atrapent que du vent; on s'en divertit, \& l'on paffe en fureté.

On a trouvé dans la même Ifle une autre forte d'amphibie, que les anciens habitans nommoient Ivana, ou Iguana, \& qu'on voit auffi fouvent dans l'eau, que fur le haut des arbres. Il tient du Lézard \& du Crocodile, \& a par deffus l'un \& l'autre que fa chair eft un manger délicieux; mais on dit qu'elle ne vaut rien pour ceux qui ont, ou qui ont eu le mal de Naples. Oviedo le met au nombre des Serpens : ce qui eft certain, c'eft que fa peau a les mêmes couleurs, \& que fa figure eft des plus horribles. Mais rien n'eft plus trompeur que fa phyfionomie, car il n'eft point d'animal plus doux \& moins malfaifant. Les plus grands ont deux palmes \& demie de long \& un peu plus d'une palme de large. L'Ivana a des pates de Lezard, la tête plus groffe, \& une queuë, qui eft le double de fon corps pour la longueur : fes dens font fort aiguës, \& il a un long \& large jabot, qui lui pend jufques furla poitrine. Ses pattes de devant font plus longues que celles de derriere, \& elles ont des doigts, dont les ongles font comme des ferres d'oifeaux de proye, mais elles font incapables de rien ferrer fortement. Enfin il a tout le long du dos comme une nageoire élevée \& crêtée en forme de fcie. On en rencontre fouvent 


\section{HIS T O R}

de très-petits, qui font aparemment d'une efpece particuliere. Cet animal eft abfolument muet, \& n'a aucune forte de cri. Sa douceur eft extrême, \& fa patience a quelque chofe d'incroyable; on le tiendra trois femaines de fuite à l'attache, fans lui donner, ni à boire, ni à manger, \& fans qu'il faffe le moindre mouvement pour fe dégager. Sa nourriture ordinaire eft un peu de Caffave, ou d'herbes, ou d'autres chofes femblables. Il ne peut nager, que quand il eft petit, dès qu'il a toute fa taille, il ne fçauroit plus avoir ce mouvement des pattes, qui le foutenoit fur l'eau. Il fait fes œufs dans le fable le long des rivieres \& des ruiffeaux, \& l'on prétend qu'il en fait jufqu'à 40 . ou so. à la fois. Oviedo a obfervé que ces œufs ne cuifent point dans l'huile, ni dans le beure, mais feulement dans l'eau. Ils ne font pas plus gros qu'une noix, \& leur enveloppe n'eft qu'une pellicule fort déliée. Comme cet animal fe laiffe aifément aprocher, il n'eft pas difficile de le prendre. On le chatoüille doucement fur le dos avec un nœud coulant, il croit que ce chatoüillement vient de quelque infecte, \& demeure quelque têms fans remuer. Mais tandis qu'il attend le moment de donner fur fa proye, il fe trouve pris lui-même par le col.

Des Canards. On ne voit pas dans les Ifles autant de fortes d'oifeaux; qu'en Europe, mais il y en a d'une beauté, dont les nôtres n'aprochent point. Les Hirondelles, les Corneilles, les Tourterelles, les Ramiers, les Oyes \& les Canards fauvages, y font à peu près. les mêmes. On y trouve auffi des Canards tout blancs par le corps, \& dont la tête eft d'un trèsbeau rouge. Il y en a encore une efpece de mufquée, qu'on prétend y avoir été aportée d'ailleurs; c'eft la feule qu'on éleve dans les baffes-cours, non feulement pour la beauté de leurs plumages, mais encore à caufe de leur groffeur, \& parce qu'ils font plufieurs pontes par an. On a obfervé que les Cannetons, qui viennent de l'accouplement des uns avec les autres, n'en font point d'autres. Au refte les anciens habitans des Lles n'avoient aucune forte de volailles domeftiques, 


\section{DE S. DOMINGUE, LIV. I. 29}

Les Oyes des Antilles n'ont des petits qu'une fois l'an- Des Oycs, née. Il n'en eft pas de même de toutes les autres efpeces de des Pintades, volailles, foit Indiennes, foit étrangeres. Toutes les fai- des Faifans. fons font bonnes pour cela, \& rien ne feroit plus aifé que de les élever, fi ces animaux n'étoient pas fujets à une ma. ladie, qu'on appelle les. Pians, \& dont il en meurt un trésgrand nombre. Ce qu'on voit plus communément dans les baffes-cours, ce font les Poules Pintades, qui y font venuës de Guinée; des Paons, qu'on a trouvés en quantité le long de la riviere Neyva; \& des Faifans. L'Ifle avoit des Pintades un peu differentes des autres, \& plus petites, mais il ne fut jamais poffible de les rendre domeftiques. Jufqueslà que, fi on mettoit de leurs œufs fous une Poule ordinaire, les petits pouffins n'avoient pas plûtôt leurs aîles, qu'ils difparoiffoient. Cet animal a le bec \& les pieds à peu près comme nos Poules: il eft de la même groffeur, mais fes plumes ont toutes une tache blanche, qui leur fait comme un œil bien moins marqué que celui des Paons; le refte eft d'une couleur plus fonçée, \& tire fur le gris cendré. C'eft cette varieté, qui lui a fait donner par les Efpagnols le nom de Pintade, ou de Poule peinte, qui dans le fonds ne lui convient pas beaucoup. Il a la tête \& le col prefque chauve, ce qui caufe une petite difformité, laquelle eft néanmoins un peu reparée par fa crête, qui eft courte, mais d'un rouge très-vif.

On croit communément qu'il y a dans la même Ine des Perdrix rouges, \& des Ortolans; on fe trompe; ce font dif- terelles, des ferentes efpeces de Tourterelles. Les nôtres y font fur tout Roffignols; 2 fort communes. Le Pic vert y a toutes les proprietés de celui des Linottes. de France, mais il l'emporte beaucoup par la beauté de fon plumage rouge \& noir fur un fond jaune. Les François après les Efpagnols l'ont appellé Charpentier parce que quand il picque le bois de fon bec, il fait un très-grand bruit. Du refte il ne peut porter ce nom, que par ironie, car bien loin de bâtir, il dérruit, \& l'on a vû de grands édifices, dont ces animaux avoient tellement criblé les poutres, 
qu'on a été contraint de les abatre. Notre Ifle a auffi fon Roffignol, dont la figure \& le chant aprochent affés peu du nôtre. Il doit fon nom au plaifir, que reffentit Chriftophle Colomb en l'entendant chanter au mois de Decembre. Mais on y trouve une Efpece de Linotte, dont le ramage a quelque chofe de fort agréable. Cet oifeau eft très-rare, \& en general le gazoüillement des oifeaux ne fait pas dans ce pays - là un des agrémens des bois \& des campagnes: s'ils charment les yeux plus que les nôtres, ils flatent beau= coup moins les oreilles.

Des Grands- Les oifeaux de proye ne manquent pas dans notre Ifle, Goliers, des Perroquets.

$\&$ il s'y en voit d'un grand nombre d'efpeces. On y trouve fur tout des Grands-Gofiers en quantité. C'eft un oifeau, qui tient du Cormoran \& du Pelican, mais il eft trop different du dernier pour lui en donner abfolument le nom; comme a fait le P. Labat. Ce qu'il a de fingulier, \& ce qui lui a fait donner le nom qu'il porte, c'eft que de la partie inferieure de fon bec, quil a fort long \& fort large, il pend une efpece de bourfe, qu'il étend prodigieurement, \& qui lui fert de magafin. Il ne ceffe point de chaffer, ou plûtôt de pêcher, jufqu'à ee qu'il l'ait rempli. Il digere enfuite à fon aife, mais affés vite, ce qu'il a ainfi ramaffé ; \& il eft inconcevable combien il en coute aux curieux, pour le nourrir. Tout lui eft bon, mais quand il eft libre, il ne vit que de poiffon, \& on ne le trouve gueres, qu'au bord de la mer, où fa couleur eft toûjours d'un cendré obfcur, \& le long des rivieres, où il eft, au moins en quelques endroits, d'un très-beau blanc. Un autre oifeau de proye affés commun aux Inles, eft le Malfenis, lequel aproche du Faucon \& de l'Aigle. Quantité d'autres, qu'on appelle indifferemment Pefcheurs ou Aigrettes, font de vrais Hérons, \& different très-peu des nôtres. Enfin les Perroquets font encore habitans naturels des Antilles, où l'on en voit de tolttes les efpeces \& de toutes les couleurs. Mais les deux merveilles de l'Amérique en genre d'oifeau, font le Flamand $\&$ le Colibry, un des plus grands, \& le plus petit de tous 


\section{DE S. DOMINGUE, LIV. I. 3 I}

les animaux qui volent, \& ne font point infectes.

Le Flamand doit fon nom aux Efpagnols, mais la raifon, Du Flamand.

qu'ils ont euë de le lui donner, n'eft pas venuë jufqu'à nous,

Ces oifeaux fe trouvent par grandes troupes dans les marais, \& comme ils ont les pieds extrêmement hauts, on diroit de loin un efcadron rangé en bataille. Ils font effectivement toûjours en garde contre la furprife de leurś ennemis, \& l'on prétend qu'il y en a toûjours quelques-unš en fentinelle, tandis que les autres font occupés à chercher leur vie. Avec cela on dit qu'ils éventent la poudre d'affés loin; ainfi on les aproche difficilement. Nos anciens Boucaniers fe fervoient pour les tuer d'un ftratagême femblable à celui , dont on dit que les Floridiens ufent pour aprocher les Cerfs. Ils fe couvroient d'une peau de Bouf, \& prenant le deflous du vent, ils aprochoient leur proye, fans que les Flamands accoûtumés à voir paître les Boufs dans les campagnes, en fuffent effarouchés; de forte qu'ils les tiroient à leur aife. Les plumes du Flamand font d'un très-bel incarnat, mêlé d'un peu de blanc \& de noir. Il eft de la grofleur d'une Poule d'Inde ordinaire. Sa chair n'eft pas bonne à manger, mais fa langue eft un morceau délicat. Quand on en peut avoir de jeunes, on les aprivoife aifément, pourvî́ qu'on leur donne à boire de l'eau falée, mais à cet âge leur plumage n'a rien de beau.

Le Colibry, qu'on appelle Oifeau-Mouche en Canada, a été nommé par les Efpagnols Tominejo, parce quavec fon nid il ne pefe qu'environ deux de ces petits pois, guion appelle en Efpagne Tominos. Il eft encore plus petit en $\mathrm{Ca}$ nada, où fon corps, y compris les plumes, n'eft pas plus gros que celui d'un Hanneton. Ses couleurs font le rouge, le noir, le verd \& le blanc, avec des nuances d'or fur le verd \& fur le ronge. Il a fur la tête une petite aigrette noire, fa gorge eft d'un rouge très-vif; fon ventre eft d'un beau blanc, \& tout le refte d'un verd de feüille de rofier. La femelle n'a de toutes ces couleurs que le blanc fous le ventre, tout le refte de fon plumage ent d'un cendré clairs.

Du Colibry. 
Le bec, \& les pattes de ce petit animal font fort longs; le Colibry des Inles a le bec un peu crochu, au lieu que l'Oifeau-Mouche du Canada l'a tout droit. Le P. le Pers prétend que le Colibry ne fait point d'autre bruit, que celui du bruiffement de fes aîles, lequel eft affés fort, parce qu'il a le vol très-rapide. Le P. Labat affùre au contraire quil a un chant fort mélodieux. Je ne déciderai point entre ces deux fentimens, parceque je n'ai point vû de Colibry vivant. Pour ce qui eft de l'Oifeau-mouche du Canada, j'en ai entendu une femelle, qui fiffloit d'une maniere très-forte, mais peu agréable. Jai fouvent vû des mâles, mais je n'en ai jamais entendu chanter un feul.

Infectes. La Mouche luifante, que les anciens habitans de nos Ifles Des Mouches nommoient Locujo, \& auquel les Efpaznols ont confervé luifantes. ce nom, a bien aufi fon merite. C'eft une efpece d'Efcarbot un peu plus petit qu'un Moineau. Il a deux yeux à la tête, \& deux fous les aîles, d'où il fort un feu, qui jette une trèsgrande lumiere, \& c'eft peut-être le plus beau Phofphore vivant, qui foit dans la nature. On voyage \& on lit même à fa clarté, \& elle étoit d'une très-grande utilité aux Efpagnols, qui s'en fervoient la nuit pour la chaffe \& pour la pêche, en fe les attachant aux pieds \& aux mains. On ajoûte que c'eft encore un excellent préfervatif contre les Mouftiques, $\&$ autres femblables infectes, dont on eft fans cela très-incommodé, \& dont le jour même on ne fçauroit fe garantir , fur tout dans les lieux un peu couverts de bois, qu'en s'expofant à un Soleil toûjours brûlant. Les Mouches luifantes fe prenoient la nuit avec des tifons; dès qu'elles voyoient du feu elles y accouroient, \& dès qu'on les avoit fait tomber, elles ne fe relevoient point. Ce qui les faifoit briller de la maniere, que j'ai dit, étoit une humeur, qui produifoit le même effet fur les mains \& le vifage, quand on s'en étoit frotté. Herrera nous aflüre qu'on les appelloit par leur nom, en leur montrant un tifon allumé, \& qu'elles venoient d'abord. Il y a bien de l'apparence que les Efpagnols avoient pris cet ufage des Infulaires.

Cependant 


\section{de S. Domingue, Liv. I.}

Cependant on peut bien croire que tant de beautés \& la fraîcheur de la nuit, convioient fort à prendre ce têms pour fe promener, ou pour voyager. Mais les Locuyos n'ont qu'une faifon, qui eft celle des grandes chaleurs, \& on" les garde bien difficilement au-delà de huit jours. Nos Mouches ordinaires, qui ont paffé dans les Ifles fur nos vaiffeaux, y ont extra-ordinairement peuplé, \& l'on ne fçauroit tuer une piece de gibier un peu loin des habitations, qu'en peu d'heures elle ne foit couverte de ces infectes, qui la corrompent d'abord. Les mêmes vaiffeaux ont fait aux Antilles un autre préfent, qui ne leur eft pas moins dommageable, ce font les Rats \& les Souris, qui s'y font fort répandus , \& y font des ravages incroyables.

Parmi ies autres infectes \& reptiles, on remarque plufieurs efpeces de Scorpions, un Efcarbot, nommé Rhinoceros, plufieurs fortes de petits Lezards, d'Araignées, de Fourmis, \& de Couleuvres. Quelques-unes de ces dernieres font affés groffes pour avaler des Poules entieres; mais nul de ces animatix n'eft venimeux, fi on en excepte certains Scorpions, qui naiffent dans la prefqu'Ine de Samana, \&t une Araignée à cul-rouge, la plus grande \& la plus monftrueure, qui foit au monde : encore n'eft-on pas fort incommodé de la picqueure de celle-ci. Pour ce qui eft de celui-là, on en parle d'une maniere fort generale, \& le fait eft même antés peu certain. Mais l'Efcarbot Rhinoceros eft un animal trop curiedk, pour n'en pas donner ici la defcription.

Quelque têms après qu’on a coupé un Palmier, une épece d'Efcarbort y produit une quantité de vers cornus, que les bor Rhinocehabitans recherchent avec foin, \& qui paffent pour un mets ${ }^{\text {ros. }}$

très délicat. Ce n'eft en effet qu'une graiffe douce \& agréable, enveloppée d'une pellicule ondulée \& en volute. II eft vrai que d'abord fa figure rebute, ise caufe une certaine horreur, que quelques-uns ne peuvent jamais vaincre: mais la plûpart s'y font bientôt. L'Éfcarbot, qui les enfinte, eft celui dont nous parlons: c'eft une forte de Mouche Tom. $I$. 


\section{H Is T O IR.E}

volante, qui a un nez fort alongé, \& fait en façon de corne un peu cintrée; d'où lui eft venu le nom de Rhinoceros. Cette corne eft ordinairement ornée d'une double 'épouffette, l'une en deffus, \& l'autre en deffous. De plus il fort de fes narines deux barbillons mobiles, qui ont plufieurs articles terminés par de jolis ombeles veloutés, qui lui fervent d'oculaires. Un cafque tirant fur l'oval lui couvre la tête, il eft tout d'une piece, un peu en boffe d'un noir luifant très-poli, d'une confiftance ferme, brufque \& caffante. Sa gueule fenduë horizontalement renferme deux mâchoires bien armées de bonnes dens. Son thorax eft offeux, accompagné de deux bras, qui ont chacun trois nouds, ou articulations. Ces bras font recoudés, \& terminés par une patte fourchuë, ardillonée \& veluë. Un peu au-deffous ils s'emboëtent dans une échancrure, qui fe trouve dans la partie fuperieure du ventre. De chaque côté il y a un pied tout femblable aux bras, que je viens de décrire, enchaffé dans un corfelet fait de plufieurs pieces, qui s'uniffent avec le plaftron. Du bas-ventre il fort pareillement deux pattes, qui ne different en rien des autres. Plufieurs tuniques rangées les unes fur les autres, terminent en bas cẹt infecte, lequel porte en deffus quatre ailes, deux interieures, fines \& tiffuës comme de la gaze, \& deux exterieures, qui font rayées, noires, ovales, feches \& raifonnantes.

Des Chiques Les Guefpes, les Bêtes à mille pieds, \& une efpece de $\&$ des Poux de Fourmi fort groffe \& toute noire appellée Flamand, laif-
bois. fent auffi quelques marques fur la peau, où elles ont mis leur aiguillon, mais ces piqueures n'ont aucune fuite fâcheufe. Il n'en eft pas de même d'un autre petit infecte. que les Infulaires appelloient Nigma, \& que les François ont appellé Chique, lequel fe fourre dans la chaire, particulierement aux pieds, où il fe fait fentir d'abord par un grand feu. Il faut même l'en tirer de bonne heure, fans quoi il gagne toûjours; comme une efpece de chancre, \& multiplie, comme la vermine. Les Efpagnols en reçûrent 


\section{DES. Domingue, Liv. I: 35}

beaucoup d'incommodités dans les commencemens, parce que ne fçachant ce que c'étoit, ni la maniere de s'en délivrer, les pieds leur pourriffoient avec les plus violentes douleurs. Une troifiéme efpece de Fourmi blanche, ent encore plus pernicieufe. Leur fubftance eft très-molaffe, \& \& leur bave, ou falive eft un diffolvant, qui fait impreffion jufques fur le fer. On les appelle Poux de bois, parce qu'elles s'attachent aux bois mous, dont elles fe nourriffent, \& qu'elles ruinent entierement. Dès qu'elles ont gagné le comble d'une maifon, c'eft fait de la charpente, \& en peu de têms. Elles commencent par dévorer les lattes, qui pour l'ordinaire font d'un bois fort tendre, puis elles s'infinuent dans les mortaifes, qu'elles rongent affés vite. On a découvert depuis peu que l'arfenic les fait mourir d'abord; \& il fuffit, pour en être bientôt délivré, de répandre un peu de ce poifon fur le chemin, que fe fraye cet infecte, \& qui eft une efpece de boyau de terre, ou de chemin couvert. Le Poux de bois fait auffi beaucoup de dégat dans le linge $\&$ dans les livres, \& il n'eft point de cofre, où il ne pénétre, aufi-bien qu'une forte de Hanneton appellé Ravet, un peu plus plat que les nôtres, \& qui ne travaille que de nuit.

Il y a beaucoup moins à dire fur les Quadrupedes naturels de notre Ifle, que fur les autres fortes d'animaux. Il ne s'y en trouva que de cinq efpeces, quand on la découvrit; \& comme ils étoient tous fans défenfes, les Chats \&les Chiens Efpagnols les eurent bientôt détruits. Les Infulaires les nommoient Utias, Chemis, Mohuis, Coris, \& Go/chis: mais je n'ai trouvé ce dernier nom, que dans les mémoires du P. le Pers. Les plus grands ne furpaffoient point nos Lapins ordinaires, dont les trois premieres efpeces tenoient beaucoup , \& tous étoient bons à manger. Oviedo dit que l'Utias étoit comme une groffe Souris, \& le Cori comme tun petit Lapin. Il y en avoit de tous blancs, \& dans d'autres les couleurs étoient mêlées. Le Cori, felon d'autres auteurs, éroit blanc \& noir, n'avoit point de queuë, \& fa 
gueule étoit femblable à celle d'une Taupe. Les Gofchis étoient de petits Chiens muets, qui fervoient d'amufement aux Dames, lefquelles les portoient entre leurs bras. On s'en fervoit auffi à la chaffe, pour éventer les autres animaux; ils étoient pareillement bons à manger, \& furent d'une grande reffource aux Efpagnols dans les premieres famines, qu'ils effuyerent. L'efpece auroit même bientôt manqué dans l'Ifle, fi on n'y en avoit apporté de plufieurs endroits du continent. Il y en avoit de plufieurs fortes; car les uns avoient la peau tout-à-fait liffe; d'autres avoient tout le corps couvert d'une laine fort douce; le plus grand nombre n'avoit qu'une efpece de duvet fort tendre \& fort rare. La même varieté de couleur, qui fe voit parmi nos Chiens, fe rencontroit auffi parmi ceux-là, \& plus grande encore, parce que toutes les couleurs s'y trouvoient, \& même les plus vives.

Nombre \& Je ne dirai rien ici des arbres \& des plantes, ni de tout figure des $\mathrm{Ha}^{-}$ce qui concerne la Botanique par raport à l'Ille, dont je vais
bitans. écrire l'hiftoire. Cette matiere eft d'une grande étenduë, \& demande un ouvrage à part, auquel je fçai que l'on travaille. Mais il eft fur tout néceffaire de bien faire connoitre les peuples, qui occupoient cette grande Inle, lorfque les Europeans y parurent pour la premiere fois. Quelques auteurs ont prétendu qu'on y trouva trois millions d'ames. D'autres en retranchent les deux tiers; peut-être ceux-ci en mettent-ils trop peu, mais il y a beaucoup d'apparence que ceux-là en mettoient trop, \& qu'il faut prendre un milieu entre ces deux opinions. Ces Infulaires étoient communément d'ue taille médiocre, mais bien proportionée. Hs avoient le teint extrêmement bazané, la peau rougeâtre, les traits du vifage hideux \& groffiers, les narines fort ouvertes, les cheveux longs, pas un poil dans tout le refte du corps, prefque point de front, les dens fales \& mauvaifes, $\&$ je ne fçai quoi de trouble \& de fauvage dans les yeux. Mais tout cela n'étoit pas également naturel. La couleur de leur peau venoit en partie du Rocon, dont ils fe frottoient 
fouvent : à quoi il faut joindre les ardeurs d'un Soleil brûlant, aufquelles ils étoient fans ceffe expofés tout nuds. Ils fe procuroient auffi par artifice cette conformation de tête, qui leur ôtoit prefque tout le front, \& dans laquelle ils trouvoient ún grand agrément. Pour cela les meres avoient foin de tenir fort ferré avec les mains, ou entre deux petits aix le haut de la tête de leurs enfans nouvellement nés, afin de l'applatir peu à peu : d'où il arrivoit que le crane replié en quelque forte fur lui-même, devenoit fi dur, que les $\mathrm{E}$ pagnols ont fouvent caffé leurs épées en voulant fraper de taille fur la tête de ces malheureux. Or il eft aifé de juger que cette operation changeoit toute la phyfionomie, \& contribuoit beaucoup à l'air farouche, qu'on remarquoit dans ce peuple.

Les hommes alloient tout nuds 2 cachoient affés mal, ce qui ne doit point être vî. Les femmes portoient une ef- plexion \&leur pece de jupon, qui dans les Dames defcendoit jufquaux pieds, \& dans les autres jufquaux genoux feulement. Les filles ne portoient abfolument rien. Ils étoient tous d'une complexion foible, d'un temperament flegmatique, un peu mélancoliques, \& mangeoient fort peu. Un Crabe, un Burgot leur fuffifoit chaque jour pour fe nourrir ; auffi n'avoient: ils prefque pas de force. Ils ne travailloient point, ne s'inquietoient de rien, \& paffoient leur vie dans la plus grande indolence, qu'il foit poffible d'imaginer. Après s'être divertis à danfer une partie du jour, s'ils ne fçavoient plus que faire, ils s'endormoient. Du refte c'étoit les hommes du monde les plus fimples, les plus doux, les plus humains, qui avoient, ou du moins, qui montroient moins d'efprit \& de mémoire, fans fiel, fans aigreur, fans ambition, \& prefque fans paffions : des enfans, plûtôt que des hommes. Ils ne fçavoient rien \& n'avoient nulle envie de fçavoir; ils ignoroient jufqu'à leur origine, \& comme on n'a pû l'apprendre que d'eux, nous ne pouvons avoir fur cela que. des conjectures bien foibles.

D'ailleurs ils n'avoient ni écriture, ni rien qui fupleât à Leurs TraE iij 
ce défaut, que des chanfons; mais ces chanfons fe changeoient à la mort du Prince regnant, ainfi elles n'établiffoient pas une tradition fort ancienne, à quelques fables près, qui étoient fort mal digerées. On en peut juger par ce qu'ils difoient de l'origine des hommes. Les premiers, felon eux étoient fortis de deux cavernes de leur Inle. Le Soleil irrité de cette fortie, changea en pierres les gardiens de ces cavernes, \& métamorphofa ces hommes échapés de leurs prifons, en arbres, en grenoüilles, \& en plufieurs autres fortes d'animaux. Cependant l'Univers ne laiffa point de fe peupler. Une autre tradition portoit que le Soleil \& la Lune étoient auffi fortis d'une grotte de la même Ifle pour éclairer le monde, \& l'on alloit en pélerinage à cette grotte, qui étoit ornée de peintures, \& dont l'entrée étoit gardée par deux Démons, aufquels il falloit rendre fes devoirs, avant que d'aller plus loin. Ces fables font voir que ces Infulaires ne doutoient point que la terre n'eut commencé par leur Inle à fe peupler, \& il eft peu de nations dans l'Amérique, en qui l'on n'ait trouvé la même prévention pour leur pays.

Conjectuses fur leur Origine.
Il y a néanmoins bien de l'apparence que la terre ferme a eu des habitans avant les Ifles. Il s'agit de fçavoir de quel côté font venus ceux, qui les ont peuplées, \& c'eft fur quoi il ne me paroît pas poffible de prendre parti. Il n'eft pas non plus fort aifé de dire pourquoi dans les grandes Antilles les habitans étoient fi doux, \& fi peu agueris, \& ceux des petites, fi feroces, fi belliqueux, fi inhumains. D'ailleurs, \& les Cannibales, qu'ils avoient au Sud pour voifins, \& les Floridiens, qui l'étoient au Nord, étoient également Anthropophages; cependant on ne fçauroit prefque douter qu'ils ne foient defcendus, ou des unş, ou des autres, ou peut-être même de tous les deux peuples : \& quelque rentiment qu'on embraffe, il reftera toûjours à expliquer, d'où vient cette difference de mœurs \& de caracteres dans les uns \& dans les autres, \& d'une partie de ces Infulaires aux peuples, d'où ils tirent leur origine. 


\section{DE S. Domingue, Liv. I. 39}

Pour revenir à leurs chanfons, qui feules leur tenoient Leurs Danlieu d'annales, ainfi que je l'ai déjà remarqué : elles étoient fes \& leurs toûjours accompagnées de danfes en rond, où celui, qui menoit la bande, commençoit feul, \& tous les autres répetoient après lui. Il regloit auffi les pas en danfant le premier. Il en faifoit d'abord quelques-uns en avant, puis il en faifoit autant en arriere : toute la troupe fuivoit. On ne manquoit jamais à la mefure, \& l'on ne fortoit point de cadence. Quelquefois les hommes danfoient feuls d'un côté, $\&$ les femmes de l'autre; d'autre fois les deux fexes étoient mêlés, \& alors c'étoit indifferemment, ou un homme, ou une femme, qui commençoit le branle. Mais dans les Fêtes publiques, \& dans les occafions importantes on chantoit \& on danfoit au fon d'un tambour, \& c'étoit ordinairement le plus confiderable de la bourgade, ou le cacique même, qui touchoit cet inftrument. Cacique, dans la langue du pays, fignifioit Prince ou Seigneur, \& les Efpagnols en ont fait un mot générique, dont ils fe font fervis, non feulement à l'égard de tous les Souverains de l'A mérique, excepté les Empereurs du Mexique, \& les Incas du Perous mais encore pour marquer les Seigneurs particuliers, qui fe trouvoient à la tête des plus petites bourgades.

Le Tambour, dont je viens de parler, n'étoit autre chofe qu'un tronc d'arbre arrondi en Cylindre, auquel on faifoit au fon duquel vers le milieu de fa longueur une ouverture en quarré long, qui paffant par le centre en diminuant toûjours, fe terminoit vers l'extrémité oppofée à deux lignes $\&$ une traverfe qui les uniffoit par le milieu. Ce Tambour, dont le fon ne pouvoit pas être fort agréable, fe couchoit de fon long fur la plus grande ouverture $\&$ avec un baton on frapoit-fur celle, qui luy répondoit. Un autre divertiffement, qu'on appelloit le jeu de Batos, n'étoit pas moins ufité parmi ces Infulaires.

Le Batos étoit une efpece de Balon d'une matiere folide, Jeu de Bamais extrêmement poreufe \& legere, de forte qu'il ne ${ }^{\text {tos. }}$ bondiffoit gueres moins que les nôtres. Ce n'étoit jamais, 


\section{$40 \quad H$ IS T O I R E}

ni avec la main, ni avec le pied, qu'on le jettoit, mais avec la tête, les hanches, les coudes, \& furtout les genoüils. Celui, qui le pouffoit le dernier, comptoit un jeu, \& la par. tie confiftoit dans le nombre de jeux, dont on étoit convenu. Les femmes aurefte y joüoient auffi-bien que les hom. mes. Gonzale Fernand d'Oviedo, qui a paffé la meilleure partie de fa vie dans le nouveau monde, dont il a écrit I'hiftoire, \& qui a long-têms commandé dans la fortereffe de San Domingo, dit que le Batos étoit fait d'une compofition de racines de certains arbres, qu'il ne nomme point, \& de plufieurs herbes, qu'on faifoit boüillir enfemble, d'où il refultoit une pâte noire, affés femblable à de la poix, mais qui ne s'attachoit pas à la main, quand elle étoit bien fêche. Il ajoûte que ce Balon bondiffoit de telle forte, qu'en le laiffant feulement tomber, il fautoit beaucoup plus haut, que l'endroit d'où il étoit parti. Le nombre des joueurs n'étoit point reglé, \& il montoit quelquefois jufquà vingt de chaque côté. Une ligne féparoit les deux bandes, \& il n'étoit pas permis de la paffer. Il y avoit dans chaque bourgade une place deftinée à cet exercice, \& une autre plus grande en dehors pour les plus nombreufes parties, comme quand toute une bourgade défioit une autre, ce qui arrivoit fouvent.

Yvrefe du La victoire fe célébroit par une danfe generale, à la fin Tabac. de laquelle on ne manquoit jamais de s'enyvrer de la fumée de tabac; \& cela étoit bientôt fait : car en premier lieu, on ne fe mettoit à fumer, que quand on étoit prêt à tomber de laffitude; \& puis de la maniere dont on fumoit, la plus forte tête devoit être étourdie d'abord. Sur des braifes à moitié allumées on étendoit des feüilles de tabac, qui n'étoient pas tout-à-fait fêches; puis on prenoit un tuyau fourchu en maniere d'Y, le pied de cette pipe fe mettoit dans la fumée, que caufoit la feüille de tabac, \& fes deux branches, dans les narines, par lefquelles on tiroit la fumée, qui montoit bientôt au cerveau. Chacun reftoit, où l'y vreffe l'avoit fait tomber, excepté le Cacique, que fes femmes venoient 


\section{DE S. D OMING E , LIV. I. $4 \mathrm{I}$}

venoient enlever, \& portoient fur fon lit. Si pendant cette yvreffe il furvenoit quelque fonge, on le prenoit pour un avertiffement du Ciel. Cependant on peut juger que ces débauches, qui étoient fréquentes, ébranloient fort le cerveau de ces Barbares, \& altéroient confiderablement leur conftitution.

Aurefte le Tabac étoit naturel à l'Ine Efpagnole; les Infulaires le nommoient Cohiba, \& appelloient Tabaco l'infOrigine du trument, dont ils fe fervoient pour fumer. On ne doute point aujourd'hui que ce ne foit là l'origine du mot de $\mathrm{Ta}$ bac, \& c'eft une erreur populaire, que de l'attribuer à linle de Tabago. Le fentiment du P. Labat, qui le fait venir de la ville de Tabafco dans la nouvelle Efpagne, ne paroît pas mieux fondé, \& cet auteur auroit bien dû ce me fem. ble, citer fes preuves. Les Efpagnols difent, Hazer un Tabaco, pour fignifier le divertiffement, qu'on prend à fumer \& à danfer en rond à la maniere des Amériquains; \& il paroît que c'eft de là qu'eft venu le terme de Tabagie fi ufité dans nos anciennes relations pour exprimer les fêtes des Sauvages. Les Brafiliens appelloient Petun ce que les Infulaires de S. Domingue appelloient Cohiba, \& il eft étonnant que cela ait été ignoré de $M$. Lemery, qui a cru ce nom François, \& l'a voulu faire dériver du verbe Grec $\pi$ rów j'étends. Car il n'y a gueres d'apparence de vouloir donner une racine Grecque à un terme Brafilien; à moins que ce $\pi \varepsilon^{\prime} \mathfrak{C}^{\prime} \omega$ ne fe foit trouvé dans la langue du Brefil, comme áṕ $\gamma^{\prime} \omega$, \& quelques autres mots Grecs fe trouvent dans la langue Iroquoife.

Ce qui eft de certain, c'eft que cette Plante, aujourd'hui fi fameure, \& dont la plûpart des hommes ont fait un de ${ }^{\text {nomsqu'elle } a}$ leurs plus indifpenfables befoins, a été parfaitement ignorée des Anciens. Comme elle vint d'abord en France par le Portugal, le mot Brafilien Petun, lui fut d'abord feul attribué. On l'appella enfuite l'Herbe à la Reine, \& la Nicotiane, parce que la premiere connoiffance nous en étoit venuë par M. Nicot Ambaffadeur du Roi Charles IX. à Lisbonne .

Tom. I. 
lequel à fon retour en France, la préfenta à la Reine Mere Catherine de Medicis. Le P. du Tertre, qui écrivoit aux Inles de l'Amérique il y a près de 80 . ans, le nomme toûjours Petun; \& Rochefort, qui écrivoit en même têms en Hollande, ne lui donne jamais d'autre nom, que celui de Tabac ; c'étoit effectivement celui, que lui donnoient les Hollandoìs, \& ils l'avoient pris des Efpagnols, avec lefquels ils en faifoient alors un grand commerce. Dans la fuitedes têms les François établis dans le voifinage de $\mathrm{S}$. Domingue, \& à S. Domingue même, s'accoûtumerent à ce terme, \&c infenfiblement il a tellement pris le deffus, que celui de Petun eft devenu bas, \& n'eft plus reçû dans le bel ufage. leurs Mœurs. Oviedo, qui eft entré dans un plus grand détail que perfonne fur tout ce qui regarde les anciens habitans de notre Ifle, fe plaint fort de ce qu'on ne s'eft pas donné le têms de s'inftruire de leurs mœurs, de leurs coûtumes, \& de leur religion, \& de ce qu'on n'y a penfé, qu'après qu'ils ont été prefque tous détruits. En effer tant qu'ils ont fubfifté, on s'eft bien plus appliqué à en tirer des fervices, qu'on ne s'étoit point avifé jufques là de tirer des hommes, qu’à les interroger fur une infinité de chofes capables de picquer la curiofité. D'un autre côté plufieurs hiftoriens fe font plaints de cet auteur, qui a, difent-ils, excedébeaucoup en parlant de la dépravation des mours de ces Infulaires : ils fe récrient fur tout contre ce qu'il a avancé, que l'infâme peché de Sodome étoir commun parmi eux, \& il y en a, qui n'ont point fait difficulté d'affûrer que cette abomination ne leur étoit pas même connuë.

J'avoüe que cette diverfité de fentimens entre des auteurs contemporains, \& des témoins oculaires, eft quelque chofe de fort embarraffant pour un hiftorien, qui cherche à s'inftruire; mais je ne crois pas qu'il foit abfolument impoffible de démêler le vrai à travers de l'obfcurité, qu'elle y refpand. Il ne faut, ce me femble, pour cela que faire attention aux vîës differentes, que ces auteurs avoient en écrivant. Effectivement il parô̂t que l'amour de la nation 


\section{DE S. DOM INGUE, LIV.. I.}

a un peu trop conduit la plume des uns, \& les a porté à ne rien épargner pour diminuer l'indignation du Public \& de la pofterité contre leurs peres \& leurs compatriotes; mais que le zele de la Religion a trop animé celle des autres, \& leur a fait exagerer un peu tout ce qui pouvoit rendre odieux les auteurs des cruautés exercées contre des peuples, qu'on a mieux aimé exterminer, que de les amener au culte du vrai Dieu. Or rien ne pouvoit mieux produire l'effet, que chacun fe propofoit, que de repréfenter d'une part ces peuples, comme n'ayant de t'homme que la figure, \& plongés dans les plus infâmes diffolutions, \& de l'autre, de les faire envifager au contraire comme des hommes fans vices \& fans paffions; on ne fçauroit donc gueres ici fe tromper en prenant le milieu entre ces deux extremités. Le cri general depuis deux fiecles charge trop la nation Caftillane, pour la vouloir abfoudre de toutes les cruautés, qu'on lui a reprochées, mais il eft bien difficile aufi de contredire en tout un hiftorien tel qu'Oviedo, lequel, après avoit dit en general que dans les Antilles, comme dans la terre ferme, les hommes \& les femmes étoient également fujets au peché que la nature abhorre, ajoûte qu'il en faut excepter les femmes de l'ine Efpagnole, qui l'avoient en horreur, non par honte, ou par fcrupule, érant les plus libertines de tout le nouveau monde, mais à caufe du tort que ce déteftable commerce leur caufoit.

Quoi qu'il en foit, quand bien même nos Infulaires auroient été exempts du crime de Sodome, il paroît indu- mal ples bitable qu'en d'autres genres d'impuretés, ils ne gardoient pas beaucoup de mefures. En effer la maffe de leur fang en étoit tellement gâtée, que la plûpart étoient attaqués de cette infâme \& cruelle maladie, dont la communication a fait à l'ancien monde, \& fur tout à l'Efpagne, un tort, que toutes les richeffes du nouveau ne fçauroient compenfer. A peine les Caftillans eurent paru fur les côtes de l'Ine Efpagnole, qu'ils en furent empeftés, \& plufieurs d'entr'eux, qui n'avoient gueres rapporté de leur voyage, que ce nual 
honteux, s'étant engagés à leur retour pour la guerre de Naples, ils le donnerent aux femmes Napolitaines, qui furent affés malheureufes pour s'abandonner à eux : celles. ci ne tarderent pas à le porter dans le camp des François, où il caufa encore de plus grands ravages, que dans celui des Efpagnols, ou du moins les premiers ne fçurent pas diffimuler, comme avoient fait les feconds. Les Italiens furpris de voir naitre ce monftre au milieu de leur pays, s'en prirent à ceux, ou qui en faifoient plus de bruit, oư qu'ils haïfoient davantage, \& le nommerent le Mal Fran. cois. Ceux-ci de leur côté ne manquerent pas de le rejetter, ou fur les femmes, de qui ils l'avoient effectivement reçû, ou fur l'air du pays, \& l'appellerent le $\mathrm{Mal}$ de $\mathrm{Na}$ ples. Les Efpagnols fpectateurs d'un combat, auquel ils avoient donné lieu, n'eurent garde de s'y mêler; encore moins chercherent-ils à mettre d'accord deux nations, qu'ils avoient tant d'interêt à broüiller enfemble, d'autant plus qu'ils ne le pouvoient, qu'en fe chargeant de la chofe du monde la plus odieufe. Et quoi que dans la fuite Oviedo \& Guichardin, l'un Efpagnol, \& l'autre Italien, \& après eux prefque tous les hiftoriens des deux nations, qui one eu occafion de parler de ce mal, ayent fait juftice aux deux parties intereffées, les noms, qu'elles avoient donnés en dépic l'une de l'autre à la nouvelle maladie, ont paffé dans l'ufage ordinaire, \& ont été adoptés par les autres nations felon leur attachement aux François \& aux Italiens. Ainfi on continuë en Italie à le nommer le mal François, \& en France à l'appeller le mal de Naples, quoi que fans confequence pour les perfonnes inftruites.

Mais fi les Efpagnols ont trouvé le fecret de préferver leur nom de cette infâmie, \& d'éviter par là une partie de l'odieux de cette pefte, dont ils ont infecté l'Europe, ils en ont fi peu garanti leur fang, fur tout dans l'A mérique, qu'il s'y trouve peu de familles de leur nation, qui ne s'en reffente. Les. Infulaires guériffoient ce mal, ou du moins y apportoient beaucoup de foulagement avec le bois de 


\section{DE S. DOMINGUE, LIV. I. 48}

Gayac: mais il revenoit d'abord, \& l'experience a fait voir que pour le guerir radicalement il y faut employer le Mercure \& les fueurs les plus violentes. Mais revenons.

Il n'y avoit rien de reglé parmi nos Infulaires pour le nombre des femmes: plufieurs en avoient deux ou trois, De leurs les autres un peu plus. Un des Souverains, qui regnoient dans line, quand elle fut découverte, en avoit jufqu'à trente, mais ces exemples étoient rares. Il paroît néanmoins que chacun avoit fur cela une liberté entiere, \& regloit le nombre de tes femmes fur fes facultés, \& comme la plûpart n'avoient gueres que le néceffaire pour vivre, le commun fe contentoit d'une femme. Quant aux degrés prohibés, il n'y avoit que le premier, fur lequel on ne fe relachoit jamais. Parmi les femmes d'un même mari il y en avoit ordinairement une plus diftinguée que les autres, mais elle n'avoit aucune fuperiorité fur fes compagnes. Toutes couchoient autour du mari, \& nulle jaloufie ne troubloit la paix du ménage. A la mort du Cacique, dont je viens de parler, on obligea deux de fes femmes à lui tenir compagnie, en fe laiffant enfevelir toutes vivantes, dans le tombeau, où on l'avoit mis; on a vû en d'autres occafions des époufes faire d'elles-mêmes \& avec joie, ce qu'on exigea de celles ci. Pour l'ordinaire la chofe étoit laiffée à leur choix, \& affés peu pratiquée.

Les femmes étoient toûjours chargées des obféques de Des Obfé: leurs époux; elles enveloppoient le corps de larges bandes de cotton, le mettoient dans une foffe affés profonde avec tout ce que le défunt avoit eu de plus précieux. Le cadavre n'étoit pas couché de fon long, mais affis fur une efpece de banc, \& l'on faifoit au fepulchre une maniere de voute avec du bois, pour empêcher que la terre ne tombât fur luii: Cette cérémonie étoit accompagnée de chants, \& de beaucoup de fuperfitions, dont on ne nous a point appris le détail : mais les corps des Caciques ne fe metroient en terre. quaprès avoir été bien vuidés \& fechés au feu. C'éroit en ces occafions que fe compofoient les chanfons, où avec les 


\section{HISTOI \&}

loüanges du défunt, on marquoit tout ce qui étoit arrivé fous fon regne; \& pendant la vie de fon fuccefleur ces chanfons, ainfi que je l'ai déjà remarqué, fe chantoient dans toutes les actions publiques. Les obféques des Caciques duroient environ quinze ou vingt jours, \& a vant que l'affiftance, qui étoit toûjours nombreufe, fe féparât, on partageoit entre les principaux conviés tout ce qui étoit refté des meubles du mort.

Les occupa- La néceffité tiroit quelquefois ces Barbares de leur inactions des Infu- tion, \& les obligeoit de s'occuper, fur tout à la chaffe, \& à
aares. la pêche. Ils fe fervoient pour le premier de ces exercices de ces petits chiens muets, dont j'ai parlé ailleurs: mais fouvent ils fe contentoient de mettre le feu aux quatre coins d'une prairie, \& en moins de rien ils la trouvoient toute pleine de gibier à moitié roti. Ils chaffoient affez peu aux oifeaux, \& la plûpart ne fçavoient pas manier un arc, ni une fleche. Ils ne laifoient pas de fuppléer à ce défaut par quelque induftrie. Ils prenoient fur tout force Perroquets. \& l'artifice, dont ils ufoient pour cela, eft affez fingulier. Ils faifoient monter fur un arbre un enfant de dix à douze ans, auquel ils metroient fur la tête un Perroquet privé. Les Chaffeurs tout couverts de feuillages s'approchoient enfuite doucement, \& faifoient crier le Perroquet; à ce cri tous les Perroquets d'alentour s'attroupoient en criant de toutes leurs forces; alors l'enfant paffoit au col du premier qu'il trouvoit à $\mathrm{fa}$ main un nœud coulant, puis le tiroit à foi , achevoit de lui tordre le col, le jettoir par terre, \& continuoit ce manege, jufqu’à ce qu'il n'en reftât pas un. Ils avoient une autre invention pour prendre les $\mathrm{Ra}$ miers ; ils imitoient affez bien le rocouëment de ces oifeaux, \& quand ils en avoient affemblé un grand nonbre, ils les prenoient dans des filets fort bienfaits; les rets, dont ils fe fervoient pour la pêche, étoient auffi très-bien travaillez.

Leur ma- Il s'en falloit beaucoup qu'avant l'arrivée des Efpagnols, pofer à cher- ces Peuples fiffent de l'or le cas, que nous en faifons. Ils ne cher del'or. 


\section{DE S. DomingUe, LIv. I. 47}

laiffoient pourtant pas de l'eftimer, \& de le rechercher avec foin, mais ils fe contentoient ordinairement des petits grains, qu'ils trouvoient aifément, qu'ils applatiffoient un peu, \& dont ils fe faifoient des pendants aux narines. Il femble même qu'ils regardoient ce métal comme quelque chofe de facré , car ils ne l'alloient jamais receüillir, qu'après s'y être preparez par de longs jeunes \& plufieurs jours de continence. Ils difoient que quand ils avoient manqué à cette pratique, ils ne trouvoient rien. Chrifophle Colomb voulut dans le commencement engager les Efpagnols à imiter un fi bel exemple, \& à ne point aller aux mines, fans s'être auparavant approchés des Sacremens de Penitence \& d'Euchariftie. Mais il eut beau dire, il ne perfuada perfonne : \& comme il eut entrepris d'agir d'autorité, on lui repréfenta que l'Eglife n'ordonnant qu'une feule fois l'année la Confeffion \& la Communion, il ne lui appartenoit pas de faire fur cela de nouveaux préceptes. Qu'au refte les Efpagnols fe trouvoient condamnés, malgré qu'ils en: euffent, à une continence beaucoup plus longue, que celle des Infulaires, puifqu'ils avoient laiffé leurs femmes en Ef. pagne; \& que vâ le peu de mauvaife nourriture, à quoi ils étoient réduits, leur vie pouvoit paffer pour un jeûne continuel \& bien rigoureux. Colomb ne voulut pourtant pas en avoir le démenti, \& ne permit jamais, autant qu'il pût, le voyage des mines, qu'à ceux, qui s'y étoient préparés de la maniere, qu'il fouhaitoit.

Les anciens habitans de l'Ifle Efpagnole travailloient peu Leur mas à la terre, \& on ne leur a trouvé aucune forte d'outils niere de culpour l'agriculture. Le feu étoit comme leur inftument uni- \& tiver la terre, verfel. Ils brûloient les herbes de leurs favannes. (c'eft un feu. terme, que nous avons emprunté des Efpagnols, \& qui veut dire plaines, \& en general tout lieu, où il ne croît que de l'herbe.) Ils brûloient, dis-je, les herbes de leurs favanes, quand elles étoient feches, \& après avoir remué légerement la terre avec un bâton, ils plantoient leur Maïz. Pour faire du feu ils ne fe fervoient point de pierres, guo: 


\section{HISTO I R E}

Que leur Ifle n'en manque point de fort propres à cela: ils ne fçavoient pas apparemment le fecret de l'en tirer. Ils prenoient d'eux morceaux de bois, l'un extrêmement poreux \& fort leger, l'autre plus denfe $\&$ plus dur; ils picquoient ce dernier dans le premier, \& le tournoient avec beaucoup de viteffe, à peu près comme on braffe le Chocolat; cette violente collifion lui faifoit jetter du feu, \& ce feu étant reçû dans l'autre bois, y prenoit, comme s'il fût tombé fur de l'étoupe.

Leurs Ca- C'étoit encore avec le feu que ces Sauvages faifoient nots ou Piro- leurs canots, ou pirogues. Ils choififfoient un arbre, puis
gues. allumoient du feu tout autour, pour le faire mourir: enfuite ils le laiffoient fecher fur pied. Cela fait, ils y mettoient le feu pour l'abbatre; \& aprés avoir pris leurs dimenfions, fuivant la grandeur, qu'ils vouloient donner à leur canot, ils le creufoient lentement avec le feu, levant le charbon avec une efpece de hache, ou de coignée d'une pierre verte très-dure. Il ne s'eft jamais trouvé, ni dans l'Ille, ni en aucun autre endroir, de carrieres de cette pierre, \& l'opinion commune eft qu'elles venoient de la riviere des A. mazones, dont on prétend que le limon expofé à l'air fe pétrifie. La difficulté eft d'imaginer par quelle voie nos Infulaires, qui n'avoient commerce avec aucune autre nation, faifoient venir ce limon pétrifié de fi loin.

Leur Gou- La forme du gouvernement établie parmi ce peuple étoit vernement. Supplicé des Yoleur6.

defpotique; la vie, les biens, la religion même des fujets étoient en la difpofition des Souverains, qui n'abufoient pas de leur pouvoir. Les Sujets de leur côté étoient extrêmement foûmis, exécutoient ponctuellement les ordres de leurs Caciques, \& s'en rapportoient fans peine à ce que ces Princes leur difoient fur toutes fortes de chofes. Ils avoient peu de loix, \& elles n'étoient pas fort féveres, néanmoins le larcin étoit regardé comme un crime atroce, \& fe puniffoit avec beaucoup de rigueur. Le voleur étoit empâlé, de quelque condition qu'il fut, \& reftoit expofé en cet état à la vûë de tout le monde. Il n'étoit même permis à perfonne d'interceder 


\section{DE S. DOM INGUE, LIV. I. 49}

d'interceder pour lui. Une figrande feverité avoit produit l'effet, qu'on en avoit prétendu, peu de gens s'attachoient à un métier fi dangereux; \& comme on ne fçavoit d'ailleurs dans cette Inle ce que c'étoit que d'attenter à la vie les uns des autres, on y vivoit dans une très-grande fécurité.

Ce peuple avoit encore beaucoup d'éloignement de tout ce qui fentoit l'avarice, \& par confequent rien n'étoit ca- fement \& pable de troubler la paix de l'Ifle. Accoûtumé à fe borner au pur befoin pour la vie, on n'y fongeoit point à théfaurifer, \& ce que la terre produifoit prefque fans culture, étoit en quelque forte à tout le monde. Du moins les plus accommodés ne manquoient jamais de fecourir ceux, qu'ils voyoient dans l'indigence. L'hofpitalité étoit auffi très-religieufement obfervée à l'égard de tout le monde; il ne falloit pas être connu, pour être reçû dans une maifon, \& on l'étoit de quiconque, comme on l'auroit été de fes meilleurs amis.

Les Principautés étoient hereditaires; mais fi un Cacique mouroit fans enfans, fes Etats paffoient à ceux de fes fours préferablement à ceux de fes freres. La raifon de Ordre dela Succeffionaux cette coûtume étoit la même, qui l'a fait établir en tant d'autres pays, fur tout dans l'Amérique, à fçavoir que les enfans des foeurs font bien plus certainement du fang de leurs oncles, que ceux de leurs freres. La même raifon auroit dû les faire encore paffer par deffus les enfans mêmes du Prince défunt, mais l'ufage étoit contraire. Dans quelques Provinces les femmes des Caciques devoient tenir compagnie à leurs maris défunts dans le tombeau, à moins que de vouloir paffer pour leur avoir été infidelles pendant leur vie; fi quelqu'une n'étoit pas affés jaloufe de la réputation d'honnête femme, pour l'acheter à ce prix, fes enfans ne pouvoient prétendre à la fucceffion du pere, l'aveu tacite, que leurs meres faifoient de leur infidélité, les faifant regarder comme illégitimes.

Quand il furvenoit quelque differend entre les Caciques, Leurs Guero \& il n'en naiffoit gueres, qu'au fujet de la pêche, il étoit res. 


\section{so H I STO I R E}

bientôt terminé, \& prefque toûjours fans effufion de fang. Auffi leurs armes n'étoient-elles pas fort meurtrieres; c'étoit des bâtons, ou des efpeces de maffuës, qu'ils appelloient Macanas, larges d'environ deux doigts, pointuës par la tête, \& ayant un manche en façon de garde, com* me les épées. Iis avoient auffi des javelots de la même matiere, c'eft-à-dire, d'un bois très-dur, \& ils les lançoient avec beaucoup d'adreffe: dans le fond c'étoit affés pour des gens tout nuds, \& qui n’avoient ancune arme défenfive. Ce qui les incommodoit davantage, quand ils étoient bleffés, c'eft lorfque les éclats de ce bois très-facile à éclater; leur étoient reftés dans la playe. Ils n’avoient pas l'adreffé de les en tirer, \& il en arrivoit toûjours quelque accident. Les habitans des Provinces Orientales fe fervoient de l'arc $\&$ de la fleche, \& ils avoient fans doute pris cet ufage des Caraibes, habitans des petites Antilles, leurs ennemis perpetuels.

Leur Nour- La nourriture ordinaire de nos Infulaires étoit le Maïz, siturc. que nous appellons en France Bled de Turquie, ou gros Mil, les Patates, \& la Caffave; on traitera de toutes ces chofes fort au long dans un Ouvrage, qui fuivra de près celui-ci, \& qui demande de grandes recherches. La chafle \& la pêche fourniffoient encore une grande reffource, mais ce qui s'y prenoit de meilleur, étoit refervé pour la bouche du Cacique, \& c'eut été un crime à un particulier, que de témoigner même la moindre envie d'en goûter. Ia feüille \& la racine d'une efpece d'Arum, ou de Pied de Veau, que les François ont nommé choux Caraibes, le Pourpier, l'Epinard fauvage, les Bourgeons des Patates \& des Mombins étoient leurs mets extraordinaires, ou plûtôt leur fervoient de ragouts, ils mêloient tout cela enfemble, en relevoient le gout par leur $A x i$, ou Piment, \& donnoient à cette compofition le nom d'Yracas. Dans le befoin, lorfque les vivres ordinaires leur manquoient, ils avoient recours aux fruits, dont leurs forêts étoient remplies; d'ailleurs ils s'accoutumoient fi bien à manger de tout, même deschofes, 


\section{DE S. Domineue, Liv. I. ST}

qui nous feroient le plus d'horreur, comme des Vers, des Araignées, des Chauves-Souris, des Couleuvres, qu'il étoit impoffible qu'ils mouruffent de faim. Mais quoique ces animaux nayent point de venin dans les Inles, une telle nourriture, \& la légereté des vivres ordinaires étoient la veritable caufe de cette foibleffe de complexion, qui rendoit ces Infulaires incapables de grands travaux. Cen'étoit pourtant pas la faute de leur pays, mais il s'en falloit bien qu'ils en tiraffent tout ce qu'il pouvoit leur fournir pour la vie. On peut même affûrer que cètte Ifle, \& en general une bonne partie de l'Amérique Méridionale a de grands avantages de ce côté là fur l'Europe, où le néceffaire roule de telle forte fur le Bled, \& les autres grains, dont on fait le pain, qu'ils ne fçauroient manquer dans un Royaume, fans y mettre le peuple en danger de périr de mifere, comme il arrive antés fouvent. Au lieu que dans cette partie du nouveau monde il y a fix fortes de nourriture auffi naturelles, que le pain, qui n'y manquent jamais, \& multiplient extraordinairement. On y peut faire par an jufqu'à trois récoltes de Maïz \& deux de Ris. Parmi les efpeces de Patates, qui font toutes fort nourriffantes \& d'un très-bon goût, il y en a une, qu'on nomme Patate de fix femaines, parce qu'on la peut manger fix femaines, ou deux mois, au plus tard, après qu'elle a été femée. Dans une touffe de Bananier, qui eft compofée au moins d'une douzaine de pieds, il y en a toûjours quelqu'un chargé de fruit, \& ce fruit eft auffi très-nourriffant. Le Manioc \& l'Igniame ne fe recueillent qu'une fois l'année, mais il arrive rarement que la récolte n'en foit pas très-abondante. Elle ne manque au moins jamais, \& ces plantes ne demandent prefque aucun foin.

La maniere, dont les habitans d'Haïti fe logeoient, ré- Leurs Màpondoit parfaitement à la fimplicité d'une vie fi frugale. fons.

Toutes leurs maifons étoient bâties fur deux deffeins; on pouvoit choifir, \& il n'y avoit aucune regle pour cela, mais les plus pauvres choififfoient celui ci. Ils commençoient par planter affés profondément en terre des pieux, de la grof- 
feur à peu près de nos foliveaux, ils les plaçoient en rond à quatre ou cinq pas de diftance les uns des autres: ils étendoient deffus des pieces de bois plattes, mais fort épaiffes, fur lefquelles ils apuyoienr de longues perches, qui fe joignant toutes par la pointe formoient un toit en figure de Cône: ils attachoient des cannes en guife de lattes à ces perches, \& pour les rendre plus folides, ils les mettoient deux à deux, \& tout au plus à une palme de diftance; ils couvroient le tout d'une paille fort déliée, ou de feüilles de Palmier, ou de l'extremité des cannes. Pour ce qui eft du bas, les entredeux des pieux fe garniffoient de cannes fichées en terre, \& très-bien liées enfemble avec une efpece de filaffe très-forte $\&$ incorruptible, qu'Oviedo nomme Befchiuchi, qui croît fur les arbres, \& qu'on voit pendre des branches. Ces murailles avoient beaucoup de folidité, \& elles étoient fi bien fermées, qu’il n'y paffoit pas un foufle de vent. Les cannes dont elles étoient compofées viennent beaucoup plus groffes dans l'Amérique, que celles qu'on voit en Efpagne \& en Italie; les liaffes, dont je viens de parler, font de differentes groffeurs, \& toutes jufqu'aux plus petites fe peuvent divifer en deux, de forte qu'on s'en fert à lier les chofes les plus fines. Outre cet ufage, elles ont encore plus d'une vertu pour la Medecine, fuivant l'auteur, que je viens de citer, mais il ne les explique point.

Ces fortes de maifons, ou pour mieux dire, de cafes, font les plus capables de réfifter aux vens, qui fouflent quelquefois impétueufement dans cette Inle. Pour leur donner encore plus de folidité, au moins dans les endroits. les plus expofés, on plantoit au milieu un grand poteau, auquel étoient attachées par le haut les extremités des perches. Les autres maifons avoient la même conftruction \& les mêmes materiaux, mais la forme étoit differente, \& approchoit fort de celle de nos granges. Le toit en étoit foutenu par une longue piece de traverfe, qui l'étoit elle même par des fourches plantées dans le milieu de la maifon, qu'elles féparoient ainfi en deux. Ces 


\section{DE S. DOm Ingue, Liv. I. 53}

maifons étoient plus grandes que les autres, mieux ornées, \& plufieurs avoient des veftibules, en maniere de portiques, couverts de paille; ils étoient deftinés à recevoir les vifites, \& Oviedo affüre que les couvertures en étoient mieux travaillées, que celles des maifons de Flandres de fon têms.

Le langage n'étoit pas entierement uniforme dans toute l'Ifle, chaque province avoit fa dialecte particuliere, mais gue. on s'entendoit par tout. La langue, qu'on parloit dans le milieu de l'Ifle, étoit la plus eftimée; on la regardoit même en quelque façon comme une langue facrée, \& elle avoit cours dans les autres Provinces. Ces langues n'avoient rien de barbare, \& s'aprenoient aifément. On peut juger de leur douceur par quelques mots, qui nous en reftent, \& que nous avons fait paffer dans la nôtre à l'exemple des Efpagnols. Notre Canot vient de leur Canoa, d'Amacha, nous avons fait Hamach, c'eft un Branle de Cotton, ou de fil, maniere de lit fufpendu par les deux extremités, qu'on attache avec une corde à deux arbres, ou à deux piliers, \& dont on fe fert affés communément dans tous les pays chauds. Nos Infulaires appelloient Uracane ces vens impétueux, qui excitent fur leurs côtes de fi dangereufes tempêtes, \& aufquels nous avons donné le nom d'Ouragan, en pronoçant l'u, comme le prononcent les Efpagnols. Le P. le Pers ajoûte à ces termes celui de Savana; mais il fe trompe; Mariana le met parmi ceux, que les Efpagnols ont confervés de l'ancienne langue des Vifigots, qui ont conquis l'Efpagne.

On ne devoit pas attendre un fyftême de Religion bien Leur Relifenfé \& bien fuivi d'une nation fi brutte, fi peu accoutumée gion. à réflechir, \& fi peu éclairée des lumieres même de la raifon naturelle. Auffi n'y a-t-on trouvé qu'un tiflu mal afforti des plus groffieres fuperftitions, aufquelles il n'eft pas difficile de reconnoitre que le Démon préfidoit d'une maniere fenfible. Veritablement il n'en devoit pas couter beaucoup à cet Efprit d'erreur, pour fe faire rendre les honneurs divins, 


\section{4

par des hommes, qui trouvant en eux, comme tous les aus tres, lidée d'un Eftre fuperieur, n'avoient, ni affés de pénétration, ni affés d'application, pour la développer. Si on en croit les auteurs contemporains, ou voifins de la découverte du nouveau monde, le Démon apparoiffoit affés fouvent à nos Infulaires, \& leur rendoit des Oracles, fur lefquels ce peuple féduit fe regloit à l'aveugle. Il eft même fort vray-femblable que les différentes figures, fous lefquelles ils repréfentoient leurs Divinitez étoient celles, fous lefquelles ils croyoient les avoir vîës. Elles étoient toutes hideufes; les plus tolerables étoient celles de quelques animaux, comme des Crapaux, des Tortuës, des Couleuvres, \& des Caymans. Mais la plûpart du têms c'étoit des figures humaines, horribles \& monftrueufes, qui avoient tout enfemble quelque chofe de bizare \& d'affreux.

Leurs Di- Delà il étoit arrivé deux chofes. La premiere, que cette vinités.

varieté de figures avoit perfuadé à ces peuples qu'il y avoit plufieurs Dieux. La feconde, que la laideur de ces Dieux les leur faifoit regarder comme beaucoup plus capables de leur faire du mal, que de leur faire du bien. Auffi ne fongeoient ils gueres qu'à appaifer leur fureur, \& à les engager par des Sacrifices à les laiffer en repos. Ils appelloient ces Idolẹs Chemis ou Zemés. Ils les faifoient de craye, de pierre, ou de terre cuite; ils les plaçoient à tous les coins de leurs maifons, ils en ornoient leurs principaux meubles, \& ils s'en imprimoient l'image fur le corps. Ainfi il ne faut pas s'étonner, fi, les ayant fans ceffe devant les yeux, \& les craignant beaucoup, ils les voyoient fouvent en fonge. Ils n'attribuoient pas à tous le même pouvoir; les uns, felon eux, préfidoient aux faifons, d'autres à la fanté, ceux-ci à la chaffe, ceux-là à la pêche, \& chacun avoit fon culte $\&$ fes offrandes particulieres.

Zemés Divinités
balternes.

Quelques auteurs, qui prétendent avoir étudié ces petrü- ples plus à fond, affûrent qu'ils regardoient les Zemés comme des Divinitez fubbalternes, \& les Miniftres d'un Etre fouverain, unique, éternel, infini, tout-puiffant, in- 


\section{DE S. DOMINGUE, LIV. T. SS}

vifible, mais non pas incréé; car ils lui donnoient une mere, laquelle avoit cinq noms differents; à fçavoir $\mathscr{A t t a -}$ beira, Mamona, Guacarapira, Tiella, \& Guamaonocan. Mais on ne rendoit à ce Dieu fuprême aucun culte, du moins extérieur, non plus qu'à fa mere, à moins qu'on n'attribuë à celle-ci, ce qui eft rapporté par D. Pierre Martyr, que parmi les Zemés il y en avoit un, quon adoroit fous la figure d'une femme, \& qu'on voyoit à fes côtez fes deux principaux Miniftres, toûjours prêts à exécuter fes ordres.L'un, difoit-on, étoit fon Hérault, c'étoit à lui à convoquer les autres Zemés, quand la Déeffe vouloit les envoyer, ou pour exciter les vens, ou pour faire tomber la pluye, en un mot pour procurer aux hommes les biens, qu'ils lui demandoient. Tout l'office de l'autre étoit de châtier par des inondations ceux, qui refuferoient de rendre à cette Divinité les hommages, qu'elle exigeoit de tous.

Dom Fernand Colomb dans la vie de fon pere, qu'il a Fourberie écrite avec moins d'exactitude, qu'on ne devoit l'attendre au fujet des. d'un homme de fon merite, \& qui pouvoit être beaucoup mieux inftruit, qu'un autre du fujet qu'il traitoit; dit que les Zemés étoient comme les efprits tutelaires des hommes, $\&$ que chacun avoit le fien, qu'il mettoit toûjours audeffus de tous les autres. Il ajoûte qu'ils les plaçoient dans des endroits fecrets, où ils ne laiffoient entrer aucun Chrétien : que quand ils craignoient qu'on ne découvrit ces lieux fe. crets, ils couroient devant pour tirer leurs Dieux, \& les aller cacher: que des Efpagnols étant un jour entrés dans la cabane d'un Cacique, ils y apperçurent un Zemés, qui faifoit grand bruit, \& difoit dans la langue du Pays beaucoup de chofes, qu'ils n'entendoient pas; que fe doutant qu'il $y$ avoit de la fupercherie, ils rompirent la Statuë à coups de pieds, \& trouverent un long tuyau, dont une extrêmité donnoit dans la tête de l'Idole, \& l'autre dans un petit coin tout couvert de feuillages, où un homme, qu'on ne voyoit point, faifoit dire au Dieu tout ce qu'il vouloit: que le $\mathrm{Ca}_{-}$ cique pria les Efpagnols de ne point parler de ce qu'ils 


\section{HISTOIRE}

avoient vâ, \& leur avoüa qu'il fe fervoit de cette adreffe pour fe faire payer un tribut, \& pour contenir tous fes Sujets dans l'obéiflance. Il dit encore que les Caciques avoient trois pierres, qu'ils confervoient fort religieufement ; prétendant qu'elles avoient chacune leur vertu particuliere, l'une de faire croître les grains femez, l'autre de faire accoucher les femmes fans douleur, \& la troifiéme de procurer la pluye \& le beau têms felon les befoins.

Proceffion Enfin on trouve dans les plus anciens auteurs la defcrip. folemnelle en tion d'une folemnité, qui eft la feule cérémonie religieufe Dieux. de ces peuples, dont on ait eu foin de nous inftruire. Le Cacique en marquoit le jour, \& le faifoit annoncer par des Crieurs publics.La Fête commençoit par une nombreufe Proceffion, cù les hommes \& les femmes mariées fe trouvoient ornez de ce qu'ils avoient de plus précieux. Les filles y paroiffoient toutes nuës à l'ordinaire : le Cacique, ou le plus confiderable du lieu, marchoit à la tête, ayant un tambour, dont il joüoit fans ceffe, \& l'on fe rendoit ainfi dans un Temple tout rempli d'Idoles, dont les figures étoient bien plus propres à repréfenter des Diables, que des Dieux. On y trouvoit les Prêtres occupés à les fervir, \& qui en leur préfentant les offrandes du peuple, pouffoient des cris \& des hurlemens affreux. Une partie de ces offrandes confittoit dans des gateaux, que des femmes apportoient dans des corbeilles ornées de fleurs; \& l'offrande finie, ces mêmes femmes au fignal, que leur en donnoit un Prêtre, danfoient \& chantoient les loüanges des Zemés, à quoy elles ajoûtoient celles des anciens Caciques, \& finiffoient par des prieres pour la profperité de la nation. Les Prêtres rompoient enfuite les gateaux confacrés par l'offrande, qui en avoit été faite aux Dieux, \& en diftribuoient les morceaux aux chefs de famille. Il falloit conferver toute l'année ces fragmens, \& on les regardoit comme des préfervatifs, contre toutes fortes d'accidens. Le Cacique n'entroit point dans le Temple, il fe tenoit à la porte affis, \& joüant fans ceffe de fon tambour, il faifoit paffer devant lui toute la Proceffion; cha- 
DE S. Dom INGUE, Lrv. I.

cun entroit en chantant, puis alloit fe préfenter à la principale Idole. Dès qu'il étoit en fa préfence, il ceffoit de chanter, \& fe fourroit dans la gorge un bâton paur fe faire vomir. L'efprit de cette ridicule cérémonie étoit de montrer, que pour paroître devant la Divinité d'une maniere religieufe, il faut avoir le cour net, \& pour ainfi dire fur les levres.

Les Zemés fe communiquoient fur tout aux Butios, ainfi appelloit-on les Prêtres du Pays, qui étoient en même-têms Médecins, Chirurgiens, \& Droguiftes. Et quoique le Démon eût, fi l'on en croit les anciens auteurs, quelque part à ce qui fe paffoir dans l'exercice de ces differens minifteres, il y entroit encore beaucoup plus de fourberie. Lorfque ces impofteurs confultoient les Zemés en public, jamais on n'entendoit la reponfe du Dieu, mais on jugeoit de l'Oracle par la contenance du Prêtre. S'il danfoit \& chantoit, c'étoit un bon figne, \& l'on en témoignoit aufitôt fa joye par toutes les démonftrations, dont on pouvoit s'avifer. Si au contraire le Miniftre des Dieux avoit l'air trifte, on s'abandonnoit aux larmes, \& on jeûnoit jufqu'à ce que la Divinité daignât faire connoître par quelque marque certaine, que fon courroux étoit appaifé.

Les Butios n'avoient d'autres diftinctions à l'exterieur, Des Prêtres qu'une figure de Zemés, qu'ils portoient toûjours fur eux : \& des Medemais ils n'oublioient rien de tout ce qui étoit capable de ${ }^{\text {cins. }}$ leur concilier le refpect des peuples; \& ils avoient fur tout grand foin de faire croire à la multitude qu'ils avoient de fréquents entretiens avec les Dieux, qu'ils étoient admis à leur plus intime confidence, \& qu'ils aprenoient d'eux. ce qu'il y avoit de plus caché dans l'avenir : ils perfuadoient fans peine une nation crédule $\&$ groffiere, dont la vénération pour eux alloit quelquefois jufqu’a leur donner le nom de Zemés, \& à les regarder comme des hommes divins; car quoiqu'ils hazardaffent fouvent des prédictions, que l'événement ne vérifioit pas, il ne leur étoit pas bien difficile de pallier leur fourberie par quelque tour d'adreffe. 


\section{8}

H I T O I R E

Dangers

'qu'ils couroient quand un malade mouroit.
Ieur maniere de traiter les malades.
Mais il s'en falloit bien qu'ils fuffent toûjours autant refpectés fous la qualité de Medecins, que fous celle de Prêtres, \& nos Infulaires n'étoient pas auffi aifés à duper au fujet de leur fanté, que quand il s'agiffoit de Religion. Lorfqu'un malade, malgré les prédictions \& les foins du Medecin, venoit à mourir entre fes mains, on ne le re. gardoit plus que comme un fourbe $\&$ un ignorant, les plus proches parens du défunt s'affembloient autour du cadavre ${ }_{2}$ lui coupoient les ongles \& les cheveux, les mêloient avec le jus d'une certaine herbe, \& lui verfoient de cette compofition dansla bouche, en le priant de leur faire fçavoir. fi c'étoit par la faute du Medecin, qu'il étoit mort. On prétend qu'à force d'operations magiques, \& d'invocations, dont on accompagnoit cette interrogation, on en tiroit une réponfe. Peut-être ne fe paffoit-il rien que de naturel, mais on fçait que dans toutes les nations, on a prétendu connoitre les fecrets refervés à Dieu feul, par des fignes d'euxmêmes fort équivoques \& fort indifférents. Quoi qu'il en foit, fi la réponfe réelle ou imaginée chargeoit le Medecin , \& qu'il n'eut pas eû la précaution de fe retirer en lieu fûr, on fe jettoit fur lui, \& on le mettoit en pieces. Mais pour en venir à ces enquêtes, il falloit que le Medecin fut déjà fufpect, \& fouvent c'étoit les faux Prêtres eux-mêmes, quỉ par jaloufie s'accufoient les uns les autres, ou d'avoir par négligence laiffé périr leurs malades, ou d'avoir ufé de quelque maléfice, pour abreger les jours de quelqu'un, à qui ils ne vouloient pas de bien.

Toutefois on convient que les Butios s'appliquoient afrés à la connoiffance des fimples; mais quand ils étoient au bout de leur fcience, ils payoient de hardieffe \& d'impofture. D'ailleurs on fe fouvenoit toûjours qu'ils étoient les Miniftres de ces Dieux, dont on redoutoit fi fort la puiffance; ainfi pour peu qu'on fût de fang froid, on ne s'avifoit gueres de les offenfer. Au refte leur maniere de traiter les malades, avoit quelque chofe de fort bizarre. Après avoir fait mille fimagrées autour du lit, ils fucçoient la 


\section{DE S. DOMINGUE, LIV. I.}

partie, où étoit le mal, puis montrant une épine, ou quelqu’autre chofe femblable, qu'ils en avoient tirée, difoient-ils, mais que dans la verité ils avoient eu foin de mettre auparavant dans leur bouche ; $\rightsquigarrow$ Voilà, s'écrioient-ils, ce qui vous s rendoit malade; c'eft un tel, ajoûtoient-ils, qui vous l'aw voit fait entrer dans le corps: a \& par là ces charlatans femoient la zifanie entre les familles.

On rencontre encore en plufieurs endroits de l'the des figures de Zemés, \& c'eft par là qu'on connoit les lieux, où il $\mathrm{y}$ a eu autrefois des bourgades. On juge la même chofe fur certain amas de coquillages qu'on trouve fous terre, parce que ces Infulaires mangeoient beaucoup de ces efpeces de poiffons, \& pour peu qu'on y creufe, on y fait des découvertes affés curieufes; car on y voit generalement tout ce qui étoit à l'ufage de ces peuples; des pots de terre, des platines pour faire cuire la Caffave, des haches \& de ces petites lames d'or, qui leur pendoient des narines, \& quelquefois des oreilles; mais fur tout on $y$ découvre quantité de Zemés de toutes les façons.

Ce peuple avoit une très-legere idée de l'immortalité de Ieurs diffel'ame \& de l'autre vie. Ils difoient néanmoins qu'il y avoit nions. un lieu, où les ames des bons étoient récompenfées: mais on ne parloit point du fupplice préparé pour les méchans. Chacun plaçoit ce Paradis dans fa Province, \& ils s'y figuroient une vie délicieufe à leur maniere. Ils fe faifoient fur tout beaucoup de fête d'y retrouver leurs parens \& leurs amis, \& d'y avoir des femmes à choifir. Quelques - uns croyoient que le féjour des ames étoit vers le lac Tiburon, où il y a de grandes plaines toutes couvertes de $M a_{*}$ meys, c'eft une forte de Fruit, auquel on a donné le nom d'A bricot de S. Domingue. Ils prétendoient que les ames faifoient leur nourriture ordinaire de ce fruit, ils ajokttoient que pour en faire leur provifion, elles prenoient le têms de la nuit, \& que tout le jour elles fe tenoient cachées dans des lieux montagneux \& de difficile accès. Cette opinion conféroit je ne fçai quoi de facré au Mamey, qui d'ailleurs 
eft excellent; \& les vivans s'en abftenoient par refpect, \& pour ne pas expofer les morts à manquer de nourriture.

J'ai déjà parlé de l'imagination de nos Infulaires touchant l'origine des hommes \& des aftres; la Caverne, d'où étoient fortis le Soleil \& la Lune, \& où j'ai dit qu'on alloit en pélérinage de tous les endroits de l'Ille, renfermoit deux Idoles, aufquelles on ne manquoit pas d'apporter de riches offrandes. On conjecture que c'eft la même, qu'on voit dans le quartier de Dondon, à fix ou fept lieuës du Cap François. Elle a 1 so. pieds de profondeur, \& environ autant de hauteur, mais elle eft fort étroite. Son entrée eft plus haute \& plus large que la plus grande porte cochere, qui foit à Paris, \& la Grotte ne reçoit du jour que par là, \& par une ouverture pratiquée dans la voute; cette ouverture paroît travaillée en façon de clocher : \& on ajoûte que c'eft par là que le Soleil \& la Lune fe font fait un paffage, pouraller fe placer dans le ciel. Toute la voute eft fi belle \& fi reguliere, qu'on a peine à fe perfuader que ce foit l'ouvrage de la nature feule. On ne voit ence lieu aucune ftatuë, mais on y aperçoit par tout des Zemés gravés dans le roc, \& toute la Caverne paroît comme partagée en plufieurs niches hautes \& baffes, affés profondes, \& qu'on croiroit y avoir été ménagées à deffein.

Origine des Les femmes, felon une autre tradition, ne font venuës Femmes. au monde, que long-têms après les hommes, mais je ne trouve rien, à quoi je puiffe me fixer pour leur origine, ni rien de fort intereffant dans ce qu'on raconte de leurs autres fables. Voilà donc en peu de mots, autant qu'il a été poffible de le connoître, quels étoient les peuples, qui habitoient l'Ine Haïti, lorfqu'elle fut découverte par les Efpagnols. Ils la trouverent divifée prefque toute entiere en cinq Royau. mes parfaitement indépendans les uns des autres; je dis prefque toute entiere, parce qu'il paroît qu'outre les cinq Rois; ou Caciques fouverains, dont nous allons parler, il y avoit quelques Seigneurs, beaucoup moins puiffans, mais qui ne relevoient de perfonne, \& portoient aufí le nom de Cacique. 


\section{L'ISLE ESPAGNOLE}

SOUS LE NOM INDIEN

\section{D'HAY T I,}

Ou comme elle étoit possédée

par ses habitans naturels

lors de la découverte.

Avec les prémiers Etablissemens

des Espagnols.

PAR LE SR DANVILLE

Geographeord"duRoi Mai 173 .

Lieues Espagnolespour létondue diun Degré

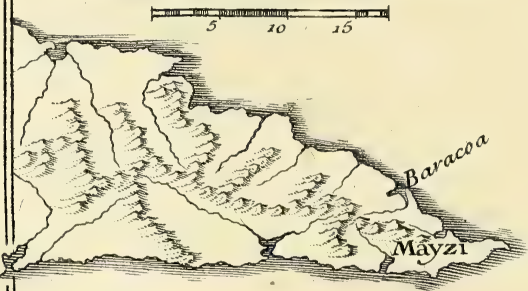

Figure trouvée dans unc sépuluere Ind.
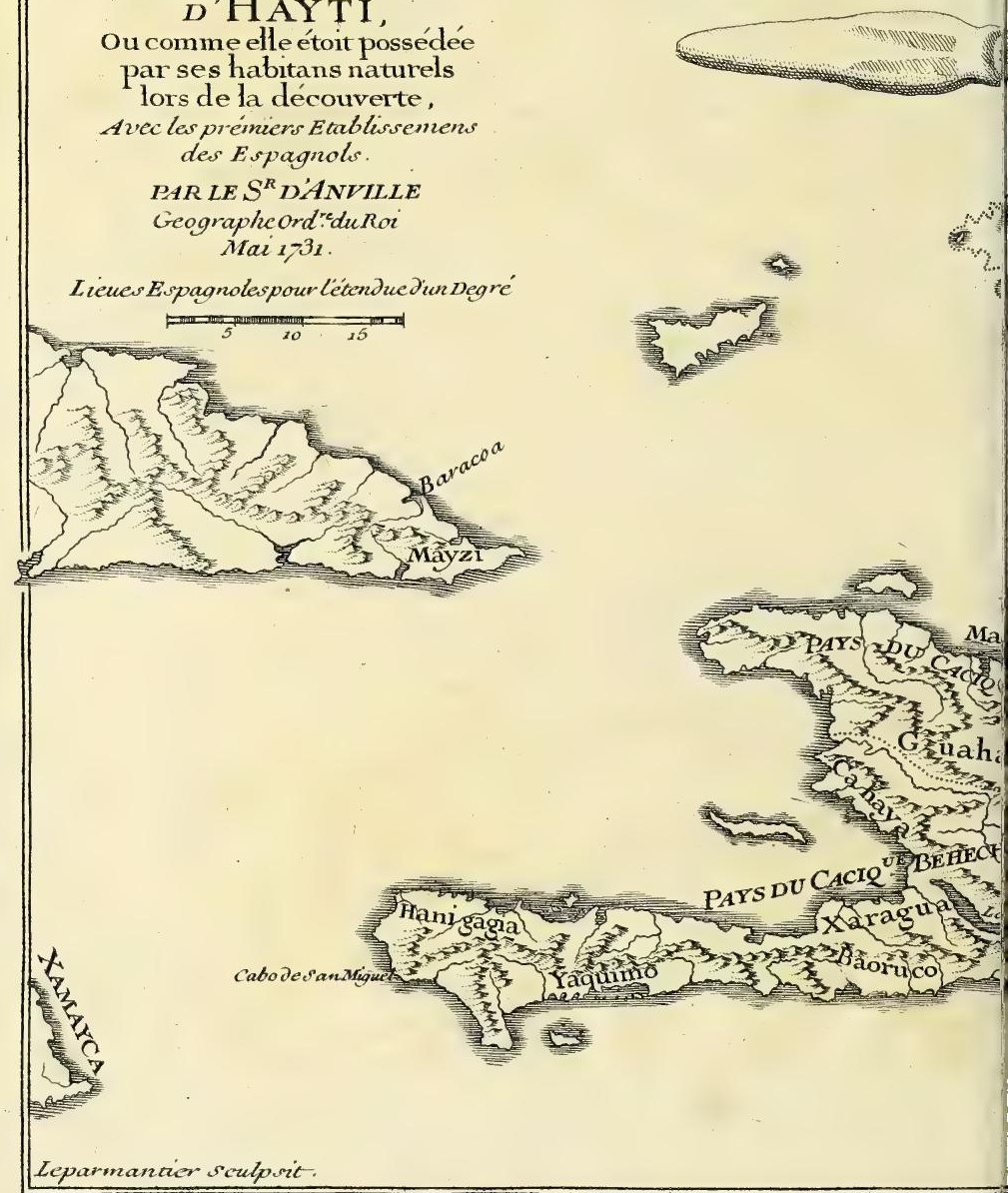
Armes de christophle colomb

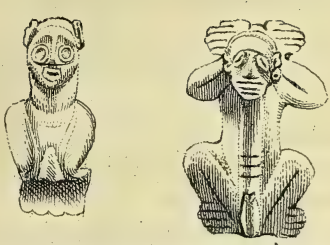

\section{? POR CASTILLAY POR LEON}

Figures superstitieuses de Z emi ou Mabouya

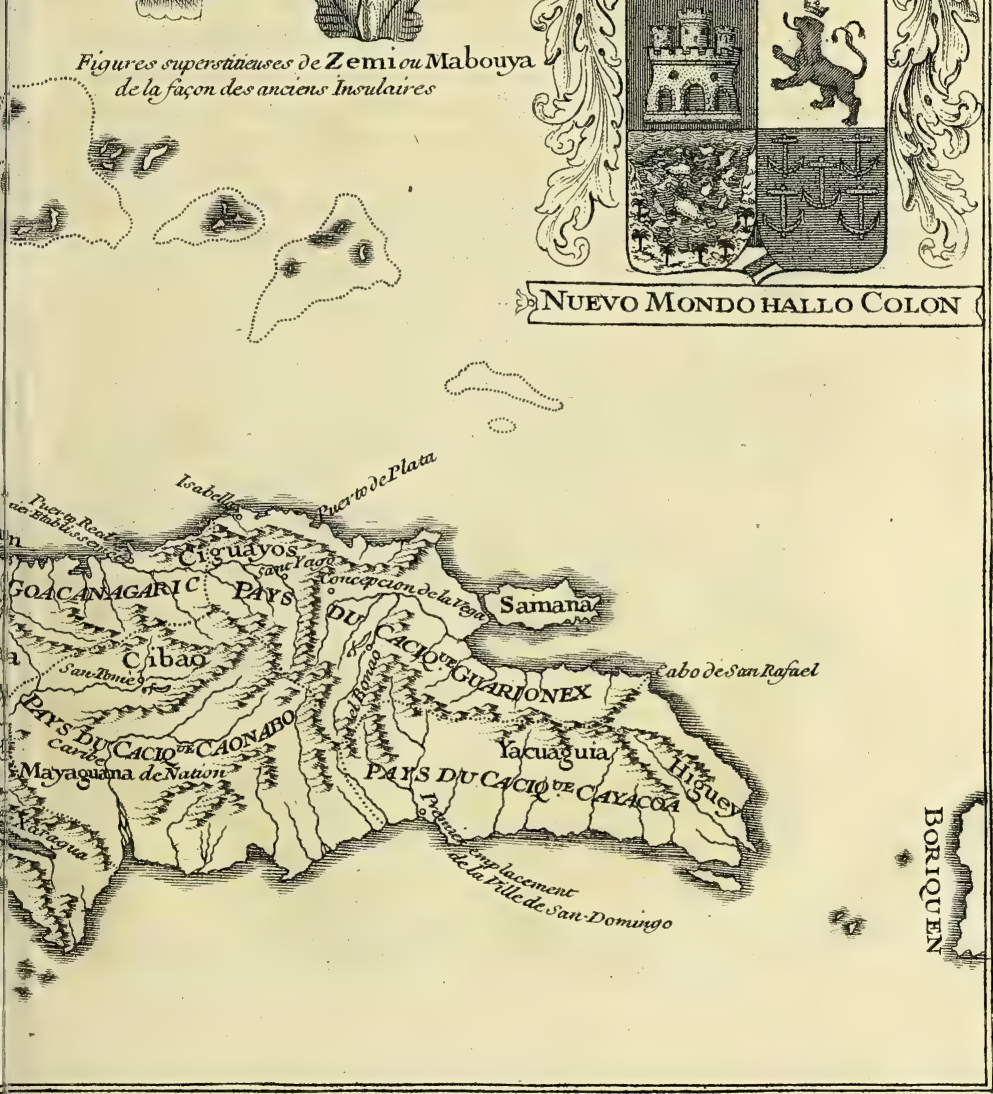





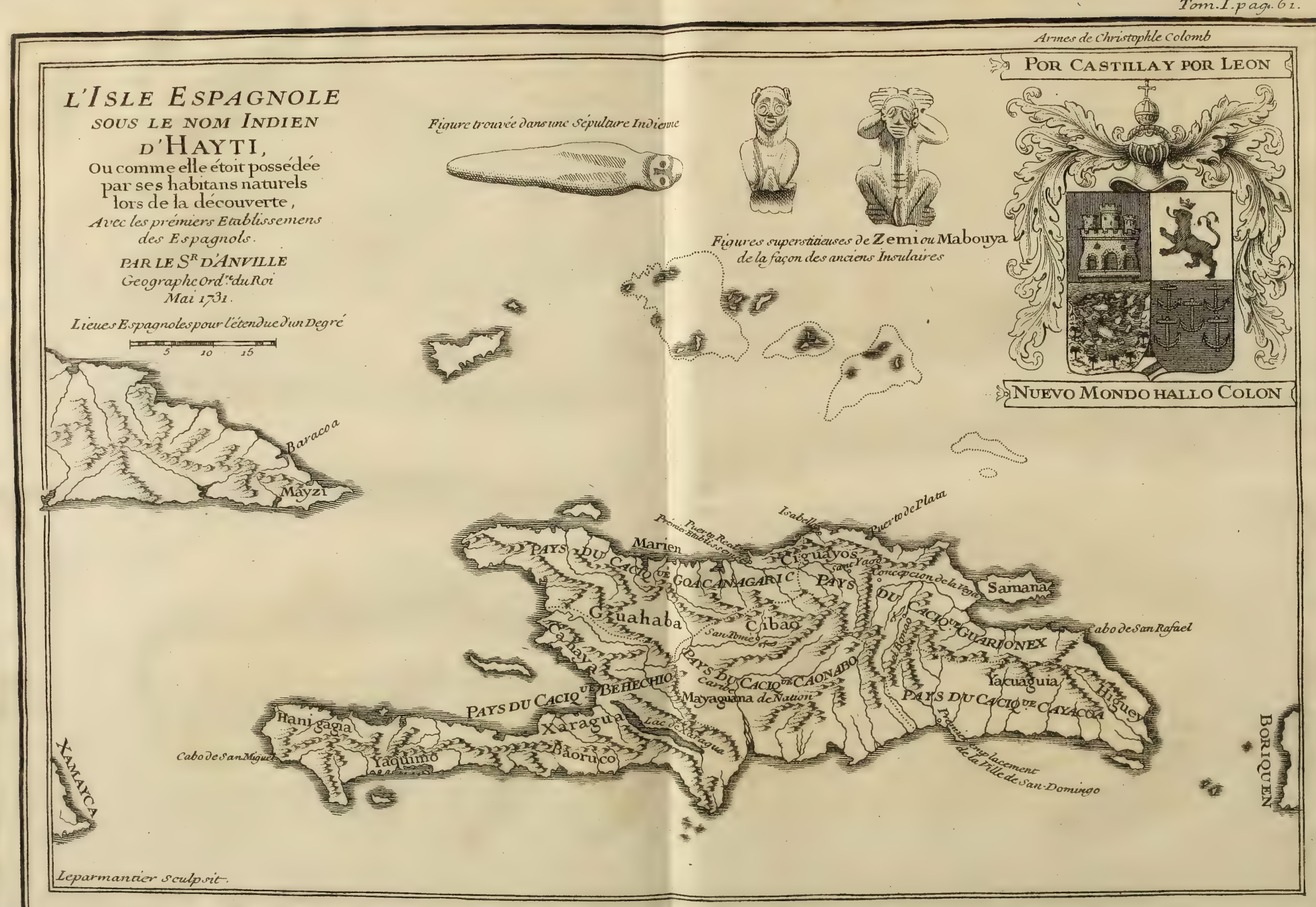





\section{DE S. D OMINGUE, LIV. I. 6 i}

Des cinq Royaumés qu'on y trouva, l'un s'appelloit Ma. Divifion de gua, qui veut dire Royaume de la plaine. Il comprenoit qu'elle sétoit ce qu'on a depuis appellé la Vega Real; ou du moins il en au téms de fá comprenoit le milieu \& la meilleure partie. La Vega Real eft Découverte. un plaine de 8o. lieuës de long, \& qui en a ro. dans fa plus grande largeur. Un auteur, qui a été long-têms fur les lieux, Barthelemy affûre qu'il y coule plus de trente mille rivieres, parmi lef- de las Cafas。 quelles il y en a douze auffi larges, que l'Ebre \& le Guadalquivir. Les autres ne font que des torrens \& des petits ruiffeaux. Elle en reçoit jufqu'à 25 . mille, d'une longue chaîne de montagnes, qu'elle a à l'Occident, \& la plûpart rouloient l'or avec leur fable. Auffi ce canton eft-il voifin des fameufes mines de Cibao, dont nous aurons lieu de parler beaucoup dans la fuite ; mais ces mines n'étoient pas du Royaume de Magua, dont le Souverain au têms de la découverte fe nommoit Guarionex. Ce Prince avoit fa capitale dans un lieu, où les. Efpagnols ont eu depuis une ville fort celebre, qu'ils avoient appellée la Conception de la Vega.

Le fecond Royaume étoit celui de Marien. Barthelemy de las Cafas ne fait point de difficulté de dire qu'il étoit plus grand \& plus fertile que le Portugal. Il comprenoit toute cette partie de la côte du Nord, qui s'étend depuis l'extrémité Occidentale de l'Ifle, où eft le Cap $\mathrm{S}$. Nicolas, jufqu'à la riviere Yaqué, connuë aujourd'hui fous le nom de Monte Chrifto, \& comprenoit toute la partie Septentrionale de la Vega Real, qui s'appelle préfentement la plaine du Cap François. C'étoić au. Cap même que Goacanaric Roi de Marien faifoit fa réfidence, \& c'eft de fon nom abregé que les Efpagnols appellent: encore aujourd'hui ce Port, el Guaric.

Le troifiéme portoit le nom de Maguana, \& renfermoir la Province de Cibao, \& prefque tout le cours de la riviere Hattibonito, ou l'A rtibonite, qui eft la plus grande de l'Ine. caonabo, qui y regnoit, étoit Caraïbe, il avoit paffé dans l'Ine en avanturier, qui cherche fortune; $\&$ comme il avoit de l'efprit \& du coeur, il fe fit bientôt eftimer \& craindre de gens, qui n'étoient ni fpirituels, ni braves; de forse 


\begin{abstract}
62 H ISTOIRE

quill parvint affés aifément à fe faire un Etat confidera. ble au milieu d'eux. Sa demeure ordinaire étoit au bourg de Maguana, d'où fon Royaume avoit tiré fon nom. Les Efpagnols en firent depuis une ville fous le nom de San fuan de la Maguana, laquelle ne fubfifte plus. Le quartier, où elle étoit lituée, eft ce que les François appellent aujourd'hui la Savane de San Ouan. Caonabo étoit le plus puiffant Monarque de l'Inle, \& celui qui fentoit mieux fon Souverain.

Ou Surragua. Le Royaume de Xaragua étoit le quatriéme, \& devoit fon nom, ou le donnoit à un affés grand lac, dont nous parlerons. ailleurs. C'étoit le plus peuplé de tous, \& le plus étendu. Il comprenoit toute la côte Occidentale de l'Ille, \& une bonne partie de la Meridionale. Sa capitale, nommée auffi Xaragua, étoit à peu près où eft aujourd'hui le Bourg du Cul-de-Sac.Les hommes y étoient mieux faits qu'ailleurs; on y voyoit plus de nobleffe, plus de politeffe, plus d'aifance, \& l'on y parloit auffi plus élegamment que dans les autres Roïaumes.Le Prince,à qui il appartenoit, fe nommoit Behechio. Il avoit une foeur nommée Anacoana, laquelle avoit époufé Caonabo ; après la mort de fon époux elle fe retira chés fon frere, qui en mourant lui laiffa fon Royaume, fes trente-deux femmes ne lui ayant pas pû donner un feul fils, qui lui fuccedât.

Le cinquiéme étoit le Higney. Il occupoit toute la partie Orientale de l'Ille, avoit pour borne à la côte du Nord la riviere d'Yaqué, \& à celle du Sud le fleuve Ozama. Les peuples de ce canton étoient un peu plus aguerris que les autres, parce qu'ils avoient fouvent à fe défendre des Caraïbes, qui faifoient continuellement des defcentes fur leurs côtes, pour en amener des prifonniers. Ces Barbares tuoient d'abord les hommes, en mangeoient les entrailles, \& en faloient les chairs ; ils châtroient les enfans mâles afin de les engraiffer, \& de s'en fervir dans leurs feftins; pour cela ils les enfermoient dans des parcs, commenous faifons les troupeaux de boufs $\&$ de moutons: ils gardoient les filles \& les femmes, pour en avoir des enfans; les vieilles \& les infirmes demeuroient efclaves.
\end{abstract}




\section{De S. Domingue, Liv. T.}

Les Peuples du Higuey étoient armés de fleches à l'exemple de leurs ennemis, mais il s'en falloit beaucoup, qu'ils s'en ferviffent auffi-bien qu'eux : auffi la plupart du têms ne fe défendoient-ils, que par la fuite. Ils avoient pour Souverain le Cacique Cayacoa, qui mourut peu de tems après l'arrivée des Efpagnols; fa veuve fe fit Chrétienne, \& fut nommée Agnez Cayacoa: elle ne furvécut pas long-têms à fon mari, auquel elle avoit fuccedé dans la Principauté, \& fes Etats pafferent à un Caciqué nommé Cotubanama, dont le féjour ordinaire fut, au moins pendant quelque tems, à la prefqu'Ifle Samana, ou aux environs. Las Cafas donne à cette Province une Reine nommée Hyguanama, \& ajoute que les Efpagnols la firent pendre : les autres Hiftoriens n'en parlent point, \& peut-être que cette femme regna immédiatement après la mort d'Agnez Cayacoa, ou que c'étoit une Cacique particuliere de quelque canton du Higuey.

Telle étoit la fituation de l'Ifle Haïti, lorfqu'elle vint à la connoiffance des Efpagnols; mais ce grand événement, qui fut pour ces Infulaires la fource de bien des maux, ne les furprit pas autant, qu'on auroit pû croire. Ils avoient été avertis peu de tems auparavant que des Etrangers viendroient s'emparer de leur Pays, \& voici ce que plufieurs d'entr'eux en rapporterent à Chriftophle Colomb. Le pere du Cacique Guarionex eut un jour la curiofité de Içavoir ce qui arriveroit dans l'Ine après fa mort ; il confulta les Zemés, après s'y être préparé par un jeûne de cinq jours. La réponfe fut que dans peu il y viendroit des hommes, qui auroient du poil au menton, \& feroient vêtus depuis les pieds jufqu'à la tête : que ces Etrangers mettroient en pieces les Zemés, \& qu'ils en aboliroient le culte; qu’ils porteroient à leur ceinture de longs inftrumens de fer, avec lefquels ils fendroient un homme en deux , \& qu'ils dépeupleroient l'Ifle de fes anciens Habitans. Cette prédiction remplit d'effroy tous ceux, qui l'entendirent, \& ne tarda pas à fe divulguer. On ne parloit plus d'autre chofe \& l'on avoit compofé fur cela une chanfon, qui fe chantoit dans de certains jours deftinés à des cérémonies lugubres. 
64 HISTOIRE

Si ce fait eft vrai, \& il eft fi unanimement rapporré par tous les auteurs de ce têms-là, qu'il eft difficile d'en contefter la verité, on ne peut douter que ce ne fût un avertiffement que Dieu obligea l'Efprit d'erreur de donner à un peuple, qu'il féduifoit depuis tant de fiecles : mais il y a bien de l'apparence que perfonne n'en profita. Il paroît même qu'on s'étoit déja un peu raffûré fur le malheur, dont on avoit été menacé, lorfque la prophétie commenca à s'accomplir de la maniere que je vais le raconter; mais il eft neceffaire de reprendre la chofe d'un peu plus loin.

Tout le monde fçait que les premiers efforts pour les nouvelles découvertes, qui ont rendu fi celebre le XV. fiecle, font dûs à la nation Portugaife, \& en particulier à l'Infant D. Henry Comte de Vifeo, Grand-Maître de l'Ordre de Chrift, \& le quatriéme des fils de Jean Premier Roi de Portugal ; le but de ce Prince, un des plus vertueux \& des plus accomplis de fon têms, étoit de chercher un paffage pour aller par mer aux Indes Orientales, en faifant le tour de l'Afrique, mais l'émulation, qu'il mit dans la Marine, perfectionna en peu de têms cet art, demeuré jufques-là très inculte, joignit d'abord à la Couronne de Portugal les Açorres, les Ifles di Cap-Verd, une partie des Canaries, Madere \& quantité de poftes très-importans, fur la côte Occidentale d'Afrique : \& forma cette célébre Ecole de navigation, d'où font fortis tous ceux, qui ont eu le plus de part à la découverte $\&$ à la conquête de l'Amérique.

Quel étoit

Le premier de tant d'habiles navigateurs, qui ceffa de Chriltophle
Colomb. borner fes vûës à l'Afrique, \& au chemin des Indes Orientales par ce côté-là, fut un Pilote Genois, natif de Savone felon plufieurs, d'un petit Bourg de la même riviere de Gếnes, appellé Cugurco, felon quelques-uns, de Nervi, felon d'autres, \& que la Capitale même de cette République, appuyée de l'autorité de D. Pierre Martyr d'Anglerie, a auffi voulu revendiquer pour fon Citoyen, peu contente de le compter au nombre de fes fujets. Il fe nommoit Chriftophle Colomb \& \& le même Martyr, que je viens de citer, affûre qu'il 


\section{DE S. DomingüE, Liv. I.}

qu'il étoit de fort baffe naiffance. Quelques-uns ont même avancé qu'il avoit appris le métier de Cardeur de laine ; mais d'autres le font originaire de Plaifance en Lombardie, \& iffu de l'illuftre Maifon de Peleftrello. Si toutefois ils n'ont pas confondu ce nom avec celui de fa premiere femme Doña Philippa Muñiz de Pereftrelo, fille du Gouverneur Portugais de Porto Santo. Herrera dit qu'on vouloit le faire defcendre des anciens Seigneurs de Cucaro dans le Montferat, $\&$ il ajoûte que cette difpute touchant fon origine devoit fe rerminer dans le Confeil fouverain des Indes.

Dom Fernand Colomb, que j'ai déjà cité, s'en tient au fentiment de ceux, qui font venir fa famille de Plaifance ; mais il ne lui donne point d'autre nom que celui de Colomb, que l'on voit, dit-il, dans cette Ville avec les armes de la famille sur plufieurs anciens tombeaux. Il ajoûte que le malheur des têms, caufé par les guerres d'Italie, avoit obligé Dominique Colomb, pere deChriftophle, à fe retirer dans l'Etat de Gênes. Il parle d'un Colomb, furnommé le Jeune, fameux Armateur de ce têms-làn, qui prit dans une occafion quatre Galeres fur les Venitiens, \& il cite le fragment d'une lettre de fon pere à une Dame de la Cour d'Efpagne, où il dit : $x$ Je ne fuis - point le premier Amiral de ma famille; qu'on me donne so le nom qu'on voudra; David a gardé les brebis, avant que » d'être Roi, je fuis le ferviteur de ce même Dieu, qui l'a » placé fur le tróne. $\infty$

Quoiqu'il en foit, la gloire de ce grand Homme n'emprunre rien de fes ancêtres, qui ne font pas connus, \& a immortalifé fon nom audeffus de prefque tous ceux, qui fe font rendus célébres dans ce fiecle-là. Je ne fçai même, s'il n'eût pas été plus glorieux à un fimple Cardeur de laine, qu'à un homme de condition, d'être monté, comme a fait Chriftophle Colomb, aux premiers honneurs, \& d'avoir élevé fa famille affés haut, pour la mettre en état de s'allier à celle de fon Souverain, \& de fe perdre, comme elle a fait cinquante ans après fa mort, dans la Maifon Royale de Portugà!.

Ce que nous fçavons de plus certain touchant fes premieTom. I. 


\section{6}

res années, c'ent qu'il fortit jeune de fon pays, qu'il y avoit fait de fortbonnes études, qu'il s'appliqua enfuite à celle de la Cofmographie, de l'Aftronomie, de la Géometrie \& de la Navigation, \& qu'il a excellé dans toutes ces Sciences. Il joignit auffi toûjours, autant qu'il lui fut poffible, la pratique à la théorie; \& quoique nous ne foyons pas fort inftruits du détail de fes premiers voyages, on fçait qu'il en a fair beaucoup \& dans toutes les mers connuës de fon têms, avant que de fonger à la découverte du nouveau monde. Il dit dans un de fes Memoires: L'année I 477. au mois de Février » je naviguai cent lieuës au delà de l'Ifle de Tyle, dont la so partie Meridionale eft à 73. degrés de la Ligne. Elle eft s auffi grande que l'Angleterre, \& les Anglois y vont trafi» quer ce n'eft pas la Tyle, dont parle Ptolomée, qui eft im» médiatement fous la ligne, mais celle que nous appellons. sa aujourd'hui Friflande.

Toutes ces courfes ne l'avoient pas fort enrichi, mais elles fur l'éxiftence d'un nouveau Monde.

le rendirent le plus habile navigateur de l'Europe, \& lui donnerent le moyen de faire quantité d'obfervations, quil'enga* gerent enfin à tourner toutes fes penfées vers l'Occident, pour y chercher de nouvelles terres; tandis que la plâpart des autres ne fongeoient encore, qu'à fe frayer par le Midi un chemin à l'Orient. Il n'ignoroit pas la prétenduë prophétie de Seneque dans Médée, ni ce que Platon a écrit dans fon Timée, qu'au delà des Colonnes d'Hercules, il y avoit eu. une Ifle nommée Atlantide, plus grande qu'aucune de celles, qui étoient alors connuës, laquelle avoit été fubmergée par un déluge accompagné d'effroyables tremblemens de terre. Il a parû même qu'il faifoit beaucoup plus de fond, qu'il ne convenoit, fur ces monumens équivoques de l'Antiquité. Il fit avec raifon plus d'attention que perfonne à ce qui fe publia peu de têms après la découverte des Açorres, des Canaries, \& Madere, à fçavoir qu'à la chute des grands vens d'Oueft, on trouvoit affés fouvent fur la Côte de ces Inles des morceaux de bois étranger, des cannes d'une efpece inconnuë, \& même des corps morts, qu'on reconnoifloit aे. 


\section{DE S. DOMINGUE, LIV. I. 67}

plufieurs fignes, n'être ni Europeans, ni Afriquains.

Ses conjectures fur l'exiftence d'un nouveau monde étoient Conjesures encore appuyées fur des fondemens plus folides, que ces bruits de Colomb.

populaires. La figure \& l'étenduë du globe de la terre, dont il étoit évident par le cours des aftres que la moitié n'étoit pas connuë, étoient pour lui depuis long têms, \& devoient, ce femble, être pour tous les Sçavans, une démonftration qu'il pouvoit y avoir à l'Occident des régions, que rien n'empêchoit d'être habitées. Il avoit enfuite remarqué que du même côté il foulloit certains vens, qui duroient affèz également pendant plufieurs jours, \& il fe perfuada qu'ils ne pouvoient être caulés, que par des terres. Ces obfervations le rappelloient à ce que Platon, après avoir parlé de fon Ine Atlantide, ajoûte, quau delà de cette grande Ifle, il y en avoit un grand nombre de petites, qu'affez près de ces dernieres étoit un continent, plus grand que l'Europe \& l'Afie jointes enfemble, \& qu'enfuite étoit la vraie mer. Et il eft affez furprenant que les chofes fe foient trouvées exactement, comme l'avoit écrit ce Philofophe deux mille ans auparavant. Car enfin, à fon Atlantide près, qu'il difoit avoir difparu, on a découvert au delà de notre Ocean un fort grand Archipel, lequel borde un continent, qui feul fait prefque la moitié de la terre, \& au delà, une mer, qui ent fans contredit la plus grande de toutes.

Il y a encore quelque chofe de bien marqué dans ce qui Theophile de a été rapporté par quelques anciens auteurs d'un navire Car- Serraris des thaginois, lequel l'an 356 . de la fondation de Rome, cher-la nature. chant à faire de nouvelles découvertes, prit fa route entre le Midi \& le Couchant, ofa bien s'enfoncer dans une mer inconnuë, fans autre Bouffole que l'attention du Pilote à obferver l'étoille du Nord, \& aborda enfin à une Ine deferte, fort fpatieufe, abondante en pâturages, coupée par tout de belles rivieres, \& dont les grandes \& épaiffes forêts remplies d'arbres d'une hauteur extraordinaire, fembloient répondre de la fertilité du terroir; que tant d'avantages, joints à la douceur du climat, engagerent plufieurs de ces avanturiers 
à y refter, que les autres s'en retournerent à Carthage, oủ ayant rendu compte au Senat de leur découverte, le Senat, peut-être plus fage, que ne l'ont été nos ayeux, crut devoir enfevelir dans un éternel oubli la connoiffance de cet évenement, fit mourir fecretement tous ceux, qui en pouvoient parler, \& laiffa ceux, qui étoient reftés dans l'Inle, fans aucune reffource pour en fortir.

Jean de Barros rapporte dans fon hifoire des Indes une chofe, qui pourroit bien avoir quelque liaifon avec ce récit, \& lui fervir même de preuve, ou en recevo'r quelque jour. Il dit que dans l'Ine de Corve, la plus Occidentale des Açor$r e s$, on trouva, lo:fqu'on la découvrit, une ftatuë équeftre de pierre, ou d'une efpece de terre cuite, montée fur un pied d'eftal de même matiere; que fur les côtés de ce pied-deftal, il y avoit des infcriptions, donr on ne put jamais déchifrer les caracteres, \& que le cavalier, vétu comme la plupart des Americains, qui ne vont pas abfolument nuds, montroit du doigt le Couchant, comme pour avertir qu'il y avoit des terres \& des hommes de ce côtélà. Or cette découverte étoit trop récente au têms que Chriftophle Colomb alla en Portugal, pour qu'il n'eût pas entendu parier de cette circonftance.

Mais on donna encore plus aux conjectures après le fuccès de l'entreprife du Pilote Italien, qu'il n'y avoit donné. lui-même, avant que d'avoir formé fon projet. Ces mêmes. Efpagnols, qui avoient fi long tems traité de vifion l'exiftence. d'une quatriéme partie du monde, par la raifon qu'elle avoit. été inconnuë jufques-là , prétendirent y retrouver des Provinces de leur Empire, que le malheur des têms leur avoit enleveés, \& furlefquelles les droits de leurs Souverains étoient inconteftables. Oviedo avance hardiment que les Antilles font. les fameufes Hefperides, fi fort célébrées par les Poëtes, \& ne craint point d'ajoûter que Dieu, en les faifant paffer fous la domination des Rois Catholiques, n'a fait que reftituer à. leur Couronne, ce qui lui avoit appartenu 3 I 50 . ans aupaxavant, du têms du Roi Hefperus, de qui elles ayoient pris. 


\section{DE S. Domingue, Liv. I. 69}

leur nom. Il ajoûte que $S$. Jacques \& S. Paul y ont prêché l'Evangile, fur quoi il cite S. Gregoire Pape dans fes Morales.

Un autre auteur, qui n'avoit pas les mêmes engagemens à flatter la nation Efpagnole, a écrit fort férieufement que notre Ifle eft l'Ophir, où Salomon envoyoit chercher de l'or'. des Paons, \& des dens d'Elephant, ce qu'il fe feroit fans doute bien donné de garde d'avancer, s'il avoit été inftuit, que ni dans IIIfle Efpagnole, ni dans aucun autre endroit du. nouveau monde, on n'a point trouvé d'Elephans. Quant à ce qu'on a reproché à ce même Ecrivain, fi eftimable d'ailleurs par fa profonde érudition, qu'il avoit placé le Paradis terreftre dans la même Ifle, on a eu tort apparemment de croire qu'il parlât férieufement, \& de ne pas regarder ce qu'il en dit comme un de ces jeux d'efprits, dans lefquels les plus grands genies s'engagent quelquefois à vouloir prouver des paradoxes.

Mais une opinion vulgaire, qui eut affez de cours du vivant de Colomb, auroit bien diminué la gloire de ce grand voyageur, fi elle avoit trouvé créance dans les, efprits des perfonnes capables de lui donner quelque autorité. Une Caravelle, difoit-on, qui portoit d'Efpagne en Angleterre des vins, \& des marchandifes comeftibles, après avoir été longtêms contrariée par les vens, n'y pouvant plus réfifter, fut contrainte de courir au Sud, puis ḋ l'Oueft, \& fe trouva enfin à la vûë d'une Ifle, où elle alla prendre terre, \& ou elle trouva des hommes tout nuds. D'autres difent que c'étoit la côte de Ferxambouc au Brefil. On ajoûte qu'il n'y eut que le Pilote, \& quelques Matelots, qui repafferent en Europe, tout le refte ayant péri des incommodités du voyage; que le Pilote étoit mort quelques années après chez Chriftophle Colomb, dont il étoit ami, \& auquel il laiffa tous fes papiers; \& que c'étoit fur fes memoires, que le Pilote Genois avoit dreffé fon plan. Mais outre que Colomb s'eft toûjours récrié hautement contre ces bruits, inventés, difoit-il, par des perfonnes jaloufes de fa gloire; tout ce qu'il y a eu d'auteurs fenfés, mêrme Efpagnols, qui ont eu occafion de parler de la découverte du. souveau monde, lui ont rendu juftice; d'ailleurs on ne voit 
Herrera. d'un auteur Efpagnol.

point qu'il ait famais fongé à paffer l'Equateur, ce qu'il auroit néanmoins dû faire, pour diriger fa route fuivant les me. moires du Pilote Andaloufien, ou Portugais, ou Bifcayen, car on le fait de ces trois Provinces-là; enfin il eût parlé plus clairement, s'il eût été plus für de fon fait, \& n'eût pas langui tant d'années à la fuite des Cours d'Efpagne \& de Portugal, faute de vouloir s'expliquer : c'eft la judicieufe remarque

Colomb fait fon plan \& le propole à diverles Puiffances. Supercherie qu'on lui fait en portugal.

Dans la verité Colomb, qui fçavoit parfaitement l'art d'obferver la latitude, oula hauteur du Pole parl'Aftrolabe, ce que perfonne avant lui n'avoit pratiqué en haute mer, quoiqu'on l'enfeignât publiquement dans les Ecoles : Colomb, dis je, ne rifquoir pas autant, qu'on s'imaginoit, à pénétrer dans l'Ocean beaucoup plus avant, qu'on n'avoit encore ofé faire, \& de quelque côté qu'il entreprît de tourner, il fçavoit que fon pis aller feroit de s'en retourner fur fes pas, fans avoir rien trouvé. Il fe flattoit même de rencontrer à la fin les terres de l'Afie; \& nous verrons dans la fuite qu'il les croyoit bien moins éloignées de ce côté-là, qu'elles ne le font en effet. Il avoit lu la Relation des voyages de Marc Paul de Venife, où il eft parlé du Catay, qui eft la partie Septentrionale de la Chine, \& d'une Inle appellée Cipango, abondante en or, \& qu'on a cru depuis être le Japon; c'étoit même fur cette relation qu'il avoit particulierement fait fon fy ftême : auffi dans la plûpart de fes expeditions, il eut fur tout en vâë le Cipango de Marc Paul de Venife.

La Republique de Gênes, dont il étoit né fujet, fut la premiere Puiffance, à laquelle il propofa fon projet, mais il n'en fut pas même écouté ; on le regarda dans fa patrie comme un vifionnaire. Il alla enfuite offrir fes fervices à Jean II. Roi de Portugal, qui le reçût bien, \& voulut que fon deffein fût examiné par D. Diego Ortiz, Evêque de Ceuta, connu auparavant fous le nom du Docteur Calçadilla, du lieu de fa naiffance, \& par deux Médecins Juifs, fort eftimés pour leur habileté dans la Cofmographie. La premiere 


\section{$D E S . D O M I N G U E$, LIV. I.}

chofe que firent ces Commiffaires, fut de demander à Colomb un mémoire plus détaillé,il le donna; \& dès qu'ilsl'eurent entre les mains, ils firent fecretement partir une Caravelle, avec ordre au Pilote de fuivre exactement tout ce qui étoit marqué dans cet écrit, qu’on lui mit entre les mains. Mais la tête \& le courage du Gênois manquoient également au Portugais; la Caravelle n'alla pas fort loin, \& après avoir effuyé quelques coups de vent affés forts, elle retourna en Portugal, tout l'équipage déteftant une entreprife, qui lui paroiffoit auffi infenfée que perilleufe.

Colomb ne put apprendre fans indignation la fuperche- Il envoye fon zie, qu'on lui avoit voulu faire, \& ne fut pas moins choqué, frere en Anqu'on rejettât fur lui le peu de fuccès d'une entreprife auffi s'enva en ES mal concertée. Il prit fur le champ la réfolution de quitter ce pagne.

Royaume, où depuis la mort de fon époufe, arrivée peu de têms auparavant, rien ne l'attachoit plus; \& craignant que le Roi, qu'il fçavoit imputer bien plus au manque d'habileté \& d'experience de fon Pilote, qu'aux mémoires, qu'on lui avoit donnés, l'inutilité de la tentative, ne le fít arrêter, il s'embarqua fans rien dire fur la fin de 1484 . il alla prendre rerre en Andaloufie avec Barthélemy Colomb fon frere, \& il envoya celui-ci en Angleterre, pour effayer de faire goûter fon deffein au Roi Henry VII. tandis qu'il iroit faire la même chofe à la Cour d'Efpagne.

Barthélemy Colomb étoit un homme de bon efprit,renommé pour les cartes marines \& les tpheres, qu'il faifoir dans la perfection pour le têms : il avoit paffé d'Italie en Portugal, aBarthélemy. Colomb en Angleterre. vant fon frere, dont même il avoit été le maître en Cofmographie. D. Fernand Colomb fon neveu, dit que s'étant embarqué pourLondres, il fut pris par des Corfaires, qui le menerent dans un pays inconnu, où il fut réduit à la derniere mifere, qu'il s'en tira néanmoins en faifant des cartes de na. vigation; quayant amaflé de fes profits une fomme d'argent, il paffa en Angleterre, préfenta au Roi une Mappemonde de fa façon, lui expliqua le projet de fon frere, \& le lui fit tellement goûter, que ce Prince le pria d'en faire venir l'an- 
teur, promettant de fournir à tous les frais de l'entreprife; mais que Chriftophle Colomb étoit déjà engagé avec la Cour de Caftille, \& n'étoit plus libre d'accepter ces offres. Il eft affés difficile de concilier ce récit avec ce que nous dirons dans la fuite du voyage de Barthélemy Colomb, fur l'autorité d'Antoine Herrera, \& de décider lequel de ces deux auteurs merite plus de créance fur ce point. On trouvera aufi peut-être un peu étrange que les deux freres s'adreffaffent en même-têms à deux Cours, qui ne devoient pas être éloignées d'accepter leurs fervices, \& dont la prompte acceptation pouvoit leur caufer de l'embarras; mais il y a de l'apparence que Chriftophle Colomb vifoit par-là au plus fûr, \& qu'il efperoit que la jaloufie, que ces deux Puifances auroient l'une de l'autre, le feroit rechercher avec empreffement de toutes les deux, \& que par-là il feroit en étas de faire fes conditions meilleures; en quoi il fe trompa.

Chriftophle Colomb arrive en Efpagne, fes premieres tentatives auprès des Rois Catholiques.

La Cour d'Efpagne étoit à Cordouë lorfque le Pilote Gênois arriva en Andaloufie, il alla auffi-tôt en Caftille, \& après avoir laiffé dans un Couvent à Palos fon fils unique, quil avoit eu de fa premiere femme, \& qui fe nommoit Diegue, il fe rendit auprès du Roi Catholique, auquel il fit préfenter un mémoire, dont voici la teneur : sereniffime - Prince, j'ai navigué dès ma jeunefle, il y a quarante ans, » que je cours les mers, je les ai toutes examinées avec foin, „ \& j'ai converfé avec un très grand nombre de gens fages de s tous états, de toutes nations, \& de toutes Religions; j’ai $\rightarrow$ acquis quelque connoiffance dans la Navigation, dans - l'Aftronomie \& la Géometrie.' Je fuis en état de rendre э compte de toutes les villes, rivieres, montagnes, \& de w les placer chacune, où elles doivent être dans les Cartes. э J'ai lú tous les livres qui traitent de la Cofmographie, de s l'Hiftoire \& de la Philofophie. Je me fens préfentement porté à entreprendre la découverte des Indes, \& je viens à $\approx V$. A. pour la fupplier de favorifer mon entreprife. Je ne w doute pas que plufieurs ne fe mocquent de mon projet s mais fi $\mathrm{V}$. A. veut me donner les moyens de l'executer, s quelque 


\section{De S. Domingúe, Liv. I. $\quad 73$}

* quelque obftacle qu'on y trouve, j'efpere de le faire réuffir.

Colomb avoit deviné jufte, quand il avoit dit qu'on Son deffeis fe mocqueroit de fon deffein. Il étoit fort mal équipé, \& eft rejetté. il fut regardé comme un homme, qui ne propofoit des chofes nouvelles, que pour fe tirer de la mifere, ou fortir de l'obfcurité, où il avoit jufques-là vécu. Il y eut pourtant un homme en place, qui en jugea autrement que les autres; ce fut D. Alfonfe Quintaniglia grand Tréforier de Caftille ; Colomb trouva en lui un protecteur, qui dans la fuite lui en procura d'autres, \& lui menagea des fecours pour l'aider à fubfifter. Quintaniglia fit plus, il obtint de la Reine Ifabelle de Caftille, que le plan du Pilote Gênois feroit examiné, \& cette affaire fut mife entre les mains du P. Fernand de Talavéra, Hieronimite, Confeffeur de cette Princeffe ; ce Religieux fit une affemblée de Cofmographes, dont le réfultat ne fut point favorable à Colomb, \& Herrera en attribuë la faute, en partie à l'ignorance de ceux, qui furent confultés, \& en partie à ce que le Gênois, craignant qu'on ne lui jouât le même tour, qu'on lui avoit joué en Portugal, ne s'étoit expliqué qu'à demi.

On lui objecta donc qu'il préfumoit fans fondement d'en Ce qu'on lui fçavoir plus lui feul, que n'en avoient fçu jufques-là les plus oppofe.

habiles navigateurs, \& les plus fçavans Cofmographes du monde : qu'affûrément, s'il y avoit des pays habitables au Couchant, on ne feroit pas à en être informé; que pour gagner les Indes Orientales par la route, qu'il vouloit tenir, il faudroit au moins trois ans, \& qu'une navigation de fi longue durée n'étoit pas une chofe à tenter par des perfonnes raifonnables. Que Seneque avoit mis en queftion, par maniere de difpute à la verité, fi l'Ocean n'étoit pas infini. ce qui donnoit au moins lieu de croire qu'il étoit d'une étenduë fi vafte, qu'il y auroit de la temerité à s'engager à en faire le tour. Enfin qu'en allant à l'Occident, on defcendoit toûjours, \& que quand on voudroit retourner en Efpagne, on fe trouveroit dans l'impoffibilité de remonter.

Tom. I.

$\mathbb{K}$ 


\section{$74 \quad$ H IS T O X E}

Lenteurs Colomb eût beau faire pour detruire des raifons fi peu qu'il eut à ef- folides. Plus elles étoient mauvaifes, \& moins ceux, de

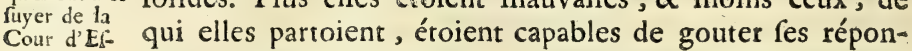
pagne. fes, \& d'en fentir la force. Il fe vit donc réduit à attendre du têms \& des conjonctures une occafion plus favorable. Cinq années entieres fe pafferent de la forte, au bout defquelles le Roy \& la Reine lui firent dire que la guerre de Grenade, où ils fe trouvoient engagés, ne leur permettoit pas de vacquer à d'autres affaires, ni de s'embarquer dans d'autres dépenfes; qu'il patientât encore un peu, \& que quand la guerre feroit finie, on l'écoûteroit à loifir. Il regarda cet avis comme une défaite, $s^{\prime}$ en alla à Sevitle, \& s'adreffa fucceffivement aux Ducs de Medina Sidonia, \& de Medina Celi. Le premier ne voulut pas même l'entendre. Quelques-uns ont dit que le fecond avoit refolu de lui faire équiper des vaiffeaux au Port de Sainte Marie, dont il étoit Seigneur, mais que la Cour refufa d'y confentir.

Ce qui eft certain, c'eft que dès lors il fongea à paffer en France, bien réfolu, fi le Roi très-Chrétien ne l'écoutoit pas, d'aller jufques à Londres pour y rejoindre fon frere, dont il n'avoit reçu aucune nouvelle, depuis qu'ils s'étoient féparés. Mais le P. Jean Perez de Marchena Francirquain, fon ami, l'en détourna, mit fon projet entre les mains de quelques perfonnes d'une érudition connuë en ces matieres là ; \& ceux-ci l'ayant approuvé avec éloge, il en écrivit à la Reine Ifabelle, auprès de laquelle il avoit du crédit. Cette Princeffe, qui étoit toûjours au camp de Sainte Foi devant Grenade, lui manda auflitôt de la venir trouver: il y alla, \& il fçut fi bien tourner fon efprit, qu'il l'engagea à donner une audiance à fon ami. Ce voyage ne produifit pourtant rien : à la verité tout ce que propofoit Colomb fut trouvé fort fenfé \& fort vrai-femblable, mais il portoit fes prétentions bien-haut; car il demandoit d'être déclaré Amiral, \& Viceroi perpetuel \& hereditaire de toutes les terres \& de toutes les mers, qu'il découvriroit. On jugeoic que c'étoit trop, s'il réuffifioit; \& que s'il ne réuffilioit 


\section{DE S. DOMINGUE, LIV. I. 75}

pas, on feroit taxé de legereté, pour avoir agi \& tantpromis fur de foibles indices.

Ce fut alors, que Colomb ne voyant plus d'apparence de rien faire à cette Cour, fongea tout de bon à paffer en à paffer en

France. Mais le Grand Thréforier, \& Louis de Sant-Angel Receveur des. Droits Ecclefraftiques de la Couronne d'Arragon, ne purent fouffrir qu'on négligeât ainfi une affaire de cette conféquence, \& engagerent le Cardinal de Mendoza Archevêque de Tolede \& Chef du Confeil de la Reine à ne point laiffer fortir d'Efpagne le Pilote Génois, fans lavoir vû. Colomb eut effectivement une longue audiance du Cardinal, qui fut très-content \& du projet, \& du caractere d'efprit de fon auteur, mais qui ne conclut rien. L'air de la Cour n'étoir point favorable aux découvertes, \& l'on y difoit publiquement qu'il ne falloit pas s'étonner qu'un Etranger fans biens preflàt fi fort l'execution d'une entreprife, où il ne mettoit rien du fien, qui lui donneroit de l'emploi, \& où fon pis aller étoit de fe retrouver ce qu'il étoit.

Colomb, à qui ces difcours furent bientôt raportés, voulut les faire cefler, \& lever tous les prétextes, quion pouvoit imaginer pour empêcher la réuffite de fon deffein, il s'offrit à payer un huitiéme de la dépenfe \& confentit de ne partager les profits, que fur le pied de fes avances. Mais il avoit beau fe prêter à tout, \& parler raifon, chaque jour voyoit naître de nouveaux obftacles, \& il defefpera entierement de les furmonter. Il étoir retourné au camp de Sainte Foy pour y faire les propofitions, dont je viens de parler, il en partir fort chagrin au mois de Janvier 1492. pour fe rendre à Cordouë, où étoit fà famille, \& il fe difpofa férieufement au voyage de France. Sur ces entrefaites Grenade fe rendit, \& Sant-Angel profitant de la joie qu'un fi grand événement avoir répanduë dans toute la Cour, repréfenta vivement à la Reine le tort qu'on faifoit à l'Efpagne en éconduifant un homme du mérite de Colomb. 
1492.

Derniers ef

forts auprès sie la heine.

* Madame, lui dit-il, il n'eft perfonne, qui ne foit furpris w que Votre Altefle, après avoir donné tant de preuves éw clatantes de fon grand cour, manque, pour épargner une » bagatelle, une affaire, qui peut avoir des fuites fi avars tageures pour l'Etat. Vous ignorés peut-être, Madame, ๙ que cet Italien eft réfolu de porter ailleurs fes memoires $\infty$ \& fes projets. Et verriés-vous fans chagrin un de vos voio fins profiter de ce que vous auriés negligé ? Que craint » Votre Alteffe? Colomb eft un homme fage, habile, plein o de bon fens \& de prudence : c'eft le témoignage unanime, s que lui rendent tous ceux, qui l'ont pratiqué ; il s'offre s à entrer dans la dépenfe, il y mettra tout fon bien, il y » rifquera fa vie, il faut qu'il fe tienne abfolument fûr de s réuffr. Enfin de fort habiles gens ne trouvent rien d'im$\infty$ praticable dans ce qu'il propofe, \& quand même le fuccès o ne répondroit pas à fes efperances, la chofe eft de natus re à être tentée fans imprudence. Il fied bien, Madame, o à une grande Reine comme vous de connoître la vafte étenduë de l'Ocean, \& rien n'eft plus capable d'illuftrer s votre regne, qu'une pareille entreprife. Je ne vois pas ๑ même que cet Etranger demande beaucoup pour ce qu'it s promet; tiendra-t-il à fi peu de chofes, que vous n'é» ternifiés votre nom par une découverte, que le ciel vous s a, ce femble, refervée?

Elle accepte Ce difcours fit fur la Reine, déjà ébranlée par les raiIes conditions propolées par Colomb. fons du grand Thréforier, tout l'effer, qu'en avoir prétendu Sant-Angel, elle donna fur le champ les mains à tout, voulut même que la chefe s'éxécuta au plûtôt, \& parce que la guerre de Grenade avoit épuifé fes finances, elle vouloit engager de fes pierreries, pour la fomme que Colomb demandoit ; mais Sant-Angeł lui dit que cela n'étoit pas néceffaire, \& qu'il avanceroit du fien tout ce qu'il faudroit. Colomb cependant étoit déjà parti pour France, Ifabelle fit courir après lui un Huiffer de la Cour, \& celui-ci l'ayant joint fans peine, il le conduifit à Sainte Foy, où la réception, que lui fit Ifabelle, effaça de fon elprit jufqu'au fou- 


\section{DE S. D O INGUE, LIV. I. 77}

venir des chagrins, que la lenteur \& les airs méprifans des Efpagnols lui avoient fait effuyer pendant huit ans. Il eut ordre enfuite de traiter avec le Secretaire d'Etat D. Juan de Coloma, \& le i 7. d'Avril on convint des Articles fui- Ou Colo: vants.

I. Que les Rois Catholiques, comme Souverains Sei- Quelles fugneurs de l'Ocean, nommeroient dès à préfent Chriftophle rent ces conColomb leur Amiral \& leur Viceroi perpetuel de toutes les Mers, Intes \& Terres fermes, qu’il découvriroit: qu'il joüiroit toute fa vie de ces Charges avec les mêmes prérogatives, quant à la premiere, dont l'Amirante de Caftille joüiffoit dans l'étenduë de fa jurifdiction; qu'il en feroit de même à proportion de la feconde, \& qu'elles pafferoient toutes deux fur le même pied à fa pofterité. II. Que pour les Gouvernemens particuliers de chaque Place, Ifle, Province, ou Royaume, les Rois Catholiques nommeroient. un des trois Sujets, qu'il leur auroit préfenté. III. Que toutes les richeffes ou marchandifes, de quelque nature qu'elles fuffent, qui feroient apportées des nouvelles Conquêtes, après que tous les frais auroient été rembourfés, l'A miral Viceroi auroit un dixiéme à prendre fur les droits du Prince. IV. Que tous les differens, qui furviendroient dans l'étenduë de la nouvelle Amirauté , au fujet du Commerce \& des fufdites richeffes \& marchandifes, feroient jugés par l'Amiral, ou par fes Lieutenans en fon nom; comme il fe pra. tiquoit à l'égard de l'Amirante de Caftille. V. Que dans tous les navires, qui feroient armés pour faire le Commerce dans les nouvelles Découvertes, le même Amiral pourroit s'intéreffer pour un huitiéme.

Les Rois Catholiques fignerent cette fameufe Capitula- Le Traité ef tion, ('c'eft le nom qu'on lui donna, ) qui leur acquit un figné du Roi nouveau monde, dans ce même camp de Sainte-Foy, où \&ais au nom ils venoient d'achever ta ruine entiere des Maures d'Efpa. gne, après 800 . ans de domination, \& voici le Brevet, qui de la fenle Couronne de fut donné à Colomb, lequel, de la maniere, dont il fut concĥ̀. quoique datté du têms auquel il fut livré, ne pouvois 
1792. avoir lieu qu'après la découverte, qu'il fuppofe déja faite.

« ERDinAND \& Is A Belle, par la grace de Dieu,

- Roy \& Reine de Caftille, de Leon, d'Arragon, de s Sicile, de Grenade, de Tolede, de Valence, de Galice, w de Majorque, de Minorque, de Seville, de Sardaigne, » de Cordouë, de Corfique, de Murcie, de Jaën, des w Algarves, de Gibralrar, \& des Inles Canaries. Comte »\& Comteffe de Barcelonne, Seigneurs de Bifcaye \& de w Molena, Ducs d'Athenes \& de Neopatrie, Comtes de - Roufillon, Marquis d'Oriftan \& de Gociado, \&c. Puif» que vous, Chriftophle Colomb, allés par notre comw mandement, avec nos vaiffeaux, \& nos Sujets à la con» quête des Ines de l'Ocean, que vous avés découvertes, » \& comme nous efperons quavec l'aide de Dieu vous en o découvrirés diautres, il eft jufte que nous vous récom» penfions des fervices, que vous rendés à notre Etat. - Nous vouluns donc que vous, Chriftophle Colomb, foyés „Amiral, Gouverneur, \& Vice-Roy des Inles \& de la ๖ Terre ferme, que vous avés découvertes, \& de toutes o celles que vous découvrirés. Que vous vous appelliés D. s Chriftophle Colomb, que vos enfans après vous fuccedent wà toutes vos Charges, que vous les puiffiés exercer par * vous, ou par ceux, que vous choifirés, pour être vos s Lieutenans, que vous jugiés toutes les affaires civiles » \& criminelles, dont la connoiffance apartient \& a aparw tenu à nos Vice-Rois \& à nos Amiraux, \& que vous » ayés les droits \& prééminences des Charges que nous s vous donnons. Et par ces Préfentes Nous commandons s à notre très - cher Fils le Prince D. Juan, aux Infants, o Ducs, Prelats, Marquis, Grands-Maîtres, Prieurs \& s Commandeurs de no Ordres Militaires; à tous ceux de » notre Confeil, \& Juges en quelque Juftice que ce foit, * Cours \& Chancellerie de notre Royaume, aux Chatew lains, Gouverneurs des Citadelles, des Places fortes, à toutes les Communautés, Juges, Officiers de la Marine, 


\section{DE S. D OMIngUE, LIV. I.}

aux vingt - quatre Cavaliers Jurés, Ecuyers, à toutes ` les Villes \& Places de notre Etat, \& à rous les Peuples, » que vous découvrirés \& fubjuguerés; de vous reconnốtre, comme Nous vous reconnoiffons, pour notre Amiral * \& Vice-Roi, vous \& vos enfans en ligne directe, \& pour toûjours. Ordonnons à tous les Officiers, que vous éta» blirés en quelque Charge que ce foit, de vous faire con₹erver vos privileges, immunités, honneurs, \& de vous ¿o faire payer les droits \& les émolumens, qui font dûs à s vos Charges, fans permettre que perfonne y mette au» cun obftacle. Car tel eft notre volonté. Nous commanso dons à notre Chancelier \& autres Officiers de notre Sceau, o de vous expedier au plûtôt nos Lettres, \& de les faire w aufi amples \& aufi avantageufes, que vous le fouhai» terés, à peine de notre difgrace, \& de trente ducats d'a* mende contre chacun des contrevenans; donné en notre o ville de Grenade le 30. d'Avril l'an 1492. Signé, Moi DE ROT. MOI LA REINE.»

« Moi Jean de Coloma secretaire du Roi \&o de la Reine ai - fait expedier les Préfentes Lettres par leur Commandement.

Au refte, quoique tour parut fe faire également au nom du Roi \& de la Reine. La Courone d'Arragon nentra pour rien dans cette entreprife; la Caftille en fit tous les frais, ce fut pour elle feute que le nouveau monde fut découvert \& conquis; \& tour le têms que vêcut Ifabelle, il ne fut gueres permis qu'à des Caftillans d'y paffer \& de s'y établir, ce qui n'empêcha point que le Roi ne parûr toûjours le Souverain, \& quelquefois même feul, comme repréfentant la Reine de Caftille fon époufe. Les ordres, qui furent remis à Colomb avant fon départ de Grenade, portoient qu'il n’aprocheroit pas des côres de Guinée à cent lieuës près des terres poffédées par le Roi de Portugal, \& nous verrons dans la luite les railons \& la néceffité de cette précaurion.

Le 12. de Mai Colomb fe mit en chemin pour l'Eftra- Embarqueo maduure, \& il arriva en peu de jours à $P_{\text {ailos, où fe faifoit lombo }}^{\text {ment }}$ de 
1492. l'armement qui lui avoit été accordé. Ce Port paffoit pour avoir les meilleurs matelots d'Efpagne, \& c'eft ce qui avoit fait fouhaiter à Colomb d'y faire les préparatifs de fon voïage. D'ailleurs, il avoit de bons amis dans le pays, \& il comptoit particulierement beaucoup fur le P. Jean Perez. de Marchena, dont nous avons déjà parlé, \& qui effectivement lui rendit de bons fervices. Le plus confiderable fut d'engager d'habiles mariniers, qui avoient quelque répugnance à fuivre un étranger dans une mer inconnuë, à prendre parti avec lui. Mais la meilleure acquifition que fit Colomb pour fon entreprife, fut celle de trois freres des plus riches habitans \& des plus habiles navigateurs de Palos; ils fe nommoient Pinçon, \& ils voulurent bien rifquer leurs perfonnes, \& une partie de leur bien dans cet armement.

La ville de Palos étoit obligée de mettre tous les ans en mer pendant trois mois deux caravelles; il y eût ordre de les donner à Chriftophle Colomb, \& l'on y joignit un petit navire, ou une troifiéme caravelle, qu'il monta luimême. Il lui donna le nom de Sainte-Marie, quelques auteurs la nomment la Gallega, \& c'étoit apparemment fon premier nom. Les deux autres bâtimens étoient la Pinta, commandée par Martin-Alphonfe Pinçon, \& la Nina que montoit Vincent-Yanez Pinçon:François-Martin le plus jeune des trois freres, fut le pilote de la Pinta. Il y avoit fur ces trois navires cent vingt hommes en tout, tant mariniers que volontaires, \& des vivres pour un an. Chriftophle Colomb mit à la voile un Vendredi troifiéme d'Août, demie heure avant le lever du foleil, après avoir fait fes devotions avec tous fes gens. Dès le lendemain le timon de la Pinta fortit de fa place, \& l'on foupçonna deux mariniers, qu'on avoir embarqués malgré eux, d'avoir caufé ce défordre, d'autant plus qu'ils avoient déjà fait la même chofe avant le départ. Pinçon fit attacher le timon avec des cordes, mais un coup de vent ou de mer le détacha peu de jours après, \& ce bâtiment eût bien de la peine à fuivre les autres.

I'onziéme 


\section{de S. Domingue, Liv. I. 8 r}

L'onziéme d'Août on apperçût la grande Canarie, \& lon alla y faire mettre un timon à la Pinta. Colomb fit auffi changer la voile latine de la Niña en voile ronde, puis il Il arrive aux gagna en quatre jours la Gomera, où il acheta des viandes fraîches, \& fit de l'eau \& du bois. Un avis, qu'il eût dans ce port, que trois caravelles Portugaifes le cherchoient à deffein de l'enlever, l'en fit fortir plûtôt, qu'il n'auroit fait fans cela, il appareilla le 6. Septembre \& fit le sud Oueft. Dès le lendemain les terres difparurent de toutes parts, \& quelques paffagers, qui fe mirent dans l'efprit qu'ils ne la reverroient jamais, commencerent à foupirer \& à pleurer. L'onziéme, Colomb fe faifoit à i so. lieuës de l'Inle de Fer, \& il rencontra un mât de navire, qui paroiffoit avoir été entraîné là par les courants. Un peu plus loin il s'aperçût que les courants portoient extrêmement fort vers le Nord, \& le r 4. au foir il obferva que l'aiguille déclinoit d'un dégré vers le Nord-Oueft. Le lendemain matin cette déclinaifon avoit crû d'un demi degré ; mais les jours fuivants elle varia beaucoup; comme on n'avoit jamais rien oüi dire de pareil, on peut juger que cette nouveauté donna à penfer à nos navigateurs. La vûë d'un oifeau affez petit, \& de quantité d'herbes, qui couvroient la fuperficie des eaux, \& paroiffoient nouvellement détachées de quelques terres, ou de quelque roche; jointe à plufieurs obfervations, que Colomb avoit faites, le porterent à ne plus naviguer que la fonde à la main, quoique fuivant fon eftime, il ne fût qu'à 400 . lieuës des Canaries. Le Commandant de la Pinta s'imagina même un jour avoir vû la terre environ à I 5 . lieuës au Nord, \& vouloit tourner de ce côté-là ; mais Colomb l'affùra qu'il fe trompoit, \& la prétenduë terre, qui n'étoit effectivement qu'un gros nuage à l'horifon, fe diffipa bientôt.

Les jours fuivants il parut beaucoup d'oifeaux de différentes efpeces, \& l'efperance, que cette vûë fit naître de des Equipadécouvrir bientôt la terre, foûtint un peu les Caftillans qui commençoient à perdre courage. Mais ne fe trouvant Tom. $I$. 
1492. pas plus avancés au bout de trois femaines que le premie jour, \& craignant que le vent, qu'ils avoient toûjours eu favorable pour aller à l'Oueft, ne leur fut contraire , quand ils voudroient retourner en Efpagne; la plûpart furent faifis de frayeur de fe voir au milieu d'une vafte mer, qu'ils regardoient comme un abîme fans fonds \& fans bornes, \& tô̂jours prêt à les engloutir. Déjà on ne parloit plus que de reprendre au plûtốt la route de Caftille; la Cour, difoit-on, ne fçauroit trouver mauvais qu'après avoir navigué plus loin, que jamais perfonne n'a fait, nous n'ayons pas été plus avant fans efperance de rien trouver, \& uniquement pour fervir à l'ambition déreglée d'un avanturier, qui n'ayant rien à perdre, fe mettoit fort peu en peine de nous voir tous perir. Il y en eût même, qui dirent affez haut, que le plus court étoit de jetter cet étranger à la mer, \& qu'ils en feroient quittes pour dire qu'il y étoit tombé par accident en contemplant les aftres.

Conduite de Colomb en cette occalion.
Colomb comprit toute la grandeur du péril, où il fe trousvoit engagé ; mais il ne fe perdit point, \& tantôt par de bonnes manieres, tantôt par des raifons plaufibles, quelquefois par des efperances bien ménagées, \& qu'il fçavoir accompagner d'un certain air infinuant, qui perfuade autant que les meilleures raifons; d'autre fois, ufant fagement de menaces, \& faifant valoir à propos toute l'autorité, dont il étoit revêtu, il vint à bout de calmer ces premieres faillies. Le premier d'Octobre il fe faifoit à 700 . lieuës des Cana* ries, mais il fe donna bien de garde de le dire à fes gens, \& par bonheur pour lui les deux caravelles ne fe faifoient. pas fi loin. Au bout de quelques jours les murmures recommencerent, \& la mutinerie s'augmenta à un point, qu'il $y$ avoit tout à craindre du defefpoir, où fe trouvoient les trois équipages; les horreurs d'une mort prochaine, \& qui paroiffoit inévitable, foit par la faim, foit par le naufrage, ayant fait prefque tourner la tête à ceux-là même, fur qui le Commandant avoit cru devoir plus compter. Il leur parla encore avec beaucoup de douceur, il leur 


\section{De S. Domingue, Liv. I. 83}

repréfenta qu'un peu de confance alloir infailliblement leur acquérir une gloire immortelle : eifin, yoyant quils ne fe raffurroient point, il fe hazarda à leur faire une propofition, qui furpendit d'abord toute la fureur, dont ils commençoient à être animés.

Il leur déclara, que fi dans trois jours la terre ne paroif- Propofition foit point, ils feroient les maîtres d'en ufer comme ils hardic quil voudroient, \& qu'il fe mettroit à leur difcretion. Cette conduite toucha les Pinçons, qui s'étoient mis à la tête des mutins; car on a toûjours regardé comme une fable, \& comme une pure calomnie inventée par les ennemis de Colomb, ce que quelques uns ont avancé, qu'ayant lui-même perdu courage, il avoit voulu retourner en $\mathrm{Ca}$ ftille, \& que les trois Pinçons l'avoient forcé à continuer fa route. Il eft certain qu'on lui reprocha cette lâcheté dans le procès qu'il eût à foûtenir contre le fifc royal pour fes droits; mais on n'y infifta pas, \& cette ridicule accufation ne fut regardée de fes parties même, que comme un de ces faits hazardés fans preuve, dont les Avocats prennent fouvent la liberté, quand ils n'ont ric a de bon à dire, de remplir leurs factums, pour en impofer à la multitude, qui croit aifément tout fans examiner.

La déclaration du Commandant fut donc prife au pied de la lettre, \& on lui fit entendre que les trois jours exIndice des pirés, on ne différeroit pas un moment à revirer de bord. Mais on prétend qu'il n'avoit rien rifqué en prenant un ter* me fi court ; qu'il y avoit déjà quelque têms qu'il trouvoit fond avec la fonde, \& que la nature du fable, ou de la vafe qu'elle raportoit, lui faifoit juger qu'il étoit près de terre. Dès le deuxiéme jour il en parut des fignes, qui raffûrerent les plus timides; c'étoit des morceaux de bois figuré, des cannes fraîchement coupées, une épine avec fon fruit; d'ailleurs on commençoit, le matin fur-tout, à refpirer un air plus frais, \& ce qui plus, que toute autre chofe, faifoit impreffion fur l'efprit de Colomb, les vents changeoient fouvent pendant la nuit : car il ne pouvoit douter que cela 
1492. ne vint d'un combat du vent de terre, contre celui, qui fouffloit ordinairement au large. Le foir de ce même jour qui fut un Jeudi II. d'Octobre, la priere finie, il avertit fes gens que cette nuit même il comptoit de voir la terre, qu'on fût fur fes gardes, \& qu'à minuit les trois bâtimens carguaffent toutes leurs voiles, fe contentant de courir fur la trinquette baffe : \& parce qu'un coup de vent pouvoit fé- . parer les navires les uns des autres, il donna des fignaux pour fe réünir. Enfin il ajoûta, qu'outre les roo0o. maravedis de rente, (ce qui revient à peu près à 800 . livres de notre monnoye,) que le Roi Catholique avoit promis à celui, qui le premier verroit la terre, il ajoûteroit du fien un pourpoint de velours.

Colomb la découvre le premier.

Sur les deux heures après minuit, un matelot, qui depuis quelque temps fe tenoit au haut du grand mât, fe mit à crier: Lumiere, lumiere; terre, terre; \& crût fa fortune faite, mais fa joye fut courte; car un domeftique de Colomb: nommé Salzedo, lui dit fur le champ que fon maître avoir déjà vû cette lumiere, \& reconnu la terre. En effet, la veille fur les dix heures du foir, Colomb étant au châtearz de Pouppe, appella fecretement un nommé Pierre Guttierez, valet de la garde-robe de la Reine, (Oviedo dit que ce fut un gentilhomme nommé Efcovado, ) \& lui montra une lumiere, qu'il venoit d'apercevoir : tous deux enfuite appellerent Rodrigue Sanchez, qui faifoit l'office de Contrôleur des Guerres, \& la lui firent voir. Un moment après il leur fit voir diftinctement la terre, \& ce fut fur le témoignage de ces deux hommes, que les ioooo. maravedis de rente furent ajugés à Colomb, atiquel ils furent exactement payés jufqu’à fa mort fur les Boucheries de Seville. On prétend que le matelot, qui le premier avoit crié terre, conçût un fi grand dépit d’avoir été fruftré d'une récompenfe, qu'il croyoit lui être dûë, qu'aufitôt après fon retour en Efpagne, il paffa en Afrique, \&

Il eft falué fe fit Mahometan. 


\section{De S. Domingue, Liv. I. 85}

d'environ deux lieuës. La Pinta, qui alloit toûjours devant, entonna la premiere le Te Deum, les deux autres bâtimens 1492: fuivirent d'abord, après quoi tout l'équipage de la Capitane vint fe jetter aux pieds de Colomb, lui demanda pardon, des chagrins qu'il lui avoit donnés, le falua en qualité d'Amiral \& de Vice-Roi, \& paffant tout à coup fans milieu d'une extrêmité à l'autre, comme c'eft affez l'ordinaire du peuple ; cet infenfé, cet avanturier, que peu d'heures auparavant on traitoit avec le dernier mépris, qu'on avoit voulu jetter à la mer, étoit un homme divin; on ne pouvoit trouver de termes affés relevés pour exprimer l'eftime, qu'on faifoit de fon génie, \& de fon courage, \& la profonde vénération dont on fe fentoit pénétré pour fa perfonne. Enfin Chriftophle Colomb fe trouva dans ce moment parvenu de la condition de fimple Pilote étranger, aux deux plus grandes dignités de la Couronne d'Efpagne, \& par leur réünion en fa perfonne, il ne vit plus parmi la nation la plus fiere de l'Europe, \& la plus jaloufe de ne point partager fa gloire avec les autres, que le Thrône au deffus de lui.

La terre, que les Efpagnols avoient devant les yeux, étoit une Ifle, qui paroiffoit avoir $\mathrm{x} 5$. lieuës de long. L'A. miral, car nous l'appellerons déformais ainfi avec les au- \& prend pofteurs Efpagnols; l'Amiral, dis-je, lui donna fur le champ !e Guanahani le nom de San-Salvador, qu'elle n'a point gardé. Comme on au nom de la en aprochoit toûjours, on ne tarda pas à en voir tout Caftille.

le rivage bordé d'hommes parfaitement nuds, dont la furprife paroiffoit extrême. Mais l'empreffement étoit bien égal de part \& d'autre, pour fe voir de près. On aborda enfin, \& Colomb faura le premier à terre, portant l'épée nuë d'une main, \& l'Etendart Royal de l'autre. Les Commandans des deux caravelles le fuivirent de près, portant auffi les Enfeignes de l'entreprife, où l'on voyoit d'un côté une croix verte, \& une F. \& de l'autre plufieurs F F. couronnées en l'honneur de Ferdinand. Tous les trois équipages furent bientôt à terre, \& la premiere chofe, qu'ils faifoient en 
142. débarquant, ćtoit de baifer cette terre', fi long-têms défirée, \& de remercier Dieu du fuccès de leur voyage. Après cela tous vinrent renouveller aux pieds de Chriftophle Colomb, ce qu'avoit fait l'équipage de la Capitane, \& ils lui prêterent dans les formés le ferment de fidelité , qu'ils lui devoient en qualité d'Amiral, \& de Vice-Roi.La prife de poffeflion fe fit enfuite au nom de la Couronne de Caftille, avec toutes les formalités requifes, en préfence de Rodrigue Efcovedo, Notaire Royal. On commença cette cérémonie par planter une Croix fur le rivage, \& après l'avoir adorée avec de grands fentimens de religion, on y grava les armẹs de Caftille. Tout étant fini, Colómb en requit acte du même Notaire de l'Efcadre.

Etonnement Tout cela fe paffoit à la vûë des Sauvages, dont l'éreciproque
des Sauvages tonnement croiffoit toûjours. Il parut même dans la fuite, \&. des Euro- qu'ils avoient long-têms regardé les. Europeans, comme peans. des hommes d'une efpece particuliere, \& d'un ordre fuperieur. En effet, la différence étoit grande entre les uns \& les autres. Les Barbares n'avoient que des cheveux affés courts, noirs, épais, que plufieurs lioient avec un cordon autour de leur tête, en maniere de treffe; du refte, ils n'avoient pas un poil fur tout le corps; \& ils voyoient les Caftillans avec de longues barbes, \& la poitrine toute veluë; ils étcient encore plus furpris de les voir habillés, que ceux-ci ne l'étoient de les voir nuds. Enfin, la couleur de la peau, \& les traits du vifage étoient fi différens - dans les uns \& dans les autres, que l'étonnement étoit réciproquement extrême, \& qu'on ne fé laffoit point de fe regarder. D'ailleurs, ce peuple paroiffoit fort doux, fans défiance, \& fans crainte. Tous étoient peints d'une maniere fort bigarrée, les uns feulement au vifage, ou autour des yeux, \& au nez, les autres partout le corps, ce qui n'embelliffoit pas leur face, déjà très-difforme par fon extrême largeur. Peut - être portoient - ils un jugement tout femblable de celle des Europeans, dont la barbe cachoit une bonne partie; car il faut convenir que tout cela 
Cependant les Infulaires ayant remarqué dans la cérémonie de la prife de poffeffion le Greffier, qui écrivoit, s'imaginerent qu'on jettoit un fort fur eux \& fur leur Ifle, $\&$ s'enfuïrent à toutes jambes, on courut après, \& on en joignit quelques-uns, aufquels on fit amitié , qu'on chargea de prefens, \& qu'on laiffa enfuite aller, où ils voulurent. Cette conduite raffura les autres, \& tous fe rendirent extrêmement familiers. Les moindres chofes qu'on leur donnoit leur paroiffoient précieufes, \& les Caftillans de leur côté fe voyant tranfportés dans un monde nouveau, où ils n'apercevoient rien de femblable à ce qui fe trouve dans celui, d'où ils venoient; ni arbres, ni plantes, ni oifeaux, ni les hommes même, ne fçavoient encore s'ils veilloient, ou fi c'étoit un fonge.

Dès le jour même l'Amiral fe rembarqua avec tous fes gens, \& les Sauvages. le fuivirent en grand nombre jufqu’à fon bord, les uns à la nage, \& les autres dans leurs canots. On les queftionna alors plus à loifir, \& l'on apprit d'eux que leur Inle s'appelloit Guanahani, \& que les habitans non feulement de cette Ine, mais encore de plufieurs autres, dont elle étoit environnée, fe nommoient Lucayos, \& c'eft de-là qu'eft venu le nom de Lucayes, que nous avons donné à toutes les Ifles, qui font au Nord \& à l'Oueft des grandes Antilles, \& fe terminent au canal de Bahama. La plûpart de ces bonnes gens, en venant à bord des trois navires, avoient apporté des Perroquets \& du cotton, parce que c'étoit ce dont les ¿Chrêtiens avoient paru faire plus de cas; on leur donna en échange de petites fonnettes, qu'on leur attacha au cou, \& aux jambes, des fragmens de pots de terre $\&$ de fayance, $\&$ d'autres pareilles babiolles, quils recevoient avec des tranfports de joye incroyables : tous voulurent en avoir, \& bientôt les trois bâtimens fe trouverent remplis de cotton $\&$ de Perroquets, qui faifoient un bruit extraordinaire.

Mais ce qui fit plus de plaifir aux Caftillans, c'eft que 
1492. la plûpart de ces Infulaires avoient de petites plaques d'or. qui leur pendoient des narines; on leur demanda d'où ils les avoient tirées, \& ils firent entendre que c'étoit d'un pays, qu'ils montroient au Sud. Sur quoi l'Amiral fe détermina à tirer de ce côté-là. Le lendemain 14 . il rangea la côte, les Sauvages les fuivant par terre : à mefure qu'ils rencontroient de leurs compatriotes, ils les appelloient pour voir, difoient-ils, des hommes extraordinaires \& des machines, qui voloient fur l'eau. De têms en têms ils fe tournoient vers les Europeans, \& leur montrant le ciel, ils leur demandoient, s'ils n'en étoient pas defcendus. Sur le foir l'Amiral leur fit quantité de préfens \& les renvoya. Le I 5 . il s'approcha d'une autre Inle éloignée de la premiere de fept lieuës, \& it la nomma l'Ifle de la Conception, mais il ne s'y arrêta point. Le 17. il moüilla l'ancre près d'une troifiéme, où il fit de l'eau; les peuples y parurent un peu plus civilifés qu'à San-Salvador, \& les femmes y étoient couvertes depuis la ceinture jufquaux genoux, les unes de pieces de cotton, les autres de feüilles d'arbres, cette Inle fut appellée Fernandine.

L'Amiral paffa de-là à une quatriéme, que les gens du pays appelloient Saumoto : il y defcendit à terre, en prit poffeffion avec les mêmes formalités, dont il avoit ufé dans la premiere, \& lui donna le nom d'Ifabelle. Enfin le 28. il fe trouva proche d'une grande terre, que les habitans des autres Inles, dont quelques-uns le fuivoient toûjours, lui nommerent cuba, \& à laquelle il donna le nom de fuana, fans fçavioir encore fi c'étoit une Ifle, ou le continent; ce nom n'a pas été heureux, non plus que celui de Fernandine, qu'on lui a voulu fubftituer dans la fuite. L'Inle a gardé jufqu’à préfent celui, qu'elle avoit reçu de fes anciens habitans. Le Port, où l'Amiral entra, eft celui, qu'on a depuis appellé Baracoa, du nom d'un cap, qui eft à l'entrée du côté de l'Ef. Comme fon navire avoit befoin d'être radoubé, il profita de l'occafion, que lui préfentoit la commodité d'un beau port, \& il prit ce têms-là pour faire vifiter le pays, 
où on l'avoit aflûré qu'il trouveroit de l'or.

Il fit choix pour cette vifite de deux hommes fort intelligens, lefquels, après avoir marché environ vingt lieuës, ne crurent pas devoir aller plus loin. A leur retour ils raporterent qu'ils avoient vû un grand nombre de villages $\&$. de hameaux, où ils avoient été reçûs comme des hommes defcendus du ciel, que tous étoient venus leur baifer les pieds, les hommes d'abord \& puis les femmes; que les uns \& les autres étoient nuds; qu'entrautres mets, qu'on leur avoit préfentés, ils avoient mangé d'une racine, qui étant cuite, avoit le goût de marons. C'étoit des Patates, dont nous parlerons ailleurs. Que le pays étoit fort beau, mais qu'ils n'y avoient rien remarqué de fingulier, fi ce n'eft du cotton en quantité, dont ces peuples ne faifoient gueres d'ufage, que pour leurs lits ou hamacs; qu'ils avoient vû differentes fortes d'oifeaux, de petits chiens, qui ne jappoient point , \& un autre animal, appellé Utias, qui tenoit beaucoup du lapin; qu'ils en avoient tué un plus grand, fait à peu près comme un fanglier, excepté qu'il avoit fur le dos un évent, par lequel il refpiroit. Qu'ayant demandé s'il y avoit de l'or dans cette terre, on leur avoit répondu qu'ils en trouveroient dans un certain canton, dont on ne ne leur avoit pas bien marqué la pofition, \& dans Bohio qu'on leur avoit montré à l'Eft. On a fçû depuis que le canton, dont on leur avoit parlé, s'appelloit Cubanacan, \& avoit effectivement de l'or, mais en petite quantité : quant à Bohio, ce n'étoit pas le nom d'un pays, mais cela vouloit dire, une terre, où il $\mathrm{y}$ avoit un grand nombre de villages \& de maifons.

L'affürance que l'on donna à l'Amiral, qu'il trouveroit de l'or dans cette région, l'engagea à la chercher : plufieurs habitans de Cuba s'offrirent à l'y conduire, \& il accepta volontiers leur offre. Son deffein étoit de faire aprendre le Caftillan à plufieurs de ces Infulaires, perfuadé que faute de fe bien entendre, on perdoit fouvent des connoiffances importantes, \& l'on couroit même rifque de tomber dans des Tom. $I$ 。 
1492. erreurs, qui pouvoient avoir des fuites fâcheufes. Les vents l'ayant contrarié au fortir de Bacacoa, il fut contraint de fe réfugier dans un port voifin, qu'il appella le port du Prince; d'où, après quelques excurfions, il alla moüiller dans un troifiéme port, auquel il donna le nom de Sainte-Catherine, dont on célébroit la fête ce jour-là. Une chofe l'inquiétoit depuis quelques jours. La Pinta s'étoit féparée de lui le 2 I. \& dès le lendemain elle avoit abfolument difparu. Cette caravelle étoit très-bonne voilliere, \& Martin-Alonfe Pinçon, qui la commandoit, avoit voulu profiter de cet avantage, pour arriver le premier à cette terre fi abondante en or, dont on avoit parlé à l'Amiral, \& y faire fa main.

Les avis, que reçût l'Amiral au port Sainte-Catherine, le confolerent un peu de cette difgrace; il y rencontra des habitans de l'Ine, dont on lui avoit parlé fous le nom de Bohio, \& que ces Infulaires nommoient Hayti. Ils lui confirmerent que leur pays abondoit en or, \& qu'il s'en trouveroit furtout une très-grande quantité dans une contrée appellée cibao. Ce nom réveilla d'abord fes premieres idées fur le Cipango de Marc-Paul de Venife, \& il ne douta prefque plus que ce ne fût le même pays. Il fe hâta donc de $s^{\prime} y$ rendre, \& il embarqua fur fon bord ces mêmes Infulaires, qui lui avoient donné de fi bonnes nouvelles, \& qui lui promirent de le mener aux mines de Cibao. Il rangea la côte du Nord de Cuba, faifant route à l'Eft, \& après avoir ainfi navigué 100 . lieuës, il fe trouva le s. de Decembre à la pointe Orientale de la même Ine.

Colomb arrive à l'Ille Hayti.

Il n'y a de cette pointe à l'Ifle Hayti que 18. lieuës, l'Amiral les fit en moins de 24 . heures. Il prit terre le fix à un gros cap, à côté duquel il trouva un port, où il entra; \& en l'honneur du Saint, dont l'Eglife honore la memoire en ce jour-là, il donna au port \& au cap le nom de Saint Nicolas. que l'un \& l'autre portent encore aujourd'hui.

Fin $d u$ Livre Premier. 


\section{H I S T O I R E \\ D E \\ L'ISLE ESPAGNOLE \\ O U D E \\ S. DOMINGUE. PREMIERE PARTIE.}

\section{I V R E S E C O N D.}

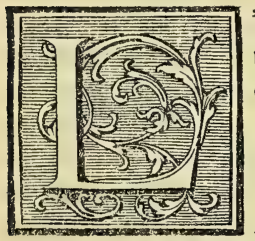

'A M I R A L eût bien voulu refter quelque

1492. têms au Port S. Nicolas, pour y rafraîchir fes Equipages, \& profiter de ce fejour, pour découvrir le pays; mais il étoit trop inquiet fur ce qu'étoit devenuë la Pinta; d'ailleurs fes guides lui difoient, que pour gagner les mines de Cibao, il falloit avancer plus loin à l'Eft. Il prit donc à gauche, \& il n'avoit pas encore fait beaucoup de chemin, qu'il aperçût devant lui une petite Ine, laquelle paroiffoit de loin avoir la figure d'une Tortuë, auffi lui en donna t-il Ifle de $l_{3}$ le nom. Un gros têms qui furvint alors, l'obligea à chercher un abri, \& il le trouva le huitiéme dans un pecit port, qui fut nommé le port de la Conception, \& que lẹs François ont depuis appellé le port de l'Ecu.

La mer continuant à être mauvaife, l'Amiral voulut reconnoître le dedans de l'Ifle, \& il en donna la com- ti te Efipagnole. miffion à fix Caftillans, lefquels ayant marché tout un jour fans rencontrer perfonne, retournerent au port \& affûrerent qu'il n'étoit pas poffible de voir un pays plus charmant, ni de meilleures terres. Colomb de fon côté avoit 
1492. entendu chanter un oifeau, dont le ramage lui parut tenir de celui du Roflignol, fes pêcheurs avoient pris à la Seine des Rayes, \& quantité d'autres poiffons affés femblables à ceux, qu'on prend fur la côte d'Éfpagne, il ne doutoit point que l'Ine ne renfermât de grands tréfors; il ne lui en fallut pas davantage pour l'honorer du nom de l'IJle Ejpagnole. On a voulu depuis en latinifant ce nom, en faire un diminutif, d'où eft venu celui d'Hifpaniola, que lui donnent plus communément aujourd'hui les Caftillans. Mais comme leurs auteurs fe font ton̂jours fervi de celui de l'Ifle Effragnole, ou même fimplement du feul mot E/pagnola, nous nous $y$. conformerons dans la fuite de cet ouvrage.

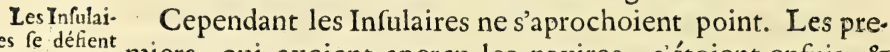

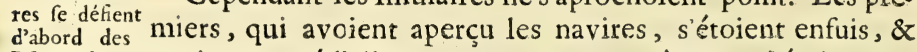
Efpagnols, \& avoient porté l'allarme par tout : ceux même, qui éroient vefent enfuite arec eux. nus de Cuba fur la Capitane, s'étoient fauvés; les Infulaires s'étoient averris par des feux d'être fur leurs gardes, \& quelque part qu'on allât, on ne trouvoit que des côtes \& des campagnes défertes. Enfin, on découvrit un jour dans un bois un grand nombre de perfonnes des deux fexes, qui s'y étoient retirées, \& qui fe mirent à fuïr, dès qu'elles s'aperçurent qu'elles étoient découvertes. On courut après, \& l'on joignit une femme, qui fut menée à Colomb; l'Amiral lui fit bien des amitiés, l'habilla fort proprement, \& la fit reconduire chez elle accompagnée de trois Caftillans \& de trois Sauvages des Lucayes, qui entendoient fa langue; il envoya le lendemain du même côté, neuf autres Caftillans, \& un Infulaire de San-Salvador; ils trouverent cette femme à 4. lieuës de-là au Sud Eft, dans une grande Bourgade, où il y avoit bien mille cabannes, mais fort éloignées les unes des autres. A leur vûë chacun commença à für, mais le Saúvage les ayant atteint, leur dit beaucoup de bien des Caftillans, \& les fit revenir. Ils n'eurent pas lieu de s'en repentir : les Caftillans firent beaucoup de préfens aux principaux d'entre-eux, \& ceux-ci de leur côté engagerent les Caftillans à paffer la nuit dans leur bourgade. 


\section{DE S. DOMIngue, Liv. II. 93}

Le jour fuivant, les Caftillans s'en retournerent au port, où grand nombre d'Infulaires s'étoient rendus la veille avec la femme, dont nous venons de parler. Elle étoit portée fur les épaules de plufieurs, \& fon mari l'avoit accompagnée découverte pour remercier l'Amiral des préfens, qu'il avoit fait à fon. époufe. Ce peuple parut à Colomb un peu plus blanc que les autres Infulaires, plus petit, auffi difforme de vifage, moins robufte, plus doux, plus poli, \& plus traitable. Tous lui confirmerent ce qu'on lui avoit déjà dit des mines de Cibao, \& comme rien ne l'arrêtoit dans ce port, il en fortit dès que la mer fut naviguable. En paffant le canal, qui eft entre la Tortuë, \& l'Inle Efpagnole, il aperçut un autre port, qu'il voulut examiner: il y entra, \& l'endroit lui fembla fi beau, qu'il le nomma $V$ alparay $\int_{0}$. C'eft ce que nous appellons aujourd hui le port de Paix.

Le Cacique du lieu vint rendre vifite à l'Amiral, dès qu'il le fçât à terre. Je ne trouve nulle part le nom de ce Seigneur, \& il y a bien de l'apparence que c'étoit un $\mathrm{Ca}$ cique particulier, ou du fecond Ordre. Il ne laiffoit pas davoir une fuite fort nombreufe, \& lui \& fon fils fe faifoient porter fur les épaules de quelques-uns de leurs fujets. Quelque têms après leur arrivée, on vit venir de la Tortuë un canot, dans lequel il y avoit 40 . hommes; le Cacique leur commanda avec menaces de fe retirer, \& ils obéirent fur le champ: ce Seigneur ne vouloit apparemment pas que ces Sauvages vinffent partager avec fes gens les liberalités des Etrangers. On lui en fit effectivement quelques unes, dont il fut très-fatisfait, \& tous s'en retournerent fort perfuadés, que ces hommes, fi differens d'eux, \& fi bien faifans, étoient defcendus du ciel.

De Valparayfo, les deux navires continuant leur route, allerent moüiller le $2 \mathrm{I}$. dans un port qui fut nommé saintThomas. C'eft le même que les François ont depuis appellé la Baye dw Can de Louife, \& qui porte aujourd'hui plus com. munément le nom de l'Acul. It fe fit là aux navires Efpagnols un concours extraordinaire de gens de tout âge \& de 
1492. tout fexe, \& l'Amiral avoit donné de fi bons ordres à fes équipages, que tous s'en retournerent charmés des bonnes manieres des Etrangers. Ceux-ci n'y perdoient rien; quel. ques-uns d'entre-eux étant allé vifiter les bourgades voifnes, ils furent reçus des habitans avec des démonftrations de la joye la plus fincere. Ces pauvres gens ne pouvoient fe perfuader que les Efpagnols fuffent des hommes ordinaires; ils ne les aprochoient qu'avec refpect, baifoient la terre où ils avoient paffé, \& les mettoient à difcretion de tous leurs biens.

La Capita- Goacanaric, Roi de Marien, avoit fa demeure 4. lieuës ne fe brife plus à l'Eft, dans le port du Cap-François, ainfi que je l'ai déjà cuieil. remarqué ; \& fa maifon étoit vis-à-vis de l'endroit, où eft préfentement la ville du Cap. Ce Prince charmé de tout ce qu'il entendoit dire des Etrangers nouvellement débarqués dans l'Ine, envoya faluer l'Amiral, \& le fit prier de vouloir bien fe tranfporter chés lui. Il accompagna fa priere de prefens confiderables; à fçavoir, d'une ceinture bordée d'os de poiffons travaillés en façon de perles, \& d'un mafque crné de plaques dun or très-fin, \& qui paroiffoit frapé au. marteau. Colomb répondit aux Députés du Roi, qu’il iroit inceffamment voir leur Maître; mais il jugea à propos de fe faire précéder par un Officier, qui eût ordre en même têms de vifiter le port, afin de voir fi fes navires y feroient en fûreté. Le 24 . 11 mit à la voile pour s'y rendre, \& comme il fe trouvoit extrêmement fatigué, ou incommodé, il s'alla d'abord jetter fur fon lit, après avoir bien recommandé au Pilote, de ne point quitter le gouvernail. Il fut mal obéi, le Pilote alla lui-même fe repofer, \& confia le timon à un jeune homme fans experience, qui fe laiffa engager dans des courans, lefquels l'entraînerent fur des bans de fable, où le navire échoüa. Le matelot, qui tenoit le gouvernail, fentant le fable fe mit à crier : au bruit qu'il fit, Colomb s'éveilla, \& füt fort furpris de trouver tous les pilotes endormis, il commanda fur l'heure de décharger le navire dans une barque, qui y étoit attachée, \& la plûpart des mą 


\section{de S. Domingue, Liv. II. 95}

telots y fauterent, mais au lieu de faire ce qui leur avoit été prefcrit, ils s'enfuïrent à une demie lieuë de-là, \& laif1492。 ferent l'Amiral dans un très-grand embarras. Il fit auffitôt couper le mât pour foulager le bâtiment, mais il ne pût réüflir à le remettre à flot, il s'ouvrit même d'abord, $\&$ il fallut fonger à fe fauver dans la chaloupe. Le banc fur lequel le navire avoit touché, étoit à l'entrée d'un port, qui eft à moitié chemin de Saint-Thomas, ou de l'Acul au Cap-François; les Efpagnols l'ont depuis établi fous le nom de Puerto Real, \& nous le connoiffons aujourd'hui fous celui de Baye de Caracole.

La caravele de Vincent Pinçon étoit une lieuë plus loin Conduite du que l'A miral, quand ce navire échoüa, dès qu'elle s'aper- Roi de Maçut de ce malheur, elle revira de bord, fit force de voiles, occafion. $\&$ arriva fort à propos, pour fauver l'équipage, dont peu de gens auroient échapé, fi la mer n'eût été extrêmement calme. Colomb fit auffi-tôt avertir Goacanaric du malheur, qui lui étoit arrivé, \& ce Prince accourut fur le champ avec fes freres lui témoigner la part qu'il y prenoit : on affûre même que les larmes lui vinrent aux yeux, en voyan: les triftes débris de ce naufrage; \& il eft certain qu'il rendit en cette occafion de grands fervices aux Efpagnols : il les fit aider par fes fujets à retirer les effets du navire, qui fe rempliffoit d'eau, il leur donna une maifon pour y tranfporter ces mêmes effets, \& il y pofa une fentinelle pour les garder, de forte que rien ne fut perdu, de ce que l'eau de la mer n’avoit pas abfolument gâté.

Quelques jours après il envoya encore faire compliment Les Euroe à l'Amiral, \& l'inviter à venir chés lui, où il tâcheroit, peans reçoiajouta-t-il, de lui faire oublier une perte, dont il fe repro- pour les plus chnit d'avoir été l'occafion. Colomb répondit qu'il iroit dès viles marque fes affaires le lui permettroient : mais le Cacique voyant qu'il tardoit trop, l'impatience le prit, il s'embarqua dans un canot, \& l'alla trouver à fon bord. Il lui renouvella fes offres de fervices, lui préfenta de l'or, \& fe chargea d'en faire venir de cibao, autant qu'il voudroit. A l'exemple du 


\section{$96 \quad$ H I s O I R}

1492.

Souverain, les Sujets témoignerent toute la bonne volonté poffible aux Caftillans, \& leur donnerent tout ce qu'ils a voient d'or pour des bonnets rouges, des fonnettes, des épingles, de la raffade, des chapelets de verre, \& autres femblables bagatelles. Jamais on ne connut mieux qu'en cette rencontre , combien le prix des chofes eft arbitraire, \& jufqu'où. va l'empire de l'opinion fur les hommes. Les Caftillans donnoient pour avoir de l'or, ce qu'en Europe les plus miferables ne s'aviferoient pas de ramaffer; des pots de terre caffés, des morceaux de verre \& de fayance; \& les Infulaires croyoient avoir fait un fi bon marché, qu'ils s'enfuyoient auffi-tôt, craignant que les Efpagnols ne fe ravifaffent.

I'Amital Enfin il n'eft pas poffible d'être plus content, qu'on

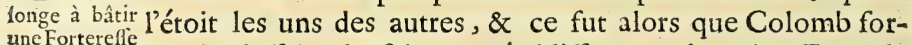
à Puerto ma le deffein de faire un établiffement dans les Etats de Real. Goacanaric. Quelques-uns fe font même imaginé qu'il avoit concerté avec fon Pilote le naufrage de fon navire, pour avoir un prétexte de laiffer dans l'Ifle une partie de fes gens. Car jufqu'où ne porte-t-on point la liberté des conjectures! Pour engager davantage le Cacique dans fes interêts, \& lui faire trouver bon qu'il bâtit une fortereffe fur fes terres, il s'attacha à lui faire plus de careffes que jamais, \& il le combla de préfens, qui, fans être fort magnifiques, charmerent ce Prince. Mais il crut devoir auffi lui infpirer de la crainte \& du refpect. Pour cela il fit tirer plufieurs coups de canon; ce qui faifit de telle forte les Infulaires, qu'à chaque coup ils tomboient par terre, comme fi la foudre les eût frappés. Goacanaric n'étoit pas moins effrayé que les autres, mais Colomb le raffûra, \& lui dit quavec ces armes il vouloit le rendre victorieux de tous fes ennemis. Pour l'en convaincre, il fit tirer un coup à boulet contre le navire échoüé ; le boulet perça le navire, \& alla tomber dans la mer; ce qui étonna fi fort le Roi de Marien, qu'il s'en retourna chés lui un peu réveur, \& perfuadé que ces Etrangers étoient les enfans du tonnerre.

Quelques 


\section{DE S. DOMINGUE, LIV. II.}

Quelques jours après l'Amiral, fur les nouvelles infances, que le Cacique lui en avoit faites, lui rendit enfin vifite. A la defcente de fa chaloupe, il rencontra un des Il vifite le freres du Prince, lequel après l'avoir complimenté, le con- rien, \& la réduifit dans une maifon, qu’on lui avoit préparée. A peine ception que y étoit-il entré, que Goacanaric l'y vint trouver, \& en fait. l'abordant il lui mit au cou une lame d'or. Ce prefent fut fuivi de plufieurs autres, \& accompagné de toutes les marques d'honneur \& d'amitié, dont ce Prince put s'avifer. Il fe retira enfuite, mais il revint bientôt, \& Colomb profita de cette occafion, pour lui faire part de fon deffein. Il lui dit donc qu'il penfoit à laiffer dans fes Etats, \& fous fa protection une partie de fes gens, tandis qu'il iroit en Europe chercher des marchandifes. Le Cacique reçut cette propofition avec un tranfport de joye, dont il ne fut pas le maître, \& ôtant de deffus fa tête une efpece de couronne d'or, qu'il portoit ordinairement, il la mit fur celle de l'Amiral. Des manieres fi bonnes, \& une conduite fi fimple acheverent de perfuader Colomb quil pouvoit compter fur le Roi Sauvage. Dès qu'il fut de retour à Puerto-Real, il fit travailler à une efpece de Fort, qui fut bientôt achevé, \& où il mit quelques pieces de canon. Il n'étoit que de bois des debris de la Capitane; mais on avoit creufé un affez bon foffé tout autour, \& l'on fe flatta que ç'en étoit affez pour tenir en refpect des gens tout nuds, fans armes, \& fort peu aguerris. Ce Fort fut nommé La Navedad, parce qu'on étoit entré le jour de Noel dans le Port, où il étoit bâti.

Sur ces entrefaites des Infulaires avertirent les Caftil. L'Amiral lans qu'ils avoient vî roder: un navire le long de la cô- reçoit desavis te vers l'Eft. L'Amiral ne douta point que ce ne fut laPinta, dont la défertion le chagrinoit bien plus depuis la perte de la Gallega. Il détacha aufitôt une chaloupe pour aller voir, fi cet avis étoit fondé, \& il remit à l'Officier, qui la commandoit, un billet pour Pinçon, par lequel il lui accordoit une amnittie en bonne forme, pourvû qu'il

Tom. $I$. 


\section{H I S T O I R E}

1493. le vint trouver fans délai. La chaloupe fit plus de 20 . lieuës fans rien trouver; ce qui donna lieu à l'Amiral de croire que la Caravelle avoit fait voile pour l'Erpagne, \& que Pinçon vouloit avoir l'honneur d'y porter les premieres nouvelles de la découverte de tant de beaux pays, s'en attribuer toute la gloire, \& prévenir le Roi \& la Reine contre lui. Ces foupçons le déterminerent à preffer fon départ, \& à remettre à un autre voyage la vifite des mines de Cibao.

Il laiffe ${ }_{3} 8$. Cette réfolution prife, il affembla tout fon monde, exhommes dans pofa la néceffité, où il fe trouvoit, de repaffer au plûtôt Iuerto Real. en Efpagne, \& combien il importoit au fervice de leurs Alteffes, qu'on n'abandonnât point le beau pays, qu'ils avoient découvert : que c'étoit ce qui l'avoit engagé à y conftruire un Fort, qu'il ne vouloit pourtant obliger perfonne d'y refter; mais que ceux, qui voudroient bien fignaler en cela leur zele pour l'Etat, ne demeureroient pas fans recompenfe, fans parler des avantages, qu'ils pourroient fe procurer par eux-mêmes au milieu de tant de richeffes. Comme il vit que cette propofition ne déplaifoit à perfonne, il choifit 38. hommes de ceux, qu'il crut les plus fages, leur donna de très-bons confeils fur la maniere, dont ils devoient fe conduire, leur recommanda furtout de fe fouvenir qu'ils étoient Chrétiens \& Caftillans, de ne point molefter les Infulaires, dont ils obtiendroient tout par amitié, de ne point fe debander, d'apprendre la Langue de ces Peuples, \& de ne rien négliger pour connoître le pays, afin de pouvoir linftruire lui-même à fon retour, qui feroit prompt. Il leur donna pour Commandant un Gentilhomme de Cordouë, nommé Rodrigue de Arana, leur laiffa du vin, du bifcuit, toutes les autres provifions néceffaires pour un an, \& afin qu'ils puffent faire un peu de traitte avec les Habitans, il leur abandonna tout ce qui lui reftoit de marchandifes, avec la chaloupe de la Gallega.

Tlpart pour

Il alla enfuite prendre congé de Goacanaric, qui lui fit un l'Efpague. prefent confiderable de caffave $\&$ de poiffons falés, \& confen- 


\section{DE S. Domingue, Liv. II.}

tit que quelques-uns de fes Sujets fiffent le voyage d'Europe. Il confia même à Colomb un de fes parens, \& lui promit 1493. d'avoir foin des Efpagnols, comme de fes propres enfans. Le quatriéme de Jạvier la Caravelle fortit de Puerto-Real, emportant affés d'or, pour faire concevoir de grandes efperances à la Cour d'Efpagne, une quantité de balles de cotton, \& beaucoup de piment. Il comptoit de faire un profit coni̊dérable fur cette derniere marchandife : \& en effet la feule jaloufie du Commerce, qui fut toûjours très-grande, depuis ce premier voyage de Colomb, entre les Efpagnols \& les Portugais, donna d'abord quelque cours au. poivre Amériquain; mais cela ne dura point: on s'apperçut bientôt que le piment étoit trop cauftique, \& il fut enfin rélegué dans le lieu de fa naiffance, où il n'eft pas même de mife fur les bonnes tables.

Colomb prit d'abord la route de l'Eft, dans le deffein de reconnoître toute la Côte de l'Ine Efpagnole. Des qu'il tunte la Côte eût paffé le Cap-François, il apperçut une montagne, qui lui paroiffoit avoir le pied dans la mer, c'eft une prefqu'Inle fort élevée, qu'il appella Monte Chrifto. Nos Cartes Françoifes lui ont confervé ce nom ; ceux qui croient que c'eft ce que nos Marins nomment la Grange, fe trompent: Monte Chrifto eft à trois lieuës au vent de la Grange, qui a été ainfi nommée, parce qu'en effet quand on découvre en mer cette monragne, on la prendroit pour une Grange bâtie fur le bord de l'eau. L'embouchure de l'raqué eft à côté de Monte Chrifto, \& l'Amiral, auquel on avoit dit que ce fleuve tiroit fa fource des Mines de Cibao, voulut le reconnoître; il y entra, \& il trouva que fon fable étoit mêlé d'un peu de pailles d'or, auff lui donna-t-il le nom de Rio del Oro; mais dans la fuite les Efpagnols lui ont rendu fon nom primitif, \& les François lui ont donné celui de Riviere de Monte chrifto. Ce fut alors, plus que jamais, que Chriftophle Colomb fe perfuada que fon Ifle Efpagnole étoit la veritable Cipango de Marc-Paul de Venife, \& la fuite fera voir combien il eur de peine à revenir de cette erreur, s'il en eft même jamais bien revenu.

T. I. 


\section{$100 \quad$ H I S T O I E}

Le Dimanche fixiéme il fortit de Rio del Oro, \& peu de

r493. 'têms après il découvrit la Pinta, qui venoit à lui. Le Capitaine

La Pinta en l'abordant, lui fit de grandes excufes de l'avoir quitté , rejoint l'Ami- \& protefta qu'il y avoit été contraint par le mauvais têms.

La fauffeté de cette excufe étoit de notorieté publique o mais la joie, dont fut pénétré l'Amiral, de fe voir délivré des inquiétudes, que lui avoit catrfées cette féparation, parue l'emporter fur fon reffentiment; il reçût les foûmiffions duz Capitaine, \& lui demanda ce qu'il avoit fait, \& où il étoit allé: Pinçon répondit qu'il étoit allé de Port en Port, qu’il avoit troqué fes marchandifes pour de l’or, dont il ávoit pris une moitié pour lui, \& avoit diftribué l'autre à fon équipage. C'étoit-là la matiere d'un procès, mais Colomb ne jugea pas à propos d'entrer pour lors dans cette difcuffion. Les deux Caravelles firent route de conferve, \& entrerent dans ın Port éloigné de 15 . lieuës de Monte Chrifto, \& où Pinçon avoit fait fa traitte. Il en avoit même enlevé de force trois ou quatre Infulaires, que l'Amiral l'obligea de remettre à terre : \& c'eft peut-être ce qui fir donner à ce Port le nom de Puerto di Gracia; mais la plûpart ont crû que c'étoit à caufe du pardon accordé à Pinçon, qui fut ratifié en ce lieu là. Oviedo raconte fort differemment, la rencontre des deux Caravelles, mais il eft aifé de reconnoître que cet Auteur, auffi bien que plufieurs de ce têms-là , eft affés peu fưr dans les chofes, qu'il rapporte fur le témoignage d'autrui, \& qu'il a trop donné dans les premiers bruits populaires, fouvent peu fondés, \& prefque toûjours mal cir conftanciés.

Suite de la Au fortir du Port de Grace, une montagne fort haute dácouvertede fe pséfenta aux yeux des Efpagnols, \& ils crurent d'abord rise. en voir le fommet couvert de néges: mais ils reconnurent bientôt que la blancheur, qui les avoit trompés, venoit dune pierre, qui couvroit toute la cime de la montagne, laquelle, pour cette raifon, fut appellée Monte di Plata; il y 3 au bas de cette montagne un joli Port, qui fut auff nom mé Pusto di plata: les François le nomment par corruption 
DE S. D O ING Ü, LIV. II. IOT Portoplarte. De-là Colomb; continuant à ranger la côte, donna à tous les Caps, qu'il aperçût, des noms, dont la plûpart 1493. ne font point venus jufqu’à nous. On prétend néanmoins, que celui, qu'on appelle aujourd'hui le vieux Cap, \& qui eft à 55 . lieuës du Cap-François, fut dès-lors nommé Cabo-Francés par Colomb. Trente lieuës plus loin les deux caravelles, après avoir tourné au Sud, fe trouverent vis-à-vis une grande Baye, où elles entrerent, \& que l'Amiral voulut faire vifiter par fa chaloupe. Elle eft formée par une prefqu'ine, que les Infulaires appelloient Samans, \& qui porte encore aujourd'hui ce nom, auffi bien que la Baye.

La chaloupe, en approchant de terre, aperçû́t quantité de Sauvages armés d'arcs \& de fléches, ce qu'on n'avoit pafla dans la point encore vî dans aucun endroit des nouvelles décou- mana. vertes. On alla à eux, \& on échangea quelques-unes de ces armes contre des bagatelles. Plufieurs de ces Barbares eurent la curiofité de voir les navires, \& on les y reçû́t bien. Colomb les queftionna beaucoup fur les mines d'or de $\mathrm{Ci}$ bao, \& fur les habitans des Inles, qu'ils avoient à l'Eft, dont le Roi de Marien avoit parlé aux Caftillans, comme d'une nation féroce \& anthropophage ; ils fatisfirent à ces queftions d'une maniere, qui fit plaifir, \& ils aprirent aux Efpagnols, qu'entre leur Ine \& celle de ces mangeurs de chair humaine, il y en avoit une autre appellée Boriquen, dont les habitans ne l'étoient point, \& où il y avoit de l'or, mais moins beau que celui de Cibao. On leur fit quelques préfens, \& on les renvoya.

Les Matelots, qui les remenoient dans la chaloupe, ou qui, pour quelque autre fujet, les accompagnoient à terre, furent affez furpris en aprochant de voir une bande de Sauvages avec leurs fiéches, cachés derriere des arbres. Ils appréhenderent quelque furprife, \& en débarquant, ils fe mirent fous les armes. Les Indiens, qui étoient avec eux, s'aperçûrent de leur défiance, \& coururęnt d'ábord vers leurs compatriotes, à qui ils firent mettre les armes bas: ils les engagerent même par le recit des careffes, qu'ils avoient: 
1493. reçûës des Caftillans, à s'aprocher d'eux. Ceux-ci de leur côté n'étoient pas encore bien raffûrés, lorfqu'ils virent les Infulaires fe parler tout bas. Leurs foupçons fe réveillerent alors, \& craignant d'être prévenus, ils fe jetterent fur les premiers, qu'ils rencontrerent fous leurs mains, \& les étendirent à leurs pieds, fans toutefois leur avoir fait beaucoup de mal. Les autres fe mirent auffi-tôt à fuïr, \& pour courir plus vîte, ils jetterent leurs armes. La paix fe fit pourtant encore une fois, par l'entremife des mêmes Mediateurs, \&: la Baye, en memoire de ce qui venoit de fe paffer, fut nommée la Baye des fléches. Mais elle n'a point retenu ce nom.

I'Amiral Le Cacique du lieu vint enfuite falüer l'Amiral fur fon fait routepour bord, \& il en fut très-bien reçu; quelques-uns de fes Sujets il efluye une voulurent même faire le voyage d'Efpagne, \& Colomb en grande tem- fut ravi. Cependant les deux équipages Caftillans s'enpête. nuyoient d'une navigation, qui ne laiffe pas d'avoir fes rifques, \& l'Amiral ne jugea pas à propos de la continuer plus long-têms. Le 16. de Janvier, il fit le Nord-Et, paffa à la vûë de Boriquen, \& découvrit même quelques unes des perites Antilles. Mais fans en approcher: enfuite, après avoir fait, par le plus beau têms du monde, 4. à 500 . lieuës en haute mer, il effuya une fi longue $\&$ fi furieufe tourmente, qu'un Jeudy I 4. de Fexrier, le naufrage parut inévitable. On fit coup fur coup plufieurs voux, dont le dernier fut d'aller nuds pieds, \& en chemife en Proceffion à l'Eglife de la Vierge, la plus proche de l'endroit, où les deux bâtimens prendroient terre. Colomb de fon côté s'avifa d'une invention affez finguliere, pour conferver la mémoire de fes découvertes, au cas qu'il pérît par la tempête. Il fit en peu de lignes une relation de fon voyage, l'écrivit fur dı parchemin, \& l'enferma dans une barrique bien fermée, qu'il jetta à la mer. En quoi il me femble qu'il n'agit pas avec fa prudence ordinaire, car toute autre Cour, que celle d'Efpagne pouvoit par-là être informée, de ce qui ne devoit être fçû que des Rois Catholiques, \& en profiter à leur préjudice. 


\section{DE S. Domingue, LIv. II. Io3}

Mais enfin le Ciel, qui le réfervoit à de grandes chofes, le délivra de ce danger; la mer fe calma, \& le Lundy dix-huitiéme il fe trouva aux aterrages de l'Ifle Sainte Marie, qui eft une des Açorres. Dom Jean de Caftañeda, çorres. qui commandoit dans cette Ifle; n'eut pas plûtôt appris l’arrivée de l'Amiral, qu'il l'envoya complimenter. Mais cette politeffe n'empêcha point Colomb de fe tenir fur fes gardes, \& bien lui en prit. Il fe croyoit obligé de s'acquitter de fon vœu en ce lieu-là, \& ayant fçû qu’affez près de la ville, il y avoit un Hermitage avec une Chapelle dediée à la Mere de Dieu, il y envoya une partie de fes. gens, réfolu d'y aller lui-même avec le refte, après leur retour. Comme ils tardoient beaucoup à revenir, il voulut fçavoir ce qui en étoit caufe, \& il apprit qu'ils avoient tous été arrêtés. Il en porta fes plaintes au Gouverneur, qui lui fit une reponfe très.fiere, \& fi nous en croyons Dom Fernand Colomb, fort infultante pour les Rois Catholiques. Il baiffa néanmoins le ton, quand l'A miral l'eut: menacé de reprefailles; il lui renvoya même fes gens, de qui Colomb apprit qu'il y avoit un ordre du Roi de Portugal de l'arrêter, \& que Caftañeda étoit fort chagrin de lavoir manqué.

Dès le commencement de la tempête, qui avoit jetté l'Amiral fur les côtes des Açorres, la Pinta avoit difparu, $\&$ tout le monde la crut perduë. Le vingt quatre Colomb s'éloigna de Sainte Marie, \& le fecond de Mars n'étant gueres qu’à Ioo. lieuës des côtes d'Erpagne, il fut affailli d'une feconde tourmente, qui ne fut, ni moins longue, ni moins rude que la premiere, \& qui le jetta fur les côtes. de Portugal. Le vent étoit devenu affez bon pour continuer fa route vers l'Efpagne, mais la mer étoit fi groffe, qu'il. fut obligé d'entrer dans la riviere de Lisbonne, d'où il dépêcha un courrier à la Cour d'Erpagne; après quoi il envoya: demander au Roi de Portugal la permiffion de moüiller dans le Port de fa Capitale. Il l'obtint, mais à peine eut-il jetté les ancres, qu'un Pilote vint lui fignifier l'ordre d'al- 


\section{ro4. H I S TOI R E}

1493. ler faire fa déclaration devant le Commandant du Port \& \&

les autres Officiers du Roi. Il répondit qu'il étoit Amiral d'Efpagne, \& qu'en cette qualité il ne devoit rendre compte à perfonne. On voulut l'engager à envoyer au moins quelqu'un de fa part; il le refufa, en difant que ce feroit la même chofe, d'y aller lui-même, ou d'y envoyer. On lui demanda à voir fes Patentes, il les montra, \& le Pilote Portugais n'eut pas plûtôt fait fon rapport, que Dom Alvare d'Acuña, qui étoit apparemment le Commandant du Port, vint au fon des trompettes \& des haut-bois le faluer à. fon bord, \& lui faire offre de tout ce qui dépendoit de lui.

Honneurs qu'il reçoit du Roi de PorEugal.

Cependant le bruit de fon arrivée, ne fe fut pas plûtôt répandu dans Lisbonne, que toute cette grande ville fut en rumeur, \& le Port couvert de barques, chacun voulant voir des hommes venus d'un nouveau monde, \& apprendre le détail d'un fi grand évenement. Le lendemain 7. de Mars, Colomb reçût une lettre du Roi D. Jean, qui le prioit de ne point partir, qu'il ne l'eût vû, l'invitoit à aller fe repofer à Sacaban, \& lui donnoit fa parole Royale, qu'il ne lui feroit fait aucune violence. Colomb délibera quelque têms fur ce qu'il avoit à faire ; il fe détermina enfin à contenter le Roi, qui lui fit faire partout des réceptions magnifiques. Le jour fuivant il alla trouver le Roi à Valparaîfo : prefque toute la Cour füt au-devant de lui par ordre de ce Prince, qui lui fit un acceüil très-gracieux, le fit affeoir \& couvrir, s'entretint long-têms avec lui fur les particularités de fon voyage, \& lui dit que, fuivant les conventions faites entre les Couronnes de Caftille \& de Portugal, les nouvelles découvertes devoient toutes lui appartenir. Colomb n'eût pas de peine à le détromper : tout le refte de l'Audiance fe paffa en politeffe de la part du Prince, \& l'on fut furpris de voir que ce Pilote, que, quelques années auparavant, on avoit regardé comme un homme de néant, \& qui fe repaiffoit de chimeres, répondoit à tout avec la dignité d'un Amiral \& d'un Vice-Roi , \& parloit toûjours fort fenfément.

Son arrivée en Efpagne.

Ce fut alors, qu'on fentit tout le tort, qu'on avoit eû de ne point 


\section{de S. Domingue, Liv. II. Tós}

point l'écouter, \& le dépit de voir fi heureufement exécuté, à l'avantage des Efpagnols, un projet, qu'on avoit rejetté avec tant de mépris, fut $\mathrm{fi}$ vif en quelques-uns, qu'ils s'offrirent au Roi d'en poignarder l'auteur, \& de lui enlever fes papiers. Mais ce Prince eût horreur d'une telle propofition; il donna ordre au Prieur de Crato de loger l'Amiral, eût avec lui le ıo. une feconde converfation très-longue, lui fit les offres de fervice les plus obligeans, \& le congédia comblé d'honneurs. L'onziéme, Colomb vit encore le Roi, qui le fit reconduire jufquà Lisbonne, par D. Martin de Norogna, \& quantité de Seigneurs lui firent efcorte. Il vit la Reine en paffant à Villa-Franca, \& il étoit à peine arrivé à la Capitale, qu'un Officier vint lui dire de la part du Roi, que s'il vouloit faire le refte du voyage par terre , fon Alteffe le feroit efcorter jufqu'à la frontiere, \& lui fourniroit generalement toutes les chofes, dont il auroit befoin. Il reçut ces offres comme il devoit, mais il ne les accepta point, \& le r 3. il fit voiles pour l'Efpagne. Il eût le vent fi favorable, que le Is. qui étoit un Vendredy, il entra dans la riviere de Saltes, dont l'embouchure forme le Port de Palos : il en étoit forti fept mois \& douze jours auparavant, \&ilavoit fait dans une efpace de têms fi court, le plus grand voyage, qui eût été entrepris en pleine mer, de mémoire d'homme.

Son arrivée fut annoncée par le fon des cloches, \& la La Pinta joye, que caufa un fi prompt \& fi inefperé fuccès, fut dans arrive en mêtles premiers momens tellement fufpenduë par la furprife, me têms que qu'on avoit encore de la peine à croire poffible un deffein, avoir été fédont on voyoit l'heuré par la dont on voyoit l'heureux accompliffement. Selon quel-premiere ques auteurs la Pinta, que la premiere tempête, dont nous tempéte. avons parlé, avoit féparée de l'Amiral, ayant pris terre à Bayonne, \& de là étant allé en Galice, Pinçon, qui la commandoit, fe rendit en droiture à Barcelonne, dans le têms que Colomb étoit encore à Palos; mais le Roi, à qui il fit demander audiance, refufa de l'écouter, ce qui lui caufa un fi grand chagrin, que s'en étant allé chés lui, Tom. $I$. 


\section{HISTOIRE}

1493. il y mourut en peu de jours. D'autres ont écrit que de Bayonne, il alla droit à Palos, où il arriva le même jous que l'Amiral, que cette rencontre, à laquelle il ne s'étoit pas attendu, le chagrina d'autant plus, que Colomb s'étoit plaint que fa défertion l'avoit empêché de vifiter les mines de Cibao, d'où il auroit apporté en Efpagne autant d'or, qu'il auroit voulu. Qu'ainfi, malgré le pardon, qu'il avoit obtenu, il craignit d'être arrêté dans Palos: qu'il en fortit fur le champs, \& y revint, dès qu'il fçût que l'Amiral en étoit parti ; mais fi malade, qu'il mourut bientôt après.

Reception Quoiqu'il en foit, Colomb fut reçầ à la defcente de fon qu'on lui fait 2 Palos. navire, avec les mêmes honneurs, qu'on auroit faits au Roi même; les boutiques furent fermées, \& les cloches recommencerent à fonner au moment, qu'il parut dans fa chaloupe. Il reçût ces marques de diftinction, \& les applaudiffemens des peuples avec modeftie \& avec dignité, \& la premiere chofe, à quoi il penfa, quand il fut en liberté, fut d'écrire au Roi \& à la Reine, qui étoient à Barcelonne, \& de leur envoyer un mémoire exact \& fuccinct de fon voyage. Il partit enfuite pour Seville avec fept Infulaires, de dix qu'il avoit embarqués : deux étant reftés malades à Palos, \& un troifiéme étant mort fur mer. Il reçût à Seville une lettre de leurs Alteffes, avec cette Infcription: A Dom Christo. phle Colomb, notre Amiral sur la mer Oceane, ViceRoy et Gouverneur des IsLes, Qui ONT E'T E' DE'COUVERTES DANS LES INDES. La lettre étoit remplie des marques les plus flateufes, \& des affûrances les plus finceres de biénveillance, d'eftime, \& de reconnoiffance; \& après bien des complimens fur le fuccès d'une entreprife, qui n'avoit point encore eu de femblable, depuis la fondation de la Monarchie, Ferdinand \& Ifabelle lui recommandoient de Pourquoi fe rendre auprès de leurs perfonnes, fitôt qu'il auroit reglé Yamérique toutes chofes à Seville, pour continuer fes découvertes.

porte le nom L'Amiral répondit à cette lettre d'une maniere très-modefte:

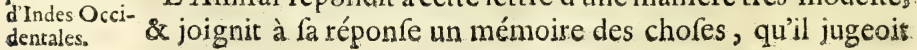




\section{DE S. Domingue, Liv. II. Tog}

inéceffaires pour un fecond voyage aux Indes. Car c'eft ainfi, qu'on commença dès-lors à nommer le pays nouvellement découvert, non feulement par émulation contre les Portugais, qui s'étoient frayé depuis peu un chemin aux Indes Orientales, dont ils avoient commencé la Conquête ; mais encore parce que Chriftophle Colomb étoit tốjours convaincu, \& avoit perfuadé aux Efpagnols, que les Inles, d'où il venoit, étoient l'extrêmité de ces mêmes Indes, où le grand Alexandre avoit porté fes armes victorieufes, \& où les Portugais fe faifoient à l'autre extrêmité, un fi. grand empire; qu'elles n'étoient pas fort éloignées du Gange, \& que l'Inle Éfpagnole étoit le Cipango de Marc-Paul de Venife.

Dès qu'il eût fait partir fa lettre, il fe mit lui-même en chemin pour Barcelonne, \& tout ce voyage fut pour lui un continuel triomphe. Les grands chemins \& les campagnes retentiffoient des acclamations des Peuples, qui quittoient tout pour le voir. On fortoit au devant de lui de toutes les villes, par où il devoit paffer, \& on ne fe laffoit point de regarder cet homme rare, qui par des routes inconnues à toute l'antiquité, avoit fçû trouver un monde nouveau. Les Indiens, qui l'accompagnoient; car je les appellerai déformais ainfi, pour me conformer à l'ufage de tous les hiftoriens ; les Indiens, dis-je, ne laiffoient pas d'avoir beaucoup de part à la curiofité des Peuples. La différence de leur couleur, de leur traits, de leurs manieres, faifoir prefque juger que c'étoit des hommes d'une autre nature, que la nôtre, \& les gens de la fuite de l'Amiral ne pouvoient fuffire à répondre à toutes les queftions, qu'on leur faifoit fur toutes les avantures de leur voyage.

Chriftophle Colomb arriva à Barcelonne vers le milieu Son Entrée d'Avril, \& il eft vrai de dire qu'on n'avoit encore rien vû en Efpagne, qui reprefentât mieux le triomphe des anciens Romains, que fon entrée dans cette grande ville. Tous les Courtifans fuivis d'un peuple innombrable, allerent au-devant de lui fort loin dans la campagne; 2 après qu'il eut 


\section{I08 H I S T O I R E}

1493. reçû les complimens, qui lui furent faits de la part du Roi \& de la Reine, il marcha jufqu'au Palais en cet ordre. Les fept Indiens paroiffoient les premiers, \& ornoient d'autant mieux fon triomphe, qu'eux-mêmes ils y prenoient part; au lieu que les Triomphateurs Romains fondoient en partie la.gloire du leur fur la mifere de ceux, qu'ils traînoient après leur char. On voyoit enfuite des couronnes \& des lames d'or, qui n'étoient pas le fruit de la violence $\&$ de la rapacité du foldat victorieux; des balles de cotton, des caiffes remplies d'un poivre, qu'on croyoit al moins égal à celui de l'Orient; des Perroquets, qu'on portoit fur des rofeaux de 25 . pieds de haut, des dépoüilles de Caymans, \& de Lamentins, qu'on publioit être les veritables Syrenes des anciens, des quadrupedes, \& des oifeaux de plufieurs efpeces inconnuës, \& quantité d'autres raretés, que la nouveauté rendoit précieufes. Tout cela étalé aux yeux d'un peuple, dont l'imagination \& la vanité portent ordinairement les chofes au-delà du naturel, fembloit le tranfporter dans ces nouvelles regions, d'où il fe flattoit de voir bientôt couler des richeffes inépuifables dans le fein de lEfpagne. Aufri entendoit-on les acclamations redoubler à chaque inftant, \& jamais homme n'eut peutctre des momens plus flatteurs, ni un jour plus glorieux: fur tout, s'il raprochoit, comme il ne pouvoit gueres manquer d'arriver, fa fituation préfente de celle, où il s'étoit vû quelques mois auparavant.

Son AudianIl fut ainfi conduit à travers une bonne partie de la vilse du Roy 8 de la Reine. le à l'audiance des Rois Catholiques, qui l'attendoient en dehors du Palais revêtus des Habits Royaux, fous un dais magnifique, le Prince d'Éfpagne à leur côté, \& aus milieu de la plus brillante Cour, qu'on eût vû de longtêms dans ces Royaumes. Dès qu'il aperçut leurs Alteffes, il courut fe profterner à leurs pieds, \& leur baifer la main; mais Ferdinand lui fit figne auffitôt de fe relever, \& lui commanda de s'affeoir fur une chaife, qui lui avoit été préparée; après quoi il reçut ordre de raconter à haute 


\section{De S. Domingue, Liv. II. rog}

voix, ce qui lui étoit arrivé de plus remarquable. Il obéit, \& il parla avec tant de réferve, \& d'un air fi noble, qu'il charma toute l'Affemblée, \& que ceux même, qui commençoient à le regarder avec des yeux jaloux, ne purent lui refufer leur eftime, ni fe difpenfer de lui en donner des marques publiques. Tout le monde fe mit enfuite à genoux, à l'exemple du Roi \& de la Reine, \& le Te Deum chanté par la Mufique de la Chapelle termina l'Audiance.

Les jours fuivans le Roi ne parut point dans la ville, qu'il n'eut le Prince fon fils à fa droite, \& Colomb à fa gauche. A l'exemple du Souverain tous les Grands d'Efpagne s'étudierent à l'envi à combler d'honneurs l'Amiral ViceRoy, \& le Cardinal de Mendoze l'ayant invité à manger, lui donna la premiere place, le fit fervir à plats couverts, \& fit effayer tous les mets, quon lui préfenta ; ce que prefque tous les Grands imiterent dans la fuite. Ses deux Freres Barthélemy \& Diego, quoiqu'ils ne fuffent pas alors dans le Royaume, eurent aufi part aux liberalités du Roi. le titre de Dom leur fut accordé, \& toute la Famille obtint des Armoiries magnifiques. Au premier de Cantille. Au fecond de Leon. Au troifiéme, une mer d'azur femée d'Ifles d'argent, la moitié de.la circonférence environnée de la terre ferme, des grains d'or répandus partout, les terres \& les Inles couvertes d'arbres toûjours verds; au quatriéme d'azur à quatre ancres d'or, \& en deffous les armes des an 60. premiere Carte de lifie $p_{3}$ ciens Colombs de Plaifance, \& pour cimier un globe fur. monté d'une croix, avec cette devife:

Por Cafilla, y por Leon.

Nuevo mundo hallo Colon.

C'eft à dire, Colomb a découvert un nouveau monde, pous les Couronnes de Caftille \& de Leon.

La principale attention des Rois Catholiques, fut enfuite de donner avis au Souverain Pontife de la découverte du nouveau monde; car on ne craignoit point d'appeller dèslors ainf une demie douzaine d'Ifles, qu'on avoit trouvées, \& à fupplier fa Sainteté de leur en accorder le Domaine. 
I493. Ce n'étoit pourtant qu'une cérémonie de bienféance ; Fer dinand \& Ifabelle étoient bien perfuadés, qu'ils n’avoienc pas befoin de la permiffion du S. Pere, pour pofféder legitimement les nouvelles acquifitions, \& l'hiftorien Herrera, dit en termes formels, que des perfonnes éminentes en fçavoir, qu'on avoit confultées fur ce point, l'avoient ainfi décidé. D'ailleurs, bien des gens en Efpagne s'étoient déjà infatués de l'opinion, dont j'ai déjà parlé, que ces Inles avoient autrefois appartenu aux Efpagnols.

Mais on fut bien aife de donner cette marque de foûmiffion au Saint Siege, occupé alors par un Sujet de la Couronne d'Arragon, \& dont on fe tenoit bien affûré. C'étoit Alexandre VI. lequel, après avoir rendu de folemnelles actions de graces à Dieu, pour un évenement fi fingulier, \& qui ouvroit une fi belle porte à la publication de l'Evangile, accorda tout ce qu'on lui demandoit. Et ce fut alors que pour prévenir tous les différens, qui pourroient naître tous les jours entre les Couronnes de Caftille \& de Portugal, au fujet des nouvelles découvertes; ce Pontife fit tracer cette célébre Ligne de Démarcation, qui partageoit entre ces deux Couronnes tous les pays découverts, \& ceux qu'on découvriroit dans la fuite, qui ne feroient poffedés par aucun Prince Catholique.

Ce qu'on entendoit par Ligne de Démarcation, étoit une ligne imaginaire, tirée d'un Pole à l'autre, laquelle coupoit en deux parties égales, l'efpace, qui fe trouve entre les Inles Açorres \& celles du Cap-Verd. Tout ce qui étoit au Couchant de cette Ligne, devoit appartenir à la Couronne de Caftille, \& tout ce qu'on trouveroit à fon Orient, étoit concedé au Roi de Portugal. Depuis, par un accord fait entre les deux Couronnes, cette Ligne fut reculée de 370 . lieuës à l'Oueft; mais dans les Bulles du Pape, où étoit exprimée cette donation, il étoit formellement déclaré que cette liberalité du S. Siege n'auroit lieu, qu'autant que les deux Souverains auroient foin de faire inftruire les habitans de ces nouvelles conquêtes des principes de notre fainte Religion. 


\section{DE S. Domingue, Liv. I. III}

Les Decrets Apoftoliques arriverent en Efpagne dans le têms, que l'Amiral avoit déjà reçû fes dépêches pour fon retour aux Indes, avec un Brevet particulier, en vertu du- leges de l'Aquel il devoit commander la flotte jufqu'à l'Ifle Efpagnole; miral font car pour le retour, elle devoit être fous les ordres d'Antoine de Torrés. On y avoit joint de nouvelles Patentes en confirmation de celles, que nous avons rapportées plus haut. Les voicy.

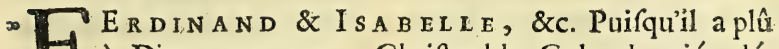
à Dieu, que vous, Chriftophle Colomb ayiés dé* couvert les Ifles, que nous avons nommées dans nos Lettres: nous vous confirmons les Priviléges, que nous vous - y avons accordés, vous reconnoiffant Amiral de l'Ocean, $\rightarrow$ depuis les Ifles Açorres jufqu’à celles du Cap Verd, \& du „Septentrion au Midy, Vice-Roy \& Gouverneur perpetuel de toutes les Terres, que vous avés découvertes, \& que » vous découvrirés. Voulons que vos Charges paffent pour s toûjours à vos enfans de l'un à l'autre, avec tous les hon* neurs, prérogatives, droits \& émolumens, qui y font s attachés, \& qui ont appartenu à nos Amiraux de Caftille \& de Leon. Vous donnons pouvoir de mettre tels Offi» ciers, Juges \& Capitaines, que vous jugerés à propos, * pour tel têms, que vous voudrés, \& de les caffer quand * il vous plaira; à condition néanmoins, que les provifions, * que vous leur donnerés, feront en notre nom, \& fcellées » de notre Cachet. Voulons de plus qu'en la qualité, que » nous vous donnons d'Amiral de l'Ocean, vous puiffiés „ commander à ceux de nos Vaiffeaux, que vous trouve» rés dans l'étenduë de nos mers, que vous leur ordonniés » de vous obéir, \& de vous donner tout ce que vous leur $\rightarrow$ demanderés, fous les peines que vous leur impoferés, \& * que nous tenons dès à préfent pour bien impofées. En» joignons à tous ceux, qui font $\&$ feront dans les Indes, w d'y demeurer ou d'en fortir, quand vous leur ordonnerés, s nonobftant appellation, \& fans qu'il foit befoin pour vous 
1493. „ faire obéir, d'autres Lettres que des Préfentes. Nous coms mandons à notre Chancelier \& à tous les Gens tenant s notre Sceau, de vous expedier au plûtôt nos Lettresconw tenant la confirmation de vos Privileges, en telle forme s que vous voudrés, à peine de notre difgrace, \& de trente w ducats d'amende contre chacun des contrevenans. Car s telle eft notre volonté. D O N N à Barcelonne le 28 , de * May 1493. Signé Moy Le Ror, Moy La Reine.» « Moy Fernand Alvarez de Tolede, Secretaire d'Etat, ai - fait expedier les Préfentes par le Commandement de leurs Alteffes.

Baptême Les honneurs, dont toute la Cour s'empreffoit à comdes premiers bler l'Amiral, ne le retinrent pas à Barcelonne un feul
Indiens. jour au delà du têms, que fes affaires demandoient, qu'il y reftât; $\&$ on lui a toûjours rendu cette juftice, que fon devoir \& le fervice de fon Prince l'ont uniquement occupé toute fa vie; mais il fouhaita pourtant de voir fes Indiens baptifés avant fon départ. Il avoit eû un très-grand foin de les faire inftruire, \& la cérémonie de leur Batême fe fit avec beaucoup d'apareil. Le Roi , la Reine, \& le Prince d'Efpagne voulurent offrir eux-mêmes à Dieu ces prémices de la Gentilité du Nouveau-monde. Le parent de Goacanaric fut nommé Dom Ferdinand d'Arragon, \& eut le Roi pour Parrain. Un autre fut nommé Dom Jean de Caftille par le Prince, à la Cour duquel il refta, \& mourut au bout de deux ans. Les autres retournerent dans leur pays. Le zele des Rois Catholiques les porta enfuite à prendre des mefures pour la publication de l'Evangile dans leurs nouvelles conquêtes, \& ils firent choix d'un nombre de Religieux \& d'Ecclefiaftiques, qui eurent tous pour Superieur le P. Boyl Benedictin Catalan, auquel le Pape donna des Pouvoirs très-étendus, afin qu'il pût exercer avec plus de liberté , \& de dignité les fonctions de fon Miniftere.

On fait un. Tout étant ainfi reglé, l'Amiral eut fon Audiance de

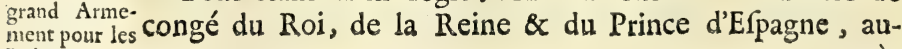
Indes

près 


\section{DE S. DOMINGUE, LIV. II. IT3}

près duquel il laiffa fes deux fils en qualité de Pages, \& fe rendit à Seville, où il trouva la flotte, qu'il devoit commander, toute prête, bien fournie d'Artillerie, \& de munitions de guierre $\&$ de bouche, non feulement pour le voyage, mais encore pour les colonies, qu'il jugeroit à propos d'établir. On y avoit auffi embarqué grand nombre de chevaux d'Andaloufie, des ferremens de toute efpece, des inftrumens pour travailler anx mines, \& pour purifier l'or, des marchandifes pour la traite \& pour les prefens, du froment, du ris, des graines de toutes fortes de legumes; enfin généralement tout ce que l'on peut defirer dans un nouvel établiflement. Plus de 1500 . volontaires, la plûpart Gentilshommes, \& quelques-uns même d'une naiffance diftinguée, voulurent faire le voyage ; \& plufieurs le firent à leurs frais. Le nombre en auroit même été plus grand, fi la flotte, qui n'étoit que de 17. navires mediocres, avoit pû les porter. Ce fut la Reine, qui défraya la plûpart de ces paffagers; \& cette Princeffe fit encore la dépenfe d'envoyer aux Indes un bon nombre d Ouvriers. Enfin on peut dire que de la part des Princes \& des fujets; il n'y eut jamais plus d'ardeur pour aucune expedition : auffi tous,jufqu'aux Matelots \& aux Manœuvres, fe croyoient affürés de faire une fortune prompte, \& des plus éclatantes.

Le vingt-cinquiéme de Septembre la flotte fortit de Départ dẹ grand matin de la Baye de Cadix , \& le cinquiéme d'Octo- la flotte.

bre elle entra dans le Port de la Gomera, une des Canaries, où elle demeura deux jours pour faire de l'eau $\&$ du bois. L'Amiral y acheta auffi des veaux, des chevres, des moutons des pourceaux, \& de toutes fortes de volailles, pour les faire multiplier dans linle Efpagnole, comme il eft arrivé, au-delà même de fes efperances. Il fe fournit encore de divers plans d'arbres , \& de toutes les graines qu'il put trouver, \& avant que d'apareiller, il donna à chaque Commandant de navire une inftruction par écrit, mais cachetée, fur ce qui fe devoit faire au cas qu'une tempête, ou quelque accident pareil le feparât de la flotte, avec Tom. $I$. 


\section{HISTOIRE}

1493. défenfe de louvrir, s'il n'arrivoit rien de pareil. Les Hiftoriens ne nous apprennent pas la raifon de cette façon d'agir fi myfterieufe.

Découverte Le fept d'Octobre on mit à la voile, l'Amiral prit un de plufieurs peu plus au Sud, qu'il n'avoit fait l'année précedente, \& Antilles. après une très-heureufe navigation tous les vaiffeaux $\mathrm{fe}$ trouverent un Dimanche troifiéme Novembre à la vûë d'uLa Domini- ne Ifle, que la circonftance du jour fit nommer la Domique.

nique. Oviedo \& quelques autres prétendent avec affez de vrayfemblance, qu'on en avoit déjà découvert une autre Ia Deffeada que l'empreffement où l'on étoit de voir la terre, avoit fait nommer la Defirée. Une troifiéme ayant paru un peu. Marigalante. au large, l'Amiral l'appella Marigalante, du nom du navi$r e$, quil montoit, \& envoya un Officier en prendre pofferfion. Le lendemain il en reconnut une quatriéme, qui fut

Ia Guada- nommée la Guadaloupe, en memoire d'une Eglife de ce loupe.

nom fort célébre en Catalogne. Il envoya auffi la reconnoître de près, \& lon fut affez furpris de trouver fur fon rivage une piece de navire, qu'on jugea avoir été travaillée en Europe. On y rencontra aufi quelques Indiens des deux fexes, que les habitans avoient enlevés nouvellement de l'Ille Boriquen, \& qu'ils avoient abandonnés à la vûë de la chaloupe, pour fe fauver plus aifément. Ces pauvres malheureux prierent les Efpagnols de les embarquer avec eux, leur montrerent les triftes reftes de leurs compatriotes, quê les Barbares avoient mangés, \& les aftûrerent qu'un pareil fort ne leur pouvoit manquer, fi on ne leur accor: doit la grace, qu'ils demandoient, \& qu'ils obtinrent.

Monterrat, Montferrat, Antigoa \& plufieurs autres Inles furent déAntigoa. couvertes les jours fuivans. La premiere prit fon nom de Notre-Dame de Mont-Serrat près de Barcelonne; \& la feconde de Notre-Dame l'Antique de Seville. Chriftophle Colomb n'oublia pas le Saint, dont il portoit le nom, \& Saint Chrif-appella: Saint Chriftophle la belle Ifle, qui le conferve encosophle.

re aujourd hui. Il rangea enfuite toute la côte de Boriquen, qu'il appella l'Ifle de Saint fean-Baptifte. On ajoûta depuis ঐे 


\section{DE S. DOMINGUE, Liv. IT. ITS}

ce nom, celui de Puerio Ricco, \& nous la connoiffons en France fous celui de Porcoric. Colomb s'y arrêta quelque têms dans une Baye, où il trouva des maifons mieux bâties, qu'il n'en avoit vû dans l'Ine E pagnole. Enfin le 22. de Novembre il entra dans la Baye de Samana, où il moüilla l'ancre, \& il y débarqua un de fes Indiens, dont il n'a jamais entendu parler depuis, quelque diligence, qu'il ait faite pour en apprendre des nouvelles. Il savança jufqu'à Monte Chrifto, où ayant envoyé fa chaloupe à terre, elle ne rencontra perfonne: on aperçut feulement fur le rivage deux cadavres étendus, \& tellement confumés, qu'on ne put diftinguer fi c'étoit des Infulaires ou des Caftillans, ils avoient encore au cou des efpeces de cordes, faites avec des herbes, ce qui fit juger qu'ils avoient été étranglés.

Le 27 . la flotte alla jetter un ancre à l'entrée de Puer- Il trouve $f_{a}$ to-Real, un peu plus bas que l'endroit, où avoit été la colonie ruiFortereffe. Et d'abord deux Indiens parurent dans un Ca- gens morts. not, \& s'aprocherent de la Capitane en criant, Almirante. On les invita à venir à bord, mais ils le refuferent, jurqu'à ce qu'ils euffent vû l'Amiral. Colomb fe montra , \& ils aborderent auffitôt fans aucune crainte. Iks le faluerent de la part de Goacanaric, \& lui firent au nom de ce Prince un fort beau prefent en or. Il leur demanda des nouvelles de fes gens, \& ils répondirent, que quelques-uns étoient morts de maladie, \& que les autres étoient entrés plus avant dans le pays avec des femmes. L'Amiral leur fit donner quelques bagatelles, les chargea d'un prefent plus confiderable pour le Cacique leur maitre, \& les renvoya. Le lendemain toute la flotte entra plus avant dans le Port, \& le premier fpectacle,qui s'offrit aux yeux des Caftillans, ce furent les ruines de la Fortereffe. Colomb envoy a fur le champs vifiter cette mafure, \& l'on n'y trouva perfonne. En avançant un peu plus dans les terres, on aperçut trois ou quatre Indiens, qui prirent d'abord la fuite; quelque têms après on vir de la terre tout fraîchement remuée, on y foüillas 


\section{I6 H I s T I R E}

149.3. \& l'on y trouva des corps tout récemment enterrés. Ils étoient habillés, \& ce fut la feule marque, à laquelle on re: connut qu'ils étoient Efpagnols.

Difcours du . Tandis qu'on déliberoit fur le parti, qu'il y avoit à prenfrere de Goa- dre dans une conjoncture, qui ne laiffoit pas d'être embamiral. raffante, un frere du Roi de Marien arriva avec une affez nombreufe fuite. Il falua d'abord l'Amiral d'un air trifte, puis il lui parla en ces termes:Dom Fernand Colomb affüre que ce fut en Efpagnol, ce qui ne paroît pas vraifemblable. « Vous étes fans doute furpris, Seigneur, de voir s votre Fortereffe en l'état, où elle eft, \& de ne retrou» ver aucun de vos gens, \& peut être avez vous déjà foup» çonné mon frere de vous avoir trahi; mis écoutés-moi » un moment, \& vous avoüerez que Goacanaric a été de^ puis votre départ le plus fidéle de vos amis, \& le plus, n malheureux de tous les hommes. A peine vos fujets * vous eurent perdu de vûë, que la diffention fe mit parmi s eux. Tous vouloient commander, \& perfonne ne vouso loit obéir. Chacun alloir, où bon lui fembloit, \& parw tout, où ils portoient leurs pas, ils exerçoient fur les - habitans toutes fortes de violences, enlevoient de force w tout l'or, quils trouvoient, ravifoient les femmes, quils » rencontroient, \& commettoient fans honte des difolus rions \& des brigandages inouis. Iandis qu'ils ne s'attas querent qu'aux peuples foumis à mon frere, il n'y eut o rien à craindre pour eux, nous ne fongions qu’à éviter * leur rencontre, \& nous efperions que vous reviendriez » bientôt faire ceffer un defordre fi criant; mais quand une so fois ils furent entrés fur les terres des autres Caciques, » ils eurent à faire à des gens, qui ne les menagerent » point, \& de tous ceux, qui furent trouvés à l'écart, pas un * feuln'échapa. Quelques-uns pénétrerent jufqu’aux mines s de Cibao, qui font dans les Etats d'un Cacique, nommé - Caonabo, lequel après les avoir maffacré tous, vint afw fieger la Fortereffe. Il n'y reftoit que quatre hommes s avec le Commandant : ils s'y défendirent quelque têms 


\section{DE S. DOMrngue, LIIV. II. II}

* avec bien de la valeur; mais vne nuit le Cacique s'é-

w tant avifé de metrre le feu en plufieurs endroits, il ne

2. fut pas poffible de l'éteindre. Les affiegés fe fauverent du

» côté de la mer, \& fe noyerent en voulant paffer à la na* ge de l'autre côté du Port. Mon frere, au premier bruit du

» liege,arma en diligencepour fecourir fes amis \& fes alliés;

* mais il arriva trop tard: il trouva Caonabo maître de tout.

» N'ayant pû délivrer les Efpagnols, il voulut les venger. Il li-

s vra bataille au Cacique , \& le défit; mais il fut bleffé, \& il

» n'eft pas encore guéri. C'eft uniquement ce qui l'a empêché

э) de venir vous témoigner lui-même combien vivement il

s a reffenti le matheur arrivé à votre Nation. жo

Quoique ce difcours n'eut pas entierement perfuadé l'A-Conduite de miral, il ne put néanmoins goûter l'avis de quelques-uns, Colomb à l'émirat, il ne put neanmoins gouter lavis de quelques-uns, gard du Roi \& furtout du P. Boyl, qui vouloient qu'on commençât par de Marien. s'affûrer de la perfonne du Cacique. Il paroît qu'il y avoit véritablement fujet de le foupçonner d'avoir fait lui-même tout le mal, quil rejettoit fur Caonabo:plufieurs l'ont cru long-têms fur des indices, qui n'étoient pourtant pas convainquants, \& pouvoient autant venir de la timidité naturelle à ces peuples, que du témoignage d'une confcience coupable. Pierre Martyr d'Anglerie, qui écrivoit quelque fois fur les premiers bruits, qui fe répandoient en Efpagne aprèsle retour des navires, (ainfi que je l'ai déjà obfervé, ) a avancé comme une chofe certaine que le Roi de Marien fut convaincu d'avoir été le meurtrier des Caftillans, que fa bleffure ne fe trouva point réelle, \& qu'il fe mit par la fuite en fureté contre la jufte vengeance, que l'Amiral fe préparoit à tirer de fa perfidie. Mais les Hiftoriens mieux inftruits ont parlé autrement, \& la fuite de l'Hiftoire nous repréfente Goacanaric tốjours tellement attaché aux Efpagnols, qu'it n'eft pas poffible de douter de la fincerité \& de fon innocence dans l'occafion, dont il sagit.

Il eft certain du moins que l'Amiral prit le parti le plus fage, en n'écoutant ni fes defiances, ni les confeils violens quion lui donnoit. « Nous ne reffufciterons pas les 
1493. morts, leur dit-il, \& puifque nous pouvons nous éta. w blir ici du confentement de celui, qui y commande, pour- quoi nous expofer au peril d'une guerre, dont nous ne w Fçaurions dire quelle feroit l'iffuë ? Soyons à la bonne w heure fur la defiance, prenons bien nos mefures pour क n'être pas furpris, \& lorfque nous nous ferons fortifiés, le „Cacique, s'il eft coupable, ne nous échapera pas. „ Colomb ne voulut pas même faire paroître qu'il foupçonnât la fidelité du Roi de Marien; mais il lui envoya un Officier, qui fous prérexte de le complimenter de fa part, eut ordre de s'affurer, s'il étoit véritablement bleffé; au cas qu'il le fût, d'examiner de quelle forre d'armes venoit fa playe, \& d'obferver foigneufement toutes chofes. L'Officier s'acquitta pirfaitement de fa commiffion, \& ne trouva rien qui pût charger le Prince In̨dien. Les Ecrivains Eipagnols , tels que D. Fernand Colomb \& Antoine Herrera, qui n'ont point b.lancé à le juger effectivement innocent, font en cela d'autant plus croyables, que l'interêt de leur Nation devoit, ce femble, leur faire fouhaiter de trouver coupable un Souverain, qui na été payé par- les Efpagnols que d'ingratitude, pour tous les fervices, qu'il a rendus à leur colonie naiffante.

II lui rend

L'Amiral, après le retour de fon Envoyé, fe confirma vifiste.

de plus en plus dans la rélolution de cultiver l'amitié de Goacanaric, \& ne voulut pas même différer à lui rendre vifite. Tout fe paffa fort tranquillement dans cette entrevîë: le Cacique fit prefent à Colomb de 800 . petites coquilles d'un très-beau luftre, du nombre de celles qu'on appelle cibas, \& qui font fort eftimées de ces peuples. (Herrera dit que c'étoit des pierres fort menuës \& fort recherchées.) Il y ajouta trois calebaffes pleines de poudre $\&$ de petits grains d'or, une couronne, \& plus de cent petites plaques du même métal. L'Amiral de fon côté donna au Cacique de petits vales de verre, des couteaux, des miroirs, \& une image de la Vierge, qu'il lui pendit au cou. Goacanaric fut extrémement fatisfait de ce prefent, dont 


\section{De S. Domingue, Liv. II. Irg}

il parut faire plus de cas, que de tout l'or de Cibao. Les moindres bagatelles lui fembloient des chofes d'un prix ineftimable; mais il n'admira rien tant, que les chevaux fur lefquels Colomb \& toute fa fuite étoient montés, \& à qui on fit faire le manége en fa préfence.

Toutes chofes paroiffant donc fûres du côté de ce Prince, l'Amiral ne penfa plus qu'à faire un établiffement fo- un lieu comlide. Il eût bien fouhaité de pouvoir fe placer dans ce faire un étaRoyaume; mais il ne trouvoit pas le pays affez bon, parce qu'il en jugeoit fur ce qu'il avoit vû en rangeant la côte. En effet les eaux y croupiffoient alors en plufieurs endroits, \& en rendoient l'air malfain. Outre cela on y manquoit abfolument de pierres pour bâtir. On a depuis. travaillé avec quelque fuccès à faire écouler les eaux; mais les pierres propres à bâtir ne s'y font point encore trouvées. D'ailleurs l'Amiral vouloit s'approcher des mines de Cibao. Il réfolut donc de s'avancer plus à l'Eft, \& le feptiéme de Decembre il partit de Puerto-Real avec toute fa flotte, dans le deffein daller placer fa colonie à Puerto di Plata, où le pays lui avoit paru beau, \& le terroir fertile. Mais il fut acceüilli en chemin d'une de ces tourmentes, que les François ont depuis appellées Nords, parce qu'elles font caufées par les vents, qui foufflent de la partie du Septentrion, \& il ne pouvoit éviter d'être jetté à la côte, \& d'y perir avec tous fes navires, fi à la faveur d'une éclaircie, il n'eût aperçû à deux lieuës à l'Ef de Monte Crifto une riviere, où il entra.

Elle avoit environ cent pas de large, \& formoit un af: Il bâtit une fez joli Port; mais un peu découvert du côté du Nord. ville fous le Un platon fort élevé, bordé de rochers, \& affez large, le. domine ce Port, \& l'on découvre de là une très - grande étenduë de plaine. Colomb ayant fait vifiter ce pays, on laffira que les terres en étoient fort bonnes, \& que l'on y trouvoit partout des pierres propres à bâtir, \& d'autres pour faire de la chaux. Il parut bien dans la fuite qu'on s'étoit trompé pour le premier article; mais tout le monde: 
1493. étoit extrémement fatigué de la mer. L'Amiral fe détermi: na donc à bâtir une ville en ce lieu-là : il en traça le plan fur le platon, dont je viens de parler; \& comme chacun mit la main à l'œuvre, toute la Colonie fut bientôt logée, oú du moins à couvert; c'étoit-là le plus preffé, \& il ne falloit ni beaucoup de têms, ni beaucoup de travail, pour dreffer une cafe, dont les feuls materiaux furent le bois, la paille, \& les feuilles de palmier. L'Eglife, l'Arfenal, le Magazin, la maifon du Gouverneur, furent bâtis de pierres, \& ne furent pas fitôt achevés. Cette nouvelle ville, la premiere, qui ait été conftruite par les Europeans dans le nouveau monde, fut nommée IJabelle, en memoire de la Reine de Caftille.

Il envoye Cependant on commençoit déjà à reffentir les premieres vifiter les mi- atteintes de la famine, foit que les provifions n'euffent pas nes de Cibao. été bien faites, foit quion ne les eût pas affés menagées, ou que les vivres euffent été gâtés: dailleurs, la continuité d'un travail, dont perfonne n'étoit exempt, \& auquel la plûpart n'étoient point accoûtumés, yles fatigues paffées, le changement de climat, \& les extrêmes chaleurs cauferent de grandes maladies; dont l'Amiral, qui s'épargnoit encore nioins que les autres, fut attaqué des premiers. Mais il ny avoit point de difficultés, ni de miferes, que ne fît dévorer l'efpérance des trélors, dont l'imagination d'un chacun lui repréfentoit l'acquifition affürée \& prochaine. Colomb étoit trop habile homme, pour ne pas profiter de ces favorables difpofitions; \& pour les entretenir, autant qu'il étoit poffible, il ne jugea pas à propos de différer plus longtêms la découverte des mines de Cibao. Ne pouvant la faire par lui-même, il en chargea un brave Capitaine nommé Alphonfe de Ojeda, auquel il donna un détachement de 15 . foldats bien armés.

Caratere Ojeda étoit un Gentilhomme, qui avoit été au fervice d'Ojeda. du Duc de Medina Sidonia, il étoit d'une très petite taille; mais on racontoit des chofes prefque incroyables de fa force $\&$ de fon adreffe. Il eut été difficile de voir un homme plus 


\section{DE S. DOMINGUE, LIV. IT. I2I}

hardi, plus entreprenant, plus ambitieux, moins intereffé, un cour plus haut, un efprit plus fécond en reffources; rien ne rebutoit fon courage, mais il n'étoit pas heureux, \& nous le verrons échoüer dans les entreprifes les mieux concertées \& les mieux foutenuës. Au fortir d'Ifabelle, il prit fa route au Midi, \& après avoir fait 8 . ou IO. lieuës par un pays inhabité, \& qui lui parut ftérile; il entra dans. une gorge de montagne très-étroite, qui le conduifit dans une grande \& belle plaine, bien peuplée, cultivée partout. \& entrecoupée d'un nombre infini de ruiffeaux, dont la plûpart fe rendent dans la riviere Yaqué. Il n'avoit plus que 10. à I2. lieuës à faire dans ce beau pays, pour gagner Cibao; mais les réceptions, qu'on lui faifoit dans toutes les bourgades, \& la quantité de ruiffeaux, qu'il lui falloit traverfer, lui firent employer cinq jours à les faire. Plus il avançoit, \& plus il fentoit qu'il approchoit d'un pays abondant en or. La plûpart des ruiffeaux, qu'il rencontra après les deux premiers jours de marche, en roullent des pailles \& des petits grains parmi le fable; enfin il fe trouva au pied des montagnes de Cibao.

Ce mot fignifie montagne pierreufe, \& il eft dérivé de ciba, qui veut dire, un Roc ou un Caillou. Rien n'eft plus de Cibao. affreux à la vûë que l'entrée de ce canton, mais on y refpire d'abord un air extrêmement doux \& fort fain ; il y coule partout des eaux pures \& cordiales, \& les Sauvages, qui accompagnoient les Caftillans, leur faifoient ramaffer de l'or à chaque pas. Ojeda, content de cette découverte, qui répondoit fi bien à tout ce qu'on avoit publié jufques-là des mines de Cibao, reprit avec quantité de monftres d'or, la route d'Ifabelle, où le récit de ce qu'il avoit vû, \& les preuves, qu'il en faifoit briller aux yeux de fes compatriotes, femblerent ranimer toute cette colonie, que la famine \& le défefpoir commençoient de réduire à une langueur mortelle, \& avoient même déjà confidérablement diminuée.

L'Amiral profita de cette heureufe conjoncture, pour Tom. $I$. 
1494. renvoyer fa flotte en Efpagne, mais il en retint pour lui Confouverte \& flotte étoit fur le point d'appareiller, lorfqu'on eut avis que cinq bâtimens, deux Navires moyens \& trois Caravelles. La punie. quelques-uns des habitans d'Ifabelle, ayant à leur tête un certain Bernard de Pife, avoient complotté d'enlever un ou deux des bâtimens, que Colomb s'étoit refervés; \& de -s'en retourner en Efpagne. L'Amiral ne crût pas devoir s'endormir un moment fur ce commencement de mutinerie; il fit faifir Bernard de Pife, il l'envoya en Efpagne prifonnier avec le projet de fa révolte, qu'on lui avoit trouvé dans fes poches, $\&$ il fit pendre fes principaux complices. Cette conduite étoit fage, mais ce n'eft pas toûjours la fa geffe, qui regle le fuccès des évenemens. Cet acte de juftice en apparence fi néceffaire, \& où toutes les formalités furent exactement gardées, lui aliéna la multitude fans retour, \& eut des fuites bien funettes pour lui \& pour toute fa famille.

L'Amiral va Cette fédition appaifée, \& la flotte ayant mis à la voile, lui-même à l'Amiral voulut vifiter lui-même les mines de Cibao, y
Cibao. mener des ouvriers, \& y conftruire une fortereffe. Il nomma pour l'accompagner un bon nombre de volontaires, \& tout ce qu'il avoit de meilleurs foldats, tous à cheval, \& après avoir établi D.Diegue Colomb, le plus jeune de fes deux freres, Gouverneur d'lfabelle, il fe mit en marche au fon des trompettes \& des tambours, \& enfeignes déployées. A l'entrée \& au fortir des Bourgades Indiennes, il faifoit la même chofe, mais il ne tira point de cet éclat tout le fruit, qu'il en avoit prétendu : il effraya même plus les Infulaires, quil ne leur infpira d'eftime \& de refpect pour les Caftillans, \& au lieu qu'au paffage d'Ojeda, on les avoit vû accourir avec empreffement au devant de cet Officier, hi offrir toutes fortes de rafraîchiffemens, \& lui rendre tous les fervices, qui pouvoient dépendre d'eux, ils fuyoient de toutes parts, dès quils entendoient ces inftrumens militaires, \& apercevoient cet équipage guerrier, qui les faifoit rrembler de peur. 


\section{DE S. Domingue, LIV. II. I23}

Ils fe raffurrerent néanmoins peu à peu, parce que Colomb n'eût pas plûtôt remarqué le mauvais effet de certe marche bruyante, qu'il s'appliqua à combler ce timide peuple de marques de la plus fincere bienvesllance. Après qu'il eût fait trois lieuës, il envoya fous la conduite de quelques Gentilshommes des pionniers, pour aplanir cette gorge de montagnes, dont nous avons parlé, \& par où il eût été fans cela impoffible à des gens de cheval de paffer. C'eft ce qui a fait donner à ce paffage le nom de Puerto de Zos-Hidalgos. En y arrivant, Colomb monta fur une des los Cavalleros. plus hautes montagnes, d'où il découvrit cette vafte plaine, qu'on rencontre au fortir de ces détroits, \& à laquelle il donna le nom de Vega Real, ainfi que je l'ai remarqué ailleurs. Il la traverfá enfuite dans fa largeur, qui n'eft en cet endroit-là que de cinq lieuës, \& il le trouva au bord du fleuve Yaqué ou Nicayagua, car les Indiens lui donnoient ces deux noms. Il eft large comme l'Ebre l'eft à Tortofe, dit Herrera; l'Amiral en trouva les bords tout couverts de Cannes, \& le nomma Rio de las Caj̃as, ne fçachant pas, ou ne faifant pas réflexion, que c'étoit la même riviere qu'il avoit appellée Rio del Oro, à fon premier voyage, \& qui fe décharge dans la mer à côté de Monte-Crifto, dont les François lui ont depuis donné le nom.

Affés près de ce fleuve, Colomb vit une groffe Bourgade, \& s'en étant approché , il remarqua que les habitans barricadoient leurs porres avec des cannes, il vit bien quils avoient peur, il leur fit amitié, \& 11 les eût bientôt rafiûrés. La même chofe lui arriva dans deux autres villages, au-delà d'une riviere, qu'il appella Rio-Verde, \& dont il trouva les eaux extrêmement fraîches. Enfin, le I5. de Mars, il arriva à lentrée de Cibao, car on nomme ainfi toute une Provin. ce, à laquelle Herrera donne autant d'étenduë, qu'en a le Portugal. L'Amiral eut encore la curiofité de monter fur. la plus haute des montagnes, qui font à l'entrée de ce beau pays, \& il vit de-là prefque toute l'llfe Efpagnole. II fut furtout charmé de la beauté de la Vega Real, qu'il 
1494. découvroit aifément toùte entiere, parce qu’il étoit prefque au milieu de fa longueur. Il s'imagina voir un jardin bien cultivé , tout coupé de canaux, qui paroiffoient comme creufés exprès, \& dont la plûpart rouloient un or très-pur avec les plus belles eaux du monde. Outre cela, dans les I8. lieuës, qu'il avoit fait depuis Ifabelle, il avoit encore découvert une mine de cuivre, une carriere d'azur, \& une d'ambre. On n'a pourtant pas entendu parler depuis ce têms. là, ni de l'une, ni de l'autre carriere. Quoiqu'il en foit, un pays, où à chaque pas on marchoit fur l'or, meritoit bien que l'on pensât à s'en affùrer la poffeffion.

Il y bâtit L'Amiral réfolut donc d'y bâtir une fortereffe, \& il la une Forteref- traça lui-même dans une prefqu'lne, que forme la riviere se.

$X$ anique. Elle ne fut contruite que de terre $\&$ de bois, mais un bon foffé en défendoit l'entrée, que la riviere laiffoit libre. L'incredulité de quelques-uns, qui s'étoient opiniâtrés à ne point croire ce qui fe difoit des mines de Cibao, jafqu'à ce qu'ils euffent vû de leurs yeux ce qui en étoit, fit donner à ce fort le nom de Saint Thomas; Colomb en confia le gouvernement à un Seigneur Catalan, nommé D, Pedro Margarit, auquel Oviedo donne quelquefois le titre de Commandeur. Il lui laiffa 96. hommes, partie foldats, partie ouvriers, \& il s'en retourna à Ifabelle, où il arriva le 29. de Mars. Il trouva cette ville dans l'état du monde le plus trifte. Les munitions de bouche étoient fur le point d'y manquer tout à fait, \& perfonne n'étoit fort en état de fe donner tous les foins néceffaires pour s'empêcher d'en être abfolument dépourvâ.

Mutinerie Cette extrême difette, la mauvaife qualité de ce qui refdaus Ifabelle' toit de vivres, que l'humidité \& la chaleur du pays avoient prefque entierement corrompu, le chagrin \& l'intemperie de l'air, eûrent bientôt caufé des maladies plus fâcheufes encore que les premieres. D'ailleurs, on manquoit abfolu. ment de remedes, \& il falloit que certains travaux nécef. faires fe fiffent. L'Amiral, dans cette extrémité, eût recours aux volontaires, lefquels fe voyant mal nourris, \& con 


\section{DE S. Domingue, Liv. II. I 2.5}

craints même par la force à des travaux pénibles \& humiliants, commencerent à̀ crier bien haut, \& furent foûtenus. Un de ceux, qui prit plus ouvertement leur parti, fut le $P$. Boyl; quelques-uns ont dit que l'Amiral n'avoit pas épargné ce Religieux dans le retranchement, qu'il s'étoit vû obligé de faire des vivres; ce qui eft certain, c'eft que la féverité de Colomb à punir les plus légeres fautes, l'avoit fouvent choqué, qu'il lui en avoit fait de grands reproches, \& qu’il en étoit même quelquefois venu, jufqu’à mettre l'Eglife en interdit : l'Amiral n'en avoit rien rabattu d'une conduite, qu'il jugeoit néceffaire, \& il faifoit d'abord ceffer l'interdit, en retranchant abfolument la Ration au Benedictin. Nous verrons bientôt les fuites de cette broüillerie.

Sur ces entrefaites on eut avis à Ifabelle, que Caonabo. paroiffoit vouloir affieger le Fort de Saint Thomas : le Capi- part pour de taine Ojeda fut auffitôt envoyé avec 400 . hommes de ce couvertes. côté là , \& eut ordre de refter dans la place, tandis que Margarit feroit des courfes fur les terres du Cacique, pour le retenir fur la défenfive. L'Amiral établit enfuite à Ifabelle un Confeil, compofé du P. Boyl, de l'Alguazil Major, de Pero Fernandez Coronel, d'Alonfe Sanchez de Carvajal, dont nous parlerons ailleurs; \& de Jean de Luxan. D: Diegue, qui étoit toûjours le Gouverneur de la ville, fut nommé Préfident de ce Tribunal. Cela fait, l'Amiral partit' avec un navire \& deux caravelles, pour aller faire de nouvelles découvertes. Il ne fut gueres que cinq mol̀s dans. ce voyage, depuis le 24 . d'Avril jufqu'an 27. Septembre: II fit prefque tout le tour de Cuba, \& s'affûra enfín que c'étoit une Ine, quoique quelques-uns ayent foutenu qu'il en avoit douté toute fa vie. Il découvrit une autre grande Ifle, à laquelle il donna le nom de Sant-Yago, mais celui de $\mathcal{F}$ amaica, que lui donnoient fes habitans, a prévalu. Il fouffrit extraordinairement par le defaut de vivres, par les. tempêtes, par divers autres accidens : il échoüa plufieurs fois, \& courut de grands rifques. Enfin s'étant avancé à l'Êt jufqu'à la Mona, petite Inle, dont j'ai déjà parlé, \& 


\section{26 HISTOIRE}

1444. qui eft entre l'Efpagnole \& Portoric, il y tomba dangereufement malade, \& on fut obligé de le ramener à Ifabelle.

Son retour

Il étoit encore fort mal quand il y arriva; mais la joie à Ifabclle, où d'y trouver fon frere D. Barihélemy lui rendit bientót la il trouve fon fanté. Il y avoit 13 . ans qu'ils ne s'étoient vûs, \& l'Aniral, thélemy. qui pendant tout ce têms-là n'a voit reçû aucune nouvelle de fon frere, le croyoit inort. Jai dit ailleurs quelles avoient été les avantures de $\mathrm{D}$. Barthélemy les premieres années après fa réparation d'avec lon frere; \& quoique dans la iuite du récit de D.Fernand Colomb, que j'ai rapporté, il y ait des chofes qui ne peuvent guere s'accorder avec la verité del Hiftoire, il paroît certain que tout n'y eft pas fabuleux : il eft même hors de toute vrayfemblance, que ce voyageur ait paffé huit ans de fuite en Angleterre, f.ns écrire une feule fois à fon frere en Efpagne. Enfin s'ennuyant de ne rien avancer avec le Roi Henry VII. il le quitta pour s'aller rejoindre à ce même frere, dont il étoit auffị de fon côté fort en peine. En paffant par Paris, il voulut faluer Charles VIII. Ce Prince lui fit un acceüil fort gracieux, lui aprit la découverte du Nouveau Monde, \& lui fit toucher cent écus pour achever fon voyage. D. Barthélemy ufa de toute la diligence poffible pour arriver en Efpagne, avant que l'Amiral en partît; mais elle fut inutile. Il fut bien reçû́ des Rois Carholiques :il leur offrit fes fervices, \& ils les agréerent. On lui donna trois navires pour porter des vivres à l'lfle Efpagnole, \& il moüiila dans le Port d'Ifábelle, peu de jours après, que fon frere en fût parti pour fes nouvelles découvertes.

Iesgens de Le fecours de vivres qu'il aportoit à la Colonie, ne guerrefecom- pouvoit venir plus à propos; mais c'étoit peu de chofes portent mal, pour tant de monde. La famine redevint bientôt extrême, arrive.

\& produifit beaucoup de delordres. Le plus grand mal vint des gens de guerre, qui étoient fous la conduite de D. Pedro Margarit. Cet Officier avoit eû ordre d'aller avec un grand corps de troupes vifiter toutes les Provinces de d'Ine ; mais il lui avoit été très-particulierement recomman- 


\section{DE S. DOMINGUE, LIV. II İ 27}

dé de retenir fes gens dans une fi exacte difcipline, que les naturels du pays n'euffent aucun fujet de fe plaindre.

C'étoit demander beaucoup à des foldats, aufquels l'on ne fourniffoir pas le néceffaire pour la vie. Auffi ne trouvant pas les Indiens difpofés à leur fournir des vivres, ils en prirent de force, fe donnerent toutes fortes de licences, \& commirent partout de grandes violences. Alors les Indiens fongerent à fe réunir pour exterminer des gens, de qui ils commençoient à fentir qu'ils avoient peu à efperer, \& beaucoup à craindre. Tous les Caciques, à la réferve du Roi de Marien, fe liguerent : tout autant de Caftillans, qui tomberent entre leurs mains furent affommés, \& il y en eut plufieurs, qqui s'étant fauvés dans une maifon, y furent brulés.

Dom Diegue Gouverneur d'Ifabelle ne fut pas plûtôt informé de ce qui fe paffoit, qu'il fit faire par le Confeil des remontrances à Margarit. Ce Commandant fier de fa Belle action \& mauvaife conduite de naiffance les reçut mal, fe retira dans le Fort Saint Tho- Margarito. mas, \& laiffa à fes gens une liberté entiere de fe procurer par toutes fortes de voyes des fecours contre la faim quiles preffoit. Il en fouffroit lui-même autant que les autres: \& l'on raconte à cetre occafion un trait bien noble de lui , \& qui lui auroit encore fait plus dhonneur, s'il ent eû d'ailleurs une conduite plus moderée \& plus reguliere. Un Indien lui aporta un jour deux tourterelles en vie; il les reçut, les paya, \& pria fes Officiers de monter avec lui au plus haut de la Fortereffe. Là tenant en fa main les deux tourterelles: $\alpha$ Meffieurs, leur dit-il, je fuis bien fâ* ché qu'on ne m'ait pas aporté de quoi bien vous régaler ๖ tous; mais je ne puis me réfoudre à faire un bon repas, * tandis que vous mourrés de faim. nn achevant ces mots, il donna la liberté aux deux oifeaux.

Mais la faim n'étoit pas le feul mal, qui le tourmentoit: Il repaffe en il fouffroit depuis quelque têms de grandes douleurs, qui Efpagne, \& y y ne lui laiffoient prendre aucun repos, ni le jour, ni la nuit. des piaintes C'étoit le mal de Naples, dont quelque femme Indienne contreles Co. 


\section{$\pi 28$ HISTOIRE}

1494. lui avoit aparemment fait prefent. Il s'imagina que cela veriture, \& il réfolut enfin de repaffer en Efpagne. Il fe rendit pour ce fujet à Ifabelle, \& comme il n'étoit pas content du Gouverneur, dont il méprifoit la nouvelle Nobleffe, il ne daigna pas même lui faire une vifite. Il fe mit enfuite à parler fort mal des Colombs, \& cette conduite lui acquit bien des partifans, à la tête defquels fe mit le P. Boyl. Ce Religieux eut même l'imprudence de publier, qu'il vouloit aller détromper les Rois Catholiques de l'illufion, que leur avoit fait l'Amiral avec fes prétenduës mines'd'or: \& paffant bientôt des menaces aux effets, Margarit \& lui s'embarquerent fur les navires, qui avoient amené D. Barthélemy. Arrivés à la Cour, ils y dirent tout le mal, qu'ils purent des Colombs. Ils ajoûterent qu’à la verité il y avoit un peu d'or dans l'Ifle Efpagnole ; mais qu'on en verroit bientôt la fin, \& que cela ne meritoit point qu'on fit tant de dépenfes, ni qu'on facrifiât tant d'honnêtes gens: que fi néanmoins on vouloit maintenir la colonie, il y falloit en. voyer des Chefs plus capables de la gouverner, que les trois freres Gênois. Oviedo prétend que ce furent le Roi \& la Reine,qui rappellerent ces deux hommes: \& quelques autres perfonnes de confidération, de qui ils vouloient être inftruits de la conduite des Colombs, contre lefquels on leur avoit déjà fait de grandes plaintes; mais il y a bien de l'apparence qu'il fe trompe. Herrera de fon côté affûre qué Margarit repaffa en Efpagne par la crainte du chatiment; qu'il avoit mérité, \& que le P. Boyl \& quelques autres de fon parti l'accompagnerent. Quoiqu'il en foit, ce fut là où fe termina l'Apoftolat du P. Boyl, le premier, dit un Aus. teur de fon Ordre, qui ait annoncé Jefus-Chrift dans le Nouveau Monde, \& auquel il trouve fort mauvais que les: Jefuites ne donnent point le pas fur Saint François Xavier.

L'Amiral Il ne faifoit que de partir d'Ifabelle, lorfque l'Amiral fait fon frere y retourna : il prévit une partie des fuites de ce voyage; Adelantado. mais il n'étoit plus têms d'y remedier. Peu de jours après 


\section{De S. Domingue, Lrv. II. T29}

il reçut une vifite de Goacanaric, qui lui témoigna fon chagrin de n'avoir pû empêcher les malheurs arrivés à plufieurs de fes foldats, \& s'offrit à fe joindre à lui pour en tirer vengeance. L'Amiral n'avoit garde de refufer un pareil offre; il fe prépara à marcher en perfonne contre les Caciques; mais avant que de quitter Ifabelle, il voulut donner à Dom Barthélemy fon frere, qu'il y laiffoit en fa place, un titre, qui le fit refpecter. Il le nomma $A d e-$ lantado, (qui veut dire, Lieutenant Géneral, ou Préfet,) dans toute l'étenduë des Indes; \& quoique les Rois Catholiques euffent trouvé mauvais qu'il eût difpofé d'une charge de cette confequence fans leur participation, ils ne laifferent pourtant pas de confirmer ce qui avoit été fait. Veritablement le fujet le méritoit : D. Barthélemy n'étoit gueres moins habile navigateur, que D. Chriftophle. J'ai même déjà remarqué qu'il avoit été fon maître de Cofmographie \& de Géographie : ce qui me feroit juger qu'il pouvoit bien être fon aîné. Il avoit beaucoup de conduite \& de fageffe : il paffa pour un des plus braves hommes de fon têms; il étoit franc \& généreux, \& il eût pu rendre de fort grands fervices à l'Efpagne, fi la jaloufie des Efpagnols, \& fon caractere un peu trop dur, n'euffent plus d'une fois rompu fes mefures \& celles de fon frere.

Rien n'arrêtoit plus l'Amiral à Ifabelle, lorfqu'il fit réflexion, que s'il fe metroit en campagne avec le peu de d'Ojeda pour flexion que sil fe metoit en campagne avec le peu de fafir de troupes qu'il avoit, il fe pouvoit réûnir contre lui affés perfonne de d'Indiens pour l'accabler. Il jugea donc plus à propos d'at- Caonabo. taquer fes ennemis les uns après les autres, \& d'employer la furprife \& la rufe avant la force ouverte. Caonabo Roi de Maguana étoit fans contredit le plus à craindre de tous les Caciques; Colomb donna fes premiers foins à s'affûrer de fa perfonne. Il fçavoit que ce Prince Caraibe faifoit beaucoup plus de cas du cuivre \& de la fonte, que de l'or, \& qu’il avoit fouvent témoigné une grande envie d'avoir la cloche de l'Eglife d'Ifabelle, parce qu'il s'étoit imaginé qu'elle parloit. Il fe fervit de cette connoiffance pour lui Tom. I. 
1494. tendre un piege, \& il chargea de l'execution Ojeda, qui commandoit toûjours dans la Fortereffe de Saint Thomas.

Ce Capitaine, après avoir reçû les inftructions de for: Général, partit, avec neuf Cavaliers bien montés, pour fe rendre à Maguana, lieu de la réfidence ordinaire du $\mathrm{Ca}$ cique, ayant fait auparavant courir le bruit qu'il étoit chargé de préfens pour ce Prince, avec lequel les Cantillans vouloient, difoit-il, par eftime pour lui, établir une paix durable. Le peu de fuite, qu'il avoit, empêcha Caonabo de foupçonner du myftere dans cette Ambaffade, \& il fit a l'Ambaffadeur une réception magnifique. Ojeda commença par remettre au Roi les préfens dont il étoit chargé, \& il accompagna cette action de beaucoup de complimens de la part de l'Amiral, puis il fit de grandes plaintes des préparatifs de guerre, qui fe faifoient partout contre une nation, qui ne demandoit qu'à vivre en bonne intelligence avec toutes les autres. Il propofa enfuite les conditions, fous lefquelles il avoit ordre de traiter : elles étoient trèsraifonnables, très-avantageufes aux Sujets de Caonabo, \& la cloche de l'Eglife d'Ifabelle, devoit être le nœud d'une fi belle union, « En attendant, dit Ojeda, mon Général m’a » ordonné, Seigneur, de vous remettre un préfent rare, \& $\rightarrow$ tel quil n'en a jamais fait de femblable à aucun Prince.

En difant cela, il fit voir des fers femblables à ceux, qu'on met aux pieds des Criminels \& des Forçats, \& des menotes de même matiere. Le tout fi bien travaillé, fi poli, \& fi luifant, qu'on l'auroit pris pour de l'argent. Il fit entendre au Cacique que la coûtume étoit de porter ces marques d'honneur aux pieds \& aux mains, \& il s'offrit à les lui mettre en particulier, afin qu'il pût fe montrer en cet équipage à res Sujets. Le Prince Caraübe donna fottement dans le piége, \& fe laiffa conduire où étoient les gens d'Ojeda, qui le garotterent, puis cet Ambaffadeur, qui avoit fon cheval tout prêt, étant fauté brufquement deffus, y fit: mettre en croupe le Cacique enchaîné , fe le fit étroitement lier corps à corps, \& gagna au galop Íabelle avec fa proye. 


\section{DE S. Damingue, Liv. IT. T3T}

La joye de l'Amiral fut grande, quand il fe vit maître du feul ennemi, qưil appréhendât dans l'ille. Le fier Caraibe, de fon côté, foûtint fa difgrace avec une hauteur, \& une fermeté dame, que rien ne pût abattre: jamais il ne fonnier, \& fa donna à Colomb aucune marque de refpect \& de foûmirfion, \& un jour que l'Amiral lui en témoignoit fa furprife, il lui répondit: qu'il ne s'humilieroit jamais devant un trâ̂tre, lequel n'avoit pas même ofé exécuter en perfonne fa trahifon, \& qu'il failoit beaucoup plus de cas de fon Officier, que de lui. Effectivement il ne rencontroit jamais Ojeda, qu'il ne le faluât. Cette fierté coûta la vie au malheureux Caonabo; l'Amiral ne crut pas devoir laiffer dans l'lfle un homme de ce caractere, \& dont la garde l'embaraffoit. Il n'ofa pourtant pas prendre fur lui de le faire mourir, il l'embarqua fur un navire, qu'il envoyoit en Efpagne, \& ce navire ayant fait naufrage, le Cacique y périt avec tout l'équipage.

Pierre Martyr d'Anglerie, qui paroît s'attacher à donner toûjours le tort aux Indiens, parce qu'apparemment ceux qui écrivoient en Cour, donnoient ce tour-là aux chofes, qu'ils y mandoient; cet auteur, dis-je, rapporte ce fait d'une maniere un peu différente. Il dit qu'Ojeda avoit d'abord voulu engager Caonabo à aller trouver l'Amiral pour traiter avec lui : que le Cacique y avoit confenti, mais dans le deffein de tuer Colomb, \& que pour en venir à bout, il s'étoit mis en marche avec une nombreufe efcorte ; qu'Ojeda, lui ayant demandé pourquoi il menoit tant de monde, il avoit répondu, qu'il ne lui convenoit pas de marcher moins accompagné : qu'alors Ojeda crut qu'il falloit le prévenir, \& imagina pour fe faifir de fa perfonne, ce que je viens de rapporter. Oviedo ajoûte, qu'un frere du Cacique, ayant apris fa difgrace, leva des trouppes, les partagea en cinq bandes, \& les fit approcher le plus près qu'il fut poffible du fort de Saint-Thomas, à deffein d'y faire des prifonniers, avec lefquels il pût échanger fon frere; mais qu'Ojeda, après plufieurs petits combats, où il y eût quelques Efpagnols, \& plufieurs Indiens tués, fit le Prince même

1494 .

Fierté du Cacique pri- 
1494. prifonnier, que celui-ci, ayant fçâ qu'on le vouloit envoyer en Efpagne, en mourut peu de jours après de dépit.

I'Amiral re- Il n'y avoit pas long-têms que le navire, fur lequel on çoit du fe- avoit embarqué le Roi de Maguana, étoit parti d'Ifabelle , gne. lorfqu'il y en arriva quatre d'Efpagne, bien fournis de tout ce qui étoit néceffaire pour ravitailler la Colonie réduite aux derniers abois par la famine : l'Amiral reçût par ces mêmes navires des Lettres, que les Rois Catholiques lui écrivoient, pour lui témoigner l'extrême contentement, qu'ils avoient de fes fervices. Ils l'exhortoient auffi à leur mander dans le plus grand détail ce qu'il avoit obfervé dans fes voyages, \& dans les Indes, à leur marquer les noms des Ifles découvertes, \& à leur envoyer des oifeaux de toutes les efpeces rares, qu'il connoiffoit. Enfin ils lui donnoient avis que tous les différens, qui étoient furvenus de nouveau entre-eux \& le Roi de Portugal, touchant la Ligne de Démarcation, étoient heureufement terminés, \& que comme on étoit convenu de placer cette Ligne de concert, ils fouhaitoient avoir fur cela fon avis, \& celui de D. Barthélemy fon frere. Ces Lettres le confolerent un peu des chagrins, qu'on lui fufcitoit tous les jours dans la Colonie, \& lui donnerent plus d'autorité pour entreprendre ce qu'il jugeoit être du bien public.

II marche contre une nombreufe armée d'Indiens $\&$ la met en déroute.

Sur la fin de cette année, il apprit que la prife de Caonabo avoit foulevé toute l'lne, \& qu'une nombreufe armée s'affembloit dans la Vega Real. Ces grands préparatifs ne l'étonnerent pas, mais il ne crut pourtant pas devoir rien négliger pour les rendre inutiles. Il fit avertir le Roi de Mam rien du deffein, où il étoit, de fe mettre en campagne à la tête de fes troupes, \& ce Prince vint auffitôt le trouver avec un bon nombre de fes Sujets; l'Amiral avoit commandé pour cette expedition 200 . hommes de pied, \& 20. chevaux, aufquels il fit joindre 20. chiens d'attache, \&x tout étant prêt, il partit d'Ifabelle le 24 . de Mars de l'an.

$₫ 495$. née 1495 . accompagné de l'Adelantade \& de Goacanaric. lequel conduifoit fes propres troupes. A peine fut-il arri- 


\section{DE S. DOMInGUe, Liv. II. I33}

vé dans la Vega Real, qu'il eût des nouvelles certaines des ennemis. Leur Armée étoit forte de cent mille hommes, \& commandée par Manicatex, un des freres de Caonabo, il l'alla chercher fur le champs, \& il la rencontra à l'endroit, où a été depuis bâtie la ville Sant-Yago. Il fit fonner la charge tout en arrivant, \& jamais armée ne rendit moins de combat.

Ces pauvres Infulaires, accoûtumés la plûpart à fe battre en fe pouffant à force de bras, ou tout au plus à coups de Macanas, furent étrangement furpris de voir les Efpagnols abattre des lignes entieres avec leurs armes à feu, dont aucun coup ne portoit à faux fur des corps tout nuds, \& qu'on approchoit auffi près quion vouloit : enfiler trois ou quatre hommes à la fois avec leurs longues épées, les fouler aux pieds des chevaux, \& lâcher fur eux de gros mâtins, qui leur fautant à la gorge, les étrangloient d'abord, \& les mettoient en pieces. En moins de rien plufieurs milliers de ces Barbares demeurerent étendus fur le Champs de Bataille, \& un très-grand nombre furent faits prifonniers. On les condamna tous à des travaux publics, à la réferve de 300. qui furent envoyés en Efpagne, comme Efclaves. Mais la Reine de Caftille ne trouva nullement bon qu'on réduisit en fervitude des gens d'un efprit fi doux, elle les renvoya dans leurs pays, \& donna de bons ordres pour em. pêcher que déformais on n'attentât à leur liberté. Elle recommanda en même têms qu'on s'étudiât fur tout à les réduire par la douceur fous le joug de l'Evangile, \& qu'on tâchât de les engager par de bonnes manieres, par la voye de la perfuafion, \& par le motif de leur interêt propre à rendre un hommage volontaire à la Couronne de Caftille.

Le Roi de Marien l'avoit déjà f.it, \& tout le têms de la Nort de famine il s'étoit chargé de nourrir cent Efpagnols. Ce n'é Goacanaric. toit pas peu de chofes dins un pays, où l'on ne femoit gueres, que pour le pur befoin, \& fi l'on confidere qu'un Caftillan mangeoit plus en un jour, qu'un Indien ne faifoit en huit. Ce Prince, après le combat, dont nous venons de parler,

$\mathrm{R}$ iij 
1495. \& dont il ne fut gueres que le fpectateur, s'en étoit retourné chés lui, chargé de la haine de toute fa nation. Son attachement pour les Efpagnols ne le fit pourtant pas plus ménager que les autres, \& l'on dit même que, pour fe fouttraire aux avanies de fes Alliés, il fut contraint de fe retirer dans les montagnes, où il mourut miférablement. Un auteur Efpagnol a extrêmement noirci la réputation de ce malheureux Cacique, \& l'accufe d'avoir porté l'impureté à des excès, qui ont fait horreur aux Infulaires mêmes. Mais il ne me paroît pas raifonnable de le condamner fur le témoignage trop juftement fufpect de fes compatriotes, qui n'ont pû lui pardonner de s'être ligué contre eux avec leurs ennemis, ni fur celui des Caftillans, qui n'ont payé fon attachement à leurs interêts, que de la plus noire ingratitude.

Tribut im- Pour revenir aux ordres de la Reine, ils arriverent trop poré à toute tard. Les Caftillans, après leur victoire, parcoururent toute l'Ifle en Conquérans, ou plûtôt en furieux, \& la remplirent d'horreur \& d'effroy. Manicatex, Guarionex, \& Cotubanama ne laifferent pas de tenir bon encore quelque têms; mais il fallut enfin ceder, \& fe foûmettre. Behechio, dont les Etats étoient les plus éloignés d'Ifabelle, fut le feul, qui ne pût être réduit pour lors. Les autres furent condamnés à un tribut annuel, qui fut reglé en cette maniere. Dans les Pays, où il y avoit des mines, \& dans les Provinces voifines, chaque perfonne au-deffus de l'âge de I4. ans, devoit payer tous les trois mois, une certaine mefure d'or : dans les Pays, où ce métal n'étoit pas commun, la Capitation étoit de 25 . livres de cotton payables aufi tous les trois mois. Manicatex, qui avoit été le principal chef de la révolte, fut obligé de fournir tous les mois une mefure d'or, qui montoit à la fomme de I 50 . pefos. On fabriqua des médailles de cuivre, qu’on donnoit à ceux, qui apportoient leur tribut; ils étoient obligés de les porter penduës à leur col, \& à chaque payement on les changeoit. Guarionex, dont le tribut étoit en or, parce qu'il étoit Seigneur de la 


\section{DE S. Domingue, LIvi. II. T35}

plus grande partie de la Vega Real, voifine des mines de Cibao; repréfenta bientôt, qu'il lui étoir imponfible de fatisfaire à ce qu'on exigeoit de lui , \& offrit en échange de faire cultiver par fes Sujets toute la longueur du chemin qu'il y a depuis Ifabelle, juqu'à la côte du Sud vers l'embouchure du fleuve ozama; c'eft-à-dire, environ 55 . lieuës de long, avec une largeur raifonnable, \& d'y femer du bled. Mais fa propofition fut rejettée : en quoi il n'eft pas aifé de comprendre la conduite de l'Amiral, qui fçachant combien il étoit difficile de faire venir des vivres de Caftille, négligeoit un moyen fûr d'éviter les fâcheufes extrémités, où la famine avoit déjà réduit plus d'une fois fa Colonie naiffante.

Ce fut alors que les Infulaires fentirent tout le poids du Defefpoir des joug, qui venoit de leur être impofé ; mais leur fimplicité Indiens, \& étoit encore fi grande, quils demandoient fans ceffe aux eut. Caftillans, s'ils ne s'en retourneroient pas bientôt chés eux. Il eft vrai que, quand ils eurent perdu toute efperance d'être délivrés de leurs impitoyables vainqueurs par une retraite volontaire, ils prirent la réfolution de s'en défaire en leur coupant les vivres. Pour cela, il convinrent de ne plus femer, \& de fe retirer dans les montagnes, perfuadés qu'ils y trouveroient toûjours dequoi fubfifter de ce que la terre produit d'elle même, \& que les Caftillans, ou périroient bientôt de mifere \& d'épuifement, ou fortiroient de l'Ifle. Effectivement les Conquérans de l'Efpagnole fe virent: bientôt à la veille d'y mourir de faim, \& pendant quelque têms ne fe foûtinrent qu'en fe nourriffant des chofes les plus dégoûtantes, \& qui font le plus d'horreur; mais le contrecoup en retomba à la fin fur les Infulaires mêmes; pourfuivis de tous côtés par les faméliques Efpagnols, \& contraints. d'errer fans ceffe, ou de fe tenir cachés dans les antres, \& dans les cavernes, fans ofer s'en écarter pour trouver de quoi vivre; ils tomberent dans un état beaucoup plus trifte, que celui, dont ils avoient voulu fe délivrer, \& l'on prétend qu'en peu de mois il en périt au moins la troifiéme partie. On 


\section{T36 HISTOIRE}

\$495. en trouva même que le déféfpoir avoit porté à fe donner la mort; mais le nombre n'en fut pas confiderable, le caractere de ce peuple n'étant pas ordinairement capable d'une telle réfolution.

Ie Roi \& Tandis que l'Amiral foumettoit ainfi à la Couronne de la Reine en- Caftille les divers Souverains, qui regnoient dans l'Ine EfCommiffaire pagnole, le P. Boyl \& D. Pedre Margarit rempliffoient la dansles Indes. Cour des Rois Catholiques de plaintes contre lui \& contre fes freres. Quelque prévenus que le Roi \& la Reine fuffent en faveur des accufés, il étoit difficile de les croire tout-à-fait innocens contre le témoignage de tels accufateurs : le feul moyen de connoître la verité, étoit d'envoyer un Commiffaire fur les lieux : on le prit, mais pour rendre ce moyen efficace, il falloit faire un bon choix, \& celui, qu'on fit, ne fut pas heureux. D. Jean Aguado, Maître d'Hôtel de la Reine, fut chargé de cette commiffion, \& leurs Alteffes lui donnerent une Lettre de créance, conçuë en ces termes : * Chevaliers \& Ecuyers, \& autres Perfonnes, qui étes dans * les Indes par Notre ordre, Nous vous envoyons Jean s Aguado, Notre Maître d'Hôtel , \& vous mandons d'as jouter foi à ce qu'il vous dira de Notre part. A Madrid o le 19. Arril I 495 .

Conduite de. Le Commiffaire arriva à Ifabelle au mois d'Ostobre, ce Commif- dans le têms que l'Amiral étoit occupé à faire la guerre
faire.

aux freres de Caonabo, lefquels avoient remué de nouveau. L'Adelantade commandoit dans la place, Aguado le traita avec beaucoup de hauteur, ufa même de menaces, \& fous prétexte d'écouter les plaintes, qu'on venoit lui faire de toutes parts contre le Gouvernement préfent, il paffa de beaucoup fes pouvoirs, \& agit en Vice-Roi , plûtôt qu'en fimple Informateur. D. Barthélemy fort furpris d'un procedé fi étrange, demanda à voir fa Commiffion, dont Aguado avoit jugé à propos de lui faire myftere, mais il répondit avec mépris qu'il ne la montreroit qu'à l'Amiral; \& qu'il l'alloit chercher, quelque part qu'il fût. Il fe ravifa néanmoins, \& avant que de fortir d'Ifabelle, 


\section{DE S. DOMINGUE, LIV. II. T37}

il fit proclamer à fon de trompe fa Lettre de créance. Il partit peu de jours après, \& 8 publia partout fur fa route, qu'il étoit venu pour faire le procès aux Colombs, \& en délivrer la colonie.

Il n'en falloit pas davantage pour affembler autour de lui les mécontens, \& prefque tout le monde l'étoit, parce que la famine étoir générale, \& toujours extêne les que la famine étoir générale, \& toûjours extrême : les feuls Colombs. gens de guerre, qui étoient continuellement en campagne, tantôt d'un côté \& tantôt d'un autre, trouvoient un peu plus de quoi vivre dans les bourgades Indiennes. Il y eut même des Caciques, qui crurent cette occafion favorable, pour faire diminuer le tribut, auquel on les avoit taxé, \& qui vinrent faire fur cela leurs repréfentations au Commiffaire, lequel ne fut pas obligé d'aller fort loin, parce que l'Amiral, à qui l'Adelantade avoit envoyé un exprès, pour lui donner avis de ce qui fe paffoit, vint en diligence à Ifabelle, Aguado fut donc obligé de rebrouffer chemin pour l'y joindre.

Il y fut reçû, comme s'il y eût fait fa premiere entrée, \& fa Commiffion y fut de nouveau proclamée au fon des de l'Amiral à trompettes, \& d'une maniere beaucoup plus autentique , qu'elle ne l'avoit été la premiere fois. Tout cela fe faifoit par l'ordre de l'Amiral, lequel affüra le Commiffaire qu'il obéïroit fans réplique à tout ce qui lui feroit intimé de la part de leurs Alteffes. Alors Aguado commença d'informer juridiquement contre lui, \& la plûpart faifirent avec joye une occafion, qu'ils crurent immanquable, de perdre des Etrangers, qu'ils n'aimoient pas, \& que la Cour fembloit abandonner. D'ailleurs les plaintes étoient favorablement reçûës, les charges parurent confidérables, \& le Commiffaire ajoutoit foi à tout. L'Amiral de fon côté fe comporta avec une modération, dont bien des gens ne l'avoient pas cru capable : il affecta même un exterieur trifte \& embaraffé, il fe revêtit de deüil, \& ne releva aucune des fauffes démarches d'Aguado, qui tranchoit toûjours du Vice Roi , \& parloit en toute rencontre d'une maniere fort imprudente.

Tome $I$. 


\section{I38 HISTOI}

1495. Les Informations faites, le Commiffaire fe difpofoit : Il fe difpo- repaffer en Efpagne, lorfqu'un furieux ouragan brifa confe à paffer en tre la côte les quatre navires, qui l'avoient aporté; mais Efpagne. comme la tourmente avoit épargné deux caravelles, que Colomb avoit fair conftruire depuis peu, l'Amiral en offrit une à Aguado, \& déclara qu'il monteroit l'autre, pour aller lui-même plaider fa caufe au Tribunal incorruptible de Leurs Alteĩes, les inftruire plus en détail, qu'il n'avoit encore pû faire, de ce qui regardoit fes nouvelles découvertes, \& prendre avec la Cour de bonnes mefures pour l'affermiffement de la Colonie. Car il n'y a nulle apparence à ce que dit Oviedo, que ce fut le Commiffaire, qui lui donna ordre de s'embarquer avec lui : la préfence d'un homme du caractere de Chriftophle Colomb ne pouvoir que gêner infiniment Aguado. Ce Commiffaire n'eut rier aे oppofer au parti, que prenoit l'Amiral, qui laiffant à la vanité de cet homme le petit éclat des honneurs, qu'il fe faifoit rendre, \& les aplaudiffemens, qu'il recevoit de la multitude; retint tout l'effentiel de fon autorité. Il confia le Gouvernement de l'Ille pendant fon abfence à fes deux freres , \& eut grand foin de pourvoir de Commandans, dont il fe croyoit fûr, les différens poftes de la Colonie: car il avoit bâti depuis peu de nouvelles Fortereffes en quelques endroits, dont il avoit jugé à propos de s'affturer. Les plus confidérables étoient la Conception de la Vega. qui devint dans la fuite une grande ville: les autres n'ont pas fubfifté long-têms.

Découverte

Sur ces entrefaites il reçut avis de quelques Caciques de mines de Saint Chrif particuliers, que dans un certain endroit, vers la partie du Sud, il y avoit des mines d'or très-abondantes. Il voulut avant fon départ éclaircir la verité de ce raport, \& il envoya fur les lieux François de Garay \& Michel Diaz. avec une bonne efcorte, à laquelle les mêmes Caciques. joignirent des guides. Garay \& Diaz fe firent conduire jufo qu’à une riviere nommée Hayna, dans laquelle on leur avoit dit qu'un grand nombre de ruiffeaux déchargeoient 


\section{De S. Domingue, Liv. III.}

de l'or avec leurs eaux. Ils trouverent que la chofe étoit veritable, \& ayant fait creufer la terre en plufieurs endroits, ils virent partout quantité de grains d'or, dont ils porterent des montres à l'Ámiral. Colomb donna auffitôt fes ordres pour bâtir en ce lieu-là une fortereffe fous le nom de Saint Chriftophle, \& ce nom s'étendit depuis aux mines, qu'on creufa aux environs, \& d'où l'on a tiré des tréfors immenfes. On peut juger de la joye, que cette découverte caufa à l'Amiral, par la fituation, où il fe troüvoit; car ces mines lui fourniffoient de quoi faire tomber la plus confidérable des accufations intentées contre lui ; \& quand bien même on auroit mieux prouvé, qu'on ne pouvoit faire, les autres griefs, dont on le chargeoit, il n'ignoroit pas qu'un fujet, quelque coupable, qu'il puiffe être, rentre aifément en grace avec fon Souverain, quand il a trouvé le fecret d'accroître fon Domaine \& de remplire les cofres.

Enfin les deux Caravelles appareillerent le ro. de Mars 1496. \& l'Amiral fit embarquer fur la fienne environ deux cens Efpagnols, la plûpart malades \& des plus pauvres de la Colonie, dont les femmes \& les parens, qui étoient reftés en Efpagne, avoient obtenu de la Cour la permiffion de les faire revenir. Il les traita fort bien pendant la traverfée, \& la reconnoiffance, autant que l'équité,en firent des Apologiftes de fa conduite, qui ne lui furent point inutiles, $\&$ des témoins de la maniere indigne, dont il avoit été traité par Aguado. L'Adelantade s'étoit auffi embarqué avec fon frere, pour vifiter Puerto di Plata, où l'on fongeoit à faire un établiffement: Les deux freres trouverent en effet l'endroit fort commode, \& ils prirent enfemble des mefures pour l'execusion de ce deffein, qui n'eut pourtant point de lieu pour lors; après quoi Dom Barthélemy retourna par terre à Ifabelle, \& l'A miral fit voiles vers l'Efpagne.

Le dixiéme d'Avril il reconnut la Guadeloupe, \& s'en approcha à deffein d'y faire de l'eau \& du bois : fa Chaloupe arrive à la étant fur le point d'aborder, le rivage parut tout bordé de

Départ do 'Amiral pour rÉpagne: 
\$496. femmes, lefquelles, armées d'arcs \& de flêches, fe mettoient en pofture de difputer la defcente. On détacha auffi-tôt deux Indiens de l'Efpagnole, qui ayant gagné la terre à la nage, avertirent ces Amazones, qu'on étoit fort éloigné de leur vouloir faire aucun tort; qu'on demandoit feulement de l'eau \& du bois, \&, s'il fe pouvoit, des vivres en payant. Elles répondirent que leurs maris étoient à la pêche de l'autre côté de l'Ifle, \& qu'elles ne pouvoient difpofer de rien fans leur agrément. Comme cette réponfe ne contentoit pas les Efpagnols, \& que la Chaloupe avançoit toûjours, nos Héroines déchocherent une grêle de flêches, dont perfonne ne fut bleffé. Elles ne revinrent pas. à la charge, \& ne penferent plus qu’à fuir, épouventées du bruit de quelques arquebufes, qu'on avoit tiré au vent pour leur faire peur. On courut après, \& l'on prit trois petits garçons \& 40. femmes, parmi lefquelles étoit l'Epoufe du Cacique. On leur fit à toutes bien des careffes \& quantité de prefens, \& ce traitement, à quoi elles ne s'étoient point attenduës, produifit l'effet, qu'on avoit efperé. On n'eut plus aucune difficulté à fe pourvoir de tous. tes les chofes, dont on avoit befoin.

Son arrivée De là Colomb continua de faire l'Eft, l'expérience n'ayant fa Eeception à point encore apris qu'il eft \& plus fûr \& plus court de la Cour. prendre au Nord, parce que les vents foufflent prefque toûjours dans ces mers là de la bande de l'Eft. Auffi la navigation fut elle rude \& longue, \& l'on y fouffrit beaucoup de la difette des vivres. Enfin l'onziéme de Juin les deux caravelles, qui ne s'étoient prefque point quittées, entrerent enfemble dans la baye de Cadix, où l'Amiral ayant rencontré trois navires tout prêts à partir pour l'ECpagnole, il fe fervit de cette occafion pour faire fçavoir fon arrivée à fes freres: après quoi il fe rendit à Burgos, féjour ordinaire de la Cour en ce têms-là. Il n'y trouva nỉ le Roi, qui faifoit la guerre en Rouffillon aux François , ni la Reine, qui s'étoit tranfportée à Loredo, où elle ordonnoir toutes chofes pour le voyage de l'Infante Jeanne 


\section{DE S. DoMInGUE, LIV. II. IUI}

fa fille, laquelle alloit en Flandres époufer l'Archiduc Philippe d'Autriche. Mais l'un \& l'autre furent bientôt de retour à Burgos, \& l'Amiral eut non feulement une Audiance favorable de tous les deux; mais il en reçut même de grands remerciemens pour fes nouveaux fervices. On ne lui parla en aucune maniere de ce qui étoit porté dans les Informations faites par Aguado, ni de tout ce que le Pere Boyl \& D. Pedre Margarit avoient dépofé contre lui ; foir qu'on eût reconnu que la paffion avoit eu beaucoup de part à ces acculations; ou que Ferdinand \& Ifabelle jugeaffent qu'il falloit fermer les yeux fur bien des chofes en faveur d'un homme de ce merite, qui avoit déjà rendu, \& qui pouvoit rendre encore de grands fervices à l'Etat, \& de la fidelité duquel on n'avoit pas le moindre lieu de douter.

L'Amiral répondit à un acceüil fi peu efperé, en propofant la continuation de fes découvertes, \& il demanda fix navires, dont trois feroient deftinés à porter des munitions de guerre \& de bouche à Ifabelle, \& les trois autres refteroient fous fes ordres. Cette demande parut raifonnable; mais on temporel. lui remontra qu'il falloit avant toutes chofes faire un établiffement folide, qui pût fervir de modele pour les Co. lonies, qu'on fonderoit dans la fuite. Il en convint, \& il fut reglé de fon avis, que le Roi \& la Reine feroient paffer à leurs dépens dans l'Efpagnole 300. hommes, à fçavoir 40. Cavaliers, 100. Fantaffins, 60. Mariniers, 20. Ouvriers en or, so. Laboureurs, 20. Artifans de differents. métiers, \& qu'on y joindroit 30. femmes; que tous ces gens-là auroient pour leur folde I4. maravedis par jour, \& tous les mois un hanegua de bled. Le maravedis revient à I.2. deniers de notre monnoye, \& l'hanegua contient fix boiffeaux , mefure ordinaire de France. L'Amiral demanda enfuite des Religieux de S. François, tant pour la conduite fpirituelle des Efpagnols, que pour linftruction des Infulaires, \& il n'eût aucune peine à les obtenir. Hl obtint aufi des Medecins, des Chirurgiens, des joüeurs de toutes fortes d'Infrumens, pour chaffer la mélancolie, fource ordinai 


\section{T42 H I S T O I R E}

1496. re de la plûpart des maladies, qui défolent les nouvelles peuplades ; \& une entiere liberté à quiconque de s'établir dans les Indes, ou d'y paffer quelque têms, pourvú qu'ils fiffent le voyageà leur frais. Le nouveau monde fut ainfi ouvert à tous les Sujets de la Couronne de Caftille, excepté aux Procureurs \& aux Avocats, qui en furent formellement exclus, de crainte, ainfi qu'il fut exprimé dans l'Edit, que la chicane ne s'introduisît avec eux dans ces pays éloignés, où elle n'avoit point été connuë jufques-là, \& où elle pouvoit retarder beaucoup les établiffemens, qu'on y vouloit faire.

Avisperni- Rien n'étoit plus fagement penfé que la plûpart de ces cieux de Co- reglemens, mais l'A miral gâta tout par une demande, qu'il s'apeupler les Indes.

vifa de faire mal à propos, \& dont il fût le premier à reffentir les dangereux effets. On avoit affés de peine à trouver des gens, qui vouluffent fe tranfporter aux Indes, pour y paffer le refte de leurs jours. Ceux, qui en étoient revenus, n'en parloient pas avantageufement, \& la couleur livide, que plufieurs en avoient rapportée, marquoit affez, \& la mifere. où l'on y avoit étéréduit, \& la malignité du climat. Pour fuppléer à cette difette de fujets, Colomb propofa de commuer la peine de ceux, qui étoient détenus dans les prifons pour crimes, ou pour des dettes confiderables, qu'ils ne pouvoient pas efperer d'acquitter, en un exil perpétuel dans les nouvelles Colonies. Cet avis, dont perfonne ne prévit alors les inconveniens, fut fuivi fans aucune difficulté . on n'excepta que les crimes de Leze-Majeté Divine \& humaine, \& il fut ftatué que ceux, qui avoient mérité la mort, ferviroient deux ans fans gages, \& les autres une année feulement, moyennant quoi, ils feroient pour le paffé à couvert de toutes les pourfuites de la Juftice, \& de celles de leurs créanciers, pourvâ qu'ils ne retournaffent point en Europe.

Il fut encore enjoint à tous les Tribunaux d'Efpagne de condamner aux mines une partie de ceux, qui avoient merité les Galeres, \& lorfqu'ils condamneroient quelqu'un 


\section{De S. Domingue, Liv. III. I43}

à un fimple exil dans les Indes, de marquer dans la Sentence le lieu du nouveau monde, où il feroit tranfporté. On ne peut nier que parmi les avantages, qu'on peut retirer des Colonies, ce n'eft pas un des moindres, que d'y pouvoir envoyer de mauvais Sujets, qui incommodent l'Etat, \& deshonorent les Familles, \& qui, tranfplantés dans une terre étrangere, y peuvent changer de mœurs \& de naturel; mais il faut pour cela que le pays foit déjà bien établi \& que la Juftice, la Police, \& la Religion y foient en vi* gueur, \& il y a bien de l'apparence que jamais Chriftophle Colomb n'eût ouvert un pareil avis, ni les Rois Catholiques foufcrit à fa propofition, s'ils euffent fait réflexion que dans une peuplade toute nouvelle, \& où l'authorité des loix n'eft pas encore affés refpectée, les bons font expofés à fe corrompre, \& ce feroit un miracle, fi les méchans devenoient meilleurs, fur tout quand ils font le plus grand nombre. Ce qui furprend, c'eft que de fréquentes \& de fâcheufes experiences, n'ayent pas encore redreffé fur cela les Fondateurs des Colonies. Un des plus fages Hiftoriens du nouveau monde avouë que l'Amiral fit en cela une grande faute, \& que des Républiques doivent avoir d'autres fondemens que des mal-faiteurs.

Enfin, Colomb eût permiffion de concéder des terreins Les feuls fitsà ceux, qui en demanderoient, \& feroient en état de les cul- jets de la Coutiver, à condition néanmoins que les métaux $\&$ le bois de rille ont droir Brefil, qui s'y trouveroient, appartiendroient au domaine, d'aller aux Inou plûtôt feroient du droit public, fauf celui Souverain : mais il fut en même têms fait de très-exprefles défenfes de recevoir fur les navires, qui partoient pour le nouveau monde, quiconque n'étoit pas né Sujet de la Couronne de Caftille La Reine fit faire, ou plûtót renouveller ce Re. glement, mal obfervé jufqu'alors, à l'occafion des difcours \& de la conduite de D. Pedre Margarit, \& du P. Boyl, lefquels étoient Sujets de la Couronne d'Arragon, \& parce qu'elle vouloit avoir droit de punir ceux, qui dans la fuite s'émanciperoient à de pareils éclats. 
I 496.

L'armement ordonné pour le troifieme voiage de $\mathrm{Co}$ lomb fe fait lentement.

Cependant, quelque empreffés qu'euffent paru les Rois Catholiques, pour le voyage, que, l'Amiral leur avoit propofé, on ne fe preffoit pas d'équiper les navires, qui lui avoient été accordés, foit que dès lors $\mathrm{D}$. Jean Rodrigue de Fonféca, qui avoit toûjours éré chargé de ces armemens, eût déjà conçû contre lui cette averfion, dont il lui donna dans la fuite tant de marques, ou que les fonds lui manquaffent. Colomb vit bien même que fes repréfentations ferviroient de peu, \& qu'il falloit prendre patience; mais il demanda, \& obtint que, du moins en attendant, on en. voyât quelques bâtimens chargés de provifions à Ifabelle, \& il profita de la même voye pour envoyer fes ordres à fon frere fur une chofe, qu'il avoit fort à cour depuis quel. que têms. Il fentoit bien qu'il avoit mal placé fa Colonie; l'air d'Ifabelle n'étoit pas mal fain, les eaux y étoient bonnes, mais tout le terrein des environs étoit fterile. On avoit beau y femer, rien n'y pouffoit, \& il falloit faire venir d'Europe jufqu'aux legumes. Il y avoit long-têms qu'il voyoit la néceffité de s'établir ailleurs, mais il n'avoit ofé faire un changement de cette nature fans l'agrément de la Cour; il le demanda, \& le tout fut remis à fa prudence.

I'Amiral or- Dès qu'il fe vit le maître de cette affaire, il manda à D. donne de pla- Barthélemy fon frere de travailler inceffamment à ce tranfport. Colonie d'Ifa- Il ne lui marquoit pas précifément le lieu, qu'il devoit choibelle. fir , mais il infinuoit en general la côte du Sud, où il avoit remarqué dans fon dernier voyage de bons ports, d'excellens pâturages, \& des terres, qui avoient toutes les apparences d'être fertiles. Il ajoûtoit que plus il pourroit s'approcher des mines de Saint Chriftophle, ce feroit le mieux; mais il lui recommandoit furtout de ne s'en rapporter à perfonne pour ce choix, \& de le faire lui-même après avoir bien examiné toutes chofes; ces ordres ne pouvoient venir plus à propos, l'Adelantade étoit fur le point de les prévenir, \& voici à Avanture quelle occafion.

d'un jeune Ef- Un jeune Arragonnois, nommé Michel Diaz, celui-là une Dame In- même apparemment, qui avoit été reconnoître les nouvelles dienne. mines 


\section{DE S. DomINGŨE, LIV. TI. I45}

mines avec François de Garay, s'étoit battu contre un autre Erpagnol, \& l'avoir dangereufement bleffé. Craignant les fuites de cet accident, il s'étoit éloigné, \& accompagné de cinq ou fix de fes amis, il avoit pris fa route vers la partie Orientale de l'Inle; de-là, cottoyant toûjours le bord de la mer, il tourna au Sud, \& arriva à l'embouchure du fleuve Ozama, où il s'arrêta. Il trouva fur la rive Occidentale de cette riviere une Bourgade Indienne, où commandoit une femme, qui le reçut bien, \& le prit tellement en affection, qu'elle réfolut de le retenir auprès d'elle. Pour l'engager plus aifément, elle lui propofa un établiffement pour les Efpagnols fur fes terres, lui fit remarquer la commodité du Port, que formoit naturellement l'entrée du fleuve, la beauté \& la bonté du pays, \& le voifinage des mines. En effet celles de Buenaventura, dont il fera parlé dans la fuite, \& dont on avoit eu depuis peu les premiers indices, n'en étoient qu'à huit lieuës. Enfin elle ajoûta, que fi tous les habitans d'Ifabelle vouloient s'y $\operatorname{tran}-$ porter, elle fe chargeoit de ne les laiffer manquer de rien, \& elle fit entrevoir à Diaz qu'il ne tiendroit qu’à lúi de l'époufer.

La Dame Indienne n'eut pas de peine à perfuader le jeune Efpagnol. S'il ne l'aimoit pas autant, qu'il en étoit aimé, il ne haüfoit point fa perfonne : \& la fortune, qu'il pouvoit efperer de faire en l'époufant, flattoit agréablement fon ambition. D’ailleurs l'établiffement propofé ne pouv́oit guexes réuffir, fans lui fournir une occafion de meriter fa grace du côté de fes Superieurs. Ainfi il entra avec joye dans les vûës de fa Bienfactrice, \& après lui avoir juré un éternel attachement, il prit par les terres le chemin d'Ifabelle, pour y négocier avec l'Adélantade fur les offres de la Cacique. En aprochant de la ville, il fçut que celui, dont la bleffure l'avoit obligé à fuir, étoit parfaitement gueri : ce qui l'enhardit davantage à fe préfenter devant $\mathrm{D}$. Barthélemy, dont il avoit été Domeftique, \& de qui il reçut effectivement le plus favorable accüeil, qu'il pouvoit efperer.

Tom. $I$. 


\section{I46 H Is T O I R}

1496. Les offres, qu'on faifoit à ce Commandant fuffifoien Fondation de pour le déterminer à entreprendre un établiffement à la San-Domin- côte du Sud; mais après qu'il eut reçû́ les ordres de fon go。 frere, il n'y eut plus à déliberer : ainfi fans différer davantage, il fe mit en marche avec Diaz. Il trouva, en arrivant chés la Dame Indienne, toutes chofes dans l'état, qu'on lui avoit dit : un Port fûr \& profond, un terrein propre à tout , \& des Indiens forr prévenus en faveur des Efpagnols. La Cacique en avoit trop bien ufé, pour qu'on ne lui laiflàt pas libre tout le côté du fleuve, où elle étoit placée ; $\&$ la rive Orientale valoit encore mieux que l'Occidentale. Le plan de la nouvelle ville y fut tracé fur le champs, \& en affés peu de têms la plus grande partie des habitans d'Ifabelle vinrent s'y établir. On la nomma d'abord la nouvelle Ifabelle, \& Chriftophle Colomb ne l'a jamais appellée autrement; mais le nom de Sam-Domingo a infenfiblement pris le deffus, \& l'on n'eft pas trop d'accord fur fon origine. Les uns ont avancé que l'Adélantade le lui avoit donné en mémoire de fon pere, qui s'appelloit Dominique : d'autres ont prétendu qu'il étoit arrivé en ce lieu-là le jour de la Fête du Saint Patriarche des Freres Prêcheurs, \& que cette Fête tomboit un Dimanche cette année-Jà, ce qui n'eft pas vrai, car elle tomboit un Jeudy. Mais l'opinion la plus vrayfemblable eft, que la premiere Eglife de la nouvelle ville ayant été confacrée à Dieu fous le nom de ce Saint Patriarche, qui eft encore aujourd'hui le Patron du Diocefe, ce nom a été donné avec le têms à toute la ville. comme de la ville même nos François l'ont étendu à toute l'Ifle. Quant à ce qui regarde Diaz \& fa Maîtreffe, il paroît qu'ils fe marierent, \& que la Cacique fut bâtifée, car toutes les fois qu'Oviedo en parle, il lui donne le nom de Catherine.

Voyage de Quoiquil en foit, un des premiers foins de Dom Bardel'Adélantade à Xaragua. thélemy en bâtiffant la nouvelle ville, fut d'y confruire une bonne fortereffe: Il en fit jetter les fondemens en fa préfence, \& ayant donné fes ordxes pour preffer les tras 


\section{DE S. Domingue, Liv. II. I47}

vaux, il entreprit un autre voyage à la côte de l'Oueft: dont voici le fujet. Nous avons vû que tous les Caciques de l'ille s'étoient foumis au tribut, à la réferve de Behechio Roi de Xaragua. Ce Prince fe flattoit que fon grand éloignement de tous les quartiers occupés par les Caftillans le mettroit à couvert de leurs pourfuites; il fe trompa , \& la fondation de San-Domingo commença à lui donner de grandes inquietudes. Il faifoit fa rélidence dans une bourgade, qui donnoit le nom à tout fon Royaume, le plus étendu de toute l'lle. J'ai parlé ailleurs de fa fituation; mais pour l'intelligence de ce que nous devons dire dans la fuite, il eft bon d'ajoûter, que toute cette côte Occidentale eft une fort grande Baye, à laquelle les François ont donné le nom de Cul-de-fac; \& que les Etats de Behechio comprenoient non-feulement toute cette Baye, Limites de ce Royaume avec le Cap Tiburon \& le Mole S. Nicolas, qui en font les deux pointes; mais encore toute cette partie de la côte du Sud, qui s'étend jufqu'à la petite Inle Beata. Ce Cacique, ainfi que je l'ai déjà dit, avoit une four nommée Anacoana, qui avoit été mariée avec Caonabo, \& qui après la mort de fon Epoux, s'étoit retirée chés fon frere. C'étoit une femme dun génie beaucoup au-deffus de fon fexe \& de fa nation, \& il s'en falloit bien qu'elle eût époufé les fentimens de fon mari contre les Efpagnols: elle les eftimoit, \& fouhaitoit fort de les avoir pour voifins, afin de pouvoir traiter avec eux. D. Barthélemny n'ignoroit pas les difpofitions de cette Princeffe; mais il fçavoit que celles de fon frere y étoient bien oppofées. Il fe flatta pourtant de gagner l'un par l'autre. D'ailleurs il lui importoit trop, \& pour fa gloire, \& pour l'avantage de la Colonie, de réduire de gré, ou de force ce puiffant Cacique à fuivre l'exemple des autres, pour y rien negliger.

Il partit donc de San-Domingo à la tête de 300. hommes, tous bien équipés, \& plufieurs montés à l'avantage , enfeignes déployées, au fon des trompettes \& des tambours, \& de plufieurs autres inftrumens, \& marcha toû- 


\section{T48 H IS T O I R E}

1496. jours en ordre de bataille, pendant les 70. lieuës; qu'on comptoit de San-Domingo à Xaragua. Behechio fut bientôt inftruit de fa marche, \& fit avancer quelques trouppes, pous lui difputer le paffage de la Neyva. L'Adélantade en ayant eu avis par fes coureurs, envoya un exprès au Cacique, pour l'affurer qu'il ne venoit point en ennemi, mais uniquement pour vifiter un Prince \& une Princeffe, dont on lui avoit dit beaucoup de bien. Behechio fut charmé du compliment, tout fon camp retentit de cris d'allegreffe, \& ces pauvres Infulaires, qu'on menoit bien malgré eux combattre des hommes, dont le nom feul les faifoit trembler, fe perfuaderent fi bien qu'ils n'avoient plus rien à craindre, qu'on les vit dans le moment courir à l'envi au-devant des Efpagnols.

Réseption Ils les rencontrerent affés près de la Neyva, leur donnerent à Xaragua. rent de leur bagage, leur rendirent pendant tout le refte du chemin, tous les fervices, dont ils étoient capables, \& les porterent même fur leurs épaules à tous les paffages des rivieres. Comme on approchoit de Xaragua, toute la Nobleffe fortit à la campagne, en danfant \& en chantant à la mode du pays. Les trente femmes du Cacique parurent enfuite, portant chacune une branche de palmier à la main, marchant en cadence, \& faifant retentirl'air de leurs chants. Elles s'approcherent ainfi du Général, lui préfenterent leurs palmes, \& fe profternerent à fes pieds. Quantité d'Indiens, qui étoient à leur fuite, firent la même chofe à tous les Efpagnols, \& l'armée fut ainfi conduite en cérémonie jufqu'au Palais de Behechio. Il étoit fort tard, quand elle $¥$ arriva, \& elle y trouva un grand repas tout préparé. Il étoit compofé d'Utias, \& d'autres animaux du pays, \& de tolstes fortes de poiffons de riviere $\&$ de mer : la joye fut gran. de pendant tout le feftin, après quoi on difribua à chacun des hamacs pour repofer.

Behechiofé Le lendemain, le foleil fut à peine levé, qu'on vit parồ-

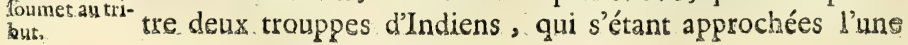


de l'autre en ordre de bataille, commencerent à fe mêler $\&$ à fe pouffer, comme ces peuples ont accontumé de faire dans leurs combats. Le jeu s'échauffant un peu,ils prirent leurs Macanas, \& s'en donnerent de bons coups fur la tête, fans fe faire beaucoup de mal. Ce divertiffement fini, l'Adélantade prit le Cacique en particulier, \& lui repréfenta que lui feul n'avoit pas encore rendu hommage aux Rois d'Efpagne, qu'il pouvoit venir de leurs Alteffes des ordres de l'y contraindre par la force, \& qu'il devoit être convaincu par l'expérience des autres, qu'il n'étoit pas en état de réfifter. Qu'il étoit de fa fageffe de prévenir les malheurs, aufquels une guerre de cette nature l'expoferoit, \& qu'en fe foûmettant de bonne grace à payer un tribut, qui ne l'apalvriroit pas, il fe procureroit l'amitié \& la protection du plus puiffant Prince de la terre. Ce difcours perfuada Behechio, que fa four y avoit apparemment préparé, mais il déclara qu'il ne pouvoit point donner d'or, n'y en ayant pas dans fes terres. Le Général lui répondit que les Efpagnols avoient trop d'équité, pour exiger de lui ce qu'il ne pouvoit pas fournir; on convint à l'amiable d'une certaine quantité de cotton \& de vivres, \& toutes chofes fe pafferent avec beaucoup de tranquilité.

Cette affaire terminée, l'Adélantade prit congé du Prince $\&$ de la Princeffe, \& fe rendit par terre à Ifabelle, où il Révolte de trouva qu'on manquoit abfolument de tout, \& que, depuis' fon départ de cette ville, il étoit mort plus de 300 . perfonnes de maladies $\&$ de miferes. Comme il ne venoit aucun navire d'Efpagne, il prit le parti d'en faire conftruire, pour y envoyer chercher des vivres, \& de difperfer, en attendant, les Efpagnols dans les Bourgades Indiennes voifines des Fortereffes; mais ces Barbares fe lafferent bientôt de: pareils hôtes, qu'ils ne pouvoient raffaffier, \& dont pour. toute récompenfe, ils recevoient toutes fortes de mauvais traitemens. Les Sujets de Guarionex étoient les plus vexés, ils perdirent aufi plûtôt patience, \& ils réfolurent de fécoüer enfin un joug, qui de jour en jour leur devenoit plus: 


\section{50 H I S T O I R}

1496. infuportable. Ils obligerent même leur pacifique Roi de $\mathrm{fe}$ mettre à leur tête', en le menaçant, s'il le refufoit, de fe donner à un autre Souverain.

Prife de ce L'Adélantade apprit cette nouvelle à San-Domingo, où Cacique. il avoit fixé fa demeure; il ne crût pas devoir donner au Cacique le têms de groflir fes troupes, ni aux autres celui de fuivre fon exemple. Il marcha promptement contre lui, \& l'ayant rencontré à la tête de I5000. hommes, il l'attaqua fi brufquement pendant la nuir, qu'après lui avoir tué bien du monde, il le fit prifonnier. Il le relâcha néanmoins à la priere de fes Sujets, qui le lui redemanderent avec les dernieres inftances, mais ce ne fut qu'après avoir fait juftice de ceux, qui avoient le plus contribué à lui faire prendre les armes. Nous verrons bientôt que des Caftillans même avoient eu grande part à cette rébellion. D. Barthélemy ne l'ignoroit pas, \& croyoit devoir diffimuler; mais il jugea que le crime de ces traitres rendoit Guarionex moins coupable, \& qu'il y eût eu de l'injuftice à le traiter en toute rigueur.

Il punit alors un autre crime de quelques Sujets de ce Prince avec beaucoup de feverité. Deux Religieux, un Hieronymite nommé le P. Romain, \& un Francif́cain appellé le P. Jean Bourguignon, avoient prêché la Foy dans ce Royaume, d'abord avec quelque fuccès, le Cacique s'étant lui-même fait inftruire de nos Saints Myfteres, \& paroiffant vouloir tout de bon fe faile Chrétien; mais la conduite des Efpagnols effaça bientôt dans fon cœur, tout ce qu'il avoit conçu d'affection pour le Chriftianifme; \& les chofes en vinrent à un tel point, que les deux Miffionnaires fe virent contraints de fortir de fes Etats. Quelque têms après, des Indiens étant entrés dans la maifon, où ces bons Peres avoient logé , y trouverent des Images; ils les prirent, \& les enterrerent dans un champs femé d'Axi, en difant: Vos fruits viendront déformais en abondance. Quelque têms après, la Mere de Guarionex arrachant quelques plantes d'A $A$ i, s'aperçût que leurs racines avoient la figure d'une Croix : elle en fut furprife, \& les montra 


\section{De S. DOMingue, Liv. II. ISI}

au Capitaine Ojeda, qui fit foüiller la terre au même endroit, y trouva les Images, \& ayant découvert les auteurs du facrilege, en donna avis à l'Adélantade, lequel crut de. voir faire un exemple de ces impies, \& ordonna qu'ils fuffent brulés vifs, ce qui fut executé.

Il reçut vers le même têms un Exprès de Behechio, L'Andélan qui lui mandoit que fon tribut étoit prêt, \& qu'il pourroit, tade va recequand il voudroit, envoyer un bâtiment au Port de Xaragua mier tribut du: pour le charger. Sur cet avis il dépêcha un courier à D. Die- Roi de Xara: gue fon frere, qui commandoit toûjours à Ifabelle, pour le ${ }^{\text {gua. }}$ prier de faire paffer une caravelle à la côte de Xaragua, \& il voulut y aller lui-même par terre, pour recevoir les premiers. hommages, que Behechio rendoit à la Couronne de Caftille. Il fut encore reçû́ de ce Roy avec un apareil \& une politeffe, où il crut reconnoitre l'efprit \& l'affection de la Princeffe fa four. Le navire arriva peu de têms après à Xaragua, \& fut chargé de cotton \& de caffave, au-delà même de ce qui avoit été ftipulé. L'Adélantade invita en. fuite le Prince \& la Princeffe à venir voir fon vaiffeau. C'étoir le premier bâtiment d'Europe, qui paroiffoit fur cette côte , \& ce qu'on avoit dit au Cacique \& à fa focur de ces: merveilleufes machines, avoir fort piqué leur curiofité. Ils en vifiterent avec beaucoup d'attention taus les coins \& les recoins, \& virent avec bien du plaifir toutes les manœuvres. qu'on lui fit faire : à la fin on les falua d'une décharge d'Axtillerie, qui d'abord leur caufa une grande frayeur, mais ayant vû que les Caftillans ne faifoient qu'en rire, ils fe raf: fürerent.

Ainfi fe pafla l'année I496. avec beaucoup de gloire pour D. Barthélemy, qui en peu de mois avoit fondé une grande ville, obligé le plus puiffant des Souverains de l'ifle à fe rendre tributaire des Rois Catholiques, \& diffipé une révolte, qui ne pouvoit manquer d'avoir de fâcheufes fuites, s'il ne l'eût étouffée dans fa naiffance. Il s'en faut bien quil ait eu autant de bonheur l'année fuivante, \& Sion en croit quelques auteurs, qui ne paroiflent pas mêे 
\$496. The fort prévenus contre lui, un peu de hauteur, qu'on crût entrevoir en lui depuis ces derniers fuccès; des manieres trop dures, qu'il ne fçût pas affez adoucir ; \& une féverité outrée dans le gouvernement, contribuerent un peu à attirer fur lui \& fur les fiens cet enchaînement de malheurs, dont nous allons voir la naiffance, \& dont fa famille ne s'eft jamais bien relevée. Il eft certain du moins, que ce furent là les prétextes, dont les ennemis des Colombs fe fervirent pour les rendre odieux à la multitude, \& pour infpirer contr'eux au Roi même des fentimens peu favorables, dont ce Prince n'eft jamais bien revenu. Ils alloient cependant au bien, \& leurs intentions ont tôkjours été droites. D. Barthélemy en particulier, ne paroît pas avoir eu dautre paffion, que celle de la gloire, \& il mit toûjours la fienne à faire fon devoir. Mais il importe beaucoup plus qu'on ne penfe, de ne 'vouloir le bien, qu'autant, \& de la maniere qu'il fe peut faire, d'être en garde contre une certaine aigreur, en quoi dégénére aifément le zéle, quand il n'eft pas tout à fait exempt d'humeur; \& de fe fouvenir, que quand l'autorité fe trouve dans une perfonne, qui n'eft pas agréable, comme dans un étranger, ou dans un homme nouveau, on ne peut trop s'étudier à en diminuer le poids, \& à en adoucir la rigueur. La fuite de cette Hiftoire nous fournira plus d'une occafion de fentir la verité \& la jufteffe de ces réflexions.

Fin du Livre Second. 


\section{H I S T O I R E \\ D E \\ L'ISLE ESPAGNOLE \\ O U D E \\ S. DOMINGUE. \\ PREMIERE PARTIE.}

\section{LIVRE TROISIE'ME.}

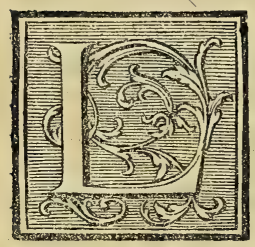

'A MIRAL, en partant pour l'Efpagne, avoit revêtu de la Charge d'Alcaíde Major , c'eft-à-dire, de Juge fuperieur, ou l'Alcaide Ma. de Grand Sénéchal de l'Ille, un certain ${ }^{\text {jor. }}$

François Roldan Ximenés, qui avoit été à fon fervice, \& qui s'étoit acquitté pendant quelque têms avec réputation de l'emploi de Juge ordinaire à Ifabelle. C'étoit un homme peu lettré, mais de beaucoup d'efprit, \& d'un grand fens naturel; ce qui avec un peu d'experience, fuffifoit pour adminiftrer la Juftice dans un pays, où il ne pouvoit gueres y avoir de procès bien épineux, ni embroüillés par la chicanne. Par malheur pour lui, pour la Colonie, dont il penfa caufer la ruine entiere, \& pour les Colombs; dont une bonne partie des difgraces furent le fruit de fes intrigues, ou occafionées par fa révolte, il étoit né le plus ambitieux, le plus hardi, \& le plus violent de tous les hommes. On prétend que le Commiffaire Jean Aguado avoit, du moins par fon imprudence, \& fes mauvaifes manieres avec Chriftophle Colomb, jetté dans fon efprit des femences de rébellion; \& il paroît certain que s'étant perfuadé que l'Amiral ne retourneroit point Tom. $I$. 


\section{IS 4 H I T O I E}

I497. dans les Indes, \& ne fe juftifieroit jamais des accufations intentées contre lui, il forma le deffein de fe faifir du Gouvernement. Il commença par s'affûrer des artifans, qui lui étoient affés attachés, parce que c'étoit lui, qui les avoit commandés pendant la traverfée, au fecond voyage de l'Amiral; il leur fit entendre que les Colombs penfoient à $\mathrm{fe}$ rendre maîtres du pays; il leur fit remarquer qu'ils les traitoient déjà en efclaves; \& il les engagea à demander qu'une Caravelle toute defagréée, qui fe trouvoit au Port d'Ifa-: belle, fut remife en état, \& envoyée en Efpagne, pour re: préfenter au Roy l'extrémité, où étoit réduite la Colonie.

Il fait fou- Dom Diegue, à qui ils s'adrefferent, pénétra d'autant lever les In- mieux leur deffein, qu'ils ne fe cachoient pas trop de la
diens. réfolution, où ils étoient, de poignarder l'Adélantade fon frere, dès qu'ils pourroient l'avoir entre leurs mains; mais comme il ignoroit tout le progrès, qu'avoit fait le mal, il crut y pouvoir remedier, en éloignant l'Alcaïde Major, fous quelque prétexte honnête. Guarionex, qui ne fe preffoit pas de payer fon tribut, lui en fournit un, qu'il faifit d'abord; il propofa à Roldan d'aller obliger ce Prince à fatisfaire à fes obligations, \& il lui donna une efcorte capable de l'en faire refpecter. L'Alcaide fe voyant à la tête d'une troupe de foldats choifis, ne fongea qu'à les débaucher, \& tous ceux, qui refuferent de s'attacher à lui, il les defarma \& les congedia. Il fit plus, car pour fufciter des. affaires aux Colombs, qui les occupaffent, \& les affoibliffent, bien loin de travailler à remettre le Cacique dans le devoir, il fomenta fa defobéiffance, \& l'engagea à prendre les armes, comme nous avons vû que ce Prince fit; après quoy. il revint à Ifabelle, \& ne garda plus de mefures avec le Gouverneur.

Entreprifes. Son premier acte d'hoftilité fut de fe faifir par force des hardies de ce clefs du Magazin Royal : il en rompit toutes les ferrures,
Rébelle. $\&$ diftribua à ceux de fa fuite une bonne partie de ce qu'il y trouva darmes \& de provifions. Il fit la même chofe dans les troupeaux, qui appartenoient tous au Ray, il en emmena 


\section{De S. Domingue, Liv. III. IT5}

les meilleures bêtes, \& après avoir fait bien des infultes à Dom Diegue, qui pour fauver fa vie, fut obligé de fe tenir enfermé dans le Château, il s'en alla avec environ 70. hommes bien armés du côté de la Conception, foulevant partout les Infulaires contre le Gouvernement. Son deffein étoit de s'emparer de cette Place, \& il s'en aprocha de fort près; mais Ballefter, qui y commandoit, lui fit dire de fe retirer, \& l'Adélantade y étant accouru avec des troupes, Roldan, qui connoiffoit la bravoure de fon Géméral, ne voulut pas fe commettre avec lui, \& s'éloigna.

Dom Barthélemy de fon côté fut effrayé du progrés, que Progrés de cette révolte avoit fait en fi peu de têms, car il apprit que la Révolte. quelques perfonnes de confideration, \& en particulier Diego de Efcobar, Commandant d'une Fortereffe, appellé la Magdelaine, y étoient déjà tuut ouvertement entrés ; \& ne fçachant pas trop à qui fe fier, il fe rendit en diligence à Ifabelle, pour y conferer avec fon frere fur le parti, qu'il y avoit à prendre dans une conjoncture fi délicate. Il y étoit à peine arrivé, qu'il reçût avis par Ballefter que fa vie n'y étoit pas en fûreté : ce Commandant l'exhortoit à le venir trouver; il le fit, \& dès qu'il fut à la Conception, il penfa aux moyens de regagner Roldan, qu'il defefperoit de réduire par la force. Il lui envoya un nommé Malaber, lequel n'oublia rien pour l'engager par la confideration du bien public à mettre bas les armes: mais tout ce que put gagner cet Envoyé, ce fut que les deux Chefs, aprés s'être donné mutuellement des otages, fe verroient dans un lieu fûr pour l'un \& pour l'autre.

L'entrevûë fe fit, mais les efprits s'y aigrirent encore davantage, \& l'Alcaïde Major en fortit réfolu à porter les de Roldan vantage \&c latcaide M. Baro chofes à toute extremité. Il en vouloit toûjours à la Con- thélemy fans ception, mais comme il n'avoit pas encore des forces fufffantes pour s'en rendre le maitre, il fe retira en attendant chés le Cacique Manicatex, dont il reçut le tribut ; \& la licence, qu'il donna à fes troupes, les ayant bientôt groffies, tandis que la faim faifoit tous les jours deferter des foldats de tout- 


\section{Is6 His TOIR}

1497. tes les garnifons, Dom Barthélemy fe trouvoit dans un embarras, qui croiffoit à chaque inftant, \& dont il ne voyoit point d'iffuë: il eut pourtant moyen de refpirer un peu par l'arrivée de deux Caravelles chargées de vivres, qui moüil-

1498. lerent à San-Domingo le 3. Février I 498. C'étoit celles, dont j'ai parlé plus haut, que l'Amiral avoit obtenuës, en attendant que fon armement fut prêt. Elles étoient commandées par le Sergent Major Pierre Fernandés Coronel, homme de merite \& fort attaché aux Colombs.

Celui - cy reçoit du. fe. cours d'EFpigne.

Au premier avis, qu'eut l'Adélantade de ce fecours, il fe mit en chemin pour la Capitale, \& fut fuivi par l'Alcaide Major, qui fe voyant prévenu par fon ennemi, \& fçachant que tous les habitans de cette ville, \& les équipages des deux Caravelles étoient fort peu difpofés à entrer dans fa rébellion, s'arrêta à cinq lieuës de la Place. Auflitôt D. Barthélemy lui envoya faire de nouvelles propofitions de paix, \& il avoit d'autant plus lieu de s'attendre qu'elles feroient écoutées, que Coronel publioit partout que l'Amiral étoit plus en faveur que jamais, \& ne tarderoit pas à arriver avec Gix Navires. Ce Capitaine avoit auffi aporté à D. Barthélemy les Provifions de la Charge d'Adélantade, fignées du Roi $\&$ de la Reine, \& il voulut bien fe charger lui-même de la commiffion d'aller trouver Roldan, mais du plus loin qu'il fut apperçu par les rebelles, on le coucha en jouë, en Iui criant : « Demeures là, traitre, fi tu avois encore tardé » huit jours, nous étions les maîtres.

Fuite de Guarionex.

Coronel vit pourtant le Chef des révoltés \& le pria d'avoir pitié d'une Colonie, qu'il déchiroit impitoyablement; fans pouvoir efperer d'en fortir à fon honneur; mais Roldan le prit fur un ton fi haut, que Coronel ne douta point qu'il n'eut des reffources, qu'on ne fçavoit pas. Peu de jours après on fçut qu'il s'étoit retiré dans le Xaragua. Tout en arrivant dans cette Province il déclara au Cacique qu'il venoit le délivrer d'un tribut que l'Adélantade lui avoit impofé fans en avoir reçu l'ordre du Roi, lequel ne vouloit point avoir le bien,mais le cour de fes alliés. Il tenoit le même langage à tous 


\section{DE S. Domingue, Liv. III. IST}

les autres Caciques, mais il n'étoit pas long-têms chés eux, fans en exiger beaucoup au delà du tribut, dont il les déli1498 vroit. Sur ces entrefaites on aprit à San-Domingo que les fujets de Guarionex, moleftés plus que jamais par les Efpagnols des deux partis, l'avoient extrêmement preffé de profiter de leur divifion pour fe remettre en liberté, mais que le paifible Cacique, pour éviter également les malheurs, à quoy l'expofoit un nouveau foulevement, \& les vexations de fes inlatiables vainqueurs, avoit pris le parti de fe retirer avec quantité de fes fujets chés les ciguayos, peuple affés aguerri, qui habitoit vers le Cap Cabron; \& qu'il y avoit été fort bien reçû́ de Mayobanex, qui en étoit le Souverain.

La retraite de ce Prince fruftroit les Caftillans du tribut, qu'il s'étoit engagé à leur payer, auffi lui en fit-on un crime, \& l'Adélantade ne crut pas devoir différer un moment à l'en aller châtier. Il lui fallut paffer des détroits de auxCiguayos,
monés qui il s'é plaine, il eut avis qu'une armée d'Indiens l'attendoit pour le combattre. 11 marcha à elle, \& après avoir effuyé une grêle de flêches, qui nebleffa perfonne, illa vit fe difperfer en un moment d'elle-même, \& gagner les montagnes. Il ne jugea pas à propos de la pourfuivre; mais quelques jours après', les Indiens s'étant aperçu que les Caftillans n'étoient point fur leurs gardes, ils tomberent fur quelques-uns d'eux, qu'ils trouverent endormis à l'écart, \& les maffacrerent. Alors les troupes fe réûnirent, on donna vivement la chaffe aux Barbares jufques dans leurs montagnes, \& l'on en tua un affés grand nombre. Mayobanex n'étoit pas fort loin de là, \& Dom Barthélemy ayant découvert le lieu de fa retraite, il y marcha aves toutes fes troupes. Il lui envoya enfuite offrir fon amitié, à condition qu'il lui remettroit Guarionex entre les mains. Le fier Indien répondit que Guarionex étoit un homme d'honneur, qui n'avoit jamais fait de tort à perfonne; au lieu que les Efpagnols étoient des voleurs \& des affarins, qui uroient des moyens les plus indignes 


\section{I58 HISTOIRE}

1498. pour envahir le bien d'autrui; qu'il ne feroit jamais affés lâche pour abandonner un Prince malheureux, fon bienfaiteur \& fon ami, qui s'étoit jetté entre fes bras. Il fit la même réponfe à fes Courtifans, qui voyant les ravages, que faifoient les Efpagnols dans tout le pays, \& touchés des cris du peuple, que cette guerre ruinoit, lui repréfenterent qu'il ne fauveroit pas Guarionex, \& qu'il fe perdroit luimême. o Il en arrivera, dit-il, ce qui pourra, mais je péw rirai plûtôt, que de le livrer à fes ennemis. Il appella auffitôt le Prince, \& lui déclara fa réfolution; Guarionex en fut attendri, ils s'embrafferent tendrement, \& s'arroferent l'un l'autre de leurs larmes. Mayobanex envoya enfuite occuper toutes les avenuës, \& tous les paffages des montagnes, \& donna ordre de faire main-baffe fur tous les Caftillans, fi on les pouvoit attaquer avec avantage.

Les Tndiens Dom Barthélemy, à qui, dans la fituation préfente de fes font défaits. Prife de Mayobanex. affaires, il importoit de gagner les Indiens, plûtôt que de les dompter, voulut encore faire une tentative, pour engager le Cacique à un accommodement; il lui renvoya trois prifonniers, qu'il avoit fait depuis peu, \& il s'avança luimême avec dix hommes de pied \& quatre chevaux feulement : mais pour toute réponfe, Mayobanex fit mourir les prifonniers, \& fe prépara au combat. Alors l'Adélantade vit bien qu'il n'y avoit plus rien à menager, \& alla fe préfenter en bataille devant l'armée ennemie, qui étoit affés nombreufe, mais qui n'eût pas plûtôt vû la belle Ordonnance des Caftillans, que faifie de frayeur, elle fe débanda, \& laiffa les deux Caciques prefque feuls à la merci de leurs vainqueurs. Le parti, qu'ils prirent, fut de fuir dans les montagnes, où le Général fe mit à leurs trouffes avec 30. hommes choifis, ayant auparavant congédié le refte de fes troupes. Il apprit deux jours après, par deux Ciguayos, le lieu, où Mayobanex étoit caché, il fit fur le champs déguifer douze de fes gens, c'eft-à-dire, qu'il les fit mettre tout nuds, $\&$ frotter de rocou à la maniere de ces Barbares, il leur donna les deux Ciguayos pour guides, \& point d'autres armes 


\section{De S. Domingue, L.iv. III. I59}

que leurs épées cachées dans des feüilles de palmier. Ils furent conduits en cet équipage jufqu'à la retraite de Mayo1498. banex, qu'ils trouverent avec fa femme \& fes enfans, \& plufieurs de fes parens. Ils s'en faifirent fans réfiftance, \& les menerent à leur Général, qui fur le champs reprit avec fa proye la route de la Conception.

Dans cette nombreufe troupe de prifonniers, il y avoit une fille de Mayobanex, que fon merite \& fa beauté avoient renduë extrêmement chere à tous les Ciguayos, \& qui avoit époufé un des principaux Seigneurs du pays. Son mary ayant appris fa captivité, affembla fes vaffaux, prit avec eux le chemin de la Conception, \& fit tant de diligence, qu'en peu de jours il joignit l'Adélantade. En l'abordant, il fe jetta à fes pieds, \& le conjura les larmes aux yeux, de lui rendre fon époufe : D. Barthélemy fut touché du naturel de cet homme, il le releva, lui fit amitié, \& lui remit fa femme, fans exiger même aucune rançon, mais il n'y perdit pas. La reconnoiffance porta ce Seigneur à faire beaucoup plus, qu'on n'auroit pû lui demander. On fut affez furpris de le voir revenir quelque têms après, avec 4 . à 500 . hommes de fes Sujets, qui portoient tous de certains bâtons brûlés , dont ces Peuples fe fervent pour remuer la terre; il demanda qu'on leur marquât un terrein, pour le cultiver, \& y femer du bled : fon offre fut acceptée, \& il fit faire en trèspeu de têms un défriché, que des Laboureurs à gage n’euffent pas fait, dit l'hiftorien Efpagnol, pour trente mille Ducats.

Les Sujets de Mayobanex, à la vûë de la générofité du Supplice Général des Efpagnols, envers la fille de leur Souverain, de Mayobàs'étoient flattés de quelque efperance de le voir bientôt délivré lui-même; ils n'épargnerent pour cela, ni larmes, ni prieres, ni préfens, mais tout fut inutile : D. Barthélemy voulut faire un exemple, qui retînt tous ces petits Princes dans la foumiffion; il rendit aux Ciguayos toute la famille du Cacique; mais il fut inéxorable fur fa perfonne. Ce refus jetta ces pauvres Infulaires dans la confternation, ils

(ection d'un Seigneur Indien.

Herrera

(1)




\section{T60 HISTOIRE}

1498. déchargerent leur refientiment fur l'infortuné Guarionex, vie à Mayobanex, qui fut conduit à la Capitale, où on lui fit fon procès dans les formes, \& où il fut pendu, comme convaincu du crime de Rébellion.

Ce qui avoit Les chofes étoient en ces termes, lorfque l'Amiral enfi fort retardé le troifiéme voyage de l'Amiral. tra pour la premiere fois dans le Port de San-Domingo. Mais il eft bon de reprendre la fuite de fon voyage, qui fut le troifiéme des quatre, qu'il a fait dans le nouveau monde. Nous avons vû avec quelle lenteur on travailloit en Efpagne à fon armement; tous les jours on lui faifoit de nouvelles difficultés, \& il fembloit qu'on ne cherchât qu'à le laffer. Cela pourtant ne venoit pas de la Cour : car le Roi \& la. Reine paroiffoient uniquement appliqués à le combler d'honneurs \& de biens. Non contents d'avoir de nouveau confirmé tout ce qu'ils avoient fait jufques-là en fa faveur, ils lui offrirent dans l'Inle Efpagnole un terrein à fon choix de 5o. lieuës de long fur 25 . de large, avec le titre de Duc, ou de Marquis; mais il n'accepta point cette grace, pour ne pas augmenter la jaloufie des grands contre lui, \& pour éviter les difcuffions, qu'elle ne pouvoit manquer de faire naître avec les Miniftres, \& les Officiers Royaux, lefquels lui reprocheroient fans ceffe d'avoir choif le meilleur pays, \& ne manqueroient aucune occafion de le chicanner. Enfuite, en confidération de la découverte des Inles de Cuba \& de la Jamaïque, dont il n'avoit tiré aucun profit, on le déchargea de contribuer d'un huitiéme des avances, pour percevoir un huitiéme des profits de tous les navires, qui alloient aux Indes. Mais on ôta de fes provifions quelques termes trop généraux, \& contre lefquels l'Amirante de Caftille s'étoit récrié : on lui recommanda en même têms de préferer toûjours la douceur à la févérité, quand elle ne feroit préjudiciable, ni à la Juftice, ni à fon honneur, \& ce fut la feule chofe, à quoi on lui fit connoître, qu'on avoit fait quelque attention aux dépofitions du Commiffaire Aguado, \& de fes autres ennemis contre lui. 


\section{De S. Domingue, LIv. III. I I I}

Le 20. d'Octobre I496. les trois navires, qu'il avoit vû partir de Cadix à fon arrivée dans ce Port, y furent de retour, \& débarquerent trois cens Indiens, que l'Adélantade avoit fait prifonniers, \& qu'il envoyoit comme efclaves en Erpagne. Les Rois Catholiques témoignerent n'approuver pas cette conduite, \& dirent tout haut que, fi ces Infulaires avoient fait la guerre aux Caftillans, ils y avoient fans doute été contraints par les mauvais traitemens de ceux-ci. Cet incident chagrina l'Amiral, \& il n'eût point d'autre parti à prendre, que de blâmer \& de défavoüer fon frere. Quelque têms après, le Doyen de Seville, D. Jean Rodriguez de Fonfeca, qui avoit toûjours la direetion des Armemens pour les Indes, \& qui n'aimoit pas l'Amiral. fut nommé à l'Evêché de Badajoz, où il alla réfider, \& fa place fut donnée à Antoine de Torrez, qui avoit accompagné Colomb à fon fecond voyage, \& avoit ramené fa flotte en Efpagne. Ce changement accélera l'Armement de Colomb : mais il n'étoit pas encore fini, lor'fque le Prince héreditaire d'Efpagne étant venu à mourir, la Reine, qui avoit beaucoup de confiance dans l'Evêque de Badajoz, le rappella auprès de fa Perfonne, apparemment pour la confoler dans fon extrême affliction, \& le chargea de nouveau des affaires des Indes. Ce retour fut un contre-têms fâcheux. pour Colomb, \& retarda encore fon départ. A la fin les ordres de la Cour ne fouffrant plus de délai, les fix Navires fe trouverent en état de partir.

Le 30. de May 1698. l'Amiral fortit du Port de San-Il part d'ECpât Lucar; \& pour éviter la rencontre d'une flotte Portugaife, gue, qui l'attendoit, difoit on, au Cap Saint-Vincent, à deffein de linfulter, il tira droit à l'Ifle de Porto-Santo, où il arriva le 7 . de Juin. Il y fit de l'eau, \& le Io. il toucha à Madere, où il fe fournit encore de beaucoup de chofes, le 19. il moüilla à la Gomera, d'où il paffa à l'Ifle de Fer. Là, il détacha trois de fes Navires, pour aller en droiture à l'Ifle Efpagnole; ils étoient montés par Alphonfe Sanchez de Carvajal, Officier de merite \& de naiffance, Tom. $I$. 


\section{I62 HISTOIRE}

\$498. dont nous avons déjà parlé , qui avoit accompagné l'Amiral à fon fecond voyage, \& avoit même fait un affés long féjour à Ifabelle; par Pierre de Arana, proche parent de l'ancien Gouverneur de la Navedad, cette premiere Fortereffe, qui avoit été bâtie dans les Etats de Goacanaric ; \& par Jean-Antoine Colomb, Génois, \& de la même famille que l'Amiral. Ces trois Capitaines devoient commander tour à tour par femaine. Ils eurent ordre de faire l'Eft quart Sud-Eft, pendant l'efpace d'environ 8 so.lieuës, enfuite de mettre le Cap à l'Oueft-Nord-Oueft, pour reconnoître l'Ine de Portoric, d'où il eft aifé de gagner San-Domingo. Les trois autres Navires, que l'Amiral s'étoit réfervés, appareillerent en même têms que ceux-ci,prirent la route des Inles du Cap Verd, y arriverent le 27.8 refterent moüillés auprès de celle de Belle-Veuë, jufqu'au s. de Juillet; de-là Colomb tira au Sud-Eft, \& voici ce qui l'engageoit à faire ce circuit.

Des Infulaires de l'Efpagnole lui avoient dit quautre-

II fait un fois il étoit venu chés eux des hommes noirs, portant des efgrand détour, peces de lances armées d'un très-beau métal, qu'ils nommoient Guanin, ils lui avoient même donné de ces bouts de lances, quil avoit portés en Efpagne, où l'on trouva, que de 32. parties, il y en avoit 18 . d'or, 6 . d'argent, $8 c$ 8. de cuivre. Suppofés la vérité du fait, on ne peut gueres douter que ces hommes noirs ne fuffent venus, ou des Canaries, ou de la côte Occidentale d'Afrique, d'où quelque tempête les avoit portés fur l'Ine Efpagnole : mais Colomb en jugea autrement; il ne pût croire, que des hommes fuffent venus de fi loin fur des bâtimens auffi plats, \& auffi fragiles, que ceux, dont fe fervoient les Afriquains, \& les Canariens, \& il fe perfuada que les hommes Noirs, dont on lui avoit parlé, étoient d'un pays beaucoup plus proche des Antilles. C'étoit pour le découvrir, qu'il prenoit fon point de partance des Ifles du Cap Verd, \& il fit la route, que j'ai dite, jufqu'à ce qu'il fe trouvât par cinq dégrés de Latitude Nord. Alors il eût à effuyer pendant huit jours un calme accompagné d'une chaleur fi exceflive, que le godron: 


\section{De S. Domingue, Liv. III. I6 3}

Ie fondit, \& que le navire fit eau de toutes parts, quoiquà l'exception du premier jour, le Soleil ne parût point \& \& qu'il y cût tốjours ou des pluyes, ou des broüillards, qui corrompirent les vivres, \& gâterent le froment; ce qui joint à la perte de prefque tout le vin, parce que les tonneaux s'ouvrirent, \& à l'accablement, où les équipages fe virent réduits, ménaçoit l'Amiral des derniers malheurs.

Oviedo a peine à accorder ce récit-, que je viens de faire d'après Herrera \& D. Fernand Colomb, avec ce qu'il prérend avoir oüi de la bouche de Fernand Perez Matteos, qui étoit premier Pilote fur le Navire, que montoit l'Amiral. lequel affuroit qu'après qu'on eut fait environ I so. lieuës, au Sud Oueft, en partant des Ifles du Cap Verd, on effuya une tempête fi furieufe, qu'il fallut couper les mats, \& jetter à la Mer une partie des Marchandifes; \& ce qui fait l'embarras de l'hiftorien, dont je parle, c'eft que D. Fernand Colomb étoit, difoit-il, avec fon Pere dans cette expedition. Mais il fe trompe affúrément: D. Fernand à la mort du Prince d'Efpagne, dont il étoit Page, fût mis en la même qualité chez la Reine, \& il y étoit encore plufieurs années après, ainfi qu'il le dit lui-même. Il eft vrai que dans la vie de fon Pere, il parle toûjours en premiere perfonne du pluriel, comme sil eût été témoin de tout ce qu'il raconte, mais il le fait dès le premier Voyage de l'A miral, \&lorfqu'il éroit encore prefque au berceau;de forte que, s'il fe trouvoit en contradiction avec Matteos, il faudroit fans balancer s'en tenir au témoignage de ce Pilote, mais il me paroît qu'on les peut concilier tous deux, en difant que les troisNavires effuyerent d'abord une violente tempête,qui incommoda fort les Navires, \& que le calme joint à une extrême chaleur, étant furvenu immédiatement après,avoit mis les équipages déja épuifés par de grandes fatigues, en grand dan ger de fuccomber tont-à-fait, \& produit tous les mauvais effets, que nous venons de rapporter.

Quoiqu'il en foit , l'Amiral, quoique malade de la golt- Il découvre fe \& \& fatigué à l'excès, voulut encore avancer d'avantage life de laTri- 
I64 HISTOIRE

I498. au Sud, pour tourner enfuite à l'Oueft, \& tint bon juf qu'au 3 I. de Juillet; mais alors l'eau commençant à lui manquer, il changea de réfolution, \& fit le Nord-quartNord-Eft, dans le deffein de gagner les Inles Caraibes. Il falloit que les courants l'euffent porté au Nord \& à l'Oueft d'une maniere bien extraordinaire les derniers jours de cette $\mathrm{Na}$ vigation, ou qu'il fe fût étrangement trompé dans fon eftine, car fur le midi du même jour 3 r. de Juillet, un Matelot nommé Perez, qui étoit à la hune, apperçût la Terre à $\mathbf{3} 3$. lieuës au Sud-Eft. Colomb ne balança pas à porter fur cette terre, laquelle paroiffant d'abord comme une montagne à trois têtes, il lui donna le nom de la Trinité : quelqủes uns ont écrit qu'il avoit fait vœu de nommer ainfi la premiereTerre qu'il découvriroit.Comme il approchoit de celleciil apperçût un Cap, ̀̀ côté duquel il y avoit un port. formé en partie par un Rocher, qui de loin avoit la figure d'une Galere; il donna au Cap le nom de Galera, \& vowlut entrer dans le Port, qui paroiffoit fort joli, mais il ne s'y trouva pas affez d'eau. Il tourna au Sud vers le premier Cap, qu'il avoit apperçû́, mais il ne s'y rencontra point de Port. Il continua à ranger la côte, \& le lendemain ayant fait environ cinq̣ lieuës à l'Oueft, il moüilla desriere une langue de terre, où il fit de l'eau $\&$ du bois, \&c qu'il nomma $P$ unta de le playa, le 2 d'Août ayant appareillé de nouveau, \& fait la même route, il aborda au Cap Occidental de la Trinité, qu'il appella $P$ unta del Arenal. ll ne douta plus alors que la. Trinité ne fut une Inle; \& comme il trouva ce moüillage affez fî̀, il permit à fes équipages d'aller à terre. Il y fut lui-même pour vifiter cette terre , \& il y étoit à peine arrivé, qu'il vit venir à lui un Indien de bonne mine, lequel avoit fur fa tête une efpece de couronmed'or. Illaborda \& remarquant que cet homme avoit envie d'une toque de velours cramoifi, quil portoit, il la lui offrit: l'Infulaire,qui étoit apparemment leCacique du lieu, l'accepta, \& lui donna en échange fa couronne d'or. 


\section{DE S. DOMINGUE, LIV. III. I6S}

qu'il prit encore pour une Ifle, \& qu'il nomma Ifla fanta, \& ce ne fut qu'au bout de quelques jours, qu'il reconnut fans la reconque c'étoit le Continent. Tandis qu'il étoit moüillé à la noîtrepour Punta del Arenal, un grand canot rempli d'Indiens s'approcha des Navires; il venoit du côté de l'Orient, \& il y avoit dedans 25 . Indiens tous jeunes gens, de belle taille, plus blancs que tous les Infulaires des Antilles, ayant la tête enveloppée d'ụne toile de cotton ouvragée avec des figures mifes en couleur: une autre toile toute femblable les couvroit depuis la ceinture jufqu'aux genoux ; ils étoient armés de boucliers, d'arcs \& de fleches, \& avoient dans leur air \& dans leur contenance quelque chofe de bien moins fauvage, que tout ce qu'on avoit vî. d'Indiens jufques-là. Deux ou trois coups de Moufquets, qu'on tira en l'air dès qu'on les eut apperçûs, leur firent tomber les rames des mains, \& ils fe mirent à parler affez haut, mais on ne conçût rien à ce qu'ils difoient; on voulut alors les attirer aux Navires, \& on leur montra toutes les babioles, qui av oient fi fort donné dans les yeux des Habitans des autres Ifles. Cela ne les ayant pas raffûrés ; l'Amiral fit joüer de tous les Inftrumens, dont les Navires Efpagnols ont accoûtumés d'être bien fournis; mais ces Barbares prenant cette fimphonie pour un fignal de combat, fe couvrirent de leurs boucliers, \& tirerent quantité de fleches. Les Efpagnols y répondirent par deux coups d'arbalêtres, uniquement pour les intimider, \& cela eut fon effet. Le canotalla fe ranger fous la poupe d'un des Navires, dont le Pilote fauta dedans, \& fit à ces Indiens de grandes careffes, qu'il accompagna de quelques préfens. Ils l'inviterent à venir à terre avec eux,mais cet hom. me ne layant pas voulu faire fans la permiffion de l'Amiral . \&rles ayant quittés pourl'aller demander,ils s'imıginerent qu'il me vouloit pas les fuivre, \& ils ne l'attendirent pas.

Cependant une chofe furprenoit infiniment l'Amiral, il Froid extraor= fe trouvoit à dix dégrez de la Ligne Equinoxiale, \&s on les Efpagnols étoit aux jours Caniculaires; toutefois les nuits \& les ma-refententforis tinées étoien: fi froides, que tout le monde étoit obligé de la 
$\$_{498}$. fe couvrir comme en Hyver. C'eft une experience, qui re fait en bien des endroits de la Zone Torride, fur-tout quand les nuits font calmes, \& , ce qui en eft une fuite ordinaire, les rofées abondantes; mais Colomb à qui cela étoit nouveau, ne fçavoit trop qu'en penfer; il remarqua au même têms que les eaux couroient vers l'Oueft avec une trèsgrande rapidité dans le Golphe, où ilfe trouvoit, \& qu'il appella le Golphe de la Baleine. Il avoit devant lui au Nord quart-Nord-Eft une Terre éloignée d'environ is. lieuës, qu'il prit encore pour une troifiéme Ine, \& à laquelle il donna le nom de Gracia; mais c'étoit une autre partie du continent. Il paffa le Canal, où il eût affez de peine à fe foûtenir, \& où il obferva que la Marée montoit $\&$ defcendoit foixante pas plus, qu'à San-Lucar de Barameda. Etant arrivé à la Terre ferme, qu'il prenoit toûjours pour une Ifle, il donna à la Côte le nom de Paria, il la trouva fort agréable, \& les Habitans, pour l'ordinaire, affez traitables, \& tous fort bien faits. Plufieurs avoient de l'Or, mais il étoit prefque tout de bas aloy; les femmes avoient des Coliers \& des Bracelets de Perles, \& elles indiquerent aux Efpagnols l'endroit, d'où l'on tiroit \& l'Or \& les Perles.

L'Amiral eut bien voulu découvrir tout ce Pays; mais fes Vaiffeaux ne pouvoient plus tenir la Mer ; d'ailleurs les vivres lui manquoient, \& il'étoit preffé de fe rendre à l'Ifle Efpagnole; ainfi après avoir employé les dix premiers joụrs d'Août à vifiter le Golphe de la Baleine, qui eft celui où fe décharge l'Orénoque ; l'onziéme il fit l'Eft,

Les habitans du pays les nomment Yuyapari. \& le treiziéme il entra dans un très beau Port, qu'il appella le Port des chats ; il eût dû l'appeller plûtôt le Port des Singes; car ce qu'il prit d'abord pour des Chats, étoient de très gros Singes, dont tout cet endroit étoit rempli; ce Port eft proche d'une des bouches de l'Orénoque. Affez près de là, il entra dans un autre Port, où il y avoit quantité de Cabanes, \& qu'il nomma le Port des Cabanes; le quatorziéme il paffa au Cap de Lapa, à deffein de for- 


\section{DE S. Domingue, Liv. III. I67}

tir du Golphe en faifant le Nord. De ce Cap qui eft la pointe de la Côte de Paria, \& le Cap Boto, qui eft la pointe du Nord-Oueft de la Trinité, il y a un peu moins de deux lieuës, \& un peu au-deffus, le Canal en a cinq de largeur; les Vaiffeaux y entrerent avant'midi, \& quoiqu'il ne fit prefque point de vent, ils y trouverent la Mer fi haute, fi bruyante, \& tellement couverte d'écumes, par le combat du courant avec la Marée, qu'ils fe virent dans un très grand danger de périr. Quelques-uns ne pouvant fe foûtenir, voulurent moüiller, mais les vagues enleverent les ancres, \& peu s'en fallut que les trois Bâtimens n'allaffent fe brifer contre quelque terre,ou ne fuffent engloutis par les vagues. Ils avoient bien éprouvé la même chofe, lorfqu'ils étoient entrées dans le Golphe par le Canal qu'ils nommoient de la Sierpe à côté de la Punta del Arenal, mais le vent les y avoit favorifés, au lieu qu'ici, étant furpris du calme, ils ne pouvoient ni avancer, ni reculer, ni s'arrêter fans danger. Auffi l'Amiral fe voyant engagé dans ce mauvais pas, dit que s'il en fortoit, il pouroît bien dire qu'il feroit forti de la gueule du Dragon, \& s'en étant enfin heureufement tiré , il donna à ce détroit le nom de la bocadel Drago, qu'il porte encore aujourd'hui.

Ce qui le fauva, fut que la Marée commençant à per- Imaginations dre, le courant de l'Orénoque prit le deflus, \& les entrầna en pleine Mer. L'étonnement de l'Amiral fut alors extrême, en voyant de l'eau douce fi avant en Mer ; car il étoit environ à 10 . lieuës du fond du Golphe, d'où fortoit cette eau. La fraîcheur des matinées, qui continuoit toûjours, ne le furprenoit pas moins, \& comme il avoit obfervé que fe trouvant environ à 100. lieuës des Açorres, l'aiguille aimantée déclinoit d'un quart de vent au Nord-Ouef, que plus il avançoit au Ponent, plus l'air étoit doux \& $\mathrm{fe}$ rein, les peuples plus traitables \& moins noirs, \& le pays plus beau; il s'alla mettre dans l'efprit, que la Mer montoit infenfiblement de ce côté-là vers le Ciel, que la terre réctoit pas ronde, \& que s'il alloit plus loin, il arriveroit 
\$. en enfin à une éminence, où fe terminoit ce bas monde, \& fur laquelle étoit fitué le Paradis terreftre; il s'imagina même que l'eau douce, qu'il avoit rencontrée fi avant en mer, pouvoit bien être celle de cette fontaine, dont l'Ecriture dit, que le jardin de délices étoit arrofé , \& d'où fortoient, par deffous la terre $\&$ le fond de la mer les quatre Fleuves, dont il eft parlé dans la Genefe. Il n'y avoit pourtant rien que de très-naturel dans ce qui caufoit fa furprife : la rapidité de l'Orénoque eft exirême en tout têms; mais furtout dans les mois de Juillet \& d'Août, que ce grand Fleuve eft encore groffi par quantité de Rivieres \& de Torrens, qui s'y déchargent alors; de forte qu'il n'eft pas. fort étonnant que fes eaux demeurent long-têms féparées de celles de la mer, au milieu de laquelle on le voit paffer impetueufement, \& franchir même les plus fortes Marées.

Découverte de la pêche des perles.
L'Amiral ne fut pourtant pas long-têms dans l'erreur; dont je viens de parler; qu'on peut regarder comme un de ces délires, aufquels les grands hommes font fouvent encore plus fujets, que les autres, \& qui étoit d'autant plus excufable dans Colomb, que le merveilleux de la découverte d'un monde inconnu à tous les fiecles paffés; l'ébloüiffoit peut-être encore un peu. Pour revenir, dès qu'il fe vit hors de la bouche du Dragon, il fit le Nord, pour entrer dans le Golphe où on lui avoit dit que fe pêchoient les Perles, \& dont il lui donna le nom. Il en fit le tour, \& fit par tout charmé de la beauté du pays.' Aubout de quelques jours, la curiofité l'ayant engagé à defcendre à terre ; quantité de Sauvages vinrent à lui , portant au col de petites lames, qu'ils nommoient Caracolis, \& qui avoient à peu près la figure des hauffecols de nos Officiers.' Ce nom de Caracolis étoit proprement celui du métal, dont ces lames étoient faites, ou plûtôt d'une compofition de métaux, où l'or dominoit. Mais ce qui augmenta de beaucoup la joye des Caftillans, c'eft qu'ils apperçûrent quan: tité de femmes, qui avoient des colliers $\&$ des bracelets de perles, qu'elles leur donnerent prefque pour rien. On leur 


\section{DE S. D O INGUE, LIV. III. $\quad \pi 69$}

leur demanda en quel endroit précifément ces perles fe pêchoient, \& elles firent entendre que c'étoit au voifinage d'une Inle, qu'elles montrerent à l'Occident. L'Amiral jugea que la chofe valoit bien la peine de s'y tranfporter; il tourna donc de ce côté-là, \& après avoir fait fix ou fept lieuës, il aborda à une Inle fort peuplée, qu'il nomma la Marguerite, laquelle a Is. lieuës de long fur fix do large; entre cette Inle \& la grande terre, que Colomb avoit enfin reconnu être un Continent, il apperçût deux autres Ifles plus petites, l'une fe nommoit cochem, qui veut dire, Venaifon, apparemment parce que le gibier y abondoit; l'autre, qui n'eft éloignée de la terre ferme, que de quatre lieuës, avoit nom Cubagua.

L'Amiral s'étant approché de celle-ci, vit au large des Indiens, qui pêchoient des perles : il leur envoya fa Cha. loupe; mais dès qu'ils l'eurent apperçuë, ils s'approcherent de l'Ifle. La Chaloupe les fuivit, \& un Matelot ayant remarqué parmi eux une femme, qui portoit au col une grande quantité de fils de perles, il prit un plat de terre de Valence, peints de differentes couleurs, fur un affés beau vernis, le mit en pieces, \& en préfenta les morçeaux à l'Indienne, qui lui donna en échange un bon nombre de fes perles. Il les porta à l'Amiral, qui le renvoya avec plufieurs autres bien fournis de plats de Valence, \& de petites fonnettes; ils ne tarderent pas à revenir avec trois livres pefant de perles, la plûpart médiocres, quelqu'unes fort groffes; car, pour ce qu'on appelle la femence de perles, ce peuple n'en faifoit point de cas, \& ignoroit même la maniere de la pêcher. Il ent certain que, fi Chriftophle Colomb eut voulu profiter de cette occafion, cette feule traitte eut pû dédommager l'Efpagne des grandes avances, qu'elle avoit faites pour le nouveau monde; mais il rappella d'abord fa chaloupe, \& appareilla fur le champ.

Il avoit apparemment de bonnes raifons pour en ufer Il arrive a ainfi; il fut pourtant accufé par fes ennemis d'avoir vou- San-Domits? lu tenir cette découverte fecrette, afin d'en profiter tout ${ }^{\text {ge }}$ 
\$498. feul; mais il eft certain, qu’encore qu'elle eut été publiée en Efpagne par le retour des Vaiffeaux, qui l'avoient faite, les Rois Catholiques en étoient déjà informés par des lettres de l'Amiral; \& peut-il en effet venir dans l'efprit d'un homme fenté que Colomb, qui n’a jamais pafté pour intereffé, ait été pour cette feule fois aveuglé par la paffion de s'enrichir au point, de fe flatter qu'une chofe de cette nature, qui avoit pour témoins les équipages de trois Navires, ne fe divulgueroit point? Ce fut le r 3 . d'Août que l'Amiral partit de Cubagua, \& ce jour-là il fit à la faveur des courans 63 . lieuës entre le lever \& le coucher du Soleil. Les jours fuivans il eût encore les vents \& les courans extrêmement favorables, \& le 19 . il fit 100 . lietiës \& fe trouva par le travers de la Beata, ayant dépaffé SanDomingo de 25 . lieuës; il en avoit pourtant été bien près; puifque fes navires furent apperçus de la ville. L'Adélantade fe douta bien que c'étoit fon frere, \& envoya une Caravelle après lui : elle le trouva entre la Beata, \& la grande Ifle, \& le conduifit le 22. à la Capitale, où il fût reçû avec des honneurs \& des acclamations extraordinaires.

Progrès de la Mais la joye que devoit lui caufer une telle réception? révolte de l'Alcaide Major" fut bien temperée par les fâcheufes nouvelles, qu'il apprit en même têms. Nous avons vû qu'en partant des Canaries, il avoit envoyé en droiture à l'hle-Efpagnole trois de fes navires; ils n'y étoient pas encore arrivés, les vents \& les courants les ayant portés fur les Côtes de la Ja. maïque, quaucun de leurs Pilotes ne connoiffoit; de forte qu'après avoir long-têms erré, fans fçavoir, où ils alloient; ils fe trouverent à la côte de Xaragua, affez près de l'endroit, où Roldan, \& fa troupe vivoient à difcretion fans Dieu, \& fans loy, au milieu des Indiens, qu'un pareil voifinage incommodoit beaucoup, \& qu'une telle conduite fcandalifoit étrangement. Les Rebelles furent affés furpris de voir fur cette côte trois Navires : ils craignoient d'abord que ce ne fuffent destroupes, qu'on envoyoit contre eux, mais ils furent bien-tôt détrompés \& raffurés : de leur côté ils: 


\section{DES. DOMINGUE, LIV. III. ITI}

n'eurent garde de faire connoître leur fituation; les Chefs allerent vifiter les Capitaines fur leurs bords, \& en furent bien reçûs; ils demanderent des nouvelles de l'Amiral, \& ils avertirent Carvajal \& fes deux collegues, qu'il n’étoit: pas aifé de remonter à San-Domingo de l'endroit, où ils fe trouvoient, les courunts dans toutes ces Mers portant prefque toûjours à lOueft, auffi bien que les vents, qui en font une des principales caufes; jufques-là qu'on avoit vû des Navires mettre fix mois à aller de la Beata à la Capitale; il conclurent de là qu'ils feroient fagement d'envoyer une partie de leur monde par terre, fur-tout ceux, qui fe trouvoient les plus incommodés de la Mer.

Ce Confeil, dont on ne pouvoit pas pénétrer le motif, L'Aicaide Ma: parut judicieux, \& fut fuivi; on débarqua des Ouvriers, jor débauche gens, qui pour la plûpart avoient été tirés des prifons, \& pagnols nouJean Antoine Colomb fut prié de les conduire. Roldan ne les vît pas plûtôt à terre, qu'il leur exaggera la longueur \& les difficultez du chemin, qu'ils avoient à faire, \& beaucoup plus encore les travaux, qui les attendoient au terme fatal de leur exil; il leur parla enfuite de la hauteur $\&$ de la dureté des Colombs, \& il leur ajoûta qu'ils pouvoient éviter tous ces malheurs, en s'attachant à lui, que dès ce moment ils feroient au bout de leurs travaux, qu'il ne tiendroit qu’à eux de mener une vie agréable, dans l'afluence de toutes fortes de biens, dont cette Province regorgeoit. Il n'en falloit pas tant pour perfuader des gens du caractere de ceux, à quil l'Alcaïde s'étoit adreffé; t toutefois, de 40. qu'ils étoient, il y en eut huit, qui déteftant fa perfidie, en allerent fur le champs avertir leurs Officiers. La furprife fut grande fur les Navires à cette nouvelle ; on affembla le Confeil pour déliberer fur ce qu'il y avoit à faire. \& il fut réfolu que Carvajal iroit par terre à San-Domingo, avec une efcorte capable de fe faire refpecter, \& mettroit tout en ufage pour ramener les Rebelles à l'obéiffance. Cette réfolution prife, \& Carvajal s'étant fait débarquer, les trois Navires, à qui l'Adélantade, averti par des Indiens. 
1498. qu'on les avoit vûs à la côte, avoit envoyé une Caravelle pour leur fervir de guide, arriverent heureufement à SanDomingo peu de jours après l'Amiral; mais comme la longueur du voyage leur avoit fait confumer les provifions, dont ils étoient chargés pour la Colonie, ils n'y porterent que de nouvelles bouches, qui firent bien-tôt croître la famine. On s'étonnera fans doute de ces frequentes difettes, dans un pays, où il $\mathrm{y}$ avoit fi peu à faire pour fe mettre en état de fubfifter indépendemment des fecours d'Europe; mais on reviendra aifément de fa furprife, pour peu qu'on faffe attention que les Caftillans, qui naturellement font très-peu laborieux; l'étoient beaucoup moins dans un pays, où la chaleur extrême, la difference du climat, \& fouvent leurs débauches, les réduifoient d'abord à une foibleffe, qui leur rendoit prefque impoffible la culture de la terre; outre quils fe voyoient environnés d'un peuple nombreux, fur lequel ils ne pouvoient s'empêcher de compter pour avoir des vivres, quelque expérience qu'ils euffent que c'étoit là une très-foible reffource pour eux, les Indiens fouvent par mauvaife volonté, \& plus fouvent encore par un effet de leur indolence \& de leur pareffe naturelle, leus manquant prefque toûjours au befoin.

I'Amiral er. Taye de les gagner.

Carvajal fuivit de près fes deux collegues, \& quoique fur fon rapport il y eût peu d'efperance de regagner les Révoltés; Colomb, à qui il importoit qu'on n'apprit en Efo pagne ce foulévement, qu’après qu'il feroit appaifé , voulut encore tenter la voye de la douceur, avant que de prendre celle de la force; mais avant toutes chofes, il crut devoir mettre dans fes interêts tous ceux, dont la fidelité pouvoit être fufpecte, \& comme il fçavoit que plufieurs fouhaitoient avec paffion de retourner en Efpagne, \& que le peu de liberté, qu'on avoit eu jufques-là fur ce point, avoit fort contribué à former, ou du moins à grofir le parti des mé contens, le 12 . de Seprembre il fit publier que, non ferslement il permettroit à quiconque de repaffer la Mer, mais qu'il fourniroit même des bâtimens, \& des yivres à ceux 


\section{DE S. DOMINGUE, LIV. III. I73}

qui voudroient s'embarquer. Plufieurs accepterent l'offre , \& l'Amiral tint parole. Roldan de fon côté n'eut pas plûtôt apris l'arrivée de Colomb, qu'il s'approcha, bien accompagné, de Bonao, Bourgade, qui s'étoit formée auprès des Mines de S. Chriftophle à $\mathbf{3} 6$. ou I7. lieuës de la Capitale. On fut quelque têms en doute du deffein, qu'il avoit en faifant cette démarche, \& $\&$ on eut tout lieu de connô̂tre par la fuite, qu'il étoit venu là également difpofé , \& à fe défendre, fi on l'attaquoit, \&à s'accommoder, fi on lui faifoit des propofitions, qu'il pût accepter avechonneur \& avec fûreté.

Il ne tint pas à l'Amiral quill ne prî́t ce dernier parti. Ne Ballefter Ballefter qui étoit toûjours Commandant de la Concep-avec Roldan tion, lui alla offrir de la part de Colomb une amniftie en fans fruito bonne forme, \& lui repréfenta le préjudice, que fa révolte caufoit à la Colonie, au fervice des Rois Catholiques, $\&$ à fes propres interêts. Cet Officier eut auffi ordre de l'affûrer, que l'amitié, dont l'Amiral lui avoit donné tant de marques, n'avoit rien perdu de fa vivacité, qu'il le fentoit au chagrin, qu'il avoit de voir un homme de for rang, dont il avoit répondu à leurs Alteffes, fe tenir à las tête d'une troupe de factieux \& de bandits, mener avec des gens, qui avoient mérité la corde, une vie, qui deshonoroit également fa religion \& fa patrie; détourner les tributs, qui fe devoient payer à la Couronne de Caftille, \& mettre en péril une Colonie naiffante, qui avoit tant coûté à l'Etat, \& fur laquelle les Rois leurs Maîtres avoient: fondé de fi grandes efperances ; que malgré tant d'excès criants, il oublieroit be paffé, s'il vouloit rentrer dans fon devoir, \& que s'il fouhaittoit d'autres garants, que fa parole de Vice-Roi \& d'Amiral, il étoit prêt, pour faciliter fon retour à l'obéiffance, d'entrer avec lui dans tous les engagemens, qui ne feroient pas contraires à la dignité de fa perfonne \& de fon caractere.

Ballefter s'acquitta de fa commiffion, avec le même ze1e. qu'il avoit déja fait paroître dès le commencement de 
1498. cette révolte, mais avecauffi peu de fuccès. Il trouva Roldan à Bonao avec Efcobar \& deux autres de fes principaux Officiers, nommés Adrien de Moxica, \& Pierre de Gamiz: il leur dit tout ce qu'il pût imaginer de plus fort, pour leur faire prendre des fentimens plus raifonnables, \& il n'en reçût que des réponfes pleines de hauteur, \& de mépris pour les Colombs, dont à les entendre parler, la vie étoit entre leurs mains; ils le chargerent même d'une lettre adreffée à l'Amiral, dans laquelle ils lui marquoient que, s'ils n'eûffent pas retenu leurs foldats, il y auroit long - têms que l'Adélantade auroit payé de fa vie les torts, qu'il leur avoit faits. Après un long détail des griefs, qu'ils avoient contre D. Barthélemy \& D. Diegue, ils ajoûtoient, qu'ils avoient long-têms foupiré après fon retour, comme après la fin de leurs maux: qu'ils voyoient bien qu'ils s'étoient flattés d'une vaine efperance, qu'ils ne pouvoient prendre aucune confiance en un ennemi , qu'ils fçavoient être réfolu à les perdre, ni reconnoître pour leur Vice-Roi un homme, qui ne craignoit point de facrifier la Juftice à fes interêts particuliers, \& à ceux de fa famille. Qu'au refte ils ne vouloient plus entendre parier d'accommodement, à moins qu'on ne leur envoyât D. Alonfe Sanchez de Carvajal.

I'amiralcntre en défiance de Eąrvajal.
Cette lettre embarraffa l'Amiral, en qui elle faifoit nầtre contre la fidelité de Carvajal des foupçons affez bien fondés. Il fçavoit que cet Officier avoit demandé à la Cour, $\&$ obtenu fans fa participation une patente, qui lui donnoit dans l'inle Efpagnole une autorité peu inferieure à la fienne , \& qu'il avoit eu Roldan \& plufieurs de fes complices fur fon Navire pendant deux jours, \& ne les avoit pas arrêtés comme il le pouvoit; on affüroit même qu'il les avoit engagés à venir à Bonao, \& avoit promis à l'Alcaïde Major, de l'affocier au gouvernement, dont il devoit, difoit-on, re faifir en dépit de l'Adélantade, \& en vertu d'une commiffion de la Cour, fi l'Amiral ne revenoit pas. On ajoûtoit qu'il étoit en commerce d'amitié avec ce Chef de la rébellion, qu'il lui faifoit des préfens, \& qu'il en recevoit. On 


\section{DE S. DOMIngue, Liv. III. I7s}

faifoit réflexion qu’à l'arrivée de Coronel, la crainte avoit parû faifir ces factieux, \& les difpofer à fe foûmettre, \& que fix autres navires étant venus depuis ce têms-là d'Efpagne, ilsavoient repris cœur, ce qui faifoit juger qu'ils comptoient d'être fouttenus. On publioit encore que Carvajal leur avoit vendu des armes, \& il étoit certain qu'il s'étoit fait efcorter par Pierre de Gamiz, jufqu'affés près de la Capitale, fous prétexte qu'il avoit à paffer fur les terres de quelques Indiens, dont il craignoit d'être infulté; enfin les Re. belles difoient tout haut que, s'ils avoient à fe choifir un Chef, ils n'en voudroient point d'autres, que Jui.

Néanmoins tout bien confideré, l'Amiral qui vouloit ab- Il ne laif́ pas folument la paix, parla raifon qu'il ne fe voyoit pas en état lui pour négoo de faire la guerre, \& que d'ailleurs la guerre civile la plus cier avec Kole. jufte, pouvoit fournir à fes ennemis bien des prétextes pour lui nuire ; l'A miral, dis-je, fe réfolut à ne rien épargner pour mettre dans la plus grande évidence la fincerité de fon procedé, \& pour convaincre les moins prévenus en fa faveur qu'on avoit tort de l'accufer de prendre toûjours plus volontiers la voye de la feverité, que celle de la douceur; il confentit à fe fervir de l'entremife de Carvajal. Il crut qu'après tout, cet Officier, qui étoit homme de condition, \& paffoit pour avoir de la droiture, ne feroit rien, qui pûr le deshonnorer, \& il fe flatta qu'une marque de confiance fi peu attenduë \& fi peu méritée, ou le lui gagneroit, ou l'engageroit du moins à le fervir fidellement. La fuite fera voir qu'il en avoit bien jugé, mais il lui donna Ballefter pour affocié, \& le chargea de la lettre fuivante pour l'Alcaide Major.

c Cher ami, mon premier foin en arrivant dans cette Lettre de $l^{3} \mathrm{~A}_{\text {- }}$

„ Capitale, après avoir embraffé mon frere, fut de deman- miralà Rol-

» der de vos nouvelles. Vous ne fçauriés douter qu'après

ma famille, vous n'ayiés depuis long-têms occupé la prin-

* cipale place dans mon coeur, \& j'ai toûjours tellement

2a. compté fur le vôtre, qu'il n’eft rien, dont jene me fus dan. 


\section{I76 HISTOIRE}

1498. * fe entierement reporé fur vous; jugés par-là de ma doür

» leur en apprenant que vous vous êtiés broüilléavec les

„ perfonnes du monde, qui me touchent de plus près, \&

s me doivent être les plus cheres. On me confola néanmoins

» en me difant que vous attendiés mon retour avec ar-

w deur; je me flattai alors que vos premiers fentimens à

* mon égard n'étoient point changés , \& je m’attendois

» qu'auffi-tôt que vous fçauriés mon arrivée, vous ne tar-

wo deriés pas à vous rendreauprès de moi ; ne vous voyant

s point paroître, \& croyant que vous apprehendiés quel.

$\$$ क que reffentiment de ma part, je vous envoyai Ballefter,

so pour vous donner toutes les affùrances, que vous pouviés

* défirer. Le peu de fuccès de cette démarche a mis le

w comble à mon chagrin; \& d'où vous peuvent donc ve-

2) nir ces défiances, que vous témoignés avoir de moi ? En-

» fin vous m'avés demandé Carvajal, je vous l'envoye ?

» ouvrés lui votre cœur, \& marqués lui ce que je puis

$\rightarrow$ faire pour regagner votre confiance; mais au nom de

w Dieu fongés à ce que vous devés à la patrie, aux Rois

s nos fouverains Seigneurs, à Dieu, à vous même : pre-

2o nés foin de votre réputation, \& jugés plus fainement de

\$ toutes chofes, que vous n'avés fait par le paffé ; confi-

» derés avec attention, l'abîme que vous creufés fous vos

๖ pieds, \& ne perfiftés pas plus long-tems dans une réfo-

» lution défefperée. Je vous ai repréfenté à leurs Alteffes;

» comme un des hommes de la Colonie, fur qui elles pou-

s voient plus fûrement compter; il y va de mon honneur

» \& du vôtre, qu'un témoignage fi avantageux ne foit

» pas démenti par votre conduite; hâtés-vous donc de

» vous remontrer tel, que je vous ai autrefois connu;

* j'arrête les Navires, qui font tout prêts à partir, dans l'ef-

* perance que par une prompte \& parfaite foûmiffion ,

» vous me mettrés en liberté de confirmer tout le bien,

» que j'ai dit de vous. Je prie le Seigneur qu'il vous ait en

o fa fainte garde. Le 2o. d'Octobre 1498.

Quel en fut le Euccès,
Cette lettre fecondée de la prudence de Carvajal , parut faire 


\section{DE S. Domingue, LIV. III. IF7}

faire impreffion fur Roldan, il fe laiffa enfin perfuader d'aller trouver l'Amiral, mais fes gens, qui craignoient d'être 1498 . facrifiés au reffentiment des Colombs, \& qui avoient de la peine à quitter leur vie libertine, s'oppoferent à ce voyage, \& s'obftinerent dे vouloir qu'on traitât par lettres \& au nom de toute la troupe. L'Alcaïde Major parut mortifié de ce contre-têms, il écrivit une lettre affés mefurée à l'Amiral, dans laquelle néanmoins il rejettoit fur l'Adélantade la faute de tout ce qui s'étoit paffé, déclaroit qu'il n'avoit rien fait contre le fervice du Roi, \& demandoit un fauf-conduit pour aller à la Capitale avec fes principaux affociés, dès qu'il feroit en liberté de le faire. Carvajal fe chargea de porter cetre réponfe à l'Amiral, \& laiffa Ballefter à Bonao. Ballefter écrivit auffi à Colomb, que fon fentiment étoit, qu'on ne refufât rien aux Rébelles, de ce qu'on pouvoit honnêtement leur accorder, furtout, qu'on leur permit de retourner en Caftille, comme plufieurs d'entr'eux le fouhaittoient avec pafion; qu'au refte il n'y avoit point de têms à perdre , que le parti des mutins croiffoit tous les jours, que déjà huit foldats de fon efcorte s'étoient donnés à eux, qu'il étoit à craindre que les autres ne fuiviffent un fi pernicieux exemple, \& que bien-tôt ces gens-là , fi on ne fe hâtoit de les diffiper, feroient en état de tout entreprendre.

Il eft affés difficile d'exprimer l'embarras, où l'Amiral fe Embarras dé trouva à la lecture de cette lettre; il fentoit la néceffité ab- 'Amiral. foluë de finir cette affaire: les tributs ne fe payoient point, ou étoient détournés par les factieux ; les Infulaires, charmés de voir leurs vainqueurs occupés à s'entre-détruire les uns les autres, ne cultivoient point les terres dans le voifinage des Efpagnols, \& efperoient de les réduire par la famine, à évacuer leur Ifle; il y avoit même toưt à craindre de ce peuple irrité, pour peu qu'on en vînt aux armes. Enfin Colomb fe perfuada, que pour rétablir fon autorité , \& le bon ordre dans les Indes, il falloit pourfuivre les Rébelles par la voye de la rigueur; mais ayant voulu affembler fes Tom. $I$. 


\section{II I 0 I R E}

\$498. troupes pour marcher contre eux, prefque tous fes foldars: refuferent de le fuivre, d'abord fous divers prétextes, \& puis tout ouvertement, en difant qu'ils ne vouloient point répandre le fang de leurs Compatriotes.

Déclaration de l'Amiral portant Ainniftie pour les Rébelles.
Alors il fallut changer de fiftême; l'Amiral fî publier une Déclaration dattée du 9. de Novembre, laquelle portoit que pour ceux, qui dans le terme de r6. jours, ou s'ils étoient trop éloignés, dans celui d'un mois, rendroient les armes; il y auroit abolition entiere du paffé, qu'ils feroient traités avec toute la douceur \& l'humanité convenable à des Chrétiens, \& des fujets des mêmes Princes, qu'on envoyeroit en Efpagne tous ceux, qui le fouhaitteroient , \&\& qu'on payeroit à chacun ce qui étoit dû de fa folde. Outre certe créance generale dont la copie fut affichée à la porte de la Fortereffe, l'Amiral envoya à Roldan, un fauf-conduit dont voici la teneur: $\propto$ D. Chriftophle Colomb Amis. ral del'Ocean, Vice-Roi \& Gouverneur perpetuel des Ifles " \& Terre-Ferme des Indes, pour le Roi \& la Reine . 2 nos fouverains Seigneurs, que Dieu conferve, \& Conक feiller dans leur Confeil d'Etat, faifons fçavoir à qui il s. apparriendra, que défirant faire ceffer les maux caufés » par la divifion, qui s'eft mife pendant notre abfence . s. entre l'Adélantade notre frere, \& l'Alcaïde Major, Fran2. çois Roldan Ximenez, \& remedier au préjudice, que le 3. fervice de leurs Alteffes reçoit de ces troubles, nous avons » jugé que ledit François Roldan devoit venir nous inf๖. truire par lui-même de fes prétentions, \& nous expofer s. fes griefs; \& en confequence avons trouvé bon de lui 2a. donner, \& lui donnons par ces Préfentes, au nom de leurs w. Alteffes, toutes les aftûrances, qu'il peut fouhaitter, tant w pour lui, que pour ceux, dont il voudra être accompa2n. gné de Bonao en cette Ville, promettant que, ni pen๖. dant le voyage, ni pendant leur féjour ici, ni jufqu’à 2) leur retour à Bonao, il ne leur fera fait aucun déplaifir: ax dequoi nous donnons fuivant la coûtume d'Épagne . on foy de Gentilhomme, \& avons figné cet écrir de notre 
DE S. DoMINGUE, LIv. III. $\quad$ I79

» main. A la nouvelle líabelle ce 29. de Novembre

s) 1498.

Cependant les Navires ne pouvoient plus differer leur Il écriwaux départ pour.l'Efpagne, le terme, qui leur avoit été prefcrit, Rois Catholiétant paffé depuis trois femaines ; quantité d'efclaves In- ques toute la diens, qu'on y avoit embarqués, étoient déjà morts, \&les aftaire. équipages, qui apprehendoient de manquer de vivres, demandoient avec empreffement qu'on les expediât. L'Amiral fut donc forcé de les faire partir, \& il ne put fe difpenfer d'inftruire par cette voye la Cour de ce qui fepafroit dans l'Inle. Il pria en même tems leurs Alteffes de lui envoyer des Religieux, pour inftruire les peuples dans la Religion Chrétienne, \& quelque habile homme, pour adminiftrer la juftice, fans quoi les Prédicateurs \& Miffionnaires ne feroient pas, difoit-il, d'une grande utilité. Il mandoit encore, qu'à la verité le changement d'air, l'excès de 1a chaleur, \& la crudité des eaux, avoient dans les comm mencemens caufé quelques maladies, mais qu'elles avoient heureufement ceffé, que les Caftillans fe faifoient au climat de l'Ifle, que le pays fe fourniffoit de vivres, \& qu'aux vêtemens \& au vin près, il ne feroit plus bien-tôt néceffaire de rien faire venir d'Efpagne pour la vie. Il parloit enfuite de la pêche des perles, fur quoi il marquoit les mefures qu'il falloit prendre pour s'en affûrer. Au fujet de Roldan, après avoir expofé en peu de mots les commencemens \& les progrès de fa révolte, il ajoûtoit, que ce chef des Rébelles prétendoit n'avoir befoin d'aucun pardon, difant que tout ce qui s'étoit paffé, n'étoit qu'un different perfonnel entre lui \& l'Adélantade; qu'encore que cela ne fút pas vrai, il croyoit néanmoins devoir s'abftenir d'être juge dans cette caufe, \& qu'il fupplioit leurs Alteffes, ou leur Confeil de vouloir bien en connoître, de faire venir en Efpagne les parties, comme l'Alcaïde Major le requeroit, \& de s'en rapporter furtout à Carvajal \& à Ballefter. Quil me répondoit pourtant pas, fi les factieux ne fo metcoient inceffamment en regle, \& s'ils continuoient leurs brigan 
$180 \quad H$ I S T O I R

1498. dages, qu'il ne fût contraint d'employer pour les réduire, toutes les forces, qu'il avoit entre les mains, fans quoi la Colonie feroit perduë; que ce foulévement étoit l'unique fujet, qui l'avoit empêché d'envoyer D. Barthélemy fon fre: re continuer la découverte de la Terre-Ferme, comme il en avoit eu la penfée, qu'il tenoit trois Bâtimens tout prêts pour cetre expédition, mais qu'il ne pouvoit fe réfoudre à fe priver d'un tel fecours, \& furtout d'un auffi brave homme que l'Adélantade, tandis qu'il n'étoit pas en fûreté dans la Capitale même. Enfin, comme il fçavoit qu'on re ceffoit de repréfenter au Roi \& à la Reine, que les Indes étoient à charge à l'état, il s'appliqua à faire voir que ces bruits n'avoient poine d'autre fondement, que la jaloufie des Grands, qui par les mauvaifes affaires, qu'ils lui fufcitoient; le mettoient hors d'état de profiter des découvertes,qu'il avoit déjà faires, \& d'en faire de nouvelles. En effet, il n'y a aucun lieu de douter que, fans la révolte de Roldan, qui étoit fomentée en Efpagne par plus d'une perfonne en place, D. Barthélemy n'eût découvert la nouvelle Efpagne; il eft certain du moins, \& Colomb le fit remarquer à leurs Alteffes, que, fi on n'eût pas fi long-têms differé fon armement, tous ces malheurs ne feroient pas arrivés, ou n'auroient pas eu les fuites fâcheufes, qui faifoient le fujet de fon inquiétude.

Roldan écrit L'Amiral fe doutoit bien que Roldan ne manqueroit pas tro fonve côté \&'ap- d'écrire de fon côté : il ne fut pas trompé dans fa conjec: pry àla Cour. ture, \& fon malheur fut que ce féditieux trouva des ap. puis parmi quantité de perfonnes puiffantes, qui furent ravis d'avoir une occafion de perdre les Colombs. L'Evêque de Badajoz étoit de ce nombre, du moins l'A miral a toûjours crû que les plus rudes coups, qui lui furent portés dans la fuite, partoient de ce Prélat. Les Rois Catholiques ne furent pourtant pas auffi airés à furprendre, qu'on l'avoir efperé, les der-niers Vaifieaux avoient apporté une affés belle Cargaifon en cotton, en or, en perles, en indigo, en bois de Brefil, \& en plitfieurs autres marchandifes précieufes, ce qui faifoit tomber 


\section{DE S. DOMINGUE, Liv. III. III}

bien des difcours, qu'on ne ceffoit point de tenir contre l'Amiral, mais nous verrons bientôt que les batteries furent 1498. fi bien dreffées, fi bien fervies, \& en fi grand nombre, que l'innocence fut opprimée, \& ne s'ent jamais bien relevée.

Pour revenir à Roldan, il prit enfin le parti d'aller trouver I'Amiral a Sand Entrevûe de ver L'Amiral à San-Domingo, mais fon veritable deffein Roldan avec étoit de lui débaucher autant qu'il pourroit de fes gens. Et l'Amiral fans il fit bien connoître par la hauteur, avec laquelle il parla, \& par les demandes, qu'il fit, qu'on ne devoit pas fe flater de lui voir mettre les armes bas. L'Amiral ne voulut pourtant pas lui faire connoître toute l'indignation, que lui caufoit une conduite $f:$ indigne, il lui fit même des propofitions fort raifonnables, \& comme Roldan lui eut répondu qu'il ne pouvoit rien réfoudre fans en avoir conferé avec fon. confeil, Colomb le fit accompagner à fon retour par Diego de Salamanca fon Maître-d'Hôtel. A peine étoient-ils arrivés à Bonao, que Roldan, comme s'il fe fut repenti des avances, qu'il avoit faites, en allant trouver fon Général, lui écrivit une lettre fort infolente, lui propofa des conditions, qu'il fçavoit bien lui-même ne pouvoir être acceptées, \& fans attendre de réponfe, partit pour la Conception, dont il efperoit de s'emparer par furprife.

L'Amiral ne fe rebuta point, il commença par publier Carvajal conme nouvelle Amniftie accompagnée de toutes les pro-modement meffes, qu’il avoit déjà faites à fon arrivée, il mit enfuite avec les RósCarvajal aux trouffes des Rébelles, \& lui donna un plein pouvoir pour agir fuivant que fa prudence \& les occurrences le demanderoient. Ballefter étoit dans le Fort de la Conception lorfque Roldan fe préfenta devant la Place; elle étoit forte \& défenduë par un brave homme, les Rébelles defefperant de l'emporter d'affaut, fe préparoient à la prendre par famine, \& en avoient déjà détourné les eaux, lorfque Carvajal les joignit. Ils s'éloignerent, dès qu’ils l'apperçurent, \& peu de jours après les négociations recommen: cerent, entre cet Officier \& Roldan. Elles furent condui: 


\section{I82 HISTOIRI}

1498. tes avec tant de dexterité de la part du premier, que lion convint enfin de ces conditions. $I^{\circ}$. Que tous ceux, qui voudroient repaffer en Caftille, le pourroient en toute liberté, \& que l'Amiral leur feroit préparer deux bâtimens au Port de Xaragua, où il étoit plus aifé d'avoir les provifions néceffaires pour le voyage. $2^{\circ}$.Qu'au lieu des Efclaves, qu'ils avoient d'abord demandés, on leur permettroit d'embarquer les jeunes Indiennes, qui fe trouveroient grofles, ou nouvellement accouchées de leur fait, mais qu'ils n'emmeneroient aucun Infulaire malgré lui. $3^{\circ}$. Que L'Amiral leur donneroit à tous des certificats de leurs fervices, \& bonne conduite, \& qu'on leur feroit reftituer tout ce qu'on avoir faifi fur eux. $4^{\circ}$. Qu'on prendroit des mefures pour la füreté des effets, qu'ils laifferoient dans l'Ifle en partant pour l'Efpagne.

Nouveaux in

Roldan figna fur le champs ces articles le quarorziécidens, quile me de Novembre, à condition, qu'ils feroient ratifiés dans rompent. dix jours par l'A miral. Colomb les figna le 2 I. \& mit à fon tour une condition. à fçavoir que les Rébelles partiroient dans cinquante jours pour l'Efpagne. Il donna auffitôt les ordres néceffaires pour que les deux Navires fe trouvaffent à Xaragua au têms marqué. Les Rébelles s'étoient mis en chemin pour s'y rendre, mais comme plufieurs témoignerent n'avoir nulle envie de paffer en Efpagne, il leur fit dire qu'il leur laiffoit fur cela une liberté entiere, \& offrit même de mettre à la folde du Roy tous ceux, qui voudroient refter dans l'Ine, \& s'y établir. Il partit enfuite pour aller vifiter Ifabelle, dont il confirma le Gouvernement à Dom Diegue fon frere, en lui recommandant d'obliger les Caciques à payer exątement les tributs, \& il envoya en même têms Carvajal à Xaragua, pour tenir la main à l'éxécution du Traité. Les Bâtimens, qu'on avoit promis aux Rébelles, étoient en chemin pour ce Port, mais ayant été battus d'une violente tempête, ils ne purent fe rendre dans le têms, dont on étoit convenu, \&r Roldan prit ce prétexte pour refufer de s'en tenir à ce qui avoit été 


\section{De S. Domingue, Liv. III. 183}

conclu. Carvajal au defefpoir de cet incident, fit faire aux Rébelles une fommation dans les formes, mais ils s'en mocquerent.

L'Amiral averti de ce qui fe paffoit, en fut d'autant plus Nouvelaccord conclu \& exédonner aux Mutins deux Navires, dont il avoit fort envie de fe fervir pour envoyer à l'Ille des Perles, \& pour consinuer enfuite la découverte du Continent. Il prit néanmoins encore fur lui d'écrire à Roldan \& à Moxica, \& il le fit de la maniere du monde la plus propre à les gagner. Il n'y réuffit pas, \& le premier lui fit une réponfe fort haute. Touteföis Carvajal ayant trouvé jour à reprendre encore une fois la négociation, on parut fur le point de s'accorder. Il eft vrai que Colomb eut befoin de tout le flegme Italien, $\&$ de toute fa modération, pour effuyer les incartades de Roldan, lequel fembloit chercher à le laffer par fes infultes, ou à l'engager à quelque coup violent, qui lui fervît de prétexte pour refter armé. Mais l'Amiral accorda tout, \& de grandes raifons l'y déterminerent. Le mal devenoit contagieux : les Indiens paroiffoient en bien des endroits fort difo pofés à fe foulever: ceux des Caftillans, qui jufques là étoient demeurés fideles, commençoient à dire tout haut, que s'ils fe fuffent joints à Roldan, ils fe feroient enrichis, \& auroient la liberté de retourner en Efpagne. Plufieurs même: parloient de s'en aller dans la Province de Higuey, où ils croyoient trouver de l'or, \& vivre dans l'indépendance, comme avoient fait les Révoltés à Xaragua. Ainfi c'étoit une néceffité pour l'Amiral de finir, à quelque prix que ce dût être, \& il ne fit difficulté fur rien. Les Articles furent enfin fignés \& executés de bonne foy.

Les deux Caravelles ne tarderent pas beaucoup après I'Amira? ba cela à mettre à la voile. Colomb fut fort tenté de s'embar-lance s'il n'ira quer fur une des deux, pour informer lui-même le Roi \& pas en Ef́ala Reine de toute cette affaire, à laquelle il venoit d'apprendre qu'on donnoit en Efpagne un tour, qui ne lui étoit goint favorable; \& il eut tout lieu dans la fuite de fe re 


\section{I84}

I499. pentir de n'avoir pas fuivi ce mouvement. Mais le zele diè bien public l'emporta fur fes propres interêts; il crut fa préfence néceffaire dans l'Ifle, où quelques Ciguayos faifoient mine de remuer, \& il fe contenta d'envoyer à fa place Ballefter \& Garcias de Barrantez, aufquels il donna un Mémoire très-circonftancié de tout ce qui s'étoit paffé, figné par Carvajal, par Coronel, \& par plufieurs autres perfonnes en place, pour être préfenté au Roy \& à la Reine.

II rend compte Après un détail exact de tous les brigandages \& des excès aux Rois Ca- en tout genre commis par les Séditieux, l'Amiral expofoit dans
tholiques de tout ce qui re- cet écrit les funeftes effets, que cette révolte avoit produits,la garde les Sédi- néceflité, où il s'étoit trouvé, de confentir à tout, pour ne
Eieux. pas mettre la Colonie en rifque, \& combien il feroit dangereux que leurs Alteffes ratifiaffent un accord foufcrit par force, \& indigne de la Majefté Royale ; il infinuoit même que depuis la confommation du Traité les Rébelles s'étoient comportés d'une maniere, qui mettoit la Cour en liberté de ne rien tenir de ce qu'on leur avoit promis; outre qu'ils étoient redevables de tous les tributs des Rois \& des Seigneurs Indiens, qu'ils avoient détournés; qu'il n'avoit pu leur donner un acquit de ces dettes, ni infirmer deux Sentences, par lefquelles ils avoient été déclarés traitres, convaincus du crime de Rébellion, \& condamnés à toutes les peines encouruës par les criminels de Leze Ma: jefté. A la fin du Mémoire l'Amiral renouvelloit fes inftances pour avoir un Magiftrat habile, demandoit qu'on y ajoûtât un Intendant des Finances, ou Thréforier Royal; reprefentoit que, fi leurs Alteffes vouloient être bien fervies par les Gouverneurs \& Commandans, qu'il établiffoit dans les Indes fous leurs Ordres, il falloit les honorer \& les récompenfer à proportion de leurs fervices; fans quoi on les expofoit à la tentation de veiller plûtôt à leurs interêts, qu'à celui du Prince : il prioit auffi qu'on lui env oyât fon fils aîné D. Diegue, pour le former aux grandes affaires, puifqu'il devoit heriter de fes deux Charges d'Amiral \& de ViceRoi. 


\section{de S. Domingue, Liv. III. I8s}

Les deux Caravelles, qui portoient ces dépêches, mirent ¿̀ la voile au commencement d'Octobre, \& le I 9 . du mêRoldan qui étoit rentré dans l'exercice de fápanteme des Charge, préfenta à Colomb une Requête de la part de 102. d'Indiens. de fes Compagnons, lefquels vouloient s'établir dans l'Ifle, \& demandoient des terres dans la Province de Xaragua. L'Amiral comprit que s'il laiffoit un fi grand nombre de ces gens-là enfemble, il étoit à craindre qu'ils ne perpétuaffent la rébellion; il tira cette affaire en longueur, \& les mécontens s'étant enfin divifés en plufieurs bandes, il ne fit plus aucune difficulté de leur accorder ce qu'ils fouhaitoient. Le plus grand nombre s'arrêta à Bonao, d'autres fe placerent au milieu de la Vega-Real, fur les bords de la Riviere verte; quelques-uns pafferent fix lieuës au delà de Sant-Yago, en tirant vers le Nord. On donna à chacun du terrein à difcretion, avec mille pieds de Manioc, \& on obligea les Caciques voifins de faire cultiver ces terreins par leurs Sujets; \& c'eft de là qu'on a pris l'idée de ces partages d'Indiens, dont il fera beaucoup parlé dans la fuite, fous les noms de Départemens, de Diftributions, de Com-Repartimientos? mandes, \& de Conceffions.

Roldan continuoit cependant toûjours à fe comporter Ojeda \& Aavec l'Amiral, plûtôt en vainqueur, qui a donné la Loi meric Vefpuce qu'en criminel, à qui on a fait grace. Colomb, de fon côté, les Indes。 diffimuloit fes infultes, dont il efperoit que la Cour le vengeroit enfin : il fe fervit même de lui, comme s'il eût eu une entiere confiance en fa fidelité, \& cela, dans une occafion délicate, où il femble qu'il rifquoit beaucoup plus, que fa prudence ne le permettoit: voici de quoi il s'agiffoit. La nouvelle de la découverte du Continent, \& de la pefche des perles, avoit extrêmément réveillé la jaloufie des rivaux, \& des ennemis de l'Amiral - Vice - Roi ; \& comme les premiers avis de la révolte de l'Alcaide Major, avoient caufé de grandes inquiétudes à la Cour, ils profiterent de cette occafion, pour jetter dans l'efprit de Ferdinand \& d'Ifabelle la femence de bien des foupçons contre lui, \& Tom. $I$. 
1499. \& contre fa famille. Ils repréfenterent cette révolte comme le fruit de la dureté, \& de l'incapacité des trois freres dans le gouvernement, \& ils blâmerent furtout l'Amiral, de n'avoir pas éteint d'abord, comme il le pouvoit, un feu capable de caufer dans les Indes un incendie général. Fonfeca, qui cette même année paffa de l'Evêché de Badajoz à celui de Cordouë, entra même fi bien dans ce dernier fentiment, qu'il écrivit fur cela des lettres affez dures à Colomb; mais celui - ci lui auroit fans doute plus volontiers pardonné l'amertume de fon ftile, que l'infidelité, qu'il lui fit dans le même têms.

Alphonfe de Ojeda étoit retourné depuis peu en Efpagne, \& il fe trouva à la Cour, lorfqu'on y reçut les Mémoires du dernier Voyage de l'Amiral. Il étoit bien venu chés le Prélat Miniftre, \& il ne pouvoit gueres ignorer que les Colombs ne lui étoient pas agréables. Cette connoiffance lui fit naître la penfée de partager avec l'A miral la gloire de fes Découvertes; il demanda à l'Evêque de Cordouë la communication des Mémoires, dont je viens de parler , \& il l'obtint fans peine. Après les avoir examinés, il comprit qu'il lui feroit aifé de continuer ce qui avoit été fi heureufement commencé ; il fit fon plan, le montra au Miniftre, qui l'agréa, \& il en reçût une permiffion par écrit, mais qui ne fut point fignée, \& qui fut même apparemment ignorée des Rois Catholiques, de découvrir tout ce qu'il pourroir du Continent des Indes, à condition, qu'il n'entreroit pas fur les terres du Roi de Portugal, ni fur celles, qui avoient été découvertes par Chriftophle Colomb, avant l'année I495. c'eft-à-dire, dans fes deux premiers Voyages : par-là, nulle partie du Continent n'étoit excluë de cette commiffion, non plus que l'Ifle des perles, ce qui étoit formellement contraire aux conventions faites entre l'Amiral \& la Couronne de Caftille.

Infidelité d'A.

Ojeda muni de cette piece, fe rendit en diligence à Semeric Vefpu ville, où il eut bientôt trouvé des fonds pour l'Armement ce.

qu'il projettoit. Jean de la Cofa, un des plus habiles Pilo- 


\section{DE S. DOMINGUE, LIV. III. I 87}

tes, qui fuffent alors en Europe, s'engagea à lui. Americ Vefpuce, riche Marchand Florentin, non feulement s'y intereffa pour une fomme confiderable, mais voulut même être du voyage; \& Ojeda en eût d'autant plus de joye, que cet Italien avoit la réputation d'être habile dans laNavigation, l'Aftronomie \& la Cofmographie. C'eft ce même Americ Vefpuce, qui à fon retour en Europe, publia une Relation de fon Voyage, dont il ne fuit aucune difficulté de s'attribuer tout l'honneur; il eut même la hardieffe d'y avancer, qu'il avoit le premier de tous découvert le Continent du Nouveau Monde, \& il en fut fi bien crû fur fa parole, quoique démentie par la notoriéé publique, que fon nom eft devenu celui de cette quatriéme partie de la terre , qui feule égale, fi même elle ne furpaffe pas les trois autres en grandeur, \& en richeffes. Exemple mémorable, \& trop fouvent renouvellé du peu de fondement de ce qu'on ap. pelle grand Nom, \& qui fait voir d'une maniere fenfible que la hardieffe \& l'impudence emportent fouvent la récompenfe dûë au mérite, \&. que l'ignorance \& l'injuftice préfident à la plûpart des jugemens des hommes.

On peut bien croire que Colomb ne fut pas infenfible Succès de ce à tant, \& de fi injuftes entreprifes contre fes droits, \& contre fa gloire; mais il eut bien d'autres plaintes à faire dans la fuite, \& qui ne furent pas mieux écoutées. Les Efpagnols, de leur côté , ont bien de la peine à digérer, qu'un étranger fans caractere, ait eu la gloire de donner fon nom à un grand Continent, qui avoit déjà été découvert par leur Amiral, \& préférablement à Ojeda, qui commandoit la flotte, où Americ Vefpuce n'éroit que paffager, \& à la Cofa qui la conduifoit. Dans le vrai, aucun des trois ne méritoit cet honneur. La premiere terre, où ils aborderent, fut à 200. lieuës à l'Orient de l'Orénoque, \& Vefpuce, pour perfuader au Public qu'il avoit le premier découvert ce Golphe, avança que fon voyage avoit duré 25 . mois; en quoi il fut démenti par le ferment, que prêta juridiguement Ojeda pour attefter le contraire. Ayant enfuite 
1499. paffé la Bouche du Dragon, ils continuerent encore leur route à l'Oneft pendant 200. autres lieuës, jufqu'au Cap de la Veles, q̨ui fut ainfi nommé par Ojeda. Ils découvrirent dans cette courfe le Golphe de Venezuela ou de la petite Venife, auquel ils donnerent ce nom à caufe d'un Village, qu'ils y trouverent bâti fur pilotis dans de petites Ifles, avec des ponts de communications de l'une à l'autre. D'autres difent que ce n'étoit que des cabannes dreffées fur des arbres. Du Cap de la Vela, Ojeda revint à la Marguerite, \& fes Navires faifant eau de toutes parts, il les mit en carene, à la côte de Cumana, auprès d'un Village nommé Maracapana, où les Indiens le reçurent avec de grandes démonftrations d'amitié , \& lui furent d'un très-grand fecours dans l'embarras, où il fe trouvoit. Il y fit même conftruire un brigantin, \& ayant enfuite pris au Nord, il mit pied à terre dans une des Ifles Caraïbes, où il fe battit pendant plufieurs jours contre les Infulaires, dont il tua un très-grand nom. bre. Americ Vefpuce a encore avancé, que de cette Ifle ils étoient revenus tout droit en Caftille, fans paffer par l'Ifle Efpagnole; mais il fut prouvé au Fifc Royal, fur le ferment d'Ojeda \& d'André de Moralez, un de fes Pilotes, que ce fut dans ce même têms quarariva tout ce que nous allons voir, qui fe paffa entre le même Ojeda \& Chriftophle Colomb. Il eft donc certain que nos avanturiers s'étant remis en mer après avoir défait les Caraïbes, frrent voiles vers l'Ine Erpagnole, \& que le 5 . de Septembre I 499. ils prirent terre au Port d'Yaquimo, où ils avoient deffein de charger du bois de Brefil, qui fe trouvoit alors en quantité dans tout ce quartier-là.

Conduite d'Ojeda avec I'Amiral.
L'Amiral en fut bientôt infruit, \& envoya l'Alcaïde Major à Ojeda, pour lui commander de fe retirer. Roldan trouva ce Capitaine affés mal accompagné dans un village d'Indiens, à fix ou fept lieuës de l'endroit, où fes Navires étoient moüillés. Hl pouvoit l'arrêter prifonnier, mais il ne le fit pas; il lui demanda feulement à voir fes provifions, \& pourquoi il coupoit du bois de Brefil, fans en avoir ob. 



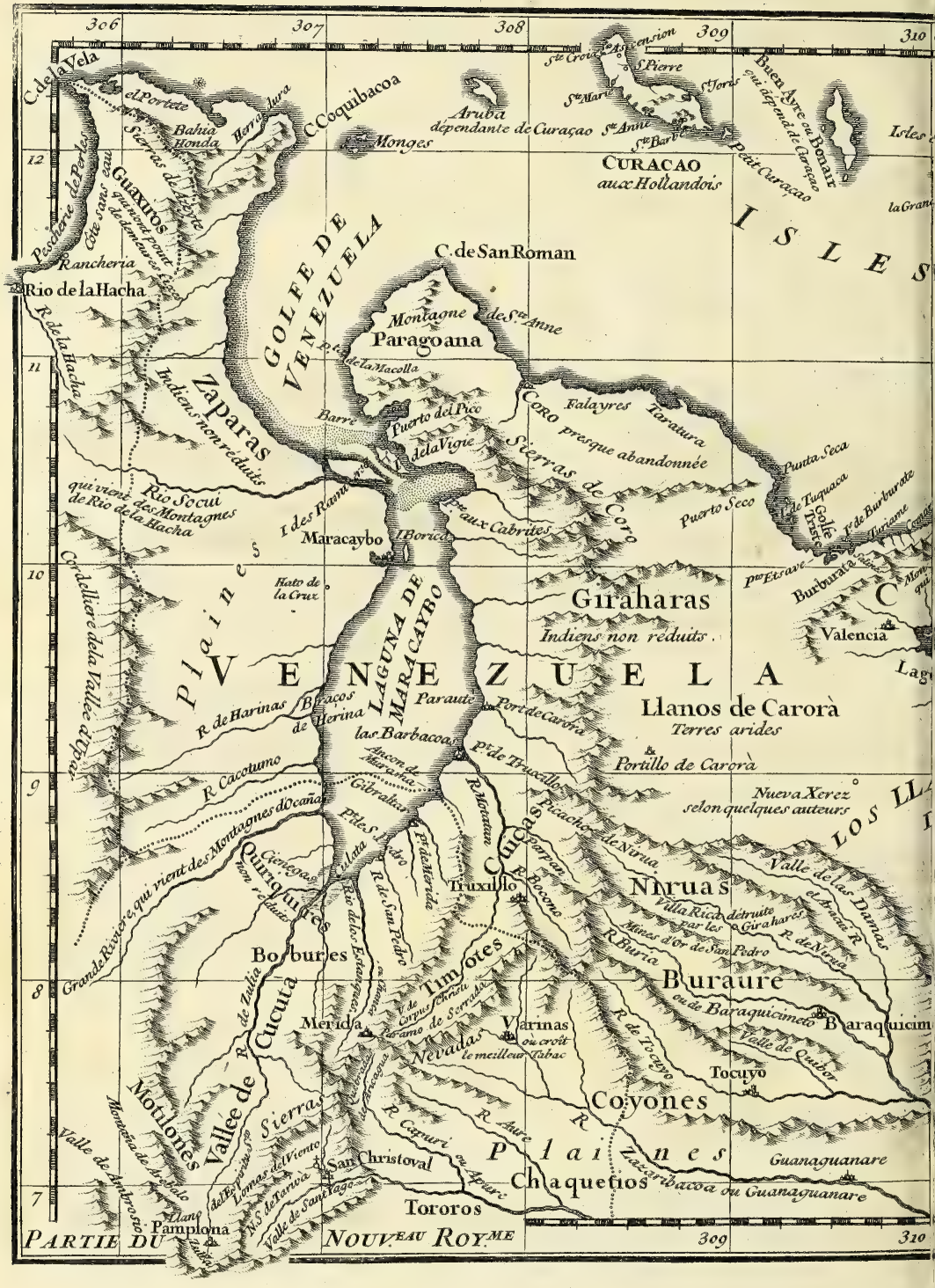





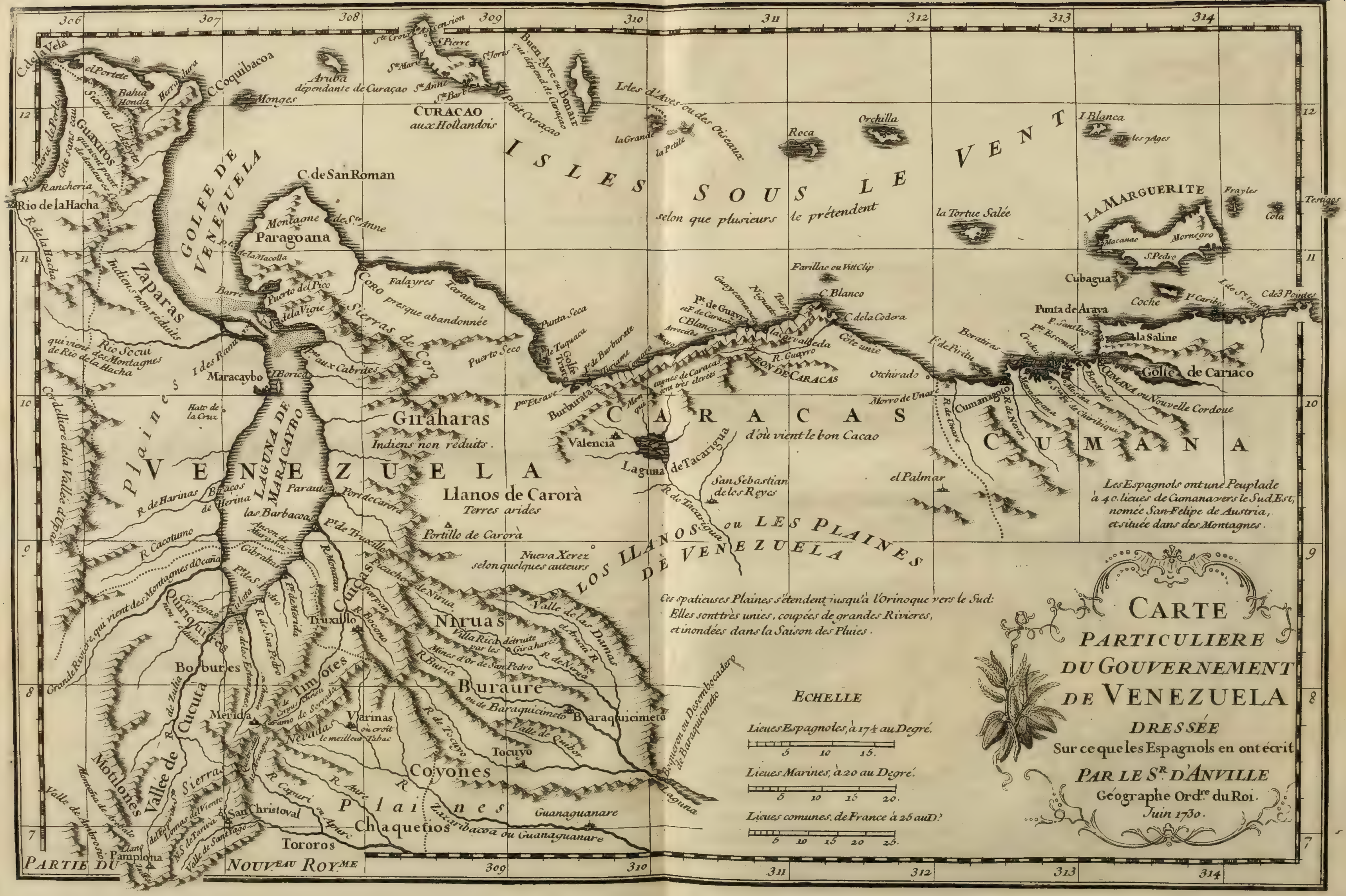



DE S. Domingue, Liv. III. 189 tenu la permiffion de l'Amiral, \& fans lui avoir envoyé faire une civilité. Ojeda répondit qu'il avoit laiffé fes pro1499. vifions dans fon Bord, qu'il comptoit bien d'aller rendre fes devoirs à l'Amiral, \& que s'il avoit differé jufques-là à s'acquitter de ce devoir, c'eft qu'il n'en avoit pas encore eu la commodité. L'Alcaìde fe contenta de cette réponfe', $\&$ après avoir vifité les Navires d'Ojeda, il reprit, fans rien entreprendre, le chemin de San-Domingo.

Quelque têms après on fçut qu'Ojeda éroit avec fes vaiffeaux à la côte de Xaragua : l'Alcaïde Major y fut encore envoyé, \& en y arrivant, il aprit que plufieurs des nouveaux habitans de ces quartiers - là s'étoient déclarés pour lui, avoient voulu contraindre par la force les autres à fuivre leur exemple, \& qu'il y avoit même eu de part \& d'autre du fang répandu. Il connut alors la faute, qu'il avoit faite, en ne s'affürant pas de ce Capitaine auprès du Port d'Yaquimo, \& il eût bien voulu la réparer, mais Ojeda étoit fur fon Bord. Il lui écrivit pour lui propofer une entrevûë, elle ne fut pas acceptée, \& après que ces deux hommes, qui fe craignoient également l'un l'autre, \& qui étoient tous deux gens d'efprit $\&$ de réfolution, fe furent quelque têms obfervés; Ojeda s'éloigna, \& alla faire quelques provifions dans la province de Cahay, à I2. lieuës de Xaragua, c'eft ce qu'on appelle aujourd'hui l'Arcahay. Roldan l'y fuivit, \& après bien des difficultés, qu'il furmonta par fon adreffe \& par fon courage, il l'engagea enfin à une conference, dont le fruit fut la retraite d'Ojeda. En quoi il faut convenir qu'il rendit un fervice effentiel à l'Amiral, qui alloit fe trouver replongé dans un abîme de troubles \& de féditions, d'où il ne lui auroit pas été facile de fe retirer. II en fut quitte pour quelques infultes, qui lui aprirent, ce qu'il fçavoit déjà bien, qu'on étoit fûr d'être appuyé en fe déclurant fon ennemi. Ojeda lui écrivit en partant que n’ayant pû venir à bout de le perdre dans fon Ifle, il alloit le faire connoître au Confeil d'Efpagne, où l'on fçauroit bien llui faire juftice. Ce fut vers la fin de Fevrier I soo. qu'il ap" A a iij 
1499. pareilla pour retourner en Caftille, d'où il étoit parti le 20. May de l'année précedente.

I500. Cependant l'Amiral ne connut bien le danger, qu'il avoit couru en cette ocafion, qu'après quil fut paffé. Le feu de la fédition mal éteint, fe réveilloit déjà de toutes parts; \& pour peu qu'Ojeda eût été inftruit de la difpofition, où étoient les efprits d'un grand nombre de perfonnes, il fe fur apparemment donné bien de garde de quitter fi aifément la partie. Mais Colomb n'ayant plus rien à craindre de ce côtélà, n'eût pas beaucoup de peine à diffiper ces commencemens d'une révolte renaiffante; les plus coupables furent pendus, \& entre autres Adrien de Moxica, \& le calme fut rétabli partout. Ce calme, à la verité, ne fut pas de durée, \& il cachoit même une horrible tempête, dont tout ce quị s'étoit paffé jufques-là, n'étoit qu'un léger prélude. En effet, tandis que Chriftophle Colomb, s'appuyant trop fur fon innocence, \& fur la protection de la Reine Ifabelle, fe croyoit inacceffible à tous les traits de fes ennemis, ceux - ci firent joüer tant de refforts, les accufations intentées contre lui, furent conduites avec tant d'art, \& vinrent de tant d'endroits, qu'il fe fit comme un cri général, contre lequel fa protedirice même ne put tenir.

Mouvement

La Cour fe trouvoit alors à Grenade, où s'étoient renàGrenade con- dus , comme de concert, environ 50. perfonnes revenus
tre les Co. lombs. depuis peu de l'Ifle Efpagnole, qui paroiffoient avoir entrepris de foulever la populace contre les Colombs \& contre la Cour, qui les foûtenoit. Ils publioient fans ceffe mille calomnies contre l'Amiral, \& il n'eft rien qu'ils n'imaginaffent pour le rendre odieux au peuple, \& fufpect au Roi, à qui l'on avoit déjà écrit des Indes, que cet étranger fongeoit à fe rendre Souverain de tous ces grands Pays; or on fçait l'impreffion, que pouvoit faire fur l'efprit ombrageux de Ferdinand, une accufation de cette nature. Un jour les Séditieux, dont je viens de parler, ayant acheté une charge de raifins, s'affirent à terre au milieu de la place pour la manger, \& fe mirent à crier, que le Roi \& les Co: 


\section{DE S. Domingue, Liv. III. IgI}

lombs les avoient réduits à la mifere, où on les voyoit, en ne leur payant pas le falaire, qu'ils avoient mérité dans les pénibles travaux des mines. Ferdinand ne paroiffoit prefque point dans les ruës de Grenade, que ces infolens ne le pourfuiviffent avec de grands cris, en lui demandant leur paye; \& s'ils voyoient paffer les enfans de l'Amiral, qui étoient encore Pages de la Reine : $\alpha$ Voilà, s'écrioient-ils, a les fils de ce traître, qui a découvert de nouvelles terres, » pour y faire périr toute la nobleffe de Caftille. $s$ Le Roi, qui n'avoit pas, à beaucoup-près, la même affection pour l'Amiral, que la Reine, fe rendit bien plûtôt à la vîë d'un foulévement fi univerfel, Ifabelle tint bon plus long-têms; elle fe laiffa pourtant perfuader à la fin, \& ce qui porta dans fon efprit le dernier coup au malheureux Colomb, ce fut une chofe, à quoi perfonne ne penfoit.

Nous avons vû qu'une des conditions du traité fait avec La Reine s'iro Roldan, portoit que ceux des Rébelles, qui voudroient re- rite contre lui, paffer en Efpagne, auroient la permiffion d'emmener avec \& le dépofe de eux les filles, ou femmes Indiennes, qui s'étoient laiffé abu- té. fer, \& fe trouvoient, ou actuellement enceintes, ou nouvellement accouchées. Plufieurs ne fe contentant pas de ces créatures, dont ils ne pouvoient pas tirer de grands fervices, avoient apparemment embarqué des hommes, ou à l'infçû, ou par la connivence de l'Amiral, lequel étoit obligé de fermer les yeux fur bien des chofes, qu'il n'étoic pas en fon pouvoir d'empêcher. Ce qu'il y a de certain , c'eft que le nombre de ces Efclaves montoit à 300 . \& la Reine, qui n'avoit rien tant recommandé, que de ne point attenter à la liberté des Indiens, ne pût voir arriver ceux-ci, fans en être outrée; cette contravention à fes ordres, dont perfonne ne s'étoit avifé de faire un crime à Colomb, lui parut un attentat impardonnable ; elle commença même à croire qu'il n'étoit peut-être pas tout à fait innocent fur tout le refte, \& après avoir envoyé partout des ordres, fous peine de la vie, de remettre en liberté tous les Efclaves, qu'on tenoit de lui, elle prit fur le champs la

I $499^{\circ}$
I 500. 
1499. réfolution de lui ôter abfolument le gouvernement du Noú-

1 veau Monde. Elle n'en prit jamais aucune, dont elle ait eu.

1500. plus lieu de fe repentir : tant il eft vrai que les Princes ne fçauroient être trop en garde contre les premiers mouvemens, lors même qu'ils ont la vertu pour objet. Effectivement, elle eût jugé l'Amiral bien moins coupable, fi elle. avoit été inftruite de la néceffité, où il s'étoit vû réduit, \& de la fituation, où il fe trouvoit alors; car il étoit venu à bout d'extirper jufqu'aux moindres femences de rébellion; il gouvernoit avec une autorité, qui ne rencontroit plus d'obftacle, il voyoit les Caftillans foûmis, les Infulaires difpofés à recevoir le joug de l'Evangile, \& celui de la domination de Caftille; fes plus grands ennemis, prefque tous. réconciliés; \& il fe flattoit que dans trois ans au plus, il augmenteroit le revenu de la Couronne de 60. millions, en: y comprenant la pefche des perles, dont il fongeoit à s'affürer par une bonne Forterefle.

Prétexte quion prend pour le rappeller.

Ce que je viens de dire fe paffoit fur la fin de cette année I499. Cependant la dépofition de l'Amiral ne fut fignée qu’au mois de Juin de la fuivante. Le tour, qu'on donna à une action d'un fi grand éclat, fut que Colomb I 500. avoit demandé un premier Magiftrat pour adminifter la juftice dans l'Ifle Efpagnole, \& prié leurs Alteffes de faire juger fon different avec l'Alcaîde Major par un homme, qui ne pût être foupçonné d'avoir favorifé une partie au préjudice de l'autre. On publia donc que ces propofitions avoient été jugées raifonnables, mais qu'on ne croyoit pas devoir partager ces deux emplois, qui d'ailleurs demandoient une autorité abfoluë, \& ne pouvoient être donnés, qu'à une perfonne de diftinction, avec laquelle il ne convenoit pas de laiffer un homme revêtu de deux auffi grandes Charges que l'étoient celles d'A miral \& de Vice-Roy perpetuels.

François de Une Commiffion fi importante \& fi délicate demandoit vovadigliaen- Gouver- un homme bien fage, bien impartial, bien défintereffé, \& neur génétal bien moderé. Le Roi \& la Reine crûrent avoir trouvé tou- 


\section{DE S. DOMINGUE, LIV. III. I93}

tes ces qualitez dans la perfonne de Dom François de Bova-

dilla, Commandeur de l'ordre de Calatrava , mais ils fe dans les Indes. tromperent affürément, \& ils ne tarderent pas à le reconnoître. En effet Bovadilla étoit pauvre, il parut intereffé, emporté, ambitieux : il gouverna pourtant, fi on en croit Oviedo, avec affés de douceur ; mais ce ne fut qu'à l'égard de ceux, que fa Commiffion l'obligeoit le plus à châtier, \& par une conduite fi peu fenfée \& fi peu excufable ; non feulement il n'entra point dans les vûës de fes. Souverains, furtout par raport aux Infulaires, \& aux auteurs des troubles paffés ; mais on fut affés furpris de le voir prendre avec ardeur les interêts des coupables, dans le têms, qu'il pourfuivoit à toute rigueur des gens, qui n'ont enfin été convaincus, que de quelques défauts d'humeur, ou d'excès de vertus.

Le premier ordre, que lui donna la Reine, fut de déclarer les Indiens libres, \& de les traitter comme tels; mais il lui étoit furtout enjoint, de tenir fecrettes fes Provifions de Gouverneur Général, jufqu’à ce qu'il eût été reçûa SanDomingo : précaution, qui fait voir que les Rois Catholiques avoient donné quelque croyance à ce qui s'étoit publié du prétendu deffein, que formoit l'Amiral, de fe ren. dre Souverain du nouveau Monde. Bovadilla mit d la voile fur la fin de Juin avec deux Caravelles feulement, \& le 123. d'Août on apperçût de San-Domingo ces deux Bâtimens, qui faifoient effort pour entrer dans le Port, d'où le vent de terre les repouffoit. L'Amiral n'y étoir pas, non plus que l'Adélantade: le premier étoit occupé à fortifier la Conception de la Vega, qui infenfiblement devenoit une Ville, \& le fecond étoit à Xaragua avec Roldan, occupé à la recherche des complices d'une confpiration, qui s'étoir formée depuis peu pour faire perir l'Alcaïde Major, \& dont les principaux auteurs étoient déja dans les prifons de la Capitale.

Au premier avis, qu'il paroiffoit deux Caravelles, Dom Son arrivée z̀ Diegue, qui commandoit dans la Place, envoya un Pilote dans une chaloupe pour les reconnoître, \& les faire 
1500. entrer dans le Port. Le Pilote, fuivant l'ordre, qu'il en avoit, commença, en abordant une des Caravelles, par demander, fi le fils aîné de l'Amiral n'étoit pas dans une des deux; on lui dit que le jeune Colomb étoit refté en Efpagne, \& que le Navire portoit un Intendant de Juftice, \& fur le foir les deux Caravelles entrerent dans le Port, mais Bovadilla voulut encore paffer la nuit dans fon Bord. Le lendemain il débarqua de bon matin, \& alla droit à l'Eglife, où il entendit la Meffe, au fortir de laquelle, étant accompagné de D. Diegue, du Sergent Major Rodrigue Perez, \& d'un grand nombre d'Officiers; il s'arrêta à la vâë de tout le peuple, \& donna fa Commiffion d'Intendant de Juftice ̀̀ lire à un Notaire Royal, qu'il avoit amené d'Efpagne; il demanda enfuite à $\mathrm{D}$. Diegue, qu'il lui remît tous les prifonniers détenus pour caufe de révolte. Il entendoit celle de l'Alcaïde Major, dont il croyoit qu'il y avoit encore des complices en prifon, \& il prétendoit en vertu de fes provifions, qu'ils ne devoient pas être réputés criminels, qu'ils n'euffent été déclarés tels à fon Tribunal: comme il ne s'expliqua point, on ne s'entendit pas d'abord, il fe picqua, \& n'en voulut pas avoir le démenti. D. Diegue répondit que tous les prifonniers lui avoient été confiés \& confignés par l'Amiral, \& qu'il n'en pouvoit difpofer, que par fon ordre : ๙ Je vous ferai bientôt connoître, reprit le Commandeur, 2. que vous devés m'obéir , \& que votre frere même eft 2. foûmis à mon autorité. o Il n'en dit pas davantage pour lors, mais le jour fuivant au fortir de l'Eglife, toute la Ville étant accouruë à la Place, il fit lire les Patentes, qui le conftituoient Gouverneur Général des Ifles \& Terre-Ferme du nouveau monde, pendant le têms qu'il plairoit à leurs Alteffes, avec un pouvoir abfolu \& fans limita. tion.

II force ỉa $\mathrm{Ci}$ - Cette leçure finie, il prêta le ferment accoûtumé, \& fur le radelle. champ il requit de nouveau D. Diegue, \& Rodrigue Perez,de lui donner les clefs de la prifon; il en reçut la même répon. fe; que la veille, \& cette fermeté l'embarrạff. Il fit lire deus: 


\section{de S. Domingue, Liv. III. igs}

autres Mandemens des Rois Catholiques, dans l'un defquels il étoit ordonné à l'Amiral, \& à tous les Commandans des Fortereffes, \& des Navires, aux Tréforiers, \& aux Gardes Magafins de reconnoître pour leur Superieur le Commandeur D. François de Bovadilla. L'autre regardoit la paye des. Soldats, \& la folde des Artifans \& des Engagés. Après cette lecture, qui mit dans fes interêts tous les gens de guerre, il fomma pour la troifiéme fois Dom Diegue de lui livrer les prifonniers, \& fur fon refus, il alla droit à la Citadelle, fit appeller Michel Diaz, qui y commandoit en qualité d'Alcaïde, lui fignifia fes Patentes, \& lui ordonna de faire fortir à l'heure même tous les prifonniers. Diaz demanda du têms, pour fe réfoudre, mais le Commandeur, qui fçavoit que l'ordre étoit venu de faire pendre D. Fernand de Guevare; un des Chefs de la derniere confpiration, \& plufieurs de fes complices, craignit que ce délai ne fut employé à les exécuter; il fit donc mettre à l'inftant fous les armes toutes les troupes, \& les équipages des deux Caravelles, \& paroiffant à leur tête, il leur ordonna d'enfoncer les portes de la Citadelle. Cette Place n'avoit pas encore d'autres défenfes, \& quoique Diaz, \& un autre Officier nommé Diego de Alvarado fe fuffent montrés l'épée à la main fur les Crenaux, le Commandeur y entra fans beaucoup de réfiftance.

Il fe fit auffi-tôt conduire à la prifon, \& ayant fait fubir un leger interrogatoire à ceux, qu'il y trouva les fers aux pieds, il les laiffa à la garde d'un Sergent, nommé Jean de Efpinofa. On eut enfuite grand foin de répandre dans le public, qu'on ne devoit pas être furpris, fi les Rois $\mathrm{Ca}$ tholiques avoient ôté le Gouvernement des Indes à Chriftophle Colomb, leurs Alteffes ayant été informées pardes perfonnes fûres, qu'il en étoit le tyran, plûtôt que le Gouverneur, qu'il fe plaifoit à répandre le fang Efpagnol; que pour enrichir fa famille, il privoit les Soldats \& les Artifans de leur paye, qu'il vifoit à s'y ériger en Souverain, qu'il empêchoit qu'on ne tirât de l'or des mînes, \& qu'on n'al- 


\section{Ig6 HIS T O I RE}

I500. lât à la pêche des perles, dont il vouloit faire le fondement de fa Principauté ; on concluoit que perfifter à le reconnoître pour Vice-Roi, c'étoit fe déclarer complice des mêmes crimes dont il étoit chargé.

Conduire de L'Amiral reçut avec affés de tranquilité les premieres Colomb a cet- nouvelles de ce qui venoit de fe paffer ; il fe perfuada que

Bovadilla étoit quelque avanturier femblable à Ojeda , \& dont il viendroit aufi aifément à bout; ou du moins que fes pouvoirs ne s'étendroient pas plus loin, que ceux de Jean Aguado; mais quand on lui eut rapporté que le Commandeur s'étoit déjà rendu maître de la Fortereffe, \& que tou. tes les troupes lui obéiffoient, l'affaire lui parut férieufe, \& il crut ne devoir rien négliger pour fe mettre en état de n'être point opprimé. Il prit donc le chemin de Bonao, après y avoir donné rendés-vous à plufieurs Caftillans, qu'il croyoit dans fes interêts, \& envoyé ordre à quelques Caciques de l'y venir joindre, avec ce qu'ils pourroient affembler de Troupes. En arrivant dans cette Place, il y trouva un Huiffier à Baguette, qui l'attendoit de la part du Commandeur, \& qui lui remit des copies legalifées de toutes les Commiffions. de ce nouveau Gouverneur. Il les prit, \& après les avoir lûës, il dit qu'il n'y avoit rien dans la premiere, que de conforme à ce qu'il avoit demandé lui-même, mais que pour les autres, il les croyoit fubreptices, étant hors de toute vrai-femblance que leurs Alteffes l'eûffent dépoüillé d'une Charge, dont elles lui avoient donné des Patentes perpetuelles \& irrévocables, \& cela, fans lui avoir fait fon procès, \& fans l'avoir même entendu dans fes défenfes; qu'ainfi, avant que de fe foûmettreà des ordres, qui lui étoient juftement fufpects, il vouloit voir quelque chofe de plus. slair \& de plus précis; qu'il alloit en écrire en Cour, \& qu'il fommoit tous les fujets des Rois Catholiques de continuerà lui rendre obéiffance, comme à leur Vice-Roi , \& de lui prêter main-forte contre quiconque attenteroit à fon autorité.

II fe met à to Il n'y eût alors perfonne, qui ne crût que cette affaire: difcretion de 


\section{De S. Domimgue, LIV. III.}

alloit dégénérer en une guerre civile, mais on fut bientôt détrompé. Jean Velafquez Tréforier Royal, \& le P. Jean de Traffierra Francifcain, arriverent peu de jours après à Bonao, \& remirent à l'Amiral une lettre, dont le Roi \& la Reine avoient chaté le Rigieux, \& qui étoit conçûë en pieds, aufiti, \& qui étoit conçue en wien qu'à fon es. D. Chriftophle Colomb, notre Amiral dans

» cean, nous avons ordonné au Commandeur D. François Bovadilla, qui - de Bovadilla de vous dire de notre part bien des cho๖ fes, \& nous vous enjoignons d'y ajoûter foy, \& d'exé» cuter ce qu'il vous déclarera en notre nom, à Madrid

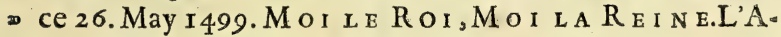
miral réflechit long têms fur cette lettre, où il remarqua que le titre de Vice-Roi ne lui étoit point donné felon l'ufage, \& après en avoir déliberé avec fes amis, il fe réfolut enfin à reconnoître Bovadilla en qualité de Gouverneur Général , \& à l'aller trouver au plûtôt. Il partit donc pour la Capitale, \& fut extrêmement furpris en arrivant, d'apprendre que le Commandeur s'étoit logé dans fa maifon, avoit faifi fes papiers, confifqué fes meubles, fes armes, fes chevaux, \& tout ce qu'il avoit d'or \& d'argent, fous prétexte de payer tous ceux, à qui il étoit redevable, \& transfexé fon frere dans une des Caravelles qui l'avoient amené , après lui avoir fait mettre les fers aux pieds, \& cela fans lui en avoir dit la raifon, \& fans garder aucune formalité de Juftice. Enfin qu'on venoit de publier une Ordonnance; par laquelle il étoit permis à tout le monde d'aller chercher de l'or, en payant au Roi l'onziéme feulement de ce qu'on en tireroit , au lieu du tiers, qu'on avoit payé jufqueslà.

Il n'avoit pas encore eu le têms de faire fes réflexions fur une fi étrange conduite, que Bovadilla, fans lui vouloir permettre de le voir, ni fouffrir que perfonne lui parlât, le fit enlever lui-même $\&$ enfermer dans la Citadelle, les fers aux pieds. Une maniere d'agir fi violente \& fi irréguliere, eut peut-être encore quelque chofe de moins furprenant, que l'applaudiffement, qu'on lui donna : ceux même $B$ b iij 


\section{HISTOIRE}

1500. qui devoient leur fortune aux Colombs, \& ne fubfiftoient que par leur faveur, furent les premiers à leur infulter, \& le propre Cuifinier del'Amiral s'offirit à lui mettre les fers aux pieds, ce qu'aucun de fes Ennemis n'avoit ofé faire.

II engage fon. C'eft dans les grands revers, qu'on connoit les Grands frere D. Bar-Hommes: Colomb fouffrit fa difgrace \& toutes les indignithélemy à fe tés, dont elle fut accompagnée, avec une fermeté d’ame o nier. qui lui fit bien autant d'honneur, que ce qui lui avoit mérité la grande élevation, d'où il fe voyoit tombé dans la plus profonde humiliation. Il fit plus : l'Adéląntade étoit encore en liberté, \& il étoit à préfumer qu'il alloit tout entreprendre pour tirer fes freres des mains d'un homme, qui Jui paroiffoit capable de fe porter aux dernieres violences, \& qui paffant vifiblement fes pouvoirs, ne pouvoit manquer d'être défavoüé : car quoi qu’Oviedo, \& même Herrera, femblent laiffer en doute, fi Bovadilla avo:t le pouvoir de toucher à la perfonne del'Amiral, \& de le traiter en criminel, fuppofé qu'il fe trouvât tel, il parût dans la fuite par toute la conduite de Ferdinand \& d'Ifabelle, qu'il n'avoit ordre, que d'informer. Auffi fut-il accufé de n'avoir pouffé les chofes fi loin, que pour plaire à l'Evêque de Badajoz. Quoiqu'il en foit, l'Amiral écrivit à fon frere parordre de Bovadilla de ne faire mourir aucun des prifonniers, qu'il tenoit dans les fers; il ajoûta de lui-même qu'il le chagrineroit extrêmement, s'il n’obéiffoit pas, \& il le conjura au nom du Seigneur, des Rois leurs Maîtres, \& de la tendre amitié, qui avoit toûjours été entr'eux, de venir fe rendre prifonnier avec lui ; « toute notre reffource, » lui difcit-il, eft dans notre innocence, \& rien n'eft plus » à défirer pour nous, que d'être menés tous enfemble en Æ Efpagne, où il nous fera aifé de nous juftifier. $»$ C'étoit demander beaucoup à un brave homme, \& du caractere de D. Barthélemy, il défera néanmoins à l'avis de fon frere, il vint à San-Domingo, où il étoit à peine arrivé; qu'il fut conduit enchâ̂né dans la même Caravelle, où étoít D. Diegue. 


\section{DE S. Domingue, LIv. III.}

Mais ce qui mit le comble à l'iniquité de Bovadilla, \& acheva de lui ôter toùt moyen d'excufer fon procedé, c'eft que tandis qu'il traitoit avec tant d'indignité des perfonnes de ce rang, il combloit d'honnêtetez l'Alcaïde Major, Roldan Ximenez, \& Guevara, leur donnoit de grandes marques de diftinction, \& faifoit mille amitiés à tous ceux, qui avoient été leurs complices. Sa premiere attention, ainfi que nous avons vû, s'étoit tournée à fauver une bande de brigands \& de féditieux, qui étoient fur le point d'expier leurs crimes par le dernier fupplice: on s'attendoit qu'il feroit au moins des informations, pour voir, s'ilsétoient coupables, ou non, mais il n'en fut nullement queftion, \& il n'eût pas même le foin de garder fur cela les bienféances. Tant de violence \& fi peu de conduite firent craindre pour la vie des trois freres prifonniers; effectivement Bovadilla en avoit trop fait, pour ne pas donner à penfer qu'il avoit deffein d'en venir aux dernieres extrêmirés. Le procès des prézendus criminels s'inftruifoit, \& tout concouroit à confirmer le public dans l'opinion, où il étoit, que la perte de leur vie fuivroit de près celle de leur liberté.

Le principal chef d'accufation contre l'Amiral, étoit, qu'il avoit differé à donner avis aux Rois Catholiques de la pê. che des perles, \& cela ajoûtoit-t'on, à deffein d'exiger de leurs Alteffes, en vertu d'une fi précieufe découverte, de nouveaux droits, \& de nouvelles prérogatives : car on n'ofa inferer dans le procès, ce qui fe publioit néanmoins avec aftectation, qu'il avoit eu deffein de s'approprier ce riche commerce; encore moins qu'il eut formé le projet de fe faire une Souveraineté dans les Indes. Les autres dépofitions, dans la plûpart defquelles on impliquoit fes freres . étoient, fa dûreté dans le gouvernement, fa cruauté dans l'adminiftration de la juftice criminelle, d'avoir retenu la folde des gens de guerre \& des ouvriers, \& d'avoir empêché de travailler aux mînes, de s'oppofer à ce qu'on batifat les Infulaires, \& de leur faire la guerre fans aucun fujet légitime, uniquement pour les rendre Efclaves, \& 


\section{H I S T O I R E}

1500. les envoyer en Caftille : de maltraiter les ferviteurs du Roi, \& de n'obéir aux ordres de la Cour, qu'autant qu'il le jugeoit à propos. On lui communiqua ces articles par écrit, $\&$ il répondit à tous d'une maniere,qui ne laiffa pas d'embarraffer fes accufateurs; elle donna encore plus à penler au Gouverneur Général, qui avoit commencé par le traiter en criminel, avant que de fçavoir, s'il l'étoit, \& qui, fans un caractere fuffifant, s'étoit fait le Juge d'un Grand Officier de la Couronne, n'ayant eu commiffion, que d'informer fuxr fa con* duite, \& de l'envoyer en Efpagne en rendre compte au Roi \& à la Reine.

Les réponfes Dans le vrai, rien n'étoit plus aifé aux accufés, que de répondre à tout ce qui leur étoit objecté. J'ai déjà dit que ce fût parl'Amiral, que la Cour eut les premieres nouvelles de la découverte des perles. Les autres accufations n'avoient rien que de vague, \& l'Amiral difoit bien, qu'étant homme il ne prétendoit pas être impeccable, mais il ajoûtoit qu'on ne pouvoit le convaincre que de ces fautes, qu'on detoit pardonner aux grands embarras, où il s'étoit trouvé; \& au défaut d'experience : il protefta que fes intentions avoient toûjours été droites, il affûra qu'on ne le convainqueroit jamais de la moindre infidelité envers les Rois fes Souverains Seigneurs; au refte il déclara que, s'il avoit bien voulu répondre, c'étoit uniquement pour empêcher qu'on ne tirât aucun avantage de fon filence, qu'il ne prétendoit le faire juridiquement qu'au Tribunal de leurs Alteffes, auquel il appelloit des procédures, qu'on pourroit faire, \& du jugement qu'on pourroit porter contre lui, \& auquel il demandoit d'être renvoyé.

Bovadilla fe L'embarras du Commandeur augmentoit ; il eut apparem-

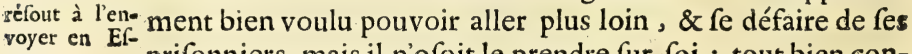
pagne. prifonniers, mais il n'ofoit le prendre fur foi ; tout bien confideré, il crut devoir fe contenter de faire rendre contre eux un Arrêt de mort, \& de les envoyer en Efpagne avec leur procès tout inftruit: \& il fe flatta que le nombre \& D'uniformité des dépofitions, la grieveté des charges, \& la 


\section{DE S. DOMINGUE, LIV. III. 2OT}

qualité des accufateurs, dont plufieurs avoient été liés d'interêt avec les accufés, feroient confirmer la Sentence. Les Prifonniers de leur côté attendoient avec quelque forte d'inquiétude quelle feroit la décifion de leur fort, quand Alphonfe de Vallejo, Capitaine de la Caravelle, où étoient les deux freres de l'A miral, vint tirer celui-ci de prifon pour le conduire à fon Bord. A la vûë de cet Officier, Colomb fût un peu troublé, \& jettant quelques larmes, Vallejo, lui dit-il : « Ou vas-tu me mener? en Efpagne, Monfeigneur, w répondit le Capitaine. Eft-il bien vrai, reprit l'Amiral' क ne me caches-tu rien? Je vous jure, Monfeigneur, repar* tit Vallejo, que j’ai ordre de conduire votre Excellence s en Efpagne. Ces afûrances \& les manieres refpectueufes de cet officier, calmerent le Prifonnier, \& il ne douta plus du retour de fa fortune. Mais Bovadilla ne voulut pas qu'il manquât rien à fon humiliation. Il fit avant fon départ publier une amniftie, en faveur de tous ceux, qui avơient eu plus de part aux rébellions paffées, \& remplit plufieurs brevets, qui lui avoient été donnés en blanc, des noms de Roldan, de Guevara, \& de tous ceux, qui étoient plus décriés par leur mauvaife conduite, \& qui avoient plus ouvertement perfecuté les Colombs; puis il ordonna à Vallejo d'aller prendre terre à Cadix, \& de mettre les Prifonniers avec toutes les Procédures, entre les mains de l'Evêque de Cordouë, \& de Gonzalo Gomez de Cervantez, parent du Commandeur, tous deux ennemis déclarés des trois freres.

Vallejo mit à la voile au commencement d'Oetobre, \& L'Amiral ar. dès qu'il fut forti du Port, il voulut ôter les fers à fes Pri- gne en Épà fonniers: mais l'Amiral s'y oppofa, \&r protefta qu'il ne les quitteroit point, que par l'ordre du: Roi \& de la Reine , \& il ordonna même dans la fuite par fon teftament, qu'après fa mort on les mit avec lui dans fon cercüeil, pour conferver jufques dans le tombeau ce gage de la reconnoiffance, dontle monde paye les fervices, qu'on lui rend. Il n'en parût pas moins fenfible à la bonne volonté du CapiTom. I. 
I 500. taine, qui, auffibien que tous fes Officiers, lui, fit $\&$ à fes freres toutes les politeffes poffibles. La traverfée fut courte \& heureufe, \& Vallejo moüilla devant Cadix le 25. de

Réception de l'Amiral à la Cour. Novembre.
Le bruit ne ne fe fut pas plûtôt répandu dans ce Port o $\&$ de-là à Seville, qui n'en eft pas éloigné, que Chriftophle Colomb \& fes deux freres venoient d'arriver chargés de fers, \& condamnés à la mort ; qu'il s'y excita une très-grande rumeur, \& qu'on y donna des marques éclatantes de l'indignation publique. Ferdinand \&Ifabelle, qui furent bientôt inftruits de toutes chofes, par un exprès . que l'Amiral leur avoit fecrettement dépêché,au moment que les ancres furent jettés, enchérirent encore fur ces démonftrations populaires, \& furent extrêmement offenfés qquon eût ainfi abufé de leur nom \& de leur autorité , pour commettre des violences qui les deshonnoroient. Ils donnerent fur l'heure de bons ordres pour mettre en liberté les Prifonniers, \& pour leur faire rendre les honneurs, qui leur étoient dûs, ils leur firent tenir mille écus, pour fe rendre inceffamment à Grenade, où la Cour fe trouvoit pour lors : ils les y acceüillirent avec des marques extraordinaires de diftinction, ils défavoüerent, \& annullerent fans rien examiner tout ce qui avoit été fait contre eux , \& ils promirent de les dédommager $\&$ de les venger.

Audience par- L'Amiral parla peu en préfence du Roi, qu'il fçavoir ticuliere obte- bien n'être pas dans fes interêts. Mais ayant été admis quelne par l'Amiral, \& ce qui s'y paffe. ques jours après à une audience particuliere de la Reine, il commença par fe jetter à fes pieds, \& en cette pofture, où il voulut demeurer quelque têms, il dit les chofes dus monde les plus touchantes, \& toucha effectivement jufquaux larmes le cœur de cette bonne Princeffe. Il la fupplia enfuite de ne point fouffrir qu'on eût impunément opprimé fon innocence, \& de lui accorder fa protection Royale contre ceux, qui jaloux de fon élévation vouloient à tou" tes forces le trouver criminel; peu contents de le perdre, s'ils ne le deshonnoroient. Ses foupirs \& fes larmes l'intey- 


\section{DE S. Domingue, LIV. III. 203}

rompirent dans ce moment, \& dirent le refte. Alors Ifabelle, en qui l'indignation prit la place de la douleur, le releva, \& fut auffi quelque têms fans pouvoir parler; ellefe remit enfin, \& lui dit avec beaucoup de douceur : a Vous 2 voyés combien je fuis touchée du traittement, qui vous ๖ a été fait, je n'ometrrai affûrément rien pour vous le fai๖ re oublier. Je n'ignore pas les fervices, que vous m'avés o rendus, \& je continuerai à les récompenfer, comme ils mé» ritent de l'être. Je connois vos ennemis, \& j'ai pénétré ๖ les artifices, dont ils fe fervent pour vous détruire: mais - comptés fur moi. Cependant pour ne vous rien diffimuw ler, j’ai peine à me perfuader que vous n'ayiés pas don» né lieu à quelques plaintes, trop univerfelles, pour n'ê2 tre pas fondées. La voix publique vous taxe d'une fé2 verité peu convenable dans uxe Colonie naiffante, \& * capable d'y exciter des révoltes, qui ébranlent fes fons demens encore mal affermis ; mais il $y$ a furtout une so chofe, que j'ai pû encore moins vous pardonner ; c'eft » d'avoir de votre chef, \& malgré mes défenfes ôté la libers té à un grand nombre d'Indiens, qui n'avoient pas mé» rité un châtiment fi févere. Votre malheur a voulu qu’au. » moment que j'ai appris cette défobéîffance; tout le mon» de fe plaignoit de vous; \& perfonne ne parloit en vos tre faveur. Je n'ai donc pû me difpenfer d'envoyer aux » Indes un Commiffaire, qui s'inftruisît, \& m'informât de ๖ la verité de toutes chofes, ou moderât une autorité, qu'on ๖ vous accufoit porter trop loin, \& qui, fuppofé que vous fuf๖ fiés coupable des crimes, dont on vous accufoit, prît le » Gouvernement Général, \& vous envoyât en Efpagne ren$\rightarrow$ dre compte de votre conduite; fes inftructions ne por» toient rien de plus. Je reconnois que jai fait un mauvais s choix , j'y mettrai ordre, \& ferai de Bovadilla un exemple, qui apprendra aux autres à ne point paffer leurs pouso voirs : mais je ne puis vous promettre de vous rétablir » fi-tôt dans votre Gouvernement; les efprits y font trop - aigris contre vous, il faut leur donner le têms de reve- 


\section{HIS TOIR}

I500. so nir ; quant à votre Charge d'Amiral, mon intention n'a » jamais été de vous en ôter ni la poffeffion, ni l'exerci. o ce, laiffés faire le refte au têms, \& fiés vous à moi:

Nonvelles Colomb comprit par ce difcours d'Ifabelle, plus,que cetpropofitions de PAmiral à te Princeffe n’avoir voulu lui faire connoître. Il jugea que JaReine, fon rétabliffement n'étoit pas felon les regles de la bonne politique, que le Roi étoit par rapport à cela fa partie fecretre, qu'on fe repentoit de l'avoir fait fi Grand, \& qu'il ne devoit pas fe flatter de faire changer la Cour en fa faveur. C'eft pourquoi, fans s'arrêter à d'inutiles inftances ? après avoir remercié la Reine des nouvelles marques de bonté, qu'elle venoit de lui donner, il la pria d'agréer qu'il ne demeurât pas dans l'inaction, inutileà fon fervice \& à l'Etat; mais qu'il lui fut permis de continuer la découverte du Continent du nouveau monde, \& de chercher quelque détroit , qui pût le conduire aux. Moluques. Ces Ifles étoient alors extrêmement célébres par le grand Trafic d'Epiceries, que les Portugais y faifoient, \& les Efpagnols fouhaittoient paffionnément de partager avec eux un commerce fi lucratif. Auffi Ifabelle approuva-t'elle avec de grands éloges ce projet de l'Amiral: elle lui promit de lui faire équipper au plûtôt altant de Navires, qu'il en demanderoit . \& l'affutra que, fi la mort le furprenoit dans le cours de cetre expedition, elle rétabliroit fon fils ainé dans toutes fes Charges.

Conduite de Mais rien ne juftifia d'avantage Chriftophle Colomb dans Bovadilla dans Ion Gouvernement. l'efprit de tous ceux, qui étoient fans paffion, que la conduite de Bovadilla; fa principale attention fut d'abord à augmenter de plus en plus la haine, quion portoit dans les Indes aux Colombs, \& il ne fit pas réflexion que cette animofité leur fairoit honneur dans l'efprit de ceux, qui connoiffoient les habitans du nouveau monde. En effet, excepté quelques Officiers, le refte n'étoit gueres que des gens ramaffés parmi la plus vile canaille, on fortis des prifons de Caftille, \& par confequent fans moeurs, fans religion . fans confcience, ou, qui n'étant venus fi loin, que pous s'en: 


\section{S. DOMINGUE, LIv. III. 205}

richir, fe perfuadoient, que les loix n'étoient point faites pour eux, \& que perfonne n'avoit droit de s'oppofer, ni à la vie licentieufe, qu'ils vouloient mener, ni aux moyens, qu'ils imaginoient d'augmenter leurs richeffes. Outre que malgré les précautions de la Reine, il s'en trouvoit de toutes les Provinces d'Efpagne, entre lefquelles on fçait qu'il y a des antipathies infurmontables, fources intariffables de querelles, \& de divifions, d'autant plus funeftes dans un nouvel établiffement, qu'il s'y rencontre toûjours des mécontens, \& que les loix y font moins en vigueur.

De tout ceci, on peut juger que le nouveau Gouverneur en voulant prendre le contre-pied de l'Amiral, ne pouvoit éviter de faire de grandes fautes. Car comme il n'y avoit dans le fond rien de reprehenfible dans celui-ci par rapport aux Efpagnols, qu'un peu de trop de féverité, \& que d'ailleurs lui \& fes freres s'étoient affés étudiés à rendre juftice à un chacun; entreprendre de faire en tout le contraire de ce qu'ils avoient fait, c'étoit s'expofer à donner dans les plus grands travers, \& ne s'attacher que des brigands; comme fit effectivement Bovadilla:il le fit même d'une maniere fi marquée, \&avec fi peu de ménagement, qu’on entendoit tous les jours les plus honnêtes gens s'écrier qu'ils étoient bien malheureux d'avoir fait leur devoir, \& de s'être tenus inviolablement attachés au fervice du Prince, puifque c'étoit un Titre pour être exclus des graces.

Le Commandeur ne fe comporta pas plus équitablement Il rend les ina à l'égard des Infulaires, qu’à l'égard des Efpagnols : car fulaires Efrlam ayant réduit à l'onziéme les Droits du Prince, \& donné, ainfi que nous l'avons vî, la liberté de faire travailler aux Mines, il falloit, pour empêcher que le Domaine ne perdît rien à ce changement, que les particuliers tiraffent une quantité d'or prodigieufe. Pour les mettre en état d'en venir à bout, il contraignit les Caciques de fournir à chaque Efpagnol un certain nombre de fes fujers, dont ceuxci fe fervoient, comme ils auroient pû faire des Bêtes de Charge; \& pour empêcher ces malheureux de pouvoir $f \_$

$$
\mathrm{C} \subset \text { iij }
$$




\section{HIS TOIR E}

I soo. fouftraire au joug, qu'il venoit de leur impofer, il commen. ça par faire un dénombrement de tous les Infulaires, puis il les rédigea par claffes, enfuite il les diftribua aux habitans, plus ou moins, fuivant qu'il vouloit gratifier un chacun. De cette forte toute l'Ine fe trouva réduite fous le plus dur efclavage, qui fut jamais. Ce n'étoit pas le moyen d'affectionner ces malheureux Indiens, ni à la Religion Chrétienne, ni à la Domination Caftillane; mais le Commandeur ne fongeoit qu’à gagner ceux, avec qui il avoit à vivre, \& il étoit affûré d'en venir à bout, en leur procurant les moyens de s'enrichir promptement \& fans beaucoup de rifque. D'ailleurs il fe flattoit qu'en faifant de gros envoys d'or en Efpagne, il fe rendroit néceffaire, \& confirmeroit d'autant plus les foupçons, qu'il avoir tâché d'infpirer à la Cour de la fideliré de l'Amiral \& \& comme il avoit pris un très-bon moyen d'engager tout le monde à travailler aux Mines, il comptoit que malgré la réduction des Droits du Souverain, il les feroit encore monter de beaucoup plus haut, que ne les avoit portés le tiers établi par Colomb.

Il fe tira effectivement en peu de mois, une fi prodigieufe quantité d'or de toutes les mines de l'Ifle Efpagnole, que, fans le malheur, dont nous parlerons bientôt, l'arrivée d'une feule flotte, pouvoit dédommager l'Efpagne de toutes fes avances, \& les payer même au centuple. On fe preffoit d'autant plus de profiter du têms, quon fe doutoit bien qu'il dureroit peu; \& il en coûta la vie à un fi grand nombre d'Indiens, qu'en peu d'années l'Inle Efpagnole parut deferte. Il eft aifé de juger avec quelle inhumanité, la paffion d'amaffer l'or faifoit traiter ces infortunés, par les traitemens barbares, aufquels les a expofés la feule cruauté , \& dont on ne fçauroit lire fans horreur le récit qu'en ont fait des Efpagnols même qui en ont été les témoins oculaires.

Grain d'or exEraordinaire.

Il eft vrai, qu'on n'a point trouvé ailleurs, ni des mines plus abondantes, ni un or fi pur. Michel Diaz \& François de Garay, dont nous avons déjà parlé plus d'une fois, s'é- 


\section{De S. Domingue, Liv. III. 207}

toient affociés pour faire travailler aux mines de Saint Chriftophle. Un jour, que leurs Efclaves déjeûnoient fur le bord 1500, de la riviere Hayna, une femme s'étant avifée de frapper la terre d'un bâton, qu'elle avoit à la main, elle fentit quelque chofe de fort dur, elle regarda, \& vit que c'étoit de l'or, elle le découvrit entierement, \& furprife de la groffeur de ce Grain, elle jetta un cri, qui fit bientôt accourir François de Garay, lequel n'étoit pas fort loin. Il ne fut pas moins furpris, que l'avoit été l'Indienne, \& dans le premier tranfport de fa joye, il fit tuer un cochon, le fit fervir à fes amis fur ce Grain, affés grand pour tenir la Bête toute entiere, \& il leur dit qu'il pouvoit bien fe vanter que les Rois Catholiques n'étoient pas fervis en vaiffelle plus riche que lui. Bovadilla achetta ce Grain pour leurs Alteffes, il pefoit 3600 . écus d'or, \& les Orfévres, après l'avoir examiné, jugerent qu'il n'y en auroit pas plus de 300. de déchet à la fonte. On y voyoit bien encore quelques petites veines de pierres, mais ce n'étoit gueres que des taches', qui avoient peu de profondeur; enfin, il ne s'en eft jamais vû nulle part un pareil, \& l'on peut juger combien cette découverte anima les efperances de ceux, qui s'occupoient à la même recherche.

Cependant on apprit à la Cour la maniere, dont les habitans de l'Ifle Efpagnole étoient traittés, \& il n'eft pas poffible d'exprimer l'indignation, qu'en conçûrent Ferdinand \& Ifabelle. Le rapel de Bovadilla étoit déjà réfolu, cette nouvelle le hâta, \& fur le champs, on nomma pour fon fucceffeur, Dom Nicolas Ovando, Commandeur de Larez, de l'Ordre d'Alcantara, \& qui fut peu de têms après Grand Commandeur de tout l'Ordre; mais fes Provifions ne portoient qu'une Commiffion pour deux ans, apparemment, parce qu'Ifabelle vouloit au bout de ce têms-là, rétablir Chrifiophle Colomb dans fa Charge de Vice-Roi. Ovando étoit un homme de mérite, fort fenfé, d'un abord gracieux, \& qui infpiroit en même-têms un grand refpect pour fa perfonne : modefte, jufqu'à ne pouvoir fouffrir les mar-

1501 . Bovadillare: voqué, Ovando envoyé à fa place. Son cas ractere. 


\section{II S T O I R E}

I5or. ques dediftinßion, ni les titres, qui lui étoient dûs; grand amateur de la Juftice, \& fort définterreffé. Le Nouveaus Monde eût été heureux d'être gouverné par un homme de ce caractere, s'il l'eût foûtenu tout entier jufqu'au bout. Mais il fembloit que l'emploi, dont on le revêtit, fût contagieux, \& transformât d'abord les hommes les plus doux \&r les plus moderés en tyrans, fufcités pour la deftruction des malheureux Indiens : à l'égard même des Ef́pagnols, il ne parut pas fe comporter toûjours avec ce défintereffement \& cette équité, qu'on lui avoit connus, ni être affés en garde contre les rapports de gens mal intentionnés; ce qui le fit quelquefois donner dans de grands travers. On lui fit équiper en diligence, une flotte de 32 . voiles, fur laquelle, On change outre les équigages ordinaires, on embarqua 2500 . hombeaucoup mes, pour remplacer dans l'Ine Efpagnole quantité de perd'habitans de Efpagno- fonnes, que la Reine voulut qu'on en fit fortir, afin de purle. ger la Colonie de tout ce qui pouvoit y caurer du trouble. Parmi ces nouveaux habitans, il y avoit plufieurs Gentilshommes, tous Sujets de la Couronne de Caftille; Ifabelle fe confirmant de plus en plus dans la réfolution d'exclure du Nouveau Monde tous ceux, qui n'étoient pas fes Sujets naturels. Il eft vrai qu'après fa mort, il n'y eût plus de diftinction fur cela entre les Caftillans \& les Aragonnois, \& que fous Charles V. tous les Sujets des differens Etats, que poffedoit ce Prince, eurent la même liberté.

Tnfructions donnces à

Comme la Cour étoit réfoluë à rappeller en Efpagne Ovando.

l'Alcaide Major, François Roldan Ximenés, \& que la Juftice ne potivoit gueres être adminiftrée par un homme de guerre, chargé d'ailleurs du Gouvernement général; elle nomma à cette importante Charge, un habile Jurifconfulte, nommé Alphonfe Maldonado, dont les Provifions furent expediées à Grenade le 3 . Septembre I $50 \mathrm{r}$. On travailla enfuite aux Inftructions du Commandeur de Larez, \& elles portoient en fubftance, qu'après avoir examiné les comptes du Commandeur François de Bovadilla, il le renvoyât en Erpagne fur la même flotte, qui l'alloir porter lui-même 


\section{DE S. DOMINGUE, IIV. III. 209}

aux Indes. Qu'il revît auffi ceux de l'Amiral, mais qu'il ne les fignât point : qu'il déclarât à tous les Caciques dans une Affemblée Générale, que les Rois Catholiques les prenoient Cous leur protection Royale, eux \& tous leurs Sujets. Qu'il ne traitât point ces Infulaires autrement que les Efpagnols, qu'il tînt feulement la main à en exiger le tribut, qu'on leur avoit impofé. Surtout, qu'il ne fouffrît point qu'on employât perfonne au travail des mines, que fur le pied d'ouvriers libres, \& en les payant exactement. Qu'il fìt bâtir des Villes \& des Fortereffes aux endroits, qu'il jugeroit convenables, qu'il les fit joüir des mêmes privileges, dont joüiffoient celles d'Efpagne, \& ne permît point aux Efpagnols, furtout aux Soldats, de s'établir ailleurs; qu'il remît le droit du Prince au tiers pour le paffé, \& à la moitié pour l'vienir. Qu'il prît bien garde, dans la coupe dubois de Brefil, de ne point laiffer arracher le pied des arbres. Qu'il ne permît à aucun étranger, furtout aux Juifs \& aux Maures, de s'établir dans les Indes, ni d'aller à de nouvelles découvertes. Qu'il ne fouffrît point que Bovadilla vendît aucun des biens immeubles ou heritages, qu'il pourroit avoir acquis dans l'Ifle $E$ pagnole; mais feulement ceux, qu'il avoit reçûs des liberalités de leurs Alteffes. Qu'il apportât tous fes foins à faire enforte, que l'Amiral \& fes freres fuffent parfaitement dédommagés de tous les torts, qu'ils avoient foufferts : \& fur cela l'inftruction entroit dains un détail, qui faifoit voir combien le Roi \& la Reine avoient à cour cet article. Carvajal eût même ordre de refter dans l'Ifle, en partie pour avoir foin des interêts des Colombs, avec lefquels il étoit demeuré trèsuni pendant leur difgrace.

Il y avoit encore quelques autres articles, qui compre- Attention de noient plufieurs Reglemens particuliers, pour le détail de la la Cour pour conduite du nouveau Gouverneur ; mais il lui étoit furtout des Indiens。 recommandé d'avoir l'œil à ce que l'on travaillât férieufement à la converfion des Infulaires. On en avoit déjà baptifé un affés grand nombre, mais la plûpart avoient reçû le Sacrement fans trop fçavoir ce que c'étoit, \& en avoient

Tom. $I$.

$\mathrm{D} d$ 


\section{TO HISTOIRI}

1503. d'abord profané la fainteté par leur Apoftafie. D'ailleurs g les cruautés, qu'on exerçoit contre eux, \& les exemples des anciens Chrétiens ne les prévenoient pas en faveur d'une Religion, dont on ne leur donnoit gueres, ni le têmis, ni les moyens de s'inftruire ;: outre que le petit nombre des Prêtres, qui étoient dans l'ine, fuffifoit à peine pour les Efpagnols. Une bonne recruë de Religieux Francifquains, qui les premiers, ont eu un établifiement fixe dans les Indes; \& les ordres, dont je viens de parler, devoient lever tous les obftacles, \& l'on s'attendit bientôt, à voir toute l'inle Efpagnole adorer Jefus-Chrift.

Tout étant prêt pour le départ de la flotte, Ovando alla recevoir les derniers ordres des Rois Catholiques, \& ayant Ovando arriété admis à leur Audiance, Antoine de Fonfeca, Seigneur pagnole. de Coca, Confeiller d'Etat, lui fit de la part de leurs Alteffes, un difcours fort long \& fort touchant, fur la maniere, dont il devoit fe eomporter dans l'exercice de fa Charge ; \& il lui recommanda fur tout la Religion, la bonté \& la juftice. Peu de jours après le Commandeur fe rendit à San-Lucar, où il s'embarqua le I3. Fevrier Isoz. Une tempête, qu'il effuya affés près des Canaries, diffipa fa flotte, \& fit périr un de fes plus grands Navires avec r 50 . hommes, qui étoient deffus. Tous les autres fe retrouverent à la Gomera, où étoit le rendés-vous général, \& où l'on achepta un Navire, pour remplacer celui, qui avoit péri. Quantité d'Efpagnols habitans des Canaries, s'offrirent à en former l'équipage, \& leur offre fut acceptée. Ovando partagea enfuite fa flotte en deux bandes, prit avec lui les Navires, qui alloient mieux à la voile, laiffa les autres fous les ordres d'Antoine de Torrez, qui devoit tout commander au retour, \& arriva le Is. d'Avril au Port de San-Domingo.

Saconduite Bovadilla ne s'attendoit à rien moins, qu'à être relevé : à l'ćgard de il vint néanmoins recevoir fon fucceffeur fur le rivage, \& sout lemonde. le conduifit à la Fortereffe, où les provifions d'Ovando furent luës en préfence de tous les Officiers Royaux \& de 
De S. Domingue, Liv. III. 2 II

Juftice. Il fut auffi tôt reconnu \& falué en qualité de Gouverneur Général, \& Bovadilla fe trouva tout à coup abfo1502. lument abandonné. Quelques-uns ont écrit qu'il avoit été fait prifonnier, mais ceux, qui paroiffent le mieux inftruits, ne le difent pas, \& il paroît même qu'il fut toûjours honorablement traité. Il n'en fut pas de même de Roldan, le nouveau Gouverneur informa contre lui, \& contre ce qui reftoit de fes principaux complices, \& les ayant tous fair arrêter, il les repartit fur la flotte, pour être conduits en Efpagne avec les pieces de leur procès. Les Indiens furent enfuite déclarés libres, \& l'on publia en même têms 1 Ordonnance du Roi $\&$ de la Reine, qui portoit, que déformais on payeroit au Domaine la moitié de l'or qu'on tireroit des mines, \& que pour le paffé, on s'en tiendroit au tiers, ainfi qu'il avoit été reglé par l'Amiral. Il eft vrai, que cette Ordonnance ne fut pas plâtôt mife Le travail
en exécution, que le travail des mines ceffa tout à coup. des Mines
cefie entiereQuoiqu'on pût offrir aux Infulaires, ils n'en voulurent plus remento. entendre parler, dès qu'ils virent qu'on ne pouvoit plus les y forcer, \& ils aimerent mieux vivre tranquillement dans leur premiere fimplicité, que de fe confumer de fatigues, pour gagner des biens, dont ils ne faifoient aucun cas. D'ailleurs, il parut exorbitant, qu'on obligeât de payer au Prince la moitié de ce qui fe gagnoit avec tant de peine \& de dépenfe, \& la plúpart vendirent leurs outils, \& fe retirerent. Plufieurs de ceux, qui étoient venus fur la flotte, demanderent à être mis à leur place, mais ils ne tarderent pas à s'en repentir. Le plus aifé étoit fait, \& il falloit déjà creufer bien avant pour trouver de l'or. De plus, ces nouveaux débarqués manquoient tout à la fois d'expérience \& de bons ouvriers; la maladie fe mit parmi eux, \& en emporta jufqu'a mille en affés peu de têms; enfin tous renoncerent à un travail, qui les accabloit, \& ne les enrichiffoit pas. Le mauvais fuccès des nouvelles Ordonnances, fit juger au Grand Commandeur, qu'il falloit y apporter. quelque moderation, ( $j$ 'appellerai déformais ainfi Ovando, par-

$\mathrm{D} d \mathrm{ij}$ 
1502. ce que fort peu de têms après fon arrivée aux Indes, in parvint à cette grande dignité par la mort d'Alphonfe de Santigliano, qui en étoit revêtu, ) il fit dire aux habitans, qu'il alloit écrire à leurs Alteffes, pour les engager à fe contenter du tiers, \& fur cette affurance, quelques-uns reprirent cour. Il leur tint parole, \& fut écouté; il fallut même dans la fuite fe relâcher encore, \& l'on en eft venu enfin à fe contenter du quint des métaux, des perles, \& des pierres précieufes : \& ce Reglement a toûjours fubfifté depuis.

Reglemens pour les nou- $8 x$ yelles Villes.

Le Gouverneur Général fongea enfuite à bâtir des villes \& des bourgades, comme on le lui avoit recommandé , \& pour cela il fit un traité avec un nommé Loüis Arriaga, par lequel celui-ci s'obligeoit à lever 200 . Familles, pour commencer quatre peuplades aux conditions fuivantes. I ${ }^{a}$. Que ces Familles feroient ttanfportées aux frais du Roi, jufques fur le lieu de leur deftination. $2^{\circ}$. Qu'il feroit donné à chacune une étenduë de terrein fuffifante, pour la faire fubfiffter, en payant au Prince les Dixmes \& les Prémices, qui lui avoient été accordées par le Saint Siege. $3^{\circ}$. Que les nouveaux habitans ne payeroient aucuns droits, \& ne feroient fujets à aucune impofition pendant cinq ans, à l'exception des Mines, de quelque matiere qu'elles fuffent, du bois de Brefil, des Salines, des Ports de mer; en un mot, de tout ce qui appartient aux Souverains par un droit inaliéna. ble. $4^{\circ}$. Qu'ils ne pourroient achetter, ni troquer de l'or des Indiens. $5^{\circ}$. Que de tout se quils négocieroient avec les mêmes Indiens, hors des limites de leurs Villes, ils en payeroient le tiers au Iréfor Royal, à l'exception des provifions de bouche. $6^{\circ}$. Que fi parmi eux il y avoit des Mineurs, qui travaillaffent eux-mêmes, \& à leurs dépens aux Mines, de tout l'or, qu'ils recüeilleroient, la moitié feroit au Roi ; mais que leurs frais feroient pris fur cette moitié. $7^{\circ}$. Que s'ils faifoient quelque nouvelle découverte, ils payeroient pareillement la moitié de l'or \& des perles, qu'ils en sireroient, \& le quint feulement des autres marchandifes. 


\section{DE S. DOMINGUE, LIV.III. 2 I3}

8. Enfin, que dans ces quatre Villes, on ne recevroit aucun Banni, aucun Maure, ni aucun Juif; que les habitans I 50.2 . y feroient toûjours prêts à exécuter tous les ordres; que les Gouverneurs leur envoyeroient de la part du Roi, fans pouvoir exiger de folde, \& que ceux, qui avant cinq ans voudroient retourner en Caftille, ne pourroient vendre aucune des chofes, qu'on leur auroit avancées des Magazins du Roi pour leur établifement. Ces Reglemens ne furent pourtant d'aucun ufage pour lors, Arriaga n'ayant pû ramaffer à beaucoup près le nombre de familles, dont on étoit convenu; mais on les trouva fi fages, que dans la fuite on les prit pour modéles, dans la fondation des nouvelles Villes, dont nous parlerons bientôt.

Les chofes étoient en ces termes, \& la flotte, qui avoit Lettre de Fer amené le Grand Commandeur, étoit fur fon départ, lorf- dinand 2 l'A. qu'on vit arriver une Chaloupe envoyée par l'Amiral, qui demandoit la permifion d'entrer dans le Port, pour y. changer un de fes Navires, lequel ne pouvoit plus tenir la mer. Mais l'ordre de l'Hiftoire demande que je reprenne les chofes de plus haut. Le Roi Ferdinand avoit fort goûté , à l'exemple de la Reine, le projet, dont ce Seigneur avoit parlé à cette Princeffe; mais les Miniftres ne s'étoient point preffés de lui fournir les vaiffeaux, qu'il demandoit, \& il aprit même que l'on travailloit fous main à faire de nouvelles informations contre lui. Tant de délais, \& un fi grand acharnement à le perdre, le rébuterent enfin, \& il dit aflés haut, qu'il étoit las de lutter contre la fortune, qu'il avoit montré le chemin des Indes, qu'on pouvoit y aller déformais fans lui, \& qu'il alloit prendre le parti de re retirer. Ces difcours furent rapportés à Ferdinand; qui en deviná aifément le fujet, \& y remedia. Ce Prince écrivit enfuite à l'Amiral, \& acheva de le regagner. « Vous devés * être perfuadé, lui manda-t-il, du déplaifir, que nous avons $\infty$ eu de votre prifon, puifque nous n'avons pas differé un mo3. ment à vous mettre en liberté. Tout le monde connoît 3. votre innocence, vous fçavés avec quel honneur \& quelle 


\section{I4 HISTOIRE}

1502. Damitié nous vous avons traité ; les graces, que vous avéz

s reçûës, ne feront pas les dernieres, que vous recevrés de

»nous; nous vous confirmons vos priviléges, \& voulons

» que vous \& vos enfans en joüiffiés. Nous vous offrons de

- les confirmer de nouveau, \& de mettre votre fils aîné en

» poffeffion de toutes vos charges, quand vous le fouhaite-

w rés. Soyés aftûré que nous aurons foin des autres. Nous

๖ vous prions donc de partir au plûtôt. A Valence le 14. de

w Mars l'an I 502.0

Il part de Ca- De bons ordres accompagnerent cette Lettre, \& tout fut dix.

bientôt prêt pour le départ des quatre vaiffeaux, qu'on avoic accordés à l'Amiral, de forte que le 9. de May il fortit du Port de Cadix, ayant avec lui Dom Barthélemy fon frere, \& Dom Fernand le fecond de fes fils, âgé d'environ I 3. ans. Comme il fçavoit que la Fortereffe d'Arzilla, fur la côte d'Afrique, poffe dée alors par les Portugais, étoit affiegée par les Maures, il s'en approcha pour la fecourir ; mais il trouva le fiege levé. Il envoya fon frere \& fon fils au Gouverneur, qui avoit été bleffé, pour lui faire compliment, \& lui offir fes fervices, \& le 20 . de May il moüilla devant la grande Canarie. Il eût enfuite les vents fi favorables, que fans changer fes voiles, il arriva le $\mathbf{1} 3$. de Juin à la vûë de l'Ine Matinino, aujourd'hui la Martınique, où il refta trois jours. Ayant appareillé de nouveau, il fut affés furpris de voir que fon plus grand Navire, qui étoit de 7o. tonneaux, ne foûtenoit plus la voile, \& donnoit du nez dans l'eau; c'eft ce qui lui fit prendre le deffein d'aller à I Inle Efpagnole pour le changer, perfuadé que la défenfe, qu'on lui avoit faite de toucher à cette Ine, devoit ceder à la néceflité, où il fe trouvoit.

IH n'yeft pas Le Grand Commandeur n'en jugea pas ainfi ; car faifant ₹eçû. \& pour- réflexion que, s'il lui donnoit entrée dans la ville, tandis

Naufrage de que Bovadilla, \& quantité d'autres perfonnes, de qui il Latotte. avoit reçu tant de chagrin, y étoient encore, il en pourroit arriver quelque défordre; ayant dailleurs une défenfe expreffe de l'y recevoir, \& n'étant pas trop de fes amis, com* 


\section{De S. Domingue, LIV. III. 215}

me il parut affés dans la fuite, il le fit prier de trouver bon qu'il ne paffàt point pardefius les ordres, qu'ils avoient tous deux. Cette réponfe, à laquelle il devoit affés s'attendre, ne laiffa pas de le mortifier; mais apprenant que la Flotte étoit fur le point de lever les ancres, il fit avertir Ovando, qu'il voyoit des fignes certains d'une rempête prochaine, \& qu'il lui confeilloit d'engager Torrez à differer fon départ. On fe mocqua de fon avis, \& la Flotte appareilla. Elle étoit encore à la vûë de la pointe Orientale de l'Inle, qu'un des plus terribles ouragans, qu'on eut encore vûs dans ces Mers, en fit périr $2 \mathrm{I}$. Navires tous chargés d'or, \& les meilleurs de la Flotte, fans qu'on en pût fauver un feul homme. Ce beau Grain d'or, dont j'ai parlé plus haut, périt en cette occafion, \& l'Ocean n'avoit peut - être .jamais reçu tout à la fois tant de richeffes dans fon fein. Mais c'étoit le prix de l'iniquité , \& de la cruauté, \& le Ciel voulut fans doute venger par la perte de tant de tréfors le fang de tant de malhetireux, quon avoit facrifiés pour les amaffer. Le Capitaine Général Antoine de Torrez, le Commandeur François de Bovadilla, Roldan, un Cacique Chrétien, dont je n'ai pu fçavoir le nom, qui avoit eu la curiofité de voir l'Europe \& l'infortuné Guarionex, qu'on envoyoit en Efpagne, je ne fçai à quel deffein, finirent leurs jours en cette occafion. Guarionex , ainfi que je l'ai dit ailleurs, avoit été fur le point de fe faire bâtifer; mais le procedé tyrannique des Caftillans, \&l'action brutale d'un fcelerat, qui enleva fon époufe favorite, \& en abufa par force, le dégouterent d'une Religion, qui avoit de tels Sectateurs, \& qu'il s'imagina peut-être authorifer de fi grands excès.

Mais ce qui fit fur tout juger que ce grand malheur étoit Leplus, petit un effet de la Juftice divine, c'eft que les onze Navires, flotte, ouétois que la tourmente épargna, étoient les plus foibles, \& les tout le bien de plus mal équippés de la flotte, \& que le plus petit, \& le fauve. plus mauvais de tous, fur lequel on avoit chargé tout le Découverts bien de l'Amiral, fut le premier, qui arriva en Efpagne. dansle Contia On remarqua aufi que la feule perfonne de diftinction, nent. 


\section{I6 HISTOIR}

1 ş02. qui fe fauva, fut un nommé Rodrigue de Baftidas. C'étoit un fort honnête homme, riche, \& habile navigateur, qui l'année précédente s'étant affocié avec le célébre Pilote, Jean de la Cofa, avoit obtenu une Commiffion du Roi, \& avoit armé deux Navires à Cadix. Il fuivit la même rou. te, que l'Amiral avoit faite dans fon troifiéme voyage, \& navigua fort heureufement. Il traita de l'or \& des perles, pouffa les découvertes cent lieuës au delà de ce qui étoit déja connu, donna le nom de Carthagene au Port, où l'on a depuis bâti cette fameufe Ville, dont nous aurons plus d'une occafion de parler dans la fuite de cette hiftoire, \& après s'être avancé jufques par-delà l'endroit, qui fut depuis appellé Nombre de Dios, fes Navires ne pouvant plus tenir la Mer, il gagna avec beaucoup de peine le Golphe de Xaragua; où il fut obligé de les échoüer. De-là, il fe rendit par terre avec tout fon monde à San-Domingo, où Bovadilla, fous prétexte qu'il avoit traité de l'or à Xaragua, larrêta prifonnier. Mais dans la fuite la Cour informée de la verité de toutes chofes, \& de la bonne conduite, que $\mathrm{Ba}$ ftidas avoit tenuë avec les Indiens dans tous les pays, où il avoit paffé, non-feulement le dédommagea de fes pertes; mais lui donna encore une récompenfe proportionnée à fes fervices.

Second royage d'Americ Vefpuce avec Ojeda.
Ojeda étoit auffi parti de Cadix, à peu près dans le même têms que Baftidas; mais comme il ne fçavoit pas de quel côté ce Capitaine avoit tourné, il ne fit autre chofe chofe,que le fuivre. Il étoit encore accompagné d'Americ Vefpuce . avec lequel il fe broüilla au fujet des vivres, dont il étoit extrêmement ménager. L'Equipage, fevoyant foutenu de Vefpuce, fe révolta, \& mit fon Commandant aux fers. Herrera prétend que la même chofe lui étoit arrivée dès le voyage précédent. Quroiqu’il en foit, le terme de celui-ci fut le même, que de celui de Baftidas, d'où Vefpuce fe rendit au Port d'raquimo, ou du Brefil, dans l'Ifle Efpagnole. Là Ojeda, qui étoit toûjours enchaîné, voyant que fon $\mathrm{Na}$ ฟire n'étoit moüillé qu'à un jet de pierre de la terre, s'a- 



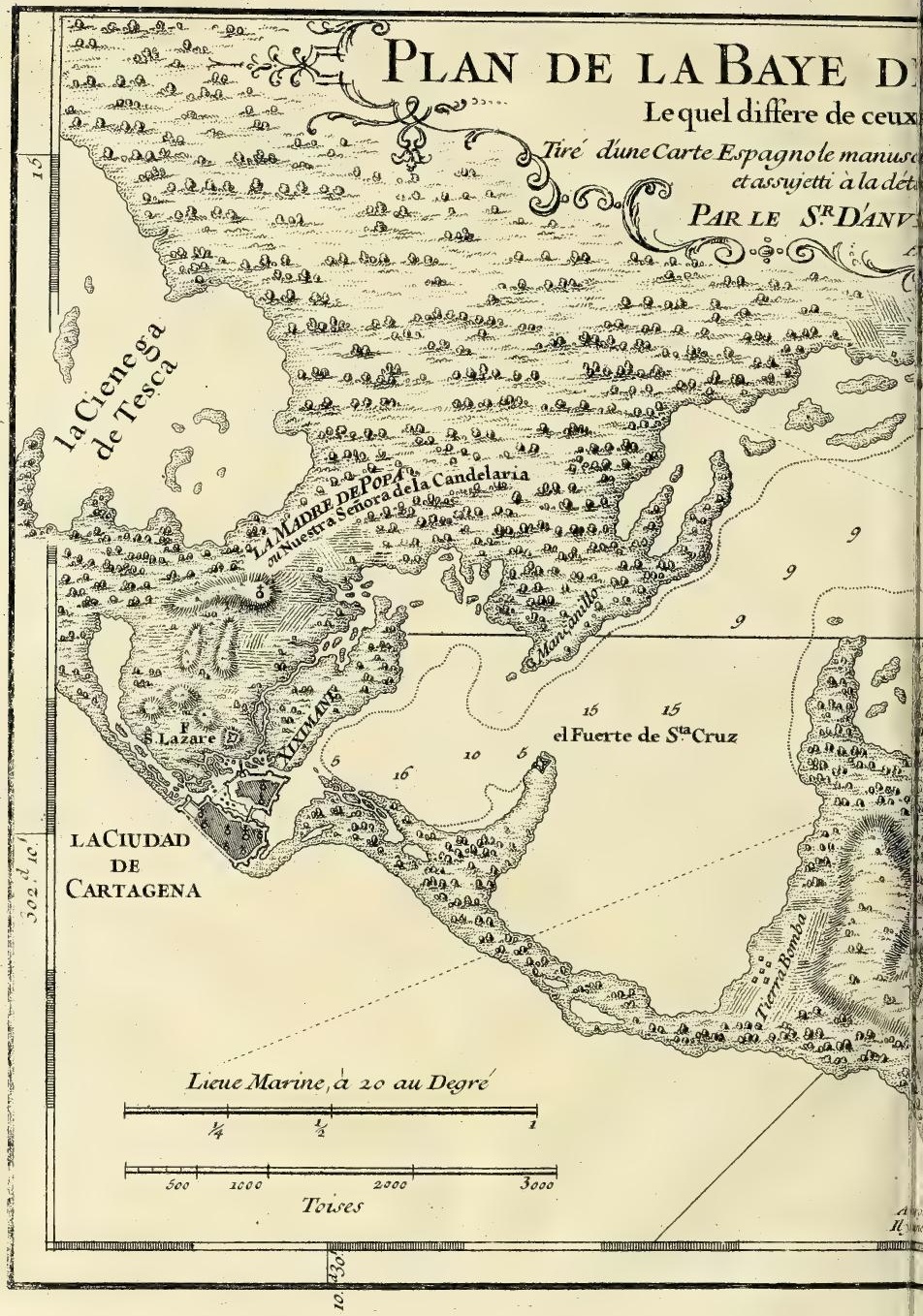





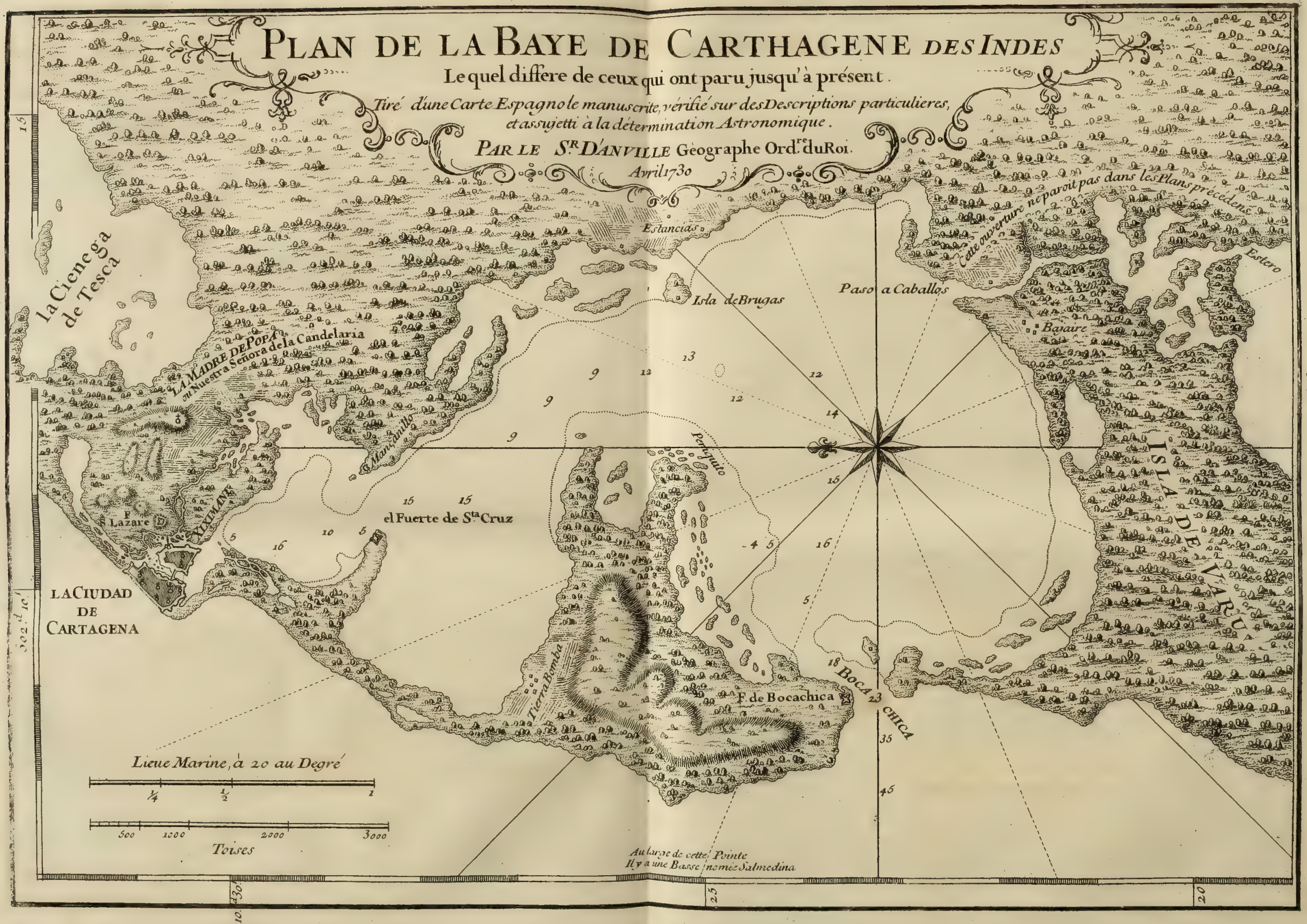





\section{DE S. DOMingue, Liv. III. 217}

vira de fe couler tout doucement dans la Mer pendant la nuit. Il fe fioit fur fa force, qui étoit effectivement extraordinaire, \& il comptoit bien de gagner le rivage en nageant, mais il s'étoit trompé, \& il fe feroit infailliblement noyé, s'il n'eut été promptement fecourû.

Cependant on peut juger de la confternation, où fut toute l'Efpagne, à la nouvelle du naufrage de la flotte des Indes ; il ne fut perfonne, qui ne la regardât comme une fui- go renverf́e te de l'injuftice, qu'on avoit faite aux Colombs; chacun fe gan. perfuadant avec beaucoup de vrai-femblance, qu'un fi grand malheur ne fut pas arrivé, s'ils euffent été en place: \& lors qu'on fut inftruit de l'avis que l'A miral avoit donné à Ovando, la Cour fit à celui-ci de grands reproches de n'y avoir pas eû d'égard. Mais ce ne fut pas feulement la Flotte, qui fe reffentit d'une fi furieufe tourmente. La Ville de San-Domingo, dont les maifons n'étoient encore que de bois \& de paille, en fut prefque toute renverfée, ce qui donna occafion de la rebâtir ailleurs, comme nous le dirons bientôt. Le travail des Mines alloit toûjours fort lentement, \& Ovando ne voyoit point d'autre remede à ce mal, que de remettre les Infulaires fous le joug. Il y penfoit férieufement, mais n'ofant pas encore heurter de front les ordres précis de la Reine, qu'il fçavoit être inflexible, \& d'une vivacité extrême fur ce point, il imagina un moyen, qui laiffant à ces malheureux toutes les apparences de la liberté, les expofoit à toutes les rigueurs d'un veritable efclavage.

Ce fut de les obliger à travailler aux Mines pour les Onoblige Caftillans, comme ils avoient fait par le paffé, avec cet- les Indiens à te différence, qu'ils feroient payés de leur travail ; \& le pré- Mines en les texte, dont on couvrit cette violence, c'eft que fans cela on n'en pourroit pas tirer le tribut, dont ils étoient chargés, la plûpart fe mettant par leur pareffe hors d'état d'y fatisfaire. Le grand Commandeur apporta encore une autre raifon de cette conduite, en écrivant au Confeil ; c'eft qu'il n'étoit pas poffible de fixer l'inconftance naturelle des InTom. $I$. E e 


\section{$2 I 8$ HISTOIRE}

$\$ 502$. diens, ni de faire ceffer leurs autres défordres, qu'en les occupant par un travail moderé. Auffi fut-il fort applaudi. d'autant plus que, fur la feule efperance, qu'il avoit donnée aux habitans, de faire réduire le droit du Prince au Tiers de l'or, \& au Quatriéme des autres marchandifes, tous s'étoient remis avec tant d'ardeur à creufer les Mînes, qu'en peu de têms la perte caufée par le dernier naufrage avoit été réparée.

Ovandofon- Ovando ne fongeoit qu'à faire ainfi fleurir le commerce ge à établir Puerto-diPlata. dans l'Ine Efpagnole, lorfqu'il fe trouva tout à coup fur les bras une guerre, dont les commencemens ne laifferent pas de l'inquietter: voici quelle en fut l'occafion. Ifabelle, la. feule Place, que les Caftillans euffent à la côte du Nord, fe dépeuplant tous les jours; \& bien des raifons, que j'ai touchées ailleurs, concourant à la faire abandonner tout-à-fait, le Gouverneur Général fongea à l'érabliffement d'un autre Port de cette côte, fur laquelle il étoit d'une extrême confequence d'en avoir un, qui pût fervir d'abry en cas de beOt Porto- foin, \& il fe détermina enfin à Puerto-di-Plata. Ce Port avoit encore d'autres avantages très-confiderables fur celui de San-Domingo, il abrégeoit de beaucoup le chemin des Navires, qui étoient encore plus affûrés d'y trouver toutes fortes de rafraîchiffemens. Il n'eft qu'à dix ou douze lieuës au plus des Mines de Cibao; qui étoient toûjours regardées comme les plus abondantes de toutes, \& celles dont l'or étoit le plus pur. Sant-Yago n'en eft gueres plus éloigné, la Conception de la Vega n'en eft qu'à dix lieuës , \& il pouvoit fervir d'Echelle à ces deux Villes, à la premiere defquelles il ne manquoit que cette commodité pour être la plus riche \& la plus commerçante de toute l'Ifle. D'ailleurs il falloit s'affûrer des Habitans de ces quartiers-là, qui étoient encore affés peuplés, \& dont on pouvoit fe fervir pour profiter du voifinage des Mines. Je ne fçai, fi dès-lors on fçavoit que les Montagnes, qui font voifines de ce Port, renferment une Mine d'Argent très-abondante, mais la chofe eft aujourd'hui certaine. 
Enfin il étoit aiféde tenir de-là en bride les Provinces Orientales dontles Peuples, qui n'avoient jamais été bien domptées; \& paffoient avec raión pour les plus aguéris de l'Ifle; ainfi Ovando n'avoit rien de mieux à faire, qu'un établiffement folide dans un lieu fi avantageux, \& nous avons vû que l'Amiral avoit eu deffein quelques années auparavant d'y bâtir une Ville. Il ne differa donc point à prendre de bonnes mefures pour cela : il arma une Caravelle à San-Domingo, y fit embarquer tous ceux, qu'il deftinoit à peupler la nouvelle Ville, \& comme il ne put leur donner des vivres pour long-têms, il leur recommanda de paffer par la Saona, où il les affüra qu'ils en trouveroient en quantité.

J'ai dit ailleurs que la Saona eft une petite Inle fort pro- Action cruelche de la Province de Higuey, la plus Orientale de l'Efpa- gnol. gnole : elle eft extrêmement fertile, \& les habitans de SanDomingo en tiroient beaucoup de provifions de toutes les fortes; les Indiens trouvant leur compte dans ce commerce, \& le profit, qu'il leur apportoit, les engageant à cultiver leur Ifle avec foin. Mais il venoit d'arriver une chofe, qui avoit rompu cette bonne intelligence, \& il eft affés furprenant qu'Ovando n'eût pas averti fes gens d'être fur leurs gardes. Ceux , qui étoient dans la Caravelle deftinée pour Puerto-di-Plata, furent donc fort furpris, qu'ayant moüillé l'ancre auprès de la Saona, \& ayant envoyé ia chaloupe à terre avec huit hommes; elle fut faluée, en abordant, d'une grêle de fléches, \& que des huit hommes pas un n'échappa. Or voici quel étoit le fujet de cette hôtilité. Pen de têms avant l'arrivée d'Ovando, une Caravelle étant venuë à la Saona pour y charger de la Caffave, tandis que le Cacique da lieu. fe donnoit de grands mouvemens pour l'expedier, un $\mathrm{Caf}$ tillan ayant apperçî un chien d'attache, qu'un autre tenoit par fa chaîne, eut l'indifcretion de dire à ce Dogue, en luị montrant le Cacique, ce qu'on a contume de dire à ces Animaux pour les agaçer, pille, pille. Il ne vouloit que badiner, dit Herrera, \& l'autre tenoit toûjours le bout de la Ee ij 
3502. corde, ou de la chaîne, qui étoit fort longue, mais il n'en fut pas le maître. D'autres difent qu'il lâcha le chien, \& le laiffa faire. Ce qui eft certain, c'eft que le Dogue éventra le Cacique, lui dévora les inteftins, \& que ce malheureux en mourut fur l'heure. Quelques-uns ajoûtent que les $\mathrm{Su}-$ jets de ce Seigneur allerent fur le champ trouver le Gouverneur Général Bovadilla, \&lui demanderent juftice d’une action fi brutale, mais qu'ils ne furent pas même écoutés; ce qui les mit en fureur; ils fçurent néanmoins diffimuler, jufqu’à ce qu'ils euffent eu le têms d'avertir tous leurs voifins, $8 t$ de les engager dans leur querelle. Cela fut bientôt fait, \& le Cacique Cotubanama Souverain de la Province de Higuey s'étant mis à leur tête, ils leverent le mafque à l'occafion, \& de la maniere, que je viens de raconter.

Ia Province On étoit alors fi perfuadé que ces Infulaires n'étoient de Higuey prend les ar- plus en état de fe foulever, qu'on ne penfa point qu'ils voulufmes.

fent porter leur reffentiment au-delà de ce qui venoit de fe paffer. On fe trompoit, \& le maffacre des huit Efpagnols, étoit la déclaration d'une guerre, que les Barbares étoient déterminés à pouffer à toute outrance. Le Grand Commandeur ne tarda pas d'en être informé, \& ne crut pas devoir négliger une affaire, qui lui parut férieufe. Jears de Efquibel, Officier de mérite, eut ordre de partir avec 400. hommes pour la Province de Higuey, \& d'y faire repentir les Indiens, d'avoir ofé fe venger. Il n'y trouva pas autant de facilité, qu'il l'avoit efperé, \& quelques-uns de fes détachemens furent bien battus. Ovando lui avoit ordonné de tâcher, s'il trouvoit les ennemis trop forts, de les amener à un accommodement, qui fauvât l'honneur de la nation, \& rétablit la tranquilité dans cette Province. Elle étoit veritablement toute en armes, \& Cotubanama fit très bonne contenance à l'approche des troupes Efpagnoles. Efquibel, fuivant fes ordres, lui offrit des conditions affés raifonnables; il les rejetta avec hauteur, \& continua quelque-têms à faire la guerre avec fuccès.

उelle ation: On commença dès-lors à rencontrer des braves parmi 


\section{DE S. Domingue, LIv. XII. 22 I}

ces Infulaires, \& il y en eut un qui fit une action, qu'on peut croire fur le témoignage des Autheurs Caftillans, toute peu vrai-femblable qu'elle eft. Deux Cavaliers Efpagnols, dont l'un fe nommoit $V$ aldenebro \& l'autre Pontevedra, apperçûrent cet Indien, qui paffoir fon chemin, \& Valdenebro fe détachant auffitôt de fon Camarade, courut fur lui la lance haute. L'Indien voulut le prévenir, \& lui tira une fléche, mais il le manqua, \& dans le moment le Cavalier lui paffa fa lance au travers du corps. L'Indien l'arrache auffitôt, faifit la bride du cheval de fon ennemi, \& l'alloit percer, lorfque celui ci lui enfonça fon épée jufqu'à la garde dans le ventre; il la retire, comme il avoit fait la lance, \& quoique le Caftillan la tînt encore par la poignée, il la lui fait lấcher. : Valdenebro prend Ion poignard, \& le plonge encore tout entier dans le corps de l'Indien, qui s'en délivre avec la même facilité, qu'il avoit fait de l'épée \& de lance. Pontevedra, qui voit fon Compagnon défarmé \& en danger, picque aufitôt fon cheval, pour le fecourir. L'Indien l'attend de pied ferme; quoique perdant tout fon fang par les trois larges plaies, que lui ayoit faites Valdenebro. Pontevedra lui en fait fucceflivement trois autres de la même maniere, \&avec le même fuccès, \& deux Cavaliers fe trouvent défarmés \& mis en fuite, par un feul de ces Hommes, qu'ils jugeoient à peine dignes de la colere de leurs Chiens. Un moment après l'Indien tomba mort faifi de deux lances, de deux épées, \& de deux poignards, \& non feu lement on peut dire que jamais Guerrier ne mourut plus glo a rieufement les armes à la main, mais par une bizarrerie, dont l'hiftoire n'avoit peut-être pas encore produit d'exemple, on vit les vidtorieux chercher leur falut dans la fuite, \& le vain cu périr avec toutes les marques de la victoire.

Il s'en fallut bien que tous les autres Infulaires fiffent parô̂́ İes Iriders rre la même valeur, que ce brave Homme. Efquibel vint en - font défcits fin à bout de leur faire quitter la campagne, \& les pourfuivit donne la pais, vivement dans les montagnes, où ils s'étoient retirés, ils. n’y firent pas même grande réfiftance, \& il en fut tué un $f$ grand nombre, que cette Province affés peuplée jufqu’alors, 
1502 .

parut toute deferte. Cotubanama demanda la paix, qu'il avoit refufée; Efquibel la lui accorda de bonne grace, \& le Cacifut fi charmé des manieres de ce Capitaine, qu’il fe fit toûjours appeller depuis Geande Efquibel. Ce n'eft pas qu'il fe fît Chrétien, mais l'ufage de ces peuples eft de prendre les noms de ceux, pour qui ils ont conçû de l'eftime \& de l'affection. Efquibel crut pourtant devoir s'affürer de la fidelité de ce Prince autrement, que par de fimples proteftations d'un dévoüement entier; il bâtit une Citadelle dans fes Etats, \& y laiffa neuf Efpagnols en garnifon fous les ordres d'un Capitaine nommé Martin de Villaman.

San-Domingo rebâti dans une fituation peu avantageufe.

Ce fut pendant cette guerre, que le Grand Commandeur fongea à rebâtir San-Domingo,prefque entierement renverfé par l'Ouragan, dont nous avons parlé plus haut. Véritablement il lui donna un air de fplendeur digne de la premiere Metropole du nouveau Monde, mais il lui fit grand tort en le changeant de place. Elle étoit, comme je l'ai déjà remarqué, fituée à l'Orient du fleuve Ozama, \& par la feule raifon qu'il y avoit des Habitations Efpagnoles de l'autre côté, le Grand Commandeur l'y tranfporta, fans faire réflexion que pour la commodité de quelques particuliers, il en faifoit perdre à la Ville deux beaucoup plus confidérables, dont l'une ne fe pouvoit abfolument remplacer, \& l'autre ne fe peut encore fuppléer, fans qu'il en coûte beaucoup. Car en premier lieu la Ville étant au Couchant, fe trouve continuellement enveloppée des vapeurs du Fleuve, que le Soleil chaffe toûjours devant lui ; ce qui n'eft pas une petite incommodité dans un un pays auffi chaud \& auffi humide, que celui - là ; en fecond lieu, elle eft privée d'une Source d'une eau excellente, dont elle joüiffoit auparavant, \& comme l'eau des puits \& celle du Fleuve font faumatres, on a été obligé d'y fuppléer par des Cifternes, dont les eaux ne font pas bonnes. Ceux, qui en vouloient boire de la fource, étoient obligés d'avoir des Efclaves, qui ne fuffent occupés, quà en aller chercher. M. Butet, que j'ai déjà cité, dit dans fon memoire qu'on a découvert une autre Source à une portée 


\section{DE S. Domingue, Liv. III. 223}

de fufil, au Nord de la Ville, \& que tous les Navires y font leur provifion d'eau : mais que les Habitans de cette Capitale trouvent qu'elle eft encore trop loin, \& aiment mieux s'en tenir à celle de leurs Cifternes, quelque mauvaife qu'elle foit, que de fe donner un peu de peine pour en avoir de meilleure. Le deffein du Grand Commandeur étoit de faire un Réfervoir avec une magnifique Fontaine au milieu de la Ville, pour y recevoir les eaux de la Riviere Hayna, qui font excellentes, \& qu'il ne falloit faire venir, que de trois lieuës, mais il n'a pas eu le têms d'exécuter fon projet.

Oviedo, qui a vî cette Capitale dans tout fon luftre , affùre qu'il ne lui manquoit que cet ouvrage, pour être une des plus belles Villes du monde. Elle eft fituée fur un terrein parfaitement uni, \& s'étend du Nord au Sud le long du Fleuve, dont le rivage bordé de jardins bien cultivés, fait un très-bel afpect. La Mer borne la vîë au Midi, le Fleuve, \& fes bords fi bien ornés, la terminent à l'Orient, \& ces deux côtés oecupent plus de la moitié de fon Orizon, parce que le Fleuve tourne un peu à l'Oueft. La Campagne des deux autres côtés eft des plus belles, \& bien diverfifiée. Le dedans répondoit parfaitement à de fi beaux dehors, les ruës étoient larges \& bien percées, \& les Maifons exactement allignées. Elles étoient bâties pour la plûpart d'une forte de Marbre, qu'on a trouvé dans le voifinage. Les autres étoient d'une efpece de terre extrêmement liante, qui durcit à l'air, \& qui dure prefque autant que la Brique. Le pied des murs eft baigné par la Mer, \& lui fait une digue affés forte, pour la mettre à l'abri de fes fureurs. Les Vaiffeaux paffent le long de la Ville, \&le moüillage y eft bon par tout, même pour les Navires de Guerre, s'ils pouvoient venir jufques-là ; mais à l'entrée du Fleuve il y a une Barre, laquelle n'a ordinairement qu'onze pieds d'eau, treize à quatorze, quand la Marée eft haute, \& quinze au plus dans les grandes Marées : il eft vrai que la. Rade exterieure eft affés fûre, fi ce n'eft depuis la mi-Juil

Situation de cette Ville. Son Port. 


\section{$224 \quad$ HYSTOIRE}

1502. let jufqu'à la mi-Octobre, qu'il regne fur cette côte du Sud des Ouragans d'une violence extraordinaire; mais, cette faifon paffée, il n'y a rien à craindre, \& il eft fans exemple qu'aucun Navire y ait échoüé, à moins que ce n'ait été par l'ignorance des Pilotes.

Des qualités Le terrein des environs de cette Ville, n'eit pas le meil-

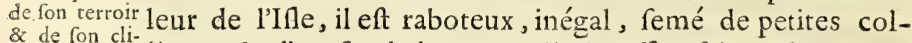
mat.Maladies, lines, \& d'un fond de pur argile; aufi y fait-on beaucoup aufquelles on de Briques $\&$ de très-belles Poteries. Elles font d'une terre $y$ eff fujet. beaucoup plus fine, \& d'un rouge plus vif, que celles de la Havane, d'ailleurs fi eftimées, \& l'eau s'y conferve extrêmement fraîche. Mais fi San Domingo n'eft pas fitué fur un terroir fertile, en récompenfe il joüit d'un air affés frais; ce quon attribuë en partie à la Riviere \& à la Mer, dont la meilleure partie de la Ville eft environnée, \& en partie au falpêtre, qui s'y trouve en abondance: les vents du Nord, qui y regnent toutes les nuits, \& les Brifes de l'Eft \& de l'Eft-Sud-Eft, qui y foufflent ordinairement tous les jours, contribuent auffi beaucoup à cette fraîcheur. Les Efpagnols y font néanmoins fujets à une maladie, qui leur eft particuliere, \& qu'ils appellent Pafmo; elle attaque les nerfs, qui fe roidiffent \& fe retirent, le fang fe congéle dans les veines, les Malades fouffrent bealicoup du défaut de refpiration, \& il eft rare qu'ils en guériffent. On a vû dans nos habitations quelques Negres mourir de ce mal; mais jamais aucun François n'en a été attaqué. La Lépre eft auffi affés commune dans cette Capitale, \& on prétend qu'elle a fa principale fource dans les eaux de Cifternes, qu'on y boit. En effet, dans les Campagnes, où l'on a des Sources \& des Rivieres en abondance, on ne voit pas un feul Lépreux. Les habitans de San-Domingo devroient bien, ce femble, s'affúter aux prix de la peine, qu'il y auroit d'aller puifer de bonne eau à la Fontaine, dont j'ai parlé, s'il ne tient qu'à cela, qu'une maladie aufi horrible ne ceffe parmi eux.

Mines dans la Il y avoit autrefois dans l'enceinte de la Ville, une MiVille. Pluye ne de vif-argent d'une abondance merveilleure, mais la Cour
abondante 


\section{De S. Domingue, Iiv. III. 225}

a ordonné qu'on la fermât, on y avoit auffi trouvé , diton, une Mine d'or, mais on ajoûte qu'elle rapportoit trèspeu. Les débordemens du fleuve Ozama, ne font ni fréquens, ni dangereux, parce que fes bords font fort élevés; du refte il pleut beaucoup dans ce quartier-là, \& il eft rare que les Séchereffes y durent plus d'un mois. Les pluyes, qui viennent pour l'ordinaire du Nord-Eft, \& du Sud-Eft, s'arrêtent à quatre lieuës fous le Vent aux environs de la Riviere Yuna; \& l'on a obfervé que tous les quartiers, qui font à l'Oueft de la Capitale jufques-aux habitations Françoifes, font fi fouvent expofés aux Séchereffes, que tous les Beftiaux y périroient de foif, fi on n'avoit pas la précaution de les mener dans les doubles Montagnes, où on les nourrit des feüilles des arbres, encore n'en fauve-t'on par-là qu'une partie. Or on ne voit rien de femblable dans les Provinces, qui font au Vent de San-Domingo. Enfin on affûre que les Tremblemens de Terre font affés frequens aux environs du fleuve Ozama, mais on ajoutte qu'ils n'y ont prefque jamais aucune fuite fâcheúe.

Pour revenir, Ovando, outre la Fortereffe, qui eft fon ouvrage, \& fa Maifon, qui étoit magnifique, y fit conftruire un Couvent pour les PP. de S. François, \& un Hopital, fous le titre de S. Nicolas, dont il portoit le nom. Quelques années après les Religieux de S. Dominique $\&$ de la Merci, vinrent auffi s'établir dans cette Capitale, \& le Tréforier Michel de Paffamonté, dont nous parlerons bientôt, y ajoûta un fecond Hôpital fous le nom de S. Michel fon Patron. Enfin on y a bâti une fuperbe Cathédrale, \& toutes fes Eglifes font fort belles. Jamais Ville ne fut plus promptemient achevée avec cette magnificence, où on l'a vûë: quelques Particuliers, qui fe trouvoient en fonds, entreprirent d'abord de bâtir des ruës entieres, dont ils ne tarderent pas à retirer leur argent avec de gros profits. D'autres fuivirent leur exemple, \& s'en trouverent également bien. San-Domingo devint ainfi prefque tout à coup une fi grande, \& une fi belle Ville, qu'Oviedo ne craignit point Tom. $I$. 


\section{H ISTOIRE}

I502. d'affûrer l'Empereur Charles Quint, que l'Efpagne n'en avoî pas une feule, qui lui pût être préférée, ni pour l'avantage du terrein, ni pour l'agrément de la fituation, ni pous la beauté \& la difpofition des Places, \& des Ruës, ni pour l'amenité des environs, \& que fa Majefté Imperiale logeoit affés fouvent dans des Palais, qui n’avoient ni les commodités, ni l'étenduë, ni les richeffes de quelques-uns de ceux de San-Domingo. Puerto di-Plata fut auffi achevé dans le même têms. Ce Port a été quelques années affés floriffant, mais il s'en faut bien que les Efpagnols en ayent tiré tous les avantages, dont ils s'étoient flattés, \& qu'ils pouvoient s'en promettre avec fondement; nous verrons dans la fuite qu'ils ne purent s'en prendre qu'à eux, fi leurs efperances furent trompées; il ne falloit que conferver les Infulaires.

Fin du Livre troifiéme. 


\section{HIS T OIRE D E \\ L'ISLE ESPAGNOLE \\ O U D E \\ S. DOMINGUE. \\ $P R E M I E R E P A R T I E$}

\section{LIVRE QUATRIE'ME。}

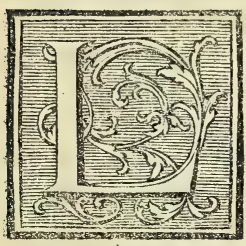

E fuccès de la derniere guerre de Higuey ayant mis le Grand Commandeur en état de donner la loy à toute l'lfle, la bonne Politique demandoit, ce femble, qu'il s'appliquât à conferver un Peuple foumis, qui pouvoit être d'une grande utilité à la Colonie Efpagnole, \& dont on avoit même abfolument befoin, fi on vouloit tirer du fein de cette terre les tréfors, qu'elle renfermoit. Il faut rendre à la Cour d'Efpagne la juftice de dire que tel a toûjours été fon plan, \& qu'elle n'a jamais rien tant recommandé aux Gouverneurs du nouveau Monde, que d'en bien traiter les anciens Habitans. Mais fes ordres ont prefque tô̂jours été fort mal executés; on lui en a même fait donner quelques-uns, dont elle ne voyoit pas les confequences pernicieufes, \& dont on a abufé, pour exercer une Tyrannie, que rien ne pourra jamais excufer, \& qui a dépeuplé les plus belles, \& les plus vaftes Regions de l'Amerique.

Ainfi fur les repréfentations que le Grand Commandeur Nonveaux fit alors aux Rois Catholiques, que la liberté renduë aux au Grand Habitans de l'Ine Efpagnole alloit produire immanquable- Commandeur 


\section{H I S T O R E}

I503. ment la ruine entiere de la Colonie; qu'on y fouffroit déconformes à jà beaucoup de la diferte des viorres, qu'on n'y étoit" plus ce qu'il avoit en état de travailler aux Mines, que les Tributs ne fe payoient
sepréfenté.

point, \& que les Indiens s'éloignant des habitations Efpagnoles, il n'étoit pas poffible de les inftruire des principes du Chriftianifme: fur ces repréfentations, dis-ie, on lui prefcrivit les chofes fuivantes, par une lettre écrite de Me. dina-del-Campo: De ne rien négliger pour gagner les Infulaires, \& les affectionner à la Nation Efpagnole, \& à la Religion Carholique : Que, s'il étoit néceffaire d'ufer envers eux de quelque violence, pour les obliger à travailler, de le faire avec toute la difcretion polfible, \& de mémager fi fagement l'autorité \& la perfuafion, que les $\mathrm{Ca}$ ciques ne puffent fe défendre de mener leurs fujets au travail, les uns après les autres: D'avoir un grand foin que tous affiftaffent aux Inftructions, qu'on leur feroit régulierement à certains jours: De faire enforte qu'ils fuffent foumis à ceux, à qui on les auroit donnés, pour les faire travailler, mais de tenir la main à ce que ceux-ci les traitaffent bien, \& leur payaffent exactement le falaire, qui auroit été reglé felon la qualité des perfonnes, \& la nature du travail: Enfin de fe fouvenir que ce peuple étoit libre, \& ne devoit pour aucune raifon être réduit en Efclavage, de le gouverner avec bonté, \& de s'attacher furtout à faire amitié à ceux, qui embrafferoient la Religion Chrétienne.

Ics départe- Quoique ces Inftuctions ne continffent rien,que de fort mens d'Indiens établis. fage, elles ne laiffoient pas d'être fufceptibles d'un mauvais fens, \& on ne manqua point de le leur donner. Effectivement ce fut en faifant femblant de s'y conformer, que le Grand Commandeur établit ces Départemens d'Indiens fi Repartimientos odieux, dont j'ai déjà parlé , \& voici de quelle maniere il le fit. Il affigna à chaque Caftillan un certain nombre d'Indiens, plus ou moins, fuivant la qualité des Perfonnes, ou l'inclination, qu'il avoit à leur faire plaifir. La Conceffion étoit conçûë en ces termes, « Je recommande à Iel 
$\Rightarrow$ tant d'Indiens, fujets de tel Cacique, \& il aura foin de les $\rightarrow$ faire inftruire des Principes de notre Sainte Foy . Et comme ces malheureux demeuroient les fix \& les huit mois de fuite dans les Mines, \& qu'il en mouroit beaúcoup, ceux, que le Gouverneur Général vouloit favorifer, faifoient aifément remplacer les morts des débris des autres Départemens, qu'on étoit obligé d'abandonner, quand ils étoient trop délabrés, \& qu’on n'étoit pas en faveur; ou de ceux, dont les Maîtres, après le terme expiré, n’avoient pas le crédit de fe faire continuer le fervice: cette difpofition a depuis éré fuivie dans tout le nouveau Monde.

Ce qu'il y eut de plus furprenant, fi néanmoins on doit être furpris que la cupidité \& l'avarice aveuglent les hommes, jufqu’à leur faire perdre de vâë leurs plus véritables interêts, \& même leurs plus preffants befoins; c'eft qu'avant que de mener aux Mines les Indiens nouvellement affervis, on ne les occupa point à cultiver la terre, pour faire ceffer une famine, qui duroit depuis fi long-têms. Du refte, pour tout ce qui regarde le Gouvernement de l'Ine, les Hiftoriens s'accordent à donner fur cela de grands éloges à Ovando. Tous ont extrêmemement loüé fa fageffe, fon attention au bien public, \& fon zele pour les interêts du Prince, \& pour l'Etabliffement de la Religion. Non content d'avoir donné un affés beau Couvent aux PP. de S. François dans la Capitale, il leur en fit encore bâtir un dans la Ville de la Conception, \& il les engagea à élever un bon nombre de jeunes Indiens, à qui ils apprenoient la Doctrine Chrétienne, à lire \& à écrire en Caftillan, \& même à quelques-uns, en qui il fe trouvoit plus d'ouverture d'efprit, un peu de Latin. Il purgea auffi la Colonie de plufieurs perfonnes de mauvaife vie, $\&$ il s'oppora autant qu'il pût, à ce qu'on envoyât des Negres dans les Indes, ayant remarqué que les premiers, qui pafferent: à l'Ifle Efpagnole, fe réfugioient chés les Infulaires, à qui ils apprenoient tout le mal, dont ils étoient capables, \& qu'ils rendirent beaucoup plus difficiles à conduire.

Ff iij

Bonnes qualités d'Ovando.

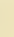




\section{HISTOIR E}

I503.

Peu de têms après l'arrivée des ordres de la Cour, don: Melures que je viens de parler, le Grand Commandeur en reçút un, prend la Cour qui auroit rompu toutes fes mefures, par rapport aux Dé-

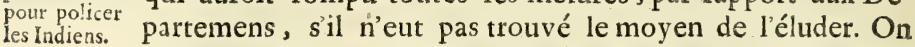
lui enjoignoit de raffembler tous les Indiens, \& d'en former de grandes Peuplades, dans le voifinage des Villes Efpagnoles, d'établir parmi eux toute la meilleure police, qu'il feroit poffible, de les accoûtumer à cultiver les terres, \&: à vivre en focieté, d'établir en chaque Bourgade une Perfonne de probité, qui la gouvernât en paix, \& ne permît pas aux Caftillans de les employer malgré eux à aucune corvée, fous quelque prétexte que ce füt, \& eût foin de faire payer exactement le falaire à ceux, qui de leur plein gré s'engageroient, foit pour les Mines, foit pour d'autres travaux; de les accoûtumer à fe vêtir honnêtement, de faire conftuire par tout des Eglifes, \& d'avoir foin qu'elles fuffent tenuës proprement, \& déffervies par des Prêtres affidus, exemplaires \& zélés; d'empê nuer leurs extorfions ordinaires contre leurs Sujets; d'exécuter fur eux, \& fur tous les Indiens en général, les ordonnances, qui avoient été faites contre les Blafphémateurs; d'abolir ce quil y avoit dans leurs fêtes, \& dans leurs réjoüiffances de contraire aux bonnes mours \& à la Religion; de bâtir des Hôpitaux pour eux, de les engager par douceur à payer les dixmes, $\&$ de procurer par tous les moyens poffibles que les deux Nations fe réuniffent par des alliances réciproques. On ne dit point ce qui avoit donné lieu à ce beau plan, qui fut plus d'une fois propofé dans la fuite, \& appuyé de toute l'autorité de la Cour, fans avoir eu fon exécution, que pendant très-peu de têms. Nous verrons en fon lieu les inconveniens, qui s'y renconsrerent: le plus réel, \& qui feul étoit capable de le faire échoüier, c'eft que les Caftillans n'y trouvoient pas leur compte, puifqu'il faifoit tomber les départemens, fur lefquels étoit fondée toute l'efperance, qưils avoient conçûë de s'enrichir. 
De S. Domingue, Liv. IV. $23 x$

C'eft ainfi que le Gouverneur Général facrifioit aux inrerêts des Particuliers, \& comme il le croyoit mal-à-propos, à ceux du Prince, un Peuple innocent, \& duquel on Etat où fe pouvoit tirer des fervices bien plus confiderables, que ceux, la Provincede qu'on en exigeoit; mais il n'eft pas aifé de fçavoir au juf Xaragua. te ce qui le porta à dépeupler prefque entierement une des plus grandes Provinces de l'Ihe, de la maniere que je vais dire. Depuis le foulévement de l'Alcaïde Major, François Roldan Ximenez, il étoitrefté dans le Xaragua un affés grand nombre de fes complices, qui y vivoient fans Dieu \& fans Foy, \& fur lefquels on croyoit avoir beaucoup gagné en les empêchant de remuer, \& de faire des affemblées contre le Gouvernement. Behechio étoit mort depuis peu, \& comme aucun de fes Enfans ne lui avoit furvêcu, fon Royaume avoit paffé à fa Sour Anacoana. Cette Princeffe, par un pur effet de l'inclination, qu'elle avoit toûjours euë pour la Nation Caftillane, s'étoit d'abord appliquée à bien traitter ceux de cette Nation, qu'elle avoit trouvés dans fes Etats, mais elle n'en avoit été payée, que d'ingratitude, \& l'on prétend que fon affection s'étoit changée en une haine mortelle. Les Caftillans s'en apperçîrent bientôt , ou peut-être même fe perfuaderent-ils que la chofe étoit ainfi, parce que naturellement ils devoient $s^{\prime} y$ attendre.Il eft au moins certain qu'il y eut quelques hoftilités de part \& d'autre. Elles cefferent à la vérité bientôt, mais les Caftillans manderent au Gouverneur Général, que la Reine de Xaragua méditoit quelque mauvais deffein, \& qu'il n'y avoit pas de têms à perdre, fi on ne vouloit pas en être prévenu.

Ovando ne crut pas devoir rien réfoudre fur un avis de cette nature, il connoiffoit affés le caractere de ceux, qui le lui donnoient, pour être perfuadé que leur querelle particuliere ne devoit pas être regardée comme une affaire d'Etat. Mais il jugea qu'un voyage dans cette Province reculée ne feroit pas hors de propos, ne fervît il qu’à remet. are les Caftillans dans l'ordre, \& à faire ceffer le fcandale. 
1503. que leur vie débordée caufoit depuis fi long-têms aux Chrétiens \& aux Infideles. Il partit donc de San-Domingo, à la tête de 300. hommes de pied, \& de 70. chevaux, après avoir publié que le fujet de fon voyage étoit de recevoirle Tribut, que la Reine de Xaragua devoit à la Couronne de Caftille, \& de voir une Princeffe, qui s'étoit dans tous les têms déclarée en faveur de la Nation Épagnole. Sur le premier avis de fa marche, Anacoana parut fort joyeufe, foit qu'elle fût véritablement innocente de ce quon lui avoit imputé, ou que n’ayant communiqué fon deffein à perfonne , elle ne craignît point qu'on l'eût pénétré. Elie fit enfuite avertir tous fes Vaffaux de la venir trouver pour groffir fa Cour, faire honneur au Général Elpagnol, \& luidonner une grande idée de fa Puiffance.

La Récep- Il en vint jufqu'à 300 . à qui les Ecrivains Efpagnols donEaion qu'on lui nent le nom de Caciques, \& la Princeffe n'eut pas plûtôt

appris que le Grand Commandeur approchoit, qu'elle fe mit en marche pour aller au devant de lui, accompagnée de toute cette Noblefre, \& d'un Peuple infini, tous danfant à la maniere du Pays, \& faifant retentir l'air de leurs chants. La rencontre fe fit affés près de la Ville de Xaragua, on parut de part \& d'autre charmé de fe voir, \& jamais on ne vit des marques d'une joye plus fincere, \& d'une plus parfaite confiance. Après les premiers complimens, Ovando fut conduit parmi des acclamations continuelles au Palais de la Reine, où il trouva dans une falle très-fpatieufe, un grand Feftin tout préparé ; tous fes gens furent aufi régalés avec profufion, \& après le repas il y eût des danfes \& des jeux de toutes les forres. La Fête dura plufieurs jours, avec une grande magnificence, \& beaucoup de varieté , \& l'on ne pouvoit fe laffer d'admirer le bon goût, qui regnoit dans cette Cour fauvage.

Il fe perfuade Les Caftillans établis dans ce pays ne voyoient pas avec princeffe a plaifir cette bonne intelligence entre le Grand Commanformé de mau- deur \& la Cacique, \& avertirent le premier de ne pas te vais deffeins fier aux démonftrations d'amitié de cette Princeffe; mais il n'étoit: 


\section{De S. Domingue, Liv. IV. 233}

n'étoit pas néceffaire de lui donner fur cela des leçons. Herrera dit qu'il fut enfin convaincu que la Princeffe Indien-pagnols ne avoit formé de mauvais deffeins contre les Efpagnols, mais il ne nous apprend pas quelles preuves il en eur. Oviedo prétend qu'il le fçut par la confeffion des 300 . Caciques vaffaux d'Anacoana, dont il tira cet aveu par les tourmens, il paroît même vouloir juftifier en tout la conduite, que tint Ovando en cette rencontre: mais les autres Hiftoriens, \& Herrera lui-même, en ont parlé comme d'une barbarie fans exemple, \& l'on en porta le même jugement à la Cour d'Efpagne. Soit donc qu'en effet ce Gouverneur fût perfuadé de ce qu'on lui avoit dit contre cette Princefle, ou que fuivant les Maximes de cette déteftable Politique, qui devine dans la fuite comme une regle générale de Conduite pour les Efpagnols dans le nouveau Monde; il réfolut de ne pas manquer l'occafion qu'il avoit entre les mains d'abatre tout d'un coup les derniers Chefs d'un Peuple, qui lui paroiffoir encore trop puiffant. Voici les mefures, qu'il prit pour empêcher qu'aucune des victimes, qu'il croyoit devoir immoler à la fûreté de la Colonie, ne lui échappât.

Il invira pour le Dimanche fuivant la Reine de Xaragua De quelle à une Fête,qu'il vouloit,difoit-il,lui donner à la maniere d'Ef- manierc Oà une Fetesquil vouloit, vando fe rend pagne, \& il lui fit infinuer qu'il étoit de faGrandeur d'y paroître maître de la avec toute fa Nobleffe. Elle donna donc à dîner à tous fes Vaf- Reine de Xa-

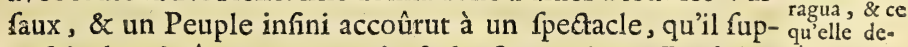
pofoit devoir être quelque chofe de fort curieux. La falle, vint. où toute la Cour Indienne étoit affemblée, donnoit fur la Place, où la Fête fe devoit célébrer, \& c'étoit une efpece d'Auvent, dont le Toit étoit foûtenu d'un très-grand nonsbre de piliers. Les Éfpagnols, après s'être fait un peu attendre, parurent enfin en ordre de Bataille. L'Infanterie marchoit la premiere, \& à mefure qu'elle arriva fur la Place, elle en occupa toutes les avenuës. La Cavalerie vint enfuite ayant le Grand Commandeur à fa tête, \& s'avança jufqu'à la maifon de la Reine, qu'elle inveftit. Cela fait tous les Cavaliers mirent le fabre à la main; ce qui commen: Tome $I_{t}$ 
1503. ça d'exciter un peu de frémiffement dans le cour de la Princeffe. Quelques momens après, Ovando ayant mis la main fur fa Croix d'Alcantara, ce qui étoit le fignal, dont il. étoit convenu avec fes gens; les Fantaflins firent main-baffe fur la multitude, qui rempliffoit la Place, en même têms que les Cavaliers mirent pied à terre, \& entrerent dans las falle où l'infortunée Anacoana étoit plus morte que vive, auffi-bien que toute fa Cour. Les Caciques furent auffitôt attachés à des Poteaux, \& ce fut alors, fi on en croit Oviedo, qu'ils avoüerent le crime de Rébellion, dont on les accufoit. On mit enfuite le feu à la maifon, \& tous ces malheureux y furent bientôt réduits en cendres. La Reine réfervée à un fupplice plus honteux, fut préfentée liée \& garottée, au Grand Commandeur, qui la fit conduire en cet état à San-Domingo, où fon Procès lui ayant été fait dans toutes les formes de la Juftice, elle fut déclarée atreinte \& convaincuë d'avoir confpiré contre les Efpagnols, condamnée comme telle à être penduë, \& executée publiquement. Oviedo nous repréfente cette Princeffe comme débordée à l'excès; mais j’ai deja averti que cet Ecrivain à toujours grand foin de faire paroître fort criminels tous ceux,qui ont éprouvé les plus triftes effets de la cruauté de fas Nation.

Horrible maffacre des Habitans de Xaragua.

Révolte de quelques Provinces affoupie fur le shamp.

Au refte, il ne fe peut dire combien il périt d'Indiens, dans cette funefte journée. On ne vit jamais une plus horrible boucherie: tout fut confondu, grands \& petits, hommes \& femmes, les innocens, \& ceux qu'on croyoit coupables. On dit même que quelques Cavaliers, par une piété, où il entroit un peu d'interêt, ayant réfervée de jeunes enfans, dont ils vouloient faire des Efclaves, \& les menant en croupe, d'autres venoient percer derriere eux ces petits Innocens, ou fi quelqu'un tomboit par terre, ils lui coupoient les jambes, \& les laiffoient en cet état fansaucun fecours. Du petit nombre de ceux, qui échapperent à la fureur du Soldat, quelques-uns fe fauverent dans des Canots, que le hazard leur fit trouver fur le bord de 
De S. Domingue, Liv. IV. 235

la Mer, \& pafferent à la Gonave, mais ils y furent pourfuivis, \& on ne leur fit grace de la vie, que pour lescondamner à une fervitude beaucoup plus dure, que la mort. D'autres pafferent dans les Provinces limitrophes, \& les fouleverent par le récit, qu'ils y firent, de ce qui venoit de fe paffer chés eux. Un des parens d'Anacoana fe cantonna dans les montagnes de Baoruco, les plus hautes \& les plus inacceffibles de l'Inle, qui s'étendent en dedans des terres, par une ligne parabolique, depuis le milieu du grand Cul-de Sac, où étoit Xaragua, jufquà la côte du Sud, \& dont les Habitans étoient extrêmement Sauvages. Plufieurs pénétrerent dans le milieu de l'Ifle. Le Grand Commandeur fit marcher contre les uns, Diego Velafquez, \& contre les autres, Rodrigue de Mefcia, avec de bonnes Troupes. Les Indiens fe défendirent pendant quelque têms, mais leurs Chefs ayant été pris \& punis; le refte fe diffipa, de forte quau bout de fix mois il ne reftoit plus perronne dans l'Ifle, qui n'eût fubi le joug des Caftillans.

Cette guerre finie, Ovando donna toute fon attention à $1 a$ fondation des Villes ou des Bourgades, qu'on lui avoit re1504. commandé de bâtir aux endroits les plus avantageux, pour l'affermiffement de la Colonie. Il obligea les Efpagnols, qui reftoient dans la province de Xaragua, de fe réünir, \& il en forma une Ville, qui fut nommée Sancta-Maria de la Vera-Paz. Elle étoit placée affés près du Lac Xaragua, à deux lieuës de la Mer, dont on l'approcha dans la fuite, fous le nom de Sancta-Maria del Pwerto. Mais le nom d'Yaguana, que les Infulaires donnoient à ce lieu là, a pris le deffus dans l'ufage ordinaire, \& les François en ont formé celui de Leogane. Cette Ville étoit éloignée de 7o. lieuës de la Capitale. A huit lieuës au Nord de San - Domingo, le Grand Commandeur fonda la ville de Buenaventura, \& dans le milieu de l'Ihe, entre les deux grandes rivieres Yaqué \& Neyva, il fonda celle de San- Fuan de la Magwana. A 24. lieuës de SanDomingo, un Commandeur de Galice, dont on na pas eu roin de nous apprendre le nom, avoit fait une habitation, 


\section{HISTOIRE}

1504. près d'un Port, nommé $A z u a$, où il y avoit et une Bour gade de Sauvages. Cette habitation devint bientôt une Ville"

Villa Nueva fous le nom d'Azua de Compoftella. Le Port d'raquimo, autred'Yaquimo. ment appellée le Port de Brefil, \& Salvatierra de la Savana, furent établis peu de têms après, \& Velafquez fut déclaré Lieutenant Général pour tous ces nouveaux établiffemens. Rodrigue de Mefcia fut chargé en même têms d'en faire un え̀ Puerto Real, un fecond dans lesTerres à $\mathbf{6}$.lieuës deSan-Domingo vers le Septentrion, qui fut nommé el cotuy; \& un troifiéme fur la même Côte du Nord, dans un canton que les Naturels du Pays nommoient Guabana. Ovando lui donna le nom de fon ancienne Commanderie, \& cette Ville fut appellée Larez de Guahana.

Etat de l'Tle Efpagnole en I. 504 .
De cette forte on comptoit en i 504. dans l'Ifle Efpagnole I5. Villes, ou Bourgades toutes peuplées de Caftillans, à fçavoir, San-Domingo, Azua de Compoftella, Villa-Nueva de Yaquimo, que les François nomment aujourd' hui Aquin; \& Salva-Tierra de la Savana, fur la Côte du Sud. SanctaMaria de la Vera-Paz, fur celle de l'Oueft; Puerto di Plata, Puerto Real, \& Larez de Guahana, fur celle du Nord. SantYago, Bonao, el Cotuy, Buenaventura, la Conception de la Vega, Bonica, \& Gohava près des Mines, \& dans le milieu des terres. Outre deux Fortereffes dans le Higuey, à la place defquelles on bâtit deux nouvelles Villes fur la fin de cette année, comme nous le verrons bientôt. Ifabelle, \& plufieurs Fortereffes, qu'on avoit bâties d'abord, pour s'affûrer des Mines de Cibao \& de Saint Chriftophle, étoient abandonnées depuis quelque têms. Le Grand Commandeur obtint dans la fuite du Roi Ferdinand des Armoiries pour toutes ces Places, \& pour l'Ine en général, \& le Brevet en fut expedié le 6. Decembre 1508. L'Hiftorien Antoine Herrera a eu grand foin de nous les tranfmettre fort exactement blafonnées, \& je les ai fait graver fur la Carte, que je donne ici de l'Ihle Efpagnole, telle qu'elle étoit au têms dont je parle.

sourelles: Cependant il y avoit plus d'un an, que Criftophle 



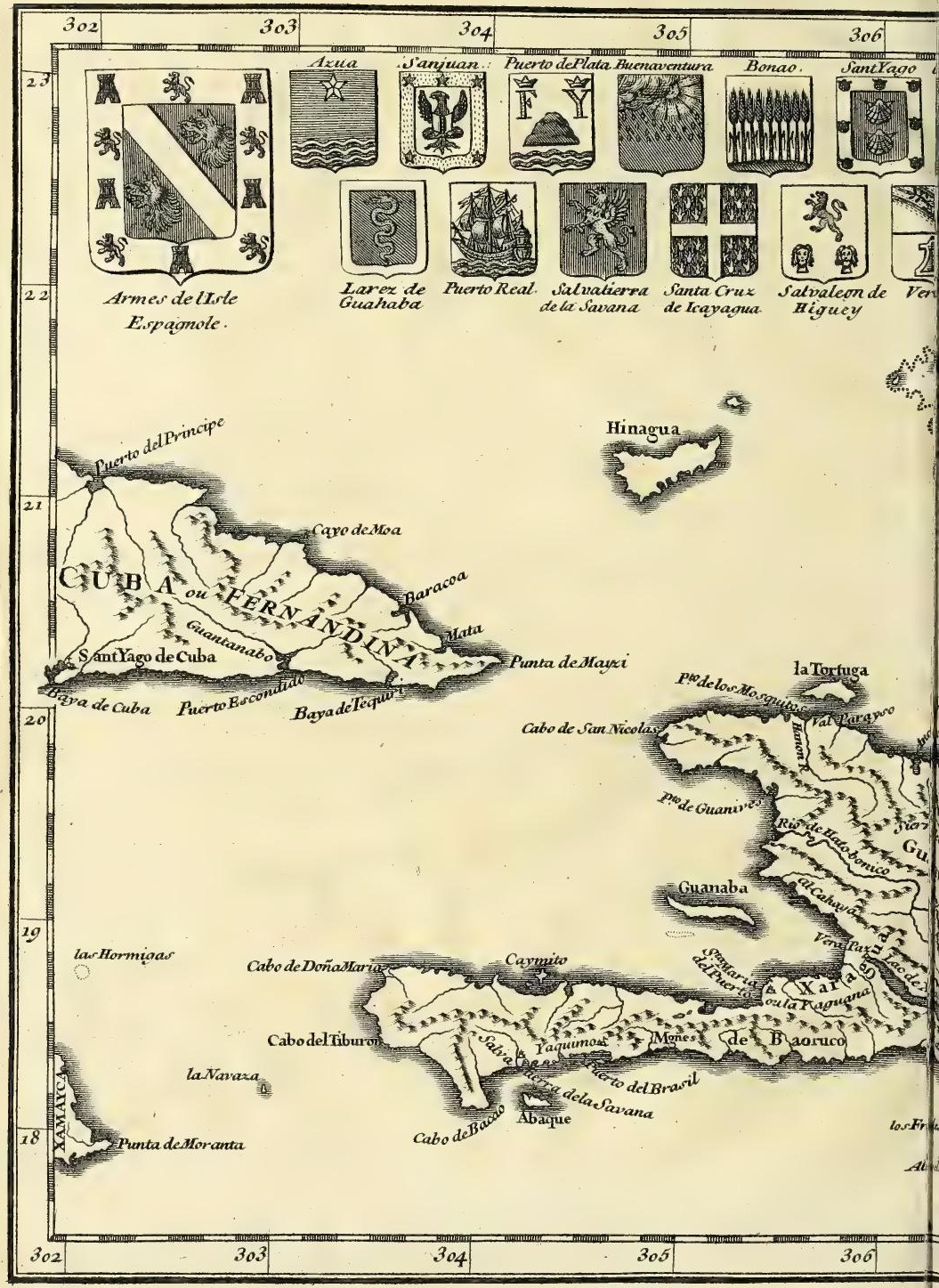




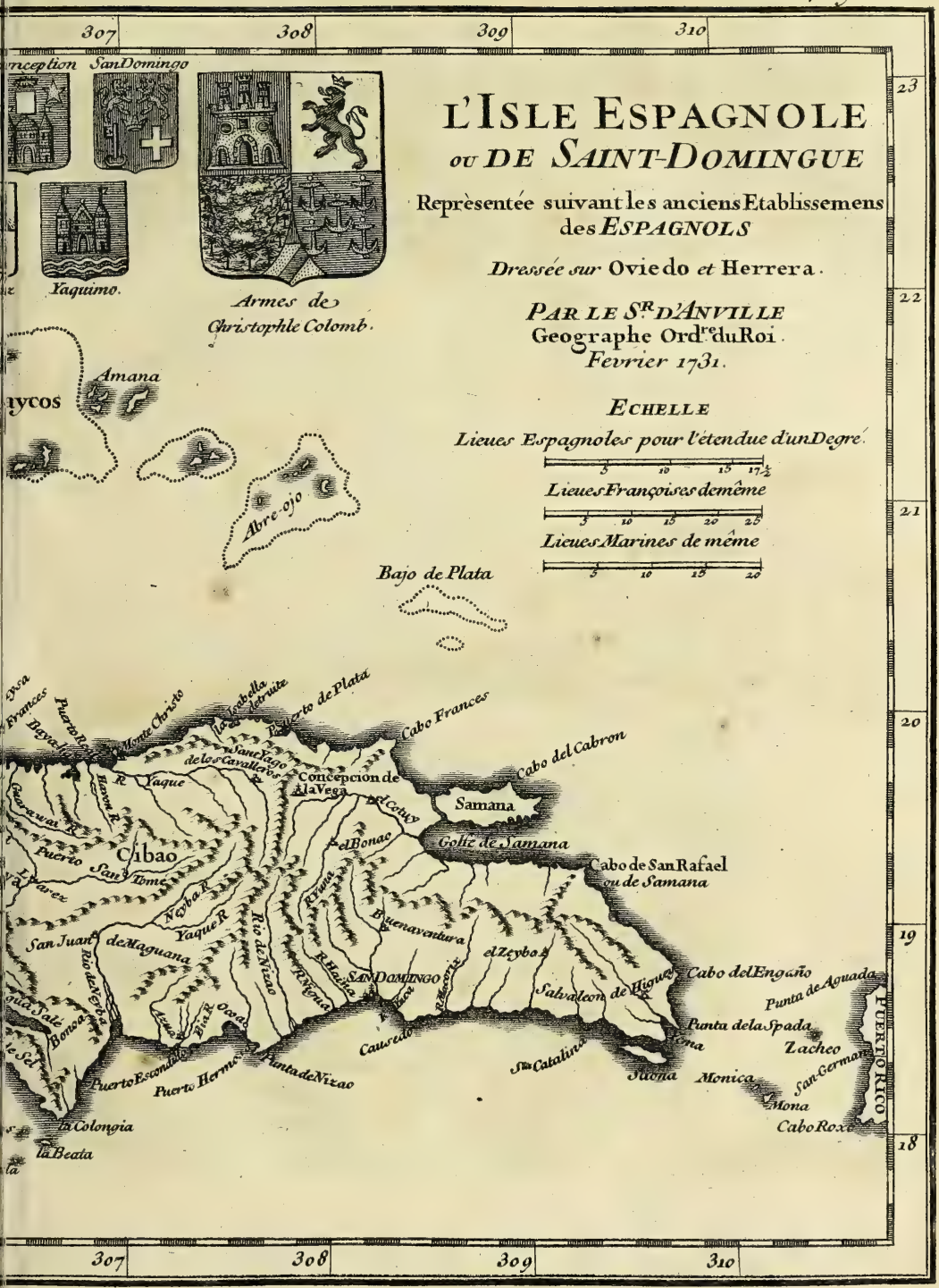





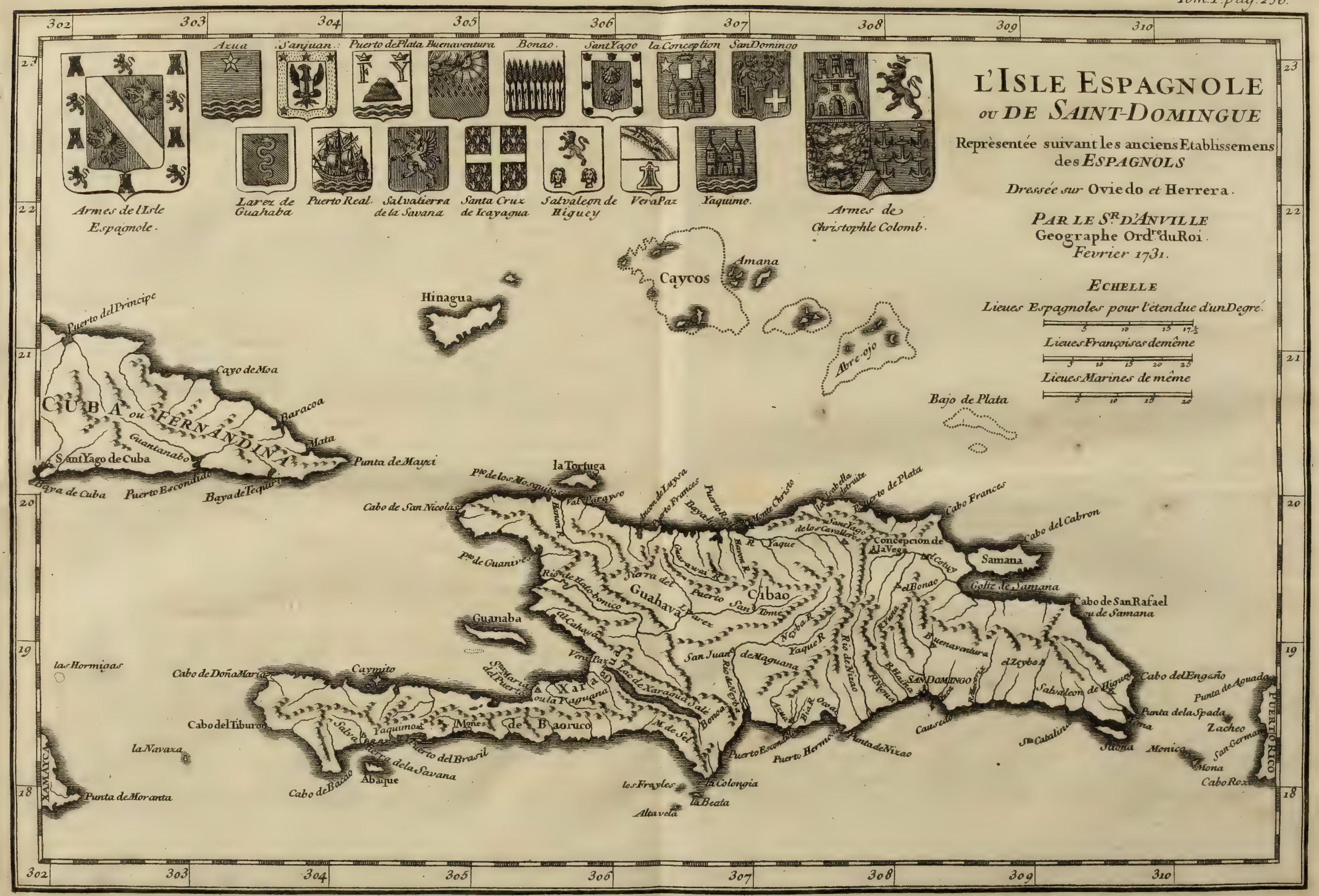



DE S. DOMINGUE, I.IV. IV. 237

Colomb étoit parti de la rade de San-Domingo, où nous l'a- 1504 . vons vû paroître peu de têms avant le naufrage de la Flotte découvertes Efpagnole, \& comme depuis ce têms-là on n'avoit appris au- phle Colomb. cune nouvelle de lui, l'on commençoit à le croire perdu , lorfqu'on fçût par une voye affés finguliere, qu'il étoit dégradé dans l'iffe de la Jamaique. Mais pour raconter les chofes avec ordre, il faut reprendre la fuite de fon voyage, où nous l'avons interrompu.

L'Ouragan, qu'il n'avoit que trop bien preffenti, l'avoit fort inquietté fur le fort de la Flotte, où nous avons vû que tout fon Bien fe trouvoit embarqué. Il eut fort défiré d'en apprendre des nouvelles, avant que de s'éloigner; \& c'eft apparamment ce qui le mit lui-même en rifque; car il eft certain qu'il fut long - têms battu de la Tempête, \& qu'il eut bien de la peine à gagner le Port d'Azua. Il y entra même feul, ayant perdu de vûë fes trois autres Navires; mais enfin ils s'y rendirent tous, \& l'Amiral ne tarda pas enfuite à gagner le Port d'Yaquimo, qui eft à 76 . lieuës de la Capitale, \& où il refta jufqu'au I4. de Juillet I502. De-là il paffa à la Jamaiqque, d'où il vouloit prendre fon point de partance. Il fit enfuite l'Oueft, pour gagner plûtôt la Terre Ferme, mais les Vents contraires, les Calmes, pendant lefquels les Cou. rans penferent le jetter fur les Jardins de la Reine, qui font au Sud de Cuba, \& une feconde Tempête, auffi forte que la premiere, le retinrent 70 , jours pour faire 60 . lieuës. Il trouva après cela, que la Tourmente avoit fort endommagé fes Navires, \& les vivres commençoient à lui manquer, de forte, que fes Equipages, perdant cœur demandoient à relâcher, ou à la Jamaïque, ou à l'Éfpagnole. Tout autre que lui l'eut fait, fans attendre même, qu'on l'en priât, mais perfonne ne fçavoit mieux que lui fe roidir contre les obftacles; il tint bon, ranima fes gens, \& attendit le vent favorâble, qui vint enfin, \& dont il profita.

La premiere terre qu'il aperçut, ce fut une petite Ine, Il découvse accompagnée de plufieurs; il leur donna le nom de los Gua- al Province majos, à caufe de la premiese, que les habitans nommoient

1502. 1 1504

$$
\text { G } \mathrm{g} \text { iij. }
$$


I502. Guanaja. I'Adélantade Dom Barthélemy Colomb eut envie 1. de vifiter celle-ci, \& y ayant trouvé une grande quantité de

1504. Pins, l'Amiral l'appella l'Ille des Pins: elle eft à r 2. lieuës du Cap de Honduras, \& de la ville de Truxillo. Quelques-uns ont voulu s'attribuer la gloire de cette découverte; mais il a été prouvé par le Procureur du Fifc Royal, que perfonne n'avoit navigué de ce côté-là avant l'Amiral Dom Chriftophle Colomb. L'Adélantade étant fur le point d'aborder dans l'Iffe, dont je viens de parler, rencontra un Canot, qui avoit à peu près la forme d'une Galere, fa largeur étoit de 8. pieds, fa longueur proportionnée , \& il portoit 25 . hommes, avec un grand attirail de femmes $\&$ d'enfans. D. Barthélemy fe rendit maître de ce perit Bâtiment, \& le conduifit à fon Frere, à qui cette heureufe rencontre fit beaucoup de plaifir. Il fe trouva dans ce Bâtiment des marchandifes de plufieurs fortes, \& dont quelques-unes venoient de l'Yucatan. C'étoit des couvertures \& des tapis ouvragés de Cotton. des épées d'un bois fort dur, des coûteaux de cailloux, de petites haches de Cuivre, \& d'un fruit, que ces Peuples nommoient Cacao, \& dont ils faifoient grand cas. Aufi s'en fervoient-ils à compofer un breuvage, qui leur tenoit lieu de nourriture \& de boiffon, \& c'étoit encore leur Monnoye ordinaire. L'Amiral leur fit beaucoup de careffes, \& les renvoya chargés de préfens, à la réferve d'un vieillard, qui lui parut avoir plus d'efprit que les autres, \& de qui il efpera de tirer plufieurs connoiffances utiles à fes deffeins.

La premiere demande quill lui fit, \& c'étoit toûjours celle, que l'on faifoit d'abord en femblables rencontres; fut , s'il $\mathrm{y}$ avoit de l'Or dans fon Pays : auffi-tôt l'Indien fe tourna vers l'Orient, \& fit entendre qu'il y avoit de ce côté - là des Pays, où ce Métal étoit en figrande quantité , que tous les meubles en étoient couverts. On lui fit voir du Corail, des Epiceries, \& d'autres Marchandifes précieufes; \& il fembla aux Caftillans, qưil leur donnoir fur tout cela les mêmes efpérances, foit qu'il le fit pour leur complaire, ou qu'on ne s'entendit pas bien. Il donna encore à connoître que dans le Pays . 


\section{DE S. DOMIMGUE, LIV. IV.}

dont il parloit, il y avoit des Navires, de l'Artillerie, toutes fortes d'Armes offenfives, \& deffenfives, en un mot, de tout ce qu'il voyoit aux Efpagnols, \& ce rapport étoit fi con-

1502. I 504 . forme aux anciens préjugés de l'Amiral, qu'il ne lui vint pas même à l'efprit de douter de la verité de ces indices, tout équivoques qu'ils étoient.

Il ne pouvoit encore s'ôter de l'efprit, que le Catay $\& x$ 1a Chine ne fuffent très-proches de l'endroit, où il fe trouvoit, \& il lui échappa un jour de dire publiquement, qu'il ne fe faifoit qu’à I 0 . journées, de l'embouchure du Gange; car il croyoit ce fleuve attenant à la Chine. Ce Pays fi riche en Or, dont l'Indien lui parloit, étoit vrai-femblablement le Perou; Colomb fe perfuada que le Royaume $d u$ Grand - Can, \& le Catay, étoient fitués à fon égard, comme Tortofe l'eft à l'égard de Fontarabie, fur deux Mers différentes à la vérité, mais peu éloignées l'une de l'autre. Cette imagination \& la créance, qu'il donna aux prétendus fignes du vieux Sauvage, lui firent grand tort;car pour peu qu'il eut continué fa route à l'Oueft, il eut bien-tôt trouvé l'Yucatan, dont il n'étoit qu'à 30. lieuës, \& apparemment toute la Côte du Mexique : mais après avoir renvoyé cet homme, \& l'avoir bien payé de fes bonnes nouvelles. il prit fa route au Levant, doubla le Cap de Gracias à Dios ler 2. Septembre, \& lui donna ce nom, parce que ces mêmes Vents d'Eft, quil l'avoient fi fort contrarié jufques-là , commençoient à lui être favorables. Le I7. il moüilia vis-à-vis une groffe Bourgade, nommée Cariari, où il fit travailler à fes Navires, qui faifoient beaucoup d'eau. Il continua enfuite à ranger la Côte, envoyant de têms en têms fa Chaloupe à terre, d'où elle ne revenoit jamais, fans lui rapporter de nouvelles affürances, qu'en avançant à l'Eft, il trouveroit des régions abondantes en Or.

Il alla de cette forte jufqu'à un Port, qui lui parut fi beau, II découvre qu'il lui en donna le nom; \& c'eft celui qu'on appelle en- porto-Belo \& core aujourd'hui vulgairement Portobelo. Il y entra le 2 . de tres Ports. 
1502. Novembre, \& en fortit le 9. Quatre ou cinq lieuës plus loin。 1 il en rencontra un autre, qu'il appella Puerto di Baftimentos. I504. parce qu'il en trouva tous les environs cultivés, \& couverts de fruits \& de Maïz. Il y demeura jufqu'au 23. \& il y fit encore travailler à fes Navires. Le 26. il entra dans un troifiéme Port fort étroit, mais extrêmement profond; il le nomma el Retrete. La facilité d'y approcher les Vaiffeaux de terre, penfa être funefte aux Cantillans; car plufieurs étant allés à l'infcu de l'Amiral dans les maifons des Indiens, ces Barbares, qui les avoient d'abord afrés bien reçus, \& qu'ils voulurent apparemment maltraitter, prirent les armes, \& eurent même l'affürance de venir attaquer les Navires. Colomb crut les intimider en faifant gronder fon Artillerie, mais comme il n'avoit fait mettre que de la. poudre dans fes Canons, les Indiens, les plus hauts \& les plus puiffants, qu'on eut encore vû, s'étonnerent affés peu du bruit, ils s'en mocquerent même, \& ajoûterent les menaces aux railleties. Quelques boulets qu'on leur envoya, \& qui abbatirent quelques-uns des plu6 hardis, les firent pourtant fuir bien loin, \& ils n'oferent plus s'approcher.

II fonge à Ce fut là, que l'A miral, ne voyant plus aucune apparence s'en retourner de trouver, ni l'Or, dont on l'avoit flatté, ni un Détroit, qui

le conduisît aux grandes Indes; ou plûtôt, ne pouvant plus tenir la Mer avec fes Vaiffeaux, qui s'ouvroient de toutes parts, il réfolut de s'en retourner en Efpagne. Et bien lui en prit, de ne pas trouver ce Détroit fi défiré ; car dans la perfuafion, où il étoit, que le Gange n'étoit pas loin , il n'eut pas manqué de s'engager fans vivres, \& avec des $\mathrm{Na}$ vires tout délabrés dans cette vafte Mer du Sud, qui par le travers, où il fe rencontroit, à plus de 2000 . lieuës d'étenduë, \& où il lui étoit inévitable de périr. Il retourna donc à Portobelo, où il arriva le 5 . de Decembre, \& pour ne pas perdre tout le fruit d'un fi long \& fi pénible voyage; il voulut avant que de quitter la Terre Ferme y faire un Etabliffement, ce que perfonne n'avoit encore entrepris, \& if jugea qu'outre l'honneur, qui lui en reviendroit, il confirmeroit 
DE S. DOMINGUe, LIV. IV. $24 \pi$ meroit encore par là les droits de fa Charge fur toutes les Mers \& les Terres du Nouveau Monde.

Il s'informa donc, d'où l'on tiroit l'or, que la plûpart des Indiens, qu'il rencontroit, venoient traiter avec lui, \& il Il rude tempéte. apprit que c'étoit des Terres d'un Cacique, appellé Quibia, \& que fes Navires pourroient remonter un grand Fleuve, nommé Veragua, au haut duquel ce Seigneur faifoit fa Réfidence. Sur cet avis il tourna de ce côté-là, \& il n'eut pas fait beaucoup de chemin, qu'il fut accueilli de la plus horrible Tempête, qu'il eût jamais efluyée. Elle étoit formée par plufieurs Vents contraires, ce qui caufoit des vagues fi exceffivement hautes, que d'un moment à l'autre, les $\mathrm{Na}$ vires fembloient s'élever jufqu'aux nuës, \& fe précipiter dans un abîme fans fond. Avec cela, il tomboit fans ceffe un déluge de Pluye, le Ciel étoit en feu, le Tonnerre ne difcontinuoit point, \& les coups fe fuivoient de fi près, que comme les Navires ne fe voyoient point l'un l'autre, on s'imaginoit toûjours que c'étoit quelqu'un d'eux, qui déchargeoit toute fon Artillerie, pour demander du fecours. Ce qui furprenoit d'avantage, c'eft que ces Bâtimens, fur lefquels on ne fe croyoit point en fûreté dans une Mer tranquille, réfiftaffent fi long-têms à une fi étrange agitation, \& qui dura 8 . jours entiers.

On n'étoit pas loin du Port, \& l'on n'ofoit en approcher, Pompe d'ears parce qu'on ne le connoiffoit pas; mais il n'y eut perfonne ou Trompe parce qu'on ne le connoiffoit pas; mais il n'y eut perfonne, Marine. qui ne crût toucher à fon dernier moment, à la vûë d'une de ces Pompes d'eaux, ou Trompes Marines, que les gens de Mer appellent Fronks, que l'on connoiffoit alors fi peu, \& qui ont depuis fubmergé tant de Navires. C'eft un Nuage agité d'un mouvement de Tourbillon, qui defcend dans la Mer, en tire l'eau, la fait monter fort haut, en forme de Colonne, \& chaffé enfuite par le Vent, crêve enfin quand il eft trop plein; \& malheur au Navire, qui fe rencontreroit en fon chemin. Le feul remede eft de tirer deffus pour le couper. L'Amiral, qui n'avoit aucune connoiffance de ce Phénomene, n'y en trouva point d'autres, que de faire Tome $I_{0}$ 
1502. réciter le commencement de l'Evangile de S. Jean; la Pom: 1 pe paffa affés près de fon Navire, fans l'endommager, \& la

1504. même piété, qui l'avoit fait recourir à Dieu, pour être préfervé de ce danger, l'empêcha de douter, qu'il ne fut redevable à fa bonté d'y avoir échappé, \& lui en fit rendre de finceres actions degraces à celui, qui commande à la Mer \& Il entre dans. aux Vents.

la Riviere de Deux jours de calme, qui fuccederent à une fi longue \& Béthléem, puis fi fâcheufe Bourrafque, donnerent lieu aux Equipages de Veragua. refpirer, mais ils mouroient de faim; il y avoit huit mois qu'ils étoient en Mer, \& fous la Zone Torride : le peu de vivres, qui leur reftoit, s'étoit gâté, \& le bifcuit même fourmilloit de Vers. Une abondante pêche de ces Poiffons, qu'on nomme Tiburons, \& qui font gros comme des Chiens d'attache, vint fort à propos pour y fuppléer. L'Amiral s'approcha enfin de terre, environ à 30 . lieuës de Portobelo, \& il appella cette Côte, la Cofta de los Contraftes. Ce n'étoit pas fans fondement; car outre ce qu'il avoit fouffert dela Tourmente, lui, qui ne fermoit jamais loeil, quand il y avoit le moins du monde à craindre pour fes Vaiffeaux; la mauvaife Nourriture, en quoi il ne fe traittoit pas mieux que le dernier des Matelots, \& les Maladies, qui avoient mis prefque tous fes gens hors de fervice, la Goutte ne le quitta point pendant tout ce têms-là, \& lui caufa des douleurs incroyables. Il prit d'abord pour le Veragua une Riviere, que le\$ Naturels du Pays nommoient Yebra, \& que Colomb, quand il eut reconnu fon erreur, appella Bethléem, parce qu'il y étoit entré le jour de l'Epiphanie, auquel les Mages entrerent dans l'Etable de Bethléem. Le lendemain, fur les indices, que lui donnoient les habitans du Pays, il paffa dans le Veragua, dont il n'étoit éloigné, que d'une lieuë. Il y trouva un Village, dont tous les habitans prirent d'abord les armes, comme avoient fait la veille, ceux qu'il avoit rencontrés dans la Riviere de Bethléem, mais il les appaifa bientôt par des préfens, \& ils lui apporterent de lor; il eft vrai, quils le lui firent extrêmement valoir, non feulement, par 


\section{De S. Domingue, Liv. IV.}

ce qu'ils l'alloient chercher fort loin dans des Montagnes efcarpées ; mais encore parce qu'ils étoient obligés de fe pré-

parer à cette recherche, par le jeûne \& la continence.
L'Amiral s'amufa peu avec ces Indiens, \& comme il avoit de $S$. Chriftotrouvé la riviere de Bethléem plus profonde,que celle de Ve- phle. Mines ragua, il y retourna. Ses Navires n'auroient pourtant pû y entrer, fi la Mer n'eut encore été gonflée à fon embouchure, par la Tempête, qu'il venoit d'efluyer, \& il eût toutes les peines du monde à en fortir, quand il voulut retourner aux. Ifles. Il envoya enfuite D. Barthélemy fon frere au Cacique Quibia, lequel fe laiffa aifément perfuader de rendre une vifite au Général des Efpagnols ; mais comme on ne s'entendoit point de part ni d'autre, la vifite fut courte, \& n'aboutit qu'à fe faire mutuellement des préfens, où chacun crut trouver fon compte; car ce Seigneur étoit véritablement très-riche en or. Le 24. de Janvier, la Riviere de Bethléem déborda fi prodigieufement, que la Capitane fut jettée avec impétuofité fur un autre Bâtiment, ce qui les endommagea confidérablement tous deux. On jugea que ce gonflement des eaux du Fleuve avoit été caufé par une nouvelle Tempête, \& ce Parage eft effectivement fort fujet aux Orages, ce qu'on attribuë principalement à de hautes Montagnes, qu'on rencontre en remontant le Veragua, \& aufquels Colomb donna le nom de Saint Chrifophle. Le 6. de Fevrier l'Adélantade retourna chés Quibia, avec 68. hommes, \& le Cacique lui donna des Guides pour le conduire aux Mines. Il les trouva fort abondantes, mais il fçut peu de têms après que ce n'étoit pas celles de Veragua, dont Quibia n'avoit pas voulu donner connoiffance aux Caftillans; mais celles d'Urira, dont le Seigneur étoit fon ennemi.

Le I б. Colomb s'embarqua dans fes Chaloupes avec 58. Bourgade bâhommes, \& alla dans la riviere d'Urira, éloignée de 7 . lieuës rie fur le Vede Bethléem, il y fut bien reçu par les Sauvages, qui lui lée par les İadonnerent de l'or pour des Curiofités d'Europe. D. Barthé- diens. \émy pouffa encore plus loin, \& partout il trouva de l'or quantité. Il n'en fallut pas davantage, pour déterminer $\mathrm{Hh} \mathrm{ij}$ 
I502. 1'Amiral à faire un Etabliffement fur les bords du Bethléenr. 1 affés près de fon embouchure dans la mer : il en chargea

3504. fon Frere, auquel il laiffa 80 . hommes avec un Navire, poue lni fervir au befoin, après quoi, il ne fongea plus qu’à faire voiles pour l'Efpagne. D. Barthélemy fit travailler avec tant de diligence tout fon monde, qu'en très-peu de têms la Bourgade fut achevée, c'eft-à-dire, que chacun eut une Cafe pour fe mettre à couvert. Mais on ne fut pas long. têms fans s'appercevoir que les Indiens ne voyoient pas volontiers ce nouvel Etabliffement dans leurs Pays; on crut même avoir de juftes fujets de foupçonner quills n'atterdoient que le départ des Navires, pour attaquer la Bourgade, \& l'Adélantade jugea à propos de les prévenir. Il partit le 30. de Mars à la tête de 74 . hommes pour le Veragua, en. rra lui cinquiéme dans la maifon de Quibia, ayant donné ordre à fes gens de le fuivre à la file, \& d'environner cette maifon. Il fe faifit fanspeine de la perfonne du Cacique, \& de rous ceux, qu'il trouva chés lui, au nombre de 50 . \& en emporta la valeur de 300 . écus d'or : mais Quibia fe fauva des mains de celui, à qui on l'avoit donné en garde, \& vint quelques jours après brûler la nouvelle habitation avec des fléches embrafées.

Ce malheur fut faivi de plufieurs hoftilités, que je paffe fous filence, \& qui obligerent enfin les Efpagnols de fonge: à la retraite; mais ils avoient perdu leur Navire, qui s'étoit échoüé dans la Riviere. L'Amiral, qu’un Vent contraire re. tenoit dans la Rade, avoit auffi perdu fa $_{2}$ Chaloupe, dont tout l'Equipage avoit été tué par les Bàrbares, en allant faire de l'eau; il fe trouvoit même en danger d'être jetté fur la Cồte, \& l'on vit le moment, que les deux Troupes féparées alloient périr ; l'une, par un trifte naufrage ; \& l'autre, par le fer des Barbares. L'Amiral ignoroit ce qui fe paffoit à terre, \& faute de Chaloupe, il ne pouvoit en être inftruit, ce qui 1 linquiétoit beaucoup ; d'autant plus, que les 50 . Prifonniers, que l'Adélantade avoient fait chés Quibia, \& qui avoient été embarqués dans fon Bord, s'étoient tous fauvés à la na- 


\section{DE S. Domingue, IIv. IV. 245}

ge, à l'exception de quelques-uns, qui s'étranglerent de déferpoir, de n'avoir pas pû fuivre les autres. Enfin plufieurs Braves s'offrirent à faire pour tirer l'Amiral d'inquiétude, ce que les Barbares venoient de faire pour fe fauver, \& le Pilote Pierre de Ledefma eut feul la permiffion de tenter une entreprife fi hardie. Il l'exécuta heureufement, \& ce fut le falut de l'Adélantade $\&$ de toute fa troupe; ils avoient effuyé avec une valeur incroyable les efforts redoublés d'un Peuple ennemi, qui croiffoit tous les jours , \& ils repréfenterent que, fi l'Amiral ne trouvoit le moyen de les emmener, ils ne pouvoient manquer d'y fuccomber. Enfin la Mer fe calma, \& avec les Chaloupes des deux autres Vaiffeaux on embarqua tout le monde. L'Amiral tira droit à Porto belo, où il fut encore obligé d'échoüer un de fes $\mathrm{Na}$. vires, qui ne pouvoit plus tenir la Mer. Il fuivit encore quelque têms la Côte, mais après avoì fait environ dix lieuës au-delà de ce qu'on appelle aujourd hui le Cap Saint-Blaife; le dernier jour de May il fit le Nord à deffein de gagner l'Ine Efpagnole ; les deux Bâtimens, qui lui reftoient, n'étant pas en état d'entreprendre un plus grand voyage. Ils ne purent même aller jufques-là, ils étoient tout ouverts, \& tout vermoulus . \& quoiqu'on travaillât jour \& nuit à vuider l'eau, elle gagnoit toûjours à vûë d'œil.

Un travail fi rude \& fi continuel, ne pouvoit pas être long- $\mathrm{Il}$ arrive à la têms foûtenu par des gens épuifés de fatigues, qui n'avoient Jamaique. pour toute nourriture qu'un peu d'huile $\&$ de vinaigre, avec du bifcuit pourri. Pour comble de malheur, une nuit il s'éleva tout à coup un Vent fi furieux, que les deux Navires ne pouvant gouverner, \& s'étant choqués, la Poupe de l'un \& la Prouë de l'autre en furent confiderablement endommagés. Echappés de ce danger contre toute apparence; ils gagnerent l'Ifle de Cuba, où ils prirent quelques rafraîchiffemens, que les Indiens leur apporterent d'eux-mêmes, \& ayant enfuite voulu tourner du côté de l'Efpagnole, les Vents \& les Courants les contraignirent de relâcher à ba Jamaïque. Ils entrerent la veille de la S. Jean dans un Porta

1502.<smiles>[AlH2]</smiles>
1504, 


\section{H Is T O I E}

1502. que les Efpagnols fe hâterent trop de nommer Puerto-Buerno: car ils n'y trouverent ni eau douce, ni vivres, ni habitans.

r.504. Ils firent un effort pour paffer à un autre, auquel on donna le nom de Santa-Gloria, \& ils y étoient à peine entrés. que les deux Navires ayant de l'eau jufques fur le Tillac, il n'y eût point d'autre parti à prendre, que de les faire échoüer : l'Amiral les fit enfuite amarrer enfemble avec de bons cables, \& conftruire fur les deux extrêmités de chacun des efpeces de Barraques, pour y loger tout fon monde, en attendant qu'il pût recevoir du fecours de l'Ine Efpagnole.

Précaution qu'il prend pour ne point s'attirer les Infulaires.

Ce qui preffoit le plus, c'étoir d'avoir des vivres; les Indiens en apporterent d'abord en quantité, \& on les leur paya avec des Marchandifes d'Europe. Auffi de peur que, fi les Caftillans avoient la liberté d'aller, où bon leur fembleroit, ils ne maltraitaffent ces Peuples, \& ne fiffent ceffer par là cette bonne intelligence, fi néceffaire dans la fituation, où l'on fe trouvoit; l'Amiral crut ne devoir permettre à perfonne de fortir des Navires, \& il fit fur cela des Reglemens très-feveres. Il fongea enfuite aux moyens de donner de fes nouvelles au Grand Commandeur, mais ce n'étoit pas une chofe aifée. De l'endroit où il étoit, il y avoit 200. lieuës à la Capitale de l'Erpagnole, on n'en comptoit , à la vérité, que 30 . de traverfe; mais il les falloit faire dans de petits Canots, qui n'ont prefque point de bord, \& que la moindre vague peut remplir, ou renverfer. D'ailleurs, on va bien ordinairement en 24 . heures de lifle Épagnole à la Jamaïque; mais il faut quelquefois plus d'un mois, pour aller de la Jamaïque à l'Ifle Efpagnole, à caufe des Vents. I'Amiral ne laiffa pourtant pas de trouver deux hommes, qui oferent l'entreprendre, \& qui en vinrent heureufement aे bout.

Un Elpagnol \& un Genois entreprennent de traverfer en Canot ì

L'un fe nommoit Diego Mendez, \& l'autre Barthélemy Fiefchi. Le premier faifoit l'office de Commiffaire fur l'Efcadre ; l’autre étoit un Gentilhomme Génois, fort attaché à la perfonne de l'Amiral, qui l'ettimoit beaucoup. On leur 
DE S. D OMINGUE, LIV. IV. 247 donna à chacun un Canot, où l'on mit fix Caftillans \& $x$ dix Indiens, de l'eau \& des vivres, autant qu'ils en pouvoient porter. Mendez eut ordre de paffer en Efpagne, le plûtôt qu'il lui feroit poffible, \& l'Amiral lui remit des Lettres pour le Roi \& la Reine, avec un Mémoire détaillé de fon Voyage. Il marquoit à leurs Alteffes, qu'après 20. ans de farigues, \& de dangers effuyés pour leur fervice, \& tels, que perfonne au Monde n'en pouvoit citer de pareils, il ne fçavoit pas, s'il poffedoit un fol ; il n'avoit pas une Maifon à lui; il ne lui reftoit de bien affúré , que les Chaînes, qu'il avoit portées, \& l'infamie dont elles avoient couvert fon Front. Fiefchi fut chargé de revenir d'abord pour tire: tout le monde d'inquiétude, fur le fuccès de leur voyage.

Le 7. de Juillet les deux Canots partirent pour aller ga- Ilsy arrivent gner la pointe Orientale de la Jamaïque, d'où ils devoient tra- après bien des verfer. L'Adélantade les y efcorta \& retourna par terre. Il leur falloit du calme, $\&$ ils ne l'attendirent pas long-têms; cependant ils n'arriverentau Cap Tiburon, qu'au commencement du quatriéme jourr,en ayant paffé un tout entier fur la perite Ifle de Ia Navazza, à fe délaffer \& à fe rafraîchir. Ils y perdirent même quelques Indiens, dont un mourut de foif $\&$ de chaud, dès le premier jourr, \& les autres pour avoir bû trop d'eau en arrivant. Ils apprirent en débarquant à l'Efpagnole, que le Gouverneur Général étoit à Xaragua, \& Mendezl'y alla trouver. lui expofa d'une maniere fort touchante, l'extrêmité où étoit réduit l'Amiral avec tous fes Equipages, \& n'oublia rien pour l'engager à le foulager au plûiôt. Ovando ne parut pas fort fenfible à tour ce qu'il put lui dire, \& foupçonna Chriftophle Colomb, d'avoir ménagé cet accident, pour avoir un prétexte de venir à l'Ifle Efpagnole. Il retint longtêms Mendez auprès de lui, fans rien réfoudre; \& ce ne fut qu'à force d'importunités, que celui-ci obtint la permiffion d'aller à la Capitale. En y arrivant il acheta un Navire, qu'il chargea Fieschi de conduire à la Jamaïque, \& il fe difpofa à paffer en Efpagne, fuivant l'ordre, qu'il en avoit: mais ce ne fut pas fitôt, qu'il l'auroit défiré , \& Fiefchi 


\section{His TOIR}

I502. ne put non plus retourner à la Jamaïque; comme l'AI miral le lui avoit recommandé, parce qu'il ne trouva per-

1504. fonne qui voulût l'y accompagner, ni encore moins rifquer un fecond voyage en Canot.

Embarras,où On peut juger à quelle extrêmité réduifit Colomb \& fe trouve l'A- fes Equipages le délai du fecours, qu'ils attendoient; le chan-
amiral. gement de nourriture, \& les fatigues d'une des plus rudes navigations, quil foit gueres poffible d'imaginer, a voient: caufé parmi eux un grand nombre de maladies; la crainte d'un fort pareil, \& la gêne, où l'on étoit retenu, exciterent bientôt de grands mouvemens contre l'Amiral. - Il n'ofe, difoit-on, retourner à l'Ille Elpagnole, d'où il » a été chaffé. Mendez \& Fiefchi font allés, ajoûtoit on . so faire fa paix à la Cour, ou l'on ne veut plus entendre э parler de lui; c'eft pour cela qu'il a échoué fes Navires » à la Jamaique, s'embarraffant fort peu de ce que de- viendront ceux, qui font avec lui. $\infty$ La conclufion, que l'on tiroit de là, fut qu'il falloit que chacun penfât bien tôt à foi, \& ne pas attendre que les maux fuffent fans remede; que le Grand Commandeur, qui n'étoit pas bien avec Colomb, ne leur fçauroit pas mauvais gré de l'avoir quitIean Fonfeca. té, que l'Evêque de Cordouë , fan Ennemi, les en recevroit mieux, quand ils arriveroient en Efpagne, \& que la Cour, voyant que perfonne ne pouvoit vivre avec cet Etranger, en délivreroit enfin la Nation Efpagnole.

Soulevement Ces difcours ne fetenoient d'abord qu'en fecret; mais le contre lui nombre des Mécontens s'étant accrû, on commença à ne

I504. plus garder de mefures. Enfin on en vint à une Sédition formée, le jour fut pris pour fortir des Navires, \& ce jour venu, qui fut le fecond de Janvier 1504 . les Sédirieux fe mirent fous les armes, ayant à leur tête François de Porras, qui avoit commandé un des quatre Vaiffeaux de l'Efcadre. L'Amiral étoit au lit avec la Goutte, Porras vint le rrouver, \& lui dit infolemment; sous voyons bien Mon๖ fieur, que votre deffein n'eft pas de retourner fitôt en - Caftille, \& que vous avés réfolu de nous faire périr ici. 


\section{DE S. Domingue, Liv. I V.}

- Je ne comprends pas, répondit l'Amiral, qui a pû 2 vous faire naître une telle penfée : vous fçavés auffi s bien que moi, que fi nous avons relâché dans cette Ifw le, fi nous y fommes encore, c'eft quil ne m’a pas été o poffible de faire autrement. J'ai envoyé demander des » Navires au Gouverneur de l'Ifle Efpagnole, que pouvoije faire de plus? \& n'y va-t'il pas encore plus de mon in* terêt, que du vôtre, de paffer en Caftille ? D'ailleurs ai* jerien fait, fans avoir demandél'avis de tout le monde? o fi vous jugés qu'il y ait encore quelque chofe de mieux - à faire, voyés entre vous ce qui convient à notre fituaw tion préfente, \& vous me trouverés toûjours très-dif« pofé à tout ce qui dépendra de moi pour votre fatisfacw tion.

11 n'eft point de perfonnes raifonnables, que ce difcours Les Séditieux n'eut contenté,mais on n'écoute plus gueres la Raifon, quand on a une fois levél'étendart de la Rébellion. Porras, dont une four étoit Maîtrefle du Tréforier Moralez, fort puiffant à la Cour, reprit brufquement la parole, \& dit qu'il nes'agiffoit plus de difcourir, mais de s'embarquer fur theure; qu'il vouloit aller en Caftille, \& que ceux, qui ne voudroient pas le fuivre, pouvoient refter à la garde de Dieu. Il s'éleva dans le moment un bruit confus de gens, qui crioient; nows vous fuivrons. Alors chacun fe déclara, \& tous fe mirent à crier, les uns, Caftille, Cafille; les autres, Seigneur Capitaine, que ferons nous? Quelques-uns même répondirent à ces dernieres paroles, qu'ils meurent. L'Amiral voulut fe lever, mais il ne put fe foutenir, \& l'on fut obligé de le remettre fur fon lit. L'Adélantade parut avec un Efponton à la main, mais on le fit rentrer dans fa Chambre, \& l'on obligea Porras à fe retirer, puifqu'on ne l'empêchoit pas d'aller, où bon lui fembloit. Il fe faifit alors de dix Canots, que l'Amiral avoit achettés des Indiens, \& il y eut: tant de preffe à le fuivre, qu'il ne refta gueres auprès des Colombs, que les Malades.

Dès le jour même, les Séditieux s'embarquerent, \& pri- Ils font pluTom. $I$. I i
1 Sox. fe retirent. 


\section{H ISTOIR}

1504. rent le chemin de la Pointe Orientale de l'Ifle. Ils commi. fieurs tentati- rent par tout de grandes violences fur leur route, prenant vespoir: paf- de force tout ce qu'ils trouvoient chés les Indiens, \& leur pagnole, mas difant d'aller fe faire payer par l'Amiral, ou de le tuer, s'il fans fruit. refufoit de les fatisfaire. « Auffi-bien, ajoûterent-ils, vous w n'avés gueres que ce moyen de fauver votre vie, car s cet homme eft bien réfolu de vous exterminer tous, com- me il a fait les Peuples, quil a rencontrés fur le Ve» ragua. $\approx$ Arrivés à l'extrêmité de l'Ifle, ils entreprirent d'abord de traverfer, fans faire réflexion que la Mer étoit fort agitée. Auffi à peine avoient-ils fait quelques lieuës, que leurs Canots s'emplirent d'eau : ils voulurent les allé. ger, \& ils jetterent tous leurs hardes à la Mer: cela ne fuffíant pas encore, ils fe déterminerent de fe défaire des Indiens, qu'ils avoient embarqués pour ramer. Ces malheureux voyant des épées nuës, \& quelques-uns de leurs Compagnons déjà étendus à leurs pieds, fauterent dans l'eau, mais après avoir nâgé quelques-têms, ils demanderent en grace qu'on les laiffàt fe délaffer de têms en têms, en tenant le bord du Canot. On ne leur répondit qu'à coups de Sabre, qu'on déchargeoit fur ceux qui s'approcherent de trop près, \& plufieurs fe noyerent. Le Vent augmentoit toûjours, \& la Mer devint fi groffe, qu'enfin, nos Avanturiers furent contraints de regagner la Terre au plus vite.

Violences

Ils délibererent enfuite fur le parti, qu'ils avoient à prenqur les Infulai- dre, \& après en avoir propofé plufieurs, qui ne pouvoient res.

venir dans l'efprit, que de gens aveuglés par le Défefpoir \& la Rébellion, ils s'en tinrent à tenter une feconde fois le paffage; mais comme la Mer ne fe calmoit point, ils fe répandirent, en attendant qu'elle fut traitable, dans les Bourgades voifines, où pendant fix femaines ils commirent des excès, qu'on auroit peine à croire. Ils fe rembarquerent enfin, mais ils n'allerent pas plus loin, que la premiere fois. Quelque-têms après ils firent un troifićme effay, qui ne réüfIit pas mieux, que les deux premiers. Alors ils renoncerent rout-à-fait à un deffein, qui leur parut chimerique , \& ils 


\section{DE S. Domingue, LIV. IV. 25 I}

ne douterent plus que Mendez \& Fiefchi n'euffent péri. Ils fe mirent aufitiôt à courir toute l'Ifle, comme des Bandits, \& il n'eft point de maux, qu'ils ne firent aux Infulaires, pour en avoir des vivres.

L'Ámiral tenoit avec ces Peuples une conduite bien differente; il faifoit garder à fes gens une très-exacte difci- toute oppofée pline, quil adouciffoit par des attentions infinies fur leurs befoins, \& par des manieres fort fimples \& fort aimables. D'ailleurs il ne prenoit jamais rien des Indiens, qu'en payant, auffi conferva-t'il long-têms leur amitié; mais comme ces Barbares n'étoient pas accoûtumés à faire de grandes provifions, ils fe lafferent bientôt de nourrir des Fameliques, qui les expofoient à manquer eux mêmes du néceffaire. Les difcours, que les Mutins avoient tenus des prétendus deffeins de l'Amiral, avoient auff fait quelque impreffion fur leur efprit, de forte qu'ils commencerent à s'éloigner, \& que les Caftillans fe virent à la veille de mourir de faim. Pour fe tirer d'un auffi mauvais pas, Colomb s'avifa d'un ftratagême, qui lui réüffit.

Il devoit y avoir bientôt un Eclipfe de Lune; l'Amiral envoya dire à tous les Caciques des environs qu'il avoit de Colomb une chofe de grande confequence à leur communiquer. Ils vivres.

vinrent, \& il commença par leur faire de grands reproches fur leur dûreté à fon égard, puis prenant un ton affuré: « Vous en ferés bientôt rudement punis, ajoûta-t'il, ๖ je fuis fous la protection d'un Dieu puiffant, qui me ven- gera: \& n'avés vous pas vî ce qu'il en a coûté à ceux » de mes Soldats, qui ont voulu fecouer le joug de mon »obéiffance? Quels dangers n'ont-ils pas couru en voulant w paffer à l'Ifle Hayti, tandis que ceux, que j'y ai envoyés, $\infty$ ont traverfé fans peine? Bientôt vous ferés un exemple » bien plus terrible de la vengeance du Dieu des Efpa- gnols, \& pour preuve de ce que je vous dis, vous allés * voir dès ce foir la Lune rougir, puis s'obfcurcir, \& vous * refufer fa lumiere; mais ce ne fera là que le prélude de » vos malheurs, fi vous ne profités de l'avis que je vous $\varpi$ donne. 
I'Eclipfe commença effectivement quelques heures après, \& les Barbares épouvantés, poufferent des cris effroyables : ils allerent fur le champ fe jetter aux pieds de Colomb, \& le conjurerent de détourner de deflus leur tête les maux, dont ils étoient ménacés. Il lui fut aifé alors de faire fes Condi. tions, on lui jura de ne plus lui laifer manquer de rien, \& on le mit fur le champ à difcretion de tout. Il fe fit un peu prier pour mieux cacher fon jeit, puis paroiffant tout à coup fe rudoucir, «Vous en ferés quitre cette fois-ci, pour la s peur, leur dit-il, je vais prier mon Dieu de faire reparoîre la s Lune, $\&$ en difant cela, il s'enferma, \& les Indiens recommenserent à jetter des cris épouvantables. Aubout de quelques momens, l'Eclipfe commença à ferdre, \& les lnfidéles demeurerent perfuadés, que cer Etranger difpofoit à fon gré de toute la nature. Ils eurent tôjours grand foin depuis ce têms-là, non feulement de ne lui rien refufer, mais encore déviter de lui donner le moindre fujer de mécontentement.

Ilreçoit des Il étoit têms que ce fecours vint à l'A miral : il fe formoit nouvelies de rinle Ef agnode. une nouvelle mutiner e parmi ceux, qui étoient reftés avec lui, \& il fe trouvort duns un grand embarras. L'abondance des vivres rétablie dans fon camp, en fufpendit pour quelque têms les efiets; mais il y a bien de l'apparence qu'ils n'eufient pas tardé à fe faire fentir d'une maniere bien funefte, s'il n'eut enfin reçu au bout de huit mois des nouvelles du Grand Commandeur. Diego de Efcobar arriva dans une Barque, \& ayant moüillé l'ancre à quelque diftance des Navires, il defiendit feul à terre, fit d'barquer un baril de vin, \& un Cochon, tendit à l'Amiral une Letre d'Ovando, \& s'étant un peu éloigné, éleva la voix, \& lui dir, que le Gouverneur Général avoit été fort fenfible au récit de fes malheurs, qu'il étoit mortifié de ne pouvoir pas encore le tirer de la trifte fituation, où il fetrouvo:t, \& qu'ille prioir d'être amuré qu'il feroit pour cela toutes les diligences pornbles, quen attendant, il le prioit d'agréer cette legere marque de fon amitié. En achevant ces mots, il fe retira, \& fe rem. bargua fur le champ. 


\section{de S. Domingue, Liv. $\mathbb{I}$. 253}

Herrera fait tout fon poffible pour juftifier un procedé fi étrange; il dit , que le Grand Commandeur craignoit avec raifon que, fi la Barque fe fut acoftée des Navires, on ne l'eut chargée de Lettres pour l'ifle Efpagnole, où l'Amiral avoit mandeur à fon plufieurs Créatures, \& un plus grand nombre encore d'Enne- égard. mis, qui chacun de leur cóté auroient pû caufer du trouble, que le choix d'Efcobar, qui avoit été complice de la Révolte de l'Alcaide Roldan, avoit éré fait fort judicieufement, puifque le Gouverneur ne pouvoit mieux s'affurer que les ordres, qu'il donnoit de ne parler à perfonne, feroiént exécutés, qu'en les confiant à un homme, qui n'avoit évitéla potence, à laquelle Colomb l'avoit condamné, que parla faveur de Bovadilla : enfin, qu'il ne s'imaginoit pas que les vivres manquaffent aux Efpagnols de la Jamaïyue. Mais le Public n'en jugea pas de même : on regarda comme une infulte faite à Colomb le choix d'un tel Envoyé, qui d'ailleurs ne devoit plus être dans les Indes, fuivant les ordres de la Cour, \& la modicité du préfent fait à un homme de ce rang, quion pouvoit bien croire n'avoir pas des vivres en abondince. L'Amiral s'apperçut même du mauvais effer, qualloit produire cette conduite d Ovando parmi fes gens, \& pour le prévenir, il feignit d'être fort content de ce Gouverneur, \& de s'entendre avec lui. Il fit à fa Lettre \& à fon Compliment, une Réponfe fort honnête, le pria de favorifer en tout Mendez \& Fiefchi, lui donna avis de la Révolte de Porras, \& lui expofa d'une maniere très-touchante: la trifte firuation, où il fe trouvoit. Cela fair, il affembla tous fes gens, \& les affüra qu'ils ne tarderoient pas à êrre fecourus.

Il ne perfuada pas les plus clairvoyants; mais il ne la:ffa point de calmer la multitude. Il le flatta auffi d'engager par la même voye, les mutins à rentrer dans le devoir. Il Porras. leur communiqua les bonnes nouvelles, qu'il venoit de recevoir, \& leur fit porter un quartier de la Bête, dont on lui avoit fait préfent : mais jamais honnêteré ne fur plus mal reçûe : Porras jura qu'il ne fe fieroit de fa vie à Colonb, 


\section{4

I jo4. qu'il continueroit à vivre, comme il faifoit, jufqu'à l'arrivée du fecours, qu'on lui annonçoit; il ajoûta qualors, s'il y avoit deux Vaiffeaux, il en prendroit un pour lui \& pour fa Troupe ; que s'il n'y en avoit qu'un, il fe contenteroit de la moitié ; qu'au refte fes gens ayant été obligés de jetter à la Mer toutes leurs hardes, \& toutes leurs marchandifes, il convenoit que l'Amiral partageât avec eux ce qui lui reftoit des unes \& des autres. Les Envoyés de l'Amiral lui ayant repréfenté, que ce n'étoit pas là des propofitions à faire à un Général ; ‘il entra de nouveau en fureur, \& dit que, fi on ne vouloit pas lui donner de bonne grace ce qu'il demandoir, il iroit le prendre de force. Il s'en retourna enfuite vers fes Complices, à qui il fit entendre tout ce qu'il voulut. leur dit même qu'il falloit que Colomb fût Magicien, \& que cette Barque, qui avoit paru \& difparu comme un éclair, étoit fans doute un pur effet de fes preftiges : mais qu'il iroit bientôt le vifiter l'épée à la main, \& qu'on verroit, fi fes charmes étoient affés puiffants, pour en émouffer 12 pointe.

L'Adélan- Il s'avança en effet, peu de têms après, jufqu'à un quart tade les défait. de lieuë des Navires, réfolu à fe fajfir de tout ce qu'il y riouveroit à fa bienféance : on ajoûte même qu'il envoya défier l'Amiral. Colomb étoit malade, \& ne quittoit point le lit : il frémit d'indignation, lorfqu'il apprit que les Rébelles étoient fur le point de le venir attaquer ; cependant quelque outré qu'il fût de leur infolence, il recommanda expreffément à l'Adélantade, qu'il envoya contre eux , avec 5o. hommes, d'offirir d'abord la paix, \& une amniftie à tous ceux, qui mettroient bas les armes; mais les Mutins ne lui en donnerent pas le têms. A peine Porras eut-il apperçu la Troupe de D. Barthélemy, quil vint fondre fur elle avec plus de fureur, que d'ordre. Une décharge, qui fut faite fort à propos fur les Séditieux, en jetta quelques-uns par terre, \& arrêta la fougue des autres, le feul Porras n'en parut pas étonné, \& ayant reconnu l'Adélantade, il courut à lui, \& d'un coup de fabre, il lui fendit fon bouclier en deux 


\section{DE S. Domingue, Liv. IV. 255}

il le bleffa même un peu à la main, ce qui n'empêcha point D. Barthélemy de le faifir par le corps, \& de le faire fon

Prifonnier. Il tourna enfuite fes armes contre ceux, qui paroiffoient vouloir encore faire réfiftance, \& il en tua plufieurs. Cette victoire ne lui coîta qu'un feul homme, \& l'on peut dire que fa valeur fauva l'A miral d'un des plus grands dangers, qu'il eût encore couru ; car pour peu que Porras eut eu d'avantage fur lui, ou même eu laiffé faire le têms, la Révolte devenoit générale.

Cependant les Infulaires furent bien étonnés, quand ils Les Rébelvirent étendus par terre, \& fans mouvement, ces hommes, tent. qu'ils croyoient immortels. Ils s'approcherent des cadavres, \& comme ils eurent par hazard touché la playe d'un des gens de l'A miral, qui n'étoit que bleffé ; celui-ci fe leva tout à coup, en criant d'une maniere terrible; ce qui caufa un fi grand faifffement dans l'ame de ces Barbares, qu'ils fe mirent à fuïr, comme fi tous ces Morts euffent été à leurs trouffes. Ceux des Rébelles, qui avoient pris la fuite, fe trouvant fans Chef, \& ne fçachant plus que devenir, prirent le parti d'aller fe jetter aux pieds de l'A miral, \& lui promirent avec ferment de lui être déformais plus fidéles; il les reçut avec bonté, mais il ne jugea pas à propos de les garder fur fes Navires, ni de leur permettre aucun Commerce avec les autres; il leur donna un Commandant, fur la fageffe duquel il crut pouvoir fe repofer; leur fit délivrer quelques Marchandifes pour les aider à fubfifter, \& leur permit de s'établir, où bon leur fembleroit, en attendant qu'on vînt les chercher pour les conduire à l'Efpagnole.

Enfin, après une année entiere de délais affectés, Ovando, contre lequel on commençoit à murmurer publique- rive àSan-Doment, fit partir pour la Jamaique une Caravelle fous la conduite de Diego de Salzedo, ancien ferviteur des Co. lombs, \& le Navire, que Diejo Mendez avoit fretté aux dépens de l'Amiral. Le 28. Juin ces deux Bâtimens arriverent heureufement au Port, où étoit l'Aimiral, qui s'embarqua auffi-tôt avec tout fon monde, \& le 28. de Juin appa- 


\section{HISTOYR}

4504. re!llia pour l'Ine Efpagnole; mais il eut bien de la peine, à caúfe des Vents contraires, à g gner la Beata, qui eft à 20. lieuës d'Yaquimo. Il ne voulut pas aller plus loin, fans en avoir eu l'agrément du Grand Commundeur, \& non feulement il l'obtint, $m$ is Ovando, ayant fçû qu'll paroiffoit à la vûë du Port, vint lui-même à la tête de toute la Nobleffè le recevoir à la defcente de Ion Navire, le logea chés lui, \& le régala fplendidement. Ce fut le I3. d'Août que l'Amiral entra dans certe Capitale.

Mauvaife mamere dis Gouverneur à̀ ton égard.

Les politefies du Gouverneur Général furprirent un peu Colomb, qui ne s'y atrendoit pas, mais il devoit, ce femble, encore moins s'attendre à ce qui arriva peu de jours après. Il avoit laiffé fur fon Bord François Porras, \& il pré endoit le mener en Efpagne les fers aux pieds; Ovando l'oblıgea à le lui livrer, dilant que c'étoit à lui de connoitre de fon crime, \& il ne l'eut pas plûtôt entre les mains, qu'il lui donna la liberté. Il fit plus, car il déclara qu'il vouloit informer fur tout ce qui s'étoit pafié à la Jamaïque, \& voir qui avoit tort, ou de ceux qui s'étoient foulevés, ou de ceux, qui étoient demeurés fidéles à l'A miral, lequel diffimula fagement un auffi grand affront, \& une injuftice fi criante, à laquelle il n'étoit pas en état de s'oppofer. Il fe contenta de dire avec affés de modération, que les droits de fon Amirauté feroient réduits à bien peu de chofe, s'il ne pouvoit pas juger un de fes Officiers, qui s'étoit révolté contre lui fur fon propre Bord, \& il fe hâta de fortir d’une Ifle, qui après avoir été le fondement de toute fa gloire, \& le commencement de fa grandeur, étoit devenuë le Théatre funefte, où il avoit reçu les plus fanglans affronts. Il fretta deux Navires, dont il partagea le Commandement avec fon frere, \& le 12. de Septembre il appareilla pour l'Eipagne.

Son arrivée Comme il fortoit du Port, le Navire, qu'il montoit fut en Efpagne. Il démâté de fon grand mât, lequel fe fendit jufqu'au tillac. II apprend la mort de la Reinc。

ne voulut pas rentrer, pour réparer ce dommage, il renvoya le Bâtiment à San-Domingo, \& il paffa dans celui de fon frere, où étoit aufi D. Fernand fon fils. Le 9. d'Octobre, après 
DE S. Domingue, Liv. IV. 257 qu'il eût effuyé une très-rude tempête, le Vent ayant tout à coup ceffé, \& la Mer étant extrêmement groffe, le roulis caffa le grand mât de ce fecond Navire. Il y remedia de fon mieux, $\&$ peu de jours après, un coup de Vent lui enleva fa ContreMifene. Il avoit encore près de 700 . lieuës à faire, \& il fe trouva fort embaraffé avec un Navire en fi mauvais ordre. Il arriva toutefois heureufement à San-Lucar à la fin de l'année, \& s'étant auffi-tôt rendu à Seville, la premiere nouvelle, qu'il y apprit, fut la mort de la Reine Ifabelle de Caftille. Il ne falloit rien moins qu'un tel coup, pour mettre le comble à toutes les traverfes, qu'il avoit effuyées fans interruption depuis trois ou quatre ans, \& que ce dernier malheur lui fit prefqu'afolument oublier, dans l'accablement où il le jetta.

Ifabelle mourut à Medina del Campo le 9. de Novembre x s04. \& toute l'Efpagne pleura long-têms une Princeffe, de cette Pránqui avoit égalé les plus grands Rois par fes qualités perfonnelles, \& dont la ruine des Maures en Efpagne, par la Conquête de Grenade; \& la Découverte du Nouveau Monde, ont relevé la gloire audeflus de celle de tous les Souverains de fon fiecle. On lui doit encore la juftice de croire, qu'il n'a pas tenu à elle que cette Découverte n'ait été pour les Habitans de ces vaftes Pays la fource d'autant de biens, qu'elle leur a caufé de maux. Elle n'eut point d'autre vûë en les affujettiffant à fa Couronne, que d'en faire des Chrétiens: elle ne recommanda rien tant à ceux, qu'elle leur envoya; que de les traiter, comme les Caftillans mêmes, \& elle n'a jamais fait paroître plus de féverité , que contre ceux, qui avoient contrevenus à fes ordres fur cet article. Nous avons vû ce qu'il en a coûté à Colomb, pour avoir ôté la liberté ¿े quelques Indiens; cependant elle l'aimoit, elle connoiffoit tout fon mérite, \& fçavoit prifer fes fervices. On ne douta point en Épagne, que fa mort feule n'eut épargné à $\mathrm{O}$ vando un châtiment exemplaire, pour le cruel maffacre de Xaragua, dont elle avoit appris la nouvelle avec un extrême chagrin; \& dans fon teftament, le bon traittement des Tom. $L$. $\mathrm{Kk}$ 


\section{$258 \quad H I S T O I R E$}

1505 .

L'Amiral

fait d'inutiles

efforts pour

etre rérabli

eord qu'il feroit d'inutiles démarches, pour fe faire rétablir dans fa charge dans fa Charge de Vice-Roy ; néanmoins, pour n'avoir point de Vice-Roi. à fe reprocher de s'être manqué à lui-mếme, il alla trouver le Roi à Segovie, lui rendit compte de fes dernieres Découvertes, lui fit un récit fort touchant de toutes les avantures de fon Voyage, \& le pria de ne point oublier fes fervices; les fers, qu'il avoit portés; les injuftices, qu'on lui avoit faites; les fatigues, qu'il avoit efluyées; \& la promeffe, que lui \& $\&$ la feuë Reine lui avoient fi fouvent renouvellée de lui rendre juftice, \& de le remettre en poffeffion de toutes. fes Charges. Ferdinand lui donna de belles paroles; mais il s'apperçut bientôt qu'il ne devoit pas s'y fier, \& qu'on cherchoit à le laffer. Toute la Cour étoit affés partagée fur ce qui le regardoit; les uns étoient d'avis qu'on lui tînt tout: ce qu'on luiavoit promis, \& de ce nombre étoient D. Diego de Deza, Archevêque de Seville, qui avoit été Dominiquain, \& Précepteur du Prince D. Jean; \& D. François Ximenés de Cifneros Francifcain, Archevêque de Tolede. L'aurorité de ces deux Prélats entraîna bien du monde dans. leur fentiment; mais le plus grand nombre étoit de ceux, qui difoient hautement, que les prétentions de Colomb étoient au-deflus de fes fervices, \& qu'il ne convenoit pas de rendre un Particulier, \&x fur-tout un Etranger fi puiffant. Son malheur fut que le Roi penfoit comme ces derniers, \& ne l'aimoit pas.

Apologue, Ce fut à peu près dans ce têms-là, que pour confondre dont il fe fert pour fermer la bouche à ses Envieux. fes Envieux, qui réduifoient prefque à rien la gloire de fes. Découvertes; il s'avifa de ce petit ftratagême, dont on a tant parlé. Un jour,qu'il étoit à table avec une grande Compagnie, le difcours tomba fur le Nouveau Monde, \& quelqu'un eût l'impolitefe de dire qu'il ne voyoit pas trop le merveilleux d'une telle Entreprife, qu'un peu de hardieffe, \& beaucoup de bonheur en avoient fait tout le méritẹ. Ce difcours fut 


\section{DE S. Domingue, Liv. IV. 259}

applaudi, \& chacun jetta les yeux fur Colomb, qui fans répondre un mot, fe fit apporter un ocuf, \& demanda, fi quelqu'un fçavoit le fecret de le faire tenir tout droit fur fa pointe. On lui en donna à lui-même le défi ; il l'accepta, cafla un peu la pointe de l'œuf, \& le fit tenir droit. Tous s'écrierent qu'ils en auroient bien fait autant. $\propto$ Je n'en doute - point, reprit-il, mais aucun de vous.ne s'en eft avifé ; \& $\rightarrow$ c'eft ainfi que j'ai découvert les Indes. Je me fuis avifé le - premier de naviguer de ce côté-là, \& il n'eft aujourd'hui.fi * miférable Pilote, qui n'y puiffe aller. Bien des chofes » paroiffent aifées après le fuccès, qu'on a cru impratiquaso bles, avant qu'elles euffent été entreprifes. Vous pouvés »o vous fouvenir des railleries, qui ont été faites de mon - Projet, avant que je l'eufle exécuté: C'étoit alors une Chis mere, une folie : fi on veut vous en croire aujourd'hui, »rien n'étoit plus aifé. » Cette ingénieufe réponfe rendit muets les Jaloux de l'Amiral, \& ayant été rapportée au Roi, elle le divertit beaucoup. Ce Prince donna enfuite bien des éloges à fon auteur; mais c'eft tout le fruit, que celui-ci en retira.

Quelque têms après, on lui fit de la part de Ferdinand des Propofitions fi peu raifonnables, qu'il en fut outré de dépit; mais ayant appris fur ces entrefaites, que le Roi Philippe d'Autriche, \& la Reine Jeanne d'A rragon fon Epoufe, arrivoient inceffamment en Caftille, pour prendie poffef- lippe d'Attrifion de cette Couronne; il efpera que la Fille \& le Gendre che.

d'Ifabelle, entreroient dans les vîës de fon Augufte Protectrice,\& dégageroient fa Parole. Dès qu'il les fçut en Efpagne, il leur écrivit, parce que fes incommodités ne lui permirent pas d'aller lui-même leur rendre fes hommages, \& il chargea D. Barthélemy fon Frere de leur préfenter fa Lettre. L'Adélantade fut parfaitement bien reçû de leurs Alteffes, qui lưi promirent de donner contentement à fon Frere, \& il crut pouvoir compter fur cette promeffe.

Je n'ai pû fçavoir ficette favorable réponfe parvint jufqu'à I'A miral; car il mourut avant le retour de D. Barthélemy. Ce Sa Mort \&: fon caractere. fut le 2o. de May, jour de l'Afcenfion, que Chriftophle 
1506. Colomb termina à Valladolid, par une mort très-Chrétien ne, une vie raifonnablement longue, puifqu'il étoit dans fa 65. année, mais plus qu’ancune autre mêlée de bonheur $\&$ d'adverfités, d'opprobres \& d'applaudiffemens; de ce que la fortune peut procurer de Grandeułs à un Particulier, \& de ce qu'elle peut lui faire effuyer de revers. Il joüit peu de fa gloire, \& des dignités, dont il fut revêtu; au contraire, il ne fut prefque pas un jour fans avoir à fouffrir, ou les douleurs les plus aiguës, ou les contre-têms les plus fâcheux, ou les chagrins les plus cuifans. Il étoit d'une taille mediocre, mais bien proportionnée, fon regard \& toute fa perfonne marquoient quelque chofe de noble, il avoit le vifage long, le nez aquilin, les yeux bleus \& vifs, le teint fin \& un peu enflammé, les cheveux blonds, tirant fur le roux, ce qui n'eft pas un défagrément dans fon Pays; le corps bien conftitué, \& une grande force dans les membres. Son abord étoit facile \& prévenant, fes mœurs douces \& ailées. Il étoit affable envers les Etrangers, humain à l'égard de fes domeftiques, enjoüié avec fes amis, \& d'une humeur fort égale envers tout le monde. Il avoit l’ame grande, un génie élevé \& vafte, l'efprit toûjours préfent \& fécond en reffources, un coeur à l'épreuve de tous les contre-têms, beaucoup de circonfpection \& de prudence dans toute fa conduite. Quoiqu'il eut paffé les deux tiers de fa vie dans une fortune des plus médiocres, il ne fut pas plûtôt en Place, qu'il prit naturellement toutes les manieres de Grand Seigneur, \& qu'il parut né pour commander. Perfonne ne fçavoit mieux que lui fe donner cette gravité bienféante, ni ne poffedoit plus parfaitement cette éloquen. ce infinuante \& fenfée, qui rendent prefque toûjours le Commandement efficace. Enfin, il avoit de la grace à tout, parloit peu \& toûjours bien, il éroit éloigné de toute oftentation, il avoit du zéle pour le Bien Public, \& furtout pour la Religion; une pieté folide, beaucoup de probité, \& l'efprit fort orné par les fciences, qu'il avoit étudiées avec foin dans l'Univerfité de Padouë : on affùre qu'il ne patfoit pas 
DE S. DOMINGUE, LIV. IV. 26I

un jour fans réciter les Heures Canoniales; en un mot, il se lui manqua pour être l'Idole des Caftillans, \& dans leur efprit un des plus Grands Hommes de fon fiecle, que d'être né parmi eux : il eft même certain qu'il eut fait beaucoup plus en faveur de cette Couronne, s'il n'eût pas eu le malheur d'y être regardé comme Etranger. Il faut pourtant avoüer, que les plus illuftres Hiftoriens Efpagnols lui ont rendu toute la juftice, qui lui étoit dûë. Oviedo ne craignit point de dire à Charles Quint, que fi on lui eut érigé une Statuë d'or, on n'eur rien fait de trop; \& d'autres fuivant le génie extrême de leur Nation, l'ont comparé à ces Heros du premier Age du Monde, dont l'Antiquité Profane a fait des Demi-Dieux. Dans le vrai, peu d'hommes fe font fait un auffi grand nom, \& à plus jufte titre.

Mais tant de qualités éminentes, ne furent point fans quelques défauts, \& tout fage, que fut Chriftophle Colomb, il n'a pas laiffé de faire des fautes. Comme il avoit paffé fans milieu de l'état de fimple Pilote, à une condition, où il n'avoit au-deffus de lui, que le Sceptre, \& de la plus profonde obfcurité, à une gloire, qu'il ne partageoit qu'avec fa Souveraine ; il fut trop jaloux de fon autorité. Il étoit naturellement colere, mais la raifon $\&$ la réflexion en réprimoient d'abord les faillies. Il ne fit peut-être pas affés d'attention, qu'il avoit à commander à une Nation haute, \& qui n'obéît pas volontiers à un Etranger, quoiqu'elle ait été plus long-têms, qu'aucune autre, fous le joug. Il fut un peu dur à l'égard des Indiens, \& quoiqu'il fût bien éloigné de les molefter de gayeté de cœur, il parut trop perfuadé, quils étoient nés pour être les Efclaves de leurs Conquerants. Du refte, il ne négligea point leur Inftruction, \& il ne tint pas à lui quils ne devinffent tous Chrétiens. So amour de 1 Ordre \& de la Difcipline, lui fir porter la féverité plus loin, qu'il ne convenoit dans de nouvelles Colo. nies. It devoit fçavoir que dans ces nouveaux Etabliffemens, il y a moins à craindre d'une fage condefcendance, qui por te à adoucir le joug, pour le faire gouter, que d'une duKk iij 


\section{HISTOIR}

\$506. reté infléxible, qui conduit aifément au défefpoir des Ef prits déjà aigris, par les incommodités inféparables d'un genre de vie auffi nouveau, \& auquel il eft fi mal aifé de s'accoûtumer.

Il fut marié deux fois, comme je l'ai remarqué ailleurs. DeDonna-Philippa Moñiz Pereftrello, il eut D. Diegue, qui lui fucceda dans fes Charges; \& de Donna-Beatrix Henriquez, qu'il époufa en fecondes Noces en Efpagne. il eût $\mathrm{D}$. Fernand ou Ferdinand, qui a écrit la Vie de fon Pere, \& qui fe fit Prêtre. Il fut d'abord inhumé dans l'Eglife des Chartreux de Seville, puis tranfporté dans la Grande Eglife de San-Domingo, ainfi qu'il l'avoit ordonné par fon Teftament. Mais il eft têms de revenir à l'inle Efpagnole.

Nouvelle Afrés peu de têms avant le départ des Vaiffeaux, quon Révolte dans envoya au fecours de l'Amiral à la Jamaïque; la Province te Higuey. de Higuey, qu'on fe flattoit d'avoir pacifiée de maniere, à n'y plus appréhender aucun mouvement, fe retrouva fubitement toute en Armes. Nous avons vû que Jean de Efquibel avoit forcé Cotubanama à recevoir la loy, \& bâti deux Fortereffes dans cette Province ; on y avoit ajoûté depuis des Etabliffemens plus confiderables, \& l'on croyoit avoir par-là ôté aux Infulaires de ces quartiers-là , jufqu'à l'envie de remuer; mais on fe trouve quelquefois réduit à des extrêmités, où une Mort prefque certaine ne paroît plus un mal, ou en paroit un plus fupportable, que celui qu'on fouffre : \& c'eft ce qui arriva aux Habitans du Higuey. Une des Conditions du Traité, que Jean de Efquibel avoit fait avec eux, étoit qu'ils laboureroient une certałne étenduë de terrein au profit du Domaine; mais, qu’on ne pourroit pas les contraindre à porter eux - mêmes à San - Domingo les Grains, qu’ils receüilleroient; qu'ils les livreroient fur les lieux à ceux, qui feroient commis pour les recevoir. Villeman, qui commandoit dans un des Forts bâtis par Efquibel, voulut malgré cette claufe, qui étoit expreffe, les obliger à charrier leurs Grains jufqu'à la Capitale, \& comme 
DE S. Domingue, LIv. IV. 263

d'ailleurs fes Soldats vivoient d'une maniere fort licencieufe, fans qu'il fongeât à y mettre ordre, les malheureux Indiens, 1506. après bien des plaintes inutiles, ne confultant plus que leur defefpoir, allerent tumultuairement attaquer la Fortereffe, la brûlerent, \& maffacrerent la Garnifon, dont il ne fe fauva qu'un Soldat.

Le Grand Commandeur n'eût pas plûtôt appris ce foule- Efquibel vement, que réfolu à mettre pour toûjours ces Indiens tre lesIndicns. hors d'état de lui caufer de pareilles inquiétudes, il fit affembler toutes les Milices, qui fe trouvoient répanduës dans les principales Villes. Diego de Efcobar, fut chargé de conduire celles de la Conception, Jean Ponce de Leon fut mis à la tête de celles de la Capitale; un autre Capitaine, dont je n'ai pas trouvé le nom, amena celles de Bonao, \& Jean de Efquibel eut le Commandement général de l'Armée, qui fe trouva forte de 400 . hommes. Il l'amena dans la Province d’Ycayagua, qui confine à celle de Higuey, où il leva un grand nombre d'Indiens aguerris, \& fort fidéles, qui lui furent d'un très-grand fecours. Il s'agiffoit d'aller attaquer l'Ennemi fur les plus hautes Montagnes du Higuey, où il s'étoit cantonné, \& où il ne manquoit de rien; car ces Montagnes, dont plufieurs ont le fommet en Terrafie, ont pour la plûpart un terrein rouge, d'une merveilleufe fertilité. Les routes, qui y conduifent, ne font pas aifées à connoître, \& il ne fut jamais poffible d'obliger, même à force de tourmens, aucun des Prifonniers, que firent les Caftillans, à leur fervir de Guides. Efquibel rencontra néanmoins un jour un Corps de Troupes affés confidérable, qu'il mit aifément en déroute; mais outre qu'il étoit aifé aux Barbares de fe fauver dans des lieux inacceffibles, on en trouva plufieurs, qui firent paroître un courage, ou plûtôt une fureur, dont les Caftillans ne laifferent pas d'être effrayés.

On en vit, qui bleffés à mort par les Arbalêtres de leurs Effets dx Ennemis, s'enfonçoient de rage leurs Fléches dans le corps, défépoir des \& après les avoir retirées, les prenoient avec les dents, \& 
r so4. les mettoient en morceaux, qu'ils jettoient contre les Chré-

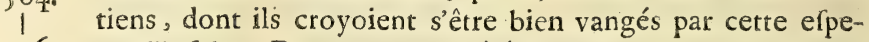
Is 06. ce d'infulte. D’autres ayant été faits Prifonniers, \& leurs Vainqueurs les obligeant de courir devant eux, pour leur montrer les chemins, fe précipitoient fur des pointes de Rochers, pour n'êre point forcés à trahir leurs Compatriotes. Il y en eût un, qui s'étant avancé à la tête de l'Armée , of́ bien y défier un Épagnol, nommé Alexis Gomez, qui - ne pût jamais lui porter un feul coup; ce fut un fpectacle affés fingulier de voir un homme tout nud, avec un Arc \& une Fléche à la main, volriger autour d'un Soldat bien armé, \& re mocquer des vains efforrs, que faifoit celui-ci pour le percer. Ce Combat, où il n'y eut point de fang répandu, réjoüit long-têms les Spectateurs; enfin l'Indien fe laffa, \& fe réjoignit à fes gens, qui le reçûrent avec de grandes acclamations.

La prife du Il y eut plufieurs autres actions, où les Infulaires firent Cacique met paroître de la réfolution \& de la conduite. On comprit alors qu'il falloit déformais peu de chofes pour les aguerrir tout à fait. Mais enfin, la prife de Cotubanama mit fin à la Guerre. Ce malheureux Cacique fe croyoit fort en fûreté dans l'ine Saona, où il s'étoit fait un efpece de Labyrinthe. On ne laiffa pas de ly découvrir : il furt mené à San-Domingo, où le Grand Commandeur le fit pendre. Tel fut le fort du dernier Roi de l'inle Efpagnole; la plûpart des autres Souverains, \& des Seigneurs particuliers, n'en avoient pas eu un plus heureux. Mais quoique les Efpagnols femblaffent vouloir témoigner le mépris, qu'ils en faifoient, en les foûmettant à un fupplice auffi infamant; il y a pourtant lieu de croire qu'ils leur euffent laiffé la vie, s'ils les avoient moins craints. Ie Higuey étant de nouveau pacifié, Ovando y fit conftruire deux Bourgades, Salvaleon fur le bord de la Mer, \& SantaOudycayagua. Cruz de Ycayagua dans le milieu des Terres. Cette derniere fut détruite au bout de quelques années, \& de fes débris s'eft formée celle qu'on appelle aujourd'hui Scibo on Zeïbo. Elle eft à 20. lieuës de la Capitale salvaleon de Higuey à 28 . 


\section{DE S. DOMingue, LIV. IV. 265}

Le fuccès de cette guerre, \& la nouvelle de la mort d'Ifabelle, mirent le comble à l'infortune des Habitans naturels de l'Ifle Efpagnole. Il eft vrai, comme nous l'avons rap- font plus malporté plus haut, que la Reine de Caftille avoit accordé aux traités que japreffantes follicitations d'Ovando, que chaque Cacique fût tenu d'envoyer fes Sujets travailler aux Mines tour à tour, à la charge néanmoins qu'ils feroient payés de leur travail. Le Gouverneur Général avoit reglé ce falaire à un Blanc \& demi par jour, ce qui montoit à peine à une demie PiaAre par mois; mais il n'eut pas plûtôt appris la mort de fa Maîtreffe, que ce payement, tout modique qu'il étoit, lui parut une charge trop pefante, \& qu'il le retrancha toutà-fait. Il femble même que dès-lors le têms du travail ne fut plus limité, \& bientôt tous les Indiens, fans diftinction d'âge, de fexe, de condition, y furent condamnés, fans que ceux, à qui on les abandonnoit, fuffent tenus à rien, qu'à les inftruire des Principes du Chriftianifme, condition que la plûpart remplirent fort mal. Le Grand Commandeur, qui felon Barthélemy de las Cafas, n’avoit pas plus de zele pour le falut de ces malheureux, que s'ils euffent été des Animaux entierement dépourvûs de raifon, vouloit néanmoins perfuader le Roi qu'il n'avoit rien plus à cœur : Ferdinand de fon côté ne ceffoit de lui recommander cet article, \& fur les réponfes, qu'il en recevoit, il ne doutoit point que toute l'Ine ne devînt bientôt Chrétienne.

Cette belle oftentation de zele, foûtenuë de grands en- Richieffes voys d'Or, faifoit regarder Ovando comme un homme né- immenfes, qui ceffaire, \& le maintenoit en place contre les efforts des le Efpagnole. Colombs, qui mettoient tout en ufage, pour être rétablis dans leurs droits. D'ailleurs rien n'étoit mieux reglé, que la Colonie, le Gouverneur Général y avoit établi la Police; la Juftice $s^{\prime} y$ adminiftroit avec exactitude, \& l'on n'y fouffroit aucun défordre; tout le monde étoit occupé, \& perfonne ne fe plaignoit. Il fe faifoit en ce têms-là dans line Efpagnole, quatre fontes d'or chaque année; deux dans la Ville de Buena-Ventura, pourles vieilles \& les nouvelIome $I$.

IL 1 


\section{HISTOIRE}

I506. les Mines de S.Chriftophle, \& deux à la Conception, qu'on appelloit communément la Ville de la Vega, pour les Mines de Cíbao, \& les autres, qui fe trouvoient plus à portée de cette Place. Chaque fonte fourniffoit dans la premiere de ces deux Villes, cent dix, ou fix-vingt mille Marcs. Celles de la Conception de la Vega donnoient ordinairement I25. Ou I 30 . \& quelquefois I 40000 . Marcs; de forte que l'or, qui fe tiroit tous les ans des Mines de toute l'If1e, montoit à 460000 . Marcs. Auffi fur le bruit, qui fe répandit en Efpagne, qu'on faifoit en très.peu de têms, \& fans rien rifquer des fortunes confidérables dans cette $\mathrm{Co}-$ lonie, pour un peu qu'on fût des amis du Gouverneur Général, il ne fe trouva plus bientôt affés de Navires, pour y porter tous ceux, qui s'empreffoient pour y aller partager tant de thréfors.

Déparze. mens donnés aux Seigneurs

Mais il ne fut pas long-têms néceffaire de paffer la mer? pour profiter des richeffes de l'Ine Efpagnole. La plûpart des Grands Seigneurs \& des Miniftres, s'aviferent de de. mander des Départemens au Roi, à qui les Indes étoient reftées en propre, par un traité fait entre lui, \& le feu Ro de Caftille; \& ils les obtinrent fans aucune difficulté. Le Grand Commandeur, qui prévit toutes les fuites de cette liberalité du Prince, s'y oppofa en vain; \& fes repréfentations furent même affés mal reçû̈ës. Les Conceffionnaires établirent des Procureurs fur les lieux, pour agir en leur nom; ces Procureurs avoient leur fortune à faire, \& à poufer les interêts de leurs Maîtres : les Infulaires en furent la vidime; on ne ménagea en rien ces malheureux , \& on fe foucioit fort peu qu'ils fuccombaffent fous le travail; parce qu'en vertu des Provifions du Roi, on fe les faifoit remplacer fur le champ. Le Gouverneur Général n’ofant leur rien refufer, encore moins châtier la cruauté de ces impitoyables Maîtres, on ne peut dire combien en peu de mois il périt de ces malheureux, qui furent facrifiés à la cupidité des Grands, \& à celle de leurs Intendans.

Exteprifes Ferdinand avoit alors à foutenir la guerre dans le Royaut 


\section{DE S. D O INGUE, Liv. IV. 267}

me de Naples. Cinq cens mille Ecus dor, qui fe tirerent me de Naples. Cinq cens mille Ecus dor, qui fe tirerent Is06.
chacune des années fuivantes de l'Efpagnole, lui fournirent odieufes du une grande reffource, pour en foutenir les frais, \& comme Grand Comil n'étoit pas infruit des moyens, dont on fe fervoit pour augmenterles remplir ainfi fes Coffres, il combloit d'éloges le Grand Com- Revenus du mandeur. Ovando encouragé par les affürances de la fatisfaction, que ce Prince avoit de fa conduite, voulut encore faire un pas en avant. Il publia une Ordonnance, par la. quelle il affermoit la Pêche, la Chaffe, \& les Salines naturelles; mais les cris de toute la Colonie contre une f odieufe innovation, étant parvenus jufqu'aux oreilles du Roi, ce Prince caffa l'Ordonnance, \& en fit une autre, qui fut dans la fuite d'une bien plus grande utilité à fes Sujets, que les Mines même.

Ce fut au fujet des Cannes de Sucre, que l'on commençoit à cultiver dans l'Ine Efpagnole. Ferdinand avoit ex- Sucre plantrêmement à cour qu'on les y multipliât, \& fes foins ne pagnole, Mifurent pas inutiles. Les premiers Rofeaux avoient été ap- ne de Cuivre. portés des Canaries, par un nommé Pierre d'Atença, \& Gonzalés de Velofa fut le premier, qui fit bâtir dans l'Ine un Moulin à Sucre. On ne peut dire avec quelle promptitude \& quel fuccès l'exemple de ces deux Habitans fut fuivi de tous ceux, qui étoient en état de faire les avances néceffaires pour de pareilles Manufactures. On crut auff avoir découvert une Mine de Cuivre du côté de PuertoReal, \& le Roi donna fes ordres pour y faire travailler; mais Ovando négligea, ou ne fut point en état de fournir aux Entrepreneurs le nombre d'Indiens,qu'ils demandoient : d'autres difent que la Mine ne fe trouva pas affés abondante, ce qui eft certain, c'eft que l'ouvrage, à peine commencé, fut abandonné. On croit que cette Mine eft ce qu'on appelle aujourd'hui le Morne rouge dans la Plaine du Cap François. On y voit des indices de cuivre, \& quelques-uns affurrent y en avoir ramaffé.

Cependant il n'étoit encore venu que très-peu de Fen- Reglement mes Caftillanes dans l'Inle Efpagnole, \& une bonne partie ${ }_{\text {riages. }}^{\text {pour les Ma- }}$ L 1 ij 


\section{HIS T O I I}

I 506. des nouveaux Colons s'étoient attachés à des filles du Pays:

1. les Genti'shommes ayant eu foin de choifir les plus qua-

y 507. lifiées. Mais ni les unes, ni les autres n'étoient tenuës à ritre de Femmes légirimes, \& plufieurs même de ces Concubinaires avoient leurs Femmes en Caftille. Pour remedier à ce défordre, Ovando chaffa de l'Ille tous ceux, qui étoient mariés, \& ne vouloient point faire venir leurs Femmes; \& obligea les autres fous la même peine à époufer leurs Concubines, ou à s'en défaire. Prefque tous prirent le premier parti, \& l'on peut dire que plus des trois quarts des Efpagnols, qui compofent aujourd'hui cette Colonie, defcendent par les Femmes des premiers Habitans de l'Ifle. Mais comme les Troubles paffés avoient fait connoître le penchant, qu'avoient les Efpagnols à la révolte; Ovando jugea. néceffaire d'ôter aux Gentilshommes, qui avoient époufé des Indiennes, les Départemens, qu'il leur avoit donnés, en les dédommageant d'ailleurs; \& cela pour les mettre hors d'état de cabaler, \& d'entreprendre de faire valoir: leurs droits fur la Succeffion de leurs Beau peres.

\$507. le, que 60000. Indiens, c'eft-à-dire, la vingtiéme partie 1508 .

de ce qu'on y en avoit trouvé r $g$. ans auparavant, felon ceux, qui en mettent le moins. Et comme il s'en falloit bien que ce nombre ne fût fuffifant, pour fatisfaire l'avarice des Conceffionnaires; le Grand Commandeur propofa de tranf. porter les Habitans des Ifles Lucayes dans celle-ci; ajouttant que c'éroit l'unique moyen d'inftruire dans la Religion ces. Peuples abandonnés, aufquels il n'étoit pas poffible de fournir des Miffionnaires, en tant de lieux differens. Ferdinand. donna dans le Piege, \& la permiffion ne fut pas plutôt publiée, que plufieurs Particuliers équiperent à leurs frais des Bâtimens pour aller faire des recruës aux Lucayes. On n'imagineroit pas les fourberies, qui furent mifes en ufage, pour engager ces pauvres Infulaires à fuivre leurs Tyrans. La plûs part les affürerent qu'ils venoient d'une Région délicieufe, oǹ étoient les Ames de leurs Parents, \& de leurs Amis 
de S. Domingue, Liv. IV. 269 défunts, qui les invitoient à les venir joindre, 40000 . de ces Barbares furent affés fimples pour fe laiffer féduire ; mais quand ils virent, en arrivant à l'Efpagnole, qu'on les avoit abufés, ils en conçûrent un chagrin, qui en fit périr un grand nombre, \& porta plufieurs à entreprendre des chofes incroyables pour fe fauver. Un Navire Eípagnolfut affés furpris d'en rencontrer une Troupe, à so. lieuës en Mer dans une Pirogue, autour de laquelle ils avoient attaché des Callebaffes pleines d'eau douce. Ils touchoient prefque à leur Ifle, lorfqu'il firent cette maiheureufe rencontre, car les Efpagnols ne manquerent pas de les reconduire au lieu de leur Efclavage.

Au défaut de l'artifice, dont il y a bien de l'apparence, que ces Sauvages ne furent pas long-têms les Dupes, on ufa fans doute plufieurs fois de violence, pour les arracher à leur fion.

Terre Natale; au moins eft-il bien certain, qu'au bout de quelques années les Inles Lucayes étoient abfolument défertes, \& comme elles font la plûpart affés fteriles, elles n'ont jufqu'ici fait envie à perfonne; les Anglois prétendent néanmoins qu'elles leur appartiennent, \& ils ont un établiffement dans celle de la Providence, fur le nouveau Canal de Bahama. J'ai lî̀ dans des Mémoíres, qui me paroiffent affés fùrs, que s'étant formé en France, on ne marque pas précifément le têms, une Compagnie pour établir ces Ines, elle y envoya un Navire chargé de tontes fortes de munitions, \& d'un nombre fuffifant d'Habitans, mais qu'ayane trop differé d'en envoyer un fecond, on n'y trouva plus perfonne. Ces mêmes Mémoires ajoûtent qu'il y a dans ces Ifles de très bons Ports, \& des Havres fort fûrs, quantité de Cochons, des Salines, beaucoup de Sources de bonne eau, des Rivieres, \& toutes fortes de Materiaux poux bâtir.

L'année fuivante r s08. le Roi Catholique fit un change- $\mathrm{Ia}$ Juftise ment dans le Gouvernement des Indes, qui diminua beau \& les Financoup le pouvoir des Gouverneurs Généraux. Jufques-là les aux. GouverFinances \& la Juftice avoient tô̂jours été adminifrées en raux. Géné- 


\section{$270 \quad H$ is To I R E}

1507. leur nom, par des Officiers, dont l'autorité trop fubordon-

1. née à la leur, étoit avilie par une fi grande dépendan-

¥508. ce, \&quelquefois opprimée, lorfqu'elle entreprenoit de s'oppofer à leurs volontés. Ceux, qui fçavoient s'accommoder au têms, en recevoient pour récompenfe le privilege de tout ofer; \& quelques-uns acquirent dans ces Employs des richeffes immenfes. On a furtout parlé d'un certain Bernardin de Sainte Claire, qui avoit été fait Tréforier par Ovando, \& qui s'étoit fervi des deniers de la Caiffe Royale pour achetter de grands héritages. Sa Table étoit fomptueufe, \& un jour, qu'il donnoit à manger au Grand Commandeur, on fervit en guife de fel, de l'or en poudre; Il fit enfin tant de folies, \& fes malverfations allerent fi loin, que fon propre Protęteur fut obligé d'en avertir la Cour. Le Roi envoya un nommé Davila pour lui faire rendre fes Comptes, \& il fe trouva redevable de 60000 . Pefos d'or. Tout fon bien fut faifi \& vendu à l'Encan, mais Ovando fit enforte par fon crédit, que tout y fût porté à un prix exorbitant. de forte que Sainte Claire, après avoir payé le Roi , fe trouva encore beaucoup de refte; mais il perdit fa Charge, qui fut alors réunie à celle d'Intendant de Juftice, fous le Titre de Tréforier Général. Le premier', qui en fut revêtu, fut un Offcier de la Maifon du Roi, nommé D. Miguel de Paffamonté, lequel arriva au mois de Novembre à San-Domingo, bien muni de Brevets en bonne forme, \& d'un ordre au Gouverneur Général de lui donner un Département d'Indiens.

D. Diegue Ce changement fut bientôt fuivi du rappel du Grand ComColomb époufe la Niéce du Duc d'Albe, \& rentre dans fes droits fur le Góuvernement des Indes. mandeur. D. Diegue Colomb, l'aîné des fils du feu Amiral des Indes, pourfuivoit avec chaleur les Droits, qu'il avoit hérités de fon Pere, fur la Vice-Royauté des Indes; \& quoiqu'il rencontrât en fon chemin les mêmes difficultés, que D. Chriftophle y avoit rencontrées, \& de plus grandes encore, il ne fe rebuta point. Les plus fortes oppofitions venoient de la part du Roi même; mais après que le jeune Amiral eut long-têms effuyé les lenteurs de ce Prin- 


\section{de S. Domingue, Liv. IV. $27 x$}

ce, il le conjura enfin de trouver bon, qu'il fe pourvât en Juftice. Ferdinand ne put lui refufer une demande fi raifonnable; \& Colomb préfenta auffi-tôt au Confeil un Mémoire contenant 42. Articles, tous conformes à ce qui avoit été arrêté entre le même Ferdinand \& Irabelle d'une part, \& Chriftophle Colomb de l'autre, avant \& depuis la découverte des Indes. L'affaire fut difcutée avec toute l'exactitude poffible, \& comme le droit de l'Amiral étoit inconteftable, il gagna fon Procès tout d'une voix; mais il n'en auroit été gueres plus avancé malgré cela, (le Roi ne manquant ni de moyens, ni de prétexres pour traîner en longueur l'éxécution de l'Arrêt, ) s'il ne fe fût procuré une Protection capable de lui faire furmonter tous les obftacles. Il époufa Marie de Tolede, fille de Ferdinand de Tolede, Grand Commandeur de Leon, Grand Veneur de Caftille, Frere du Duc d'Albe, \& Coufin Germain du Roi Catholique, dont le Duc d'Albe étoit d'ailleurs le Favori, depuis qu'il l'avoit très-utilement fervi dans la guerre de Naples, \& contribué plus que perfonne à le faire rappeller en Caftille. Le premier effet de cette alliance fut, que les deux Freres fe mirent d'abord à folliciter fortement en faveur, l'un de fon Neveu, \& l'autre de fon Gendre. Ferdinand voulut leur donner de belles paroles à fon ordinaire, mais ils ne s'en contenterent pas, \& ils parlerent fi haut, qu'ils obtinrent enfin une partie de ce qu'ils demandoient.

Ovando fut révoqué, \& l'Amiral fut nommé pour le Mais la remplacer, mais il n'eut que le titre de Gouverneur Géné Charge de ral, avec la même autorité, les mêmes Privileges, \& les fupprimée. mêmes appointemens, qu'avoient eû fes deux Prédéceffeurs. Je le trouve néanmoins quelquefois nommé Vice-Roi, \& Donna Maria de Tolede fon Epoufe n'eft jamais appellée que Vice-Reine, dans les Auteurs, que jai lus, mais il paroît que c'étoit des Titres d'Honneur, qu'on leur donnoir fans confequence, en faveur fans doute d'une alliance, qui l'uniffoit de fi près à la Maifon Royale. Dès que cetre affaire eut été concluë. l'Amiral repréfenta au Roi, que fos 
1508. Alteffe pourroit fur de fauffes informations, faire quelque. fois des Réglemens, qui tourneroient au préjudice de fa Charge, \& qu'il convenoit au bon ordre, \& au bien du fervice, que le Gouverneur Général eût la liberté de faire des Remontrances, avant que d'être obligé d'éxécuter. Cela lui fut accordé: mais comme cette précaution étoit particulierement contre les Favoris, qui rendent fouvent les Souverains mêmes les Miniftres de leurs paffions; une telle demande, \& plus encore l'ufage, que l'Amiral fit de la permiffion, qu'il obtint, lui fufciterent des ennemis puiffants, qui lui cauferent dans la fuite bien des chagrins.

Caufes du rappel d'Ovando.

Quant à Ovando, fa difgrace ne fut pas feulement le fruit du crédit des Protecteurs de D. Diegue; elle venoit de plus loin, \& l'on prétend que la feuë Reine Ifabelle, avoit prié Ferdinand de le rappeller, ne voulant pas mourir fans affûrer la punition du Mafracre de Xaragua. Mais le Grand Commandeur avoit fait une faute bien moins excufable encore dans un homme, qui devoit connoître la Cour \& les Miniftes; il s'étoit broüillé avec Fonfeca, qui avoit encore changé fon Evêché de Cordouë pour celui de Palencia; \& voici à quelle occafion. Fonfeca avoit fait donner le Gouvernement de la Citadelle de San-Domingo à une de fes Créatures, nommé Chriftophle de Tapia: cet Officier en arrivant à la Capitale, trouva la Place prife, le Grand Commandeur l'avoit donné à Diego Lopez de Salzedo fon neveu. Tapia ne laiffa pas de préfenter fes Provifions au Gouverneur Général, qui les mit par refpect fur fa tête, \& en les lui rendant, lui dit : « J'informerai le Roi de cette a affaire, \& je ne ferai rien que ce qui me paroîtra le mieux s pour le fervice de fon Alteffe.

Il écrivit effectivement au Roi , \& lui repréfenta que Tapia étant pourvâ de la Charge de Fondeur d'or, qui étoir très-lucrative, elle devoit lui fuffire; d'ailleurs que la $\mathrm{Ci}$ tadelle de San-Domingo étoit fon Ouvrage, \& qu'il étoir bien naturel qu'il pût difpofer de fon Gouvernement, d'au- 
tant plus qu'on ne lui avoit jamais difputé le droit de nommer à ces fortes de Plices. Quelque têms après, Tapia ayant 1508. mal parlé du Grand Commandeur, il fut mis en Prifon dans la Fortereffe même, par ordre d'Alphonfe Maldonat, qui en qualité d'Alcaïde Major, étoit encore à la tête de la Juftice. Mais comme on l'eût envoyé Prifonnier en Efpagne, l'Evêque de Palencia le fit déclarer innocent, \& engagea le Roi à nommer François de Tapia fon Frere au Gouvernenement de la Fortereffe de San-Domingo. Ovando reffentit vivement cette mortification, mais il n'en devint pas plus fouple à l'égard du Miniftre, contre lequel il fut même foutenu dans une occafion; ce fut ce qui acheva de le perdre, \& peut-être que fans cela tout le crédit de la Maifon de Tolede eut cedé à la haine de Fonfeca contre les Colombs. Ovando le crut ainfi, mais il fut, ou du moins affecta de paroître affés peu fenfible à fa révocation.

Un Hiftorien, qui a trop voulu le juftifier, pour être toûjours cru fur ce qui le regarde, affure qu'il fut extrême- penfad'Ovana ment regretté dans les Indes, \& que l'Ifle Erpagnole en par- pel. ticulier le pleura long-têms. Il ajoûte qu'on ne vit jamais un homme moins intereffé, qu'il dépenfa en ouvrages publics tous fes Revenus, \& que quand il partit pour retourner en Efpagne, il fut obligé d'emprunter 500 . Caftillans pour les frais de fon voyage. Après tout, ces grandes marques d'affection \& d'attachement, qu'on lui donna au moment, qu'on apprit fon rappel, ou ne furent pas générales, ou ne durerent pas long-têms; car il eft certain que, peu de têms après fon arrivée en Caftille, divers Particuliers lui intenterent Procès, \& lui demanderent des fommes trèsconfidérables. Toute fa reffource fut que, ces demandes n’ayant pas été faites dans les 30 . jours, qui lui avoient été donnés pour la reddition de fes Comptes, il n'étoit plus obligé d'y répondre; ce que le Roi voulut bien autorifer par un refcrit. Il paroît auffi qu'il avoit acquis du Bien en fonds dans les Indes, puifqu'une des. Inftructions, qui fu. rent données à l'Amiral, fût d'avoir foin qu'on lui conferyất Tome I. 
1508. tout ce qui fe trouveroit lui appartenir légitimement. Une autre Inftruction portoit que la Flotte, que D. Diegue commanderoit en allant d'Efpagne aux Indes, feroit au retour des Indes en Efpagne fous les ordres du Grand Commandeur, lequel fut très-bien reçû́ du Roi Catholique, \& ne parut point du tout à la Cour comme un homme difgracié.

Iśeg. de la fin de l'année x 508 . pour y mettre ordre à fon embarrAmiral, \& quement, le Roi l'y fuivit de près, \& lui donna plufieurs San-Domin- Audiences particulieres, où il entra dans un fort grand dégo.Il fe brouiil- tail de tout ce qui concernoit les Indes. Mais il ne lui rele d'abord avec le Minif- commanda rien tant, que d'établir la Religion, \& furtous are. d'attirer par les voyes les plus éfficaces les Peuples au Chriftianifme. De Seville D. Diegue paffà à San-Lucar, où il s'embarqua le 9 . de Juin avec fa Femme, fon Frere D. Fernand, fes deux Oncles, quantité de Nobleffe, beaucoup d'Officiers, \& un bon nombre de Demoifelles, qui étoient à la fuite de la Vice-Reine. Le Voyage fut hemreux, \& la Flotte moüilla dans le Port de San-Domingo le ro. de Juillet. Comme il n'y avoit point encore de : Maifon affectée aus Gouverneur Général, l'Amiral jugea à propos de fe loger dans la Fortereffe, laiffant à François de Tapia, qui étoit venu avec lui pour prendre poffeffion de cette Place, le foin de chercher un autre logement. Il refufa même de le faire recevoir en qualité de Gouverneur, mais il eut bientôt tout lieu de fe repentir d'une démarche, qui parut peus mefurée à fes meilleurs amis. Tapia prit le parti de repaffer en Efpagne, pour y faire fes plaintes, elles y furent écoutées, on fit expedier fur le champ un Ordre à l'Amiral d'évacuer la Citadelle, \& de la remettre au Tréforier Général Paffamonté. Tapia revint peu de têms après, \& Paffamonté le mit en poffeffion de fon Gouvernement \& de for logement, il avoit encore gagné à fon voyage un département d'Indiens, que l'Amiral eut ordre de lui donner. 


\section{DE S. Domingeve, Liv. IV. 275}

Cependant l'arrivée du nouveau Gouverneur Général \& de fa nombreufe famille, avoit donné à l'Ifle Efpagnole un luftre, qu'elle n'avoit pas encore eu. J'ai dit que la Vice. Reine avoit amené avec elle un bon nombre de Demoi- nouvelle face. felles; on les maria d'abord aux plus riches Habitans, \& elles contribuerent extrêmement à adoucir les mœurs de ces anciens Colons, devenus déjà prefque à moitié Sauvages. Divers accidens arrivés coup fur coup, \& dans lefquels les Efpagnols furent affés heureux pour reconnoître la main de Dieu,qui les frappoit, ne fervirent pas peu non plus à les faire rentrer en eux mêmes, \& à leur faire reprendre leurs premiers fentimens de Religion, dont il ne reftoit plus dans leur cour, que de legeres traces.

Au mois d'Août de l'année précédente r 508 . un Oura- \& Ouragans gan avoit fait périr à la Côte jufqu’à 20. Navires : au mois de Juillet de celle-ci, il en furvint un autre très-violent, qui fit des dégats incroyables, \& renverfa une grande partie des Maifons de la Capitale; \& ce qui fit furtout regarder ces acçidens funeftes, comme des effets de la colere du Ciel, c'eft ce que les Indiens publierent alors, \& affürerent unanimement, à fçavoir, qu’avant l'arrivée des Caftillans, ces Ouragans étoient très-rares fur leurs Côtes. Ce qu'il y eut de fâcheux, c'elt que plufieurs reconnoiffant que c'étoit Dieu, qui les frappoit, ne fe rendirent point juftice fur leurs cruautés, \& n'ouvrirent point les yeux, ni fur leur avarice, ni fur leurs diffolutions, ni fur quantité d'autres défordres criants, mais s'imaginerent que le Seigneur les puniffoit uniquement à caufe de leur peu de refpect pour le S. Sacrement de l'Autel, qui étoit en bien des endroits gardé avec très-peu de décence. Ils firent donc bâtir par tout de belles Eglifes, \& l'Hiftorien Oviedo, qui fut quelques années après Gouverneur dela Citadelle de San-Domingo. affûre que depuis I 520. jufqu'en I 535. qu'il écrivoir fes Mémoires, aucun Ouragan ne fe fit fentir fur les Côtes de l'Ine Efpagnole. Auffi y continuë-t'on encore aujourd'hui d'avoir un foin particulier des Eglifes, qui font tous $\mathrm{Mm} \mathrm{ij}$

1509.

La Colonic de l'Efpagnole (1)

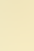




\section{$276 \quad H$ I S T O $\mathrm{r} \mathrm{E}$}

1509. tes très-belles, fort riches, \& fort ornées, tandis que la plî́: part des Habitans n'ont pas dequoi fe couvrir; mais l'Ennemi du falut des Hommes, qui fit ainfi prendre le change aux Efpagnols des Indes, navoient garde de les inquieter fur ces Temples materiels, qu'ils érigeoient en l'honneur de Jefus-Chrift, tandis que, s'abandonnant fans honte à toutes fortes d'excès, ils profinoient d'une maniere criante les véritables Temples du S. Efprit; \& l'on doit peutêtre regarder la ceffation du Fleau, qui les affligeoit, moins comme une récompenfe de leur pieté mal entenduë , que comme le comble $\&$ la punition de leur aveuglement.

Sources de

la décadence

Quoiqu'il en foit, il n'y avoit pas i 8. ans, que l'Ifle Efde l'Ifle Efpa- pagnole étoit découverte, \& la Colonie Caftillane étoit déjà gnole.

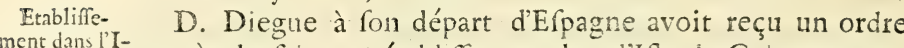
parvenuë au terme de fa grandeur.San-Domingo,qui fut bientôt remis de fes dernieres pertes, pouvoit dès-lors aller de pair avec les plus belles Villes d'Efpagne, \& les furpaffoit toutes en richeffes \& en magnificence: mais tout cela commença bientôt à décliner, \& la décadence fut prefque aumi précipitée, que l'élevation avoit été rapide; bien des chofes y ont contribué, mais furtout le grand nombre de Colonies, qui font forties de celle ci, car on peut dire qu'elle eft la Mere de toutes celles, qui compolent le Vafte Empire des Expagnols dans l'Amérique, \& c'eft, dis-je, en bonne partie ce qui l'a réduite dans l'érat d'épuifement, où nous la voyons aujourd'hui. fie des Perles. exprès de faire un établifiement dans l'Ifle de Cubagua, que Il dure peu \& l'on appelloit communément, l'Ifle des Perles. Au premier quelles en fulrent les fuites, bruit de cette entreprife, plufieurs Habitans de l'Efpagnole s'offrirent à l'Amiral, \& furtout ceux, qui avoient à leur fervice des Efclaves Lucayes. On avoit reconnu que ces Infulaires avoient tous une très-grande facilité à demeurer long-têms fous l'eau, \& l'experience avoit montré qu'ils étoient peu propres au travail des Mines. L'Amiral eut ef. feativement égard à cela dans le choix, qu'il fit des now: 


\section{de S. Domingue, Liv. IV. 277}

veaux Colons de Cubagua, \& pendant plutieurs années; il fe fit dans cette. Ine des fortunes immenles par la pêche des Perles. Des Hiftoriens afûrent que le Quint du Roi y montoit tous les ans à I 5000 . Ducats, mais bientôt les Plongeurs, qu'on ménagea encore moins, qu'on ne faifoit les Mineurs dans l'Efpagnole, périrent tous, \& les Perles difparurent prefque en même têms des Côtes de Cubagua. Alors cette Ifle, dont les terres ne font abfolument bonnes à rien, qui n'a ni bois, ni eau douce, \& qui n'étoit plus recommandable, que par un excellent Port, où l'on avoit bâti une jolie Ville, fous le nom de nouvelle Cadix, \& une Fontaine, dont l'eau Odoriferante \& Medecinale furnâge tur celle de la Mer, lorfqu'elle s'y décharge; cette Ifle, dis-je, fut entierement abandonnée; \& à peine la connoit-t'on aujourd'hui: fes Habitans pafferent à la Marguerite, qui s'eft foutenuë un peu plus long têms; on y voit même encore quelques Habitations, qui s'entretiennent par le Commerce du Tabac, quils font avec les Hollandois de Coraçol; mais il n'y eft plus du tout queftion de Perles. On en trouve encore de têms en têms quelques-unes dansces Mers, à r so. lieuës à l'Oueft de la Marguerite. Il y en a une pêche dans le Gouvernement de Rio de la Hacha, près d'une Bourgade, appellée la Rancheria, mais les Perles en font d'une couleur matte, \& n'ont pas l'eau fort belle.

Ia même année, qui avoit vî̀ commencer l'établifement de IIfle des Perles, vit prendre une forme plus folide à de Portoric. celui, dont un an auparavant on avoit jetté les fondemens dans celle de Boriquen, ou de Portoric. Cette life eft fituće par les I7. \& I8. dégrés de Latitude-Nord, \& n'a pas 20. lieuës dans fa plus grande largeur, qui fe prend da Nord au Sud; mais fa longueur de lEft à l'Oueft eft de 40. Elle a peu de Plaines, beaucoup de Collines, des Montagnes très-haures, des Vallées extrêmement fertiles, \& d'affés belles Rivierres. Il paroît que fes Habitans, ainfi que je l'ai déjà obfervé , \& ceux de l'Ine Eipagnole, avoient une même origine; on remarquoit dans les uns \& dansles 


\section{HISTOIR}

1509. autres la même douceur; mais comme cenx de Portoric étoient fans ceffe aux Prifes avec les Caraibes des petites Antilles, ils étoient encore moins policés, \& un peu plus aguerris.

Ponce de

Leon pafte

dans cette Inle \&y trouvedes Mines d'o:"

J'ai dit en parlant de la derniere guerre du Higuey, que Jean Ponce de Leon y avoit conduit les Milices de SanDomingo. Il avoit été fait depuis Gouverneur de la nouvelle Ville de Salvaleon, \& comme les Indiens de ces quartierslà avoient grande relation avec ceux de Portoric, il fçut de cenx-ci, qu'il y avoit beaucoup d'or dans leur Pays. Il en donna aufít tôt avis à Ovando, \& lui demanda la permiffion d'aller voir de fes yeux ce qui en étoit; il l'obtint . arma une Caravelle, \& s'embarqua avec quelques Caftillans, \& des Infulaires du Pays, qui s'offrirent à lui fervir de guides. Il aborda fur les Terres d'un Cacique nommé $\mathcal{A g u e y . ~}$ naba, qui le reçut bien, le logea chés lui; \& ayant fçü que les Efpagnols fouhaittoient fort de fçavoir, s'il y avoit des Mines dans l'Ine, après leur avoir donné tout le têms de fe repofer; non feulement il les affùra qu'ils en trouveroient en quantité, maisil voulut les conduire lui-même à celles , qui dépendoient de lui. Il pouffa même la générofité jufqu’au bout, car il déclara quil les leur abandonnoitavec plaifir, fi le Commandant vouloit bien lui accorder fes bonnes graces. Celui-ci n'avoit garde de rejetter une offre fi avantageufe o il combla de careffes \& de préfens le Cacique Indien, qui depuis ce têms-là ne voulut plus être appellé , que Jean Ponce de Leon. Enfin le Gouverneur de Salvaleon ayant pris des Montres de toutes les Mines, qu'il avoit vifitées, fe rendit en diligence à San-Domingo, pour inftruire le Grand Commandeur du fuccès de fon voyage.

Ilenfait Golverneur deline.
Ovando fit mettre au Creufet l'or de Portoric, lequel fut eftimé moins pur, que celui de l'Ifle Efpagnole, mais c'étoit de l'or, \& la Conquête de l'Ine fut réfoluë. Ponce de Leon en fut chargé, \& ne tarda pas ày aller rejoindrefes gens, qu'il avoit lainés auprès d'Agueynaba. Il les trouva tous en parfaite fanté, \& qui fe loüoient fort des bonnes ma. 
DE S. DOM MEUE, LIV. IV.

nieres du Cacique, \& de toute fa famille; il vit bien d'abord qu'il ne faudroit point faire la guerre à ces Petples, pour les foûmettre, \& il fe flatta d'obtenir le Gouvernement de l'ifle: mais il fe trouva bien loin de fon compte, lorfqu'étant retourné peu de têms après à San-Domingo, pour y prendre quelques arrangemens avec Ovando, il le trouva rappellé, l'Amiral D. Diegue Colomb à fa place, \& un Gouverneur nommé par le Roi pourl'Ine de Portoric. Ce Gouverneur étoit D. Chriftophle de Sotomayor, Frere du Comte de Camiña, qui avoit été Secretaire dı Roi Philippe I. Un homme de cette confideration ne devoit pas s'attendre à trouver de l'oppofition à fon entrée dans un Gouvernement, qu'il tenoit immédiatement du Souverain; il ne put néanmoins obtenir de l'Amiral, qu'il l'en mit en poffeffion. D. Diegue fit plus, il nomma de fon autorité pour Gouverneur de Portoric un certain Michel Cerron, \& lui donna Michel Diaz pour fon Lieutenant. Ce qu'il y eut de plus fuprenant, c'eft que la Cour ne foutint point Sotomayor, \& que le Grand Commandeur, ayant appris ce qui s'étoit paffé à ce fujet dans les Indes, demanda \& obtint le Gouvernement de Portoric, pour Jean Ponce de Leon, qui en alla prendre poffeflion dès la même année, trouva moyen de faire une querelle d'Allemand à Cerron \& à Diaz, \& les envoya Prifonniers en Efpagne.

Au milieu de ces Révolutions, le Gouverneur, qui avoit Révolte des? d'abord été nommé par la Cour, étoit demeuré fans em- Indiens de ploi. Ponce de Leon lui offiit de le faire fon Lieutenant \& fon Alcaide Major, \& il accepta cet offre; mais ayantreçû de grands reproches, de ce qu'il s'étoit abaiffé jufqu'à fe faire le fubalterne d'un fimple Gentilhomme, \& dans une Ine, dont il avoit eu le Gouvernement, il quirta cet emploi \& demeura fimple particulier dans l'Ifle, où le nouveau Gouverneur ne trouva pas les facilités à s'établir, dont il s'étoit flatté. Agueynaba étoit mort, \& fon frere, qui lui avoit fuccedé, n’avoit pas hérité de fon affection pous les 


\section{HISTOIRE}

1909.

Efpagnols. Le nouveau Gouverneur,qui avoit joint fes Trou.

pes à celles de Cerron, s'étoit imaginé pouvoir difpofer de toute l'Ifle, comme d'un Pays de Conquête: il avoit commencé par bâtir une Bourgade, il avoit enfuite vou. lu faire des Départemens d'Indiens, comme il fe pratiquoit dans l'Ifle Efpagnole, mais il s'apperçut bientôt qu'il avoit été trop vite. Les Infulaires, qui, fur le bruit de ce qui s'étoit paffé dans leur voifinage, fe figuroient les Efpagnols comme autant de Dieux defcendus du Ciel, fubirent d'a. bord le joug, fans ofer faire la moindre réfiftance; mais ils n'en eurent pas fi-tôt reffenti la pefanteur, qu'ils penferent aux moyens de le fecoüier. Ils s'affemblerent; \& la premiere chofe, dont ils convinrent, fut qu'on commenceroit par éclaircir le point de l'immortalité de ces cruels Etrangers. Ia Commifion en fut donnée à un Cacique nommé Brayaus, qui s'en acquitta en cette maniere.

Conment ils s'aflürent que les Efpagnols ne font pas immortels.

Un jeune Efpagnol nommé Salzedo faifant voyage, paffa chés ce Seigneur; Brayau le reçut, comme fi c'eut été le meilleur de fes amis, \& le régala de fon mieux pendant plufieurs jours. Salzedo, après s'être bien repofé, prit enfin congé de fon Hôte, qui le voyant fe charger de fon pacquet, l'obligea de prendre quelques-uns de fes gens, pour le porter, \& pour l'aider lui-méme à paffer quelques endroits difficiles, qui fe rencontroient fur fa route. Après qu'il eut marché quelque têms, il fe trouva au bord d'une riviere, qu'il falloir traverfer: un de fes Guides, à qui Brayau avoit donné en fecret fes ordres, fe prefenta pour le charger fur fes épaules; \& le jeune Efpagnol accepta fon offre avec joye. Quand il fut au milieu de la riviere, fon porreur le laiffa tomber, \& avec l'aide de fes Camarades, qui le fuivoient, il le rint dans l'eau, jufqu'à ce qu'il ne remuât plus. Alors ces Sauvages tirerent le corps à terre, \& ne pouvant encore s'affùrer qu'il fût mort, ils fe mirent à lui demander pardon de lui avoir laifé avaler tant d'eau, lui proteftant que c'étoit par mégarde, qu'ils l'avoient laiffé tom. ber, \& qu'on n'avoit pu faire plus de diligence pour le tirer. 
DE S. DOMINGUE, LIV. IV. 28 I En difant cela ils pleuroient, comme sils euffent été les hommes du monde les plus affligés, \& ne ceffoient de tourner le Cadavre \& de le retourner, pour voir, sil ne donneroit pas quelque figne de vie.

Ce jeu dura trois jours, au bout defquels la puanteur, Plufieuts Efqui exhaloit de ce corps, les raffûra, \& ills donnerent avis à leur pagnols font

Cacique de ce qui s'étoit paffé. Brayau ne voulut s'en raporter quà fes yeux; il vint, \& fut convaincu. Il fit fon raport aux autres Caciques, \& tous, abfolument détrompés de la prétenduë immortalité de leurs Conquérans, réfolurent de s'en délivrer à quelque prix que ce fût. L'affaire fut conduite avec beaucoup de fecret, \& comme les Caftillans ne fe défioient de rien, il y en eut une centaine de maffacrés, avant qu’on fe fû̀t apperçu de la moindre altération dans les Indiens. Sotomayor périt en cette rencontre : il avoit eu dans fon Département le Cacique, frere d'Agueynaba avec tous fes Sujets: la Soeur du Prince Indien, qui l'aimoit, l'avertit d'être fur fes gardes; il reçut encore le même avis d'un Caftillan, il s'en mocqua, \& le lendemain il fut affaffiné avec quatre de fes gens. Tout le refte des Efpagnols, qui fe trouvoient reduits à la moitié de ce qu'ils avoient été, auroit fubi le même fort, fans la diligence \& l'intrepidité du Gouverneur.

Au premier bruit de la révolte, Ponce de Leon fe mit en Hiffoire d'ua campagne, \& il vengea d'un maniere fi terrible la mort des Efpagnols, qu'il ôta pour toûjours aux Infulaires l'envie de Chien faremuër. Il n'avoit avec lui que des Braves, mais aucun d'eux ne contribua plus à lui foûmettre les Habitans de Portoric, qu'un grand Chien, qu'on appelloit Berezillo. Cet animal avoit plûtôt étranglé un homme, qu'il ne l'avoit regardé, \& dans les rencontres, qu'il y eut entre les deux $\mathrm{Na}$ tions, il faifoit plus de befogne qu'aucun Soldat. Aufia avoit-il la paye d'Arbalêtrier, qui étoit la plus grofle de toutes. Il fut, tant qu'il vêcut, la terreur des Ennemis, \& il finit giorieufement fa carriere au lit d'honneur. Plufieurs années après la Conquête de Portoric, des Caraibes ayant Tom I. $\mathrm{Nn}$ 
\$509. fait à leur ordinaire une irruption dans cette Ine, ils y trouve. rent les Caftillans \& leur Chien, qui après avoir étendı

3510. fur la place un très-grand nombre de ces Barbares, obligerent le refte à s'embarquer au plus vite. Le brave Berezillo, emporté par l'ardeur du Combat, fe jetta à la nage \& les pourfuivit affés loin; mais s'étant approché trop près d'un Canot, on lui tira une flêche, dont il fut tué tout roide. Il fut extrêmement regreté, \& fa mémoire s'eft long-têms confervée dans les Indes, où le bruit de fes exploits avoit pénetré partout. Cet animal paroiffoit avoir du jugement, \& fçavoit fort bien difcerner les ennemis d'avec les amis. On lui attribuë auffi cette générofité du Lion, dont par les prieres \& la foûmiffion on appaife, dit-on, la fureur ; \& l'on en raporte un exemple affés fingulier. Une vieille Indienne avoit eu le malheur de déplaire à quelques Efpagnols, qui réfolurent de la faire dévorer par Berezillo: ils lui donnerent une lettre à porter dans un endroit, où ils fçavoient bien qu'elle ne pouvoit aller, fans rencontrer ce Chien. Elle le trouva en effet, qui vint d'abord à elle la gueule beante, elle ne fe perdit point, elle montra la lettre à l'animal, \&

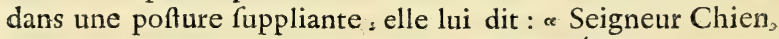
» je m'en vais porter cette lettre à des Chrétiens, je vous ». prie de ne me point faire de mal. $\infty$ A ces paroles Berezillo s'arrête, vient flairer quelque têms l'Indienne, qui étoit faifie de frayeur, \& s'en va, fans lui faire aucun mal.

Cequi porze les Indiens à fe founetsre,

Il y a pourtant bien de l'apparence que les Habitans de Portoric ne fe feroient pas tenus fiaifément pour fubjugués, fi, en voyant les Efpagnols fe multiplier de jour en jour dans leur Inle, ils ne s'étoient pas fottement perfuadés, que les nouveaux venus étoient ceux-là mêmes, qu'ils avoienc fait mourir, \& qui étoient refufcités. Dans cette penfée ils crurent que ce feroit folie à eux, de continuer à faire la guerre, \& qu'il valoit mieux plier de bonne grace fous l'autorité de gens, qui renaiffoient de leurs cendres, que de les irriter de nouveau par une opiniâtre réfiftance. Ils s'abandonnerent donc à la difcretion de leurs Vainqueurs, quis 


\section{DE S. Domingue, LIV. IV. 283}

les envoyerent fur le champ aux Mines, où en peude têms is perirent prefque tous.

Enfin la Jamaique fut auffi mife fous le joug la même année que Portoric \& Cubagua; \& voici ce qui détermina l'Amiral à cette entreprile. Le Roy Catholique avoit con- Jamaique, çû de trop grandes elperances des dernieres Découvertes le d'Or,\& de Chriftophle Colomb, pour ne pas saffurer la poffeffion dansla noude tant de riches Pays; il touhaitoit fort pouvoir charger fie. d'une entreprife auffi difficile Alphonie de Ojeda, dont la hardieffe \& la bravoure étoient à toute épreuve, mais Ojeda, après tant de voyages, n'en étoit pas devenu plus riche, \& n'étoit nullement en état de faire les avances, que demandoit une Conquête de cette nature: Dailleurs il étoit actuellement dans l'Ifle Efpagnole, d'où il n'étoit aparemment pas forti depurs le fecond voyage, qu'il avoit fait avec Americ Vefpuce, avec lequel nous avons vû qu'il s'étoit broüillé. Jean de la Cofa, quoiqu'il n'eût pas été de ce fecond voyage, étoit toûjours de fes amis; \& ayant fçû́ ce qui empêchoit qu'on ne le chargeât de l'entreprife, qu'on méditoit, il s'offrit à lui porter les ordres \& les infructions de la Cour, \& à l'aider de fon bien, pour faire les frais, dont le Roy ne vouloit pas fe charger. Comme Ojeda étoit toûjours bien auprès de l'Evêque de Palencia, \& que d'ailleurs il étoit généralement eftimé, \& que Jean de la Cofa faifoit entendre qu'il l'accompagneroit volontiers dans cette expédition, la propofition de celui-ci fut acceptée.

Dans le même têms un autre Gentilhomme fort riche, nommé Diego de Nicueffa, qui avoit été au fervice de D. Henrique Henriquez Oncle maternel du Roy, \& qui paffoit pour homme de tête \& de réfolution, arriva de l'Ine Efpagnole, \& vint à la Cour, pour y traiter de quelques affaires, dont l'Amiral l'avoit chargé. Il entendit parler de ce qui fe ménageoit enfaveur d'Ojeda, \& il repréfenta qu'un homme feul ne pouvoit pas établir une fi grande étenduë de Pays, il propofa de partager en deux cette Conceffion. \& il répondit de l'établiffement des Provinces, dont on vou

$\mathrm{N} n$ ij 


\section{HISTOI R}

\$509. droit bien le charger. On trouva qu'il avoit raifon, on fit deux Gouvernemens de cette partie du Continent, qu'on vouloit peupler, on en regla les limites, \& les Provifions pour les deux Gouverneurs furent fignées. Ojeda eut depuis le Cap, auquel il avoit donné le nom de la Vela, jufqu'à la moirié du Golphe d'Uraba, \& tout ce Pays fut nommé la Nowvelle Andalousie. Le partage de Nicueffa fut depuis le même Golphe, jufqu'au Cap Gracias à Dios, \& cette Province fut appelkée la caftille d'Or. On abandonna aufi la Jamaïque aux deux Gouverneurs en commun, pour en tirer des vivres, \& les autres chofes, dont ils pouvoient avoir befoin: Jean de la Cofa fut fait Sergent Major, \& Lieutenant du Gouverneur de la Nouvelle Andaloufie, \& les ordres furent donnés pour preffer les armemens, que demandoient de pareilles entreprifes.

La Cofa ne put freter qu'un Navire \& deux Brigantins, fur lefquels il embarqua environ 200. hommes. Nicuefla arma quatre grands Vaiffeaux \& deux Brigantins, qu'il remplit d'une quantité prodigieufe de provifions. Ils arriverent tous deux à San-Domingo prefque en même têms, quoique Nicuefla fût parti plus tard que la Cofa, \& qu'il fe fût arrêté à l'Inle de Sainte Croix, une des petites Antilles, où il enleva 100 . Caraibes, qu'il vendit enfuite comme Efclaves : on regardoit alors cet enlevement comme legitime, par la raifon que ces Barbares étoient Anthropophages. Les deux Gotiverneurs ne furent pas long-têms enfemble, fans avoir de grands démêlés, au fujet des limites de leurs Provinces. La Jamaïque fut la premiere pomme de difcorde, qui les broüilla, \& tous deux vouloient avoir le Golphe de Darien. Ojeda, qui n'avoit \& ne connoiffoit, que fon épée, fit propofer à Nicueffa de vuider leur querelle en fe battant: Nicueffa lui fit réponfe qu'il y confentøit, mais à condition que chacun d'eux mettroit en dépôt cinq mille Caftillans, pour être donnés au vainqueur. Il fçavoit bien qu'Ojeda ne trouveroit jamais cette fomme, \& il ne vouloit que l'obliger à fe tenir en repos. Enfin la Cofa les mit 


\section{De S. Domingue, Liv. 1V. 285}

d'accord au fujet du Darien, les ayant fait confentir à prendre pour leur ligne de féparation la Riviere même, qui fe décharge dans le Golphe, \& qui en a pris le nom, ou lui a donné le fien.

Quant à la Jamaïque, ce fut l'Amiral, quî les accorda, en fe faififfant de cette Ine; il y envoya Jean de Efquibel avec 70 . hommes, pour y faire un Etabliffement en fon nom, \& pour y commander fous fes ordres. Dom Diegue avoit vivement reffenti qu'on eut difpofé fans fa participation de tant de riches Pays, que fon pere avoit découverts, \& qui, en vertu des Capitulations faites avec lui, \& fi fouvent con ${ }^{-}$ firmées, devoient être de fon Gouvernement. Ces abondantes Mines de Veragua, où Chriftophle Colomb avoit efluyé tant de fatigues, \& couru tant de dangers, lui tenoient furtout fort au cour, mais il n'avoit pû digerer qu'on lui ôtât jufqu'à la Jamaïque, qui étoit, pour ainfi dire, à fa porte; \& comme il jugea qu'inutilement il feroit fur cela des répréfentations, il crut que le plus court étoit de fe faire juftice à foi-même, \& de prévenir les deux nouveaux Gouverneurs. Il mit enfuite tout en ufage pour traverfer leurs entreprifes, mais ce fut envain. Ojeda de fon côté dit tout haut que, s'il trouvoit Efquibel à la Jamaïque, il lui feroit couper la tête. Il mit à la voile avec cette fanfaronade le ro. de Novembre, ayant avec lui 300 : hommes fur deux Navires \& deux Brigantins. Nicueffa avoit auffi augmenté fon Armement d'un Navire, \& appareilla le 22. Efquibel ne put être prêt à partir, qu’après eux; mais il paroit que ni l'un, ni l'autre ne toucha à la Jamaïque, peut-être pour ne s'y pas rencontrer.

L'Amiral ne devoit point douter que tous les coups, Mécontenqu'on lui portoit, ne vinffent, au moins en partie, de l'E- temens donnés vêque de Pulencia, dont le credit étoit plus grand que ja- quelles en fumais. Herrera raporte l'origine de cette indiffofition du Prélat contre les Colombs à quelques paroles du premier Amiral, au fujet de fes Armemens : car comme il avoit prefque toûjours été très-mal fervi, il y a bien dè Nn iij 


\section{HISTO I E}

1509. l'apparence qu'il s'en plaignit; \& peut-être ne le fit-il pas toûjours avec affés de ménagement. D'ailleurs Fonfeca ne pouvoit ignorer que le Roy Catholique n'étoit point favorable à Chriftophle Colomb, \& pour l'ordinaire il fuffit d'être dans la difgrace du Prince, pour encourir celle de६ Miniftres. Ce qui eft certain, c'eft que la famille des Colombs trouva toûjours l'Evêque en fon chemin, qu'on lui attribua toûjours une bonne partie des chagrins \& des malheurs du Pere \& du Fils, \& que tous ceux, qui fe déclarerent contre eux, de quelque maniere que ce fût, fe tinrent affürés de fa protection.

Conduite Dom Diegue de fon côté, quoi que les Hiftoriens s'acpeu politique cordent à nous le repréfenter comme un fort honnête homme, plein de probité, de Religion, \& de zele pour le bien public, paroît n'avoir pas été affés fur fes gardes, pour ne pas donner prife à des gens attentifs à profiter de fes moindres fautes, \& capables même d'y ajoûter la calomnie, comme ils firent plus d'une fois. On s'étoit attendu qu'il feroit favorable aux Indiens, du moins autant que l'avoit été fon Pere, \& qu'il aboliroit ces injuftes Départemens, imaginés par fon Prédeceffeur : par là il eût gagné ces Peuples, \& mis tous les gens de bien de fon côté. Il les defaprouvoit veritablement, mais la Cour étvit intereffée à leur confervation, \& il eut peut-être inutilement entrepris de les fupprimer. Le moyen d'ailleurs de renoncer au plus beau privilege de fa Charge, \& aux profits immenfes qu'il en pouvoit tirer? La chofe étoit certainement dangereufe à tenter, \& il y avoit peu d'efpérance de réüflir. Pour peu que l'interêt propre fe joigne à ces confiderations, ce qui n'étoit que difficile, devient bientôt imporfible. L'Amiral laiffa donc les chofes fur le pied, où il les avoit trouvées, fi ce n'eft qu'il changea de main la plúpart des Départemens, les ôtant à ceux, dont il n'avoit pas lieu d'être content, pour en gratifier fes Créatures. On peut bien juger que cette démarche fit crier contre lui beaucoup de perfonnes, \& le bruit courut que fi le Grand Comman- 


\section{DE S. D OMINGUE, LIV. IV. 287}

deur d'Alcantara ne fut pas mort dans ces circonftances, il eut été renvoyé dans les Indes pour le relever.

Mais Ferdinand lui donna alors une mortification, qui L'Audience ne lui fut peut-être pas moins fenfible, que lui auroit été Royale étafon rappel; il établit à San-Domingo une Cour Souveraine, Domingo: fous le nom d'Audiance Royale, \& déclara que deformais, on pourroit interjetter appel à ce Tribunal des Sentences du. Gouverneur, même dans les cas, qui lui avoient été refervés jufques-là. Dom Diegue eut beau fe récrier contre une innovation, qui dégradoit abfolument fa Charge, \& lui donnoit un Superieur dans fon Gouvernement, la Cour ne parut pas faire grande attention à fes plaintes, \& le Tribunal a toûjours fubfifté depuis.

Les Infulaires diminuoient cependant à vûë d'œil ; d'ail- Les Negres leurs, il falloit être des amis de l'Amiral, ou avoir du cré- introduits dit à la Cour, pour en obtenir. L'exemple de Nicueffa fit pagnole. naître à plufieurs la penfée d'aller dans les petites Antilles, pour y enlever des Caraïbes; un habitant arma une Caravelle à ce deffein, \& fit defcente dans la Guadeloupe; mais il y trouva les Barbares fur leurs gardes, \& fut obligé de fe rembarquer avec perte, fans avoir pû faire un feul Efclave. D'autres furent un peu plus heureux, mais il s'en fallut bien qu'ils retiraffent leurs frais, \& la mortalité s'étant mife parmi les Indiens de l'Efpagnole, il fallut enfin avoir recours aux Noirs d'A frique, fans lefquels les Colonies les mieux établies dans le nouveau Monde, feroient aujourd'hui, pour la plûpart, très-peu de chofe.

Dès le têms du Grand Commandeur, on avoit commencé à introduire quelques Negres dans les Indes; mais ils n'y étoient que tolérés, \& il y avoit même un Edit du Roi Catholique contre cette nouveauté, à laquelle Ovando avoit toûjours été contraire. Ce Gouverneur craignoit que cette Nation, qui paroiffoit indocile \& fiere, ne fe révoltât, fi elle fe multiploit, \& n'entraînât les Infulaires dans fa révolte; mais on changea bientôt de fentiment. La néceflité obligea de s'en fervir a \& l'ufage fit voir qu'on ne 


\section{HISTOIRE}

1509. les avoit pas bien connus. Effectivement, outre qu'un Negre fait autant de befogne, que fix Indiens, il s'accoûtume bien plûtôt à l'efclavage, pour lequel il paroît né; ne fe chagrine pas fi aifément, fe contente de peu de chofes pour vivre, \& ne laiffe pas, en le nourriffant mal, d'être fort \& robufte. Il a bien naturellement un peu de fierté ; mais il ne faut pour le dompter, que lui en montrer encore davantage, \& lui faire fentir à coups de foüet qu'il a des Maîtres. Ce qu'il y a d'étonnant, c'eft que le châtiment, quoique pouffé quelquefois jufqu'à la cruauté, ne lui fait rien perdre de fon embonpoint, \& qu'il en conferve même affés peu de reffentiment pour l'ordinaire.

Atrivée des On remedia dans le même têms à un grand défordre, pP. Domini- qui s'étoit gliffé dans toute l'Ifle, au fujet des Indiens. zọle \& le fuc- Ces malheureux, livrés à l'avarice des Habitans, n'étoient nulcès qu'il eut• lement inftruits de nos Myfteres; quoique cette Inftruction eut été l'unique prétexte de l'inftitution des Départemens. Mais les Conceffionnaires avoient crû fatisfaire à toutes leurs obligations fur ce point, en les faifant baptifer, comme files Adultes, pouvoient recevoir ce Sacrement dans la Foy de l'Eglife, auffi bien que les Enfans. Les premiers, qui firent ouvrir les yeux fur une irréligion fi criante, furent les PP. de S. Dominique. Il venoit d'arriver d'Espagne quatre de ces Religieux, \& ils s'étoient acquis d'abord une grande réputation par leur zéle, \& une aufterité de vie furprenante. Ils s'éleverent encore avec beaucoup de force contre plufieurs autres abus, dont le principal étoit l'ufure, \& l'on peut dire, qu'en très-peu de têms, ils firent changer de face à toute la Colonie; en quoi ils furent merveil. leufement fecondés par l'Amiral. Ils établirent des Catéchifmes reglés pour les Enfans des Colons, \& pour les Infulaires, \& ils trouverent dans ces derniers une docilité. qui les charma. Auffi après avoir travaillé avec un fuccès, qu'ils n'avoient ofé fe promettre, à les affranchir de l'efclawage du Démon, ils fongerent à les fouftraire à cette efpece de fervitude, où on les retenoit; ils fe déclarerent hau- 
DE S. DOMINGUE, LIV. IV. 289

tement contre les Départemens; mais dès qu'ils voulurent toucher cette corde, la vénération, que leur avoient attirée I510. l'éminence de leur Sainteté, leur défintereffement, \& leur zéle, fe changea en une violente perfécution, ainfi que nous le verrons bientôt.

Sur ces entrefaites, on apprit des Nouvelles bien triftes des deux Gouverneurs, qui étoient partis l'année précédente d'Ojeda. pour le Continent. Ojeda avoit d'abord pris Terre dans le Port de Carthagene, découvert, \& ainfi nommé en I sOI. par Rodrigue de Baftidas, ainfi que nous l'avons dit plus haut; mais où il n'y avoit encore aucun Etabl.ffement. Il y avoit là des Indiens d'une taille avantageufe, extrêmenent braves, \& tous, les Femmes auffi bien que les Hommes, fort adroits à tirer de l'Arc, \& à lancer leurs Zaguayes, qui font des efpeces de Lances. Outre cela, ils avoient l'ufage d'empoifonner leurs Fléches, \& le Poifon, ciont ils fe fervoient, étoit très-fubtil. D'ailleurs, un certain Chriftophle Guerra, \& d'autres Efpagnols après lui, étoient venus fur leurs Côtes depuis Baftidas, \& les avoient fort maltraités. Ojeda avoit des ordres bien précis de tenir une conduite plus moderée, de prendre ces Peuples par la douceur, \& de tâcher de les gagner à Jefus-Chrift, par le moyen des Religieux, qui l'accompagnoient; avant que de leur parler de les foumettre à la Couronne de Caftille. Ses Inftructions portoient à la vérité que, s'ils refufoient opiniâtrément de recevoir l'Evangile, il les pourfuivît fans miféricorde, \& en emmenât le plus, qu'il pourroit, pour les faire Efclaves.

Ojeda voulut effectivement commencer par faire amitié à ces Barbares; mais ils répondirent à fes avances de maniere à lui faire comprendre que, s'il vouloit s'établir dans leur Pays, il falloit fe préparer à la Guerre. La Cofa n'éroit pas de cet avis, \& vouloit aller dans le Golphe d'Uraba, dont les Habitans étoient plus doux; mais Ojeda ne crut pas qu'il fût de fon honneur de fuïr devant des Hommes nuds; il les attaqua, en tua beaucoup, fit environ 60. Prifonniers, qu'il envoya fur fes Navires, \& pourfuivant fa Tom. $I$. Oo 
1510. viß̌oire, il s'avança jufqu’à un Village, qu'il trouva aban. donné. Les Caftillans, qui avoient perdu quelques-uns des leurs dans les premieres Charges, crurent alors n'avoir-plus rien à craindre d'un Peuple battu \& intimidé, \& fe débanderent pour piller. Les Indiens l'avoient prévû, \& s'étoient mis en embufcade dans tous les endroits, par où les Chrétiens pouvoient fe retirer. Ils ne les virent pas plûtôt répandus fans ordre \& fans défiance par la Campagne, qu'ils donnérent fur eux de toutes parts: tous y périrent, \& le feul Ojeda fe fauva, par fon extrême agilité, dans l'épaiffeur des Bois, laiffant fon fidéle Alcaïde Jean de la Cofa s \& 70. de fes Gens, étendus fur la place.

Quelques jours s'etant enfuite paffés, fans que ceux, qui étoient reftés fur les Navires, entendiffent parler de rien, ils envoyerent la Chaloupe à Terre. Elle y trouva Ojeda caché dans des Mangles, tenant fon épée d'une main, ayant fur fes épaules fon Bouclier percé de 300. coups de Fléches, \& prêt à expirer de faim \& de foibleffe. Ils allumerent dus feu, ils lui donnerent à manger, \& revenu à foi, il leur xaconta fa trifte Avanture, \& leur témoigna fon chagrin de n’avoir pas fuivi le confeil de la Cofa, 8 r fon défefpoir d'avoir perdu le meilleur de fes amis. Comme il s'entretenoit ainfi de fes malheurs, il apperçut au large des Navires. C'étoit Nicueffa, qui fe trouvoit par hazard fur cette Côte, \& qui ayant appris le défaftre de fon Rival, lui envoya dire, qu'il ne s'agiffoit plus de leurs anciens démêlés, \& qu'il pouvoit difpofer de lui \& de tous fes Gens, pouf venger le fang Efpagnol, indignement répandu par des Barbares. Ojeda n'étoit pas dans une fituation à rejetter une offre pareille; il répondit, comme il devoit à une honnêteté faite d'une maniere fi noble : on débarqua 400 . Hommes des deux Efcadres; les deux Gouverneurs fe mirent à leur tête, \& l'on marcha vers le Village, où l'on ne doutoir point que les Indiens ne fuffent rentrés.

Ils y étgient effectivement dans une très grande fécurité, lorfque les cris des Perroquets les avertirent quion venois 
DE S. DOMINGUE, LIV. IV. 29r

les attaquer; ils n'en furent pas beaucoup émus: mais les Efpagnols tomberent fi brufquement fur eux, que tout ce qui ne prit pas d'abord la fuite, fut paffé au fil de l'Epée, ou tué à coups d'Arquebufes. Les Vainqueurs entrerent enfuite dans le Village, y mirent le feu en plufieurs endroits, \& en peu d'heures tout ce qui voulut fe fouftraire aux flammes, fut tiré, ou percé par les Efpagnols, qui les attendoient au paffage. On ne fit aucun Prifonnier; mais dès qu'on ne vit plus d'Ennemis, on fongea au Butin, il fut grand, \& Nicueffa eut pour fa part la valeur de 7000. Caftillans. Cette expedition ainfi terminée, les deux Chefs fe féparerent fort contents l'un de l'autre : Nicueffa prit la route de Veragua, \& Ojeda celle du Golphe d Uraba. Celui-ci, chemin faifant, enleva quelques Indiens dans un endroit, où il fut obligé de relâcher; il y trouva auffi de l'Or, \& ayant manqué la Riviere de Darien, il s'arrêta vis-à-vis de certaines hauteurs, qui font à la pointe Orientale du Golphe d'Uraba, \& fur lefquelles il jetta les fondemens d'une Ville, qu'il nomma Saint Sebaftien, Il mit auffi tout fon Gouvernement fous la protection de ce Saint Martyr, dans l'efperance qu'il le garantiroit des Fléches empoifonnées des Barbares.

Les Peuples de ces Quartiers-là étoient Cannibales, \& Ojéda n'ayant pas affés de Monde pour leur réfifter, s’il leur prenoit envie, de l'inquiéter, comme il arriva en effet peu de jours après, il envoya un de fes Navires à l'Ine Efpagnole, avec tout fon Or \& tous fes Prifonniers, \& recommanda au Capitaine, qui fe nommoit Encifo, de lui amener le plus qu'il pourroit d'Hommes, d'Armes, \& de Provifions. Il travailla enfuite à des retranchemens, où il pût être en fûreté contre les entreprifes des Indiens; mais les vivres lui ayant bientôt manqué, ce fut une néceffité pour fes Gens, d'en aller chercher dans les Campagnes \& dans les Villages. Ils y trouverent partout les Barbares en fort grand nombre, très-peu traitables, \& fi bien armés, qu'ils furent contraints de fe retirer au plus vîte dans leurs re. $\mathrm{O}$ o ij 
I5 ro. tranchemens, où ils ne tarderent pas à effuyer toutes les: horreurs de la famine. Il en étoit déjà mort un grand nombre, \& le refte s'attendoit au même fort, lorfqu'un Bâtiment parti de l'Ine Efpagnole, vint moüiller l'ancre au pied de Saint Sebaftien. Il étoit commandé par un certain Bernardin de Talavera, qui fuyant les pourfuites de la Juftice, \& ayant trouvé auprès du Cap Tiburon un Navire appartenant à ces Génois, s’en étoit emparé avec le fecours d'une Troupe de Gens de même étoffe que lui, s'étoit embarqué deflus avec eux, \& avoit appareillé, fans trop fçavoir. où il vouloit aller. Enfin la Providence avoit dirigé fa route vers Saint Sebaftien, dont les Habitans étoient fur le point de mourir de faim. Le Gouverneur acheta toute la Carguaifon du Navire, \& Talavera n'ayant rien de mieux à faire, s'engagea avec tout fon. Monde à demeurer avec lui.

Ojeda s'étoit flutté que les Indiens, voyant fa Place fo bien ravitaillée, prendroient enfin le parti de le laiffer en repos; il fe trompa, ces Barbares n'en parurent que plus acharnés à la perte des Efpagnols; \& comme ils fe furent apperçus que leur Général leur tuoir lui feul p’us de Monde, que tous les autres enfemble, ils crurent que, s'ils pouvoient fe-défaire de lui, ils auroient bon marché du refte : ils mixent en Embuficade quatre de leurs meilleurs Archers, avec ordre de ne tirer, que fur le Chef. Ojed a parut bientot, \& attiré par un gros d'Indiens, qui faifoient femblant de fuir. devant lui, il tomba dans l'Embufcade : fon Bouclier, qui le couvroit tout entier, le garantit pendant quelque têms; mais ayant fait un mouvement, pour venir fondre l'Epée à la main fur ceux, quil'artaquoient, il fut blefté à la cuiffe d'une Fléche, qui la lui perça de part en part. Dès qu’il fe fentit frappé, il fe retura, lans que les Barbares ofaffent le fuivre, ou s'en miffent en peine, parce que la Fléche qui l’avoir bleffé, étoit empoifonnée. Auff s'artendoit t-on à Saint Sebaftien de le voir bientôt mourir enragé, comme il étoit déjà arrivé à plufieurs, lorfqu'il s'avifa d’un Remede。 


\section{DE S. DOMINGUE, $\mathbf{L}$ I v. I V.}

dont bien peu de Gens auroient le courage de fe fervir ; il fit rougir dans le feu deux Plaques de fer, \& ordonna à fon Chirurgien de les lui appliquer aux deux ouvertures de fa playe; ; le Chirurgien refufa d'obéir difant qu'il ne vouloit pas être le meurtrier de fon Général; mais Ojeda le ménaçant de le faire pendie, il fe rendit. Le Malade fồtint cette cruelle opération, avec une conftance de Heros, fon remede opéra en confumant l'humeur froide, que le poifon avoit glifée dans fa bleffure; mais il lui enflanma de telle forte toute la mafle du fang, quon employa une barrique entiere de Vinaigre à tremper des linges pour le rafraîchir, dans l'ardeur, qui le brûloit.

Cependant on étoit déjà au bout des provifions, qu'on avoit achetées de Talavera, \& Encifo ne revenoit point. La vîë de l'extrême mifere, où l'on alloit retomber, effraya les Efpagnols, \& tous demanderent unanimement qu'on les remenât à San-Domingo. Ojeda eut beau leur réprífenter que leur falut dépendoit de leur union; \& qu'avec un peu de patience ils fe verroient bientôt en état de ne manquer de rien; il ne perfuada perfonne. Il s'offrit enfuite d'aller lui-même à l'llfe Efpagnole hâter le fecours, quil en attendoit, ajoûtant que, fi dans go. jours il ne $p$ roiffoit point, ils teroient libres de faire tout ce qu'ils jugeroient à propos. Tous y confentireut, il s'embarqua fur le Navire Genois, laiffant, pour commander à S. Sebuftien. François Pizarre, qui s'eft rendu depuis fi fameux dans la Conquête du Perou. Dès qu'il fut en mer, il voulut agir en Muître, mais Talavera, à qui étoir le Bâtiment, \& de qui l'Equipage dépendoit, commença par le mettre aux fers. C'étoir le fort de ce Capitaine, de ne pas faire un voyage, fans être ainfi enchainé par ceux mêmes, qui étoient fous fes ordres: trait, ce me femble, rrop bien marqué, pour n'y pas reconnoître la Jufice Divine, qui lui remettoit fans ceffe devant les yeux la trahifon, qu'il avoit faite au malheureux Caonabo. Mais fa captivité dura peu, jamais navigation ne fut plus traverfée, Talavera fut bientôt

O o jij 
1510. obligé d'avoir recours à lui, \& après avoir long-têms lutté contre les Courants \& les Vents, le Navire ouvert de toutes parts alla fe brifer fur la Côte de Cuba.

Ojeda ainfi dégradé dans un Pays, qu'il ne connoiffoit point, ne crut pas avoir d'autre parti à prendre, que de s'aprocher de la Jamaïque, où il efperoit de pouvoir aifément traverfer dans quelques Canots, qu'il acheteroit des Indiens. Il ne fçavoit apparemment pas que fon plus court de beaucoup étoit de paffer à l'Ifle Efpagnole. Il fit cent lieuës en fuivant toûjours le rivage de la Mer, \& ce qu'il eut à fouffirir dans ce voyage eft incroyable. Entre autres avantures il fut obligé de marcher 30 . jours de fuite, ayant de l'eau jufqu'à la ceinture, perdant même quelquefois terre; heureux, quand il pouvoit rencontrer quelques Mangliers, où il fe perchoit, poưr y paffer la nuit. Avec cela il ne trouvoit prefque rien à manger; ni d'autre eau pour boire, que celle, où il marchoit, laquelle étoit faumatre \& fort boüeufe. Il encourageoit tout fon Monde par la confiance, qu'il avoit en la Mere de Dieu, à laquelle il fe croyoit redevable d'être échapé d'une infinité de dangers; \& comme ìl en portoit toûjours fur foi une Image, il la fufpendoit à une branche d'arbre toutes les fois, qu'il étoit obligé de s'arrêter; il faifoit mettre auffi-tôt fes Gens à genoux, \& tous enfemble rendoient leurs hommages à celle, qui eft le Refuge affùré des affligés. Il fut même alors fi convaincu, qu'elle lui avoit fauvée la vie, qu'avant que de quitter l'Ifle, il lui fit bâtir une petite Chapelle. Enfin, réduit à 35 . Hommes de 70. qu'll en avoit, en débarquant à Cuba, \& ne pouvant plus fe traîner, il arriva avec bien de la peine, dans les Etats d'un Cacique, lequel ayant appris le trifte état, où fe trouvoient les Efpagnols, envoya au-devant d'eux plufieurs de fes Sujets, qui les chargerent fur leurs épaules, \& les conduifirent chés leur Prince. Ils y furent très-bien reçus, \& ils y etrent tout le têms \& les moyens de fe rétablir. De-là, ils pafferent chés un autre Cacique, qui ne les traita pas moins bien; \& ne fe trouvant plus qu'à 20. lieuës de 


\section{De S. Domingue, Liv. IV. 295}

la Jamaïque, un nommé Pierre de Ordas s'offrit à y paffer dans un Canot, pour aller demander du fecours à Efquibel.

Ils n'eurent pas de peine à obtenir du Cacique un Canot bien équipé; de Ordas fit heureufement le trajet, \& préfenta au Gouverneur de la Jamaïque une Lettre de fon Général, qui le conjuroit de ne le pas abandonner dans fon malheur. C'étoit-là une belle occafion pour Efquibel, de fe venger d'un homme, qui l'avoit ménacé avec tant de hauteur ; mais il fe picqua de générofité, il fit armer en diligence un Bâtiment, \& l'envoya à Ojeda fous la conduite de Pamphile de Narvaez. L'acceuiil, qu'il lui fit à fon arrivée à la Jamaïque, répondit à cette premiere démarche, \& $c$ quand il l'eut bien régalé pendant plufieurs jours, il le fit conduire à l'Ifle Efpagnole fur le même Bâtiment, qui l'étoit allé prendre à Cuba. Talavera n'eût garde de le fuivre dans un lieu, où il fçavoit qu'il ne pouvoit éviter le châtiment de fes crimes; mais il s'arrêta mal à propos à la Jamaïque; l'Amiral ayant fçu qu'il y étoit, envoya des Soldats pour le faifir, \& le fit pendre.

Ojeda aprit en arrivant à San-Domingo, qu'Encifo en étoit parti, il y avoit déjà quelque têms, pour lui porter un fon caractere. grand convoi d'Hommes \& de vivres à Saint Sebaftien. Il ne douta prefque point qu'il n'eût péri, puifqu'il n'en avoit eu aucunes nouvelles dans toute fa route, \& bien loin de perdre courage, il fe flatta de réparer bientôt toutes fes pertes avec le fecours des amis, qu’il avoit laiffés en grand nombre dans l'Ifle Efpagnole. Mais il ne fut pas long-têms fans éprouver que l'amitié eft rarement aflés forte, pour tenir contre la mauvaife fortune. Tout le Monde lui tourna le dos, quand on le vit malheureux, \& fans reffource. II fut donc obligé d'abandonner fon Entreprife, \& il en mourut peu de têms après de chagrin; fi pauvre, qu'il fallut mandier un Linceul pour l'enfevelir. Jamais homme ne fut plus propre pour un coup de main, pour faire \& pour fouffrir de grandes chofes fous les ordres, ou la direction d'un autre; 


\section{HISTOIRE}

IS IO. neût le coeur plus haut, ni plus d'ambition de fe faire un grand nom, ne s'embarafla moins de la Fortune, ne montra plus de fermeté d'Ame, \& ne trouva plus de reffources dans fon courage; mais ne fut moins fait pour êrre chargé en Chef d'une grande Entreprife, la conduite \& le bonheur lui ayant. toûjours manqué également.

Ce qui ar-

Cependant les so. jours, que les Hubitans de Saint Seriva à fes gens baftien avoient promis d'attendre leur Gouverneur, étoient

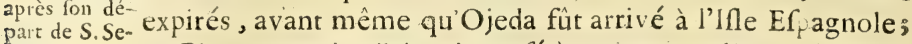
baflien. \& Pizarre avoit d'abord penfé à quitter un lieu, où jl n'y avoit nulle efpérance de s'établir; mais quand il fallut s'embarquer, les deux Brigantins, qui reftoient aux Efpagnols, fe trouverent trop petits pour contenir tout le Monde, quoiqu'il n'y eût plus que 60 . Perfonnes; on convint donc de différer jufqu’à que ce nombre fût encore un peu diminué, $\&$ il ne fallut pas attendre beaucoup. Alors on tua, \& on fit faler quatre Cavales, aufquelles on n'avoit jamais voulu roucher, quoiqu'on eût été réduit à de grandes extrêmités, parce que ces Animaux épouvantoient les Indiens : on $\mathrm{fe}$ partagea enfuite fur les deux Brigantins: Pizarre en monta un, \& donna le commandement de l'autre à un Flamand de Valenciennes, dont on ne nous a pas marqué le nom. Ils n'éroient pas encore bien loin en Mer, qu'il s'éleva un Vent des plus violents, \& le Brigantin du Flamand reçut un coup de Mer fi furieux, qu'il s'ouvrit dans le moment à la vûee de Pizarre, à qui il ne fut pas poffible d'en fauver un feul Homme.

Rencontre 'E'Encifo, \& de Pizarre.
Les Vents continuant à être contraires, ce Capitaine fe vir contraint de tourner du côté, où Ojeda étoit allé débarquer d'abord, \& où j’ai déjà remarqué qu'on bâtit depuis la Ville de Carthagene. Comme il s'approchoit de ce Port, il apperçut au large un Navire \& un Brigantin, c'étoit Encifo, qui conduifoit à Saint Sebaftien des Provifions en quantité, des Chevaux, des Verats, des Armes; en un mot, rout ce qui eft néceffaire pour l'établiffement d'une Colonie, \& a 50 . Hommes, tous Gens d'élite. Il étoir parti de l'Ine Efpagnole 。 


\section{DE S. DOMINGUE, LIV. IV. 297}

Efpagnole, avant qu'on y eût eu des nouvelles d'Ojeda, qu'il croyoit encore dans fa Fortereffe. Ainfi, il ne douta prefque point en vonyant Pizarre \& fa Troupe, que ce ne furfent des transfuges, qui avoient abandonné leur Général , \& il fallut, pour le détromper, lui montrer un Ecrit, par lequel Ojeda établiffoit Pizarre fon Lieutenant pendant fon abfence, \& confentoit que, fi dans cinquante jours, il ne les fecouroit point, ils priffent tel parti, qu'ils voudroient.

Il n'eut rien alors à repliquer; mais il leur déclara qu'en vertu de la convention faite avec leur Gouverneur, en partant de Saint Sebaftien, il fe croyoit dans lobligation de Semble à S. I'y aller attendre, \& qu'il falloit qu'ils l'y accompagnaffent. Cetre propofition les fit frémir, \& ils les conjurerent avec les dernieres inftances de ne les point remener dans un lieu, dont l'idée feule leur faifoit horreur, par le fouvenir de ce qu'ils y avoient fouffert. Ils ajoûterent que, s'il ne vouloit pas leur permettre de retourner à l'Ifle Erpagnole, il confentît au moins, qu'ils allaffent joindre Nicueffa dans la Caftille d'Or. Encifo n'avoit garde de donner les mains à une telle démarche, ni de permettre que la Caftille d'Or fe peuplât aux dépens de la nouvelle Andaloufie, \& il fit fi bien, partie par amitié , partie par autorité , qu'il les obligea de le fuivre. Ce qu'ils avoient tant appréhendé leur arriva bientôt ; comme ils entroient dans le Golphe, le Navire, que montoit Encifo, toucha fi rudement contre une Batture, par la négligence du Timonnier, qu'il fut brifé en un moment, \& quon eut à peine le têms de fauver les Hommes, avec un peu de Farine, de Bifcuit, \& de Fromage. Toutes les Bêtes furent noyées, \& la Colonie fe trouva en peu de jours réduite à manger les extrêmités des Palmiers.

Pour comble de difgrace, ils ne trouverent plus que la Place de Saint Sebaftien, les Indiens ayant réduit en cen. dres toutes leurs Cafes \& la Forterefle. Un Troupeau d'une efpece de Cochons fort petits, que la Providence fit def- réduite la Co. cendre des Montagnes, les nourrit pendant quelques jours; Il trouvent cette Ville brûlée. Extrêmais cette reffource épuifée, il ne reftoit d'efpérance, que Tom. $I$. 
1510. dans la Guerre. Auffi Encifo ne différa-t-il pas à fe mettre en Campagne avec cent Hommes bien armés. Il n'alla pas loin; \& trois Indiens l'arrêterent tout court d'une maniere, qui dut fort humilier les Efpagnols. Ils vinrent à lui l'Arc bandé, \& ils eurent vuidé leur Carquois, avant que leurs Ennemis fe fuffent reconnus. Aucune de leurs Fléches ne porta à faux, puis ils difparurent comme un éclair, laiflant Encifo avec la plûpart de fes Gens bleffés, \& dans l'impuiffance d'avancer. Son retour en cet état jetta toute la Colo. nie dans un déféfpoir affreux, \& l'on fut quelque têms fans fçavoir quel parti prendre.

Caractere Enfin, un de ceux, qui étoient venus avec Encifo, nommé de Vafco Nu- Vafco Nugnez de Balboa, donna un avis, dont le fuccès . boa. quoiqu'il n'y eût point d'autre part, que le fouvenir de ce qu'il avoit vû quelques années auparavant, fut la premiere fource du grand crédit, qu'il acquit bientôt après dans cette Colonie, \& de la grande réputation, où il parvint dans la fuite. Il eft vrai qu'il étoit de caractere à aider la fortune , \& à profiter des moindres occafions de s'élever. C'étoir un Homme de 35 . ans, qui étoit paffé aux Indes fort jeune, \& avoit eu un établiffement confidérable dans l'Ifle Efpagnole à Salvatierra de la Savana. Quelques Auteurs ont affûré qu'il avoit accompagné Ojeda dans fon Expedition, dont nous décrivons les fuites; mais il me paroît difficile qu'un Homme tel, que nous l'allons bientôt voir, hardi, entreprenant, intrépide, infatigable, plein d'ambition, formant toûjours quelque nouveau Projet, \& ne pouvant refter en place, n’eût point fait parler de lui dans les différentes. Avantures, dont nous avons parlé au fujet de cette Expedition, s'il s'y étoit trouvé ; \& il me paroît plus de vraifemblance dans ce que d'autres ont écrit, que fes affaires étant fort dérangées, \& cra gnant les pourfuites de fes Créanciers, il s'étoit embarqué furtivement dans le Navire d'Encifo.

Dequelle La maniere même, dont on dit qu'il s'y prit, toute exmanjere il traordinaire qu'elle eft, n'a rien d'incroyable, ni de fur- 


\section{De S. Domingue, Liv. IV. 299}

prenant, par rapport à lui. Comme le bruit eut couru, que quantité de Perfonnes chargées de dettes avoient pris des pafe méfures avec Encifo, pour s'embarquer fur fon Navire, \& ${ }^{\text {re-Ferme. }}$ paffer en Terre Ferme, les Créanciers avoient obtenu de l'Amiral un Navire bien armé, lequel eut ordre de ne point perdre Encifo de vûë, qu'il ne tût bien loin en Mer. Ce Navire n'eut pas plâtôt repris la route de San-Domingo, que Balboa, qui s'étoit fait porter à Bord dans un Tonneau, en fortit, \& parut tout à coup fur le Pont. Encilo, qui n'avoit point été prévenu, entra dans une fort grofle colere, \& menaça norre Avanturier de le dégrader fur la premiere Ifle déferte, qu'il rencontreroit; puifqu'auffi bien la défertion, \& la banqueroute qu'il faifoit à fes Créanciers, méritoient la mort; mais Balboa s'humilia tellement, \& tant de Gens intercédérent pour lui, que le Commandant s'adoucit. Nous verrons bientôt que Balboa fut moins reconnoiffant de cette grace, qu'il ne parut avoir de reffentiment de la peur, \& des menaces, qu Encifo lui avoient faites.

Ce qui eft certain, c'eft que voyant tout le Monde perdre courage, il dit qu'il fe fouvenoit, qu'étant dans ces parages avec Rodrigue de Baftidas, dont nous avons parlé ailleurs, ils pénétrérent jufqu'au fond de ce même Golphe, où ils étoient; \& quayant mis pied à terre, ils apperçurent au Couchant d'une belle \& large Riviere, une Bourgade fituée fur un Terrein fertile, \& fous un Ciel fort pur; \& que les Habitans de ce beau Pays paffoient pour ne point empoifonner leurs Fléches. Tout le Monde fembla revivre à ce récit, \& fans différer d'un moment, tout ce qui put tenir dans le Brigantin paffa le Golphe, qui a fix lieuës de large, \& les chofes fe trouverent précifément, comme Balboa les avoit repréfentées. Mais il fallut tout en arrivant combattre 500. Braves Indiens, qui avoient à leur tête un Cacique nommé cemaco, \& qui, après avoir mis en fûreté leurs Femmes \& leurs Enfans, s'étoient avancés, bien réfolus, de ne pas permettre aux Efpagnols de s'établir dans Deur Pays. Quelque affûrance qu'eût donné Balboa, que Pp ij 

roître, \& le foin qu'ils avoient eu d'occuper une petite Colline, qui dominoit toute la Plaine, donnoient à penfer aux plus hardis. Dans cette extrêmité, les Chrétiens eurent recours au Ciel, \& firent vœu à Sainte Marie l'Ancienne de Seville, d'y envoyer faire un Pelerinage en leur nom, d'y offrir un Préfent confidérable en Or \& en Argent, \& de donner à la premiere Ville, qu'ils bâtiroient, le nom de cette fameufe Eglife. Encifo fit enfuite jurer tout fes Gens, qu'ils mourroient plutotót que de fuïr, après quoi il fit fonner la Charge. Les Indiens s'ébranlerent en même têms, ne voulant pas attendre qu'on les vînt attaquer. Le premier choc fut vif; mais les Barbares n'en foûtinrent pas un fecond, \& les Efpagnols le virent bientôt lans Ennemis, tous ayant été tués, ou étant en fuite.

rie l'Ancienne du Da-

Is marcherent auffi-tôt vers la Bourgade, où ils ne trouverent perfonne, mais qui étoit remplie de vivres; ils parcoururent tout le Pays fans voir un feul Homme, ni dans les Campagnes, ni dans les Cafes, où ils firent un trèsgrand butin en Cotton $\&$ en Or. Ils peferent cet Or, qui étoit très-fin, \& il y en avoit le poids de dix mille:Pefos, en petits Bijoux à l'ufage de ces Barbares. Une Expedition $f^{2}$ heureufe mit Balboa en grand crédit, \& rendit la vie \& la joye aux Efpagnols, lefquels pour commencer à s'acquitter de leur Vou, jetterent fur le chample fondement d'une Ville, qui fut nommée Sainte Marie $l_{\alpha}$ Ancienne $d u$ Daricn, parce qu'elle fut placée fur le Bord du Darien, que j’ai dit ailleurs, fe décharger dans le Golphe d'Uraba. Elle a été la premiere Ville, \& le premier Siege Epifcopal du Continent de l'Amérique, mais elle ne fubfifta pas long-têms, ainfi que nous le verrons dans la fuite. Au refte, il y a bien de lapparence qu'Encifo ne fit pas réflexion, qu'en tranfpo:tant.fa Colonie fur la Rive Occidentale du Darien, il la tiroit de la nouvelle Andaloufie, que ce Fleuve féparoit de ta Cantille d'Or; \& il n'eft pas hors de vrai-femblance, que 


\section{De S. Domingue, Liv. IV. 301}

Balboa avoit fes vûës, en lui faifant faire cette fauffe démarche. Effectivement, l'affaire ne fut pas plûtôt engagée fans retour, que celui-ci eut grand foin de faire obferver, que la Colonie n'étant plus dans le Gouvernement d'Ojeda, Encifo, qui tenoit toute fon autorité de ce Gouverneur, n’avoit plus fur elle aucune jurifdiction; \& comme ce difcours remuoit déjà tous les efprits, Encifo fit une feconde faute, qui précipita fa dégradation, \& dont Balboa fut peut - être encore l'Auteur. Il s'avifa, je ne fçai pourquoi, de défendre fous peine de la vie aux particuliers la traitte de l'Or.

On ne manqua pas de dire que fon deffein étoit de pro. Encifo défiter feul de cette Traitte, \& fur le champ on lui déclara, pouillé du que n'étant plus dans la nouvelle Andaloufie, dont il avoit dement. Fotété déclaré Alcaïde Major par Ojeda; on ne le reconnoiffoit me du Gouplus en rien. On forma enfuite une efpece de Gouverne- vernement ement Républiquain, fous l'autorité de deux Alcaides, pour te Marie. adminiftrer la Juftice, \& d'un Regidor, pour regler la Police. Vafco Nugnez de Balboa, \& Jean de Zamudio, furentchoifis pour remplir les deux premieres Places, \& l'on donna la troifiéme à François Valdivia. Ce changement ne fut pourtant pas univerfellement applaudi, ou du moins plufieurs fe repentirent bientôt d'y avoir donné les mains, \& il fe forma trois Partis dans cette République, lefquels penferent l'étouffer dans fa naiffance. Les uns vouloient avoir un Commandant, \& redemandoient Encifo, au moins jufqu'à ce que le Roi leur eût donné un Gouverneur : d'autres étoient d'avis qu'on appellât Nicueffa, \& qu'on lui obéît, puifqu'on étoit dans fon Gouvernement. Plufieurs enfin, prétendoient maintenir ce qui avoit été fait, \& ajoûtoient que, fi l'on jugeoit qu'abfolument la Colonie eût befoin d'un Chef, il n'en falloit pas choifir d'autre, que Vafco Nugnez de Balboa, qui les ayoit tirés de la mifere, ò̀ Encifo les avoit mal à propos engagés.

Sur ces entrefaites, environ la mi-Novembre, on fut La nouvelaffés furpris d'entendre tirer du Canon dans le Golphe, on le Colonie acPp iij 
I5 10.

fa pour Gouverneur \& l'envoye chercher.

Avantures de Nicuella.

y répondit, \& peu de têms après, on aperçut deux Navires ; ils étoient commandés par Rodrigue Enriquez de Colmenarez, qui portoit des Provifions, \& 70. Hommes à Nicueffa, dont il étoit intime ami, \& duquel il parut fort inquiet de ne point apprendre de nouvelles. Il fut bientôt inftruit de cout ce qui fe paffoit dans cette Colonie, \& voyant qu'il y avoit un nombre confidérable de Gens, qui demandoient Nicueff s pour Gouverneur, il travailla à groffir ce parti, \& à le mettre en érat de prévaloir fur les deux autres. II commença par gagner l'affection de la multitude, en lui abandonnant la meilleure partie de fes Provifions; il repréfenta enfuite le droit inconteftable de fon ami ; il fit obferver l'avantage, qui reviendroit à la Colonie, de joindre fes forces à celles de Nicueffa, \& il perfuada fi bien tout le monde, qu'il fut chargé lui-même de lui en aller faire la propofition. Il accepta cette commiflion avec joye; mais avant que de voir quel fut le fuccès de fon Voyage, il eft à propos de reprendre la fuite des Avantures du Gouverneur de la Caftille d'Or.

A peine s'étoit-il féparé d'Ojeda, qu'une très-violente Tempête difperfa tous fes Bâtimens. Lope de Olano fon Lieurenant le quitta pendant la nuit, fous prétexte qu'sl ne pou. voit pas tenir la Mer, alla joindre le gros des Vaiffeaux, qui étoient entrés dans le Chagre, s'y fit reconnoître pour Commandant, en difant que la Caravel e, que montoit Nicueffa, étoit fans doute périe; \& paffa enfuite au Veragua,à deffein d'y faire un établiffement; mais le déf ut de vivres, \& plufieurs contre-têms furvenus coup fur coup, rendirent fon projet $1 \mathrm{~m}$ poffible, \& quantité de fes gens moururent de mifere. Il paffa dans la Riviere de Bethléem, croyant y trouver plus de facilité à sétablır, mais comme il ne fe vit pas plus avancé de ce côté-là , il réfolut de retourner à l'Ine Efpagnole. D'autre part Nicueffa dégradé fur unc Côte inconnuë, y perdit fa Caravelle, \& fe vit contraint de chercher par terre le Veragua . où étoit le rendés vous général. Dans cette marche un trèsgrand nombre defpagnols périrent de mifere, ou par le fer 


\section{DE S. Domingue, Liv. IV. 303}

des Sauvages. D'autres l'abandonnerent, fans trop fçavoir, où ils alloient : tous fouffrirent de la faim, de la foif, \& de la chaleur au delà de l'imaginable. Enfin quatre Matelots arriverent dans une chaloupe à l'entrée de la Riviere de Bethléem, où ils rencontrerent Olano, auquel ils donnerent avis que Nicueffa venoit par terre le long du rivage de la Mer. Olano crut cette occafion favorable pour rentrer en grace auprès de fon Général, \& fur le champ il envoya au devant de lui un Brigantin, avec quelques provifions, \& des fruits du pays. Le Brigantin nalla pas bien loin fans rencontrer Nicueffa, qui tout charmé, qu'il devoit être d'un fecours, auquel il devoit la vie, n'en changea pourtant rien à la réfolution qu'il avoit prife de punir du dernier fupplice fon Lieutenant; effectivement la trahifon de cet Officier lui avoit déjà couté 400 . hommes, \& l'avoit réduit dans le plus trirte état du monde, il lui fit néanmoins grace de la vie, à la priere de fes gens, qui fe jetterent tous à fes pieds, pour la lui demander, mais ille retint Prifonnier, réfolu de l'envoyer en Efpagne à la premiere occafion.

La joye de cette réünion ne fut pas longue, la plûpart des Bâtimens avoient été jettés à la Côte, \& les vivres manquerent bientôt tout-à-fait ; on fut alors obligé depermettre à quiconque d'en aller chercher par tout, où il pourroit, \& comme les Indiens étoient fur leurs gardes, \& bien armés; il falloir tous les jours combattre, \& on ne le faifoir jamais fans perdre du monde. Ces hoftilités réciproques réduifirent bientôt les Caftillans aux dernieres extrêmités, \& l'on affure que plufieurs d'entre eux ayant un jour trouvé le corps d'un Indien, qui avoit été tué dans une rencontre, \& commençoit à fentir mauvais, ils le mangerent \& en creverent tous Enfin Nicueffa ne voyant nulle apparence de s'érablir au milieu d'un Peuple fi feroce, laifla une partie de fes gens dans la Riviere de Béthléem fous les ordres d'Alphonfe Nugnez \& conduit par un Matelot. qui avoit été du dern er Voyage de Chriftophle Colomb. il alla avec les autres à Portobelo. Il y trouva tout le gio 


\section{$304 \quad H$ I S T I I E}

5510. vage couvert d'une multitude infinie d'Indiens armés de Zaguayes, qui lui tuerent 20. hommes, qu'il avoit fait mettre à terre dans un endroit écarté. Il liu fallut donc aller plus loin, \& à fix ou fept heuës de là, ayant trouvé le Port, que Colomb avoit nommé de Baftimentos, il y entra, en difant: Paremos aqui en el Nombre de Dios, « Arrê. cons-nous ici au nom de Dieu s : il en prit poffeffion pour le Roi Catbolique, \& il y commença une Fortereffe, qui fut appellée Nombre de Dios.

Les Indiens ne paroiffoient pas encore, mais on ne trouNoit rien pour vivre. La famine fut bientôt extrême, les maladies fuivirent; les trois quarts des Efpagnols en moururent, \& le refte fut réduit à une fi grande foibleffe, qu'ils ne pouvoient pas tenir leurs armes. Il falloit pourtant travailler, fi on vouloit fe mettre en fûreté contre les Barbares, dont on pouvoit à toure heure être attaqué. Le Général fit un effort, mit le premier la main à l'œuvre, \& quoiqu'il ne s'épargnât en rien, il ne put éviter, ni les murmures, ni les malédictions de fes gens, à qui le défefpoir 2voit ôté en même têms le courage \& la raifon. Ceux, qui étoient reftés dans le Béthléem, n'étoient pas moins à plaindre; la faim les porta jufqu'à manger des Animaux venimeux : aufli s'empoifonnerent-ils pour la plûpart, \& il n'en reroit pas demeuré un feul, fi Nicueffa ne les eût envoyé chercher: après quoi, il fit partir une Caravelle, pour aller demander du fecours à l'Ine Efpagnole. Il voulut enfuite traiter des vivres avec les Indiens, dont il avoit découvert les Villages, mais on trouva par tout ces Barbares bien réfolus à ne fe pas laiffer approcher. On fe mit en devoir de leur enlever de force, ce qu'ils refufoient d'accorder de bonne amitié, \& en payant; mais ils fe défendirent bien, \& obligerent les Efpagnols à fe retirer avec perte.

Sa mauvai- Nicueffa fe trouvoit dans cette fâcheufe fituation, lorffe conduite. que Colmenarez arriva, pour lui faire une propofition, qui auroit pû le dédommager de toutes fes pertes, s'il avoit fçu en profiter; mais fes malheurs avoient aigri fon natu- 


\section{De S. Domingue, Liv. IV. 305}

rel, \& peut-être même un peu troublé fa raifon, \& ce qui devoit naturellement lui procurer un établiffement capable de contenter fon ambition, ne fervit quà précipiter fa ruine. Colmenarez ayant trouvé fon ami avec 60 . perfonnes dans l'état du monde le plus déplorable, nuds pieds, couverts de méchants haillons, décharnés, pouvant à peine fe foutenir, il fut quelque têms fans pouvoir lui parler autrement, que par fes larmes. Il lui expliqua enfuite le fujet de fon Voyage, \& l'on peut imaginer avec quels tranfports de joye il fut écouté ; mais quelle fut la furprife de ce géné¿eux ami, lors qu'ayant fait à Nicueffa une defcription des Richeffes, quon avoit trouvées fur les bords du Darien, il lui entendit dire en préfence de ceux, qui étoient venus avec lui, que cette nouvelle Ville avoit été bâtiefur fon terrein, que fes Fondateurs méritoient d'être punis, \& que quand il feroit fur les lieux, il verroit de quelle maniere il en uferoit à leur égard. Un difcours fi peu à fa place ne tomba point à terre; mais par une feconde imprudence, qui mit le comble à la premiere, Nicueffa envoya devant lui une Caravelle, tandis que fans néceffité il s'amufoit à vifiter certaines Ifles, où il croyoit apparemment trouver de l'or. La Caravelle avec la nouvelle de fon arrivée, apprit auffi dans quelle dirpofition il venoit, deforte que comme il eut paru peu de jours après à la vûë du Port, l'Alcaïde Vaf́co Nugnez de Balboa parut fur le rivage, \& lui fit crier, qu'il pouvoit s'en retourner à Nombre de Dios, \& qu'on étoit fort réfolu à ne point le laiffer débarquer dans aucun endroit de la Province de Darien.

Une déclaration fi précife \& fi peu attenduë le frappa \& l'interdit à un point, qu'il fut quelque têms fans pouvoir proferer une parole; puis ayant un peu repris fes fens : $\propto$ Vous ¿ m'avez appellé, leur dit-il, pour vous gouverner, qui x vous a fait changer fi-tôt de fentiment? On vous a fans - doute fait quelque mauvais rapport de moi, mais donnés ` vous le têms de me connoître par vous mêmes, \& fi * vous me jugés indigne d'être votre Commandant, vous Tom. I. 


\section{HISTOIS}

1310.

` ferés de moi ce que vous voudrés. „On ne répondir ce difcours, que par des menaces \& des railleries; \& comme il étoit fort tard, il prit le parti de moüiller l'ancre, \& de paffer la nuit dans fa Caravelle. Dès que le jour parut, on lui fit dire qu'il pouvoit débarquer, mais au moment qu'il mit pied à terre, il s'apperçut qu'on vouloit fe. faifir de fa perfonne. C'étoit effectivement le deffein de fes ennemis, mais comme il étoit extrêmement leger à la coura fe, il leur échappa, \& s'enfuit dans le Bois. Mais qu'y faire feul \& fans vivres? il fe rapprocha bientôt, \& envoya dire aux Habitans de Sainte Marie que, s'ils lui affurroient la vie, il confentoit à être leur prifonnier, duffent-ils l'enchaîner. Une fi étrange propofition ne fervit qu'à le rendre méprifable, \& fut reçuë d'une maniere à lui faire tou氏 craindre. Ses affaires n'étoient pourtant pas encore auffi déLefperées qu'il le croyoit, \& peut être même auroit-il pû les. racommoder, s'il ne fe fut pas encore ôté la feule reffour. ce , qui lui reftoit. Balboa s'étoit bientôt repenti de s'être oppofé à fa Réception, il lui avoit même fauvé la vie le jour qu'il defcendit à terre, en empêchant qu'on ne s'opiniârrât à le pourfuivre, \& il entreprit de faire revenir en $f_{3}$ faveur fon Collegue Zamudio, qui paroifioit le plus animé de tous contre lui; il pouffa même fi loin les chofes, qu'un certain Francois: Benitez, s'étant avifé de dire en fa préfence, qu'il ne falloit pas recevoir dans la Ville un auffi méchant homme que Nicueffa, il lui fit donner fur le champ cent coups d'Etrivieres pour lui apprendre à parler. Il envoya enfuite avertir Nicueffa de fe retirer dans fon Brigantin, \&x de n'en point fortir, quelque invitation qu'on lui en fit,à moins que lui même ne fût du nombre de ceux qui l'in viteroient. Il parloit ainfi apparemment parce qu'il a voit cons. moiffance de ce qui fe tramoit contre lui.

Ce qui ent certain, c'eft que peu de têms après, trois Habitans de Sainte Marie, nommés Etienne Barrientos, Diego de Albitez, \& Jean de Veginez, feignant d'être de fes amis, l'allerent trouver à fon bord, \& après lui avois 


\section{DE S. DOMINGUE, LIV. IV:}

bien fait des excufes de tout ce qui s'étoit paffé, lui dirent que c'étoit l'ouvrage de quelques mutins fans aveu, que tous les honnêtes gens le fouhairtoient véritablement pour Gouverneur, quil les fuivit fans rien craindre, \& quil ne fe repentiroit pas de s'être fié à eux. Les plus fages font rarement en garde contre les difcours, qui les flattent dans un point, fur lequel ils fe flattent eux-mêmes; \& d'ailleurs la fagefle de Nicuefla l'avoit déjà abandonné dans des occafions, où il lui étoit encore moins pardonnable de n'avoir pas été en garde contre la furprife, \& d'avoir fuivi fes premiers mouvemens. Il donna donc dans le piége qu'on lui tendoit, malgré tout ce que lui avoit fait dire Balboa pour l'en garantir, \& il fe mit à la difcretion de fes Ennemis. Ceux - ci le livrerent fur le champ à Zamtdio, qui lui ordonna de partir fans délai, de ne s'arrêter nulle part, qu'll ne fût arrivé en Caftille, \& d'aller rendre compte au Roi \& au Confeil de la perte de tant de Caftillans, qu'il avoit facrifiés à fon ambition, ou qu'il avoit fait périr par fa mauvaife conduite. Lui de fon côté prit le Ciel à témoin de la cruauté, qu'on exerçoit envers lui, \& de linjultice, qu'on lui faifoit dans fon propre Gouvernement, il cita fes Ennemis au Jugement de Dieu, \& ajoûta, qu'il les attendoir à ce Tribunal redoutable, d'autant qu'il voyoit bien qu'il ne lui feroit jamais poffible de porter fes plaintes à celui du Roi.

Il eut beau dire, il ne gagna rien, \& peu de jours après, Sa Mort. On on l'embarqua avec 17 . Hommes fur un méchant Brigan rejette fes rin, en lui difant qu'il pouvoit aller, où bonlui fembleroit. ceux d'Ojeda Depuis ce têms-là, on n'a jamais oüi parler de lui, \& An-furl'Amiral toine Herrera regarde comme une Fable ce que quelques uns ont écrit, que dans l'Ifle de Cuba on avoit trouvé cette Infcription fur un Arbre: Lci l'infortuné Nicueffa a fini fes malheurs or $\int a$ vie. Au refte trop de gens étoient intereffés dans l'Ifle Efpagnole aux deux Armemens, dont nous vemons de voir la trifte cataftrophe, pour qu'on ne recherchât point les caufes de tant de malheurs; chacun en raifonna 


\section{HISTOIRE}

1510. fuivant fa paffion, \& les Ennemis de l'Amiral ne manquerent point de lui faire un crime de n'avoir pas fécouru les deux Gouverneurs, comme il le pouvoit felon eux.

Le peu de Cependant rien n'étoit, ce femble, plus injufte qu'une pafondement de reille accufation. Pour montrer qu'elle étoit fondée, il faltion. loit faire voir que ce fut D. Diegue, qui empêcha Encifo d'être de retour à S. Sebaltien avant qu'Ojeda en partît, \& qui retarda le fecours, que Nicueffa avoit envoyé chercher à l'If le Efpagnole. Or non feulement, il n'y a aucune apparence que ces retardemensayent pu être imputés à ce Seigneur, \& je n'ai vâ aucun Hiftorien, qui les ait mis fur fon compte; mais il eft évident que la Caravelle dépêchée à San-Domingo par Nicueffa , étoit à peine partie de Nombre de Dios lorfque ce Gouverneur fut appellé à Sainte Marie l'Ancienne. Enfin on ne peut difconvenir que ces deux hommes n'ayent paru dans toute leur conduite très-peu capables des entreprifes, dont ils s'étoient chargés ; que le premier étoit un brave homme, très propre pour un coup de main ${ }_{2}$ mais qu'il avoit befoin d'être dirigé par gens, qui euffent plus d'habileté , \& de fang froid que lui ; \& que les premiers malheurs, qui accueillirent le fecond, lui firent tourner la tête, \&\& le rendirent méconnoiffable à fes meilleurs amis.

Après tout, l'Amiral, qui avoit des prétentions affés légitimes fur la partie du Continent, qu'on avoit abandonnée à Ojeda, \& à Nicueffa, \& qui pouvoit efperer d'y faire un jour valoir fes droits, ne fut apparemment pas trop fâché que les chofes y euffent auffi mal tourné. Mais pour char ger un homme de ce rang, \& dont la probité n'a jamais été douteufe, d'un trait auffi odieux, que feroit celui d'avoir laifo fé périr exprès tant de braves gens, \& rendu inutiles tane de dépenfes; il ne fuffit pas de fimples conjectures, fondées fur l'efperance d'un avantage éloigné, il faut des preuves . \& l'on n'en produit aucune.

Fin du Quatriéme Livre. 


\section{H IS T O I R E \\ D E \\ L'ISLE ESPAGNOLE \\ $\mathrm{OU}$ D E \\ S. DOMINGUE. \\ PREMIERE PARTIE。}

\section{IVRE C I N Q U I E'M E.}

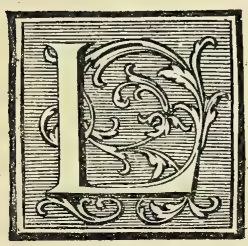

ES triftes avantures, dont j’ai fait le récit dans le Livre précédent, rendirent mémorble dans les Indes l'année I ro: I Création d'Emorable dans les Indes l'année is 10: la vêchés dans fuivante plus heureufe, y vit enfin la l'inle Efpaconfommation d'une affaire, quela feuë gnole.

Reine Ifabelle avoit euë extrêmement à cœur, mais que plufieurs contre-têms avoient toûjours retardée. A peine le Pape Jules II. étoit monté fur le Thrône Pontifical, que les Rois Catholiques, perfuadés de ce qu'on leur mandoit fans ceffe de l'Ine Efpagnole, que les Indiens y multiplioient à vûë d'oeil, \& que le Chriftianifme faifoit parmi eux de très-grands progrès, prierent ce Pontife d'en ériger quelques Villes en Evêchés. Ils demanderent d'abord qu'on établitt un Archevêché dans la Province de Xaragua, \& qu'on lui donnât pour Suffragans, Larez de Guahaba; \& la Conception de la Vega. Le Pape n'eut aucune peine à confentir à cette demande; l'érection fut faite, \& trois fujets furent propofés \& acceptés pour remplir les trois nouveaux Sieges; à fçavoir, le Docteur Pierre de Deza, Neveu de l'Archevêque de Seville, pour l'Archevêché de Xaragua,le P. Garcias de Padilla Francif. Qq iij 
I5II. quain, pour l'Evêché de Larez, \& le Licentié Alonfe Mana fa Chanoine de Salamanque, pour celui de la Conception.

Les chofes en demeurerent pourtant là, \& je n'ai pu en fçavoir la raifon: les Bulles ne furent point expediées; Ifabelle mourut: les Villes propofées perdirent beaucoup de leur luftre, fi on en excepte la derniere, \& le Roi Ferdinand, lorfque dans la fuite il reprit cette affaire, propofa un nouvel arrangement, que le Pape approuva. Il confife toit à fupprimer la Métropole de Xaragua, \& à ériger SanDomingo, la Conception, \& S. Jean de Portoric, en Evêchés Suffragans de Seville, \& cela fut accordé. Les trois mêmes Sujets, qui avoient déjà été nommés, le furent de nouveau, le Docteur Deza à l'Evêché de la Conception, le P. de Padilla, à celui de San-Domingo, \& le Licentié Manfa, ̀̀ celui de $\mathrm{S}$. Jean. Les Prémices \& les Dixmes de toutes chofes, à l'exception des Métaux, des Perles, \& des Pierres précieufes; la Jurifdiction Spirituelle \& Temporelle, \& les mêmes Droits \& Prééminence, dont joüiffoient les Evêques de Caftille furent attribués par le Pape aux trois nouveaux Siéges. Le Roi agréa cette difpofition, \& fit avec les trois Evêques un Concordat, dont les principales conditions furent, qu'ils s'engageoient pour eux , \& pour leurs Succeffeur\& à diftribuer les Dixmes au Clergé, aux Hôpitaux, \& aux Fabriques, \& que les Bénéfices \& les Dignitez feroient à fa. nomination.

Les Infu-

3aires prefque entierement exterminés.

Le premier Evêque de la Capitale n'eut pas la confolation de voir fon Eglife, il mourut en Ef́pagne peu de têms après for Sacre.Plufieurs accidens retarderent auffi le départ de celui de 1a Conception, \& cependant il arriva une chofe qui fit bien du bruit, \& que l'autorité Epifcopale auroit fans doute affoupie dans fa naiffance. L'Ifle Efpagnole perdoit infenfiblement tous fes Habitans naturels; \& quoiqu'on eât eu tout le têms de reconnoître le tort, que ce dépeuplement caufoit à la Colonie . bien loin d'en profiter pour conferver au moins ce qui reftoit de ces Infulaires, il fembloit qu'on prît à tâche, d'en extermi- 
DE S. Domineue, Liv. V. 3TI ner toute la race. Le Roi nểme, qui- jufques-là avoit fait de fi fages Ordonnances en leur faveur, trompé par des ISIT. perfonnes, dont les derniers Réglemens gênoient la cupidité, fembla les abandonner à la difcretion de leurs Tyrans, \& permit que déformais on ne leur donnât point d'autre falaire, que la vie \& lentretien, à condition de payer d'abord à fon Domaine un Paros, c'eft-à-dire, environ une demie Piftole de notre monnoye pour chaque tête d'Indien. Les PP. de S. Dominique eurent beau fe récrier contre cette nouveauté , qui devoit naturellement apporter un obftacle infurmontable à la converfion de ces Peuples, \& repréfenter qu'il y alloit même de l'interêt du Roi, \& de la Na. tion de les traiter avec plus de douceur \& de ménagement; on n'eut aucun égard à leurs remontrances, ce qui détermina enfin ces zelés Miniftres à s'armer de toute la vigueur Apoftolique, pour réprimer par les armes Spirituelles un fcandale, qui faifoit blafphêmer le nom du Seigneur parmi les Infidelles.

Cette réfolution prife, le P. Antoine Montefino Prédicateur, Sermon qui avoit une grande réputation d'éloquence \& de fainteté, d'un $P$. Domonta en Chaire à San-Domingo, \& en préfence de l'Amiral les fuites qua'il du Tréforier Royal, de tout ce qu'il y avoit dans cette $\mathrm{Ca}$ - euto pitale de perfonnes en place, \& d'un très nombreux $\mathrm{Au}$ ditoire, il déclara les Départemens d'Indiens illicites; il ajoutra que le terme de Tutelle, dont on ufoir pour coloxer cette tyranie, cachoit une véritable fervitude, à laquelle contre toutes les Loix Divines \& Humaines, on affujettiffoit des Innocens; que cette conduite fi contraire à l'efprit du Chriftianifme, avoit déja fait périr des millions d'hommes, dont on répondroit à Dieu, \& dépeupleroit infailliblement tant de vaftes Provinces, dont le Maître des Na. ¿ions n'avoit pu donner l'Empire aux Rois Carholiques, qu'afin qu'ils en engageaffent tous les Habitans fous le joug aima. ble de fon Evangile.

C'étoit la toucher les affiftans par leur endroit fenGble, auff murmura-t-on beucoup contre le Prédicateur. 


\section{I2 HISTOIR E}

I5II. Il fut même arrêté qu'il feroit réprimendé, comme s'il eût manqué au refpect, qu'il devoit au Roi, \& à ceux, qui gouvernoient fous fes Ordres. Mais ceux, qui s étoient chargés de cette commiffion, furent bien furpris, lorfque le P. de Cordouë, auquel ils s'étoient adreffés d'abord, comme au Superieur de la Maifon, leur déclara que le P. de Montefino n'avoit rien dit, qui ne fût vrai, \& qu'il ne fût néceffaire de dire: que tous tant qu'ils étoient de Religieux de leur Ordre penfoient comme lui, \& que le Sermon, dont ils faifoient tant de bruit, étoit une chofe concertée entre eux. Ceux, à qui il parloit, furent extrêmement choqués de ce difcours, \& le prenant fur un ton fort haut, il lui dirent qu'il étoit bien étrange que de fimples Particuliers fans caractere fe donnaffent la hardieffe de blâmer publiquement des chofes établies par le confeil de Perfonnes fages, \& par l'autorité du Souverain;en un mot qu'il falloit néceffairement que leP. de Montefino fe retractât en Chaire,ou que tous les Dominiquains fortiffent de l'Ine. Le Superieur les écouta fort parfiblement jufqu’au bout, \& feignant d'être ébranlé par leurs menaces, il les affùra que dès le Dimanche prochain le P. de Montefino feroit fon poffible pour les contenter.

Le jour marqué,il fe fit à l'Eglife un concours extraordinaire. Le Prédicateur parut, \& commença par dire que, fi l'ardeur de fon zéle dans la caufe du monde la plus jufte, l'avoit empêché de mefurer affés fes expreffions, il prioit ceux, qui avoient pû s'en tenir offenfés, de les lui pardonner; qu'il fçavoit le refpect, qui étoit dû aux Perfonnes, que le Prince avoit fait dépofitaires de fon autorité; mais qu’on fe trompoit fort, fi on prétendoit lui faire un crime, de s'être élevé contre les. Départemens d'Indiens. Il dit fur cela des chofes plus fortes encore que la premiere fois; car après être entré dans un détail extrêmement pathétique des abus, qui fe commettoient tous les jours en cette matiere, il demanda quel droit des gens, qui étoient fortis d'Efpagne, parce qu'ils n'y avoient pas de pain, avoient de s'engraiffer de la fubftance d'un Peuple né auffi libre qu'eux? Sur quoi fon- 


\section{de S. Domingue, Liv. V. 3 I 3}

dé ils difpofoient de la vie de ces malheureux, comme d'un bien, qui leur fût propre? qui avoit pû les autorifer à exercer fur eux un empire tyranique? s'il n'étoit pas têms déformais de mettre des bornes à une cupidité, qui enfantoit tant de crimes, \& fi on vouloit encore lui facrifier I 5. à 20000. Indiens, qui reftoient à peine de plus d'un million d'ames, qu'on avoit trouvé dans l'Ine Efpagnole en y abordant?

Une démarche fi hardie fir concevoir aux Officiers Royaux qu'ils gagneroient peu à traiter cette affaire fur les lieux; ils en écrivirent au Roi, \& Paffamonté furtout le fit d'une maniere très-forte, \& chargea de fa lettre un Religieux Francifquain, nommé le P. Alphonfe de Efpinar; fur quoi Oviedo remarque fort judicieufement, que ce qui fit en tout ceci un plus mauvais effet dans l'efprit des Peuples, ce fut de voir une fi grande diverfité d'opinions entre les deux Ordres Réguliers, qui étoient alors feuls établis dans l'Ine, fur un point, qui intereffoit fi fort la confcience; les uns permettant fans aucune difficulté, ce qui paroiffoit aux autres un crime irrémiffible $\&$ digne de toutes les cenfures de l'églife.

Les PP. Dominiquains n'ignoroient pas ce qui fe tramoit contre eux, \& comme ils fçavoient auffi que plufieurs per- ne au Confeil fonnes puiffantes à la Cour, \&r les Miniftres même, étoient Indiens, intereffés à foutenir les Départemens; ils prirent le parti d'envoyer le $\mathrm{P}$. de Montefino plaider lui-même fa caufe auprès du Roi. Le Miffionnaire trouva, ainfi qu'ill'avoit prévû, toute la Cour \& Ferdinand même fort prévenu contre lui. Mais comme il étoit extrêmement éloquent, il n'eut pas beaucoup de peine à faire revenir le Roi en fa faveur. Ce Prince commença d'entrevoir qu'on lui avoit déguifé la vérité; toutefois ne voulant rien décider fur fes propres lumieres; il affembla un Confeil extraordinaire, où ce grand procès fut plaidé avec beaucoup de vehémence de part $\&$ d'autre. Ceux qui parlerent en faveur des Indiens, infiftesent beaucoup fur ce principe, que tous les Peuples font Tome $I_{0}$

R r 
yร́r. nés libres, \& qu'il n'eft jamais permi à une Nation d'a:tenter à la liberté d'une autre, dont elle n'a reçû aucun. tort.

Les autres oppoferent à cette vérité des raifons plus fpecieufes que folides, \& dont plufieurs perfonnes fages ne laifferent pourtant pas d'être ébloüis. « Les Indiens, direntso ils, doivent être regardés comme des Enfans incapables dé क fe conduire, puifqu'ils ont à cinquante ans l'efprit moins - avancé, que les Efpagnols ne l'ont ordinairement à dix : on » fçait que les chofes les plus aifées à concevoir, ne peuvent * leur entrer dans la tête; que dès qu'on ceffe de leur par٪ ler, ils oublient dans le moment les vérités, qu’on so leur avoir le plus inculquées dans la mémoire; qu'on ne ¿ peut même s'affurrer qu'ils retiendroient les plus courtes ^ prieres, fi l'on manquoit un feul jour à les leur faire réci- ter ; qu'on a beau les vêtir, \& leur faire fentir l'indé» cence de leur nudité , dès qu'ils font hors de la vuëde so leurs Maîtres, ils'dechirent leurs habits en mille pieces , क \& courent tout nuds dans les Bois, où ils s'abandonnent w fans honte à toutes fortes d'infamies; que la fouveraine fé\$ licité felon eux eft de ne rien faire, \& que cette conti» nuelle oifivęté, outre les autres vices qu'elle enfante, pro$\infty$ duit cette extrême indolence, qu'on remarque en eux » pour les chofes de la Religion; enfin il paroît certain qu'ils » font d'autant moins capables d'ufer bien de la liberté, qu'on क leur laifferoir, qu’aux défauts \& à l'incapacité des Ens fans, ils joignent les vices des Hommes les plus corrom20 pus.

Il étoit véritablement quelque chofe de tout cela, mais il n'y avoit aucun article, qui ne fût extrêmement exaggeré ; c'eft ce que le P. de Montefino s'appliqua furtout à faire fen¿ir. Il y réüfit parfaitement, après quoi il ne lui fut pas difficile de renverfer toutes les confequences, qu'ón en tiroit; mais fans parler de l'interêt des Miniftres \& des Favoris, rendre abfolument la liberté aux Indiens, \& réduire la meilleure partie des Habitans des Colonies Efpagno. 


\section{DE S. Domingue, LIv. $V$.}

les à l'état d'indigence, d'où ils étoient fortis, c'étoit prefque la même chofe. Or c'eft là un de ces inconveniens, contre lefquels en matiere de Politique, l'évidence même du droit tient rarement. Il fallut pourtant accorder quelque chofe à-l'équité de la caufe, que défendoient les PP. de S. Dominique; le Roi vouloit mettre fa confcience en rûreté, \& avoir égard à la claufe du Teftament de la feuë Reine Ifabelle, qui étoit précife en faveur des Indiens; \& voici ce qu'on imagina pour concilier des interêts \& des fentimens fi opporés.

Il fut déclaré que par provifion, \& en attendant un plus ample examen, les Indiens feroient réputés libres, \& trai- des Indiens. tés comme tels, mais que les Départemens à cela près refreroient fur le pied, où ils étoient. C'étoit reconnoître le droit de ces Peuples à la liberté, en même têms qu'on les retenoit réellement dans un dur efclavage; de fimples Réglemens du Prince ne fuffifant pas pour en adoucir le joug, \& véritablement tous ceux, que le Roi fit alors, \& qui étoient fort fages, furent la pluppart fans effet. Comme les Bêtes de charge s'étoient extrêmement multipliées dans l'Ifle Efpagnole, il fut expreffément défendu de faire porter aux Infideles aucun fardeau, ni de fe fervir du Bâton, ou du Foüet pour les punir; il fut auffi ordonné de nommer des Vifiteurs, qui feroient comme les Protecteurs des Indiens, \& fans le confentement defquels il ne feroit pas permis de les mettre en prifon. Enfin on regla qu'outre les Dimanches \& les Fêtes, ils auroient dans la femaine un jour de récréation ; \& que les Femmes enceintes ne feroient affujetties à aucune forte de travail. Nous verrons dans peu le cas que l'on fit de ces Ordonnances.

L'A miral fongeoit alors à s'affûrer de l'Ifle de Cuba, crai- Préparatífs gnant que, s'il differoit d'y faire un établiffement, la Cour pour la Conn'en donnât la commiffion à quelqưun, \& ne féparât ba. encore cette Ifle de fon Gouvernement. Il y envoya donc Diego Velafquez, pour la conquerir, y bâtir une Ville, \& La gouverner en qualité de fon Lieutenant. Velafquez étois 


\section{I6 HISTOIR E}

I511. un des plus anciens Colons de l'Inle Efpagnole, il y avoit eu les premiers Employs, \& il s'en étoit toûjours acquité avec beaucoup de bonheur, \& de conduite; il avoit d'ailleurs des qualités très-aimables, \& paffoit pour un homme plein d'honneur \& de droiture. On n'eût pas plûtôt publié qu'il étoit chargé de l'Entreprife de Cuba, qu'il y eut un véritable empreffement à l'y fuivre, à quoi ne contribua pas peu le bruit, qui s'étoit répandu, que cette Ifle avoit des Mines d'Or. Ainfi l'on vit arriver à Salvatierra de la Savana, où fe faifoit l'armement, plus de 300 . Volontaires de toutes les parties de linte Efpagnole, outre les Troupes réglées, qui furent envoyées par l'Amiral.

Préparatifs

Tout étant prêt, Velafquez mit à la voile avec quatre đes Infulaires Bâtimens, \& alla débarquer vers l'extrêmité Orientale de pour fe défen- Cuba, où eft la pointe de Mayci, \& où commandoit un $\mathrm{Ca}_{\text {a- }}$ Efpagnols fe-cique nommé Hatuey. Ce Seigneur étoit né dans l'Ifle Eflon les Indiens. pagnole, il en étoit forti pour éviter l'efclavage, où il voyoit tous fes Compatriotes condamnés, \& avoit paffé à l'Ine de Cuba, où avec le fecours de ceux, qui l'avoient fuivi en grand nombre, il s'étoit rendu Maître de ce Canton, \& y regnoit paifiblement. Comme il craignoit toûjours que les Caftillans ne fiffent dans Cuba, ce qu'il avoient fait dans fa patrie, il avoit foin d'entretenir dans l'Ine Efpagnole des Efpions, afin d'être averti à têms, \& de pouvoir fe difpofer à recevoir l'Ennemi, quand il viendroit l'attaquer; mais parce qu'il ne comptoit pas beaucoup fur fes forces, il avoit communiqué fes défiances à plufieurs autres Caciques, \& il avoit un fort grand foin d'entretenir une étroite union avec eux. Un jour qu'il raifonnoit de toutes ces chofes avec quelques-uns de fes Voifins, il leur dit, que toutes leurs précautions feroient inutiles, fi avant toutes chofes ils ne tâchoient de fe rendre propice le Dieu des Efpagnols. a Je le to connois, ajoûta-til, ce Dieu, le plus puifant de tous les - Dieux, je fçai le moyen de le gagner, \& je vais vous l'ap* prendre . Auffi-tôt il fe fait apporter un panier, où il $y$. 2voit de l'or, \& le montrant aux Caciques, , $\propto$ Le voilà, dit" 


\section{DE S. DOMINGUE, LIV. V.}

so il, le Dieu des Efpagnols, célébrons une Fête en fon hons neur, il nous regardera d'un ceil favorable. o Tous à l'inf15E.T. tant fe mirent à fumer autour de ce panier, puis à chanter $\&$ à danfer, jufqu'à ce qu'ils tombaffent d'yvreffe $\&$ de fatigue.

Le lendemain matin Hatuey raffembla les Caciques à leur réveil , \& leur tint ce difcours. a J'ai beaucoup refléchi fur l'af\$ faire, dont je vous ai parlé; mon efprit n'eft pas encore - tranquille, \& tout bien confideré , je ne penfe pas que nous \oyons en fûreté, tandis que le Dieu des Efpagnols fera par* mi nous.Par tout où ils le trouvent,ils s'y établiffent pour le poffeder:il eft inutile de le cacher,ils ont un fecret merveilleux pour le découvrir; fi vous l'aviés avalé, ils vous éventreroient pour l'avoir; je ne fçache que le fond de la Mer', w où ils n'iront pas affurément le chercher, c'eft-là, qu'il le o faut mettre; quand il ne fera plus parmi nous, ils nous laifo feront en repos, car c'eft uniquemement ce qui les attire w hors de chés eux. w L'expedient fut trouvé admirable, les Caciques prennent auffitôt tout l'or qu'ils avoient, le vont jetter à la Mer affés loin du Rivage, \& s'en reviennent fort contents, comme fi avec leur or ils avoient noyé toutes leurs craintes. Aufli Hatuey fut-il fort furpris, lorfquau bout de quelque têms il vit parô̂tre les Efpagnols.

Il ne laiffa pourtant pas de faire d'abord bonne contenance', \& il fe mit en devoir de s'oppofer au débarquement, mais fa réfitance ne fut pas longue. Aux premieres décharges, que les Caftillans firent de leurs Arquebufes, toute cette multitude d'Indiens, quibordoient le Rivage, s'enfuit dans le bois, \& l'o a mort ne jugea pas à propos de les fuivre pour lors. Après quelques jours de repos. Velafquez voulut fe délivrer d'un Ennemi, qui à la faveur de fa retraite, pouvoit l'incommoder beaucoup; il fit chercher le Cacique avec foin, \& l'ayant enfin trouvé, il lui fit expier par le feu, la faute, qu'il avoit faite de ne s'être pas foumis de bonne grace à des Conquerans, auf quels il n'étoit pas en état de réfifter. C'eft de lui, qu'on rap. porte ce trait fi célébre dans 1 Hiftoire du Nouveau Monde. R $r$ iij 


\section{H T}

IรีI1. \& par où l'on peut juger à quel point les Efpagnols s'étoiente rendus odieux aux Indiens: il étoit déja attaché à fon poteau, lorfqu'un P. de S. François voulut faire un dernier effort pour le gagner à J. C. après qu'sl l'eut exhorté long. têms à avoir pitié de fon ame, \& à ne pas s'expofer à brû. ler éternellement, tandis qu'il pouvoit lui procurer un bonheur fans fin dans le Paradis, Hatuey s'avifa de lui demander, s'il y avoit des Efpagnols dans ce lieu de Délices, dont il lui parloit. « Il y en a, répondit le Pere, mais il n'y en » a que de bons. Le meilleur n'en vaut rien; reprit le Ca» cique, \& je ne veux point aller, ou je puiffe craindre » d'en rencontrer un feul. Le Miffionnaire épuifa en vain toute fon éloquence, pour lui faire changer de penfée. Hatuey ne voulut plus l'écouter \& fe laiffa brûler.

Touteline Après cette exécution, Velafquez ne trouva plus d'Ence foumet. nemis. Tous les Caciques vinrent les uns après les autres, lui rendre leurs hommages, \& la Conquête de la plus grande, \& d'une des plus belles Inles du monde, ne couta pas un homme aux Efpagnols, aufquels elle eft d'un grand fecours par fa fituation, \& par la commodité de fes Ports, les plus beaux de l'A mérique. Quelques Auteurs ont crû que Chriftophle Colomb l'avoit nommée Ferdinandine, ils fe trompent, il la nomma la Juana; \& ce fut en I5 I4. que le Roi Catholique lui fit changer ce nom, pour lui donner le fien, mais le nom Indien l'a emporté fur les deux autres. Ce qui fit négliger fi long-têms cette grande Inle, c'eft qu'elle paffoit pour n'avoir pas, ou pour avoir bien peu d'or; effectivement, on n'y en a pas trouvé beaucoup, mais on a enfin ouvert les yeux fur les autres avantages, qu'on en pouvoit tirer, \& c'eft encore aujourd'hui une des plus floriffantes Colonies du Nouveau monde.

Créance des Indiens de Cuba.
Les Peuples de Cuba étoient à peu près du même caractere, \& avoient apparemment la même origine que ceux des trois autres grandes Antilles; mais on a cru trouver dans leurs traditions des preuves, qu'ils avoient eu autrefois quelque connoifance de la Création du Monde \& du Déluge. 
Ils difoient que l'Univers avoit été créé par trois perfonnes, que la Terre avoit été.toute couverte par les Eaux, qu'il ne s'étoit fauvé de ce Déluge qu'un Vieillard, lequel avoit fabriqué un grand Batteau, où il s'étoiti embarqué avec toute fa Famille, \& des Animaux de toutes les efpeces. Ils ajoûtoient à cela l'Hiftoire du Corbeau \& de la Colombe, celle de l'yvreffe du Vieillard, \& du crime d'un de fes Enfans, comme elles font dans la Genefe : excepté qu'ils ne donnoient au Pere que deux fils, dont l'un a été, difoient-ils, le Pe. re de tous ceux, qui font vêtus, \& l'autre, qui fur le Criminel, le Pere de ceux, qui vont nuds; ce fut un nommé Gabriel de Cabrera, qui le premier fit cette Découverte , \& voici comment. Un jour, qu'il traittoit de Chien un vieux Sauvage. o Pourquoi, lui demanda ce Vieillard, mappelles. so tu Chien? Ne fommes nous pas tous Freres, \& defcendus s des deux fils d'un homme, qui fit bâtir un grand Navire s pour fe fauver d'une grande innondation? Ce difcours ayant fort furpris Cabrera, il fit plufieurs queftions à l'Indien, \& en tira tout ce que je viens de rapporter: mais commela chofe lui parut fort finguliere, il craignit de n'en être pas crût fur fa parole, il fit répeter les mêmes chofes à l'Infulaire devant plufieurs perfonnes, elles furent bientôt publiées par tout, \& l'on en tira toutes les confequences, qu'on vou: lut. Pour 'moi, en fuppofant la vérité de ce récit, dont il. paroît qu'effectivement on ne fçauroit gueres douter, jen'y trouve rien de fort merveilleux. Il y avoit déjà bien desannées, que les Efpagnols connoiffoient l'Ifle de Cuba, Chriftophle Colomb y avoit débarqué à fon premier voyage, \& en avoit emmené des Habitans avec lui, lorfquil paffa à linle Efpagnole: \& dans plufieurs autres occafionsion étoit allé chés eux : ce Vieillard pouvoit fort bien avoir appris de quelque Caftillan, tout ce qu'il dit à Cabrera.

Il y a cependant bien de l'apparence, que les anciens $\mathrm{Ha}$ bitans de Cuba avoient quelques connoiffances par rapporc à l'autre vie, que ceux des autres Ifles n'avoient pas, ou du moins ne développoient pas auffi bien qu'eux, \& je 
I5II. fonde ma conjecture fur ce qui arriva au premier Amiral des Indes, Chriftophle Colomb, dans le fecond Voyage, qu'il fit à Cuba. Un jour qu'il entendoit la Meffe dans cette Ifle, un vieux Cacique arriva pour lui rendre vifite, \& lui faire un préfent de Fruits du Pays; la nouveauté du Spectacle le furprit, \& le refpect, dont il voyoit les Caftillans pénétrés, lui en infpira à lui-même; il n'ofa interrompre le Sacrifice, mais la Meffe finie, \& ayant fait à l'A miral fon Compliment \& fon Préfent, il s'affit par terre à côté de lui, \& lui parla en ces termes, rapportés par Herrera, \& par D. Pierre Marzyr d'Anglerie. a Tu es venu avec de grandes forces dans w cette Terre, que tu ne connoiffois point, \& tu y as répan$\approx$ du une grande terreur. Mais tu fçauras que nous croyons 2 ici qu'après cette vie, il en a une autre; \& que toutes s les Ames, au fortir de leur Corps, ne vont pas au même endroit. Que celles, qui ont bien vêcu, \& furtout » \& qui ont aimé la paix \& le repos des Peuples, font reçûës x dans un lieu de délices, où elies joüiffent de l'abondance s de toutes fortes de biens: que les autres, qui n'ont pas s eu une conduite réguliere, qui ont aimé le défordre, so \& qui ont troublé le repos des Peuples, font précipitées »dans un lieu ténébreux, où il y a beaucoup à fouffrir. Si $\approx$ donc tu crois mourir un jour, \& que Dieu rend à cha» cun le bien \& le mal, qu'il aura fait, tu te donneras bien » de garde de nuire à ceux,qui ne t'offenfent point. $»$ Colomb fut affés étonné de ce Difcours, \& en profita pour donner au Cacique quelque teinture de Chriftianifme.

IรI 2.

Quoiqu'il en foit, la nouveile de la Conquête de l'Inle

D. Barthé- de Cuba, fit fans doute beaucoup de plaifir au Roi Catholemy Colomb lique : mais ce Prince recevoit fans ceffe des plaintes contre I'Ifletipagno- I'Amiral. Il eft vrai que, malgré le peu d'affection, qu'il lui le \& pour- portoit, il ne laiffoit pas d'entrevoir, que la plûpart de fes quoi.

plaintes éroient uniquement fondées fur la jaloufie de fes Ennemis. Il jugea néanmoins à propos de lui envoyer D, Barthélemy fon Oncle, avec un Mémoire fort détaillé de coutes les, chofes à quoi il l'avertiffoit de prendre garde. 
DE S. DOMINGUE, LIV. V. 321

Dom Barthélemy avoit toûjours confervé fa Charge d'Adélantade; le Roi y ajoûta le Gouvernement, \& la proprieté fa vie durant de la petite Ine Mona, lüi afligna un département de 200. Indiens, \& lui donna encore la Charge de faire travailler aux Mines, qu'on pourroit trouver dans l'Ille de Cuba : cette Charge étoit très-lucrative.

Les Peuples de Cuba, après qu'ils eurent paffé fous la domination des Caftillans, ne demeurerent pas fi longtêms privés des fecours fpirituels, que l'avoient été ceux de l'Ifle Efpagnole. Le Licentié Barthélemy de las Cafas, qui s'eft depuis rendu fi célébre par fon zéle \& fes travaux, pour le falut \& la confervation des Indiens, avoit fuivi Velafquez, dont il étoit ami, dans fon Expedition. Il étoit paffé jeune aux Indes, s'étoit fait Prêtre depuis peu, \& cherchoit toutes les occafions de fe fignaler dans l'exercice de fon Miniftere. Il travailla avec fuccès à la converfion de ces pauvres Infulaires, qu'on venoit de mettre fous le joug. Il leur trouva un très-beau naturel, $\&$ une fi grande docilité, qu'il ne craignoit point de publier, qu'il étoit fans comparaifon plus aifé de faire embraffer le Chriftianifme à ces Infidéles, que d'obliger les Efpagnols à vivre chrétiennement. D'ailleurs, fon zéle pur \& défintereffé, fa charité compatiffante \& toûjours active, la fainteté de fa Vie, fa fermeté à empêcher les. Vainqueurs d'abufer de leur Victoire pour maltraitter les Vaincus; tout cela charma de telle forte ces Peuples, qu'ils s'abandonnerent à lui avec une confiance fans bornes. Par-là, non-feulement, il fe vit en état d'en faire des Chrétiens; mais il fut encore d'un grand fecours à la Colonie Efpagnole, qui courut plus d'une fois rifque d'être étouffée dans fa naiffance, \& n'évita gueres fa ruine, que par l'afcendant qu'avoit pris fur les Infulaires l'Homme Apoftolique, dont je parle.

Ce fut alors que Jean Ponce de Leon,qui fe trouvoit fans em- Ponce de ploi dans l'Ine de Portoric, parce que Cerron \& Diaz avoient Leon cherche eu le crédit de fe faire rétablir dans les leurs, ne penfa plus Jauvence. qu’à tenter quelque Découverte. Il n'y avoit pas alors un Tom $I$.

Las Calas travaille à la converfion des Peuples de Cuba. 


\section{HISTOIRE}

I512. feul Gentilhomme aux Indes, qui ne fût prêt à faire de ces tentatives, que Colomb avoit mifes fi fort à la mode, \& qui ne fe flattât de fe faire un grand Nom, \& un grand Etabliffement par cette voye. Ponce de Leon avoit amaffé de grands Biens, pendant qu'il avoit été en place ; il avoit de l'expérience, du courage, \& de l'efprit ; tout cela lui répondoit du fuccès de fon projer, qui n'avoit rien d'ailleurs que de fort fenfé; mais une folie, qu'il s'étoit mife dans la tête après plufieurs autres Efpagnols, n'eût gueres moins de part à fon entreprife, \& lui donna à lui-même un air d'Avanturier, \& de Chevalier errant, qui a un peu terni fa gloire.

Surquoi il Il couroit depuis long-têms parmi les Habitans des Anie fondoit. tilles une opinion, que dans une Ifle appellée Bimini, (c'ett une des Lucayes, affés près du Canal de Bahama) il fe trouvoit une Fontaine, dont les eaux avoient la vertu de rajeunir les Vieillards, qui s'y baignoient. Les Infulaires de Cuba, s'étoient furtout donné beaucoup de mouvement pour découvrir cette précieufe Source, \& au têms, dont je parle, il y avoit encore dans Bimini, quelques reftes d'un Villa. ge, dont les Habitans étoient originaires de cette grande Inle. Herrera place ces Infulaires tranfplantés dans le Continent de la Floride, \& fans faire mention de la Fontaine de Bimini, dit qu'on donnoit la vertu de rajeûnir à un Fleuve de cette grande Province. Il eft vrai que tous ces Peuples étoient naturellement fort crédules, \& que ceux, qui les ont connus, n'ont point été furpris qu'ils ayent donné dans de femblables Chimeres; on fçait auffi que les Efpagnols naturellement portés au Grand \& au Mervieilleux, pouffent affés loin la crédulité en tout genre, mais on aura pourtant quelque peine à croire, jufqu'où ils fe laifferent infatuer en cette occafion; car ce fut au point de n'être pas même capables de fe détromper. En effet, quoique plufieurs euffent avancé malheureufement leurs jours en courant après cette prétenduë Fontaine de Jouvence, \& que plufieurs même the fuffent pas revenu de cette ridicule recherche; on s'ima. 


\section{De S. Domingue, Liv. V.}

gina que la raifon, pourquoi ceux-ci ne retournoient point, c'eft quiils avoient trouvé ce qu'ils cherchoient, \& ne vouloient plus fortir de ce délicieux féjour, où ils joüiffoient dans l'abondance de toutes chofes d'un Printêms perpétuel.

Mais perfonne ne fe laiffa enchanter de ces douces rê- Il décourre veries d'une maniere plus étonnante, que Ponce de Leon. la Floride par Ce Capitaine ne fe promettoit rien moins, que la découverte d'un troifiéme Monde, \& c'étoit trop peu pour une fi vafte entreprife, que les jours, qui lui reftoient fuivant le cours ordinaire de la nature. Il falloit commencer par recouvrer ceux, qui s'étoient écoulés, \& s'affûrer pour toûjours la confervation d'une verte \& floriffante jeuneffe: il réfolut donc de ne rien négliger pour trouver la Fontaine rajeuniffante. Il partit un Jeudi premier jour de Mars I 5 I 2. du Port de Saint Germain, dans l'Ifle de Portoric, avec deux Navires, qu'il avoit équipés à fes frais, \& après avoir rangé toute la Côte Septentrionnale de l'Inle Efpagnole, il fe trouva au milieu des Lucayes. Il s'informa exactement partout de la Fontaine miraculeufe, goûta de toutes les eaux, qu'il rencontra, même de celles des Marais les plus bourbeux ; enfin, comme il alloit toûjours devant lui, il apperçut le Continent, où ayant abordé, non pas le jour, comme quelques - uns l'ont cru, mais dans la lemaine de Pâques Fleuri, \& y ayant vû , en mettant pied à terre, une Campagne toute femée de fleurs, il lui donna le nom de Floride.

- Cette découverte inefpérée le confola un peu de n'a- Enquoicetvoir pas trouvé la Fontaine de Jouvence; \& c'eft ce qui te décontererte fait voir combien la réputation des Hommes a quelquefois des ble à IIfle Effondemens peu folides; car enfin une Découverte, où le feul pagnole. hazard a eu part, a immortalifé un Avanturier, qui l'a fait en ccurant après une Chimere. Au refte, on ne fçait pas bien au jufte en quel endroit Ponce de Leon débarqua. On fçait feulement, qu'il reconnut une bonne partie de la Côte Oc. cidentale de la prefqu'Ifle, \& qu'il donna aux Inles des Martyrs \& des Tortuës les noms, qu'elles portent encore 
aujourd'hui : que partout, où il voulut faire defcente, il trouva des Sauvages en grand nombre, \& fort réfolus à ne pas fouffrir qu'il s'établît chés-eux; qu'il eut une connoiffance affés diftincte du Canal, qui porte aujourd'hui le nom de nouveau Canal de Bahama, par où quelques années après les Navires commencerent de prendre leur route pour retourner en Europe : que ce fut ce qui donna accafion d'établir le Port de la Havana, lequel n'eft qu'à deux petites journées du Canal, \& cela, pour fervir d'entrepôt à tous les Vaiffeaux, qui venoient de la nouvelle Efpagne, \& que cet Etabliffement a été une des principales caufes de la décadence de l'Ifle Efpagnole.

Ponce de Leon fut donc obligé de fe contenter d'avoir vî́ le premier la Floride, il courut encore depuis affés longtêms après fon Inle enchantée, \& il s'en retourna fort mal en ordre, \& fort chagrin à Portoric, où il eut encore à effuyer bien des railleries, fur ce qu'on le voyoit revenir plus vieux qu'il n'étoit parti. Il ne laiffa pas d'aller en Cour donner avis de fa découverte; il fut bien reçu de Ferdinand, qui lui permit de bâtir des Forts, \& de mener des Colonies dans la Floride, \& dans l'Ifle de Bimini, lui promit le Gouvernement de tous les Pays, qu'il découvriroit, \& confentit même quil levât du Monde pour cela, foit en Efpagne , foit dans les Indes. Je ne fçai ce qui l'empêcha de profiter de ces permiffions; mais il eft certain qu'il étoit encore en Efpagne fur la fin de IsI4. qualors le Roi lui ordonna d'armer pour aller faire la Guerre aux Caraïbes, qui défoloient 'IIfle de Portoric, \& qu'il retourna peu de têms après dans cette Inle, d'où il ne fortit point avant l'année I 52 I.

Les Dépar- Cependant le P. Pierre de Cordouë avoit fuivi de près le remens d'In- $\mathrm{P}$. de Montefino, fon Inférieur, en Efpagne, où l'on ne ceffoit més de nou- point de tenir des Confeils, \& de faire des Confultations чеаแ.

touchant la caufe des Indiens, que ces Religieux avoient portée au Tribunal du Roi. Enfin ce Prince fit appeller le P. de Cordouë, \& lui dit q qu'il étoit fort perfuadé de la pureté de fon zéle; mais que l'avis de prefque tous les Jo. 
DE S. DOMINGUE, LIV. IV. 325 rifconfultes, \& les Theologiens de fon Royaume, étoit de ne rien changer à ce qui étoit établi a à quelques abus, \& à quelques défordres près, contre lefquels il alloit prendre toutes les plus juftes mefures. Qưil s'en retournât donc dans fa Miffion; mais que lui \& fes Religieux ceffaffent d'invectiver contre une chofe approuvée d'un fi grand nombre de perfonnes fages, \& qu'ils continuaffent à éclairer \& à édifier les Indes par les lumieres de leur Doctrine, \& par la fainteté de leur vie, comme ils avoient fait jufques-là ; fans fe mêler en aucune maniere de la Police, ni du Gouvernement,

Ce difcours fit comprendre au P. de Cordouë \& à fes Religieux que du train, dont les chofes iroient à l'avenir, il leur feroit déformais fort difficile d'être bien d'accord avec les Efpagnols du Nouveau Monde, \& que s'ils vouloient vérirablement faire du bien parmi les Barbares, il falloit chercher des Contrées, où ils fuffent feuls avec ces Peuples. Ils Continent de fupplierent donc Ferdinand de trouver bon qu'ils allaffent prêcher Jefus-Chrift dans quelqu'unes des Provinces de l'Amérique, où les Efpagnols n'euffent point encore d'Etabliffement, \& ils lui expliquerent le projet de celui, qu'ils y vouloient faire. Le Prince goûta leur deffein, accorda les permiffions, qu'on lui demandoit, \& fit expedier des ordres pour l'Amiral, de fournir à ces Miffionnaires toutes les chofes, dont ils auroient befoin pour leur fainte entreprife. Le P. de Cordouë \& le P. de Montefino s'embarquerent peu de têms après pour l'Inle Efpagnole, où l'Amiral leur fit armer un Vaiffeau, y mit des vivres en abondance, leur fit délivrer avec profufion tout ce qu'ils lui demande. rent, \& les fit tranfporter à la Côte de Cumana, qu'ils avoient choifie, pour y commencer leurs travaux Apoftoliques.

Le P. Pierre de Cordouë n'y alla pas lui-même, fa pré- Ils commenfence étant plus néceffaire dans l'Ine Efpagnole, où le Roi cent la avifeavoit envoyé de bons ordres pour établir ces Religieux c̀̀s. mieux qu'ils n'étoient; mais il choifit pour cette expedition 


\section{HISTOIR}

1512. le P. de Montefino, avec les Peres François de Cordouë, \& Jean Garcez. Le Pere de Montefino tomba malade en paffant à l'Ifle de Portoric, \& fa maladie tirant en longueur , fes deux Compagnons furent obligés de continuer leur route fans lui. L'endroit, où ils débarquerent fut affés près de celui, où l'on bâtit depuis la Ville de coro , qu'on appelle autrement Venezuela, pour les raifons que j'ai dit ailleurs, en parlant de la premiere expedition d'Alphonfe d'Ojeda, avec Americ Vefpuce, dans le Continent de l'Amérique ; car ce fut fur les ruines même de la Bourgade, à laquelle Ojeda donna le nom de petite Venife, que la Ville de Caro ou de Venezuela fut conftruite. La Bourgade Indienne fubfiftoit encore au têms, dont je parle, \& les Miffionnaires y furent parfaitement bien reçus, logés \& fournis de toutes les les chofes, dont ils pouvoient avoir befoin. Ils profiterent de ces heureufes difpofitions, pour engager ce bon Peuple à embraffer le Chriftianifme, ils en furent écoutés, \& ils avoient tout lieu de fe promettre une abondante Moiffon, lorfqu'un Navire Efpagnol vint malheureufement rompre toutes leurs mefures.

Trahifons

Ce Navire cherchoit à furpendre les Indiens, \& à les faites aux Indiens par les Efpagnols.

enlever pour les vendre. Commerce infâme, qui fe faifoit alors affés ouvertement, quoiqu'il ne fût pas autorifé; mais on obligeoit les Officiers Royaux à fermer les yeux, en leur donnant part au Butin. On n'avoit pas même honte de colorer ce brigandage du titre d'expedition contre les Cannibales, \& peu s'en falloit qu'on ne prétendît s'en faire un mérite devant Dieu, comme d'une Guerre fainte. D'ailleurs, il y avoit une Déclaration du Roi, qui permettoit de réduire en captivité tous les Mangeurs de Chair humaine, \& on fuppofoit, fans examiner, tous les Habitans du Nouveau Monde coupables de ce crime. Comme ce n'étoit pas la premiere fois qu'on avoit fait de femblables tentatives à la Côte de Cumana, les Peuples y étoient fur leurs gardes, mais cette fois-ci la préfence des Religieux les raflûra, \& loin de fuir à leur ordinaire, voyant les bons 


\section{DE S. Domingue, Liv. V: 327}

Peres fe faire une Fête de cette rencontre, ils prirent part à leur joye, \& parurent très-difpofés à faire aux Efpagnols, en leur confidération, tous les plaifirs, qui pourroient dépendre d'eux. Plufieurs jours fe pafferent ainfi, pendant lefquels on fe fit mutuellement bien des amitiés : enfin, le Patron du Navire invita le Cacique du lieu à venir dîner fur fon Bord : il y alla avec fa Femme \& 17 . autres Indiens, \& à peine furent-ils embarqués, que le Capitaine, qui fe tenoit tout prêt, fit appareiller, \& prit la route de l'Inle Efpagnole.

A la premiere nouvelle de cet enlevement, les Miffion- Elle retom. naires accoururent fur le Rivage, \& ils y trouverent toute la be fur les P. Bourgade dans un tranfport de colere, dont peut s'en fallut, quains. qu'ils ne fuffent fur le champ la victime; un refte d'eftime, pour leur vertu, \& de vénération pour leurs perfonnes en arrêta les premieres faillies : ces Barbares fe laifferent même perfuader par les proteftations des deux Religieux, qu'ils n'avoient eu nulle part à une fi noire trahifon, \&t qu'ils en avoient abfolument ignoré le projet; mais la vie des Serviteurs de Dieu n'étoit pas pour cela en fûreté. Sur ces entrefaites il parut un autre Navire, dont le Capitaine étant defcendu à terre, fut extrêmement touché de voir toute une Bourgade en pleurs, \& des Religieux dans une fituation à ne pouvoir pas fe répondre d'un jour de vie. Les Miflionnaires de leur côté, à qui cet Officier parut honnête homme, conçurent quelque efpérance de fortir du danger, oì ils fe trouvoient; ils lui dirent que le Ciel, l'avoit fans doute envoyé pour être leur Libérateur, qu'ils ne lui demandoient pour cela, que de vouloir bien porter une Lettre à l'Amiral. Ce Capitaine s'en chargea volontiers, \& la rendit à Dom Diegue, que le P. François de Cordouë, après avoir expofé en peu de mots le fait, conjuroit de renvoyer les Indiens chés-eux, n’y ayant que ce moyen-là de leur fauver la vie.

Effectivement, les Sauvages revenus bientôt à leur pre- I'Audienmiere fureur, ne purent être appaifés, que par l'affurance fufe de rendre 


\section{HISTOIRE}

1513. qu'on leur donna du retour de leurs Gens, dans l'efpace de jurtice aux In. quatre Lunes. Si ce terme expiré, rien ne paroiffoit, les diensqui məf-Peres confentoient d'être mis à mort. Ils avoient auffi écrit facrerent les deux Mifion. nastes. au P. Pierre de Cordouë, pour le prier de preffer la conclufion de cette importante affaire; mais toutes leurs diligences furent inutiles. Les Captifs étoient vendus, lorfque les Lettres arriverent à San-Domingo, \& l'on ajoûte même que c'étoit des Officiers de l'Audiance Royale, qui les avoient achetés. L'Amiral n'avoit point, ou très-peu d'autorité fur ces Magiftrats, \& ni la confidération de deux Religieux, dont la vie dépendoit de la délivrance des Indiens injufte. ment enlevés, ni les inftances de leurs Confreres, ni l'infâmie, dont la Nation alloit fe couvrir, ni le difcredit de la Religion; ni l'interêt public ; rien ne fut capable d'empêcher des perfonnes commifes pour rendre la Juftice à fe noircir de la plus criante iniquité, qui fut jamais. Ainfi les quatre Lunes étant expirées, fans que les Miflionnaires reçuffent aucune nouvelle; les Barbares les maffacrerent impitoyablement à la vîë l'un de l'autre.

Cependant, fi ceux-mêmes, qui par le devoir de leurs Charges, \& par la confiance, dont le Prince les honoroit, étoient plus obligés de tenir la main à l'exécution des Ordonnances, les tranfgreffoient ainfi fans honte, \& dans les points les plus effentiels; on peut juger de quelle maniere les autres fe comportoient en toute occafion à l'égard des malheureux Indiens: \& il eft vray qu'on les traittoit avec une inhumanité, qui ne fe peut imaginer. On les accouploit, comme on auroit fait des bêtes de fomme, \& après les avoir exceffivement chargés, on les contraignoit à grands coups de foüet de marcher. S'ils tomboient fous la pefanteur du fardeau, on redoubloit les coups, \& l'on ne ceffoit point de frapper, qu'ils ne fe fuffent relevés. Un Habitant un peu à fon aife ne fortoit jamais, qu'il ne fe fit porter dans une efpece de hamac par deux Indiens. On féparoit les Femmes d'avec leurs Maris; ceux-ci étoient pour La plûpart confinés dans les Mines, d'où ils ne fortoient 
DE S. DOM I GUE, L I v. V. 329

point; on occupoit celles-là à la Culture des Terres, \& dans le têms même, que les uns \& les autres étoient plus $15 \div 40$ chargés de travail, on les nourriffoit d'herbes \& de racines. Aufie rien n'étoit plus ordinaire, que de les voir expirer fous les coups, ou de pure fatigue; les Meres, dont le manque de nourriture avoit fait tarir ou corrompre le lait, tomboient mortes d'inanition \& de chagrin fur les corps de leurs Enfans morts, ou moribonds. On porta encore bientôt les chofes plus loin: quelques Infulaires, pour fe fouftraire à la tyrannie, s'étoient réfugiés dans les Montagnes, on créa un Officier, fous le nom d'Alguazil del Campo, pour donner la chaffe à ces transfuges, \& cet Officier entra en Campagne avec une meute de Chiens, qui mirent en pieces un très-grand nombre de ces miférables. Quantité d'autres, pour prévenir une Mort fi cruelle, bûrent du jus de Manioc, qui eft un poifon très préfent, ou fe pendirent à des arbres . après avoir rendu ce trifte fervice à leurs Femmes \& à leurs Enfans. Voilà quels étoient dans la pratique ordinaire ces Départemens, qu’on avoit repréfentés à la Cour, comme abfolument néceffaires pour la converfion de ces Peuples, \& que les Docteurs d'Efpagne avoient approuvés, faute d'être inftruits.

Ceux même, qui en ufoient plus modérément,travailloient Ils fe coño fort peu pour la plûpart à en faire des Chrétiens, \& plufieurs vertiffent. prétendirent qu'ils en étoient incapables. D'autres, par une raifon toute contraire, foûtinrent qu'il n'étoit pas à propos de leur apprendre des vérités, qui en leur ouvrant \& leur élevant l'efprit, les rendroient plus clair-voyants, \& moins traitables. On alla jufqu’à empêcher les Miffionnaires de leur expliquer l'Evangile; \& on fe porta dans ces occafions à des violences fcandaleufes, jufques dans les Eglifes. Il eft vrai, que ces précautions étoient affés inutiles dans le commencement : la plûpart des Infidéles, jugeant du Dieu des Chrétiens par la maniere, dont fes Adorateurs en ufoient avec eux, ne concevoient pas une idée fort avantageufe de fa bonté \& de fa fainteté. Toutefois, comme l'Evangile porte avec foi une lumiere pénétrante : fa clạrté perça enfin Tom. $I$. 
I5I4. les ténébres, que la naiffance, la prévention, la haine, les violences, \& les fcandales des Chrétiens lui oppofoient dans le coeur des Infulaires; \& on les vit avec étonnement, furtout depuis l'arrivée des Religieux de Saint Dominique, demander le Bâtême avec des empreffemens, dont on ne les croyoit pas capables. Il eft vrai que les bons exemples des Miffionnaires des deux Ordres, \& les foins, qu'ils fe donnoient pour l'inftuction, \& même pour le foulagement de ce Peuple, ne pouvoient pas manquer de produire ce bon effet; mais cela vint un peu tard. On ne comptoit plus dèslors qu'environ 14000 . Indiens dans l'Ifle Efpagnole, \& cette même année rs I 4. de nouveaux Ordres de la Cour acheverent de les réduire prefque à rien. Voici quelle en fut l'occalion.

Le Roi en- On continuoit à rendre à l'Amiral auprès du Roi tous les voye dans J'Erpagnole des Diftribu: teurs d'lsdiens. mauvais Offices, dont on pouvoit s'avifer; \& ce Prince ne paroiffoir pas toûjours également en garde contre les impreffions, qu'on vouloit lui donner; d’ailleurs le Confeil étoit fort opporé à Dom Diegue. Ce fut ce qui engagea un Gentilhomme nommé Rodrigue d'Albuquerque , parent du Docteur Zapata, Confeiller d'Etat, \& fort accrédité à la Cour , à demander qu'on créât en fa faveur l'Emploi de Diftributeur des Indiens. Il l'obtint, à condition d'agir de concert avec Paflamonté, en qui le Roi avoit une très grande confiance, \& qui étoit l'Ennemi déclaré de l’Amiral. Albuquerque muni d'un fi beau. Privilege, arriva tout triomphant à San-Domingo, \& commença par révoquer tous les Départemens åtuellement exiftants, à l'exceprion de ceux, qui avoient été accordés par le Roi même; enfuite, il ne diffimula point qu'il avoit befoin d'argent, \& l'on comprit d'abord ce qu'il vouloit dire : l'enchere fut bientôt aux Départemens, \& ils furent ajugés à ceux, qui en offrirent davantage. Voici en quels termes étoient conçuës les provifions, que donnoit ce Diftributeur. « Rodrigue d'Albuquer$\approx$ que, Diftributeur des Caciques \& des Indiens, au nom ss du Roi \& de la Reine, nos Souverains Seigneurs, en 


\section{DS. DOARG UE, LIV. V. 33 I}

* vertu des Parentes Royales, que je tiens de leurs Altefles, * de l'avis \& du confentement du Seigneur Michel de Paf$\rightarrow$ famonté, Thréforier Général en ces Inles \& Terres Fermes » pour leurs dites Altefles; je vous commets à vous, $N$. so tel Cacique avec tant d'Indiens, \& mon intention eft que \% vous vous-en ferviés pour le Labourage, pour les Mines , \& \& pour le Ménage, tout le têms de votre vie, \& d'un $x$ de vos Heritiers, Fils ou Fille, fi vous en avés; à conso dition que vous obferverés à leur égard les Ordonnances: * finon, les Indiens vous feront ôtés, \& vous aurés encore * à répondre devant Dieu de votre défobéiffance; leurs Al» teffes déchargeant leur confcience fur la vôtre : outre les $\approx$ peines, que vous encourrés, \& qui font contenuës dans les $\approx$ fufdites Ordonnances. $\infty$

D'Albuquerque étoit trop intereffé, pour ne pas commettre de grandes fautes dans l'exercice d'un pareil employ; repaffe en ES d'ailleurs il venoit de fe faire autant d'Ennemis, qu'il avoit dépoüillé de gens de leurs Départemens, en quoi confifroit tout leur bien. On écrivit donc fortement contre lui en Cour, mais bien loin que ces plaintes fuffent écoutées, Zapata obtint pour fon parent un Brevet du Roi, par lequel ce Prince approuvoit tout ce qu'il avoit fait au fujet de ces partages, \& fuppléoit en vertu de ra Puiffance Royale à tous les défauts, qui pourroient y être intervenus; défendant à quiconque de fe mêler de cette affaire. Quant à l'Amiral, il ne put digerer le dernier coup, qu'on venoit de lui porter, \& il crut fa préfence néceffaire en Efpagne, pour empêcher que fes Ennemis ne lui en portaffent encore de plus violents; il partit au grand contentement de Paffamonté, \& des autres Officiers Royaux, qui craignoient peu fes mauvais offices en Cour, \& qui étoient charmés de fe voir par fon abfence les feuls Maîtres du Gouvernement.

Vers ce même têms D. Barthélemy Colomb, Oncle de l'A. Mort de D。 miral, mourut dans l'Ifle Efpagnole, \& le Roi réünit à fon Barthélemy。 Domaine la petite Ifle Mona, dont l'Adélantade étoit Sei. 
1.513. gneur. Pour ce qui eft des 200 . Indiens, dont ce Prince la: voit gratifié, ils furent donnés à la Vice-Reine, qui étoit reftée dans les Indes. Ferdinand regretta veritablement D. Barthélemy, qu'il eftimoit; il ne l'avoit pourtant pas voulu employer dans les Découvertes, quoique perfonne n'y fût plus propre que lui. Il trouvoit déjà cette Maifon trop puiffante, \& l'Adélantade, s'il eut découvert le Mexique, étoir homme à faire fes conditions auffi bonnes, que les avoit faites l'Amiral fon frere. Le Roi lui auroit donné plus volontiers de l'employ dans fes Armées en Europe, \& D. Barthélemy s'y feroit diftingué; mais fes ombrages l'emporterent apparemment fur la confideration des fervices, qu'il pouroît tirer d'un auffi bon fujet.

Nouveau Cependant le crédit du Docteur Zapata ne put foutenir Diftributeur des Indiens, mort en arri-tenir, \& contre les gens de bien, que fon avarice fcanda. vant, \& non fans foupçon de poifon.

ISI5. peine ce nouveau Diftributeur des Indiens fut-il arrivé, bien réfolu, à ce qu'il paroiffoit, de faire fa Charge fans aucun refpect humain, qu'il mourut, non fans quelque foupçon d'avoir été empoifonné. Il paffoit pour un homme fort integre \& fans paffion; mais il s'étoit broüillé tout en arrivant avec les Officiers Royaux, parce qu'il prétendoit qu'en vertu de fes Provifions il devoit avoir part au Gouvernement. Pour éviter de pareilles conteftations à l'avenir, le Roi lui ayant donné pour Succeffeur le Licencié Lebron, il marqua au jufte jufqu'ou s'étendoient les bornes de fa Charge, \&lui recommanda expreffément de ne rien entreprendre au-delà. Quelque têms auparavant Paffamonté, qui fe croyoit peut-être coupable, \& commençoit à craindre les fuites du Voyage de l'Amiral, avoit demandé une permiffion de pafer en Efpagre. Ferdinand, qui devina fa penfée, lui écrivit de ne point s'inquietter, que fes fervices lui étoient agréables, \& qu’il n'écouteroit perfonne à fon préjudice. 
DE S. Domingue, Liv. $\mathbf{V}$.

La mortalité fut grande cette même année parmi les Infulaires, \& l'on fe crut à la veille d'en voir l'Inle Efpagnole entierement dépeuplée. Surquoi on pria le Roi de permet- Efpaanols tre qu'on y tranfportât une partie des Habitans de Cuba. diens.

Ferdinand ne jugea pas à propos d'accorder cette permiffion, ce qui fut caufe que plufieurs abandonnerent la Colonie, pour aller s'établir dans les Ines voifines \& dans le Continent. $\mathrm{Ce}$ fut apparemment pour donner le moyen de remplir ce vuide, qu'il y eut de nouvelles défenfes d'empêcher les Mariages des Efpagnols avec les Indiennes. Le but du Confeil avoit toûjours été d'unir de telle forte les deux Nations , qu'elles n'en fiffent plus qu'tune, mais ce projet n'eut pas d'abord tout le fuccès, qu'on en avoir efperé. Les Efprits étoient encore trop aigris de part \& d'autre, pour s'unir de la maniere, que le Prince le fouhaittoit : la feule paffion, à laquelle toutes les autres cedent, formoit des liaifons, qui n'avoient point d'autre nœud, que le libertinage.

Les PP. Dominiquains voyoient tous ces défordres fans y pouvoir apporter de remede, \& la continuation de la tyranD. Barthélemy de Las nie, qu'on exerçoit fur les pauvres Indiens, fans ofer mê- fle Efraguole. me s'en plaindre, mais le Licencié Barthélemy de Las Cafas ; Son carastere. qui n'avoit pas les mêmes ménagemens à garder,entra en lice contre les fauteurs des Départemens. C'étoit un homme d'une érudition fûre, d'un efprit folide, d'un naturel ardent, d'un courage, que les difficultés faifoient croître, \& d'une vertu héroïque; rien n'étoit capable de lui faire changer defentiment, quand il étoit perfuadé qu'il y alloit de la gloire de Dieu de le foutenir ; \& comme il avoit rendu à la Religion. \& à l'Etat des fervices effentiels dans l'thle de Cuba, fon crédit étoit grand dans toutes les Indes. Son feul défaut étoit d'avoir l'imagination trop vive, \& de s'en trop laifer dominer. Un homme de ce caractere ne pouvoit gueres manquer d'entrer dans les fentimens des PP. de S. Dominique, \& perfonne n'étoit plus propre à pouffer vivement cette affaire, comme il fit, fans fe laffer jamais, jufqu'à la mort. 
1515 .

Il palie en Efpagne pols y plaider la caufe des IBdiens.

Mort du Roi Ferdinand.
II ne pouvoir fe perfiader que le Roi Catholiqque eût été bien informé de toutes chofes, \& il jugea quiil étoir néceffaire de l'en bien inftruire; il paffa donc en Efpagne, arriva à Seville fur la fin de cette année is is. \& l'Archevêque Dom Diego de Deza lui ayant donné des Lettres de recommandation pour le Roi, il partit pour Placentia, où étoit la Cour. Il dit en deux mots au Prince, en lui rendant les lettres de l'Archevêque, qu'il étoit venu de l'Elpagnole uniquement pour donner avis à fon Alteffe, qu'on tenoit dans les Indes, à l'égard des naturels du pays, une conduite, qui caufoir une grande diminution de fes revenus, \& chargeoit fa confcience; que quand il lui plairoit de l'écouter plus au long, il lui en diroit d'avantage. La réponfe du Roi fut, que fes affaires ne lui permettoient pas de lui donner beaucoup de têms, mais qu'il fit fon Mémoire, \& qu'il le liroit. Au fortir de cette Audiance le Licenciéalla trouver le Pere de Matienço Dominiquain. Confeffeur du Roi, à qui il dit qu'il fçavoit que Paffamonté avoit écrit contre lui en Cour, que l'Evêque de Palencia, \& le Commandeur Lopé de Conchillos lui feroient contraires, parce qu'ils avoient dans l'Ine Efpagnole des Départemens d'Indiens, lefquels étoient les plus maltraités de tous, \& qu'il ne pouvoit compter à la Cour. que fur lui, \& fur la juftice de la caufe, quil défendoit: il lui expofa enfuite toutes les cruautés, qu’on exerçoit fur ces malheureux Infulaires, \& le conjura au nom du Seigneur de prendre la défenfe de la Religion, de la Juftice, \& de l'Innocence.

Le Confefleur rendit compte à Ferdinand de cet entretien, \& ce Prince lui dit d'avertir Las Cafas de l'aller attendre à Seville, où ill'écouteroit aufí long-têms, qu'il voudroit. Cette réponfe donna de grandes efperances au Licencié, auquel le P. de Matienço confeilla de voir l'Evêque de Palencia, \& le Commandeur Lopé de Conchillos, à qui il falloit s'attendre que le Roi communiqueroit tout ce qu'il lui diroit ; il fuivit cet avis, le Commandeur le reçut bien, \& lui fit efperer qu'il ne feroit pas contraire à fes deffeins, 
DE S. D OMING UE, LIV. V. 335 mais l'Evêque lui parla fort durenent; il fe flatta que l'Archevêque de Seville, balanceroit en fa faveur le crédit de 1516. ce Prélat, \& il partit pour fe rendre auprès du Roi. La premiere chofe quil apprit en arrivant à Seville, fut la mort de ce Prince, arrivée à Madrigalejos le 23. de Janvier I 5 I 6. il prit fur le champ le parti d'aller en Flandres, inftruire le Prince Charles de ce qui fe paffoit dans les Indes, avant qu'on eût penféà le prévenir ; mais il ne crut pas devoir faire une pareille démarche, fans en avoir eu l'agrément du Cardinal Ximenez, qui venoit d'être déclaré Régent du Royaume, il l'alla donc trouver à Madrit, il en fut bien reçı, mais fon voyage de Flandres ne fut pas approuvé. Le Cardinal lui donna plufieurs Audiances particulieres, après quoi il voulut l'entendre dans une Afremblée, où fe trouverent avec lui le Doyen de Louvain, qui fut depuis le Pape Adrien VI. Zapata, l'Evêque d'Avila \& les Docteurs Carvajal, \& Palecios Rubios.

Les mêmes perfonnes s'étant affemblées une autre fois pour déliberer fur ce que Las Cafas avoit dit, le Cardinal fe fit repréfenter les Inftructions, qui avoient été dreffées \& envoyées à l'Ifle Efpagnole en is I 2. au fujet du Voyage du P. de Montefino : puis il ordonna au Licencié de convenir avec des. Rubios d'un Reglement, où l'on menageât les interêts des Indiens, fans abandonner entierement ceux des Efpagnols. Ce n'étoit pas une chofe ailée; Rubios \& Las Cafas en vinrent néanmoins à bout, \& il ne fut plus queftion, que de trouver des fujets capables d'exécuter ce qu'ils avoient arrêté. Le Cardinal pofa d'abord pour principe qu'il n'en trouveroit, qui euffent la droiture, le défintereffement, la prudence, \& le zéle néceflaires, pour une Commiffion de cette nature, que dans l'Etar Régulier; mais parce que les PP. de S. Dominique, \& ceux de S. François avoient tô̂jours été oppofés de fentiment dıns l'affaire principale, dont il s'agiffoit ; il jugea qu'il falloit exclure ces deux Religions, comme parries intereffées, \& après y avoir penfé quelque têms, il fe détermina à choifir l'Ordre de S. Jerôme.

Le Cardinal Ximenez cherche les moyens deremedier aux des. 


\section{HIS T O I R}

I 516. Il envoye lui choifir un certain nombre de fes Sujets, aufquels il pû́c des PP. Hie- confier une affaire de confequence pour le fervice de Dieu, ronymites à I'IReEfpagnole en qualité de Commiffaires. \& pour celui du Prince, \& qui fuffent en état de fe $\operatorname{tran} f-$ porter aux Indes. Le Général fur cette lettre affembla le Chapitre de la Province de Caftille, où les intentions du Cardinal Regent ayant été expofées, on nomma 12 . Religieux, dont on lui envoya les noms par quatre Prieurs, qui Paffurrerent que fon choix dans ce nombre ne pouvoit tomber, que fur des fujets d'une prudence reconnuë, \& d'une capacité à toute épreuve. Ximenez, qui connoiffoit le Général, comme un homme d'un difcernement fûr, lui envoya Las Cafas, avec ordre de lui expofer l'état des affaires des Indes, afin que cette connoiffance le pût diriger dans le choix, dont il fe remettoit à lui, de trois perfonnes, qu'il y vouloit envoyer avec une autorité prefque abfoluë. Le Général écouta le Licencié aves plaifir , prit de lui toutes les inftructions dont il avoit befoin, \& nomma enfin pour le Voyage des Indes le P. Louis de Figueroa, Prieur de la Mejorada d'Olmedo, lequel fut déclaré Chef de la Commifion, le P. Bernardin de Manzanedo, \& le Prieur du Couvent de Seville, dont je n'ai pû trouver le nom; mais ce dernier n’ayant pas été en état de faire le Voyage, on lui fubftitua le P. Alphonfe de S. Dominique, Prieur du Couvent d'Ortega.

Reglement arrêté entre Las Cafas \& Rubios.
Cette nouvelle s'étant aunifitôt répanduë dans Madrid, \& le reglement dreffé par Las Cafas, \& par Rubios, étant devenu public, bien des gens fe récrierent contre cette conduite du Cardinal. Le reglement fe propofoit trois chofes, d'inftruire les Indiens dans la Foy, de les occuper, \& de les mettre en état de payer à la Couronne de Caftille le Tribut, qui leur avoit été impofé. Pour parvenir à ces fins, il étoit ftatué qu'on fépareroit les Infulaires des Efpagnols, qu'on en formeroit plufieurs Villages, que dans chacun de ces Villages, il y auroit un Miflionnaire, auquel on procureroit fur les Sauvages toute l'autorité, qui feroit jugée néceffaire 
DE S. Domingue, Liv. V. 337 ceffaire pour rendre fon miniftere efficace, \& fa perfonne refpectable, que l'on affigneroit à chaque Famille un héritage, qu'elle cultiveroit à fon profit, \& que le Tribut feroit taxé fuivant la nature du terrein, où le Village feroit fitué.

A cela on oppofoit, $\mathbf{I}^{\circ}$. Qu'il étoit étrange qu'on reglât une affaire de cette confequence fur le feul témoignage d'un oppofe àce homme, qui avoit à la vérité de bonnes intentions, mais dont on connoiffoit affés le zéle turbulent, \& dont l'imagination extrême groffiffoit les objets, \& lui faifoit même voir des chofes, qui n'étoient pas. $2^{\circ}$. Qu'après une expérience de tant d'années, on devoit être convaincu de l'incapacité des Indiens, pour ce qui regarde les chofes de la Religion, \& cette forte de Police, qu'on vouloit introduire parmi eux: de leur indolence, que rien ne pouvoit réveiller, de leur légereté, \& de leur inconftance, que rien n'étoit capable de fixer. $3^{\circ}$. Que quand bien même on en pourroit faire des Chrétiens, le vrai moyen d'empêcher qu'ils n'appriffent jamais rien de nos SS. Myfteres, étoit de les réünir, comme on fe propofoit de faire, dans des Villages, où Maîtres d'eux-mêmes, jamais ils ne pourroient fe gêner, ni à écouter le Miffionnaire, ni à réfifter au penchant furieux, quiles entraînoit dans toutes fortes de vices.

Le Cardinal fit affés peu d'attention à ces clameurs de Inftuctions gens, qu'il fcavoit avoir leurs raifons pour parler de la for- données aux te , il alla toûjours fon chemin, \& fit travailler aux Inftruc-res. tions des Commiffaires. La premiere fut qu'en arrivant à l'Ine Efpagnole, ils commenceroient par licencier les Indiens, qui avoient été donnés à l'Evêque de Burgos; (c'étoit Fonfeca, qui venoit encore de changer fon Eglife de Palencia, pour celle de Burgos) au Commandeur Lopé de Conchillos, à Ferdinand de Vega, \& généralement à tous ceux des Miniftres \& des Seigneurs de la Cour, qui avoient obtenu des Départemens du feu Roi Catholique. Par la feconde il leur étoit enjoint d'affembler les Efpagnols, pour leur déclarer qu'ils étoient envoyés pour examiner leur conTom. $I_{q}$ 
\$5 16. duite, dont on avoit fait de grandes plaintes, \& remédier aux abus, s'il y en avoit. La troifiéme leur ordonnoit de bien faire fentir à tout le monde que dans cette recherche, ils auroient uniquement en vûë le bien public \& celui des particuliers, puifqu'il s'agiffoit de prendre des mefures pour la confervation d'un Peuple, qui faifoit en quelque forte toute leur richefle; que pour les en convaincre ils les prioient de vouloir bien dire leur penfée fur toute cette affaire, \& qu'ils feroient charmés de trouver de concer avec eux un fyftême, qui accordât tous les interêts. La quatriéme portoit quils appelleroient enfuite les principaux $\mathrm{Ca}_{2}-$ ciques, \& leurs parleroient en cestermes. « Le Confeil des - Rois Catholiques,vous regardant comme un Peuple libre . * Sujet de leur Couronne, \& Chrétien, nous a envoyé ici * pour oüir vos griefs; ne craignés point de déclarer les w torts, qu'on vous a faits, afin qu'on y remedie, \& qu'on en puniffe les Auteurs; nous ferons auffi fort aifes d'ap» prendre de vous-mêmes ce qui fe peut faire pour votre ` foulagement; car perfuadés vous bien que leurs Altef2 fes ont à cœur vos interêts, autant que vous-mêmes, \&c 2 n'épargneront rien pour vous en donner des preuves fenw. fibles. $\cdots$ En cinquiéme lieu, les Commiffaires devoient envoyer des Religieux vifiter tous les quartiers de l'Ifle, oì il y avoit des habitations, pour y bien examiner toutes chofes, \& leur en faire un rapport fidele, furtout il leur étoir recommandé de ne rien négliger, pour fçavoir au jufte de quelle maniere on avoit traitté jufques-là les Indiens, de s'informer exactement de l'état des Mines, de voir, s'il étoit à propos de réünir les Naturels du Pays, \& d'en former des Bourgades, comme le propofoit le Licencié de Las Cafas \& au cas que ce projet leur parût convenir, de l'exécuter: de faire enforte que les Bourgades fuffent chacune de 300. Indiens, qu'elles euffent toutes une Eglife, un Hôpital, un Cacique; d'avoir foin que Ies Habitans des Bourgades éloignées des Mines s'appliquaffent aux travaux de la terre, Toit poux faire des vivres, foit pour cultiver le Cotton, le 


\section{De S. Domingue, Liv. V. 339}

Gingembre, la Caffe, l'Indigo, les Cannes de Sucre, \& les autres Plantes qui fourniffoient dès-lors à un très-grand Commerce; de regler que les Caciques commandant des Bourgades, auroient quatre fois plus de terrein, que les autres, \& que chacun de leurs Sujets feroit tenu de leur donner tous les ans quinze journées de fon travail; de nommer des Vifiteurs Royaux, dont chacun auroit infpection fur un certain nombre de Bourgades; de ftatuer qu'il ne sentreprendroit jamais rien de confiderable dans une Bourgade fans le confentement du Miffionnaire, du Cacique, \& du Vifiteur; de déclarer que ce Vifiteur feroit tốjours un Caftillan nommé par le Roi, \& que fon principal foin feroit d'empêcher quon ne fit aucun tort aux Indiens de fon diftrict; d'avertir les Caciques, qu'ils pourroient, avec l'agrément du Vifiteur \& du Miffionnaire, condamner au Foüet; mais que pour les crimes, qui mériteroient d'autres peines, la connoiffance en feroit refervée aux Juftices établies par le Roi ; d'empêcher que les Indiens n'euffent aucune forte d'armes; de ne fouffrir pas qu'ils fuffent nuds; de ne leur point permettre d'avoir plus d'une femme, ni de changer celle, qu'ils auroient une fois prife; de décerner la peine du foüet contre les adulteres; d'affigner les appointemens des Vifiteurs, partie fur le Domaine, \& partie fur les Villages de leur dépendance; ceux du Miffionnaire fur les Décimes, les Meffes \& les Offrandes, mais de leur défendre de rien recevoir, ni pour les Baptêmes, ni pour les Confeffions, ni pour les Mariages, ni pour les Enterremens, \& de tenir la main à ce qu'ils euffent tous un Sacriftain, qui apprît à lire aux Enfans, \& leur enfeignât la langue Caftillane.

Le dernier article regardoit l'Or. Les Indiens n'étant plus Réglemear fous ta puiffance des Particuliers, il s'enfuivoit qu'ils tra- Mines. vailleroient aux Mines pour leur compte, mais voici ce qui fut recommandé aux Commiffaires à ce fujet. $x^{\circ}$. Qu'ils fiffent enforte d'engager ces Infulaires à y travailler. $2^{\circ}$. Que Theure d'entrer au travail \& d'en fortir fût fixée. $3^{\circ}$. Que 


\section{HISTOIRE}

x516. perfonne $n^{2} y$ füt employé avant l'âge de vingt ans, ni après cinquante. $4^{\circ}$. Qu'il n'y eut jamais à la fois plus du tiers dư Village dans les Mines, \& que les mêmes n'y reftaffent pas audelà de deux mois de fuite. $5^{\circ}$. Que les Femmes n'y fuffent point admifes, à moins qu'elles ne s'y offriffent d'elles-mêmes, \& avec l'agrément de leurs Maris. $6^{\circ}$. Que les Mineurs gardaffent ce qu'ils auroient tiré des Mineraux , jufqu'au têms de la Fonte; qualors tout ce qui s'en trouveroit dans la Bourgade fût porté par les Mineurs, accompagnés du Vifiteur \& du Cacique, au lieu, où fe feroit la Fonte. $7^{\circ}$. Que de ce qui en proviendroit, on fît trois parts égales, dont la premiere feroit pour le Roi, \& les deux autres feroient diftribuées entre le Cacique, le Mineur, \& la Bourgade, après néanmoins qu'on en auroit tiré dequoi payer les frais de la Fonte, les outils, \& toutes les dépenfes communes. $8^{\circ}$. Que dans toute l'Ille il y êt douze Mineurs Caftillans, dont l'employ feroit de découvrir les Mines, \& de les montrer aux Indiens, à qui feuls il feroit permis d'y travailler, \& que les appointemens de ces Mineurs Généraux, fufent affîrés moitié fur le Tréfor , \& moitié fur les Indiens. $9^{\circ}$. Que ceux des Efpagnols, qui avoient, ou auroient dans la fuite des Efclaves Caraibes, pourroient les faire travailler aux Mines pour leur compte, mais à condition de payer au Roile dixiéme, s'ils étoient mariés, \&z le feptiéme, s'ils ne l'étoient pas ; \& pour leur donner moyen d'avoir des Efclaves, le Roi s'engageoit à fournir des Caravelles toutes équipées, avec défenfe fous peine de la vie de courir fux d'autres, que fur des Cannibales.

Ies Com- Il y avoit plufieurs autres Articles d'une moindre confémiflaires ont un plein pou- quence, \& l'on étoit entré fur toutes chofes dans un dévoir touchant tail infini; mais comme il pouvoit fe faire, que tout bien l'exécution de se plan. examiné, les Commiffaires ne jugeafient pas qu'il convînz de rien changer aux Départemens; on leur marqua de quelle maniere ils en devoient ufer en ce cas, pour foulager les Infulaires, moderer l'autorité de leurs Maîtres, \&' s'affûre⿻ que leur Inftuction ne feroit plus négligée, comme elle 


\section{DE S. Domingue, Liv. V. 34 T}

l'avoit été jurques-là. C'étoit le point que le Régent d'Efpagne, à l'exemple des feus Rois Catholiques Ferdinand \& Ifabelle, avoit le plus à cour, \& qu'il recommanda plus particulierement aux Commiffaires.

Cependant, comme une autorité défarmée couroit rifque de n'être pas fort refpectée, \& que le maniement des armes, l'adminiftration inmédiate des Finances, \& l'exercice de la Juftice, du moins de la criminelle, ne convenoient pas à la profeffion des Commiffaires, le Cardinal étoit fon autodonna à ces Religieux un Adjoint fous le nom d'Adminif-rité.

trateur. Ce fût le Licencié Alphonfe Zuazo, qui fut choifi pour cet Emploi, \& fon autorité ne fut bornée, que par celle des Commiflaires, parce qu'il devoit faire tout feul l'office des Auditeurs Royaux, lefquels furent interdits, pour avoir abufé de leur pouvoir. Les Provifions de Zuazo ayant été envoyées par le Cardinal à Zapata pour les figner, il refufa de le faire, difant, qu'il ne lui paroiffoit pas con* venable de donner un fi grand crédit dans les Indes à un particulier fans caractere. Le Doczeur Carvajal fut de fon fentiment, \& le Licencié, qui fe foucioit affés peu de l'Emploi , qu'on lui avoit deftiné, vouloit s'en retourner à Valladolid, d'où on l'avoit fait venir; mais le Cardinal ayant mandé Carvajal \& Zapata, leur fit une verte reprimande de ce qu'ils avoient ofé trouver à redire à fa conduite, \& leur commanda de figner. Ils obéirent, mais ce ne fut qu'après avoir pris leurs précautions, pour n'être point inquietés dans la fuite.

Barthélemy de las Cafas, avoit paru au Régent d'Efpa- Ias Cafas gne un homme trop néceffaire dans les Indes, pour qu'il Protecteur ne l'y renvoyât pas avec honneur. Il lui fit délivrer un Bre- des Indiens, vet de Protecteur Général des Indiens, avec cent pefos d'appointemens, \& il lui ordonna d'accompagner les Commiffaires, de les aider de fon crédit auprès des Naturels du Pays, \& de les inftruire de tout ce qu'il étoit important qu'ils fçûfént. Il avoit fait armer à Seville un Navire, pour les porter tous à l'Ille Efpagnole, \& il défendit de laiffe: 


\section{HIS TO I R E}

1516. partir pour les Indes qui que ce fût avant eux, de peur que, fi l'on étoit prévenu, avant leur arrivée, de ce que por. toient leurs Inftructions; on ne prit des mefures pour empêcher l'execution de fes ordres. Il profita auffi de la même occafion, pour envoyer en divers quartiers du Nouveau Monde plufieurs Religeux de S. Dominique \& de S. François; \& Herrera dit, que ces derniers étoient au nombre de 14. tous fortis des Couvens de Picardie, extrêmement eftimables pour leur Doctrine, \& pour leur vertu, \& qui avoient à leur tête un Frere du Rui d'Ecoffe, à qui la fainteté de fa vie donnoit encore plus de relief, que l'éclat d'une fi haute naiflance.

Arrivée des

Les Commiffaires mirent à la voile le jour de la Sainte Commifiaires Martin; mais Zuazo ne put être prêt pour faire le voyage aux Indes, \& leur conduite. avec eux, outre que le Navire fe trouva fi plein, qu’il fallut y en joindre un fecond, fur lequel Las Cafas s'embarqua. Ces deux Bâtimens étant arrivés à Portoric, le Protecteur Général des Indiens fouhaitta de faire le refte du Voyage fur celui, où étoient les Commiffaires; mais ces Religieux; qui fçavoient que tout l'odieux de leur Commiffion étoit tombé fur cet Eccléfiaftique, \& qui ne vouloient pas partager avec lui la haine publique, s'y oppoferent. Ils moüillerent à San-Domingo, le 20. de Decembre, \& allerent defcendre chés les PP. Francifcains, où ils ne demeurerent que trois jours. On leur demanda à voir leurs Provifions, \& ils les montrerent; alors tout le monde fe foûmit, \& ils fe tranfporterent auffi-tôt dans le Palais de l'Audiance Royale. Il commençoit pourtant à s'élever quelques murmures, fur ce que le bruit s'étoit répandu qu'ils alloient abolir les Départemens; mais ils les appaiferent promptement par un coup de vigueur, qui fit naître en même têms quelque lueur d'efperance à ceux, qui avoient des Indiens en leur pouvoir. Ils fçurent que l'auteur du bruit, dont je viens de parler, étoit l'Alcaide Tapia; ils le manderent, \& lui firent ane févere correction; peu de têms après, ils furent informés que Tapia avoit maltraitté un particulier, qu'il foup. 


\section{DE S. DOMINGUE, LIV. V. 343}

çonnoit de lui avoir attiré cet affront, fur quoi ils l'interdirent, \& le condamnerent à une amende de 10 . Pefos d'Or.

Ils firent enfuite publier, qu'il n'y avoit rien de décidé rouchant les Indiens, qu'ils alloient s'inftruire avec foin de l'état des chofes, \& ne régleroient rien qu’après une mûre l'Adminiftradélibération. Ils déclarerent néanmoins libres tous les In- teur, \& la diens, qui appartenoient aux abfens; ils avoient fur cela des tint. ordres du Cardinal, qui ne fouffroient point d'explication. Le 3. d'Avril 1517. Alphonfe Zuazo arriva, \& après avoir communiqué fes Pouvoirs aux Officiers Royaux, il commença par les citer, auffi bien que les Juges d'Appellation, à comparoître devant lui, pour rendre compte de leur conduite. Il fit la même chole à l'égard de tous les Gonverneurs, \& généralement de tous ceux, qui étoient en place, ou y avoient été ; après quoi il rendit plufieurs Sentences, aufquelles il fallut fe foúmettre, parce qu'il n'y avoit point d’appel. Il s'appliqua enfuite à régler la Police, il fit conftruire plufieurs Edifices publics, \& il paroît qu'il gouverna affés paifiblement tout le têms, que dura fon adminiftration. Il ne tarda pas même, ce femble, à rétablir l'A udiance Royale, que les Commiffaires avoient interditte en arrivant, ainfi que je l'ai remarqué plus haut.

Les chofes procédoient dans le même efprit de fermeté Les Com\& de douceur de la part des P P. Hieronymites, \& l'on miffaires ne étoit déjà tout revenu de la frayeur, qu'avoit caufée d'abord difpofés à pas rela nouvelle de leur Commiffion. Ils avoient même diftri- mettreles Inbué dans la Ville \& dans les Habitations Efpagnoles les In- té. Las Cafas diens, qu'ils avoient ôtés aux abfens, \& l'on fut entierement fe broüille convaincu qu'ils n'avoient nulle envie de toucher aux Dé aveceux \& partemens, lorfqu'on les vit s'appliquer avec beaucoup de pagne. foin à corriger les abus, qui s'y étoient gliffés. Las Cafas ne s'étoit point attendu à une conduite fi contraire à fes vûës, il fit fes repréfentations d'abord, d'une maniere affés moderée; mais voyant qu'on n'y avoit aucun égard, il éclatta. en invectives, \& en menaces. Il fit fonner bien haut fa 
qualité de Protecteur des Indiens, qu'il voyoit; difoit-il, avec douleur dans l'oppreffion, malgré les ordres précis, qu'on avoit de les en tirer. Tout ce qu'il gagna par ce procedé, auquel le contrafte de celui des Commiffaires donnoit un air d'emportement, fut de, s'attirer de telle forte tout le Monde, qu'il crut fa vie en danger, \& alla fe renfermer dans le Couvent des PP. Dominiquains. Il écriyit en Cour contre les Commiflaires, qui de leur côté écrivirent auffi contre lui , \& furent plus écoutés, de forte qu'il $y$ eut ordre de faire repaffer le Licencié en Épagne. Il l'avoit prévenu, outré de la derniere démarche des PP. de $\mathrm{S}$. Jérôme, qqui avoient enfin conclu à ne point toucher aux Départemens.

Raíons pourquoi les Commillaires se torichent point aux Dé-

Ce qui leur avoit fait prendre ce parti, étoit le danger véritable, ou prétendu, que les Indiens, rendus à eux-mêmes, ne vouluffent plus entendre parler de fe faire Chrépartemens. tiens. D'un autre côté, quantité de perfonnes, des Religieux mêmes, continuoient d'affùrer que ces Peuples étoient abfolument incapables de rien comprendre au Chriftianifme; \& foutenant qu'ils avoient à peine affés de raifon; pour être diftingués des Brutes, ils en concluoient que le feul moyen de les faire vivre en hommes, étoit de les laiffer fous le joug. On les y laiffa donc; mais à cela près; on ne peut imaginer plus d'attention, qu'en eurent les Commiffaires, à leur procurer tous les adouciffemens, dont leur captivité étoit fufceptible. Ils mirent en vigueur toutes les Ordonnances de I 512 . ils en firent de nouvelles, qui furent jugées fort fages, \& ils prirent toutes les mefures poffibles pour les faire exécuter. Mais il n'en eft point contre la cupidité, furtout contre une cupidité aveugle, qui ne penfe qu'au préfent. Les Départemens pouvoient être bons; on auroit pû même les regarder comme néceffaires dans les commencemens, que les Indiens paroiffoient véritablement bien peu hommes, fi les Reglemens de la Cour euffent été obfervés; mais ç'eût été un miracle qu'ils le fuffent: Las Cafas \& les Dominiquains avoient raifon dans le fonds de 
De S. Domingue, Liv. V. 345 $\$$ 'y oppofer, \& s'il y avoit de l'exagération dans ce qu'ils publioient des défordres, qui s'y étoient introduits, il y en avoit certainement davantage dans ce que d'autres avançoient de l'incapacité, \& du peu de jugement de ces Peuples.

Les foins des PP: de Saint Jérôme ne fe bornerent pas à la feule Inle Efpagnole; ils s'étendirent à toutes les parties du Nouveau Monde, où l'Efpagne avoit des Etabliffemens. Ils envoyerent des Miffionnaires en plufieurs endroits, \& ils confierent à des perfonnes fûres le foin d'empêcher que les Indiens ne fuffent maltraittés. Cette conduite leur gagna tous les cours dans l'Amérique; mais Las Cafas ne les ménageoit point en Cour, il ne craignit pas même de les accufer d'avoir confervé les Départemens, pour donner à plufieurs de leurs proches, qui les avoient fuivis dans les Indes, les moyens de senrichir promptement; \& cette accufation n'étoit pas fans quelque fondement. Les bons Peres avaient envoyé dans l'Ifle de Cuba quelques Particuliers, qui fe difoient de leurs parens, \& les y avoient fait pourvoir d'un bon nombre d'Indiens, que ces nouveaux venus ne traittoient pas mieux, que n'avoient fait de tout têms les autres Conceffionnaires.

D'ailleurs, diverfes difpofitions, que ces Religieux avoient été contraints de faire, en changeant les Départemens de main, avoient été funeftes aux Indiens : la Maladie s'étoit Un des Commife parmi eux. comme il ne manquoit gueres d'arriver miffaires pafen femblable occafion, \& pour comble de malheur, la pe-gne. tite Vérole acheva peu de têms après, ainfi que nous le verrons en fon lieu; de dépeupler prefque entierement les grandes Antilles; mais Las Cafas n'apprit ces nouveaux malheurs, que long-têms après : il étoit parti de San-Domingo au mois de May, \& tout en débarquant, il s'étoit mis en chemin, pour aller trouver le Cardinal Ximenés à Aranda. Il ne put le voir, parce qu'il étoit malade, \& il paffa à Valladolid, où l'on publioit que le Prince Charles fe rendroit inceffamment. Il y fut fuivi de près par le Pere de Mançanedo, un des trois Commiffaires, que les deux auTome $I$. 


\section{HISTOIR}

1517. tres avoient jugé à propos d'envoyer en Efpagne, poure ré. pondre aux accufations du Protecteur des Indiens. Le Religieux fut d'abord mieux reçu, que fon adverfaire, de tous: ceux, qui compofoient le Confeil; mais il avoit affaire à un homme, en qui le courage tenoit lieu de flegme, contre l'éloquence duquel il n'étoit pas aifé de tenir, \& qui par fa conftance venoit à bout des plus grandes difficultés.

Zas Cáas Le Licencié, avant que de partir de l'Inle Efpagnole, \& Zuazo reçoivent quelçue (avoir laifé périr à la Cóte de Cumana, les deux Peres tion de la Dominiquains, dont nous avons parlé, plûtôt que de ren-
Cour. voyer les Indiens, qu'on en avoit enlevés. Zuazo, au Tribunal duquel cette affaire avoit été intentée, paffoit pour: être fur cela dans les fentimens du Protecteur des Indiens; mais il eut défenfe de la terminer fans la participation des Commiffaires, \& il n'en fut plus parlé. Il reçut dans le même têms quelques autres mortifications de la Cour. \& les pouvoirs des PP. Hieronymites, furent confiderablement étendus aux dépens des fiens. Sur ces entrefaites on apprit que le Roi Charles étoit arrivé à Villaviciofa, que de-là, il avoit pris la route de Tordefillas, pour y vifiter la Reine fa Mere, \& que le Cardinal Ximenés étoit mort. On fçut en même têms, que les Grands de la Cour avoient repréfenté au nouveau Roi le tort, que leur avoit fait le Cardinal, en leur ôtant leurs Départemens, que les Seigneurs Flamands, qui étoient tout puiffants à la Cour, avoient demandé d'entrer en partage de cette grace, \& que le jeune Prince, qui ne voyoit pas les conféquences de ce qu'on lui propofoit, avoit accordé tout ce qu'on lui avoit demandé. Ces nouvelles allarmerent extrêmement Las Cafas, lequel, quoiqu'appuyé du crédit de $M$. de Chiévres, avoit fait inutilement de très-vives repréfentations fur cette liberalité dù Roi. Enfin il imagina un moyen, qu'il crut infaillible, de procurer du foulagement à fes chers Indiens. Il propofa d'envoyer des Negres \& des Laboureurs dans tous les lieux, où les Efpagnols avoient commencé de s'établir. Il fit goû* 


\section{De S. Domingue, Liv. V.}

rer ce projet, d'abord à M. de Chiévres, enfuite au Cardimal Adrien, puis à d'aurres Seigneurs Flamands; il paffa au mal Adrien, puis à d'autres Seigneurs Flamands; il paffa au On envoye
Confeil des Indes, qui étoit alors compofé de l'Evêque desNegres
aux Indes. de Burgos, de Fernand de Vega Grand Commandeur de Caftille, de D. Garcia de Padilla, du Licencié Zapata, de D. Pierre Martyr d'Anglerie, \& de D. Francifco de los Cobos, fans parler de M. de Chiévres, qui entroit dans toutes les affaires, \& du Doyen de Befançon, qui depuis la mort du Grand Chancelier Sauvage, arrivée depuis peu, faifoit les fonctions de cette Charge, \& étoit de tous les Confeils. Le Roi figna une Ordonnance, pour faire tranfporter quatre mille Negres aux quatre grandes Antilles: un Seigneur Flamand, Grand Maître de la Maifon de ce Prince, en obtint le Privilege, \& le vendit vingt-trois mille Ducats aux Génois, ce qui gâta tout : les Génois mirent leurs Negres à un prix extrême, \& ils en vendirent trèspeu.

Le P. de Mançanedo ne s'endormoit pas plus que Las Cafas, mais il fut moins bien fervi, \& quoiqu'il eût eu mifaires \& une Audiance favorable du Prince, il comprit bientôt que teur font rém le regne des Commiffaires étoit expiré, \& fe retira à fon voqués,

Couvent. Ia Commiffion des PP. de S. Jérôme n'avoit pas dû être fort agréable à l'Evêque de Burgos; \& ce Prélat fe retrouvant par la mort du Cardinal Ximenés à la tête des affaires des Indes, ne fut pas long-têms fans la faire révoquer; mais rien ne contribua peut-être plus à cette révocation, qu'un démêlé , furvenu entre les Commiffaires \& les Officiers Royaux, à la tête defquels étoit Paffamonté, \& voici qu'elle en fut l'occafion.

La nouvelle étant venuë à San-Domingo, que le Roi Charles d'Autriche avoit pris poffeffion de fes Royaumes I 518. d'Efpagne, Paffamonté \& les autres Créatures du feu Roi Ferdinand, qui avoient tenu les premieres places dans le Confeil de l'llle, \& dont le crédit avoit été réduit à peu de chofes, par l'arrivée des Commiffaires \& de l'Adminiftrateur crurent que le têms étoit venu de fe relever, ils s'affem. $\mathrm{X} \times \mathrm{ij}$ 


\section{HIS T O I R E}

\$5 I8. blerent portr déliberer fur le parti, qu'ils avoient à prendre, \& réfolurent d'envoyer une folemnelle députation au nouveau Roi, pour le féliciter fur fon avénement à la Couronne; mais comme ils étoient fur le point de procéder à l'Elec. tion d'un Député, ils furent affés furpris de recevoir de la parc des Commiffaires une défenfe de choifir aucun Juge, ni Officier Royal. La raifon de cette défenfe n'étoit apparemment pas celle qu'on alléguoit, à fçavoir, que le fervice du Roi ne permettoit pas à des perfonnes publiques de s'ab. fenter pour un têms fi confidérable. Ce qui eft certain c'eft qu'elle irrita étrangement ceux, à qui elle étoit faite, qu'elle ne fervit qu'à hâter l'Election, \& quele Licencié Luc Vafquez d'Aillon, un des Juges de l'Audiance Royale, fut nommé.

Zuazo ef: rappellé, \& Figueroa envoyé à fa place.

Les Commiffaires ne voulurent pourtant pas en avoir le démenti, ils prierent Zuazo de retenir ce Député , \& de lui enlever tous fes papiers : il le fit, \& par cette démarche, il attira fur foi tout le fort de l'orage; car quoique d'abord la la Cour lui eût fait juftice, \& donné abfolument le tort aux Officiers Royaux , ceux-ci firent joüier tant de refforts, qu'erfin il fut révoqué , \& le Licencié Rodrigue de Figueroa nommé pour le relever. Les Commiffaires furent en même têms rappellés; mais cette révocation n'eut point de lieu pour lors. Avant que de travailler aux Inftuctions de Figueroa, le Roi voulut avoir l'avis de fon Confeil, \& les Flamands prévenus par Las Cafas furent àavis qu'on lui donnât ordre de caffer les Départemens. Les raifons, dont ils appuyerent leurs fentimens, firent d'autant plus d'impreffion fur l'efprit du Prince, qu'ils parloient contre eux-mêmes; mais les Efpagnols opinerent fortement au contraire, \& le Roi ne fe croyant pas encore en état de porter un Jugement définitif,jugea à propos de donner à Figueroa un plein pouvoir, pour agir fuivant ce qui lui paroîtroit plus convenable,après qu'il auroit pris fur les lieux l'avis des. Gens fages \& défintereflés.

Ordres don- Las Cafas, dans une Audiance particuliere, que lui avoit nés à cet ad- donnée le Roi, s'étoit plaint à ce Prince, que fous prétexte 
DE S. Domingue, Liv. $V$.

đaller enlever des Caraibes, pour en faire des Elclaves; on enlevoit indifféremment tous les Indiens, comme s'ils miniftrateur. euffent tous été Antropophages, quoique plufieurs ne le fuf- Conduite de fent pas. Il avoit fait furtout mention de l'Ifle de la Trinité, rôme avant. dont les Habitans étoient, difoit-il, fort doux, \& qui cou- leur rappel. roit rifque d'être bientôt dépeuplée, fi fon Alteffe ne faifoit ceffer ce défordre. Charles profita de ces lumieres, \& recommanda au nouvel Adminiftrateur de tirer de captivité tous ces prétendus Cannibales. Les attentions du Prince, \& les mefures qu'il prenoit pour faire ceffer tous les abus, qui s'étoient introduits dans le Nouveau Monde, étoient le Triomphe de Las Cafas; mais la conduite, que tenoient dans les Indes les PP. de Saint Jérôme, ne lui faifoit pas moins d'honneur. Ils avoient enfin reconnu, que le Syftême de réünir les Indiens, \& d'en compofer des Bourgades, étoit non-feulement pratiquable, mais néceffaire même, fi on vouloit les conferver, \& lorfque fur la fin de I5 18. Figueroa leur porta la permiffion, qu'ils avoient demandée, de repaffer en Efpagne, ils avoient déjà formé plufieurs Bourgades fur le Plan, dont nous avons parlé plus haut. Ils avoient auffi réveillé l'affoupiffement des Efpagnols fur les Cannes de Sucre, que plufieurs fe contentoient encore de cultiver dans leurs Jardins, comme une curiofité, au lieu de donner leurs principaux foins à un objet, fi capable de faire fleurir la Colonie.

Enfin l'Ille Efpagnole commençoit par leurs foins à pren- La petice 'dre une nouvelle face, lorfqu'un accident imprévû ruina de Verole défole i belles efpérances : ce fut la petite Vérole, dont j'ai parlé Antilles. plus haut, laquelle enleva un fi grand nombre d'Infulaires dans les grandes Antilles, qu'à peine pouvoit - on croire, qu'elles euffent été autrefois peuplées. Herrera fe donne beaucoup de peine, pour prouver que cette Maladie étoit naturelle aux Peuples de l'Amérique, mais fes preuves paroiffent fort peu convainquantes. D'ailleurs, il ent certain que ce font les Européans, qui ont porté ce mal dans. les quartiers Septentrionnaux du Nouveau Monde, \& il ne l'êt. 


\section{HISTOI $\mathbb{R}$ E}

1518.

pas moins que les Infulaires des Antilles n'étoient pas plus fçavants dans l'art de le guérir, que les Sauvages du Canada \& de la Floride. Effectivement, dès qu'ils fe fentirent attaqués de ce mal, ils commencerent par s'aller jetter tous dans la Riviere, pour tempérer l'ardeur, qui les dévoroit; \& le même Herrera convient qu'il ne faut point chercher d'autre caufe de la mortalité, qui fuivit. Or, il me paroît évident que, fi la petite Vérole n'eût pas été quelque chofe de nouveau pour ces Peuples, l'expérience leur auroit appris qu'ils trouveroient la mort, où ils cherchoient du foulagement; \& que s'ils en euffent toûjours ufé comme ils firent au têms, dont je parle, ces vaftes Régions n'euffent été depuis long-têms, que de grands déferts.

Les Four- A ce trifte Fléau, qui n'étoit tombé que fur les Indiens; mis font un gât dans les ines. mais dont le contre-coup fut la ruine de notre Ifle; il en fucceda un autre, qui pour avoir eu une caufe fort legere en apparence, ne laiffa pas de produire des effets très-funeftes. Il parut tout à coup dans l'Ifle Efpagnole, \& dans celle de Portoric, une quantité fi prodigieufe de Fourmis. que la furface de la Terre en fut couverte. Celles de Portoric avoient des aiguillons, dont les picqueures caufoient une douleur plus vive que celles des Abeilles; dans l'Efpagnole elles n'avoient pas cette incommodité, mais elles y firent un dommage infini. Dans l'une \& dans l'autre on étoit contraint, quand on vouloit prendre un peu de repos, de pofer les quatre pieds du lit dans quatre grands baffins remplis d'eau. Tous les Orangers moururent dans l'Efpagnole, auffibien que les Cannes de Sucre, dont la VegaReal étoir déjà tellement remplie, qu'elle pouvoit efperer

Herrera. d'être bientôt en état, dit un Auteur Efpagnol, de fournir du Sucre à toute l'Europe, \& à toute l'Afie; mais cet Hiftorien n'a pas apparemment prétendu qu'on prít fa propofition à la lettre. La perte des Caffiers, ou Caneficiers fut encore plus confiderable. C'étoit alors le plus grand Commerce de l'Ine, \& il n'en refta pas un feul pied. On avoit beau noyer les Fourmis, dont on voyoit les arbres tout 


\section{DES. Domingue, Liv. V. $35^{\text {H }}$}

noirs, un moment après c'étoit à recommencer. On auroit dit que tous les arbres avoient paffé par le feu : quantité même fécherent par la racine, \& il eft arrivé plufieurs fois, qu'après avoir brûlé des monceaux d'œufs de ces Infectes, qu'on trouvoit dans la terre jufqu'à la hauteur de quatre palmes, le lendemain on voyoit fortir des mêmes endroits un aufi grand nombre de Fourmis, que fi l'on n'avoit rien fait.

Les P P. de Saint François firent en cette occafion une Comment expérience, qui leur réüflit, mais que tout le monde n'é- on fait moutoit apparemment pas en état de faire. Ils mirent trois ou tes. quatre livres de Mercure fublimé fur une terraffe de leur Couvent, toutes les Fourmis d'une demie lieuë à la ronde y accoururent, \& moururent dans le moment, qu'elles toucherent à cette compolition. On eut enfin recours au $\mathrm{Ciel}_{\text {, }}$ après avoir tenté toutes les autres voyes de fe délivrer d'un fi terrible Fléau; il fe fit partout des Proceffions générales, mais comme on ne pouvoit convenir du Mediateur, qu'on devoit fe choifir auprès de Dieu, pour appaifer fa colere , on le tira au fort, \& le fort tomba fur S. Saturnin : on lui fit des vœux, \& les Fourmis difparurent peu à peu. La Fête du Saint Martyr fut pendant plufieurs années célébrée avec beaucoup de folemnité dans les deux Ines, \& on y en fait encore aujourd'hui une mémoire particuliere, en reconnoiffance d'un fi grand bienfait, obtenu, à ce qu'on croit, par fon interceffion. Aux Fourmis fuccederent les Chiens, qui s'échapant des habitations, fe mirent à donner la chaffe aux Cochons fauvages. Ces Animaux avoient multipliés dans l'Inle Efpagnole d'une maniere incroyable, \& comme ils s'y nourriffoient de fruits \& de racines d'un goût trèsdélicat, leur chair étoit exquife. Les Chiens en firent périr une quantité prodigieufe, \& on eut bien de la peine à les empêcher de les détruire tout à fait.

Sur ces entrefaites, le Licencié Rodrigue de Figueroa prit Arrivée du terre à San-Domingo pour y faire l'emploi, quavoit eu niftrateur.DéZuazo. Cet Adminiftrateur étoit toújours demeuré fort uni part desPP.de S. Jerôme. 


\section{$32^{2} \quad$ HISTOIRE}

15 i8. avec les PP. de Saint Jérôme, \& comme fon infléxible é. quité lui avoit attiré de grands Ennemis à la Cour, parce qu'il avoit tenu la main à ce que les Courtifans ne rentraffent point en poffeffion des Départemens, que les Peres Commiffaires leur avoient ôtés, ceux, que la féverité de fon Gouvernement n'accommodoit pas, n'avoient eu aucune peine à le mettre mal dans l'efprit du Prince $\&$ des Miniftres. Il n'avoit pû oppofer à ces batteries, que le fuffrage des gens de biens, \& les cris des pauvres, qui ne fe font pas ordinairement entendre fort loin : auffi avoit il fuccombé, \& il vivoit en particulier à San-Domingo; mais les Peres de Saint Jérôme, à qui le Roi avoit fait dire qu'il étoit fatisfait de leurs fervices, \& qu'ils pouvoient revenir en Erpagne, quand ils voudroient, profiterent, au grand regret de tous ceux, qui vouloient le bien, des Navires, qui avoient amené Figueroa pour repaffer la Mer. Ils apprirent en débarquant, que le Roi étoit à Barcelonne, \& ils y allerent pour lui rendre compte de leur adminiftration, \& de l'état, où ils avoient laiffé les Indes. Ils fouhaittoient fort de pouvoir l'informer, que le grand mal des Colonies du Nouveau Monde, \& en particulier de l'Ifle Efpagnole, venoit du peu de fubordination, \& des partis, dont elles étoient déchirées : défordres, qui étoient fomentés par ceux mêmes, qui auroient dû y apporter remede. Ils fe plaignoient principalement du Tréforier Général Paffamonté, en qui ils prétendoient, que les efprits factieux \& inquiets trouvoient toûjours une protection fû́re contre les Superieurs; \& les Gens de bien, quand ils étoient en place, un ennemi déclaré , qui n'épargnoit pas la calomnie pour les perdre, ainfi qu'il venoit d'arriver à Zuazo, \& qui s'attachoit furtout à perfécuter tous ceux, qu'il croyoit dans les interêts de l'A miral ; dont il avoit caufé tous les chagrins. Les amis que Paffamonté avoit en Cour, fe douterent apparemment, ou découvrirent quelque chofe du deffein de ces Religieux : ce qui eft certain, c'eft qu'après avoir long-têms follicité une Audiance, fans la pouvoir obtenir, ils prirent enfin le 


\section{de S. Domingue, Liv. V. 353}

partide s'en retourner dans leurs Couvents, comme avoit fait le P. de Mançanedo leur Collegue.

Las Cafas ne lâcha point fi aifément prife, j’ai dit qu'il avoit propofé d'envoyer aux Indes des Negres \& des La- follicite l'enboureurs, \& que l'une \& l'autre propofition avoit été agréée. boureurs dans J'ai ajoûté ce qui avoit fait échoüer l'envoi des Negres: les Ifles.

celui des Laboureurs n'avoit gueres eu plus de fuccès, parce que le Licencié s'en étant fait charger lui-même, les Seigneurs de la Cour, qui ne le voyoient pas de bon oeil, s'étoient oppofés à ce que leurs Vaffaux priffent parti avec lui. Il étoit cepend̉ant venu à bout d'en lever 200. qu'il fit embarquer à Cadix; mais le Vaiffeau, qui les portoit, ayant relâché à Portoric, on les lui débaucha tous jufqu'au dernier. Quelque têms après la nouvelle de la grande mortalité des Infulaires, caurée par la petite Vérole, étant parvenuë jufqu’à lai, il fit de nouveaux efforts pour réparer cette double perte, mais il ne put fléchir l'Evêque de Burgos, qui lui dit nettement, que le Roi n'étoit point d'humeur à entrer dans des projets, où l'on ne voyoit rien de certain, que beaucoup de dépenfe. Il vit bien qu'il ne franchiroit jamais cette barriere, \& il réfolut de ne plus traitter avec ce Prélat de ce qui concernoit les Indes.

Il s'adreffa de nouveau aux Seigneurs Flamands, \& au Grand Chancelier Gatinara. Il leur dit qu'il avoit un moyen le plan d'une fûr d'établir une Colonie, qui feroit d'un grand profit pour le. Royaume, \& qu'il répondoit du fuccès, fi dans toute l'étenduë du Pays, qu'il choifiroit pour cela, on ne permettoit à perfonne de s'établir, que de fon confentement. Il ajoûta que les cruautés des Efpagnols ayant aliené tous les Indiens, il feroit prendre à ces nouveaux Colons un habit particulier, afin de faire croire aux naturels du Pays, qu'ils étoient d'une autre Nation. Cet habit devoit être blanc avec une Croix de la couleur, \& à peu de chofe près de la figure de celle de Calatrava, \& Las Cafas portoit même fes vûës jufqu'à fonder dans la fuite un Ordre Militaire, qu'il fe flattoit de faire approuver par le S. Siege, \& par le Ro: Tome $I$. 
\$519. Catholique. Ie plan détaillé, qu'il donna de ce projet à MM. de Chievres \& de Lachaux, qui étoient fes deux plus déclarés Protecteurs, portoit entre autres chofes, que dans l'efpace de mille lieuës de côtes, qu'il demandoir, il apprivoiferoit \& civiliferoit en deux années jufqu'à dix mille Indiens; que dans trois ans il leur impoferoit un Tribut de. 15000. Ducats, \& qu'en dix ans il le feroit monter à 60000 . qu'il bâtiroit trois Bourgades, dont chacune auroit fa Citadelle, \& cinquante de fes Chevaliers de Garnifon ; qu'il s'inftruirois avec foin de tous les endroits, ouil y auroit de l'Or, \& en informeroit exactement le Roi ; qu'il meneroit avec lui I2. Miffionnaires des deux Ordres, de S. Dominique \& de S. François : dix Infulaires de l'Efpagnole, \& tous les Indiens, qui de la Terre-Ferme avoient été tranfportés dans cette Ifle. Pour l'entretien de fes Chevaliers, il fe contentoit dus douxiéme de ce que le Roi retireroit du Pays, mais il demandoit que ce revenu fût continué à leur pofterité , jufqu'à la quatriéme génération, qu'ils fuffent faits Chevaliers. aux Eperons dorés, \& que toute leur race fût à jamais exem= pte de Taxes \& d'Impots; furtout il ne vouloit pas qu'on pût jamais établir des Départemens dans aucune de fes Colonies.

Entreprife Ce deffein fut fort approuvé de ceux, à qui il le comhardie de Las muniqua, ils lui confeillerent de le propofer au Confeil, Ca!as. mais M. de Chievres \& le grand Chancellier, ayant été obligés fur ces entrefaites d'aller fur les Frontieres de France, pour négocier un accommodement avec cette Couronne, \& le Confeil ne paroiffant pas écouter trop favorablement les propofitions de Las Cafas, ce Licencié perdit parience, \& prit une réfolution, où fa prudence fut moins confultée, que fon zele. Il alla trouver tous ceux, qui avoient le titre de Prédicateurs \& de Théologiens du Roi, \& en engagea huit, partie Eccléfiaftiques, \& partie Religieux Dominiquains, à aller déclarer en plein Confeil que tous ceux, qui le compofoient répondroient à Dieu de tout le mal, qui fe faifoit dans les Indes, puifqu'ils ne vouloient 


\section{DE S. Domingue, Liv. V. 355}

pas y apporter le remede, qui étoit en leur pouvoir, après toutes les repréfentations, qu'on leur avoit faites fur cela.

Le P. Michel de Salamanque porta la parole, \& ayant été admis au Confeil, il dit tout ce que le vehement Licencié lui avoit infipiré. On eut la patience de l'écouter jufqu'au bout, mais quand il eut fini, l'Evêque de Burgos le regardant d'un oil févere, lui demanda, qui l'avoit rendu fi hardi, \& depuis quand les Prédicateurs du Roi fe mêloient du gouvernement de l'Etat? Le Docteur de la Fuente répondit au Prélat, quills étoient chargés des interêts de la Maifon de Dieu, pour lefquels ils devoient toûjours être prêts à donner leur vie; qu'il n'étoit pas furprenant que des Maîtres en Théologie, qui pouvoient, fans qu'on y trouvât à redire, parler dans un Concile Général, donnafient aux Confeillers \& aux Miniftres du Roi des avis fur les fautes, qu'ils commettoient dans l'exercice de leur charge. Qu'ils venoient donc par office leur déclarer que, fi lion ne reformoit les abus, qui s"étoient introduits dans les Indes, ils monteroient en Chaire, \& diroient publiquement tout ce dont ils les avoient inutilement avertis en particulier; qu'ils ne croiroient pas s'ils y manquoient, avoir fatisfait à la plus effentielle de leurs obligations, qui étoit de prêcher l'Evangile; \& de dire la vérité au Roi, \& à fes Miniftres.

Dom Garcias de Padilla prit la parole, \& dit que le Confeil avoit dans toutes les occafions fait tout ce qu'il devoit, qu'on le pouvoir prouver par les actes mêmes, qu'on vouloit bien leur communiquer, encore que leur témérité méritât des châtimens, plûtôt qu'une telle condefcendance; mais qu'on vouloit une bonne fois leur faire fentir à eux-mêmes toute l'irrégularité de leur conduite. La Fuente répartit qu'il feroit bien de leur montrer ces pieces, qu'ils les loüeroient, fi elles étoient dignes de loüanges; mais que, fi elles n'étoient pas felon Dieu, \& la Juftice, ils leur donneroient leur malediction, auffi bien qu'à leurs Auteurs, ๙ ce - qu’à Dieu ne plaife, ajoûta-t-il, qu'il tombe fur vos Sei- 
1519. $\infty$ gneuries: $\infty$ En difant cela, il fortit avec fa Troupe. Aty bout de quelques jours, ils furent mandés au Confeil, \& on leur fit lecture de toutes les Ordonnances, qui avoient été dreffées au fujet des Indes; elle occupa tout le têms, \& ils fortirent fans rien dire. Après quelques autres jours, ils préfenterent un écrit, où après un expofé pathétique de tous les défordres, qui fe commettoient aux Indes, ils propofoient quelques moyens d'y rémedier. Leur écrit fut lû; on leur parla avec beaucoup de douceur, \& on leur affûra qu'on auroit égard à leurs bons avis.

Junte ex. Las Cafas attendit enfuite quelque têms, pour voir ce rraordinaire que produiroit une démarche d'un fi grand éclat, \& où ner la caufe des Indiens. aboutiroient les promeffes du Confeil; mais ne voyant rien paroître, il fit une nouvelle tentative auprès des Seigneurs Flamands. Ceux-ci, qui profitoient de toutes les occafions d'entrer plus avant dans le miniftere, \& qui par cette raifon étoient ravis de trouver les Miniftres Efpagnols en défaut, confeillerent au Licencié de récufer tout le Confeil des Indes, \& en particulier l'Evêque de Burgos. Il le fit, demanda au Roi une Junte, \& par le crédit de ceux, qui l'avoient pouffé à faire cette démarche, il obtint ce qu'il fouhaittoit. La Junte fut compofée de Dom Juan Manuel qui avoit été le confident du feu Roi Philippe I. Pere de Charles, de D. Alphonfe Tellez, frere du Marquis de Villena, tous deux du Confeil d'Erat, \& de celui de la guerre : du Marquis d'Aguilard, Grand Veneur \& Confeiller d'Etat : du Licencié Vargas, qui avoit été Grand Tréforier du feu Roi Catholique, du Cardinal Adrien, Grand Inquifiteur d'Efpagne, \& de tous les Seigneurs Flamands, qui entroient au Confeil d'Etat. Le plan du Protecteur des Indiens fut mis fur le Bureau, examiné avec foin, \& approuvé en fon entier,excepté que les I000. lieuës de côtes, qu'id demandoit, furent réduites à 300. depuis le Golphe de Paria, jufqu'à Sainte Marthe. C'étoit encore beaucoup pour un homme, dont les fonds \& les reffources n'alloient pas fort loin.

Il eft vrai, que cette Déliberation ne fut pas plûtôt rene 


\section{De S. Domingue, Liv. V. 357}

duë publique, qu’il s'éleva contre elle un cri général; quantité de Perfonnes nouvellement arrivées des Indes, \&r tout le Confeil récufé, en parlerent comme d'une extravagance, qui ne pouvoit être fortie, que du cerveau creux d'un Avantu- beration de la. rier ambitieux, \& fans jugement, lequel ajoûtoit-cn, feroit dépenfer au Roi bien de l'argent, \& facrifieroit à fes folles idées la vie de tous ceux, qui feroient affés mal avifés pour 1e fuivre; \& le malheur de Las Cafas fut que l'événement le condamna dans l'efprit de ceux, pour qui l'événement eft la feule regle de juger. Cependant un foulevement $f$ univerfel donna à penfer à plufieurs de ceux, qui avoient opiné en faveur du projet, \& ils demanderent qu'on en déliberât de nouveau. Mais les Flamands ayant obtenu que le Licencié fût oüi, il fẹut par fon éloquence détruire abfolument toutes les objections, qu'on lui faifoit.

Celle, qui avoit le plus arrêté les perfonnes les plus indifferentes, regardoit les avantages, que la. Couron- répond à tout ne devoit tirer de la nouvelle Colonie; on ne voyoit pas objecte, d'umême furquoi le Roi retireroit fes avances; mais ce fut ne maniere à où triompha l'éloquence du Protedeur des Indiens. Il com le monde. menca par un grand lieu commun, où il fit voir combien il importoit au. Prince que le nouvelles Colonies fuffent adminiftrées par des perfonnes, dont la probité, le défintereffement, le zele du bien public, ne puffent être révoqués en doute, \& fuffent à l'épreuve de tout : il fit voir enfuite que tous les défordres de ces fortes d'Etabliffemens, venoient uniquement du défaut de ces qualités, \& après avoir rendu cette vérité très-fenfible,il fçut appliquer de telle forte à fon fujet tout ce qu'il avoit dit de plus plaufible', qu'il ne laifia aucun doute dans l'efprit des affiftans, que s'il étoit fecondé,il n'eût un fuccès complet. Il finit par un exemple, qu'il fit valoir beaucoup au-delà de ce qu'il valoit en effet mais qu' on ne laifí pas de regarder comme une preuve fans réplique : a 11 y a fix $\infty$ ans, dit-il, que D. Pedrarias Davila commande dans la Cap * tille d'Or, le Roi depuis ce têms-là, a dépenfé 54000 . Du * cats dans cette Province, \& n'en a retiré pour fon Quine Y y iij Junte.

(1) 


\section{H I S T O I R E}

1519. \$ que 3000. Pefos; mais je fuis en état de prouver que le

»Gouverneur \& fes Officiers, en ont tiré un million d'or.

» il eft vrai quil en a couté la vie à une multitude innom» brable d'Indiens.

Il obtient tout ce qu'il fouhaite.

Cette derniere circonftance pouvoit donner lieu de répondre au Licencié que, fi les richeffes immenfes, que Pe. drarias avoit tirées de la Caftille d'Or, étoient le prix du fang de tant de malheureux, fon exemple ne prouvoit rien pour une Colonie, où l'on fe propofoit de laiffer la liberté aux Habitans naturels; mais on ne lui fit pas cette inftance, de laquelle après tout il fe feroit affés aifément débaraffé,en difant que, pour ne point réduire les Indiens en Efclavage, il ne prétendoit pas pour cela n'en retirer aucun fervice, qu'il $\mathrm{y}$ avoit plufieurs moyens de les obliger à travailler aux Mines, quand ce ne feroit que pour être en état de fatisfaire au Tribut, auquel on n'auroit aucune peine à les foumettre; qu'en les traitant bien, on les conferveroit ; qu'en veillant à ce qu'ils ne fuffent point armés, on les tiendroit toûjours dans l'obéilfance, \& que fi les profits, qu'on retireroit de leur travail, étoient moins prompts, ils feroient plus durables. Enfin la déliberation de la Junte fut confirmée, les Provifions du nouveau Gouverneur furent fignées, \& les ordres donnés pour l'armement des Vaiffeaux, qui devoient porter la nouvelle Colonie au lieu de fa deftination.

Ce qui fe paffe entre Evêque de Darien \& Las Calas.
Mais la Victoire du Protecteur des Indiens demeuroit imparfaite, tant qu'on ne ftatuoit rien pour le foulagement des Habitans naturels de l'Ifle Efpagnole, \& des autres Colonies actuellement exiftentes dans le Nouveau Monde : \& non feulement il eut encore cette confolation avant fon départ, mais ce fût même ce fecond avantage remporté fur fes Adverfaires, quilui affûra le premier, $8 x$ il dut en bonne partie ce double triomphe au crédit des Seigneurs Flamands. Voici comment la chofe arriva. D. Juan de Quevedo Francifcain, Evêque de Sainte Marie l'Ancienne du Darien, venoit d'arriver en Efpagne, \& c'étoit lui, qui avoit apporté les 3000. Pefos, que le Gouverneur de cette Provin- 


\section{De S. Domingue, Liv. V. 359}

ce envoyoir au` Roi pour fon Quint. Ce Prélat qui avoit apparemment quelque affaire au Confeil, après avoir examiné d'où venoit l'air du Bureau, s'étoit fort attaché à Las Cafas, qu'il voyoit en grande faveur auprès des Flamands, \& fort eftimé du Roi même. Un jour que le Docteur Mota Evêque de Badajoz, un des Confeillers d'Etat, qui favorifoit d'avantage le Licencié, donnoit à dîner au Prélat nouvellement arrivé de l'Amérique, Las Cafas s'y trouva auffi, avec D. Juan de Zuniga, frere du Comte de Miranda, qui fut depuis Gouverneur de Philippe II. \& l'Amiral des Indes, D. Diegue Colomb.

Après la table, le difcours tomba fur les Indes, \& Las Cafas commença par dire à l'Evêque du Darien, qu'il avoit eu grand tort de ne pas procéder par la voye des cenfures contre le Gouverneur \& fes Officiers, pour les contraindre de ceffer les vexations tyranniques, qu'ils faifoient aux Naturels du Pays. Comme le Prélat n'étoit pas en tout du fentiment du Protecteur des Indiens, la converfation ne tarda pas à s'échauffer; on difputa vivement, \& long-têms, \& l'on n'auroit pas même fini fitôt, fi l'Evêque de Badajoz n'eût été obligé de fortir, pour aller au Confeil, où il ne manqua pas de rapporter au Roi ce qui venoit de fe paffer chés lui, entre l'Evêque du Darien \& Las Cafas. Ce Prince, qui ne demandoit qu’à être inftruit, ne fut pas fâché de trouver des Perfonnes, qui puflent lui apprendre le pour \& le contre d'une chofe,qu'on ne pouvoit affés éclaircir , \& il dit à l'Evếque de Badajoz qu'il vouloit entendre les deux parties, qu'il les avertît de fe trouver au Confeil, un jour qu'il lui marqua, \& qu'il donnât le même ordre de fa. part à l'Amiral des Indes, \& à un Pere Francifcain, qui étoit arrivé depuis peu de l'Ifle Ef́pagnole à Barcelonne, où fe trouvoit la Cour. Ce Religieux gardoit encore moins de mefures, que Las Cafas, en parlant des affaires du Nouveau Monde, \& ceux, à qui la liberté de fes difcours ne plaifoit pas, l'accufoient de parler un peu par interêt, ou par ambition, pour faire fa cour aux Seigneurs Flamands, \& fe 
rşr. frayer par-là un chemin à l'Epifcopat.

LaCaufe Le jour marqué le Roi parut dans une grande Sale du desIndienseft Palais, fur un Trône fort élevé, \& avec tout l'appareil dela difcutée en Royauté. M. de Chievres, -l'Amiral Colomb, l'Evêque du Roi. Darien, \& le Licencié Aguirre, étoient affis fur un banc à fa droite; le Chancelier Gatinara, l'Evêque de Badajoz, \& plufieurs autres Confeillers d'Etat, étoient aflis fur un autre banc à fa gauche, Las Cafas \& le P. Francifquain, dont je n'ai point trouvé le nom, fe tinrent de bout contre la muraille vis-à-vis du Roi. Chacun étant placé, M. de Chievres , \& le Chancelier, montant chacun de leur côté les dégrez du Trône, fe mirent à genoux aux pieds du Roi, \& lui parlerent quelque têms tout bas, ils fe remirent enfuite à leur place, \& le Chancelier fe tournant vers l'Evêque du Darien, liai dit: Reverend Evêque, fa Majefté vous ordonne de $\infty$ dire votre fentiment, touchant la maniere, dont on doit w. traiter les Indiens, $s$ Et Herrera remarque que ce fut la premiere fois, qu'on donna le titre de Majefté au Roi d'Erpagne, \& que ce fut parce qu'il venoit de recevoir la nouvelle de fon élection à l'Empire.

Difcours de L'Evêque fe leva aufi-tôt, \& après un affés long préam'Evếque $\mathrm{d} u$ Darien.

bule fur l'honneur, qu'il avoit de parler devant un fi grand Prince, il fit entendre que les chofes, quil avoit à dire, étoient de nature à n'être communiquées-qu’au Roi \& à fon Confeil, \& qu'ainfi il fupplioit fa Majefté de vouloir bien faire fortir tous ceux, à qui il n'étoit pas à propos de faire part de chofes, qui devoient être fecrettes. Il infifta même après un fecond ordre du Roi, ajoûtant qu'il ne convenoit, ni à fon âge, ni à fon caractere, d'entrer dansaucane forte de conteftations. Enfin le grand Chancelier lui dit que tous ceux, qui étoient préfents, avoient été appellés pour être du Confeil, \& que Sa Majefté vouloit qu'il parlât ; il obéit, mais fans entrer dans aucın détail, après avoir dit qu'il y avoit cinq ans, qu'il étoit parti pour la Terre Ferme; il ajoûta que depuis ce têms-là on n'avoit rien fait, ni pour le fervice de Dieu, ni pour le fervice du Prince: 


\section{DES. DOMINGUE, Liv. V. 36 r}

Princesque lePays fe perdoit au lietr de s'établir;que le premier Gouverneur, qu'il y avoit vû,étoir un méchant homme, que le fecond étoir encore pire, \& que tout alloit fi mal, qu'il s'étoit cru dans l'obligation de paffer en Efpagne, pouren informer fa Majefté. Puis venant au fait, fur lequel on avoit demandé fon avis; il dit que tous les. Indiens, qu'il avoit vûs, foit dans les Pays d'où il venoit, foit dans tous ceux où il avoit paffé, lui avoient paru nés pour la fervitude, qu'ils étoient naturellement pervers, \& que fon fentiment étoir qu'on ne les abandonnât pas à eux-mêmes, mais qu'on les divifat par bandes, \& qu'on les mit fous la difcipline des plus vertueux Efpagnols : fans quoi on travailleroit envain à en faire des hommes, \& on ne viendroit jamais à bout d'en faire des Chrétiens. Quand il eut ceffé de parler, Las Cafas reçut ordre de répondre, \& il le fir en ces termes.

* SIRE, je fuis un des premiers Caftillans, qui ayent

- paffé dans le Nouveau Monde; j’ai vû toutes les differen-

Réponfe de

* tes conduites, qu'on y a tenuès avec les Naturels du Pays

2. je n'aurois jamais fini, \& j'abuferois de l'honneur, que

" me fait V. M. fi j'entrois dans le détail des horreurs ,

\$ dont j’ai été témoin, ou que j’ai apprifes de perfonnes fû-

- res. Je m’en fuis déjà expliqué plus d'une fois au Con-

» feil, \& à V. M. même, qui n'aura pas oublié ce que j'ai

* pris la liberté de lui dire; mais je croirois trahir la caufe

* de l'innocence, fi je laifiois fans réplique devant une fi

* augufte afiemblée, ce qui vient d'être avancé par l'llluf-

- triffime Evêque de Terre Ferme. En premier lieu, ce Pré-

- lat ne peut parler que des Habitans de fa Province, \&

- n'y auroit-il pas de l'injuftice à juger de tous ces Peuples par

- un feul ? Secondement il reproche aux Indiens leurs vi-

» ces, \& je m'affure que, s'il y veut faire un peu réflexion,

» il conviendra qu'ils n'en ont gueres, qu'ils n'ayent pris

- des Chrétiens, \& que dans ceux mêmes, que les Chré-

- tiens ont pris d'eux, ils les y ont bientôt furpafrés d'une

* maniere fenfible. Peut-il en effet nier que l'orgeüil, l'aTom. $I_{0}$ 


\section{HISTOIRE}

I.519. varice, lambition, le blafphême, les trahifons, \& quan» tité de Monftres femblables, n’ont point encore gagné

» ces Infideles, 'qu'ils n'en ont pas même l'idée , \& que

» tout l'avantage, que nous pouvons nous flatter d'avoir fur

* eux, fe réduit à un peu plus d'ouverrure $\&$ de culture d'ef-

» prit \& d'élevation dans les fentimens? Avantages, qui

- Font bien remplacés dans ces Peuples par une grande

p. fimplicité , une douceur inalterable, \& beaucoup de

?) bonne foy. Ils ne font pas, dit-on, capables de fe con-

o duire ; \& comment done fe font-ils fi long-têms main-

a. tenus fotis le gouvernement de leurs Caciques? qui les

* a jufqu'ici préfervés de ces guerres inteftines, dont les

- Etats de la Chrétienté les plus floriffants, \& les mieux

* reglés ont été \& font encore fi fouvent déchirés? Mais

- enfin fuppofons ce quil faudroit commencer par prouver.

^ qu'ils ont befoin de Tuteurs; où les trouver ces Tuteurs?

- parmi les Efpagnols? \& comment en ont ils été traités

- jufqu’à préfent? ne feroit-ce pas confier aux Loups la

- garde desAgneaux? tous les coins \& les recoins duNouveau

- Monde, retentiffent des cris de ces malheureux, qui gé-

w miffent fous une tyrannie, dont celle des Denys \& des

2Phalaris n'étoit que l'ombre. Ils font nés pour l'efclavage:

*. \& depuis la naiffance du Monde ils ont été les moins Efcla-

» ves de tous les Hommes, fans interêt \& fans paffion.

w Ne flattons point notre cupidité, ne nous aveuglons point

w fur notre condition; toutes les Nations font également

„libres, \& il n'eft permis à aucune d'entreprendre fur la

- liberté des autres; ufons-en à leur égard, comme nous

๖. aurions voulu qu'ils en euffent ufé avec nous, s'ils avoien

m paru fur nos Rivages, avec la même fuperiorité de for-

- ces, que nous avions fur eux, quand nous les avons

\$ découverts. Et pourquoi tout ne feroit-il pas égal de part

» \& d'autre? depuis quand le droit du plus fort a t-il préo

¿ valu \& prefcrit contre celui de la Juftice? par quel Aro

æo. ticle du Chriftianifme eft-il autorifé ?

2. Mais qu'aurions nous à dire, fi ces Peuples, trouvant 


\section{De S. Domingue, Liv. V. $3 \sigma_{3}$}

क une occafion de nous rendre tout le mal, que nous leur s avons fait, ils fe mettoient en devoir d'en profiter ? car ento fin au droit de repréfailles ils joindroient celui, que donne * la néceflité de fe précautionner pour l'avenir. Rien de fem» blable n'a autorifée, \& rien n'autorifera jamais au Tribunal » de la Pofterité les concuffions, les fourberies, les vio* lences, les rapines, les cruautés, par le moyen defquel๖ les nous fommes déià venus à bout d'exterminer des Peuœ ples fans nombre. Ce font pourtant des Chrétiens, que s je mets ici en parallelle avec des Idolâtres; \& ce qu'il 2. y a encore de plus étonnant, c'eft que tous les crimes, w dont je viens de parler, font colorés du fpecieux prétexw te de zele. Mais dans quel Pays du Monde les Apôtres » \& les Hommes Apoftoliques ont-ils jamais crú avoir droit „ fur la vie, fur les biens, \& fur la liberté des Infidel„ les? quelle étrange maniere de prêcher l'Evangile, cet» te loy de grace \& de fainteté, qui d'Efclaves du Démon, - nous fait pafier à la liberté des vrais enfans de Dieu, que de réduire en captivité ceux, qui font nés libres, de » déchirer à coups de Foüet des Innocents, dont tout le s crime, par rapport à nous, eft de ne pouvoir fupporter - les travaux, dont nous les accablons; d'innonder leur Pays эs d'un déluge de fang; de leur enlever jufqu’au néceffai- re, \& de les fcandalifer par les plus honteux excès ! Voi- la, SIRE, ce qu'on cache à votre Majefté, voila ce que ๖ j’ai vû, \& furquoi je ne crains point d'être démenti. Ju* gés à prefent la caúfe des Indiens felon votre fageffe, vos tre équité, votre Religion, \& je m’aftùre qu'ils foufcris ront fans peine à votre Arrêt.

Las Cafas ayant fini fon difcours, le P. Francifquain eut ordre de dire fon fentiment, il obéit, \& commença par affûrer, qu’ayant été chargé par deux fois de faire le dénombrement des Infulaires de l'Efpagnole, il en avoit trouvé au fecond plufieurs milliers de moins quau premier; que la diminution devenoit de jour en jour plus fenfible, \& que par rapport à cette Inle le mal, auquel on cherchoir un reZ z ij

Difcours d'un P. Frans cifquain. 


\section{HIs Tor I E}

I519, mede, paroiffoit incurable. Il dit enfuite qu'il craignoit bien que la mefure des crimes des Efpagnols, ne fût à fon comble dans les Indes, \& que Dieu ne les exterminât de ces nouvelles Conquêtes, qu'ils avoient prefque entierement dépeuplées, fans aucune raifon, \& contreleurs plus vérita. bles interêts. $\propto$ Car enfin, continua t'il , lorfque Dieu dit à * Caïn : Voici le fang de votre frere Abel, qui crie vers moi s de la terre, il ne s'agiffoit que d'un homme; \& fera-t'il fourd, * ce même Dieu, aux cris,qu'élevent vers le Ciel ces déluges

s de fang, dont tant de vaftes Provinces font encore teintes ? - SIRE, par les playes adorables du Sauveur des Hommes, \& ^ \& par les facrés Stigmates de mon Pere S. François, je vous w conjure de mettre fin à une tyrannie, dont la continuation w ne pouroit manquer d'attirer fur votre Couronne tout w le poids de l'indignation du Souverain Seigneur des Rois a de la terre.

Sentiment L'Amiral des Indes fut le dernier de tous, dont on dede l'Amiral. manda l'avis, \& il le donna en peu de mots. Il dit qu'il n’avoit jamais approuvé les Départemens : \& il ajoûta que, fi l'on ne fe preffoit de remedier aux défordres, dont le $\mathrm{Li}$ cencié \& le Francifquain venoient de parler, \& qui n'étoient que trop réels; les Indes ne feroient plus bientôt qu'un vafte défert : que c'étoit en partie pour repréfenter tout cela au fẽu Roi Catholique, qu'il étoit venu en Efpagne, \& qu'i! pouvoit affurer fa Majefté que cette affaire étoit une des plus importantes, qu'elle eut à terminer, \& une de celles, qui intereffoient autant fa gloire \& fa confcience.

On ne con- L'Evêque du Darien fe leva alors, \& demanda la perclut rien, \& miffion de parler de nouveau; mais le Chancelier lui dit pourguoi. que, s'il avoit quelque chofe à repliquer à ce qui venoit d'être expofé, il le mît par écrit, \& que le Roi y feroit toute lattention, que la chofe mériteroit. Ce Prélat fit deux mémoriaux, qui ne concernoient que la Province du Darien: quand il les eut achevés, il envoya demander à dîner au Chancelier, à qui il étoit bien aife de les communiquer en particulier; \& celui-ci fit prier M. de Lachaux 


\section{DE S. D Om InGUE, LIV. V. 365}

de s'y trouver, parce que ce Seigneur avoit été mis par Las Cafas au fait de ces affaires. Pendant le repas, on demanda à l'Evêque ce qu'il penfoit de l'entreprife du Licencié, \& il répondit, qu'il l'approuvoit fort. On pouvoit douter qu'il parlât bien fincerement, parce qu'il fça voit qu'il faifoit fa cour en parlant ainfi. Fort peu de têms après, une fiévre maligne l'emporta en trois jours, \& il ne fe parla plus des Indes. Charles étoit fur fon départ, pour aller recevoir la Couronne de l'Empire, \& fa Flotte l'attendoit à la Corogne. D'ailleurs, il ne voyoit pas encore bien clair dans cette affaire, \& il s'étoit apperçu que la picque \& la jaloufie entroient pour quelque chofe dans la protection déclarée, que fon Chancelier \& les Flamands donnoient à Las Cafas. Il ne voulut donc rien conclure, qu'il n'eût reçî́ des Informations moins fufpectes, \& qu'il n'eût eu le loifir de réfléchir plus qu'il n'étoit alors en état de faire fur une matiere, dont il commençoit à comprendre toute la diff. culté \& toute l'importance.

Tandis que ces chofes fe paffoient en Efpagne, on fit la découverte del'Yucatan \& du Mexique, \& ce grand évenement, en attirant l'attention de toutes les Indes, \& bientôt après une bonne partie de celle de la Cour d'Efpagne, porterent à l'Ine Efpagnole un coup mortel, dont elle ne s'eft jamais relevée. J'ai dit, en parlant du dernier Voyage de Chriftophle Colomb, que cet Amiral s'étoit avancé fort près de l'Yucatan, \& que de fatix avis l'avoient empêché de continuer faroute de ce côté-là. La découverte, qưil fic enfuite de la Province de Veragua, où il trouva de l'or; \& celle, que fit quelques années après Jean Ponce de Leon de la Floride, furent apparemment caufe qu'on ne fongea pas fi-tôt à reprendre cette navigation. Enfin vers le commencement de l'année i 5 17.0u fur la fin de la précédente. L'Etat floriffant, où étoit l'llle de Cuba fous le Gouvernement de Velafquez, y ayant attiré une bonne partie de tout ce qu'il y avoit de plus confidérable dans les Indes; ce Gouverneur ne voulut pas perdre une fi favora- 


\section{H I S T O I R E}

I sr6. ble occafion de s'étendre, en conquérant de nouvelles Pro-

| vinces, qui augmentaffent fon Gouvernement, ou de fe

Is 9. fortifier dans fon Inle, en la rempliffant d'Efclaves, qui miffent les Habitans en état de s'enrichir par la culture des Terres.

Velafquez Il propofa donc une expedition fur quelque endroit de s'y rend indé- la Terre Ferme, où l'on n'eût pas encore été, dans le deffein pendant de l'Amiral. d'y faire un établiffement, fi le Pays en valloit la peine. ou d'enlever des Indiens, s'ils étoient Cannibales, ou du moins d'y traitter de l'or, s'il s'y en trouvoit. Quelques Mémoires affûrent, qu'avant que de faire cette entreprife, il en demanda la permiffion à l'Amiral $\mathrm{D}$. Diegue, dont au fonds il n'étoit que le Lieutenant; mais il y a bien de l'apparence qu'ils fe trompent. D. Diegue étoit en Efpagne depuis trois ans, \& il s'en falloit beaucoup que Velafquez fût demeuré dans la fubordination, où il devoit être à l'égard de fon Général, à qui il avoit obligation de la place, qu'il occupoit. Il s'étoit rendu fort indépendant dans fon Ine, \& nous apprenons d'Oviedo que ce qui l'avoit 'engagé, ou l'enhardiffoit à tenir cette conduite avec l'A miral, étoit la protection du Tréforier Général Michel de Paffamonté ; fes amis obtinrent même pour lui des provifions de Gouverneur abfolu, \& indépendant; mais l'Amiral eut le crédit de les faire révoquer, \& tout ce que les Protęteurs de Velafquez purent faire en fa faveur, ce fut une Declaration du Roy, qui ôtoit à $\mathrm{D}$. Diegue le pouvoir de le rappeller, comme il avoit toûjours été en droit de le faire: mais qui ne lui donnoit point droit de fe fouftraire à fon autorité.

Cependant ce qu'avoit prévû le Gouverneur de Cuba, ne manqua pas d'arriver. Plufieurs perfonnes aifées, des Matelots \& des Soldats en grand nombre s'offrirent à lui, \& un des plus confidérables Habitans de Cuba, nommé François Fernandez de Cordouë, s'engagea à faire une bonne partie des frais de l'entreprife, bien entendu que la conduite lui en feroit confiée. Velafquez accepta fon offre, fit armer à Sant-Yago, Capitale de Cuba,deux Navires \& un Brigan- 


\section{DE S. Domingue, Liv. V. 367}

tin, fur lefquels il embarqua i ro. Soldats, \& Fernandez ayant mis à la voile, alla achever de s'équipper à la $\mathrm{Ha}$ vane, d'où il fortit le 8 . de Fevrier. Dès qu'il eut doublé

1517

I519. le Cap Saint-Antoine, qui eft l'extrêmité Occidentale de l'Ine de Cuba, fon premier Pilote, nommé Antoine de Alaminos, fut d'avis de tirer droit à l'Oueft, apportant pour raifon que l'ancien Amiral, fous lequel il avoit fervi fort jeune, avoit toûjours témoigné une grande envie de naviguer de ce côté-là. Il n'en fallut pas davantage pour déterminer Fernandez, qui n'avoit point encore pris de parti fur la route, qu'il devoit tenir, \& après trois femaines d'une rude \& périlleufe navigation, il apperçut la Terre.

L'ayant approchée d'aflés près, il remarqua une grande Bourgade, qui paroiffoit éloignée de la Mer d'environ devix te de l'Yucalieuës. Toute cette Côte étoit fort peuplée, \& le rivage fut Cap de Cutoen un moment couvert d'Indiens, qui fembloient charmés che.

de voir les Efpagnols. Ce n'étoit pourtant qu'une feinte, les premiers Caftillans, qui débarquerent, furent vigoureufement attaqués dans le têms, qu'ils croyoient pouvoir comprer davantage fur l'amitié de ces Barbares, \& il y en eut 15. de bleffés. Ces Peuples r'étoient point nuds, comme la plûpart de ceux, qu'on avoit découverts jufques-là , \& ils étoient affés bien armés : leurs armes défenfives étoient le Bouclier, \& une efpece de Cuiraffe doublée de Cotton: les offenfives étoient l'Arc \& la Fléche, des Epées, ou plûtôt des Coûteaux de pierre, une maniere de Lance, \& la Fronde. D'ailleurs, ils fe battirent bien, \& avec ordre. Tout auprès de l'endroit, où fe paffa cette action, il y avoit quelques Edifices de Maçonnerie, \& entr'autres des Tem. ples, où l'on trouva quantité d'Idoles de Terre cuitte, dont les unes avoient à peu près la figure, que nous donnons aux Démons; d'autres celle de Femmes: \& toutes, quelque chofe de monftrueux. On y voyoit aufi repréfenté à.découvert l'infàme péché de Sodôme. Cet endroit fut appellé la pointe, ou le cap de Cotoche. Un Ecclefiaftique nommé Alphonfe Gonzalés, qui étoit apparemment le Chapelain 


\section{H I S T O I R E}

rsi7. du Général, ou un des Aumôniers de l'Armée, entra pen-

17. dant le combat dans quelques - uns de ces Temples, \& en

rfig. enleva de petits coffres, dans lefquels il y avoit des Idoles de Terre \& de Bois, avec des efpeces de Médailles d'un affés mauvais or, des Bagues, des Pendans-d'Oreilles, \& des Couronnes de même métal. L'agilité avec laquelle les Indiens fe retirerent, empêcha qu'on ne fìt d'autres Prifonniers, que deux jeunes gens, qui furent infruits \& bâtifés. L'un fut nommé Julien, \& l'autre Melchior, \& on s'en 1ervit utilement dans la fuite en qualité d'Interpretes.

Ce quife Fernandez fort content de certe Découverte fit rembarpaffe à Cam- quer tout fon Monde, \& continuant de cottoyer le Rivage, peche. il arriva à la vûë d'une groffe Bourgade, que les Gens du Pays nommoient Kimpech, \& où l'on a depuis bâti la V.l'e de Campeche. Ce qui le furprit davantage, c'eft que dans une fi grande étenduë de côte, il n'apperçut pas une feule Riviere. Nos Cartes ne laiffent pourtant pas d'en marquer quelques unes, entre la pointe de Cotoche \& Campeche; mais il eft vrai de dire, qu'il y a peu de Pays moins arrofé que celui-là, \& l'on n'y boit ordinairement que de l'eau de Puits, qui eft, dit-on, excellente. Les Efpagnols en firent en cet endroit; \& comme ils fongeoient à fe rembarquer, une Troupe de so. Indiens vêtus de camifoles $\&$ de mantes de cotton, s'approcherent d'eux, \& leur demanderent par fignes, s'ils ne venoient pas des Pays, d'où le Soleil fe leve, \& les inviterent à venir dans leur Bourgade. Ce qui leur étoit arrivé à Cotoche, leur rendit cette invitation fufpecte, \& ils fe contenterent dentrer dans quelques Temples, qui n'étoient pas loin de-là, \& dans lefquels, outre les choles, qu'ils avoient trouvés dans les premiers qu'ils avoient vû, ils apperçurent des traces de fang toutes frấches, \& des croix peintes fur les murailles. Comme on les avoit vû enter dans ces Temples, ils y furent bientôt environnés d'une grande multitude de Gens de tout âge \& $\&$ de tout fexe, qui paroiffoient extrêmement furpris de leur figure. Quelques momens après il parut comme deux 


\section{DE S. DOMINGUE, LIV. V.}

Ef́cadrons, qui marchoient en bon ordre, \& venoient à eux armés de la même maniere, que ceux de Cotoche. Dans le même moment il fortit d'un Temple environ dix Prêtres, vêtus de mantes blanches fort larges, ayant une chevelure affés épaiffe, \& très-mal en ordre; ils portoient à la main des Réchauds de Terre pleins de Feu, où ils jettoient une forte de Gomme, qu'ils nomment Copal, \& ils en faifoient aller la fumée du côté des Efpagnols, en leur difant de fe retirer de leur Pays, parce qu'ils craignoient qu'ils ne les fiffent mourir.

Cette cérémonie étoit à peine finie, qu'on entendit plu- Et à Potosfieurs Inftrumens de guerre, qui fonnoient la charge. Alors les chan.

Caftillans, qui ne fe fentoient pas afiés forts pour réfifter à un Peuple furieux, dont le nombre feul auroit pû les accabler, fe rapprocherent de la Mer toûjours en bataille, \& furent affés heureux pour fe rembarquer, fans avoir perdu un feul homme. Ils naviguerent encore fix jours faifant le Sud, \& après avoir effuyé un coup de Vent, qui les mit à deux doits du naufrage; ils allerent faire de l'eau dans une Anfe, où il y avoit une Bourgade, que les Habitans nommoient Potonchan. Il y eut là un grand combat, où 40. Efpagnols refterent fur la place, \& tous les autres furent bleffés, à l'exception d'un feul. Fernandez, qui s'expofa beaucoup, y fut percé de 12. Fléches, \& non pas de 33. comme l'a écrit Gomara. Antoine de Solis fe trompe encore davantage, quand il affûre que ce Général y fut tué. Il fallut enfin céder à la multitude, \& abandonner les Morts. Les Bleffés eurent bien de la peine à regagner leurs Chaloupes, \& l'on fe trouva encore bien plus embaraffé, quand il fallut faire la manœuvre.

Dans une conjoncture fi trifte, il n'y avoit point d'autre Retour de parti à prendre, que de s'en retourner à l'Inle de Cuba, Fernandez à mais je ne fçai ce qui détermina Fernandez, ou les Pilotes, à tourner vers la Floride : peut-être y furent-ils forcés par les Vents \& les Courans. En effet, ils eurent le têms fi favorable, que le quatriéme jour ils apperçurent la Terre. 
I5 1 7. Fernandez y débarqua avec fon premier Pilote, \& 22. hom| mes de ceux, qui étoient les moins bleffés. Alaminos ne fut

I.519. pas plûtôt fur le rivage, qu'il fe fouvint davoir été là avec Jean Ponce de Leon, \& il ajoûta qu'il y falloit être extrêmement fur fes gardes. Fernandez profita de cet avis, \& comme il avoit befoin d'eau, \& qu'il falloit laver beaucoup de linges; il y fit travailler inceffamment, après avoir pofté des fentinelles à toutes les avenuës du Bois. Cette précaution fervit de peu, au bout d'une heure les fentinelles eurent à peine le têms de donner l'allarme, qu'une armée de Barbares tomba fur les Efpagnols. Le Pilote Aldminos fut bleffé à la gorge; le feul Soldat, qui n'avoit point été bleffé à Potonchan, \& qui étoit à la garde la plus avancée, fut enlevé , \& ne parut plus, \& l'on dut regarder comme une efpece de miracle, que tous les autres n'y périrent pas. Ils furent pourfuivis jufqu'à leurs Navires, que plufieurs furent contraints de gagner à la nage, \& Fernandez ayant mis fur le champ à la voile, il arriva en deux fois 24 . heures aux Martyrs; un des deux Navires y toucha rudement, \& s'ouvrit, ce qui ne l'empêcha pas de continuer fa route avec les autres, \&de gagner la Havane, d'où Fernandez fe rendi à la Ville di Saint-Efprit, lieu de fa réfidence ordinaire. Il écrivit de là au Gouverneur de Cuba que, fi-tôt qu'il fe porteroit bien, il iroit à Sant-Yago, pour lui rendre compte de fon Voyage; mais il mourut au bout de ro. jours. Les deuss jeunes Indiens, qu’il avoit amenés avec lui de la pointe de Cotoche, l'avoient affuré qu'il y avoit de l'or dans leur Pays : fur ce témoignage, qui te trouva faux, on exaggera fort le fuccès dune expedition, qui dans le vrai avoit abouti à très-peu de chofe, \& avoit été funefte à tous ceux, qui y avoient eu part.

Telle fur la premiere Découverte de l'Yucatan: quelques Modernes difent Jucatan; mais ils ne font point encore une pour contiautorité fuffifante, pour contre-balancer celle des Ecrivains muer les Dé- de toutes les Nations, qui continuent à écrire \& à pronon-
couvertes. cer Zucatan. On n'eft pas trop daccord fur l'origine de ce 
nom, \& il y a bien de l'apparence, qu'il a été formé de quelques termes de la Langue du Pays, qu’on aura pris d'abord pour le nom de quelques Chefs, ou de quelque Bourgade, ou même de toute la Contrée. Quoiqu'il en foit , Velafquez parut fort content, \& réfolut de n'en pas demeurer là. Il arma en diligence trois Navires \& un Brigantin, fur lefquels il mit 250. Ef́pagnols, \& quelques Infulaires de Cuba pour les fervir. Les trois Navires étoient commandés par trois Capitaines de nom \& d'experience, ils fe nommoient Pierre d'Alvarado, François de Montejo , \& Alphonfe Davila; \& il chargea de cette expedition, J'homme du monde, qui en étoit le plus capable. Il fe nommoir Jean de Grijalva, \& il étoit, non pas le parent de Velafquez, comme l'a écrit Gomara, qui a été fuivi par Solis , mais feulement fon Compatriote, l'un \& l'autre étant natifs de Cuellar. Oviedo affüre qu'il y eut jufqu’à 40 . Gentilshommes, qui prirent parti avec lui ; mais le même Gomara, dont je viens de parler, fe trompe encore, quand il dit que dans fes Inftructions il étoit marqué expreffément que, s'il trouvoit l'occafion de faire un Etabliffement en Terre Ferme, il ne la manquât point. A la vérité, cet Auteur, que la plûpart des Ecrivains de fa Nation ne citent gueres, que pour le refuter, n'a parlé en cela qu'après Bernard Diaz de Caftillo, qui avoit accompagné Fernandez dans la Découverte de l'Yucatan, qui fut du Voyage de Grijalva, \& qui fuivit Cortez à la Conquête du Mexique; mais Herrera ne balance pas à fuivre le fentiment contraire, fur l'autorité de Barthélemy de Las Cafas, qui a long-têms vêcu familierement avec Velafquez \& Grijalva , \& qui affüre que ce dernier avoit une défenfe expreffe de faire aucun Etabliffement.

Cette défenfe eut de grandes fuites, mais elle fut encore Caractere plus funefte à Velafquez, qu’à Grijalva. Si elle a privé celui- de Grijalva. ci de la Gloire d'être le Conquérant du Mexique, elle ne lui a pas ôté celle d'en être eftimé très-capable, \& a fait regretter qu'il ne l'ait pas été. Effectivement, du caractere A a a ij

$15 \times 7$
15190 
I518. dont tous les Hiftoriens s'accordent à nous repréfenter ce I Capitaine, il eut infailliblement fait la Conquête des Pays,

\$519. qu'il a découvert, fi on ne l'eut arrêté, \& il n'y eut pas rendu le nom Efpagnol odieux: fa Victoire n'eut été deshonorée par aucun crime, \& vrai-femblablement, il ne fe feroit jamais oublié qu'il étoit, ni ne fe feroit laffé d'être le Lieutenant de Velafquez. A toute la valeur \& la conduite qu'on peut défirer dans le Chef d'une Entreprife de cette nature, il joignoit un naturel aimable, de la douceur, des mours, de la probité, beaucoup de Religion; mais furtout une modeftie \& une foûmiffion aux ordres de fes Superieurs, qu'on eut admirée, dit Las Cafas, dans un Religieux; il ne fe croyoit point permis de paffer fes pouvoirs dans le moindre de leurs Articles, \& nous verrons qu'il fut la victime de fon obéiffance. Mais pour châtier les crimes des Mexir quains, lefquels crioient vengeance au Ciel, il falloit une Verge de Fer, \& les vertus de Grijalva n'étoient pas des inftrumens propres à feconder en cela le couroux d'un Dieu irrité, qui avoit trop long-têms fufpendu fon bras. D'un autre côté, Velafquez s'étoit par de mauvaifes voyes fouftrait à l'o. béiffance de l'Amiral fon Bienfaiteur, \& la Providence ménagea tellement toutes chofes, qu'il fut traitté de la même maniere par celui, qu'il fubftitua imprudemment à Grijalva.

Son départ. Cependant tout étant prêt pour le départ, l'Efcadre fortit du Port Sant-Yago le 8. a'Avril I 5 I8. felon Herrera, qui a été fuivi par Solis; ou, fi l'on en croit Oviedo, le 25. Janvier. On pourroit néanmoins concilier, ou du moins rapprocher ces deux fentimens. En effet, Oviedo, qui ef entré dans un très-grand détail des circonftances de cette expedition, ajoûte que Grijalva, au fortir de Sant-Yago, alla moüiller l'ancre à Boiucar, qui n'en eft pas loin, pour y prendre quatre hommes fort experimentés dans la navigation; que le I2. de Fevrier, il entra dans la Baye de Matance, oì il fe fournit de vivres : qu'y ayant fait la re. vâë de fes Troupes, il fe trouva I 34 . Hommes de débas: 


\section{De S. Domingue, Liv. V. 373}

quement. Que quantité de volontaires l'y vinrent joindre de tous les quartiers de l'Ifle, qu'il refta là deux mois, au bout defquels, ayant fait une feconde revûë, il compta 200. Hommes, fans y comprendre les Equipages de fes Navires, dont le nombre étoit augmenté d'une Caravelle; qu'il fortit de la Baye de Matancele 20. d'Avril, \& qu'il fut 10 . jours à gagner le Cap Saint-Antoine, qui n'en eft cependant éloigné que de 70. lieuës; mais fur cette Côte les Courants portent à l'Eft, \& font quelquefois affés forts.

Du Cap Saint-Antoine, l'Efcadre fe trouva en huit jours de navigation à la vûë d'une Ifle, que fes Habitans nommoient Cozumel, \& qui a retenu ce nom, quoique Grijalva lui êt donné celui de Sainte-Croix, parce qu'il y aborda le jour, qu'on célébre dans l'Eglife l'Invention de la Croix du Sauveur. Il y fit dire la Mefle ce jour-là même, \& s'étant un peu avancé pour reconnoitre le Pays, il ne rencontra perfonne, finon une Indienne de la Jamaique, Il y avoit environ deux ans, qu'un coup de Vent avoit jetté cette Femme fur l'Ifle de Cozumel, tandis qu'elle étoit à la Pêche avec ro. Hommes; ceux-ci furent d'abord mafiàcrés par les Infulaires, qui garderent cette Femme, \& la firent Efclave. Elle apprit aux Efpagnols qu'à la vîë de leurs Navires, tous les Habitans s'en étoient enfuis dans les Montagnes, \& Grijalva l'ayant priée de les aller trouver pour tâcher do les faire reyenir; elle y confentit; mais elle eut beau affûrer ces Barbares qu'on n'avoit aucun deffein de leur faire le moindre tort, elle ne gagna rien. Voyant enfuite les Efpagnols fur le point de fe rembarquer, elle les pria de la recevoir fur un de leurs Navires, \& elle l'obtint fans peine.

Entre plufieurs Temples, que les Efpagnols apperçûrent dans lifle de Cozumel, \& qui étoient tous biens bấtis de Croix dans. dans line de Cozumel, \& qui étoient tous biens batis de PYucatan \& briques, ou de pierres; ils en remarquerent un, qui avoit fon origine. la figure d'une Tour quarrée, auprès duquel étoit une Croix de pierre, environnée d'une baluftrade de même fabrique. Ils apprirent, apparemment de la Jamaïquaine, que cette Croix étoit adorée des Indiens, fous le titre du Dieu de la A a a iij 


\section{4 \\ H I S TOIR}

I5 8. pluye, \& qu'ils ne s'y adreffoient jamais en vain pour avoir 1. de l'eau du Ciel. J'ay déjà obfervé que dans la premiere

I519. Découverte de l'Yucatan, on avoit rrouvé en plufieurs endroits des Croix, qui étoient pour la plûpart peintes fur les murailles, \& voici ce qu'Herrera rapporte de l'origine de ce culte. Il dit que François de Montejo, celui-là même, qui montoit un des trois Vaiffeaux de cette Efcadre, étant allé en I 527 . pour faire la Conquête de l'Yucatan, il fut reçu fans réfiftance dans une Bourgade appellée Mini, où on lui raconta que peu de têms avant l'arrivée de François Fernandez de Cordouë dans leur Pays, un de leurs Sacrifificateurs, nommé Chilan Combal, qui paffoit pour un grand Prophete, publia que dans peu des Hommes blancs, \& ayant du poil au menton, viendroient des quartiers, d'où le Soleil fe leve, planteroient partout des Croix, \& qu’à ce fignal tous leurs Dieux s'enfuiroient; que ces Etrangers s'empareroient du Pays; mais qu'ils ne feroient aucun mal à ceux, qui fe foumettroient volontairement à leur Empire, \& adoreroient le feul Dieu, que leurs Vainqueurs leur prêcheroient. Le Devin, continuë Herrera, après avoir parlé de la forte, fit faire une mante de cotton, \& dit que c'étoit là le tribut, qu'exigeroient leurs nouveaux Maîtres; il fit auffi dreffer une Croix, \& à fon exemple on en éleva de tous côtés; peu-de têms après, les Efpagnols ayant paru fur les Côtesde l'Yucatan, on leur demanda s'ils ne venoient point des Pays, d'où le foleil fe leve, \& dans la fuite, les $\mathrm{Ha}$ bitans de ce Pays, ayant vû les Gens de la fuite de Montejo rendre de grands honneurs à la Croix, ils ne douterent plus que la Prophétie de Combal ne s'accomplît.

Il eft bleffé à Potonchan \& découvre la Nouvelle Efpagne.

Pour revenir à Grijalva, ce Général étant parti de Cozumel, s'approcha de la Terre Ferme, \& arriva en huit jours à Potonchan, où il trouva les Peuples fort réfolus à lui difputer la defcente. Il ne laiffa pas de la faire; mais il y eut trois hommes tués \& foixantebleffés. Il fut lui-même bleffé, s'étant expofé comme le dernier des Soldats, il marcha enfuite à la Bourgade, où il n'y avoit plus perfonne, \& quoi- 
DE S. D omingue, LIv. V. 375 qu'il eût envoyé faire aux Habitans les propolitions les plus avantageufes; il ne put les engager à revenir, de forte que ne voyant aucune efpérance de traitter avec eux, il fe rembarqua. Plus il avançoit, plus le Pays lui paroiffoit cultivé \& peuplé ; les Habitans plus à leur aife \& plus policés : les Edifices plus propres \& mieux bâtis; \& un Soldat s'étant avifé de dire qu'il lui fembloit être dans une nouvelle Efpagne, cette parole dite au hazard, paffa auffi-tôt de bouche en bouche; \& c'eft ainfi que le nom de Nowvelle Efpagne eft demeuré à toute cette vafte contrée.

Grijalva cependant foupiroit après une Riviere, où il Ilentredans pût s'arrêrer quelque têms, \& par ce moyen prendre un peu la Riviere de plus de connoiffance de l'interieur du Pays. Il en découvrit tonnement enfin une, qui fe jette par deux embouchures dans ce que l’on a depuis appellé le Golphe du Mexique; mais s'étant approché de celle des deux branches, qui lui parut la plus naviguable, il n'y trouva pas encore affés d'eau pour y faire entrer fes deux plus grands. Vaifleaux, le parti, qu'il prit, fut de renforcer les Equipages des deux autres, fur l'un defquels il s'embarqua, réfolu de remonter la Riviere le plus haut, qu'il lui feroit poffible. Il étoit à peine engagé duns le courant du Fleuve, contre lequel fes Bâtimens eurent long têms à combattre, qu'il apperçut affés près de lui un fort grand nombre de Canots, remplis d'Indiens armés, qui paroiffoient fort réfolus de défendre la defcente. Leurs cris \& leurs menaces n'épouvanterent pourtant pas les Efpagnols, qui s'avancerent en bon ordre jufquà la portée du trait. Le Général leur avoit furtout recommandé de ne fire aucune démonftration, par où l'on pût juger qu'ils venoient comme Ennemis; \& les Indiens de leur côté furent fi frappés de la figure de ces Errangers, de la belle ordonnance, dans laquelle ils avançoient, de lintrépidité, quils faifoient paroitre, malgré leur petit nombre, de la forme de leurs Armes, \& de celle de leurs Navires; que la furprife fufpendant toute la fureur, dont ils étoient animés, ils refterent comme immobiles, \& qu'un filence general 


\section{HISTOIRE}

1518. fucceda tout à coup aux clameurs, dont un moment auparavant toutes les Campagnes \& le Rivage de la Mer reIs I9. tentifoient.

Il prend Le Commandant profita d'une fi heureufe conjoncture pour polfetlion du fauter à terre; ceux, qui étoient avec lui, en firent autant, pofe aux $\mathrm{Ha}$ - \& tous les autres le fuivirent de près. Il les rangea en $\mathrm{Ba}$ bitans de fe taille à mefure qu'ils arriverent, fit déployer l'Etendart Roi dEfpa- Royal, \& s'appercevant que cette action avoit redoublé légne.

Réponfe La maniere, dont cette propofition fut reçuë, fit condes Indiens. noître à Grijalva qu'il s'étoit mépris, s'il avoit crû avoir affaire à des Sauvages. Il n'eût pas plûtôt fait fa propofition, que le plus confiderable de la Troupe Indienne, voyant la fureur renaître fur le vifage de fes Gens, leur impofa filence de la main, \& adreffant la parole au Général, il lui dit : Ce n'eft pas une paix, que vous nous offrez, mais une 


\section{De S. Domingue, Liv. $\mathbb{V}$.}

so guerre que vous nous déclarés; car qui a jamais entendu ๖ parler d'une paix, dont la premiere condition demande - une folimiffion, telle qu'on a droit de l'exiger de Gens ٪ qu'on a fubjugués par la force? Vous deviés bien, avant » que de nous propofer de reconnoître votre Prince pour w notre Mâitre, vous informer, fi nous étions mécontents de w celui, auquel nous obéiffons. Toutesfois comme je ne fuis s pas revêtu d'une autorité fuffifante, pour vous donner une w réponfe décifive, je vais rendre compte à mes Superieurs, de so ce que vous prétendés, \& je vous ferai fçavoir leur derniere » réfolution. o Il fe retira en finiffant ces mots, \& laiffa les Efpagnols un peu intrigués, voyant qu'ils avoient affaire à des Gens, qui penfoient trop bien pour être des Ennemis méprifables. Mais leur inquiétude ne fut pas de longue durée. Le même Indien, qui leur avoit parlé, revint fort peu de têms après avec une nombreufe fuite, \& leur préfenta toutes fortes de Provifions en abondance de la part de tous les Caciques des environs; $\propto$ Voici, dit - il enfuite, des w gages de la paix, que nous acceptons. Mes Maitres क ne craignent point la Guerre, \& l'exemple de ce qui eft » arrivé dans l'Yucatan, ne les a point intimidés; mais ils » jugent que la Paix eft toûjours préférable à la plus heu$\infty$ reufe Guerre. $\infty$

Cette déclaration combla de joye les Indiens, pour le Entrevíe du moins autant que les Efoagnols, \& on commencoit à trait- Général \& du ter enfemble avec beaucoup de cordialité , lorfque le Ca-Tabafco. cique du lieu parut avec une garde affés peu nombreufe $\&$ défarmée, confervant néanmoins un certain air de Prince, qu'il foutint encore mieux dans la maniere, dont il parla au General. Car après lui avoir fait étaler une quantité de raretés du Pays, dont il vouloit lui faire préfent, \& parmi lefquelles il y avoit beaucoup d'ouvrages travaillés en Or. * J'aime la Paix, dit-il, fans lui donner le têms de w faire fon remerciement ; j'aime la Paix , \& c'eft pour la * maintenir entre nous, que je vous prie d'accepter ce Pre- fent, \& de vous éloigner de ces lieux, de peur que la méTom I. $\mathrm{Bb} \mathrm{b}$ 
1518. w fintelligence ne fe mette parmi vos Sujets \& les miens. * 1. Le General lui répondit, que fon deffein n’avoit jamais été

1519. de rien faire, qui pût lui caufer la moindre inquiétude, \& lui fit entendre quil ne tarderoit pas à partir. Le Cacique, fur cette affürance, prit congé de lui, \& les Efpa* gnols s'embarquerent dès le même jour. C'eft ainfi que Solis raconte cette entrevâe, qui fe fit fur le Bord de Grijalva, où ce General s'étoit retiré, après avoir déclaré fes intentions à l'Envoyé des Caciques.

Pourquoi Herrera, qui marque expreffément cette circonftance, Grijalva ne \& quelques-autres, qui ne font pas toutes également vrai-
fait point d'établifferinent femblables, ajoûte que plufieurs Éfpagnols témoignerent dans ce lieu- beaucoup d'envie de s'établir dans un lieu, où tout les portoir là. à efpérer qu'ils y trouveroient de grandes richeffes; mais que le General leur oppofa les ordres contraires, qu'il avoit de Velafquez, \& l'imprudence qu'il y auroit de laiffer derriere eux des Ennemis, tandis qu'avec leurs forces affoiblies, ils feroient obligés de continuer la découverte, quils avoient commencée. Il dit encore que les Indiens interrogés, où l'on trouvoit de l'Or, ne répondirent qu'en montrant de la main un Pays fitué à l'Occident, \& en repetant plufieurs fois Culua. Quoiqu'il en foit, la Riviere, où l'Efcadre étoir entrée, portoit le nom de Tabafco,auquel les Efpagnols fubftituerent celui de Grijalva, mais qui eft refté à la Province qu'elle arrofe, \& qui le conferve encore aujourd'hui.

Rio de Ean- Au fortir de cette Riviere, le General continua de randeras. Pre- ger la Côte jufqu'à une autre Fleuve, qui fut nommé Rio moifiance de de Banderas, parce qu'étant par fon travers on apperçut des Motczuma. Indiens, qui ayant mis des efpeces de Banderoles au bout d'une maniere de picques, fembloient inviter les Caftillans à defcendre à terre. François de Montejo eut ordre de re. connoître cette Riviere avec deux Batteaux armés, \& Grijalva le fuivit d'affés près avec tout le refte de fon monde. Les uns \& les autres furent parfaitement bien reçus des $\mathrm{Habi}$ tans, qui traitterent avec eux la valeur de I 5 . mille Pezos en or, pour les plus viles Marchandifes d'Efpagne. Grijalva apprit 
De S. Domingue, Liv. V. 379

dès-lors, \& fut encore mieux inftruit dans la fuite, que ces invitations, \& la bonne réception, qu'on lui avoit faite en cet endroit, étoient en conféquence d'un ordre d'un puiffant Roi voifin de cette Province,\& qui avoit nom Motezuma : que ce Prince,qui avoit éré exactement informé de fon approche, \& qui avoit, dit-on, des preffentimens de fes malheurs prochains, avoit mandé, aux Commandans de fes Frontieres, d'aller au-devant des Efpagnols, de leur porter de l'or pour traitter, \& de tâcher de découvrir quel étoit au jufte le deffein de ces Etrangers. Le General fit encore en ce lieu-là toutes les cérémonies d'une prife de poffeffion, \& il eft à obferver que c'étoit au nom de Velafquez, Gouverneur de Cuba, que fe faifoient tous ces Actes publics.

L'Efcadre n'étant pas en fûreté dans cette rade, où rien ne la défendoit des Vents du Nord, Grijalva donna avec bien du regret l'ordre d'appareiller, \& après avoir paffé deux ou trois Inles peu confiderables, fans s'y arrêter, il en aperçut une,qui lui parut bien peuplée, \& il y fit mettre pied à terre une partie de fes gens. Il y avoit en effet dans cette Ifle plufieurs Edifices affés beaux , \& un Temple entr'autres d'une ftructure afiés finguliere, il étoit ouvert de toutes parts, \& il y avoit au milieu un dégré tout découvert, par où l'on montoit à une efpece d'Autel, fur lequel on voyoit des Statuës d'une figure horrible. Grijalva eut la curiofité de le vifiter de plus près, \& il y trouva cinq ou fix Cadavres, qu'il jugea avoir été facrifiés la nuit précedente. Ce qui lui fit donner à l'Ifle le nom d'Ifle des Sacrifices. On l'appelle aujourd'hui plus communément la Caye du Sacrifice. Il vit la même chofe dans une autre Inle un peu plus éloignée, que les Infulaires nommoient Culua.; \& qu'il crut être cette Terre abondante en Or, qu'on luịavoit indiquée à Tabafco. Effectivement, il y traitta beaucoup d'Or, \& il la nomma Saint Fean d'Ulua. Cette Ine \& la précedente, font en elles-mêmes très-peu de chofe, celle-ci ferme le Port de la Vera Cruz, du côté du Nord, \& nous aurons ailleurs occafion d'en parler plus au long.

$\mathrm{B} b \mathrm{~b}$ ij 


\section{$380 \quad$ H S T O I R E}

1518. Le General Efpagnol eut bien voulu prendre poffeffion de tant de riches Pays, autrement que par des formalités. II

I5 İ. croyoit même, \& c'étoit le fentiment prefqu'unanime de Grijalva en- ceux, qui l'accompagnoient, pouvoir interpreter fur cela les
vove demander de intentions de Velafquez; mais fon obéiffance fut la plus for-

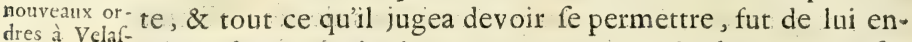
quez. Velaf- voyer donner avis de tout, pour recevoir de nouveau fes ordres. Il lui dépêcha le Navire, que commandoir Pierre d'Alvarado, il chargea deffus tout l'or, \& toutes les raretés, qu'il avoit ramafées jufques-là, \& y il fit embarquer les malades, qui n'étoient pas en état de lui rendre aucun fervice. Velafquez de fon côté étoit fort en peine de ne point apprendre des nouvelles de cette Efcadre, \& envoya un Vaiffeau commandé par Chriftophle de Olid, pour s'informer de ce qu'elle étoit devenuë. Un coup de Vent, qui maltraitta fort ce Navire fur les Côtes de l'Yucatan, contraignit Olid de s'en retourner au plus vîte à Sant-Yago, d'où il étoit parti; \& comme fur ces entrefaites Alvarado arriva au même Port', Velafquez fe confola aifément de l'inutilité du Voyage de l'un, par les bonnes nouvelles, que l'autre lui apporta de ce qu'on commença dès - lors à nommer la Nouvelle Efpagne.

Qui s'em- Il eft vrai que, quand il eut appris qu'on n'avoit pas mêportemal-à- me bâti un Fort dans une fr grande étenduë de Pays, il

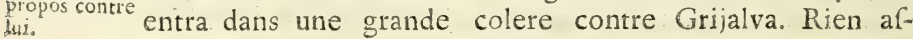
fürément n'étoit moins raifonnable; mais outre que Las Cafas, qui a dit beaucoup de bien de ce Gouverneur, convient qu'il étoit quelquefois très-difficile à contenter, foit pour ce qui regardoit le Commandement, foit pour fon fervice particulier, \& qu'il n'étoit pas aifé, même en faifant fon devoir, d'éviter fon indignation, il avoit encore un défaut, qui étoit de croire, fans beaucoup examiner, ce qui étoit au défavantage des autres. Or dans un Confeil Général, où Grijalva avoit mis en déliberation, fi on ne confruiroit pas une Fortereffe dans la Nouvelle Efpagne, Pierre d'Alvarado avoit été pour l'affirmative, \& il n'eft 


\section{De S. Domingue, Liv. V. 38 r}

pas hors de vrai femblance que, dans le récit, qu'il fit à Velafquez de tout ce qui s'étoit paffé à ce fujet, il parla de fon Commandant d'une maniere peu favorable, ou peu mefurée; c'eft du moins ce que paroît infinuer Antoine Herrera. Solis dit pofitivement qu'Alvarado voulut excufer fon Général, mais qu'il le fit foiblement, comme font ordinairement tous ceux, qui défendent un fentiment contraire à celui, qu'ils ont foutenu; il y a auffi bien de l'apparence que le Gouverneur de Cuba, n’ayant. pas ofé de fon chef, \& fans en avoir eu l'agrément de ceux, qui Commandoient dans l'Ifle Efpagnole, donner ordre de faire des établiffemens en Terre Ferme, eût fort fouhaité que Grijalva l'eût pris fur lui.

Ce qui eft certain, c'eft qu'après avoir violemment invectivé contre ce Capitaine, dont tout le crime étoit de continuela lui avoir obéi ; il prit fur le champ la réfolution de faire de la Nouvelun nouvel armement, \& d'en donner le Commandement à un autre. Mais cet emportement lui coûta cher dans la fuite, \& il fe-feroit épargné bien des chagrins, s'il eut rendu plus de juftice à fon compatriote, lequel, tandis qu'on lui faifoit fi injuftement fon procès à Sant-Yago, pourfuivoit fes Découvertes le long du Golphe de Mexique. Il s'étoit remis en Mer peu de têms après le départ d'Alvarado, \& après avoir reconnules hautes Montagnes de Tufpa, il fe trouva dans la Province de Panuco; y ayant rencontré une Riviere, qui lui parut affés profonde, il y fit entrer fes Navires, mais à peine y avoit-il moüil. lé les Ancres, que le Vaiffeau commandé par Alphonfe Davila, lequel s'étoit apparemment un peu plus avancé que les autres, fut attaqué par une Flotte de Canots Indiens, \& il auroit fans doute fuccombé, s'il n'eût été fécouru à propos. Grijalva ayant joint toutes fes forces, tomba fi brufquement fur les Burbares, que la plûpart n'eurent pas même le têms de fe fauver, \& qu'il en fut tué un grand nombre. Cet incident fit donner à cette Riviere le nom de Riviere des Canots. Grijalva en étant forti , cottoya la B b biij 


\section{$382 \quad$ His T O R}

I5I8. Province de Tlafcala; il s'avança enfuite jufqu'à une poin-

1. te, où les Courans fe trouverent contraires, \& fi forts, que

I5 I9. le Pilote Alaminos, après plufieurs efforts pour la doubler, déclara qu'il y avoit trop à rifquer à s'opiniâtrer davantage.

Il retourne Plufieurs perfonnes des plus confiderables de l'Efcaà l'Ine de $\mathrm{Cu}_{\text {ba }}$ dreception fre firent alors une derniere tentative pour engager Grique lui fait jalva à faire un établiffement, \& l'on prétend qu'il ne paVelafquez. rut pas alors s'en éloigner beaucoup, quoiqu'il y ait bien de l'apparence, qu'il ne voulut que gagner du têms, pour attendre la réponfe de Velafquez: mais François de Montejo ayant opiné au contraire, il reprit fes premiers fentimens, \& fit voiles vers l'Ifle de Cuba, où il arriva fur la fin d'Octobre. Il apprit en paffant à Matance les grands préparatifs de Velafquez pour une nouvelle expédition, \& comme il ignoroit encore les difpofitions de ce Gouverneur à fon égard, il fe flatta qu'il ne fongeroit point à confier fa Flotte à d'autres, qu'à lui. Mais il fe trouva bien loin de compte, lorfqu'au lieu des amitiés \& des remerciemens, à quoi il s'étoit attendu, Velafquez lui fit publiquement les reproches les plus fenfibles, \& lui parla de la maniere la plus dure. Il ne répliqua, qu'en lui montrant l'ordre qu'il avoit reçî́ de lui-même, mais le Gouverneur étoit fi peu

Solis. capable d'entendre raifon, dit un Hiftorien, qu'il reconnoiffoit avoir donné l'ordre \& en puniffoit l'exécution, comme il auroit dû́ faire la défobéiffance. Il envoya Jean de Salzedo à l'Ifle Efpagnole, pour faire agréer fa nouvelle entreprife aux Peres de S. Jerôme, \& ayant dreffé fon Plan fur les Memoires de Grijalva, il fongea tout de bon à donner un Commandant à fa Flote.

Fernand : Il jetta d'abord les yeux fur Balthafar Bermudez, qui étoit mé Capitaine fon Compatriote, auffi bien que Grijalva: Antoine \& BerGénéral de la nardin Velafquez, fes proches parens; Vafco Porcallo, \& née à la Conquête de la mais les uns portoient trop haut leurs prétentions, les au-
Nouvelle EfNouvelle Ef- tres n'avoient pas tout ce que demandoit un employ de
pagne. 
de S. Domingue, Liv. V. 383 cette importance. La voix publique nommoit Grijalva, \& ce fuffrage univerfel auroit fait revenir tout autre, que Velafquez. Enfin Amador de Lariz, Tréforier Royal, \& André Duero, Secretaire du Gouverneur, profiterent de cette irréfolution, pour faire tomber le choix fur leur ami commun, \& l'homme du monde, qui convenoit le moins aux vûës de Velafquez. Ces vûës étoient fort extraordinaires \& infiniment difficiles à remplir; ce Gouverneur vouloit un Commandant, qui eût tout le mérite d'un Conquérant, \& qui n'en eut pas l'ambition, mais qui fût affés fimple ou affés moderé, pour n'avoir en vûë que la gloire d'autruy; \& tandis qu'il ne vouloit pas voir que Grijalva feul étoit capable de tout cela, on lui fit agréer le plus ambitieux des hommes, \& le moins propre à n'agir qu'avec fubordination à la tête d'une Armée. Ce fut le célébre Fernand Cortez, celui peut être de tous les Conquerans du Nouveau Monde, dont on a dit plus de bien \& plus de mal.

Fernand Cortez naquit à Medellin en Eftramadoure en Quelilétoit. I485. de Parents Nobles : fon Pere fe nommoit Martin Cortez de Monroy, \& fa Mere Carherine Pizarro Altamirano. On eut affés de peine à l'élever, \& jufqu'à l'âge de quatorze ans il fut très-infirme; mais alons fa fanté ayant paru fe fortifier, il fut envoyé à Salamanque pour achever fes Etudes. Il fit affés bien fes Humanités; \& le deffein de fon Pere étoit qu'il s'appliquât à la Jurifprudence, mais comme cette occupation ne convenoit pas à fon humeur. il y renonça bientôt, retourna dans fa famille, \& peu de têms après il obtint de fes Parens la permiffion d'aller fervir en Italie, fous le célébre Gonzalve de Cordouë; mais une maladie, dont il fut atraqué en chemin, rompit ce Voyage. Dès qu'il fut guéri il eut envie de paffer aux Indes, \& fon Pere y ayant confenti, lui donna des Letres pour le Grand Commandeur D. Nicolas Ovando, duquel il étoit parent. Ce fut en I 504 . quil s'embarqua, \& quoiqu'il ne fût que dans fa vingtiéme année, \& qu’il n'eûtaucune ex- 


\section{HIS TOIRE}

is I8. perience, il fit pourtant paroítre beaucoup de fermeté \& de réfolution, dans de fort grands dangers, aufquelsil fut exporé

I519. pendant la Traverfée. Ovando le reçut bien, \& le garda quelque têms chés lui. Enfuite il lui donnna de l'employ dans la Ville d'Azua de Compoftelle. Il étoir bien fait, fon air \& fes manieres avoient quelque chofe de fort aimable, il étoit généreux, fage, difcret, il ne parloit jamais mal de perfonne, \& il avoit une converfation fort enjoüée; il obligeoit de bonne grace, n'avoit rien à lui, \& ne vouloit pas même qu'on publiât fes bienfaits, mais il fçavoit merveilleufement l'art de faire fervir cette générofité \& cette modeftie aux fins, qu'il fe propofoit, qui étoient de fe faire des amis, \& de s'élever.

Sesavantures. En r s r r. il paffa dans l'Ifle de Cuba avec Velafquez, qui le fit fon Secretaire, mais l'année fuivante quelques mécontens, qui vouloient porter leurs plaintes contre le Gouverneur à l'Audience Royale de San-Domingo, cherchant un homme affés hardi, pour fe charger dune pareille Commiffion, s'adrefferent à Cortez, qui l'accepta, \& entreprit de paffer dans un Canot à l'Ifle Efpagnole. Velafquez, qui eut le vent de ce complot, le fit arrêter, \& condamner à être pendu. Quelques perfonnes de confideration obtinrent fa grace; cependant le Gouverneur voulut l'envoyer Prifonnier à San-Domingo, \& l'embarqua dans un Navire, qu'il y envoyoit; mais il fe fauva en fautant dans la Mer pendant la nuit. Il fut pourtant repris, mais fes Protecteurs firent entierement fa paix avec Velafquez, lequel dans le fond l'aimoit \& l'eftimoit. Il eut encore une affaire fâcheufe au fujet de fon mariage avec une Demoifelle de bonne Maifon, \& d'une grande vertu nommée Catherine Suarez Pacheco, \& Velafquez, qui s'y trouva engagée avec les Parens de la Demoifelle, le fit mettre en Prifon; mais il s'en tira heureufement, \& il gagna même tellement les bonnes graces de fon Gouverneur, que depuis ce têmslà perfonne n'en fut plus favorifé que lui. Auffi devintil très-riche, \& il exerçoit l'Office d'Alcaïde à Sant-Yago 


\section{De S. Domingue, Liv. V. 385}

Capitale de l'Inle, lorfque ces mêmes amis, qui l'avoient jufques là fervi fi utilement, le firent nommer Capitaine Général de la Flotte, qu'on armoit pour la Nouvelle Efpagne.

Ce choix au refte n'étoir pas auffi étrange, qu'il pouvoit Soncaracere. le paroître, bien que Cortez n'eût gueres eu jufques-là que des emplois plus propres à faire connoître fon efprit \& fes ralens pour les affaires, qu’à montrer fa valeur, \& à lui acquerir de l'experience au fait des Armes; il n'avoit pas laiffé de faire voir en plufieurs occafions qu'il étoit Soldat \& Capitaine; il s'étoit furtout fort diftingué dans la Conquête de l'lfle de Cuba, \& depuis en diverfes actions, qui fe pafferent dans cette Ine entre les Efpagnols \& les Infulaires. Auffi fa nomination fut-elle affés généralement applaudie du Peuple; mais ceux, qui le connoiffoient plus intimement, jugerent d'abord que ce choix feroit fatal à fon Auteur. On affûre même qu'un de ces foux, qui en divertiffant difent fouvent des vérités utiles, ayant un jour rencontré le Gouverneur \& le Capitaine Général, qui le promenoient enfemble, fe mit à crier que Velafquez avoit fait un beau coup, \& que bientôt il lui faudroit une feconde Flotte, pour courir après Cortez. Velafquez demanda à celui-ci, s'il entendoit ce que difoit cet homme, Cortez répondit que c'étoit un fou qui parloit, cependant la prédiction ne tarda pas à fe vérifier.

Ce qui contribua encore beaucoup à tromper le Gou- Velafqueź verneur de Cuba, c'eft quil crut avoir fuffitamment pris obtient plufes mefures contre tout ce qu'on pourroit entreprendre à de la Cour. fon préjudice. Auffi-tôt après l'arrivée de Pierre d'Alvarado, qui lui apporta les premieres nouvelles de la Découverte de la Nouvelle Efpagne, il avoit envoyé en Europe Benoit Martin fon Chapelain , pour rendre compte au Roi de routes chofes, \& des projets, qu'il formoit pour tirer avantage de tout ce qui s'étoit fait; il avoit chargé cet Eccléfiatique de ce qu'il y avoit de plus précieux dans ce qui avoit été apporté de la Terre Ferme, \& il l'avoit fait 


\section{HIS TOIR E}

I5I8. fuivre de près par Gonzalez de Guzman, auquel il recom*

I manda, auffi bien quau Chapelain, dagir en tout de con-

1519. cert avec Pamphile de Narvaez, qui étoit à la Cour depuis quelque têms, \& auquel il eut toûjours une très-grande confiance. Narvaez avoit effectivement bien avancé fes affaires avant.l'arrivée des deux autres, \& fur les avis, qu'il lui en donna, Velafquez crut devoir te promettre toutes chofes de la protection de l'Evêque de Burgos; il avoit effectivement afiés bien pris fes mefures, pour mettre dans fes interêts ce Prélat, dont l'autorité croiffoit tous les jours, \& qui vers la fin de l'année I I 9 . fut déclaré Préfident d'un nouveau Confeil établi fous le nom du Confel des Indes. Il s'étoit fait ami de Paffamonté, \& il en ufoit mal avec l'Amiral, que l'Evêque de Burgos n'aimoit pas. Ce Prélat fit donc valoir auprès du Roi le zele \&lesfervices du Gouverneur de Cuba; il fongea même à fe l'attacher, en lui faifant époufer Donna Mayor de Fonfeca fa Niéce, \& le 13. de Novembre 1518 . il fit figner au Roi un Concordat en vertu duquel ce Prince nommoit Velafquez Adélantade, \& le déclaroit fon Capitaine, \& Lieutenant Général dans l'ine de Cuba, \& dans tous les lieux, qui avoient été, ou feroient dans la fuite découverts par fes foins \& fous fes ordres; il lui donnoit même la permiffion de lever pour cela du monde, par tout, où il voudroir, \& jufques. dans l'Ifle Efpagnole, \& regloit d'une maniere très-avan. tageufe pour lui les profits, qui fe tireroient de toutes fes entreprifes dans le Continent.

Ses difgraces. On peut bien juger qu'un pareil traité, de fi grands. Privileges, \& la nouvelle dignité accordée au Gouverneur de Cuba, qui par là, de fimple Lieutenant de Colomb, devenoit quelque chofe de plus, que fon égal, à l'Amirauté près . ne fit pas beaucoup de plaifir à celui-ci; mais le malheureux Velafquez reçut un peu tard ces graces, \& n'en joüit pas long-têms; elles ne fervirent même qu'à l'engager dans des entreprifes, qui lui devinrent funeftes, ainfi que nous le verrons bientôt ; peu d'années après il fut réduit à un 


\section{DE S. DOMINGUE, L IV。 V. 387}

état, où il fit beaucoup plus de compaffion, qu'il n'avoit pû caufer de jaloufie; \& fi fon infortune eut plufieurs caufes differentes, la premiere \& la principale fur le tour, que prit pour lui l'entreprife de la Nouvelle Expagne; mais dont il ne pût fe prendre qu'à lui même.

Il avoit fait des frais conliderables pour cette expedition, \& ne doutoit pas qu'elle ne dût lui procurer les plus grands égard.

Etabliffemens \& le couvrir de gloire; mais pour cela il falloit la faire par lui-même, ou choifir mieux fon Lieutenant. Herrera prétend que Cortez travailla prefque aufi-tôt qu'il fut nommé pour commander la Flotte, à fécoüer toute dépendance de fon Général, \& qu'il voulut partir furtivement pendant la nuit de Sant-Yago, craignant que Velafquez, qui te repentoit déjà de fon choix, ne voulut l'arrêter. Solis aftûre le contraire fur le témoignage de Bernard Diaz de Caftillo, témoin oculaire, dont j’ai déjà parlé, \& dont je ne crois pourtant pas que l'autorité foit telle, que celle d'Herrera ne la puiffe balancer, d'autant plus que Solis lui même ne fait aucune difficulté de le critiquer \& de l'abandonner fouvent. D'ailleurs cet Hiftorien, après s'être bien donné de la peine à nous vouloir perfuader que le Gouverneur de Cuba, \& le Capitaine Général de la Flotte, fe quitterent avec toutes les marques d'une confian. ce entiere de la part du premier, \& d'une parfaite foumiffion de celle du fecond; convient que celui ci étoit à peine forti du Port de Sant-Yago, qu'on réüffic enfin à infpirer de violents foupçons contre lui à Velafquez, qui fit dès-lors de grands,mais d'inutiles efforts pour s'affürer de fa perfonne.

Quoiqu'il en foit, Cortez fit voiles de Sant-Yago le 8. de Novembre de l'année I 5 I8. \& gagna en peu de jours 8. de Novembre de l'année I 5 I8. \& gagna en peu de jours d'ôter à Cor-
le Port de la Trinité, où il avoit beaucoup d'Amis, qui tezle Comvoulurent le fervir de leurs perfonnes, \& de leur bourfe. mandement Il lui vint auffi un renfort confiderable de la Ville du S. Efprit, qui n'eft pas éloignée du Port de la Trinité ; mais tandis que tout étoit en mouvement dans ces deux Villes pour feconder fon entreprife; Velafquez fe détermina en-

1518.

1

1519.

Conduite de

Cortez à fon
Velalquez tâche envain de la Flotte. 


\section{H I S T O I E}

1518. fin à tout tenter, pour lui en ôter la conduite, \& commença par envoyer un ordre exprès à François Verdugo,

×5ร19. Con beau-frere, qui exerçoit l'emploi d'Alcaïde Major à la Irinité, de le dépofer juridiquement de fa Charge. Il étoir plus aifé de donner une telle Commiffion, que de l'executer: Cortez étoit bien fùr de tous ceux, qui étoient fous fes ordres, \& Verdugo fentit qu'inutilement il expoferoit l'autosité, dont il étoit revêtu, s'il fe mettoit en devoir d'obéir. D'ailleurs il fut charmé de la maniere, dont Cortez lui parla; de forte qu'il jugea à propos de ne rien faire, jufqu'à ce qu'il eût écrit à Velafquez, \& reçû de nouveau fes or dre. La plûpart des Officiers de la Flotte écrivirent auffi de leur côté, pour repréienter au Gouverneur l'injuftice , qu'il vouloit faire à un homme de mérite, dont tout le crime étoit apparemment d'avoir des envieux; \& le danger, qu'il y avoit de révolter toute L'Armée, fi on pouffoit à bout fon Général. Enfin Cortez écrivit lui même, \& le fit d'une maniere fort mefurée, mais qui, fans fortir des bornes du refpect, qu'un fubalterne doit à fon Superieur, faifoit voir une Nobleffe de fentimens, que Velafquez ne lui avoit peut-être pas affés connuë, \& un peu de ce reffentiment, qui ne fied pas mal à la vertu calomniée.

Cortez fe Ces dépêches parties, le Capitaine Général crut que ce hiâtc: de par- qu'il avoit à faire de mieux dans les circonftances, où il fe trouvoit, étoit de fortir de l'ille au plûtôt. Ayant dons envoyé par terre une bonne partie de fes Soldats à la Havane fous la conduite de Pierre d'Alvarado, il s'y rendit par Mer, après avoir couru un grand danger, fon Navire étant de. meuré échoué fur un récif, d'où on eut bien de la peine à le tirer.Il acquit encore à laHavane un nouveau tenfort de volontaires, la plúpart gens de mérite \& de fervice; \& comme toute cette Nobleffe,qui fe donnoit ainfì lui, n'épargnoit rien pour fe bien équiper, il ne fe pouvoit rien voir de plus lefte $\&$ de plus brillant, que toute cette Armée Navalle. Mais tandis que les derniers préparatifs pour le départ fe faifoient avec une diligence \& une conduite, qui faifoient admirer davanta: 


\section{De S. Domingue, Liv. V. 389}

ge de jour en jour le Capitaine Général; Gafpar de Garnica arriva de Sant-Yago avec des lettres de Velafquez, pour Pierre de Barba, Commandant à la Havane: par lef-

1518 . 1 1519. quelles il étoit enjoint à cet Officier d'arrêter Cortez, \& de l'envoyer Prifonnier à la Capitale.Le Gouverneur recommandoit en même têms à Diego de Ordaz,\& à Jean Velafquez de Leon,de prêter main-forte à Barba, \& après leur avoir marqué l'indignation, qu'il avoit conçuë contre Verdugo, qui n’avoit pas executé un pareil ordre à la Trinité, il leur faifoit comprendre qu'il ne recevroit atcune excufe de leur part, s'ils fuivoient un fi pernicieux exemple, \& s'ils lux manquoient dans l'affaire du monde, qui l'intereffoit le plus.

Cette feconde tentative ne lui réüfit pourtant pas mieux que la premiere; elle fut même généralement défaprouvée, Flotte: elle \& Cortez fe voyant foutenu, leva le mafque. Quelque têms le. après le bruit courut que Velafquez fe préparoit à venir en perfonne à la Havane, ce qui ne fervit qu'à faire preffer le départ. La Flotte étoit compofée de dix Navires, $\&$ d'un Brigantin. Cortez ayant divifé toutes fess Troupes en onze Compagnies, il les mit fous les ordres des Commandans de ces onze Bâtimens, \& par-là ces Capitaines devoient commander avec une égale autorité fur Mer, \& fur Terre. Cortez prit le Commandement de la premic re Compagnie, les autres Capitaines furent Jean Velafquez de Leon, Alphonfe Fernand de Portocarrero, François de Montejo, Chriftophle de Olid, Jean de Efcalanté, François de Morla, Pierre d'Alvarado, François Sancedo, Alphonfe Davila, \& Ginez de Nortez, qui montoit le Brigantin. François de Orozco, qui avoit fervi avec beaucoup de réputation dans les Guerres d'Italie, fur chargé de l'Artillerie, \& Antoine de Alaminos fut déclaré premier Pilote. Toutes chofes étant ainfir reglées, \& rien ne retenant plus Cortez à la Havane, il appareilla le io. de Fevrier i 5 i 9 . après avoir mis folemnellement fon expédition fous la prorection du Prince des Apôtres, \& fait peindre dans fon grand Etendart une Croix avec ces paroles, qui furent C c c iij 
1519.

Velafquez manque un Navire de Cortez qui alloit en Erpagne.

montrées au Grand Conftantin, In hoc figno vinces.

On peut aifément juger quel fut le chagrin de Velafquez, lorfqu'il vit que fon Ennemi lui avoit échappé ; mais rien ne dut lui être plus fenfible, que de voir fa conduite blâ- mée, \& fes projets déconcertés par ceux mêmes, fur qui il avoit cru pouvoir compter divantage. Il rélolut pourtant de n'en point avoir le démenti, \& s'il ne fit pas d'abord connoître toute la vivacité de fon reffentiment, c'eft qu'il voulut fe donnerle loifir de bien prendre fes mefures. Vers la fin de Juillet il fçut qu'un Navire de la Flotte de Cortez, où étoient Porto Carrero, Montejo, \& le Pilote Alaminos, avoit pris terre dans fon Inle, affés près de la Havane, il fe mit auffi-tôt en devoir de s'en rendre le maître par furprife, mais l'adreffe, l'activité \& la hardieffe d'Alaminos, qui le premier ofa s'abandonner aux Courans du Canal de Bahama, lui firent encore manquer fon coup, \& le Navire arriva heureufement à Seville, au mois d'Octobre. Pour entendre le fujet de ce Voyage, il faut reprendre les chofes de plus haut.

Confeil é- Cortez ayant reconnu la petite Ifle de S. Jean d'Ulua, tabli dans l'armée. Corcez fedémet entre fes mains du Gézéralat. forma le deffein de s'établir dans fon voifinage, \& y traça effectivement le plan d'une Ville; mais avant que d'aller plus loin, il voulut donner une forme de Gouvernement à fa Colonie, en attendant les ordres de la Cour. Il en fit lui-même la propofition à fes Officiers, \& par eux à tout le Peuple. Elle fut bien reçuë, on s'affembla pour choifir les Magiftrats de la nouvelle Ville, \& quoique le Général eût laiffé en apparence à chacun la liberté du fuffrage, tout fe paffa felon fes défirs. On forma un Confeil compofé de deux Alcaides, qui furent Porto Carrero, \& Montejo; de quatre Regidors ou Confeillers, qui furent Davila, les deux Alvarado, \& Sandoval, d'un Alguazil Major, qui fut Jean d'Efcalanté ; \& d'un Procureur Général, qui fut François Alvarez Chico. Dès le lendemain de cette Election, le Confeil étant affemblé, Cortez fit demander la permiffion d'y entwer; elle lui fut accordée d'abord, \& ayant pris fa place après 
DE S. Domingue, L r v. V. $39 \mathrm{r}$ le premier Confeiller, quoique tous lui euffent déferé la premiere; il repréfenta qu'il fe trouvoit à la tête d'une $\mathrm{Ar}$ mée, fans aucune autorité pour la commander; la Commiffion, que lui en avoit donné Diego Velafquez, ayant été révoquée par ce même Gouverneur : qu'il avoit fait jufques là les fonctions de cette Charge, par la feule déférence volontaire de ceux, qui l'avoient d'abord reconnu pour leur Chef: qu'il avoit été néceffaire d'en ufer ainfi, tant qu'il n'y avoit pas eu dans l'Armée une autorité fuffifante, poux fe donner un Général, que cette néceffité ne fubfiftoit plus, qu'il prioit le Confeil d'ufer de fon droit, \& de n'avoir égard dans un choix de cette importance, qu'à la gloire de la Nation, \& au bien du fervice. Après avoir ainfi parlé, il mit fur le Bureau les Provifions, qu'il avoit reçuêes de Velafquez, \& fe retira.

Cortez n'avoit rien rifqué en fe démettant ainfi d'un le Confeil Commandement, qui dansle fond ne tenoit à rien, \& que le choifit de le moindre mécontentement pouvoit lui ravir; fa partie étoit Capitaine Gébien liée, \& toutes les voix furent pour recevoir fa démiffion, néral. Fonda- mais à condition qu'on l'obligeroit à accepter de nouvelles vera Cruz. Patentes de Général, provifionnelles néanmoins, \& jufqu'à ce que le Roi en̂t déclaré fa volonté. Cet Acte de Jurifdiction du Confeil avoit été précedé par la Cérémonie, quas fut faite avec de grandes formalités, de donner à la nouvelle Ville le nom de Villa ricca de la Vera Cruz, elle fut appellée Villa ricca, à caufe de l'Or, qu'on avoit trouvé en cet endroit, \& le furnom de Vera Cruz y fut ajoitté, parce qu’on y étoit arrivé le Vendredi Saint.

Quelque têms après, on fut affés furpris de voir entrer 11 reçoit dis dans le même Port, un petit Bâtiment qui venoit de fecours \& apCuba, \& portoit ro. Soldats Commandés par François velles de Cude Sauçedo , auquel s'étoit joint un autre Officier, nommé ba \& envoye Louis Marin. La facilité avec laquelle ils fe donnerent à Cor- des dépêches tez, fit juger qu'ils navoient point eu dautre deffein que de prendre part à une expedition, dont on fe promettoit de grandes chofes; mais ils apprirent au Capitaine Géné 
ral des nouvelles, qui lui donnerent un peu à penfer. IIs lui dirent qu'il devoit s'attendre que Velafquez ne négligeroit rien pour le perdre; qu'il avoit eu avis de la Cour que le Roi l'avoit nommé Adélantade de l'Ille de Cuba, \& qu'il en étoit d'autant plus animé à la vengeance, que cette nouvelle dignité fembloit lui affùrer, \& le droit \& le pouvoir de fe venger. Ce fut ce qui le fit réfoudre à députer au Roi les deux Alcaïdes au nom de la Colonie,pour lui rendre compte de tout ce qui s'étoit paffé, tant à légard du Gouverneur de Cuba, que depuis que l'Armée étoit entrée dans la Nouvelle Efpagne; \& il chargea les deux Députés de tout ce qu'il y avoit de plus précieux parmi les Préfens, qu'on avoit reçus, \& le butin, que l'on avoit fait.

Vers la fin de l'année, Velafquez reçut des Lettres de fon Chapelain, qui étoit toûjours à la fuite de la Cour, \& qui lui mandoit que les Provifions dAdélantade avoient été expediées, que fes Pouvoirs en vertu de cette Charge, s'étendoient, non-feulement à toute l'Ine de Cuba, mais encore à toutes les Provinces, qui feroient découvertes \& conquifes par fes foins \& fous fes ordres, \& qu'il pouvoit compter fur toute la Protection de l'Evêque de Burgos; mais il ajoûtoit que Porto Carrero \& Montejo étoient arrivés en Cour, avec beaucoup d'Or \& des nouvelles du Mexique, qui avoient caufé une grande joye au Roi; que l'Evêque de Burgos agifloit de fon mieux pour faire regarder Cortez comme un Rebelle, qui méritoit dêtre puni; mais qu'il ne répondoit pas de pouvoir détruire dans l'efprit du Prince les impreffions, qu'y avoient faites en faveur de ce Général les Efperances d'une fi belle Conquête, ni de contrebalancer les fuffrages de tous les Ordres du Royaume, qui élevoient jufqu'au Ciel le courage \& la conduite d'un homme, trop heureux ce femblè, pour être jugé criminel.

Il fait un

Ces avis exciterent dans le cœur de Velafquez desfen: grand arme- timens bien oppofés, mais qui concoururent à lui faire mortez \& le prendre la réfolution de tout rifquer, pour avoir raifon d'un ingrat 


\section{DE S. DOMIngUe, LIv. V. 393}

ingrat, qui lui ayant obligation de tout ce qu'il étoit, alloir;s'il n'y mettoit ordre au plûtôt, lui enlever la gloire \& les profits de la plus grande Entreprife, qui eût encore été tentée dans confie à Narle Nouveau Monde. Occupé de ces idées, il parcourut toute I'Ine de Cuba, pour tâcher d'infpirer à la Nobleffe \& au Peuple toute fa paffion, ou du moins de faire naitre dans leurs cours le défir de partager avec l'Armée de Cortez les Thréfors de la Nouvelle Efpagne, \& l'honneur d'ajouter une fi belle Couronne à toutes celles, qui brilloient déjà fur le front de leur Souverain. Velafquez étoit aimé, ce qu'il propoloit n'avoit rien, qui ne parût d'une exécution aifée; d'ailleurs il n'épargna ni fon crédit, nifon bien; auffi vint-il à bout de lever en fort peu de têms une Armée très-lefte, \& de mettre en mer la plus nombreule Flotte, qui fût encore fortie d'aucun Port des Indes. Elle étoit compofée d'onze grands V aiffeaux, de fept plus petits, \& de plufieurs Barques ou Bateaux ; \& il $\mathrm{y}$ avoit deffus 800 . hommes de la meilleure Infanterie, qui fút aux Indes, \&80. Cavaliers. Le premier deffein de Velafquez étoit de la commander lui-même ; il changea néanmoins de fentiment, \& il donna pour Général à fa Flotte Pamphile de Narvaez, qui étoit revenu depuis peu d'Efpagne. C'étoit un ancien Officier, qui s'étoir acquis une grande réputation dans les Indes, \& dont l'attachement aux interêts du Gouverneur étoit à toute épreuve. Velafquez le nomma fon Lieutenant, \& lui recommanda fur toutes chofes de ne rien négliger pour fe faifir de la perfonne de Correz, de le lui envoyer fous bonne garde, dès qu'il l'auroit en fa puiflance, de prendre le Commandement des deux Armées réünies, de pourfuivre la Conquête commencée, \& d'y établir en même têms l'authorité du Roi, \& les droits de l'Adélantade de Cubá.

Cependant l'Audience Royale de San-Domingo fut bientôt informée de ces préparatifs, \& en craignit les fuites... Elle dépêcha auffitôt à Velafquez l'Auditeur Luc Vafquez d'Aillon, pour l'engager à remettre ce grand different à fa décifion, avec ordre de n'épargner, ni la perfuafion, ni les menases, pour le détourner d'une Entreprife, qui ne pouvoit manquex Tom. Io

Ddd 
de lui attirer l'indignation du Roi , quelqu'en fút le fuccès; de lui remettre devant les yeux fa perte inévitable, \& l'infamie , dont il fe couvriroit, fi, pour fatisfaire fa paffion, il allumoit dans les Indes un incendie, qui embraferoit peut-être toutes les Colonies Efpagnoles; \& fi toutes ces confiderations ne fuffifoient pas pour l'obliger à defarmer, de le lui commander fous peine de défobéiffance, \& d'être traité comme rébelle. Vafquez exécuta ponctuellement fes ordres, mais il ne gagna rien fur l'efprit d'un homme, qui en vertu de fa nouvelle dignité, prétendoit n’avoir plus de Superieur dans le Nouveau Monde. La Flotte mit à la voile au mois d'Avril i s20. L'Auditeur s'y embarqua, dans la penfée que, quand il n'auroit plus affaire qu'à Narvaez, il en viendroit plus aifément à bout; mais il fut trompé dans fon attente. Arrivé au Mexique, \& voyant Narvaez rejetter avec obftination toute voye d'accommodement, il lui fit intimer une défenfe fous peine de la vie de paffer outre, fans avoir reçûu les ordres de l'Audience Royale. Ce coup d'authorité, qui partoit d'une perfonne revêtuë d'un caractere refpectable, commençoit à faire impreffion fur l'armée, \& le Général en craignit les fuites. Pour les prévenir, il fit fur le champ embarquer l'Auditeur dans une Caravelle, qu'il envoyoit à l'rhe de Cuba, en lui difant que fa trop longue abfence de l'Iffe Efpagnole pourroit préjudicier au fervice de l'Empereur. Mais Vafquez engagea le Patron de la Caravelle à le mener en droiture à San-Domingo, où l'on fut extrêmement furpris d'un tel attentat. D'un autre côté les efperances, que Velafquez avoit fondées fur un fi puiffant effort, s'évanoüirent bientôt par la défaite \& la prifon de Narvaez, dont les fuites furent, ainfi qu'on le lui avoit prédit, la perte de tout fon bien, \& la difgrace de fon Prince. Mais le recit de ce grand Evenement, appartient à une autre Hiftoire, \& m'é: carteroit trop de mon fujet.

Fin du cinquiéme Livre. 


\section{H I S T O I R E \\ D E}

\section{L'ISLE ESPAGNOLE}

O U D E

S. DOMINGUE.

PREMIERE PARTIE.

\section{I V R E S I X I E' M E。}

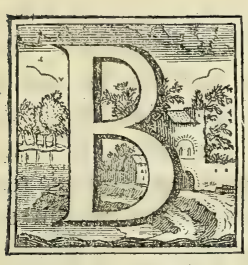

I $\mathrm{E}$ loin que les nouvelles acquifitions des Caftillans dans les Indes duffent fainoit en quelque façon néceffaire pour la confervation $\&$ l'utilité de ce grand corps de Monarchie, qui fe formoit autour d'elle, dont elle devenoit naturellement le centre \& comme le cœur, \& dont les membres difperfés ne pouvoient gueres avoir de communication entre eux, que par fon Canal. Elle eût été d'ailleurs fort en état de fe foutenir encore par elle-même, fi l'on eût voulu profiter de l'experience du paffé, pour la confervation des Infulaires, mais on les pouffa plus que jamais à bout, \& après qu'on les eût réduit à une poignée de monde; ce petit refte d'un million d'hommes, qui avoit fubi prefque fans réfiftance le joug de deux à trois cens Efpagnols s tint pendant treize ans en échec, \& fut fur le point de chaffer de l'lle une 


\section{HISTOIRE}

I519. Colonie puiffante, qui occupoit de grandes Villes, tenoit de bonnes Fortereffes, \& ne manquoit de rien pour attaquer \& pour fe défendre. Voici de quelle maniere la chole arriva.

Cacique

Chrerien nommé Hensy donne en commande.

Dans la Ville de San-Juan de la Maguana, un jeune Efpagnol nommé Valençuela, avoit hérité depuis peu par la mort de fon Pere d'un Département d'Indiens, qui avoient à leur tête un Cacique Chrétien, nommé Henry, dont les Ancêtres avoient regné dans quelque canton des Montagnes de Baoruco. Henry avoit été élevé dès fa plus tendre enfance dans le Couvent des Peres de S. François de la Vera- $\mathrm{Paz}$, dans la Province de Xaragua, \& il y avoit fort peu de têms, qu'il en étoit forti. La feuë Reine lfabellc avoit fort recommandé qu'on procurât aux Enfans des Caciques la meilleure éducation, qu'il feroit porfible, \& pendant plufieurs années ce fut là une des plus grandes occupations des PP. de S. François dans l'Inle Efpagnole. Ifabelle avoit bien prétendu qu'on ne s'en tînt pas là, mais qu'après avoir formé l'efprit \& le cœur de ces jeunes gens, on les employât aux chofes, dont ils fe feroient rendus capables; mais en cela, comme en bien d'autres articles, fes intentions n'avoient pas été fuivies. Les jeunes Caciques, après avoir bien appris la Religion, la langue Efpagnole, à lire \& à écrire, \& même un peu de Latin, étoient compris dans les Départemens, comme les derniers de leurs Sujets, \& n'étoient gueres diftıngués du commun, que par de plus mauvais traitemens.

Le Cacique Menry eft maltraité pa fon maître.
Celui, dont je parle, à peine forti de chés les PP. de $S_{\text {: }}$ François,avoit été donné aụ pere de Valençuela, il étoit bien fait, d'une taille avantageufe, d'un bon caractere: un air de fageffe répandu fur toute fa perfonne, une phyfionomie heureufe, de l'efprit, \& de la pieté, prévenoient d'abord en fa faveur: en un mot on voyoit en lui tout ce qu'une bon. ne éducation peut produire dans un fujet bien préparé , \& perfonne ne méritoit moins le malheureux fort, où il fe trouvoir réduit. Il le fupportoit néanmoins avec affés de 


\section{DE S. Domingue: Liv. VI.}

patience, \& il fervoit avec fidelité le Maître, qui lui étoit échû; mais la mort de ce Maître lui rendit bientôt fa condition infuportable. Valençuela ne l'eût pas plûtôt en fonpouvoir, quil lui fit tous les maux, dont il put s'avifer, jufqu’à vouloir débaucher fa femme. Henry fe plaignit, \& fes plaintes ne firent qu'empirer fa condition. Il crut avoir plus de juftice du Lieutenant de Roi de San-Juan, nommé Pierre de Badillo, il la lui demanda, mais cet Officier, bien loin de l'écouter, le 'menaça de le punir févérement, s'il lui arrivoit une autre fois de parler contre fon Maître.

Rebuté à ce Tribunal, il s'adreffa à l'Áudience Royale ; Il n'en peur mais tout le fruit de la Supplique, qu'il lui préfenta, fut avoir juftice. une letre de recommandation pour Badillo. Cet Officier fentit bien par la foibleffe de cette démarche, qu’on le laiffoic affés le maître d'en ufer, comme il le jugeroit à propos; il reçut fort mal Henry, lorfque ce Cacique lui préfenta la Lettre de l'Audience Royale, \& Valençuela redoubla fes mauvais traitemens, quand il fçut le danger qu'ił auroit couru, fi l'on avoit fait droit au Chef de fes. Indiens fur fes plaintes. Henry ne voyant plus de reffource, tâcha de gagner fur lui de fouffrir en filence un mal devenu néceffaire, \& de couler le plus doucement, qu'il lui feroit poffible, le têms qui reftoit de fon fervice ; car l'Ordonnance qui défendoit de faire travailler les Indiens au-delà d'un certain terme, fans difcontinuer, s'exécutoit alors avec affés d'exactitude, ayant été apparemment renouvellée par.les PP. de S. Jerôme.

Ce terme érant expiré, le Cacique trouva moyen Ilferetire de s'éloigner avec un bon nombre de fes gens, \& il !eur \& forme un perfuıda fans peine de s'attacher à lui, en leur promettant quel il fe cano qu'ils ne ferviroient plus les Efpagnols. Il chercha enfuite tonne dans les un pofte, dont la fituation le mît en füreté contre les pour- Montagnes de fuites de Valençuela, \& il le trouva dans les Montagnes de Baoruco, où avec quelques armes, dont il avoit eula précaution de fe fournir , il attendit tranquillement qu'ọn D.dd iij 


\section{HIS T O IR I}

I519. vint à lui, Il n'attendit pas long-têms, Valençuela n'eute pas plûtôt appris fa fuite, qu'il fe mit à fes troufres avec une douzaine d'Efpagnols, \& ayant découvert fa retraite, il fe préparoit à l'attaquer, lorfque le Cacique s'étant un peu avancé, lui dit, fans s'émouvoir beaucoup, qu'il poüvoit s'en retourner, \& qu'il fe flattoit en vain que, nilui, ni aucun des fiens fe foûmît jamais à travailler fous fes ordres. Une pareille déclaration mit en fureur le jeune Efpagnol, qui méprifant un ennemi, qu'il ne connoiffoit pas affés, fit figne à fes gens de le faifir; alors Henry à la tête de fa petite Troupe, fe jetta de furie fur les Efpagnols, qui ne s'attendoient pas à une telle charge, en étendit deux fur la place, \& contraignit les autres de fuir, la plûpart bien bleffés. Il ne voulut pointant pas qu'on les pourfuivit, mais adreffant la parole à Valençuela, qui avoit reçû lui-même une bleffûre à la tête: a Allés,lui dit-il, remerciés Dieu de ce que so je vous laiffe la vie, \& fi vous êtes fage ne revenés pas ici.

Tes Efpagnols font défaits en plufieurs tencontres.

I5 20.

La nouvelle de ce qui venoit de fe paffer, fe répandit bientôt par tout, \& l'Audience Royale crut ne devoir rien négliger, pour arrêter le mal dans fa fource. Elle donna ordre qu'on fit marcher incefamment 80 hommes pour ranger le Cacique à la raifon, avant qu'il pût fe fortifier. Henry averti de ces préparatifs, s'alla retrancher dans un Bois où les Soldats Efpagnols l'ayant trouvé après une marche. qui les avoit mis prefque hors d'haleine, il ne lui fut pas difficile de les défaire; une partie fut tuée fur le champ. prefque tous les autres furent bien bleffés, \& il ne s'en feroir pas fauvé un feul, s'ils euffent été pourfuivis. Cette action donna une grande réputation au Cacique, \& produifit des mouvemens bien differents dans l'efprit des Indiens, \& dans celui des Efpagnols. Ceux-ci s'apperçurent avec étonnement qu'ils avoient à faire à des hommes, \& ceux-là reconnurent avec plaifir que leurs tyrans n'étoient pas invincibles. Un grand nombre de ces derniers, qui fe rencontroient: dans les habitations Efpagnoles s'échapperent, \& vinIent le joindre à Henry, qui en affés peu de têms fe trot- 


\section{De S. Domingue, Liv. VI. 399}

va à la tête de 300 . hommes, fur lefquels il pouvoit compter.

Il les arma le mieux, qu'il lui fut poffible, \& il s'étudia Ildifcipline furtout à les difcipliner. Il les tenoit continuellement en fes Troupes haleine, il leur faifoit faire l'exercice des armes Europeen- la défenfive. nes, dont il fe vit avec le têms fuffifamment pourvû; il les accoûtuma à combattre avec ordre; en un mot ce jeune Cacique, qui de fa vie n'avoit vû la guerre, dreffa fon plan aufí-bien, qu'auroit pû faire le plus experimenté $\mathrm{Ca}$ pitaine, \& rendit formidables aux Conquerans de fa $\mathrm{Pa}-$ trie une poignée de ces mêmes hommes, qu'ils avoient prefque mis jufques là au rang des Brutes. Mais ce qui lui fit plus d'honneur dans cette guerre, c'eft l'attention, qu'il eut de fe tenir toûjours dans les bornes d'une fimple défenfe. Il eft vrai qu'il ne fut pas toûjours en cela exactement obéi : fes gens, furtout dans les premieres années, firent quelques courfes dans le plat Pays, \& commirent à fon infçî́ quelques hoftilités, mais on lui a rendu la juftice de croire qu'il n’y avoit point eu de part, \& qu'il avoit feulement été quelquefois obligé de diffimuler ce qu'il ne pouvoit empêchèr.

On envoya en divers têms plufieurs partis contre lui , Sa moderæ. \& ils furent toûjours battus; mais il ufoit de fes avantages tion dans fes avec une moderation, qui donnoit un nouveau luftre à fes victoires. victoires. Il la fit furtout paroître dans une rencontre, où il pouvoit en agir autrement, \& affoiblir fon Ennemi, fans qu'on eût rien à lui reprocher. Il avoit repouffé un corps confiderable de Troupes Efpagnoles, \& en avoit fait un grand carnage. $7 x$. Soldats, que la fuite avoit fouftraits au fer des Victorieux, rencontrerent une Caverne creufée dans le Roc, \& s'y cacherent, dans l'efperance de pouvoir gagne: la plaine à la faveur de la nuit; ils y furent découverts par un parti Ennemi, lequel ayant environné la Caverne, en boucha toutes les iffuës avec du Bois \& d'autres matieres combuftibles, \& fe préparoit à y mettre le feu, lorfque Henxy furvint. Il reprocha à ces furieux leur barbarie , fit déa 


\section{$400 \quad H$ I s $T$ T $\mathrm{R}$ B}

1520. boucher la Caverne, laiffa les Efpagnols en liberté d'allet où ils voulurent, \& fe contenta de les défarmer. C'étoit fouvent l'unıque butin, qu'il faifoit, mais par là infenfiblement fd Troupe fe trouva armée de toutes pieces, \& fes Indiens commencerent à manier parfaitement les armes Efpagnoles, excepté l'Arquebufe, dont il ne leur fut jamais poffible de fe fervir.

Sa vigilan- Le dépit des Efpagnols augmentoit en voyant ces Sauvamaniere il guelle ges, contre qui ils n'avoient gueres daigné jufques là emgouven ne fa ployer que desChiens, non feulement ofer leur tenir têre, mais République. encore les battre en toutes rencontres. Cependant ils ne connoiffoient pas encore à quel homme ils avoient affaire. Le jeune Cacique ne s'endormoit point fur fes fuccès, \& l'on auroit peine à imaginer jufyu'où il portoit la vigilance \& la précaution, pour ne rien perdre de fes avantages, \& pour maintenir fa petite République en bon état. 11 avoit fait des $\mathrm{Ha}$ bitations dans les lieux écartés, \& où il n'étoit préfque pas poffible de pénétrer. Les plus foibles \& les femmes $s$ y appliquoient à la culture de la terre, \& y éleroient des Beftiaux \& des Volailles; ils y avoient aufi de bonnes meutes de Chiens, four la Chaffe du Cochon, enforte que l'abondance regnoit au milieu de cet affreux défert.

Ses mefures Les mefures, qu'il prenoit pour mettre fa perfonne en fûpour mettre la perfonnę en iureté. reté, n'étoient pas moins juftes. Il avoit cinquante Braves: qui ne l'abandonnoient point, dès qu'il étoit en Campagne, $\&$ avec lefquels il accouroit dabord aux premieres nouvelles de l'approche des Ennemis. Hors de là, quoiquil comptât aflés fur la fidelité de tous fes gens, pour n'appréhender aucune trahifon de leur part : comme il pouvoit arriver que quelques-uns tombaffent entre les mains des Efpagnols, \& fe trouvaffent expofés à le découvrir malgré eux ; pour parer à cet inconvenient, il avoit foin qu'aucun d'eux ne fçut jamais, où il fe retiroit; enforte que; quand il les avoit envoyés quelque part, jamais ils ne le retrouvoient à l'endroit, où ils l'avoient quitté. Outre cela il poftoit des Sentinelles 


\section{DE S. Domingue, Liv. VI. 40 I}

tinelles à toutes les avenuës de fes Habitations; mais il ne fe repofoit pas tellement fur leur vigilance, qu'il ne vifitât lui-même exactement tous les poftes; ainfi il étoit partout, \& l'on ne fçavoit jamais précilément où il étoit. Ses Sujets croyoient qu'il ne dormoit point, \& il dormoit effectivement très-peu, jamais deux fois de fuite au même endroit, toûjours à l'écart, \& au milieu de deux de fes confidens, armés de toutes pieces. Après un fommeil fort court, il fe mettoit à faire la ronde autour de fes quartiers, $\&$ on ne le voyoit gueres fans un Chapelet au col, ou à la main; car il avoit toûjours été fort dévot à la Mere de Dieu, en qui il faifoit profeffion de mettre toute fa confiance.

Sa Troupe groflffoit tous les jours, les Negres mêmes défertoient par bandes pour laller joindre, \& la terreur de fon nom avoit tellement glacé tous les courages, en même têms que fa bonne conduite déconcertoit toute la Politique Efpagnole, qu'il ne fe trouvoit plus perionne, qui voulût marcher contre lui. On ne pou voit fe perfuader qu'il demeurât long-têms fur la défenfive; \& comme rien ne fait de plus rapides progrès que la crainte, quand elle s'eft une fois répanduë parmi le Peuple, on s'imagina bienı ôt voir ce formidable Cacique porter par tout le fer $\&$ la défolation : d'où il arriva qu'un aflés grand nombre d'Habitations, des Villes mêmes, \& des Bourgades fe trouverent peu-à peu abandonnées, \& ne fe font point rétablies depuis.

Dans cette extrêmité, on crut devoir tenter la voye de Un Pere la négociation, \& un Religieux Francifquain, nommé le P. Francifquain Remy, du nombre de ceux, qui, felon Herrera, étoient ve- avec le Caçnus de Picardie, s'offrit à aller trouver Henry, qu'il avoit que.

eu, il n'y avoit pas encore long-têms, fous fa conduite. Il comptoit fur la pieté \& fur le bon naturel du Cacique, \& il ne fe promettoit rien moins, que de l'engager à mettre bas les armes, pourvâ qu'il pût lui faire des Propofitions raifonnables, \&r lui donner de bonnes affitrances. Son offre fut acceptée, on le chargea de promettre au Chef, \& à tous Tome $I$.

Ia terrets de fon nom fe répand par tout, \& les effets qu'elle produit. 


\section{H IS T O I R}

I519. ceux, qui l'avoient fuivi, un pardon général pourle paffé, 1. \& quant à l'avenir, une exemption entiere de travail. On lui: 152I. remit à cet effet un plein pouvoir par écrit, dans la forme la plus ample, qui fe pouvoit fouhaiter, \& 2 l'on fit armer une Barque, dont le Pilote eut ordre de débarquer le Religieux. feul, vis-à-vis de la Beata, vers l'endroit où les Montagnes de Baoruco aboutiffent la Mer, \& de s'éloigner enfuite un peu, enforte néanmoins, qu'il ne perdît point le P. de vûë , \& qu'il pût fe rapprocher au moment, qu'il feroit rappellé. Tout cela fut ponctuellement exécuté, \& le Francifquain ne fut pas plûtôt à terre, qu'il vit fortir d'entre les Montagnes une Troupe d'Indiens, qui l'environnerent. Il les pria de le me. ner à leur Chef, \& il leur dit que s'ils n'ofoient prendre fur eux de faire cette démarche fans fon confentement, ils allaffent le lui demander, qu'ils n'auroient aucune peine à l'ob. tenir, dès qu'ils lui apprendroient que le P. Remy, dont il avoit été difciple à la Vera-Paz, vouloit lui parler, \& avoit des chofes agréables à lui dire.

De quelle

Ces Indiens, qui ne connoiffoient point ce Religieux, lui maniere il eft répondirent que leur Cacique n'avoit pas befoin de fa vifite reçû́ des Indiens.

que tous les Efpagnols étoient des traitres, qu'il avoit bien la mine d'être un Efpion, \& que toute la grace, qu'ils pouvoient lui faire, étoit de ne pas le traiter comme tel. En difant cela, ils le dépoüillerent, \& le laifferent nud fur le rivage. Par bonheur pour le bon Pere, Henry n'étoit pas loin, \& fut averti d'abord de ce qui fe paffoit, il accourut dans le moment pour empêcher qu'on ne fe portât à quelque vio. lence contre un homme qu'il eftimoit, \& pour lequel il avoir confervé beaucoup de reconnoiffance \& de vénération. II fut fenfiblement touché de l'état, où il le trouva, il l'embraffa tendrement, \& fut quelque têms fans pouvoir s'expliquer autrement, que par fes larmes; après quoi il lui fit de très-finceres excufes de la maniere, dont on l'avoit traité.

Ce qui re Le Miffionnaire voulut profiter d'une fi favorable difpopaffe entre lui fition pour engager le Cacique à rendre la paix à fa Patrie, 


\section{DE S. Domingue, LIV. VI. 403}

\& lui dir fur cela les chofes du monde les plus fortes \& les plus touchantes. Henry n'y parut pas infenfible, mais il répondit qu'il ne tenoit qu'aux Efpagnols de faire ceffer la guerre, dans laquelle tout le bornoit de fa part à fe défendre contre des Tyrans, qui en vouloient à fa liberté \& à fa vie; qu'encore qu'il fe vît en état de vanger le fang de fon Pere, $\&$ celui de fon Ayeul, qui avoient été brûlés vifs à Xaragua, \& les maux, qu'on lui avoit faits à lui-même, il ne fe déparriroit jamais de la réfolution, quil avoit prife, de ne faire aucune hoftilité, fans y être contraint, qu'il ne prétendoit rien autre chofe, finon de fe maintenir dans fes Montagnes; qu il croyoit ufer de fon droit, \& qu'il ne voyoit pastrop, fur quoi fondés, on vouloit le contraindre à fe foumettre à des Etrangers, qui ne pouvoient appuyer leur pof feflion, que fur la violence : que quant aux affúrances, qu'on lui donnoit d'un traitement plus doux, \& même d'une en* tiere liberté, il feroit le plus imprudent des Hommes, s'il fe fioit à la parole de gens, qui n'en avoient tenu aucune depuis leur entrée dans lifle; qu'au refte il tâcheroit de fe con ferver toûjours dans les fentimens de Religion que le Pere lui avoit infpirés, \& qu'il ne rendroit jamais le Chriftianifme refponfable des violences, des brigandages, des injuftices, des impietés, \& des diffolutions de la plûpart de ceux, qui le profeffoient.

Le P. Remy répliqua, \& fut toûjours écouté avecrefpeĉ, mais il ne gagna rien. Le Cacique fit chercher fon habit pour rien. Extrếle lui rendre, mais il avoit été mis en pieces, \& on n'en Colonie fe avoit point d'autre à lui donner. Henry en eut un vrai cha- trouve rédus grin, lui renouvella fes excufes, le conduifit jufqu'au bord de la Mer, l'embraffa de nouveau en prenant congé de lui , \&. zentra dans fes Montagnes, d'autant plus réfolu à fe bien défendre, qu'on venoit de lui faire connoître, combien on le craignoit. On fçut quelque têms après que Badillo, dont linjuftice avoit été une des principales caufes de ce foule. ¥ement, \& qui étoit parti depuis peu pour l'Efpagne, avec des richeffes immenfes, avoit péri avec tous fes tréfors. E e e ij 


\section{H I S T I R}

I519. à la vûë du Port de Cadix. Il n'y eut perfonne, qui ne ré-

1 connut la main de Dieu dans un châtiment fi.prompt, \& f

I5.2. marqué; mais cet Officier n'étoit pas le feul coupable, dont le Ciel fut en quelque façon engagé à punir les excès; plufieurs les expierent par les mains de ces mêmes Indiens, qui en avoient été i'occalion \& l'objet, \& il n'y eut pas alors un Habitant de l'Ine Efpagnole, qui ne crût fes biens \& $f_{a}$ vie même en danger; le parti de Henry faifant de $f_{i}$ grands \& de fir rapides progrès, qu'il y eut lieu d'appréhen. der la ruine entiere de la Colonie.

Voyage \& Une lettre écrite au Roi Catholique par l'Audience Roya* Avanture d'un Navire Anglois. le, à peu près dans le têms, que commença cette Révolte, nous apprend en quel état fe trouvoit alors la Colonie de l'Ifle Efpagnole; mais avant que de rapporter ce quelle contenoit, il eft bon de dire à quelle occafion elle fut écrite. Une Caravelle de San-Domingo étant allé charger de la Caffave à l'Ifle de Portoric, le Capitaine Ginez, qui la commandoit, fut affés furpris dy voir arriver un Navire de 2 s. Tonneaux, lequel avoit deux Canons braqués fur le devant, \&, qui confideré de près, ne lui parut point Efpagnol. Il arma auflitôt fa chaloupe pour l'aller vifiter, \& il reconnut qu'il étoit Anglois. Ceux, à qui il s'adreffa, lui dirent qu'ils étoient partis d'Angleterre avec un autre Bâtíment, pour aller chercher les Terres du Grand Cam; mais qu'une furieufe tempête les avoit féparés; qu'ils s'étoiene enfuite trouvés dans une Mer. toute couverte de Glaces; qu'ayant été affés heureux pour s'en débaraffer, ils avoient été tranfportés dans une autre Mer, dont l'eau boüilloir, comme fait celle, qui eft dans une Chaudiere fur le feu; qu'après s'être encore fauvés d'un fi dangereux parage, ils étoient allés reconnoître l'Ifle des Moruës, où ils avoient rencontré so. Bâtimens, Efpagnols., Erançois \& Portugais; qu'ils avoient voulu defcendre à terre pour reconnoître le Pays, mais que les Indiens les avoient fort malrraités, \& avoient tué entre autres leur Pilote, qui étoit un Piémontois : que s'étant remis en Mer, ils avoient ran. 


\section{DE S. Domingue, Liv. VI. MOS}

gé la Côte jufqu’à la Riviere de Chico, (c'eft celle, que nous nommerons bientôt le Jourdain), \& que de-là ils avoient traverfé à I Inle de Portoric.

Ginez leur demanda à quel deffein ils étoient venus là, \& ils répondirent que c'étoit pour y charger du Bois de Brefil, \& pour être plus en état de rendre compte à leur Roi de ce que c'étoit que les Ifles, dont on parloit tant. Ils le prierent de leur marquer la route, qu'ils devoient tenir pour paffer à l'Efpagnole, \& il ne crut apparemment pas qu'il y eut aucun inconvenient à faire ce qu'ils fouhaittoient, d'autant plus qu'ayant examiné de plus près leur Navire, il vit bien qu'en vain il s'oppoferoit à leur deffein: qu'ils étoient en état d'aller malgré lui par tout, où ils voudroient, \& que d'ailleurs ils avoient quantité de Marchandifes de traitte, fur lefquelles ceux, qui les acheteroient, pourroient faire un grand profit. Ils appareillerent donc pour l'Ifle Efpagnole, \& paffant à la petite Ifle Mona, ils y débarquerent une partie de leurs gens. Ils refterent deux jours moüillés à l'entrée du Port de San-Domingo, attendant réponfe à la demande, qu'ils avoient envoyé faire de traitter leurs Marchandifes. Cette réponfe ne vint point , parce que le Gouverneur de la Citadelle, à qui leur Envoyé s'étoit adreffé, \& qui avcit fait demander à l'Audience ce qu'il avoit à faire, fe laffa d'attendre la réfolution des Auditeurs, \& s'avifa de tirer le Canon fur le Navire Anglois; ce Bâtiment leva aufi-tôt fes Ancres, retourna à Portoric, y vendit une partie de fa Carguaifon à des $\mathrm{Ha}$. bitans du Bourg de Saint Germain , \& ne parut plus de. puis. Les Auditeurs Royaux trouverent fort mauvais que le Gouverneur de la Fortereffe eût tiré fur ce Navire, \& lui en firent un crime à la Cour : \& dans la Lettre, qu'ils. écrivirent au Roi à ce fujet, après avoir reprefenté à ce Prince le mauvais état,où fe trouvoit cette même Forterefle, dont les Fortifications avoient befoin d'être réparées, \& qui manquoit également d'Hommes, d'Artillerie \& de Munitions, ils le fupplierent de faire réflexion aux articles fui.

Ee e iij 


\section{HIST I I E}

I5r9. vans, quils prenoient la liberté de lui expofer.

Que la Colonie de l'Ine Efpagnole, non feulement étoit

I 2 I. la premiere, que les Caftillans euffent établie dans les InIt Efpagnole des, mais que c'étoit encore elle, qui actuellement nourrifen cette an- foit toutes les autres; que la Ville de San-Domingo devenée. noit tous les jours plus peuplée, plus riche, \& plus floriffante; que fon Port étoit continuellement rempli de $\mathrm{Na}$ vires de toutes les parties des Indes, qui y venoient charger des Cuirs, de la Caffe, du Sucre, du Suif, \& d'autres Marchandifes de même prix , des Vivres, des Chevaux, \&r des Porcs. Que Buenaventura \& la Majorada étoient au milieu de très-abondantes Mines d'Or, mais que ces Mines étoient fermées, faute d'Ouvriers, \& que ces deux Villes n'avoient pour fe foûtenir qu'un peu de Caffe; que Bo. nao abondoit en Caffave, en Maiz, \& en autres Victuailles; que la Ville d'Azua avoit beaucoup de Sucre, \& que fon terrein étoit fi fertile, que des Cannes plantées depuis fix ans étoient auffi fraîches, que fi elles euffent été de l'année même, ou de la précédente; qu’outre cela elle avoit encore des Mines d'Or dans fon voifinage; quil y avoit auffi beaucoup de Sucre à $S$. Jean de la Maguana, \&qu'il y étoit le meilleur \& le plus beau de toutel'Ifle; que tout le pays d'alentour étoit plein de Mines, \& fourniffoit une très-grande quantité de Vivres; qu'on y avoit planté peu d’années auparavant un Palmier, lequel portoit déjà des Dattes: que la Ville d'Yaguana avoit un bon Port, des Mines, de la Caffe, \& tout ce qui étoit néceffaire pour y établir un grand Commerce; qu'à Puerto Real on alloit recommencer à tirer de l'Or des Mines, qui étoient dans fon diftrią; que Puerto di-Plata étoit très-floriffant, \& qu'il y venoit un très-grand nombre de Vaiffeaux de Caftille, qui tous y trouvoient leur charge de Sucre; enfin que Salvaleon de Higuey commençoit à faire des Sucres, \& que fes Campagnes nourriffoient un très - grand nombre de Troupeaux. Les Auditeurs n'ajoûtoient point, ce qui étoir zéanmoins véritable, qque cette grande quantité de Sucre. 


\section{DE S. Domingue, LIv. VI. 407}

qui fe fabriquoit dans l'Ifle Efpagnole, \& ailleurs, étoit un effet des foins, que s'étoient données les PP. de S. Jerôme, \& le Licencié Alphonfe Zuazo. Parlant enfuite des autres Ifles, ils difoient, que dans celle de Cuba, de huit Villes ou Bourgades, qui y avoient été bâtiespar Velafquez, il y en avoit fix, où l'on ne faifoit point d'autre commerce, que celui de $\mathrm{A}^{\prime} \mathrm{Or}, \&$ qu'on ne voyoit des Métairies \& des Troupeaux, qu'aux environs de la. Havane: toute l'Ine étant fort montueufe, \& affés fterile: qu'il y avoit deux Peuplades dans la Jamaïque, Oriftan \& Seville: que cette Inle avoit peu d'Or, mais qu'on y faifoit beaucoup de Sucre, \& que quelques Habitans s'étant avifés d'y planter de la Vigne, y avoient fait de très-bon Vin clairet. Le memoire repréfentoit enfuite à fa Majefté que, fi elle vouloit conferver des Colonies fi utiles, il étoit abfolument néceffaire d'y envoyer grand nombre de Negres, \& il entroit dans un très-grand détail des moyens, qu'on pouvoit prendre pour établir ce Commerce \& le faire circuler dans tous les lieux, où il en feroit befoin. Les Hiftoriens ne difent point l'effet, que produifirent ces repréfentations \& ces avis, mais que la Cour entra en grande inquiétude au fujet du Navire Anglois, qui avoit paru à Portoric \& à San-Domingo. On y auroit fort fouhaitté que le Gouverneur de la Fortereffe de cette Capitale, au lieu de l'obliger à s'éloigner, eût fait enforte de s'en faifir, pour l'empêcher d'apprendre à ceux de fa Nation la Route des Indes, où l'on étoit déjà dans de grandes allarmes, de ce que les François commençoient à s'y montrer très-frequemment.

Cependant Charles-Quint s'étant rendu à la Corogne, où j'ai dit qu'étoit la Flotte, fur laquelle il devoit s'embarquer, pour aller prendre poffeffion de l'Empire, l'Amiral D. Diegue, qui ne ceffoit point de folliciter fon rétabliffe- Indes. Maument dans tous les droits de fes Charges, avec la permif- de Figueroa. fion d'aller exercer celle de Vice-Roi des Indes, l'y fuivit \& obtint, du moins en partie, ce qu'il demandoit. Charles

1520

L'Amira
15190

I $52 \mathrm{r}$.

De lintede Cuba 


\section{H I S T O I R E}

I 5 i 9.

I 52 I.

reconnut fans peine, que ce qu'on avoit écrit contre lul étoit faux dans la plûpart de fes points, \& fort ex ggeré dans le refte. Il jugea d'ailleurs que les fervices du Pere demandoient quelque indulgence pour le Fils. Enfin on faifort de grandes plaintes de Figueroa, lequel ayant voulu remettre tous les Indiens en liberté , s'étoit attiré les Officiers Royaux, \& fur tout le Iréforier Général Paffamonté. Dans le vrai, Figueroa avoit donné prife fur lui, il avoit débuté d'une maniere fort odieufe, ayant voulu faire le procès à Zuazo fon Prédeceffeur, qui étoit en vénération dans l'Ifle, \& qui mit effectivement fon innocence \& fa probité dans la plus grande évidence. Mais ce qui acheva de le perdre, ce fut fon avarice, car elle le porta à vexer les Peuples, d'une maniere, qui mit tout le monde contre lui, \& obligea le Roi à révoquer fa Commiffion; il ne le rappelle pourtant pas; il lui donna même une place dans l'Aucience Royale, \& lui laifla l'adniniftration des Indiens. Herrera dit qu'il forma deux peuplades de ces Infulaires, à qui on donna toute liberté de vivre à leur maniere, mais qu'ils firent paroître tant d'ıncapacité à fe conduire, une fi grande pareffe, \& fi peu de précaution pour fe procurer même le néceffaire, qu'on demeura convaincu de la néceffité des Départemens. Toutefois la petite République, établie dans les Montagnes de Baoruco par le Cacique Henry, faifoit fentir le contraire d'une maniere, qui ne fouffroit point de réplique. Quoiqu'il en foit, Figueroa ne garda pas longtêms les deux Emplois, qu'on luı avoit laiffés ; il s'y comporta fi mal, qu on lui fit fon Procès à San-Domingo pour concuffions; il fut condamné à une très-groffe amende, \& déclaré incapable de pofieder jamais aucun Office Royal. Il en appella au Confeil des Indes, \& pafla en Eipagne pour faire agir fes amis; mais la Sentence de l'Audience Royale fut confirmée, \& l'Arrêt du Confeil lui fut fignifié à Tolede en I 525 .

Nouveaux

Pour revenir à l'Amiral, le Roi lui ayant permis de reseglemens. tourner aux Indes, fit écrire à Paffamonté que fon intention 


\section{DE S. Dominger, LIV. VI. 409}

tion étoit qu'il vécut en bonne intelligence avec le Gé. néral; \& pour aller au-devant de toutes les conteftations, les bornes de la jurifdiction de l'un \& de l'autre furent reglées par une Déclaration, qui entroit dans les plus petits détails. Par ce Reglement l'autorité de l'Amiral fe trouvoit extrémement diminuée; le Roi établit même un Surveillant, qui eut droit d'informer contre lui, mais qui ne pouvoit faire autre chofe, que d'envoyer les informations au Confeil. Le quint pour l'or; fut en même têms réduit au dixiéme dans l'Ille Efpagnole, où l'on commençoit à en tirer très-peu, faute d'Ouvriers pour travailler aux Mines: mais en récompenfe, il fe faifoit beaucoup de Sucre, \& ce feul objet étoit capable de rendre la Colonie floriffante. On avoit établi depuis peu des P P. de S. Dominique \& de S. François à la Côte de Cumana. Le Roi recommanda fort à l'Amiral de ne les laiffer manquer de rien. Enfin, comme on avoit déjà reçû la nouvelle de la révolte du Cacique Henri, D. Diegue eût ordre de preffer fon départ, \& de ne rien négliger pour mettre fin à ce foulevement. Il s'embarqua au. commencement de Septembre, \& deux mois après il prit terre à San-Domingo.

Son arrivée fit plaifir à quelques-uns, \& donna du chagrin aux autres, furtout à ceux, dont l'autorité fe trouvoit af- fon arrivée à foiblie par la préfence d'un auffi grand Seigneur. Dom Diegue de fon côté, ne parut pas fe mettre beaucoup en peine de regagner ceux, qui lui avoient été mal affectionnés; il compta, ce femble, un peu trop fur fon crédit, \& il commença par un coup d'autorité, qui juftifia les craintes de plufieurs ; quelques Gouverneurs particuliers, qui lui avoient obligation de leurs places, s'étoient voulu rendre indépendans; il fut bien aife de leur faire fentir qu'il étoit encore leur Superieur; il les interdit, \& envoya des particuliers pour gouverner en leur place, \& pour leur faire rendre compte de leur adminiftration. Zuazo fut choifi pour l'Inle de $\mathrm{Cu}$ ba, où, avec les mêmes vertus, dont il avoir donné de fi grandes preuves dans l'Ile Efpagnole, il eut le même fort, 


\section{HISTOIRE}

3520. c'eft-à-dire, que les gens de bien \& les pauvres lui don. nerent mille benedictions; \& que ceux, qui ne vouloiens pas que leur conduite fût éclairée de fi près, firent de grandes plaintes contre lui. Les chofes allerent fi loin, que l'Amiral fut obligé de paffer dans l'Ifle : fa préfence déconcerta les mutins, il n'eut que des loüanges à donner au vertueux Zuazo, dont la Commiffion étant finie, il rétablit Velafquez dans l'exercice de fa Charge, goûtant fans doute, le plaifir de fe voir redevenu l'arbitre du fort d'un homme, qui n'avoit payé fes bienfaits, que d'ingratitude, \& avoit voulu tirer au bâton avec lui.

Expedition On étoit alors fort occupé à marquer les Peuples, qui de Luc Vaf- devoient être regardés comme Antropophages, \& la moindans la Elori-dre conjecture paffoit aifément pour une preuve en ce point. de.

On connoiffoit, par exemple, affés peu cette grande partie du Continent, à laquelle on a étendu depuis le nom de Floride. Jean Ponce de Leon n'en avoit découvert, que les Côtes les plus voifines de la prefqu'llte, qui fe termine aus Canal de Bahama, \& quelques - uns de fes Gens y avoient apparemment été mangés par les Sauvages: ç'en fût affés pour déclarer Cannibales tous les Floridiens. C'étoit ouvrir un grand champ à l'avidité de ceux, qui ne cherchoient qu'à faire des Efclaves : car toutes ces Régions Septentrionnales paffoient pour être fort peuplées, \& les hommes y. paroiffoient plus robuftes, que dans les Provinces Meridionnales. On réfolut donc de les mettre fous le joug. L'Auditeur Royal Luc Vafquez d'Ayllon, dont nous avons déjà parlé, forma une Compagnie, arma deux Navires, \& s'étant embarqué à Puerto di Plata, il s'éleva jufqu'au trente-deuxiéme degré de Latitude Nord. Il apperçut bientôt la Terre, \& comme il la côtoyoit de fort près, pour chercher un débarquement commode, il apperçut une affés grande Riviere, où il entra, \& à laquelle un de fes Capitaines, ou Pilotes, appellé Jourdain, donna fon nom. Afrés près de l'embotzchure de ce Fleuve, il y a un Cap, qui fut appellé le Cap de sainte Helene, parce qu'il fut découvert le jour, qu'ons 


\section{DE S. DOTINGUE, LIV. VI. $\operatorname{LII}$}

célébre la Fête de cette Sainte Impératrice.

Dès que les deux Navires eurent paru à cette Côte, les

1520. Sauvages, qui n’avoient jamais rien vú de femblable, accou- fut le fuccè so rurent en foule fur le Rivage, ce qui réjoüit fort les Efpagnols. Il eft vrai que lair de ceux-ci, leurs barbes, leur habillement, leurs armes effrayerent les Barbares à un point, qu'ils s'enfuirent à toutes jambes vers le Bois; on courut après, \& on en arrêta un avec fa Femme. On leur donna à manger, on les habilla, on leur fit beaucoup de careffes, on les chargea de préfens, \& on les renvoya fort fatisfaits. Ce bon traitement fit revenir une partie de ceux, qui s'éroient retirés, \& leur curiofité les porta à vifiter les $\mathrm{Na}$ vires. Dès qu'on les y eut embarqués, Vafquez mit à la voile, \& reprit la route de lifle Efpagnole; mais Dieu ne permit pas qu'il tirât aucun fruit dune fi indigne trahifon. Un de fes Navires périt en Mer, \& perfonne ne s'en fauva. Ies Indiens, qu'il avoit fur fon Bord, moururent tous de chagrin, les uns pendant la traverfée, \& les autres, peu de têms après leur arrivée à l'Ifle Efpagnole. Il ne laifla pas d'aller en Efpagne, où il vanta fort fon expedition \& fa découverte, qu'il faifoit aller de pair avec celle de la nouvelle Efpagne; \& il fit tant, qu'il obtint de l'Empereur des provifions de Gouverneur de la Province de Chicora. J'ai déjà dit que la Riviere de Jourdain fe nommoit chico, on appelloit chicora le Pays,qu'elle arrofe. Mais cet honneur ne fervit qu'à engager Vafquez dans des dépenfes qui le ruinerent. Quelques-uns ont même écrit, qu'il périt dans un fecond Voyage, qu'il fit au même lieu, où il avoit abordé la premiere fois, \& il eft certain, que cette extrêmité de la Floride, qui eft limitrophe de la Virginie, na jamais été établie par les Efpagnols. La Province de Chicora faifoit partie de ce qu'on a long-têms appellé la Floride Françoife, \& qui eft connuë aujourd'hui fous celui de Caroline. Il s'étoit fait peu de têms auparavant une autre entreprife, qui n'eut pas un fliccès plus heureux. L'A miral, en partant d'Erpagne, avoit embarqué fur fon Bord un ancien Habitant de San-Domingo. Effij 
1.5.20. nommé Antoine Serrano,il fit avec lui un Traité pour formeì des Etabliffemens dans les Ines Caraïbes, \& dès qu'ils furent arrivés à l'Ifle Efpagnole,Serrano travaille à fes prépara rifs. Son deffein étoit de peupler la Martinique,la Guadeloupe, Mont-Serrat, la Barbade , \& la Dominique ; \& il devoit y demeurer en qualité de Commandant, jufqu'à ce que l'Amiral, ou la Cour y eût envoyé des Gouverneurs ; mais ce projet, pour lequel l'on avoit déjà fait de grandes dépenfes, échoüa, fans que j’aye pû fçavoir ce qui l'empê cha de réüflir.

Ias Cafas Cependant Barthélemy de Las Cafas ne s'étoit pas plus repalie auxIn-endormi que D. Diegue Colomb. Il avoit auffi fuivi le des.

Roi à la Corogne, où après quelques difficultés il obtint à. peu près tout ce qu'il vouloit. I1 n'y eut pas jufqu'à l'Evếque de Burgos, qui, pour ne pas s'attirer les Seigneurs Fla. mands, \& le Cardinal Adrien, que Charles laiffoit en Efpagne avec une autorité prefque fouveraine, ne s'étudiât à lui faire plaifir en tout ce qui dépendit de lui. Il s'embarqua enfin à Seville avee 200. Laboureurs, qu'il avoit levés de nouveau, \& une fuite affés peu proportionnée à Ses vaftes deffeins. Il eut une traverfée fort heureufe jufqu’à Portoric; mais il y apprit des nouvelles, qui ne durent pas lui faire beancoup de plaifir.

Deux Do-

Nous venons de dire que les P. P. de S. Dominique \& miniquains maffacrés à la Côte de Cumana. de Saint François, s'étoient établis depuis petı à la Côte de Cumana; c'étoit déjà un grand acheminement à l'exe. cution des projets du Licencié; d'autant plus que ces Miffionnaires avoient gagné d'abord la confiance des Habitans de cette Province. Mais un évenement tout pareil à celui, qui avoit déjà côtré la vie à deux Dominiquains, vint encore troubler de fi belles efpérances. Un nommé Alphonfe de Ojeda: ( je n'ai pû fçavoir, s'il étoit parent du premier, fi célébre dans cecte Hiftoire par fes entreprifes \& fes malheurs; ) avoit enlevé des Indiens affés près d'un Village nommé'Maracapana, à quatre lieuës du Port de Chiribichi, où deux Beligieux du même Ordre, que les deux précedens, avoient 


\section{DE S. Domimgue, Lrv. VI.}

$4 I_{3}$

twe petite Maifon, qu'ils appelloient le Couvent de Sainte Foy : mais ayant eu l'imprudence de defcendre à terre au Village même de Maracapana, qui n'étoit qu'à trois lieuës de l'endroit, où il avoit fait fon coup, le Cacique du lieus lui dreffa une embufcade, où il périt avec environ fix Efpagnols de ceux, qui l'accompagnoient, le refte fut affés heureux pour fe fauver à la nage. Le Cacique donna auffitôt avis de ce qu'il venoit de faire à un autre Seigneur Indien nommé Maraguey, dont le Village étoit à quatre lieuës du fien, \& affés proche du Monaftere de Sainte Foy, \& lui confeilla de fe défaire des deux Religieux, qu'il avoit dans fon voifinage, afin de délivrer une bonne fois le Pays de l'inquiétude, où le tenoient les Caftillans. Maraguey goûta fort cet avis, \& ne differa à le fuivre, que jufqu'au lendemain qui étoit un Dimanche. Les deux Religieux, qui ne fçavoient rien de ce qui s'étoit paffé, furent pris au dépourvî, \& maffacrés dans le têms, que l'un fe préparoit à dire la Mefle, \& que l'autre, qui n'étoit pas Prêtre, venoit de fe confeffer pour communier. Les Barbares pillerent enfuite, ou brúlerent tout ce qu'ils trouverent dans la Cha. pelle $\&$ dans la Maifon, \& mirent le feu à l'une $\&$ à l'autre.

La nouvelle de ce défaftre arriva à l'Ine Efpagnole fort Embarras peu de têms après le retour de l'Amiral, \& la réfolution de Las Caras: y avoit été prife d'aller enlever tous les Habitans de $\mathrm{Cu}$ mana, pour les tranfporter dans sette Ine, où ils remplaceroient les Infulaires. L'exécution en avoit été commife à un Gentilhomme nommé Gonzalez de Ocampo, \& il s'étoit déjà embarqué à San Domingo avec 300. Hommes de bonnes Troupes fur cinq Bâtimens abondamment pourvûs de tout ce qui étoit néceffaire pour une pareille expédition. Ce fut fur ces entrefaites, que Las Cafas débarqua à PorIoric; on n'y parloit que de la révolte de Cumana, \& de la terrible vengeance, qu'on fe préparoit à en tirer, \& il avoit eu à peine le têms de faire réflexion fur un accident, qui dérangeoit abfolument fon projet, lorfque l'Efcadre d'Ocampo vint moüiller au même Port où il étoit. Ce Ca. Eff iij 


\section{4r4 HIS T O I R}

1520. pitaine étoit fon ami,le Licencié lui montra fes Provifions, \& voulut lui perfuader qu'en vertu du pouvoir, dont il étoit revêtu, lui feul avoit droit de prendre connoiffance de ce qui fe paffoit à la Côte de Cumana, comprife toute entiere dans fa conceffion : mais il ne gagna rien.

Il s'oppofe Ocampo, que la vâë de fon ami avec une Croix de envain à 'ex-Chevalier fur fon habit Ecclefiaftique, \& fuivi d'une troupe pedition con-
treles Indiens de Cumana. plaifanta beaucoup fur fes projets, puis prenant un ton plus férieux, il lui dit, qu'il avoit fes ordres \& qu'il ne dépendoit pas de lui d'y rien changer; qu'll éroit bien mortifié d'un contre-tếms fi fâcheux'; mais que c'étoit à l Amiral , \& à l'Audience Royale, qu'il devoit faire fes reprélentations; il mit peu de têms après à la voile, \& le Licencié fuivit fon confeil, laiffa fes Laboureurs, \& prefque tout fon monde à Portoric, \& paffa fans differer à San-Domingo. Il y trouva l'Amiral fort bien diffofé en fa faveur, \& il ne rencontra aucune difficulté à faire enregiftrer \& proclamer fes provilions. On peut bien juger que cette proclamation ne fit pas plaifir à tout le monde; mais Las Cafas ne laiffoit pas d'avoir des amis, \& il y en eut même d'affés généreux pour lui ouvrir leurs bourfes.

Succès de Pendant ce têms-là, Ocampo alla prendre terre à l'Ifle cette expedi- de Cubagua, où il laifla trois de fes Navires. Son but étoit sion. de faire des Efclaves; pour y réüfir, il ne falloit pas fe montrer fur la Côte avec toutes fes forces, \& non feulement, il n'y parut quavec deux Bâtimens, mais il fit même cacher tous les Soldats, quiil y avoit embarqués, \& l'on ny voyoit jamais que cinq ou fix Matelots pour faire la manœuvre. Cette fraude, toute groffiere qu'elle étoit, lui réüffit ; il fe vit bientôt environné de Pirogues remplies d'Indiens, à qui il préfenta du Bifcuit de Caftille, dont ces Peuples étoient fort friands. Il ne put neanmoins lever abTolument tous leurs foupçons. Ces Barbares $s$ attendoient bien qu'on ne laifferoit pas impunie la mort des Efpagnols, qu'ils avoient madacrés. Ocampo avoit beau leur afturer qu'il 


\section{DE S. Domingue, LIv. VI. 4 Is}

venoit de Caftille, plufieurs lui répondirent qu’il vouloit les tromper, qu'affurément il venoit d'Hayti, \& qu'il avoit I5 20 . quelque deffein contre eux. A la fin pourtant, il leur fit tant boire de Vin d'Efpagne, qu'il vint à bout de noyer toutes leurs craintes dans cette agréable liqueur, \& qu'ils commencerent à fe rendre extrêmement familiers. Il les reçut avec une affabilité , qui acheva de les féduire, \& un jour qu'un Cacique nommé Gil Gauzalez, qui avoit eu le plus de part à la défaite d'Ojeda, l'étoit venu voir avec un bon nombre de fes Vaffaux, il fit paroître tout à coup fes Soldats, \& le retint prifonnier avec toute fa fuite. Le Cacique voulut fe défendre, \& fut tué en combattant; quel. ques-uns des principaux furent pendus aux Vergues, \& les autres refervés pour les Mines. Le Général Efpagnol fit enfuite avertir les trois Navires, qu'il avoit laiflés à Cubagua, de le venir joindre, \& dès qu'ils furent arrivés, il tourna du côté, où les Efpagnols avoient été maffacrés, fit fa defcente fans prefque aucune réfiftance; força une Bourgade, où l'on fe défendit foiblement, fit pendre \& empaler une partie des Habitans, remplit fes Navires d'Efclaves, qu'il envoya fur le champ à l'Ine Efpagnole, pardonna aux autres Bourgades, qui implorerent fa clemence, \& avec ce qui lui reftoit de Caftillans, il fonda une Ville, qu'il nomma Tolede.

Rien n'étoit plus contraire aux droits de Las Cafas, que cet Etabliffement, \& le Licencié avoit toûjours craint quelque chofe de femblable de l'expedition d'Ocampo; auffi ne ceffoit-il de demander le rappel de cet Officier à l'Audience Royale;mais on ne lui répondoit rien de précis, \& l'on traînoit l'affaire en longueur, pour tâcher de le laffer. Les Audireurs, plus Marchands que Magiftrats, vendoient tout, juf qu'à la Juftice, \& fe trouvant Juges \& parties d'un homme, qui prétendoit fouftraire à leur cupidité 300 . lieuës de Côte, mais n'ofant s'oppofer directement aux ordres de l'Empereur, ils en éludoient l'execution, tantôt fous un prétexte, \& tantôt fous un autre; dans l’épérance que le

Difficultés qu'on fait à Las Cafas pour fon exa pedition. 


\subsection{H I S T O I R E}

1920. Licencié, fatigué de tant de délais, s'accommoderoít enfin avec eux. Neanmoins, voyant qu'il ne fe rebutoit point . ils s'aviferent d'ordonner une vifite de fon Navire, \& comme on ne minqua pas de le trouver incapable de foûtenir la Mer, il fut condamné \& démoli.

I 521 .

Las Cáas ennuyé de tant de chicannes, perdit enfin

Las Cafas patience, \& menaça de retuurner en Efpagne, pour inforentre en ac-mer 1 Empereur du peu d'égard, qu'on avoit pour fes orcommode- dres. Ces menaces eurent leur effet, on fe rendit un peu. I'Audience Royale. plus traitable, \& on lui fit des propofitions, aufquelles il aima mieux foufcrire, que de s'expofer de nouveau aux variations de la Cour \& des Confeils. Il figna donc en I $2 \mathbf{2}$. un Traité, qui portoit l'établiffement d'une Compagnie. où entrerent tous ceux, qui étoient alors en place dans 1 Ine Efpagnole. Toutes les difficultés furent applanies après la conclufion de ce Traité ; on lui donna les mêmes Vaiffeaux, qui avoient porté Ocampo à la Côte de Cumana, \& I 20. Hommes de bonnes Troupes, qui fous les ordres du même Ocampo, devoient faire la guerre aux Indiens, fuppofé que ces Barbares entrepriflent de molefter la nouvelle Colonie, ou qu'on les reconnût pour Antropophages. L'Efcadre partit de San-Domingo au mois de Juitlet, \& prit la route de Portoric, où Las Cafas ne put retrouver aucun de fes Laboureurs. Quelques-uns étoient morts, les autres avoient pris parti dans l'lle, \& n'en voulurent plus fortir. On peut juger du chagrin, que cette perte lui caufa, après ce qu'il lui en avoit coûté dargent \& de fatigues pour affembler ces gens-là, \& les amener jufqu'aux Indes. Mais il n'étoit encore qu'au commencement de fes malheurs.

De Portoric il alla débarquer tout droit à Tolede, dont les Habitans étoient fi rebutés d'avoir continuellement à lutter contre les Indiens, qu'ils foupiroient après une occafion d'en fortir. Ils profiterent de celle-ci, s'embarquerent fur les Navires, qui avoient apporté Las Cafas \& fa Colonie, \& jamais il ne fut poffible d'en engager un feul à sefter avec lui. Les Troupes, que devoit commander Ocam- 


\section{DES. DOMINGUE, LIV. VI. 417}

po fuivirent une fi dangereux exemple, \& cet Officier fe trouvant par-là fans emploi, ne jugea pas à propos de faire le trifte perfonnage de Général fans Troupes. Il prit congé de fon ami, dont il ne pouvoit que plaindre le fort, \& fit voiles avec tous les autres du côté de l'Ine Efpagnole. Tout autre que Las Cafas auroit renoncé à une entreprife, contre laquelle tout fembloit confpirer; mais nous avons déjà vû plus d'une fois qu'il ne fe rebutoit pas aifément. Il commença par fe loger \& conftruire des Magafins; il fit enfuite avertir les Indiens par une Femme Chrétienne de leur $\mathrm{Na}$ tion, nommée Marie, laquelle fçavoit un peu de Caftillan, qu'il avoit été envoyé par l'Empereur pour faire ceffer les trahifons, \& les mauvais traitemens, qu'on leur avoit faits jufqu'alors, \& leur procurer, avec la connoiffance du vrai Dieu, tous les biens, qu'ils pouvoient fouhaitter. Ayant enfuite remarqué la néceffité, où étoient les Efpagnols de Cubagua, de venir chercher de l'eau dans la Riviere de Cumana, fur laquelle Tolede étoit fitué ; il voulut faire conftruire une Fortereffe à l'embouchure de cette Riviere, afin d'en affûrer l'entrée contre les entreprifes des Indiens; mais fon deffein échoüa par la malice de ceux mêmes, pour qui il vouloit travailler, \& qui lui débaucherent fon Architecte.

Ils firent pis encore. Las Cafas n'avoit pas long-têms pra. Il retourse tiqué les Peuples de cette Province, fans reconnoître que à l'Ifle Efpala meilleure Monnoye, pour trafiquer avec eux, étoit le poule, \& $\mathrm{Vin}$; quavec cette liqueur on ne manquoit ni d'Or, ni d'Efclaves; ces Barbares allant plus avant dans les Terres enlever d'autres Indiens pour les vendre aux Efpagnols. Mais outre ce qu'il y avoit d'inique dans ce Commerce, le feul ufage, que ces Indiens faifoient du Vin, étoit plufque fuffifant à un homme aufí zelé, que l'étoit Las Cafas, pour en abolir le Commerce; car tant, qu'ils avoient de quoi boire, ils ne défenyvroient point, \& il en arrivoit tous les défordres, qu'on peut imaginer dans les hommes de la terre les plus brutaux. Il fongea donc férieufement, Tom I. 


\section{$418 \quad$ H S T O I R}

I52I. aux moyens de remedier à un fi grand mal, \& il fut bier ? tôt convaincu qu'il n'y en avoit point d'autre, que de défendre abfolument aux Efpagnols de porter du Vin aux Sauvages. Mais il n'avoit point d'authorité fur les Efpagnols de Cubagua, ou du moins on n'y reconnoiffoit point la fienne. Il falloit commencer par l'y établir, \& il l'entre. prit. Il paffa dans l'Inc, \& repréfenta à celui, qui y commandoit fous le titre d'Alcaide Major, que la Province de Cumana étoit toute entiere de fa dépendance, \& qu'il n'étoit permis à perfonne d'y faire le Commerce, que fous fon bon plaifir. L'Alcaïde fe mocqua de fes prétentions, \& comme il étoit certain qu'inutilement on travailleroit à policer les Indiens, tant qu'on leur porteroit du Vin, \& qu'on leur en porteroit, tant que le Commerce feroit libre aux Efpagnols; le Licencié réfolut d'aller porter fa plainte à l'Audience Royale de San-Domingo, déterminé, fi elle ne lui faifoit pas juftice, d'aller jufqu'en Efpagne la demander à l'Empereur.

Ies Indiens pendant fon abfence attaquentla Nourelle Tolede.

Il partit donc pour l'Ifle Efpagnole, laiflant fa petite Colonie fous les ordres de François de Soto, auquel il re. commanda principalement deux chofes : la premiere de ne point faire fortir du Port deux Bâtimens, qu'il y laiffoit z feconde, que, fi les Indiens venoient l'attaquer en trop grand nombre, \& qu'il ne fut pas poffible de leur réfifter, il fe retirât avec tout fon monde, \& tous fes effets à Cubagua.' Soto executa fort mal le premier de ces deux ordres; peine Las Cafas avoit mis à la voile, que les deux Bâtimens furent envoyés l'un d'un côté, \& l'autre de l'autre, pour chercher des Perles, de l'Or, \& des Efclaves. Mais Soto ne tarda pas à être puni de fa défobéiffance. On eut bien. tôt des indices que les Sauvages machinoient quelque confpiration contre les Efpagnols, dont le nombre venoit d'être fort diminué par le départ des deux Bâtimens. Le Commandant ordonna qu'on mît les armes en état : la poudre s'étant trouvée moüillée, il voulut la faire fécher, \& les Indiens s'en étant apperçûs, parce qu'ils la virent étendre au Soleil , cru- 


\section{DE S. Domingue, Liv. VI. 4Ig}

rent Poccafion favorable pour executer leur deffein. Ils vinrent fondre fur les Efpagnols en jettant de grands cris, mirent le feu à la Ville, \& tuerent deux ou trois hommes, qui n'avoient pas eu le têms de fuir.

Soto accourut au premier bruit, \& reçut d'abord dans le bras une Fleche empoifonnée. Il ne laiffa point de ga- gnols font ogner le Jardin des PP. de Saint François, où environ vingt bligés de fe Perfonnes s'étoient retirées, \& d'où il gagna le Fleuve fans de Soto, être apperçu, par le moyen d'un petit Canal, que les Religieux avoient creufé , \& fur lequel ils avoient tô̂jours un ou deux Canots. Les Sauvages le pourfuivirent, mais trop tard; toute la Troupe eut le têms de gagner un endroit de la Côte, où l'on avoit accoûtumé de charger du Sel, \& où il fe rencontra quelques Bâtimens, qui les reçûrent. Soto n'étoit pas venu jufques-là : ayant paffé trois jours \& trois nuits fans boire \& fans manger, il demanda un peu d'eau pour éteindre la foif, qui le tourmentoit cruellement; mais à peine l'eut-il bûë, qu'il entra dans un accès de rage, qui l'emporta bientôt. On a depuis obfervé que le poifon. dont fe fervoient ces Peuples, operoit à mefure qu'on bî̀voit, \& qu'on mangeoit, \& que pour en guérir, il ne falloit abfolument rien prendre o jufqu’à ce qu'on eût fait les remedes convenables.

Un bon Frere Francifquain, nommé le Frere Denys, qui ne s'étoit pas trouvé dans le Jardin pour s'embarquer avec cubagua évales autres, n'eut pas un fort plus heureux que Soto. Après être demeuré trois jours caché, fans prendre aucune nourriture, il fe perfuada que les Sauvages, aúquels il n'avoit jamais fait que du bien, lui donneroient au moins la vie, \& il alla fe livrer à eux; mais ils le maffacrerent impitoyablement ; après quoi , étant paffés en très-grand nombre à l'Ine de Cubagua, ils intimiderent tellement l'Alcaïde Major, Antoine Flora, qui avoit 300. Hommes en état de combattre, qu'il n'eut pas le courage d'attendre qu'on le vînt attaquer. Il s'embarqua avec tout fon monde fue deux Caravelles, \& gagna l'IRe Efpagnole, où les Gens 
I52I. de Soto s'étant rendus prefque en même têms, ils portereñ tous enfemble à San-Domingo, la trifte nouvelle d'une révolution, qui étoit le fruit de l'imprudence des uns, \& de la lâcheté des autres. Les derniers furent affés furpris quon ignorât dans cette Capitale le Voyage du Licencié Las Cafas, qui étoit parti de Cumana long-têms avant eux. Le fait eft, que fon Pilote ayant pris la Côte de San-Domingo pour celle de Portoric, étoit allé débarquer au Port d'Yaquimo, \& j'ai déjà obfervé plus d'une fois, que les Vents \& les Courants ne permettent prefque pas de remonter à la voile de ce Port à la Capitale. Las Cafas n’avoit pas laiffé de l'entreprendre; mais après y avoir perdu deux mois . il s'étoit vâ contraint de fe faire mettre à.la Côte, \& de pourfuivre fon voyage par Terre.

De quelle Il prit fa route par Yaguana, ou Leogane, \& il fe repofa maniere Las quelque têms dans cette Ville. S'étant remis en chemin,

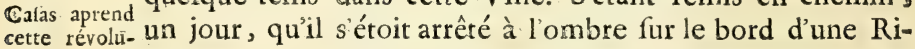
sion. viere, pour y laifer tomber la plus grande chaleur, fes Gens apperçûrent des Efpagnols, qui paroiffoient venir de San-Domingo; ils les joignirent, \& leur ayant demandé s'ils ne fçavoient point de nouvelles; « On a appris, répon¥ diremt-ils, que le Licencié Barthélemy de Las Cafas avoir » été maffacré avec la plus grande partie de fes Gens à la s. Côte de Cumana. x. Ceux, à qui ils parloient fe mirentà rire, \& afû̀rerent qu'on verroit bientôt le contraire : mais Las Cafas, qui avoit entendu tout ce. Dialogue, s'étant avancé, \& ayant fait aux Voyageurs plufieurs queftions fur les circonftances de cette nouvelle, ne douta point qu'elle n'eût un fondement réel, \& levant les mains aux Cieux: * Vous êtes jufte, Seigneur , s'écria-t-il, \& votre jugement w eft droit. $\$$ Il arriva peu de têms après à la Capitale, où il fçut toutes chofes au vrai. Il en fut fenfiblement souché, mais fans en être abbattu: il travailloit pour Dieu, \& ne fe recherchoit en rien; mais quand il avoit fait tout ce qui dépendoit de lui, il n'avoit aucune peine à fe foumettre à tout ce que la Providence ordonnoit, ou permettoit par 


\section{DE S. Domingue, Liv. VI. $42 \bar{r}$}

rapport à fes projets. Par-là il corrigeoit ou expioit ce que fon zéle pouvoit avoir de vicieux On peut dire auffi 1521 . qu'il entreprenoit au-deffus de fes forces, \& peut-être n'avoit-il pas toute l'habileté néceflaire pour conduire une entreprife de cette nature. Mais il faut encore avoüer, qu'il étoit difficile qu'il n'échoüât point, ayant prefque toûjours tout le monde contre lui.

Quoiqu'il en foit, comme rien ne l'attachoit plus au Il fe fair fiecle, il fe fentit infpiré de le quitter, \& les PP. Domini-Dominiquains quains n'eûrent pas beaucoup de peine à profiter de cette difpofition, où il fe trouvoit, pour acquerir un homme de ce merite; d'autant plus qu'il avoit toûjours été uni de fentimens avec eux. Il prit donc l'habit de Frere Prêcheur, \& ne parut plus occupé, que du foin de fe fanatifier; jufqu’à ce que de nouvelles occafions d'exercer fon zéle pour le falut \& la confervation des Indiens, le tirerent de fa folitude à l'occafion, que nous verrons bientôt. Au refte, je fuis bien aife d'avertir ici que ce faint homme, ayant vî fur la fin de fes jours la maniere, dont les Hiftoriens Oviedo, \& Gomara ont parlé de lui, \& le tour, qu'ils ont donné à fes avantures, ne put s'empêcher d'en témoigner quelque reffentiment, \& c'eft ce qu'Antoine Herrera, qui lui rend beaucoup plus de juftice, a cru devoir remarquer dans fon excellente Hiftoire des Indes Occidentales.

Cependant l'Amiral D. Diegue, \& l'Audience Royale Les Indtens également touchés, \& de l'affront, que la Nation venoit de Cumana de recevoir fur. la: Côte de Cumana, \& du danger, où font punis \& trouvoit la Colonie de Cubagua par la fuite de fa Garnifon, frrent armer un Efcadre de quatre ou cinq Navires, pour raffûrer les uns \& venger fur les autres le fang Efpagnol; \& ils en donnerent le commandement à un homme de merite, nommé Jacques de Caftellon. Cet Officier alla débarquer d'abord à l'ine de Cubagua, où fa préfence fit reprendre cour à tout le monde; il entra enfuite dans la Riviere de Cumana, \& il envoya plufieurs partis contre les Indiens, dont on fit un grand carnage. On choifit les plus

Ggg iij 


\section{2

I52r. confiderables parmiceux, qui tomberent vifs entre les mains des Efpagnols; ils furent pendus, \& les autres condamnés à l'Efclavage. Mais comme il falloit, ou abandonner abfolument la Pêche des Perles, qui étoit alors dans fa plus grande abondance, ou s'affurer de l'embouchure de la Riviere de Cumana, d'où les Habitans de Cubagua étoient obligés de tirer toute leur eau douce; le Commandant Efpagnol reprit le deffein, qu'avoit eu Las Cafas de bâtir une Fortereffe à cette embouchure, \& il l'executa. Alors l'Ine des Perles devint extrêmement floriffante, on y bâtis des Maifons de pierres, \& il s'y forma une jolie Ville fous le nom de nouvelle Cadix, ainfi que je l'ai dit ailo leurs.

I 522 .

Les Negres

J'ai auffi remarqué plus haut, qu'on s'étoit enfin détermife multiplient l'Efpagnole, par les Negres : mais ces nouveaux Efclaves dans l'inle Ef- étoient de mauvais Mineurs, \& depuis ce têms-là , les Mines
pagnole.

font demeurées fermées. En récompenfe les Negres étoient très-propres aux Manufactures de Sucre, \& l'on peut juger 。 de ce que cette Marchandife produifoit alors, parce quon affûre communément, que ces magnifiques Palais de Madrid \& de Tolede, qui font l'ouvrage de Charles-Quint , ont été entierement bâtis du provenu du feul droit d'entrée des Sucres de l'Ifle Efpagnole. Cependant on peut bien croire que les Negres ne furent pas traités dans ces commencemens avec trop de douceur par des Gens accoûtumés à regarder les Indiens, comme des animaux defsitués de raifon; car outre que la figure \& la couleur rapprochoient ceux-ci beaucoup plus des Européans, que ceuxlà ; l'efclavage, où l'on retenoit les Infulaires, étoit uniquement fondé fur le droit du plus fort, au lieu que les $\mathrm{Ne}$ gres, ayant été achetrés, \& vendus par leurs propres Compatriotes, il fembloit qu'on dût avoir moins de fcrupule de leur faire fentir tout le poids de la fervitude.

Moltens.

IIs fe ré-

Ce qui eft certain, c'eft que leur patience, quoiqu'ils en ayent fur cela plus qu'aucun autre Peuple de la Terre, fut 


\section{DE S. Domingue, Liv. VI. 423}

bientôt pouffée à bout. Ils formerent donc le deffein, \& conçurent même l'efpérance de fe remettre en liberté. La זévolte commença par ceux, qui étoient au fervice de 1'Amiral. D. Diegue avoit une Sucrerie dans le voifinage de la Capitale, où il faifoit travailler cent Efclaves, la plûpart Negres. Le 27. de Decembre de l'année I522. une vingtaine de ces derniers, joints à un pareil nombre d'une autre Sucrerie, qui appartenoit au Licencié Lebron, ayant זrouvé moyen d'avoir des armes, fe jetterent fur quelques Efpagnols, qui ne fe défioient de rien, les tuérent, \& prirent le chemin de la Ville d'Azua, dans le deffein de la furpendre, \& après l'avoir pillé, d'aller fe donner au $\mathrm{Ca}$ cique Henry. L'Amiral, qui fut d'abord averti de leur marche, fe mit dans le moment à leurs trouffes avec peu de monde, après avoir donné fes ordres, pour fe faire fuivre d'un corps de Troupes reglées, ou des Milices du Pays. Il arriva le fecond jour furle bord de la Riviere Nizao, \& il réfolut d'y attendre fes Gens. Il apprit là que les Rebelles étoient entrés dans l'habitation d'un nommé Michel de Caftro, quils y avoient fait beaucoup de dégât, tué un Caftillan, \& enlevé un Negre avec douze Indiens; que de. là ils s'étoient rendus à une lieuë d'Ocoa, où ils avoient campé, dans le deffein de piller au point du jour une Sucrerie, que Zuazo avoit dans le voifinage; qu'ils étoient réfolus d'y tuer tous les Chrétiens, de renforcer leurs Troupes de 120 . Negres qui y étoient, \& d'aller avec ce renfort s'emparer de la Ville d'Azua.

Michel de Caftro étoit dans la petite Troupe de l'Amiral; au récit de ce qui étoit arrivé dans fon habitation il $\underset{\text { nais. }}{\text { fa pu- }}$ y. courut lui troifiéme, fans en rien communiquer à fon Général; \& il y trouva les chofes, comme on les avoit rapportées. Alors un quatriéme Efpagnol l'ayant joint au même lieu, il envoya dire à $\mathrm{D}$. Diegue qu'il alloit donner fur les Negres à deffein de les harceler, pour les empêcher de xien entreprendre jufqu'à l'arrivée des Troupes, \& qu'ille prioit de lui envoyer du fecours. L'Amiral fit aufi-tôt pare 


\section{H. T T O R}

1522. tir huit Cavaliers, \& quelques Fantaffins en croupe; \& Caftro, qui avoit eu le têms de connoître la foibleffe des Negres, fe crut avec ce renfort en état de les défaire, \& fe prépara à les attaquer. Les Negres de leur côté, voyant venir à eux cette poignée d'Efpagnols, fe rangerent en afo fés bel ordre, \& reçurent de bonne grace la premiere Charge; mais ils furent fi maltraités à la feconde, qu'ils n'eurent pas le courage d'en attendre une troifiéme. Câftro eut un bras percé d'un bâton brûlé par le bout, ce qui ne l'empêcha point de chercher fon Negre \& fes douze Indiens, lefquels à fa voix fortirent de l'endroit, où on les avoit cachés, \& vinrent le joindre. L'Amiral furvint vers le midy avec tout fon monde, \& fit pourfuivreles fuyards, dont peu échapperent, \& comme à mefure qu'on les faififfoit . on les pendoit à l'Arbre le plus proche, tout le chemin en fut bientôt bordé. Ce fpectacle intimida tellement les $\mathrm{Ne}$ gres, qu'ils n'ont pas ofé depuis fe révolter contre les Efpagnols dans cette Ifle.

1523.

Mauvais

L'année fuivante, fur les repréfentations, qui furent faites à l'Empereur, que les Départemens des Indiens ne fubfervices rendus à l'Amiral ז́éco

fiftant plus, les Officiers de l'Audience Royale, réduits à leurs appointemens, ne pouvoient plus foutenir leur rang, ni entretenir leurs familles, ce Prince les augmenta de moitié, de forte qu'ils montoient à 300000 . Maravedis. L'Amiral reçut par la même voye des lettres fulminantes du Confeil des Indes. Paffamonté, qui n’avoit encore pu s'accommoder avec aucun Gouverneur, avoit des raifons par. ticulieres de deffervir D. Diegue, \& il avoit envoyé en Cour un Mémoire contre lui, dont on crut, ou l'on fit femblant de croire qu'au moins une partie étoit vraye. Il lui reprochoit furtout d'avoir ufurpé prefque tous les droits de l'Audience Royale, \& d'avoir donné à la Déclaration de l'Empereur, qui le rétabliffoit dans fa Charge de ViceRoi , une étenduë, qu'elle ne pouvoit avoir. Sur cette accufation il fut enjoint à $\mathrm{D}$. Diegue, fous peine de décheoir de tous fes privileges, \& même de tous fes titres, de re- 


\section{DE S. Domingue, Liv. VI. 425}

mettre les chofes dans leur premier état, \& afin qu'il ne pût pas prétendre caufe d'ignorance d'un tel ordre, l'Audience Royale fut chargée de le faire publier, \& de tenir la main à fon exécution.

Fort peu de têms après l'Amiral reçut une autre lettre, par laquelle le Confeil lui mandoit, qu'ayant à regler plu- pellé en Expafieurs chofes, qui concernoient fon Gouvernement, on ju- connoitre lon geoit fa préfence néceffaire en Efpagne, \& qu’on le prioit de s'y rendre au plûtôt. Il comprit parfaitement qu'il étoit révoqué ; d'autant plus, que le P. Louis de Figueroa, un des trois Commiffaires envoyés par le Cardinal Ximenez à l'Ifle Efpagnole, venoit d'être nommé à l'Evêché de la Conception, \& déclaré Préfident de l'Audience Royale, avec toute l'authorité de Gouverneur. Il obéit donc, mais étant arrivé à la Cour, il plaida fi bien fa caufe auprès de l'Empereur, que ce Prince 8 tout le Confeil ne purent s'empêcher de reconnoitre fon innocence fur tous les chefs d'accufation, dont on l'avoit chargé. Il n'eut pas plus de peine à mettre dans la plus grande évidence fon exacitude à faire obferver les Ordonnances, fon zele pour le bien public, \& pour le fervice de l'Empereur, \& que tout fon malheur venoit de ce que Paffamonté \& les autres Officiers Royaux ne voyoient pas volontiers un homme, qui les éclairoit de fi près, ou dont l'authorité les incommodoit. Il ne paroiffoit pas difficile après cela d'obtenir qu'on lui fît juftice fur toutes fes prétentions, \& il la follicita vivement auprès de l'Empereur. Charles-Quint accorda enfin à fes Importunitez des Commiffaires, mais l'affaire traîna fi fort en longueur, que le malheureux D. Diegue, par un fort tout femblable à celui de fon Pere, \& même dans un âge bien moins avancé, vit trancher fes jours, au milieu de fes inutiles pourfuites, ainfi que nous le verrons bientôt.

L'Empereur occupoit alors fans ceffe le Confeil des In- Nouveaux des à chercher les moyens de conferver le peu, qui reftoit Reglemens des a chercher les moyens de conferver le petr, qui reftoit puur les Ino d'Indiens fideles dans l'Ife Efpagnole. Enfin après plufieurs diens. Tom. $I$. 


\section{$426 \quad H$ is ror $\mathrm{R}$ E}

1523. Affemblées de Théologiens, de Canoniftes \& d'autres Per1 fonnes habiles, \& d'une expérience confommée; le pre-

I525. mier jour de Septembre de cette même année i 525 . Sa Majefté fit écrire aux deux Superieurs Généraux des Dominiquains \& des Francifquains, que la diverfité des fentimens 。 touchant la maniere d'en ufer avec les Indiens, ne lui permettant pas de prendre une réfolution fixe \& invariable, \& le Siege Epifcopal étant vacant, il leur donnoit fur cela toute fon authorité, déchargeoit fa confcience fur la leur, \& recommandoit à l'un \& à l'autre, d'impofer à ces Infulaires tel tribut \& tel travail, qu'ils jugeroient convenables. Ce qui obligeoit l'Empereur de s'adreffer à ces deux Re. ligieux, c'eft que le P. de Figueroa Evêque de la Conception, \& nommé Préfident de l'Audience Royale, venoit de mourir en Efpagne, \& qu'avant qu'il eût un fucceffeur en état d’agir, il pouvoit arriver bien des défordres . que ce Prince vouloit prévenir. Une autre Ordonnance, que rendit Charles-Quint dans le même têms, faifoit voir que la Colonie de l'Ine Efpagnole étoit déjà fort diminuée. Cas elle déclaroit que quiconque voudroit aller s'y établir, furtout à la Conception, outre le paffage, qu'on lui donneroir gratis, pourroit avoir fix Efclaves Negres, \& cela contre une déclaration faite quelques années auparavant, par laquelle il étoit défendu d'avoir dans une habitation plus de Noirs . que de Blancs. Au refte ç'étoit la Conquête du Mexique 。 qui avoit caufé le dépeuplement, dont nous parlons, \& il fut encore augmenté par la Conquête du Perou, dont il n'eft pas poffible de faire comprendre quelle fut l'occafion, fans remonter au têms de la fondation de Sainte Marie l'Ancienne du Darien, \& fans reprendre la fuite de ce qui fe pafo fa dans cette Colonie, après qu'on en eût chaffé Nicueffa. C'eft ce que je vais faire en peu de mots

Baalboa s'em. J'ai dit qu'on y avoit établi une efpece de République, Pauthorité fous l'authorité dé quelques Magiftrars. Les Parrifans de Nidansla Pro- cueffa, \& ceux d'Encifo n'ayant pu réuiffir à faire changeg vince du Dasien。 cette forme de Gouvernement, elle fubfifta, mais en appa 


\section{DE S. D OMINGUE, Liv. VI. 427}

rence feulement, parce qu'infenfiblement Balboa s'attira toute l'authorité. Cela parut principalement par la maniere , dont il en ufa à l'égard d'Encifo, à qui il of bien faire le Procès. Je ne trouve nulle part, fi depuis la dépofition de ce Commandant, il étoit furvenu quelque nouvelle broüillerie entre lui \& Balboa; mais il y a bien de l'apparence qu'ayant un parti déclaré en fa faveur, il fit de nouveaux efforts pour maintenir fon droit, \& fe porta pour Alcaide Major. Ce qui eft certain, c'eft que Balboa le fit mettre en Prifon, l'accufa d'avoir ufurpé une Charge, dont le Roi feul pouvoit lui donner les Provifions, \& cela fur la fimple nomination d'un Particulier, qui n'avoit jamais eu d'authorité dans la Province, \& qui étoit mort; qu'il confifqua tous fes biens, \& ne lui rendit la liberté, à la priere des plus confiderables Habitans, qu'à condition, qu'il s'embarqueroit pour la Caftille, ou pour l'Iffe Efpagnole, fur le premier Navire, qui partiroit de Sainte Marie.

Il fongea enfuite à fe procurer les fecours, dont la Colo- Il envoye des nie avoit befoin, \& ayant fait regler dans le Confeil qu'on manderdufeenvoyeroit demander à l'A miral des provifions, des muni- ral. tions, \& des Hommes, il fit nommer pour cette Commiffion le Regidor Valdivia fon ancien ami. Il repréfenta enfuite qu'il étoit à propos d'informer la Cour, de la fituation préfente de la Province du Darien, \& des grandes richeffes, qu'on efperoit y découvrir, \& il perfuada à Zamudio fon Collegue de paffer lui-même en Caftille. Il avoit en cela deux vûës; la premiere, de refter feul faifi de toute lauthorité, \& la feconde, d'avoir à la Cour un homme. qui eût autant d'interêt que lui, à prévenir le Roi \& fes Miniftres, fur tout ce qui s'étoit paffé d'irrégulier au fujet de Nicueffa \& d'Encifo. Celui-ci de fon côté étuit bien rélolu à tirer raifons des injuftices, qu'on lui avoit faites, \& il fe prépara à profiter du Bâtiment, qui devoit porter $\mathrm{Val}$ divia \& Zamudio à San-Domingo, pour fortir dune Colonie, où fon Ennemi étoit le maitre. On avertit Balboa qu'Encifo comptoit de s'embarquer avec les deux Députés , moins 


\section{H Is TO I RE}

ISII. pour déferer à l'Arrêt, qui l'y condamnoit, que pour aller 1. porter fes plaintes au Tribunal du Roi. Balboa fit alors fes 3524. réflexions fur les fuites, que ce voyage pouvoit avoir, \& travailla fous main à l'empêcher. Des Perfonnes, qui fe difoient amis d'Encifo, l'allerent trouver, \& lui dirent que, s'il vouloit refter à Sainte Marie, ils fe faifoient fort de le faire agréer à Balboa: qu'ils fçavoient même que ce $\mathrm{Ma-}$ giftrat étoit très-difpofé à bien vivre avec lui, \& qu’ils ne le croyoient pas éloigné de le rétablir dans la Charge d'Alcaïde $\mathrm{M}$ ijor. Mais Encifo ne prit pas le change, \& Balboa pour s'affîrer d'une protection, qui pût le mettre à couvert de l'orage, remit à Valdivia un préfent confiderable en Or pour le Tréforier Général Paffamonté, dont il fçavoit que le crédit étoit fort grand auprès du Roi, \& des Principaux Miniftres.

Il faitla guerre aux Iridiens avec fuccès.

Valdivia fut fix mois entiers dans fon Voyage : à cela près fa négociation eut tout le fuccès, que Balboa s'en étoit promis, il revint avec des provifions \& des Hommes, \& rendit à l Alcaïde Major des Lettres de l'Amiral, qui l'affuroit d'un plus puiffant fecours, dès que le Renfort, qu'il attendoit lui même de Caftille, feroir arrivé. Mais il s'étoit paffé pendant ces fix mois bien des chofes, qui avoient fort relevé les Efperances de Balboa, \& dont il ne tarda pas à donner avis à D. Diegue, par le même Valdivia, qu'il lui dépêcha une feconde foîs. Il s'étoit mis à la tête d'une Troupe de I 30 . Braves, parmi lefquels étoient Rodrigue Enriquez de Colmenarez, cet ami de Nicuefía, dont nous avons parlé plus haut François Pizarre, \& Diego de Almagro; que nous verrons bientôt entreprendre la Découverte du Perou; \& il avoit fait des Courfes dans tout le Pays jufqu'à Nombre de Dios, répandant partout la terreur de fon nom, \& ne donnant fon amitié à ceux, quila recherchoient, qu'au prix de leur Or: aufi en revint-il tellement chargé à Sainte Marie, que le Quint du Roi, dont Valdivia fut chargé, pour le remetrre au Tréfor Royalà SanDomingo, fut de 300 . Marcs d'Or, qui faifoient I 5000 . Pefos, Mais il y avoit plus encore. 


\section{DE S. Domingue, Li v. VI.}

Un jour, que le fils d'un Cacique allié avoit préfenté à Balboa \& à Colmenarez une grande quantité d'Or; comme on le pefoit pour en faire la répartition, il furvint une affés groffe querelle, au fujet du partage, \& l'on fut fur le Premiers de la point d'en venir aux mains. Le jeune Cacique, qui étoit Mer dusud \& préfent, en fut furpris \& fcandalifé, \& s'étant approché de du Perou. la Balance. il la fecoüa violemment \& renverfa tout l'Or, qui y étoit; puis fe tournant vers les Efpagnols, " puifque o vous vous querellés pour fi peu de chofe, leur dit-il, \& » qu'apparemment c'eft ce 'métal, qui vous a fait abandono ner votre Parrie, effuyer tant de fatigues, courir tant de » dangers, \& inquieter tant de Peuples, qui joüiffoient o d'une paix profonde, que rien n'avoit encore troublé ; je s veux vous faire connoitre un Pays, ou vous aurés dequoi o vous contenter. Mais pour y pénétrer', il vous 'faut bien » dautres forces, que celles, que vous avés : vous aurés »à combattre des nations nombreufes, $\&$ des Rois puifo fans, qui ne manquent, ni de courage, ni de tout ce » qui eft néceffaire pour fe bien défendre. » On lui demanda de quel côté étoit ce Pays fi opulent, \& il répondit qu’après avoir marché fix jours de l'endroit, où ils étoient alors, allant tô̂jours au midi, ils trouveroient un Cacique très-riche en Or, \& au-delà line Mer d'une érenduë immenfe, fur laquelle il y avoit des Vaifeaux peu inferieurs en grandeur à ceux des Efpagnols; enfin qu'er fuivant fur cette Mer le même air de vent, ils arriveroient dans un Royaume, où l'Or étoit fi commun, qu'on s'en fervoic aux uages les plus ordinaires. Ces avis réjoüirent fort les Cafillans, \& les empêcherent de reffentir la confufion, que leur devoient caufer l'action \& les reproches de l'Indien; Balboa reprit peu de têms après la route de Sainte Marie; fort réfolu de ne rien négliger, pour profiter de tout ce qu'il venoit d’apprendre, \& Valdivia étant arrivéquelques jours après lui de fon premier Voyage, il le fit repartir fur le champ, pour porter à l'Amiral de fi heureufes nou. velles, \& l'engager à ne point differer le fecours, qu'il lui ayoit promis. 


\section{HISTOIRE}

IS II. ।

I 524 .

Balboa reçoit de fâchenfes nouvelles

1513.

I5 24.

On fut bien des années fans fçavoir ce qu'étoit devenư cet Envoyé : ce ne fut qu'en I5 I9. qu'on apprit par hazard qu'ayant fait naufrage fur de petites Inles nommées les Caymans , qui font au Nord Oueft de la Jamaïque, \& ay ant voulu - paffer à la Terre Ferme du côté de l'Y ucatan, il étoit tombé entre les mains d'un Cacique,qui le facrifia à les Idoles \& le mangea. Balboa de fon côté, après s'êrre défennuyé quelque têms à faire de nouvelles Conquêtes, fe lafla d'attendre, \& voulut paffer lui-même à San Domingo, \& de là en Caftille, où il comptoit bien qu'avec l'Or, qu'il y porteroit . il furmonteroit tous les obftacles; mais la Colonie s'oppofa à ce Voyage, \& il fallut contentir que quelque autre le fît pour lui. Il s'en confola par l'arrivée de deux Navires, que l'Amiral lui envoyoit : ils étoient chargés de munitions, \& portoient une Recruë de 110 . hommes choifis. Balboa reçut par la même voye des Provifions de Capitaine Général fignées de Paffamonté, auquel le Roi avoit, difoiton, donné ce pouvoir. Mais il eut en mêmetêms des nouvelles bien fâch ufes de Caftille. Zamudio lui mandoit que le Roi étoit extrêmement indigné contre lui, \& qu'Encifo lui rendoit de fort mauvais fervices à la Cour; qu'il rejettoit fur lui une bonne partie des violences, qu'on avoit exercées contre le malheureux Nicueffa, \& qu'sl y avoit ordre de luii faire fon procès. Il fut effectivement condamné pour le Civil à indemnifer Encifo de toutes les pertes $\&$ de tous les frais, qui'il lui avoit caufés; mais pour le Criminel, Ferdinand ne voulut pas qu'il y eût de Jugement porté, que l'acculé n'en̂t été oüi.

Balboa comprit, en apprenant ces nouvelles, quil étoit perdu, file fuccès de la grande Entreprife, qu'il méditoit , ne lui meritoit l'abolition du paffé. Il réfolut done de ne plus la differer, \& ayant choifi r 90 . hommes, fur lefquels il crut pouvoir compter. Il travailla avec toute la diligence poffible à faire fes provifions, à regler toutes chofes dans la Colonie pour le têms de fon abfence, \& à difcipliner fa Troupe. Enfin, au commencement de Septembre 


\section{DE S. DOMINGUE, LIV. VI. 43 I}

de l'année I 5 13. 11 s'embarqua fur un Brigantin, qui le porta dans les Terres d'un Cacique, nommé Careta, avec lequel il avoit fait alliance. De-là, il prit le chemin des Montagnes avec des Guides, que lui avoit donnés le Prin1524 ce Indien. Il lui fallut combattre fur la route une nombreufe armée de Barbares, qui l'attaquerent avec affés de réfolution, mais que quelques coups d'Arquebufe tirés fort à propos, diffiperent auffitôt après la premiere charge ; \& le 25 . du même mois, fes Guides l'ayant averti qu'on voyoit la Mer de deflus une Montagne, qu'ils lui marqquerent, il y monta feul, \& la découvrit en effet. Le premier fignal, qu'il en donna, fut de fe mettre à genoux, \& d'élever les mains au Ciel, pour rendre graces à Dieus d'un évenement fi avantageux à fa Patrie, \& fi glorieux pour lui. Il fit cela par deux fois, \& à la feconde, toute la Troupe en fit de même; après quoi, tous eurent la permiffion de venir voir une Mer, fur laquelle on leur avoit affùré qu'ils trouveroient de fi grands thréfors.

Balboa ne manqua pas de leur faire obferver, qu'il n'y avoit plus aucun lieu de douter de la fincerité du récit,que leur avoit fait le jeune Cacique, puifque jufques-là tous y étoit parfaitement conforme: \& il ajoûta que le même Dieu, qui les avoit fi heureufement conduits, dans toutes leurs entreprifes, ne les abandonneroit pas au milieu d'une expedition, dont le but principal étoit la propagation de l'Evangile. Balboa parloit bien; \& d'ailleurs il avoit dans le fouverain degré le talent de gagner tous ceux, qui étoient fous fes ordres, parce que toute la diftinction, qu'il affectoit, c'étoit de prendre pour lui les plus rudes travaux, \& les plus grands dingers. Auffi eur-il le plaifir dans cette occafion, comme dans toutes les autres, de voir tous fes Gens difpofés à le fuivre partout, où il voudroit les mener. Il réfolut bien d'en profiter; mais il ne crut pourtant pas devoir s'expofer plus avant avec fi peu de monde, \& il jugea même à propos de s'affûrer d'abord de tous les Caciques des environs de tous les lieux, par où il auroit à paffer. 
1513 .

1

I 524.

Il en prend poffefion.

Il fe borna donc pour lors à prendre poffention du Pays, où il fe trouvoit, \& de la Mer, qu'il venoit de découvrir. Cette Mer forme en cet endroit un Golphe,auquel il donna le nom de Saint Michel, en mémoire du jour, qui fut deftiné pour la cérémonie, dont je viens de parler, \& qui fut le 29. de Septembre. Ce jour là , après que Balboa eût fait à terre toutes les formalités requifes en pareilles rencontres, il entra dans la Mer jufqu’à la ceinture, tenant fon Epée haute d'une main, \& fon Bouclier de l'autre, \& dans cette fituation, adreffant la parole aux Caftillans \& aux Indiens, qui bordoient le Rivage : « Vous m’êtes témoins, leur dit-il, s que je prends poffeffion de cette Mer pour la Couronne $\approx$ de Caftille, \& je protefte que je fçaurai bien avec cette Epée w lui en conferver le Domaine. s Il s'embarqua enfuite avec une partie de fes Gens fur des Canots Indiens, qui fe rencontrerent là ; il reconnut de petites Ifles, autour defquelles il fe faifoit une très - abondante Pêche de Perles, \& il leur en donna le nom: puis ayant voulu pouffer au large, il fe trouva prefque hors de la vûë de terre, \& fut affailli d'une violente Tempête, dont il ne fe fauva que par une efpece de Miracle.

IS I 4 .

Echapé de ce péril, où fa témerité l’avoit engagé, il retourna à Sainte Marie, où il n'arriva que le $\mathbf{I}_{4}$. de Jan-

1524. vier IS I4 ayant, felon fa coûtume, fait plufieurs excurIl retourne fions fur les Terres de differens Caciques, dont il gagna les

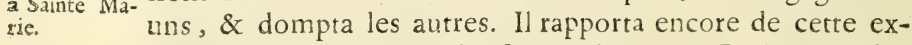
pedition de grandes richeffes en Or \& en Perles, \& fon premier foin, aprês s'être un peu délaffé de tant de fatigues, fut d'inftruire le Roi \& les Miniftres de l'importante Découverte, qu'il venoit de faire, des fuites avantageufes, qu'elle pouvoit avoir, \& de la néceffité de ne point différer à en profiter. Il confia fes Lettres à un nommé Pierre de Arbolancho , $8 x$ il les accompagna d'une très.grande quantité d'Or, \& des plus belles Perles qu'il eût, tant pour le quint du Roi, que pour faire des préfens à cetix, quil lui importoit plus de mettre dans fes interêts. Arbolancho par- 


\section{DE S. DOMINGUe, Liv. VI. 433}

tit au commencement de Mars, \& remplit à fon arrivée toute la Cour dune très-grande joye. Fonfeca, pour lors Evêque de Burgos, \& le Commandeur Lopé de Conchillos gouvernoient en ce têms-là toutes les affaires du Nouveau Monde avec une authorité prefque fouveraine, parce que le Confeil des Indes n'étoit pas encore établi. Ces deux Seigneurs firent au Député de Baiboa un acceüil très-gracieux, \& ils voulurent qu'il eût l'honneur de préfenter lui-même au Roi , ce dont il étoit chargé pour ce Prince de la part de la Colonie. Ferdinand le reçut bien, lui fit diverfes queftions, aufquelles cet Officier répondit d'une maniere très-favorable à Balboa, \& le Prince ordonna en effet à l'Evêque de Burgos d'avoir foin que les fervices de ce Commandant ne fuffent pas fans récompenfe.

Le malheur de Balboa fut qu'Arbolancho n'arriva point en Épagne deux mois plûtôt: mais les grands coups étoient drarias Davidéjà portés; le Roi, à qui l'on avoit fait comprendre que neur de la la Colonie établie fur le Darien, alloit devenir un grand Provincedus objet, s'étoit déterminé à lui donner un Chef, qui fût de caractere \& d'un rang à y contenir le Peuple dans la foûmiffion, \& à y faire refpecter l'authorité fouveraine. Il propofa cette place au Commandeur D. Diegue del Aguila; mais ce Seigneur, je ne fçai pour quelle raifon, le remercia. On lui propofa enfuite D. Pedrarias Davila, Officier de naiffance \& de merite, \& à qui le furnom de Galand \& de Joufteur, n'ôtoit pas la réputation de brave Homme, qu'il s'étoit juftement acquife par plufieurs belles actions. Quelques autres Seigneurs s'étoient mis fur les rangs; mais l'Evêque de Burgos ayant appuyé Pedrarias, il fut préferé. On travailla en diligence à fes Inftructions, \& il partit le I2. d'Avril I \$14. peu de jours avant l'arrivée d'Arbolancho.

La Flotte, qui le portoit, étoit de I5. Vaiffeaux bien Sonarrivée équipés. Il menoit avec lui le Pere Jean de Quevedo Fran à Sainte Macifquain, facré Evêque de Terre Ferme ; car c'eft le Titre qu'on luidonne ordinairement, quoique fon fiege fût à Sainte Tom. $I$. 


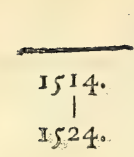

434

II I S TOIR

Marie l'Ancienne. C'eft le même Prélat, dont nous avons parlé: ailleurs à l'occafion des délibérations, qui furent faites en préfence de Charles - Quint, au fujet des Indiens. Un bon nombre de Miffionnaires du même Ordre de Saint François 。 des Ecclefiaftiques, \& environ 2000. tant Soldats,qu'Habitans $s_{\text {. }}$ étoient fur cette Flotte. Le Roi avoit donné pour Lieutenant: au nouveau Gouverneur, Jean de Ayora, pour Alcaïde Major, Jean de Efpinofa, qui fut dans la fuite Préfident de l'Audience Royale de San Domingo , \& Gouverneur de l'Ine Efpagnole, \& pour Alguazil Major, Charge, qui répond 丸. celle de Grand Prevoft, Encifo; ce qui fut pius que toute autre chofe de mauvais augure pour Balboa. Il y avoit outre cela quatre Officiers Royaux, aufquels, auffi bien quà l'Evêque, le Gouverneur avoit ordre de communiquer toutes chofes. Gonzale Fernandez d'Oviedo y Valdez, dont nous avons une Hiftoire du Nouveau Monde, que jai déjà citée plufieurs fois, étoit un de ces quatre Officiers, \& fon emploi étoir celui de Contrôleur des Mines, \& des Fontes de l'Or. Cette Flotte arriva vers la fin de Juillet, au Golphe d'Uraba, \& moüilla à une lieuë \& demie de Sainte Marie . où Pedrarias envoya aufít-tôt donner avis de fa venuë.

Sa. Récep- Celui qui fut chargé de cette Commiffion, étant entré zion. dans la Ville, demanda à parler au Commandant: on le lui montra, \& il fut fort furpris de voir un homme fi célébre avec une fimple Camifole de Cotton, ou de Cannevas fur fa chemife, un Caleçon, \& des fouliers de corde: faifant couvrir de feüilles une affés méchante Cafe, qui lui

Rlervarss fervoit de demeure ordinaire. Mais l'Hiftorien, qui rapporte cette circonftance, remarque fort judicieufemènt, que c'étoit par cette fimplicité, que Balboa étoit devenu la terreus de tant de Nations, \& s'étoit tellement attaché tous ceux . qui compofoient la Cơlonie du. Darien, qu'encore quon y: comptât à peine 450 . Hommes en état de porter les armes, Pedrarias, avec toutes les forces, qu'il avoit amenées d'Efpagne, ne feroit jamais venu à bout, de fe mettre en poffeffion de fon Gouvernement. fi Balboa eût entrepris. 


\section{DE S. Domingue, Liv. VI. 435}

de s'y oppofer. Ce Gouverneur ne s'étoit pas même attendu à y être reçû fans obftacle; mais il fut agréablement trompé. Son Envoyé s'étant approché de Balboa, lui dit: * Monfieur, D. Pedrarias Davila, que fon Alteffe a nommé * Gouverneur de cette Province, eft dans la Rade avec fa ^ Flotte. $\infty$ Balboa, fans paroître ému, lui répondit : « Affü* rés-lui qu'il eft le bien venu, \& que tous ce que nous fom$\rightarrow$ mes ici de Sujets du Roi, fommes très-difpofés à lui rendre lesrefpects \& l'obéiffance, que nous lui devons. $\mathrm{Ce}$ pendant il s'éleva dans la Ville un affés grand murmure, ,ill fe fit des Aflemblées, \& il ne tint qu’à Balboa, que toute la Colonie ne fe foulevât en fa faveur; mais il avoit pris le parti de la foumiffion, \& il ne s'en départit point. Il ne voulut pas même que perfonne parût armé devant le Gouverneur, \& il alla au devant de lui avec tous fes Braves, comme un Préfident à la tête d'un Confeil. Il lui fit fon Compliment de la maniere la plus refpectueufe, \& l'ayant conduit dans fa Cabane, il lui fit fervir un repas, qui confiftoit en pain de Maiz, en Caffave, en Fruits \& en Racines du Pays, avec de l'eau du Fleuve pour toute boiffon.

Dès le lendemain, Pedrarias commença à examiner, fi Il fait kairs tout ce qui fe difoit, \& tout ce qui avoit été mandé au Roi, le procès à des grandes Entreprifes \& des Conquêtes de Balboa, étoit conforme à l'exacte verité, \& il trouva qu'en tout cela il n'y avoit rien d'exaggeré, que la Mer du Sud étoit découverte, \& tout le Pays, jufqu'à cette Mer, entierement foumis; mais les gens qui l'avoient fuivis d'Efpagne, \& qui s'étoient imaginé qu'il n'y avoit qu'à fe baiffer, ou à tendre des filets dans la Riviere pour avoit de l'Or, fe virent bien loin de compte, lorfqu'ils eurent oüi faire le récit de ce qu'il en avoit coûté aux anciens Colons pour s'enrichir. Peu de jours après le Gouverneur fit publier l'ordre, qu'il avoit , de finir le procès de Balboa,\& il commanda à l'Alcaide Majo de faire fa Charge. Ce Magiftrat commença par fe rendre mấ. tre de la Perfonne de l'acculé, \& après avoir examiné les Charges contenuës dans le Memoire d'Encifo, il le con: 


\section{$436 \quad$ H I S T O I R}

I5r4. damna à une très-groffe amende, puis il le mit en liberté.

Cette affaire terminée, Pedrarias, fuivant le Plan, que

1524. Balboa s'étoit propofé, prit des mefures pour faire des Sa mauvai- peuplades dans les endroits, que ce Capitaine avoit marvant au Roi. qués; mais tandis qu'il paroiffoit agir avec lui dans une bonne intelligence, qui charmoit tout le monde, il écrivit au Roi que la Colonie du Darien n'éroit pas à beaucoup près fur un auffi bon pied, qu'on l'avoit mandé à fon Alteffe. D'autres Lettres partirent en même temps, où les anciens Colons faifoient de grandes plaintes contre quelques Offciers, qui étoient venus avec le Gouverneur, \& la fuite fera connoître que ces dernieres accufations étoient mieux fondées que les premieres.

Etat où $f$ trouve la $\mathrm{Co}$ lonie. Balboa eft nommé Adélantade de la Mer du Suld.
En effet, Pedrarias avoit trouvé la Colonie dans un état très-floriffant; tout le monde étoit content, on ne voyoit que Fêtes, on n'entendoit que chants d'allegreffe au fon de toutes fortes d'Inftrumens; les Terres étoient enfemencées, \& commencoient à fournir aflés de vivres pour nourzir les Habitans : les Caciques étoient, non feulement foumis, mais pour la plûpart tellement affectionnés aux Efpagnols, que ceux-ci pouvoient aller feuls, fans rien craindre, d'une Mer à l'autre. Auffi le Roi ayant parfaitement démêlé la verité au travers des nuages, dont on vouloit l'obfurcir, écrivit l'année fuivante à Pedrarias, que voulant reconnoître les grands fervices, que lui avoit rendu Vafco Nugnez de Balboa, il le créoit fon Adélantade pour la Mer du Sud, \& les Provinces de Panama \& de Coyba; qu'il prétendoit qu'on lui obêit dans l'étenduë de ce diftrict, comme à lui-même, \& qu'il vouloit que tout le monde fçût l'eftime, qu'il faifoit de fon mérite : enfin, qu'encore qu'il dût être fubordonné au Gouverneur Général, fon intention étoit qu’on ne le gênât en rien, fur tout ce qui regarderoit le fervice \&r le bien de l'Etat. Le Roi ajoûtoit qu'il reconnoîtroit le zele de Pedrarias pour fa perfonne au traittement, qu'il feroit d. Balboa, dont il fouhaittoit qu'il prît les avis en touter chores. 


\section{De S. Domingue, Liv. VI. 437}

Rien n'étoit plus flatteur pour Balboa, que ces Lettres de fon Prince, mais elles ne firent apparemment quavancer fa perte. Pedrarias étoit un homme violent, \& il s'en fallut bien qu'il gouvernàt avec la même douceur, qu'avoit fait l'Adélan- lui fait couper tade. Dès l'année is I s. Oviedo paffa fecrettement en Caf- la téte. tille pour y faire de grandes plaintes contre lui. Il en avoit été fort maltraité, auffi bien que Balboa, \& ils avoient même été mis en prifon, je n’ai pû fçavoir à quel fujet. Balboa écrivit de fon côté au Roi une grande Lettre dattée du I6. Octobre Is Is. dans laquelle il fe plaignoit fort du Gouverneur. L'année fuivante l'Evêque le réconcilia, mais la réconciliation, fi elle fut fincere, ne fut pas de durée, puifque deux ans après Pedrarias fit faire le procès criminel à Balboa, contre lequel on l'avoit aigri de nouveau par de faux rapports. La Mort de Nicueffa, \& les violences exercées contre Encifo, lui furent encore reprochées; on y ajoûta le crime de Félonie, qui confiftoit en ce qu'il avoit, difoiton, voulu ufurper le Domaine du Roi. Il eut beau fe récrier contre de pareilles accufations, dont les unes ne devoient plus avoir lieu après le Jugement défnitif porté contre lui par l'Alcaïde Major, \& les autres étoient abfolument fauffes : il eut la tête coupée à Sainte Marie, au grand regret de toute la Colonie. Il n'avoit que 42 . ans, \& le Roi perdit en lui le plus grand Sujet, qu'il eûr alors dans les Indes. Ce qu'il avoit fait dans le peu d'années, qu'il avoit Commandé dans la Caftille d'Or, ne laiffe aucun lieu de douter qu'il n'eût bientôt découvert \& conquis le Perou, fi on ne lui eût pas donné de Superieur au moment, qu'il fe difpofoit à partir pour cette grande expédition.

Les PP. de S. Jerôme, qui gouvernoient l'Inle Efpagnole, lorfque la nouvelle de cette exécution y arriva, \& dont l'authorité, ainfi que je l'ai marqué ailleurs, s'étendoit fur exercées par Pedrarias. tous les Gouverneurs des Indes, témoignerent beaucoup led'Or. de reffentiment contre Pedrarias, \& lui en écrivirent en des termes, qui durent lui faire connoître ce qu'on penfoit de cette action dans toute l'Amerique. Ils ajoûterent 


\section{H IS TO I R E}

ISI7. qu'ils avoient reçû beaucoup d'autres plaintes de fa con1 duite, \& qu'il ne devoit pas ignorer que l'intention du Roi I524. étoit, qu'il ne fit rien fans la participation du Confeildefa Province. Il étoit déjà bien tard pour donner ces avis à Pedrarias, du moins touchant la maniere, dont il en ufoit a l'égard des Indiens; ou, s'il fut averti à têms, il profita bien peu de l'avertiffement. Las Cafas fans le nommer. mais en le défignant de maniere à ne s'y pouvoir tromper. nous le repréfente comme une bête féroce déchaînée par le Tout-Puifiant dans fa fureur, pour exterminer un peuple; dont il falloit que les crimes fuffent montés à leur comble, pour mériter tout ce que Pedrarias lui fit fouffrir. C'eft tout dire que ce Gouverneur ravagea \& défola depuis le $\mathrm{Da}$ rien jufqu'au Lac Nicaragua s 00. lieuës d'un Pays très peuplé, le plus beau \& le plus riche, quil fût poffible de voir, \& que fans diftinction d'Alliés \& d'Ennemis, il exerça indifferemment fur tous des cruautés, qu'on ne pourroit jamais croire, fi les preuves n'en avoient été dépofées au Greffe du Fifc Royal, auquel Las Cafas ne craint point de renvoyer fes Lecteurs.

Sainte Ma- Cependant on peut bien juger qu'un homme de ce rranf́portée à caractere fouffroit fort impatiemment la dépendance, où il Panama.

fe voyoir de tant de Superieurs, \& ce fut le défir de fecoüer un joug, auquel il ne pouvoit fe réfoudre à fe foumettre. qui contribua plus que toute autre chore à la deftruction de Sainte Marie l'Ancienne; car il s'imagina qu'en allant s'établir fur la Mer du Sud, l'éloignement le pourroit plus aifément fouftraire à l'authorité de ceux, qui commanderoient dans l'Ifle Éfpagnole, \& le délivreroit de l'obligation, qu'on lui avoit impofée de prendre les avis du Confeil

I5 I8. de fa Province. En Is I8. il envoya lAlcaïde Major Diego de Efpinofa à Panama, avec ordre d'y bârir une Ville, ce qui fut exécuté. Il écrivit en même têms au Roi quele Pays, où étoit fituée Sainte Marie, n'étoit pas propre à un grand établiffement, \& qu'il convenoit au bien de la Cotonie de tranfporter le fiege Epifcopal à Panama. Il reçut 



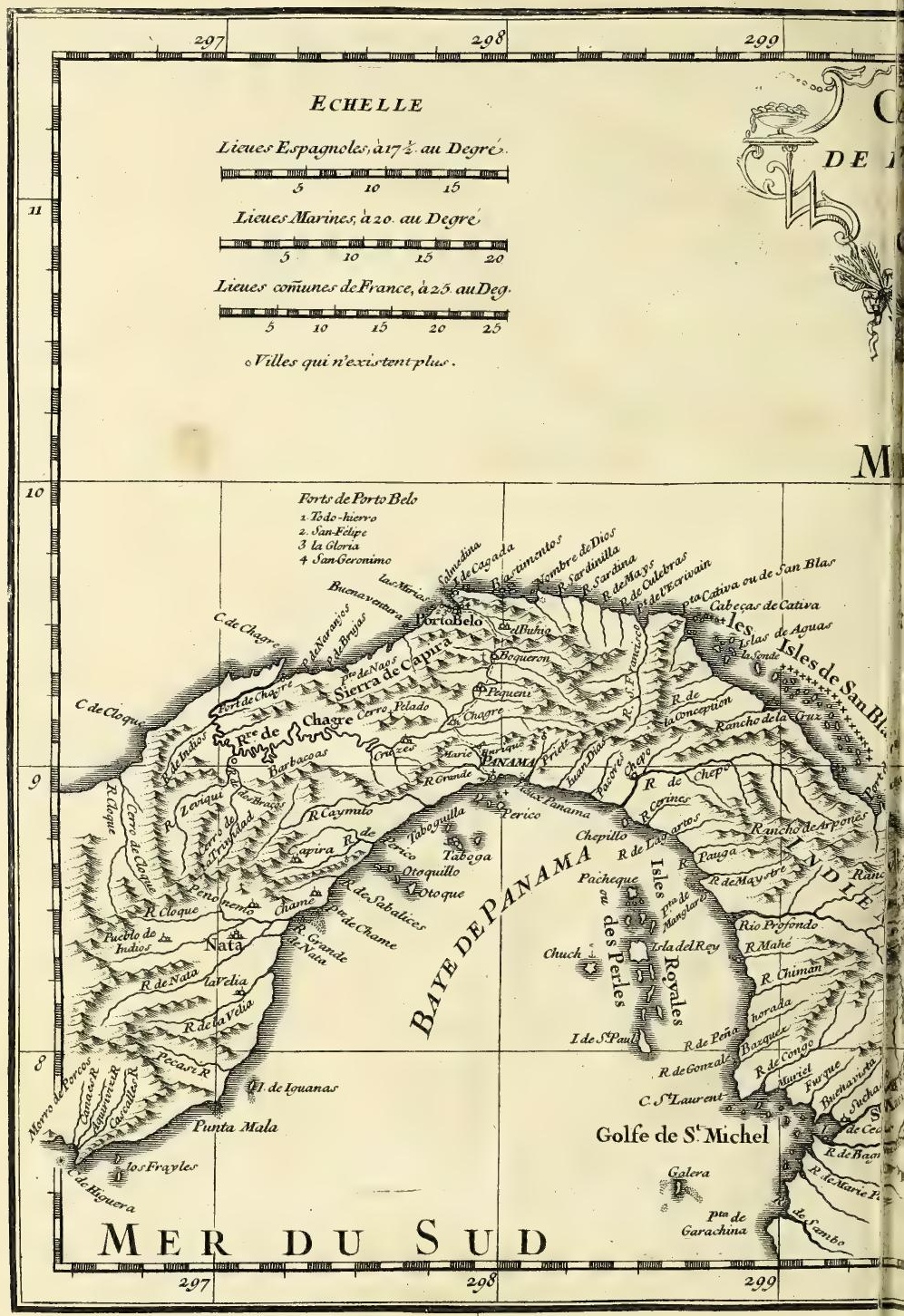


PARLES S. D'ANVILLE

Géographe Ord"duRoi.

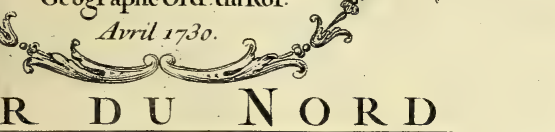

\section{R D U NO R D}

Islas de Tarit

$S$ MARTHI

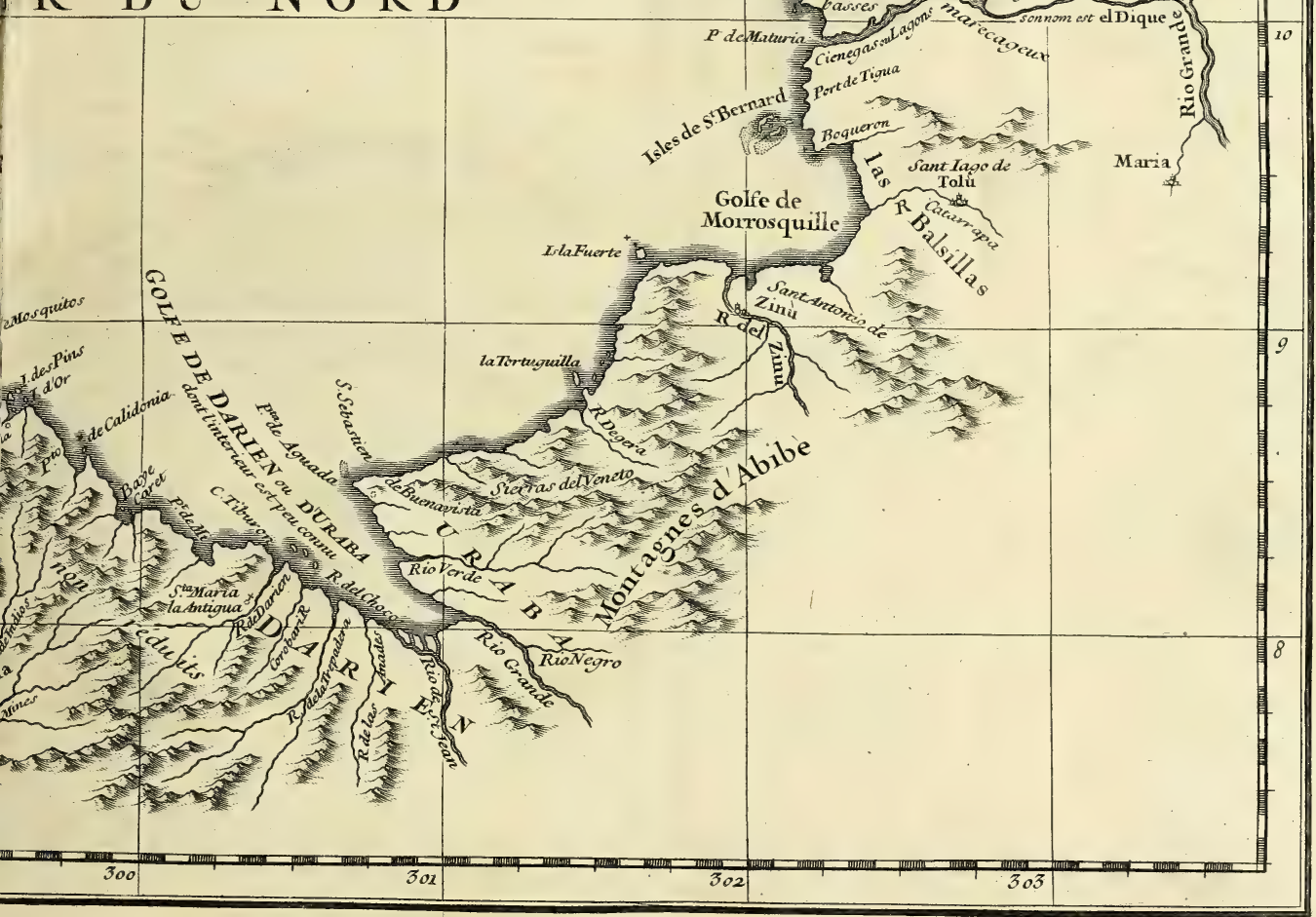





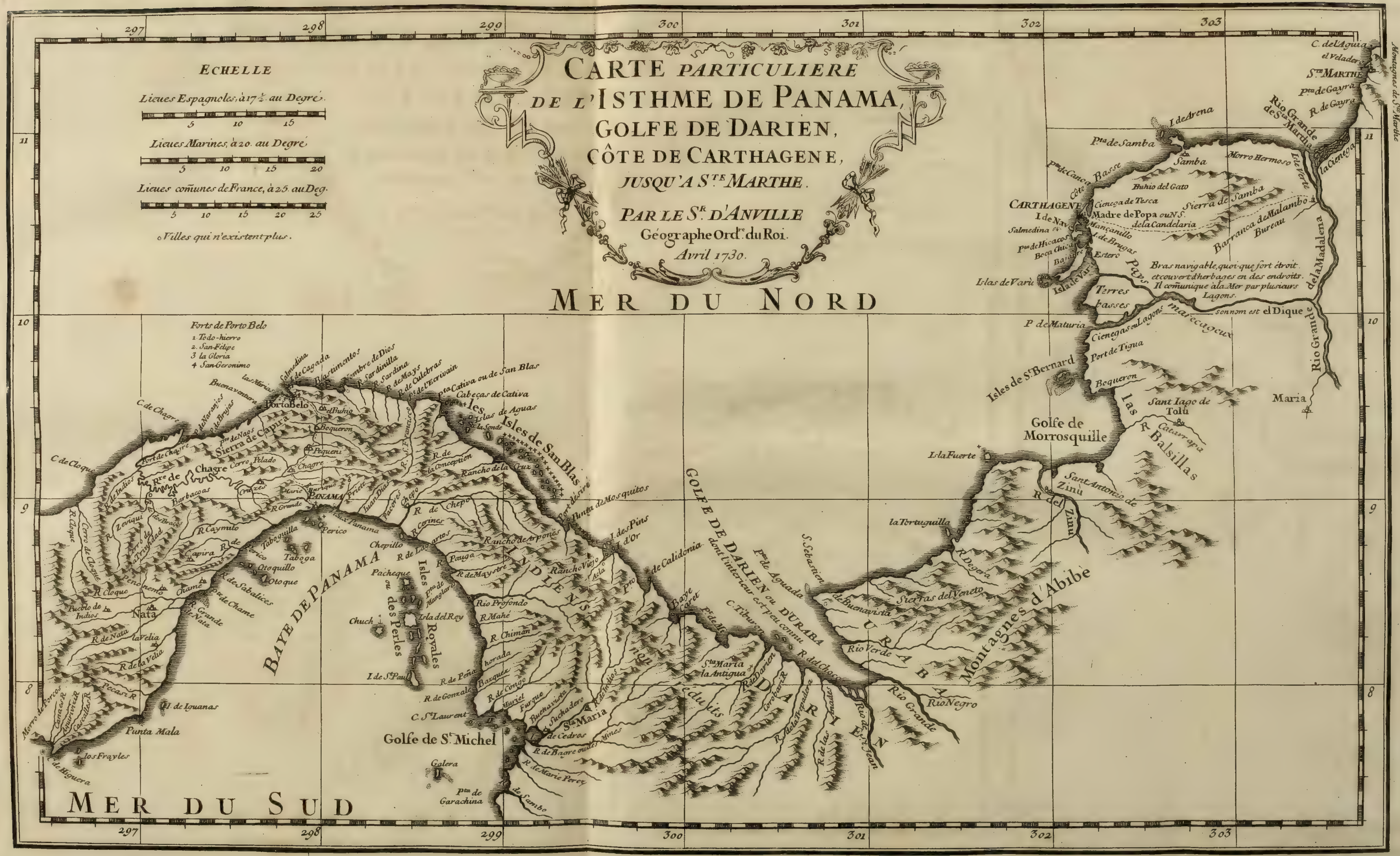





\section{DE S. Domingue, Liv. VI. 439}

lannée fuivante une réponfe favorable, \& aufi-tôt il envoya ordre à Oviedo, qui commandoit fur le Darien en qualité de fon Lieutenant, de tranfporter à Panama tout ce qu'il y avoit d'Habitans à. Sainte Marie, \& jufqu'aux Troupeaux.

Cela fait, il reprit le projet des Découvertes dans la Mer du Sud, formé par Balboa. Il fongeoit auffi depuis quelque tout de bon à têms à peupler les environs du Lac Nicaragua, dont il te du Perou. prétendoit avoir fair la premiere découverte, \& il avoit envoyé un nommé Herrera à l'Ifle Efpagnole, pour lui en amener un puiffant fecours. Herrera trouva moyen d'engager dans cette entreprife un riche Habitant, qui avoit nom Jean de Bafurto, lequel fit à ce deflein une grande levée d'Hom. mes \& de Chevaux. Mais comme l'armement traîna un peı. en longueur, Bafurto apprit en arrivant à Panama, que Pedrarias avoit donné le Commandement de l'entreprife de Nicaragua à fon Capitaine des Gardes, François Fernandez de Cordouë. Il en témoigna beaucoup de reffentiment , \& Pedrarias pour l'appaifer, lui propofa de continuer les. Découvertes fur la Mer du Sud, qu'un nommé Pafcal de Andagoya avoit pouffées en I \$22. jufques à Cuzco. Bafurto accepta la propofition avec joye, mais ne trouvant point a Panama toutes les chofes, dont il avoit befoin pour une entreprife de cette confequence, il prit le parti d'aller s'équipper à l'Ine Efpagnole, \& mourut dans ce Voyage à Nombre de Dios. On n'en eut pas plûtôt avis à Pana. ma, que François Pizarre \& Diego de Almagro, qui s'é. toient puiffamment établis dans cette Ville là, repréfenterent au Gouverneur qu'il n'étoit pas de fon honneur d'aller chercher hors de fa Province des Sujets, pour exécuter de pareils deffeins; qu'il s'y en trouvoit d'auff propres qu'en aucun autre endroit des Indes, \& que leur experience \& leurs longs fervices méritoient bien qu'on leur donnât la préference fur des Etrangers.

Pedrarias fe laiffa d'autant plus aifément perfuader, que Aflociation fans rien mettre du fien, il pouvoit faire fes conditions auff entre Pizarre, 


\section{$440 \quad H$ I $S$ T O I R E}

1524.

Fernand de

Lucques pour

la Conquéte

du Perou.

bonnes qu'il voudroit, \& il les fit en effet très-avantageufes. Pizarre, Almagro, \& un Ecclefiaftique fort riche, nommé Fernand de Lucques, lequel avoit été Ecolatre de l'Eglife de Sainte Marie l'Ancienne, firent entre eux une affociation, dont les principaux articles furent, que Pizarre, qui étoit homme de main, \& qui toute fa vie avoit Voyagé , \& fait la guerre aux Indiens, feroit chargé de l'exécution du projet; qu'Almagro fourniroit toutes les provifions; \& feroit tous les préparatifs, \& que Fernand de Lucques feroit obligé à toutes les autres dépenfes néceffaires. Ce traité fit grand bruit dans Panama, où l'on ne pouvoit comprendre que des Perfonnes fi fages, \& fi éclairées engageaflent tout ce quils avoient au monde, pour aller à la Conquête d'un pays, où l'on n'avoit encore trouvé que des. Marais \& des Terres fteriles, \& il ne fut perfonne, qui ne crût que la tête leur avoit tourné, lorfque pour cimenter leur affociation on vit Fernand de Lucques dire la Meffe, féparer l'Hoftie en trois, \& après en avoir pris une partie, donner les deux autres à fes Affociés. Veritablement les commencemens de cette expedition n'en promettoient pas une iffuë fort heureufe, mais le courage, l'induftrie \& la conftance de Pizarre, furmonterent tous les obftacles. Il partit de Panama vers la mi-Novembre i 524 . avec un reul Navire, \& gagna avec bien de la peine la Riviere \& la Province de Biru, qui eft limitrophe du Royaume de Quito, \& d'où lon prétend qu'eft venu le nom de Piru, duquel par le changement d'une lettre, \& en gardant la prononciation Efpagnole,nous avons formécelui de Perou. Mais la fuite de cette expedition a fi peu de rapport à l'Hiftoire que j'écris, que je pafferois les bornes d'une jufte digreffion, fi j'en difois davantage.

Etabliffe- L'année, qui fuivit le départ de Pizarre, le Licencié Marment de l'Ifle cel de Villalabos un des Auditeurs Royaux de San-DominMarguerite \& de Sainte Marthe.

go, fit un traité avec la Cour, pour l'établiffement de l'Ifle Marguerite, \& il y a bien de lapparence que ce traité eut fon effet aux dépens de l'Ifle Efpagnole, car une des conditions 
DES. Domingue, LIV. VI. 44 I conditions fut, qu'il y meneroit un certain nombre de familles Caftillanes, qu'il ne pouvoit gueres tirer d'ailleurs. Ce fut auffi la même année que Rodrigue de Baftidas, ( je n’ai pû fçavoir fi c'étoit le même, dont nous avons parlé ailleurs ,) partit de San-Domingo, avec un Efcadre pour peupler la côte de Sainte Marthe, dont il avoit obtenu le Gouvernement avec le titre d'Adélantade ; mais cette expedition lui fut très-funefte: fes propres gens fe mutinerent contre lui, \& comme il fe fût embarqué, pour retourner à l'Ifle Efpagnole, dans le deffein fans doute d'y demander main-forte à l'Audience Royale, pour ranger les féditieux à la raifon, il mourut dans l'fle de Cuba, où il avoit été obligé de relâcher.

Le Tréforier Général Michel de Paffamonté mourut l'année fuivante I 526. à San-Domingo; \& les amis des Co1526. lombs ne douterent point alors que cette famille, délivrée Paffamonté. d'un tel ennemi, ne reprît le deffus, mais elle n'en avoit pas pour un, \& les plus à craindre n'étoient pas ceixx, qui fe montroient plus à découvert. Les Épagnols avoient enfin prévalu dans les Confeils fur les Flamands, \& il n'y en avoit pas un en place, qui ne vît avec plaifir l'abbaiffement d'une Maifon, qu'ils regardoient toûjours comme Etrangere. D'ailleurs les Conquêtes de Cortez, \& de plufieurs autres, tous Efpagnols naturels, fembloient avoir obfcurci la gloire du Grand Chriftophle Colomb, du moins dans l'efprit jaloux de leurs Compatriotes; \& le Mexique, la Floride, l'Yucatan \& le Perou dépeuploient infenfiblement l'Ifle ¿ffpagnole, \& les autres Provinces,dont l'établiffement avorit été l'ouvrage des deux précédens Amiraux des Indes; je dis, les deux précédens Amiraux, parce que Dom Diegue étoit mort au commencement de cette même année.

Nous avons vû que cet Amiral en arrivant en Efpagne avoit trouvé la Cour à Victoria, il l'avoit fuivie pendane miral D.Die deux ans entiers dans les Villes de Burgos, de ValladoIid, de Madrid \& de Tolede. Enfin l'Empereur partant de Tome $I$ 。 $\mathrm{Kk} \mathrm{k}$ 
I526. cette derniere pour fe rendre à Seville, D. Diegue, quine fe portoit pas bien, voulut encore le fuivie, \& réfolut de prendre fon chemin par Notre-Dame de Guadeloupe , qu’il étoit bien aife de vifiter par dévotion. Il étoit beaucoup plus malade, qu'il ne penfoit, \& Oviedo qui étoit alors en Efpagne, dit que, l'étant allé voir deux jours avant fon départ de Tolede, il n'omit rien, non plus que plufieurs de fes amis, pour le détourner de fe mettre en chemin dans l'état, où il étoit, \& dans une faifon auffi incommode. Ils n’y réüfirent pas, $\mathrm{D}$. Diegue leur dit qu'il défiroit d'aller faire une neuvaine à Notre-Dame de Guadeloupe, \& qu'il efperoit recouvrer fa fanté par l'interceflion de la Mere de Dieu. Il partit de Tolede en Litiere le 2 I. de Février, \& arriva le même jour à Montalvan, qui n'en eft éloigné, que de fix lieuës. Alors fon mal augmenta tout-à-coup de telle forte, qu'il vit bien que fa fin étoit proche. Il s'étoit confeffé \& avoit communié avant que de partir de Tolede; il employa tout le lendemain de fon arrivée à Montalvan à mettre ordre aux affaires de fa confcience, \& le jour fuivant, qui fut un Vendredy 23, de Fevrier, il expira dans les fentimens d'un parfait Chrétien.

Erat de fa Il avoit laiffé à San. Domingo toute fa famille, qui confamille. fiftoit en deux Filles, \& trois Fils, dont l'aîné appellé $D$. Loüis, n'avoit pas plus de fix ans: les deux autres avoien nom Diegue \& Chriftophle. Les deux filles, qui étoient les aînées, fe nommoient Philippine \& Ifabelle. Dom Loüis fue falué Amiral des Indes, dès qu'on eût appris la mort de fon Pere,mais il refta fans aucune authorité dans l'Ille Efpagnole,oì Gafpard de Efpinofa, que nous avons vûAlcaïdeMajor à Sainte Marie l'Ancienne \& à Panama, commandoit en qualité de Juge de Réfidence, ou de Préfident. La Vice-Reine Donna Maria de Tolede, crut que fa préfence à la Cour pourroit achever ce que le défunt Amiral fon Mari avoit commencé, \& s'embarqua pour l'Efpagne, menant avec elle la feconde de fes Filles, \& le fecond de fes Fils. Elle trouva en arrivant l'Empereur parti pour Boulogne, où il devoit rea 


\section{DE S. D ORINUE, IIV. VI. 443}

cevoir la Couronne Imperiale, \& s'étant renduë auprès de l'Impératrice, qui la reçut avec toute la diftinction poffible, elle maria quelque têms après Ifabelle Colomb fa Fille à D. George de Portugal, Comte de Gelves, \& Dom Diegue fon Fils fut reçû Page du Prince d'Efpagne, qui̊ fut depuis le Roi Philippe II. L'Empereur ordonna en mê me têms qu'on augmentât les revenus du jeune Amiral s \& fit plufieurs autres graces femblables à cette Famille ; mais il ne jugea pas à propos de lui faire juftice fur fes prétentions, \& Dom Loüis ne put jamais obtenir la permiffion de prendre le titre de Vice-Roi des Indes, quoique Ion Pere eût obtenu quelque têms avant fa mort, un Arrêt, qui affuroit fon droit. Il y a bien de l'apparence qu'on prétendoit en revenir.

Les années fuivantes, le dépeuplement de notre Ifle devint très-fenfible, \& c'étoit prefque toûjours les plus aifés, qui en fortoient. Dès qu'il s'agiffoit de quelque nouvelle Conquête, on ne manquoit point de s'addreffer aux peuple. Habitans des Ifles, \& plus ordinairement à ceux de l'Efpagno1e. Ainfi, après les Entreprifes de Luc Vafquez d'Ayllon, de Marcel de Villalobos, \& de Rodrigue de Baftidas, dont jai parlé, François de Montejo ayant eu ordre d'armer poux peupler l'Yucatan, Heredia, pour bâtir Carthagene, \& Pamphile de Narvaés, pour faire un établifiement dans la Floride, en emmenerent avec eux un grand nombre des meilleurs Sujets. Il eft vrai que dès l'année précedente $x 526$. le r6. de Novembre il avoit été rendu un Arrêt, par lequel il étoit défendu aux Habitans des quatre grandes AntilJes d'en fortir, pour aller s'établir ailleurs, fans permiffion; il y étoit même expreffément marqué que, fi l'Empereut envoyoit quelqu'ụn faire un établiffement dans la Terre Ferme, \& qu'on ne pût fe difpenfer de lever des Hommes dans l'Ifle Efpagnole, comme étant les plus propres de tous à ces entreprifes; on auroit foin de les remplacer d'autant d'Hommes, qu'on y meneroit d'Efpagne, \& c'eft à cette occafion, qu'il fut permis indifféremment à tous les Sujets

$\mathbb{K k ~ k ~ i j ~}$ 
1527. de l'Empereur, de paffer aux Indes, \& de s'y établir. Maiss l'Arrêt, dont je viens de parler fut mal executé.

Audience Vers le même têms la Cour voulant moderer la grande auRoyale du
Mexique Dif- thorité, que fe donnoit Fernand Cortez dans fa Conquête, Mrict de celle établit une Audience Royale pour le Mexique. Par-là , le difde San-Do- trict de celle de San-Domingo fut borné aux grandes Antilles, mingo. $\&$ à cette partie du Continent, qui eft entre l'Orenoque, \& la grande Riviere de la Magdelaine. On en a encore retranché depuis le Gouvernement de Sainte Marthe, pour l'ajoûter à celle du nouveau Royaume de Grenade. Ainfi les limites de celle de San Domingo, font aujourd'hui de ce côté-là à Rio de la Hacha. Certe étenduë de Jurifdiction Civile \& Criminelle, qui eft demeurée à San-Domingo, jointe à celle, que lui donne fa Metropole pour Spirituel, empêche que cette ancienne Capitale du Nouveau Monde, après l'avoir difputé pour la grandeur, la magnificence \& les richeffes aux premieres Villes d'Efpagne, ne foit prefque réduite à la condition des plus obfcures Bourgades. Effectivement le peu d'Argent, qu'on y voit, vient de ceux, qui ont des caufes à porter à l'un ou à l'autre Tribunal, lefquels confervent toûjours la prééminence, que leur ancien. neté leur donne fur tous les autres : fans parler du droit de Primatie, qui eft attaché à l'Archevêché de San-Domingo.

Union des. La même année 1527 . qui vit les changemens, dont je deux Evê- viens de parler, les deux Evêchés de San-Domingo \& de chés de 1 Irie la Conception, furent réünis à caufe de la modicité de leurs revenus, \& ce fut la premiere de ces deux Villes, qui conferva le Siege Epifcopal. Le Licencié D. Sebaftien Ramirez de Fuente Leal fut aufi-tôt nommé pour occuper ce grand Siege, \& déclaré Préfident de l'Audience Royale . avecla même authorité, qui avoit été donnée au P. Loüis de Figueroa fon Rrédeceffeur. Dès qu'il fut facré, l'Empereur le preffa de le rendre aux Indes, \& parce que les derniers Evêques s'étoient plaints que les Juges Royaux empiettoient fans ceffe fur la Jurifdiction Ecclefiaftique; $\mathrm{Sa} \mathrm{Ma-}$ jefté donna de bons ordres pour empêcher cet abus. Elle 


\section{DE S. Domingue, Liv. VI. 445}

tranfporta auffi à l'Evêque de San-Domingo, \& à celui de Sant-Yago, dans l'Ine de Cuba, le pouvoir, qu'elle avoit donné peu auparavant aux Superieurs des Dominiquains \& des Francifcains au fujet des Indiens; perfuadée que les chofes fouffriroient moins de difficulté , étant décidées par des perfonnes de ce caractere, \& de cette authorité. Mais comme ces deux Prélats avoient encore peu d'expérience des affaires du Nouveau Monde, Sa Majefté leur donna pour Adjoints dans cette Commiffion D. Gonzalez de Guzman, Gouverneur de Cuba, \& le Pere Pierre Mexia, Superieur Général des Religieux de Saint François. D. Gonzalez avoit depuis peu fuccedé à Velafquez, mort de chagrin, après avoir vû échoüer toutes fes tentatives contre Fernand Cortez, dont la derniere acheva de le ruiner.

Dom Sebaftien Ramirez arriva à l'Efpagnole fur la fin de I 528 . \& l'on ne fut pas long-têms fans reconnoître le Thréfor ; que le Nouveau Monde polfedoit dans la perfonne de cePrélat. Auffi peut-on dire, que les principales Provin. ces, qui compofoient alors l'Empire Erpagnoi dans les Indes, \& que l'Evêque de San-Domingo gouverna prefque tou- conduite. tes l'une après l'autre, n'ont jamais été mieux reglées, que fous fon adminiftration. Il crut devoir fes premiers foins, dès qu'il fut dans fon Diocefe, à y rétablir la Paix \& la bonne intelligence, ce qui étoit devenu plus facile par la mort de Paffamonté. Il vuida en peu de têms, ou accom. moda tous les procès entre les Particuliers, il fit comprendre à ceux, qui étoient en place, que leur interêt \& celui de la Colonie demandoient qu'ils agiffent toûjours de cor. cert entre eux \& avec lui , \& pour s'attacher le peu d'Indiens, qui reftoit encore foumis aux Efpagnols, il infitua une Ecole en leur faveur, \& prit toutes les mefures les plus juftes, pour empêcher qu'on ne les moleftât en rien.

Cela fait, il tourna toutes fes vûës du côté des Indiens. On tâche révoltés. L'Empereur lui avoit fort recommandé de ne rien de gagner les négliger pour finir une guerre, qui étoit devenuë fort one- Indiens révolo reufe au Fifc Royal, ruinoit les Particuliers, \& faifoit dé-

1528.

I 529.

Nouvel E: vêque de San. 西

(1)




\section{H Is T O I $\mathrm{x}$}

1528. ferter l'Ifle. Quelque têms auparavant le $P$. Remy s'ẻtoit I laiffé perfuader d'aller une feconde fois trouver le Chef des

I529. Rébelles, \& il y avoit été accompagné par un Cacique Chrétien, nommé Rodrigue, fort affectionné à la Nation Efpagnole. Mais peu s'en étoit fallu que le bon Pere n'eût été maffacré par les Barbares, \& Rodrigue n'en avoit pas été quitte pour la peur; les Indiens le regardant comme un homme, qui trahiffoit fa Nation, l'avoient arrêté \& pendu d un arbre. On avoit enfuite eflayé de les divifer, en faifant les plus magnifiques promeffes à ceux, qui reviendroient dans la Colonie; \& cette démarche n'ayant encore rien produit, on avoit fait un effort pour les dompter, puifqu'on défefperoit de les gagner.

Onneréufitic

Trois Corps de bonnes Troupes pénétrerent en même la force. eurent d'abord quelque avantage, mais le Cacique ayant fait retirer tout fon monde dans les lieux les plus inacceffibles, les Caftillans n'oferent les y fuivre, \& s'en retoura nerent. D'un autre côté Henry n'avoit pas toûjours été le Maître d'empêcher bien des défordres, qui fe commettoient par les Rébelles dans les habitations Efpagnoles, parce que plufieurs Avanturiers de fa Nation, s'étant faits Chefs de Bande, ne le reconnoiffoient point pour leur Général, \& n'avoient pas à beaucoup près, ni fa moderation, ni fa prudence. Il vint toutefois à bout avec le têms de les réünir tous fous fes ordres; mais fi la guerre en devint moins préjudiciable aux Particuliers, par le bon ordre, quil établit dans ces nouvelles Troupes, \& par la réfolution, où il fe maintint, de ne pas combattre, fi on ne l'attaquoit, elle en étoit devenuë beaucoup plus difficile à finir. C'étoit la fituation, où fe trouvoient les chofes, lorfque Dom Sebaftien Ramirez arriva à l'Ifle Efpagnole; \& il y a bien de l'appaxence que, s'il entreprit de terminer cette guerre,ce fut plûtôt pour obéir aux Ord̉res précis qu'il en avoit reçus, que dans l'efpérance d'y réüfrir; car il trouva les Efpagnols extrêmement découragés. Au refte on ne pouvoit gueres s'y prendre maieux qu'il fir. 
DE S. DOMInGUe, LIV. VI. 447

Illeva 150 . Hommes, dont il donna le commandement à un vieux Gentilhomme de Ledefma, nommé Saint Michel, qui étoit venu fort jeune dans l'Ifle du têms de Chriftophle Colomb , \&r s'étoit établi à Bonao. Il avoit fervi dans toutes les Guerres avec honneur, \& s'étoit fi bien accoutumé à marcher dans les endroits les plus difficiles, qu'aucun Indien ne fçavoit s'en tirer mieux que lui, ni grimper avec plus de facilité fur les Montagnes les plus hautes \& les plus efcarpées. Il entra avec fes Soldats dans les endroits les plus impénétrables du Baoruco, \& il fuivit le Cacique de défilé en défilé, avec une diligence incroyable. Il s'en approcha enfin de telle forte, qu'un jour ils fe trouverent chacun fur le fommet d'une Montagne, ayant entre eux une efpece de Ravine fort creufe, oì couloit un Ruiffeat? affés profond. Ils étoient fi proches, qu'ils pouvoient fe parler \& \& ils commencerent par convenir d'une Tréve pour quelques jours. Ils eurent enfuire quelques entretiens, dans l'un defquels le Capitaine Efpagnol demanda au Cacique. fi une bonne Paix ne lui paroiffoit pas plus fouhaittable pour lui , que la fituation, où il fe trouvoit : il ajoûta qu'il avoit pouvoir de traitter avec lui à des conditions, dont il fe flattoit qu'il feroit content; qu'on lui permettroit de choifir tel endroit de l'Ine, qu'il trouveroit plus à fa bienféance , \& d'y vivre avec les fiens dans une indépendance entiere : qu'on exigeoit de lui, pour toute condition, la reftitution de l'Or, que fes gens avoient enlevé depuis peu à des Efpagnols venus de Terre Ferme, après les avoir mafracrés.

Henry répondit à cette propofition quili ne tenoir pas à On entre lui que la paix ne fe conclût, qu'il ne vouloir de mal à en acconodes perfonne, mais qu'il n'étoit pas de fa prudence de fe remettre à la difcretion de gens, qui lui avoient fi fouvent manqqué de parole: toute fois que, fi on pouvoit luidonner des affîrances capables de lever toutes fes craintes \& fes foupçons, il ne s'éloigneroit pas des voyes d'accomodement. Alors S. Michel lui montra fon plein pouvoir, $8 z$ 


\section{HISTOIRE}

1529. après quelques autres difcours, les deux Chefs convinrene d'un rendés-vous fur le bord de la Mer, où chacun ne poutroit amener que huit hommes. Henry fe trouva exactement au lieu marqué, \& y prévint même l'heure, dont on étoit convenu. Il avoit fait apporter tout l'Or, que les Efpagnols redemandoient, \& préparer fous une feüillée un grand repas pour regaler S. Michel. Celui-ci de fon côté avoit fait les mêmes préparatifs; mais, quoiqu'il agit fincerement, il s'avifa mal-à-propos d'une manœuvre, qui gâta tout.

Il y avoit auprès de là un Navire Efpagnol; S. Michel Eaitrompre: fit prier celui, qui le commandoit de s'approcher, \& celuici y ayant confenti, Henry fut affés furpris de voir arriver en même têms $S$. Michel par terre, Tambour battant \& Enfeignes déployées, \& un Navire, qui fembloit avoir envie de tenter une defcente. Le parti, qu'il prit alors, fut de fe retirer, \& de s'aller mettre en füreté , mais il laiffa fon efcorte au lieu deftiné à la conference, \& ordonna à celui, qui la commandoit, de dire au Capitaine Efpagnol, qu'une incommodité fubite l'avoit empêchéd'attendre plus long-têms; de lui fervir le repas préparé, de lui remettre tout l'Or qu’il lui avoit redemandé, \& de lui témoigner le défir fincere, qu'il avoit, de bien vivre avec tout le monde. Ses ordres furent ponctuellement executés. S. Michel parut fort mortifié de ne point trouver le Cacique, \& témoigna affés qu'il foupçonnoit la véritable caufe de fa retraitte. Il ne laiffa pas de faire beaucoup d'amitié aux Indiens; il accepta l'Or, qu'ils lui préfenterent, fe mit même à table, leur marqua l'eftime, qu'il faifoit de leur Chef, \& les pria de lui dire qu'il vouloit être de fes amis, \& qu'il l'exhortoit à faire ceffer de fa part toute hoftilité, comme il fe faifoit fort de les faire ceffer de la part des Efpagnols. En effer on fut près de quatre ans depuis cette négociation, fans entendre parler du Cacique, ni de fes gens, \& le Préfident profita de cette tranquilité pour mettre en exécurion plufieurs Reglemens, dont l'Empereur l'avoit chargé. 


\section{De S. Domingue, Liv. VI. 449}

Tandis que ces chofes fe paffoient dans l'Ine EfpagnoIe, il arriva dans la partie du Continent foûmife à fon Audience Royale un changement, qui eut des fuites bien triftes pour ce malheureux Pays. Les Auditeurs Royaux ayant voyée dans la reçû́ plufieurs plaintes, que des Particuliers fortis des Ports Venezuelzo de leur Ine pour aller chercher des Efclaves, dépeuploient toutes les Côtes de la Terre Ferme, \& y commettoient les plus affreux brigandages, crurent que, pour remedier à un défordre fi criant, il falloit multiplier les Etabliffemens. dans la penfée que les Gouverneurs arrêteroient la licence de ces Avanturiers ; \& comme toute cette Contrée , qui eft aujourd'hui connuë fous le nom de Province de Venezuela, étoit une des plus expofée à leurs courfes, le Facteur Royal Jean d'Ampuez eut ordre en I $\$ 27$. d'aller s'y établir avec 60. hommes, qu'on lui donna. L'endroit, où. cet Officier débarqua ; fut ce que les Indiens appelloient La Coriane, \& où j'ai dit qu'Alphonfe de Ojeda avoit trouvé une Bourgade bâtie à la maniere de Venife au milieu d'une Lagune. Un puiffant Cacique nommé Manauré y commandoit à des Indiens très-braves, \& le Général Efpagnol ne pouvoit rien faire de mieux, que de s'allier, comme il fit, avec ce Seigneur, qu'il y trouva très-difpofé.

Alors rien ne s'oppofant à l'exécution de fes ordres, il La ville de bâtit la Ville de Coro dans une fituation très-avantageufe, Coro bâtie par les onze degrés de latitude Nord. On n'y peut avoir par Jean à la vérité que de l'eau de puits; mais l'air y eft très-fain, \& la terre y produit des Simples, dont l'ufage fort facile rend aux Habitans le miniftere des Medecins peu néceffaires. Cette Ville a été très-floriffante; aujourd'hui c'eft peu de chofe, \& le Siege Epifcopal en a été transferé à Caraque. Les Lions font affés communs dans cette Province, mais il n'y font pas fort redoutés, un homme avec le fecours d'un Chien en vient aifémentà bout; d'un autre côté les Tigres y font terribles : \& il n'eft point rare de les yoir entrer dans les Cafes des Indiens, \& en emporter dans leur gueule l'homme le plus fort, avec la même facilité Tome $I$. 


\section{$45^{\circ}$ H I S T O I R}

1527. que le Chat fait une fouris. On y a aufi vû des Couler.

vres d'une groffeur \& d'une grandeur prodigieufe. La Vil-

\$529. le de Coro a deux Ports; l'un au Nord, dans une Anfe, que forme le Cap S. Romain, \& où la Mer eft toûjours tranquille; mais ce Port a très-peu d'eau : l'autre eft à l'Oueft; il eft afrés profond, mais la Mer y eft toûjours agitée. Les Inles de Curaçao, ou Coraçol, d'Oruba \& de Bonayre n'en font qu’à I4. lieuës. D'Ampuez s'en rendit le maître, \& bien lui en prit.

L'Empereur La Conquête d'une fi belle Province, dont le Lac Matede cette racaibo, duquel nous donnerons ailleurs la defcription, fait Province à des Allemands. comme le centre, couta peu aux Efpagnols, mais leur Général commençoit à peine à gouter le fruit de fes travaux, \& de fa bonne conduite, qu'il lui failut ceder la place à des Etrangers, qui ne fçurent pas profiter de fon exemple. Dès l'année fuivante is 28. les Velfers, riches Marchands d'Ausbourg, qui avoient fait de grandes avances à l'Empereur, ayant oüi parler du Venezuela, comme d'un Pays très abondant en Or, propoferent à ce Prince de leur en abandonner le Domaine à titre de dédommagement, \& ils lobtinrent à ces Conditions conditions. $\mathbf{x}^{\circ}$. Qu'ils en acheveroient la Conquêre au nom depart \& de la Couronne de Caftille, qu'ils occuperoient tout ce qui
d'autre. eft entre le Cap de la Vela, où finiffoit le Gouvernement de Sainte Marthe, \& celui de Maracapana, en tirant deux lignes Nord \& Sud d'une Mer à l'autre; \& qu'ils s'empareroient auffi de toutes les Ifles, qui font dans cette efpace, à l'exception des trois, dont nous avons parlé, \& qui demeureroient à Jean d'Ampuez. $2^{\circ}$. Que dans toute l'étenduë de cette conceffion, ils formeroient deux peuplades, \& conftruiroient trois Fortereffes ; qu'à cet effet ils leveroient au moins 300 . Hommes, qu'ils fourniroient 50. Mineurs Allemands pour être difperfés dans toutes les Provinces occupés par les Caftillans dans les Indes, \& que cesconditions feroient remplies dans un an.

L'Empereur s'engagea de fon côté à rendre perpetuelle héréditaire dans la famille des Velfers la Charge d'Al- 


\section{DE S. Domingue, LIV. VI. $45^{S}$}

guazil Major, \& celle d'Adélantade, dans la perfonne \& la pofterité de celui, qu'ils choifiroient d'abord pour en être revêtu; à leur donner quatre pour Cent de profit, fur tout ce qui fe tireroit du Pays, dont ils feroient la Conquête: à affürer 400000 . Maravedis d'appointements \& de penfion viagere au Général, \& 200000. au Lieutenant, qu'ils mettroient à la tête de cette entreprife; à les exempter du droit dEntrée pour toutes les Provifions de bouche, qu'ils feroient venir d'Efpagne; à leur abandonner 12 . lievës de terrein en quarré, pour le faire cultiver à leur profit : à leur permettre de prendre autant qu'ils voudroient de Chevaux, de Cavalles, \& de toutes fortes de Beftiaux dans les Ifles du Vent; \& fur cet article on remarquera en paffant que n'y ayant gueres alors d'Ifles peuplées dans ces Mers, que les grandes Antilles, on entendoit par Ines du Vent ces mêmes grandes Antilles, \& fous le nom d'ifles de deffous le Vent, Curaçao \& les autres, qui font prefque fur la même ligne, ainfi que je l'ai remarqué au commencement de cette Hiftoire.

Il fut encore ftipulé par ce Traité que les nouveaux Conceffionnaires pourroient faire les Indiens Efclaves, s'ils ne vouloient pas fe foûmettre de bonne grace: mais à condition de garder les Reglemens, qui avoient été faits pour leur inftruction, \& la maniere de les traiter; qu'il leur feroit auffi permis d'achetter ceux, qui étoient déjà réduits en captivité, mais qu'en tout cela ils ne feroient rien fans la participation des Miffionnaires \&.des Officiers Royaux, \& qu'ils payeroient au Domaine le quatriéme de leurs Efclaves; que pendant fix ans ils auroient le même droit, que les Sujets de la Couronne de Caftille, de tirer des Arfenaux de Seville toutes les chofes, dont ils auroient befoin pour s'équiper : enfin qu'ils feroient foûmis à tout ce qui avoit été ftarué au fujet des nouvelles Conquêtes. Et parce qu'il s'y étoit prefque par tout introduit un grand défordre, lequel confiftoit en ce que chaque Particulier cachoit avec foin tout ce qu'il pouvoit traiter en fecret d'or, ou de marchandifes prétieufes, ce qui fraudoit le Roi de la meilleure

I 527

Is 29 .

Divers Reglemens. 


\section{H I S T O IR}

1528. parrie de fon Quint, on donna aux Officiers Royaus

। les pouvoirs néceffaires pour faire par tout de très-exactes

3529. recherches; \& il fut enjoint à l'Audience Royale de SanDomingo, de tenir la main à ce quaucun Navire des Inles $\&$ des autres Pays, fur lefquels s'étendoit fa jurifdiction, n’allât faire la traite dans le Venezuela.

Arrivée des Ce fut un nommé Alfinger, à qui les Velfers confierent Allemands à l'établiffement de leur Colonie, \& ils lui donnerent pour
Coro.

Lieutenant Barthélemy Sailler. Ces deux Hommes arrive. rent à Coro vers le commencement de l'année 1529. avec trois Navires, qui portoient 400 . Hommes de pied, \& 80 . Chevaux. D'Ampuez eut bien voulu fe maintenir dans fon gouvernement, mais il vit bientôt que c'étoit une chofe impoffible, \& qu'il falloit ceder la place, trop heureux encore qu'il lui fût permis de s'aller cantonner dans les trois petites Ifies,que l'Empereur lui avoit refervées. Il y alla donc, \& il emporta avec lusi toute la profperité , dont le Venezuela avoit joüi fous fon adminiftration. La plûpart des Allemands étoient Lutheriens; ainfi quoiqu'on les eût obligés à mener avec eux un bon nombre de Religieux Dominiquains, la converfion des. Infideles fut ce quiles occupa le moins. Ils n'avoient point d'autre vîë, que de ramaffer de l'Or. \& tout ce que la plus furieufe cupidité , \& la brutalité la plus féroce peuvent employer de moyens pour en avoir ils les mirent en ufage aux dépens d'un million d'Indiens qui périt de toutes les manieres les plus cruelles, par les mains de ces Hérétiques.

Zeur mau- Une des premieres Victimes, qu'ils voulurent immoles fe conduite \& à leur avarice, fur le Cacique Manauré ; ils le mirent à la Torture, pour lui faire dire, où étoit fon Or, \& il feroit apparemment mort fous les coups, s'il n'avoit été affés heureux pour fe tirer de leurs mains, \& s'enfuir dans les Montagnes, où ils le pourfuivirent inutilement. Ils pénétrerent enfuite dans le Lac Macaraibo, \& avancerent bien loin dans les Terres, cherchant partout des Mines, \& ne voulant point entendre à faire aucun établiffement. Ils en. trerent même dans le Gouvernement de Sainte Marthe, \&z 
DE S. D OMING UE, L IV. VI. 453 partout, où ils porterent leurs pas, ils y laifferent de fanglantes marques de leur paffage. Les Indiens, pour la plit. part, leur apportoient tout ce qu'ils pouvoient avoir d'Or, $\&$ plufieurs alloient au-devant d'eux, avec toutes fortes de rafraîchiffemens, dans l'efpérance d'obtenir par-là d'en être mieux traités; mais il en arrivoit tout le contraire; ce qui jetta ces Barbares dans un défefpoir, dont leurs impitoyables Tyrans ne tarderent pas à fentir de triftes effets. Alfinger trouva enfin à qui parler, il fut bien battu en plufieurs rencontres, \& fa Troupe fut en peu de têms réduite à trèspeu de chofes : ceux, qui avoient échappé aux Fléches de ces Barbares, étant mort des exceflives fatigues, aufquelles les expofoit la foif infatiable de l'Or, qui les dévoroit.

Il s étoit répandu un bruit, que bien avant dans le Pays Mort du il y avoit une Maifon toute d'Or; comme rien n'eft plus Commandant crédule,qu'une violente paffion, Alfinger réfolut de ne point de la Troupe s'arrêter, qu'il n'eût ce beau Tréfor en fa puifrance. Il lui falloit traverfer de vaftes Pays, où il n'étoit pas affûré de trouver des vivres; ainfi en ayant amaffé une bonne provifion, il en chargea un nombre d'Indiens, qu'il avoit fait enchainer à peu près comme des Galériens, \& chacun avec fa chaîne, qui lui pendoit au col, avoit à porter une charge, qu'on n'auroit pas voulu donner à des Mulets. Auff le chagrin \& l'épuifement en firent périr la plûpart, \& lorfque quelqu'un de ces malheureux étoit tombé fous le poids, pour ne point perdre de têms à détacher le collier, qui le tenoit, \& ne point arrêter les autres, avec lefquels il étoit attaché, on lui coupoit la tête fur le champ. Cependant la maifon d'or ne parut point, \& Alfinger vit trancher fes jours dans fa chimerique pourfuite. Son Lieutenant, qui fut apparemment fon fucceffeur, ne lui furvêcut pas long-têms, \& le Gouvernement de cette Province, prefquentierement dépeuplée, \& réduite dans l'état le plus trifte, ayant été long. têms fans être rempli par les Velfers, l'Audience Royale crut devoir y pourvoir, au moins par provifion, \& jufqu'à ce que l'Empereur eût déclaré fur cela fa volonté. 


\section{4

1529. Elle envoya donc à Coro le Capitaine Jean de Carvajal Uì Gouvet. pour y commander, \& tâcher d'y rétablir les chofesdans l'orneur Elpaginol envoyé dans cette province y commet de grands excès. fe porta, firent prefque oublier ceux, quy avoient commis les Aliemands. Le cri en vint jufqu'à San-Domingo, d'où l'on fut contraint de lui envoyer au plus vîte un fucceffeur. avec un Alcaïde Major, pour lui faire fon procès. Il fe défendit long-têms, mais il ne put éviter à la fin de porter fa qête fur un échaffaut. C'eft ainfi, qu'on dépeuploit les plus belles I'rovinces de l'Amérique, dans le têms même que l'Empereur fe donnoit plus de mouvemens, pour faire décider une bonne fois, de quelle maniere on en devoit ufer à l'égard des Indiens. Cette même année I 520 . Il fe tint par fon ordre une grande Affemblée des plus habiles Theologiens \& Jurifconfultes d'Efpagne, pour examiner ce point, déjà fi fouvent difcuté fous fon Regne, \& fous celui de fon Prédéceffeur, sil étoit permis de donner les Indiens en tutelle, ou en commande.

On exami- Ceux, qui renoient pour l'affirmative, pofoient pour médenouveau principe, que le Nouveau Monde feroit plus à charge, la liberté des Endiens. qu'utile à l'Etat, fi l'on en ufoit atitrement, \& qu'aucun Particulier ne trouveroit fon avantage à s'y établir, d'où s'enfuivroit le dépériffement de toutes ces Colonies. Or. ajoûtoit-on, n'y auroit-il pas de l'injuftice à obliger le Prince de fe priver des profits de tant de Conquêtes, qui lui ont coûté des fommes immenfes; \& fes Sujers, de ce qu'ils ont acquis au péril de leur vie, \& après tant de fatigues? Où eft donc le grand mal d'affujettir au travail \& à la dépendance des Peuples incapables de fe conduire eux-mêmes, fans prévoyance, fans aucune forte de foin, tant qu'lls font abandonnés à eux mêmes, fujets aux vices les plus infâmes, pouffant pour la plûpart l'inhumanité à des excès inconnus dans les autres parties du monde; affervis dune maniere renfible au Démon, dont ils font le joüet; qu'on ne peur 


\section{DES. DOMINGUE, IIV. VI. 455}

s'affûrer de voir vivre en hommes, beaucoup moins en Chrétiens, qu'autant qu'on fera en état de les y contraindre? Ils ajoûtoient que parmi ceux, qui penfoient autrement, on ne connoifoit que deux fortes de perfonnes; les uns fans experience, que la moindre idée de fervitude effrayoit, \& qui ne vouloient pas approfondir les raifons, qu'on avoit de mettre ces Nations fous le joug : les autres, gens paffionnés, qui agiffoient bien moins par le mouvement d'un vrai zéle, \& d'une charité fincere, que par l'efprit d'ambition, qui les portoit à voutoir dominer feuls fur ces Peuples.

Ceux, qui foutenoient le fentiment contraire,prétendoient qu'on fuppofoit aux Indiens des vices, qu'ils n'avoient pas, ou qu'on les exaggeroit du moins confidérablement, pour avoir une raifon plaufible de les opprimer; quon avoit d'autant plus mauvaife grace de leur ôter la liberté, par le motif de les faire vivre en Hommes \& en Chrétiens, que jufqu'alors on ne s'en étoit fervi, que comme on fait ailleurs des Bêtes de Charge; enforte qu'on avoit bien plus travaillé à les abrutir, qu’à leur ouvrir, \& leur éclairer l’efprit; qu'il n'étoit pas vrai qu'on ne pût tirer aucun avantage du Nouveau Monde, fi l'on ne maintenoit les Départemens; mais que quand cela feroit, ce n'étoit pas une raifon pour réduire en captivité des Hommes libres, dont on avoir reçû aucun tort.

J'ai déjà obfervé que dans cetre conteftation,les deux partis convenoient affés, que fi lesCommandes, ou Départemens euf. fent été fur le pied,où ils devoient être, \& où les Rois Catholiques les avoient long-têms fuppofés, rien n'auroit été plus avantageux aux Peuples du Nouveau Monde. Norre fiecle a vîu enfin ce projet perfectionné, \& executé dans plufieurs endroits de l'A mérique Meridionnale, d'une maniere, qui fera l'admira. tion des Siécles futurs, moins prévenus que le nôtre. De quelques traits odieux, dont la malignité \& la jaloufie cherchent à le défigurer, tout efprit impartial conviendra qu'il n'en fut jamais de plus grand, ni plus conforme à l'humanité, à la raifon, aux véritables principes du Chrifianifme: que lantiquité cela fans effer.

\section{西}




\section{$45^{6}$ HIS}

3529. Profane n'a rien produit, qui puiffe entrer en paralelle avec certe entreprife, ni avec les mefures, qui ont éré prifes pour le foûtenir; que fes plus fameux Conquerans \& fes plus fages Le* giflateurs dont elle a fait des demi-Dieux, font bien au-deffous des Auteurs d'un fi noble deffein, le feul, qui pût engager les Habitans du Nouveau Monde à benir le jour, auquel ils ont: connu ceux de l'Ancien. Mais rien n'étoit moins foutenable dans la Pratique, que les Départemens, fur le pied où on les avoit mis; rien de plus tyrannique, rien qui choquât davantage toutes les Loix Divines \& Humaines; \& dût-on fuppofer ces Peuples plongés dans les vices les plus honteux, \& plus incapables encore, qu'on ne les faifoit, de fe conduire par la raifon; rien ne peut excufer les cruautés inoüies, qu'on exerçoit contre eux. Enfin la déliberation de l'Afremblée fut, qu'il falloit les laifer joüir d'une liberté entiere, tant qu'ils ne prendroient point les armes contre les Chrétiens; les traitter comme les autres Sujets de la Couronne, leur envoyer des Miffionnaires, pour leur précher l'Evangile, \& les obliger feulement à payer la Dixme à l'Eglife, \& un Tribut annuel au Prince; le tout fuivant leurs facultés. Cette décifion révolta étrangement les Conceffionnaires, \& leurs cris étant venus jufquaux oreilles de l'Empereur, ce Prince fe trouva dans une plus grande incertitude que jamais.

Abus qui Le Préfident de San-Domingo n'étoit pas moins emfétoient parmi les barraffé de fon côté, à l'occafion que je vais dire. Les Corfés parmi les Erpagnols dans les Indes. faires de France \& d'Angleterre commençoient à fe multiplier dans les Mers du Nouveau Monde, \& y troubloient fort le Commerce des Efpagnols. Il étoit aifé de prévoir que ces Pirates, ayant une fois pris ce chemin-là, n'ayant pour l'ordinaire rien à perdre, étant tous gens déterminés \& aguerris, \& la plûpart des Navires, qui alloient d'Amérique en Efpagne, étant très-richement chargés, ils cauferoient de grandes pertes aux nouvelles Colonies, fi on n'avoit foin de ne laiffer partir aucun Bâtiment, que fous une bonne efcorte; ce qqui feroit d'une grande dépenfe: mais ce n'étoir 


\section{De S. Domimgut, IIV. VI. 457}

n'étoit pas encore là ce qui inquietoit davantage le Préfident. Les Efpagnols étoient eux-mêmes des Corfaires beaucoup plus à craindre, que les Etrangers, \& pilloient également \& les effets du Prince, \& ceux des Particuliers; d'où il arrivoit que plufieurs Habitans fe trouvoient tout à. coup ruinés, \& quittoient un Pays, où ils étoient fans reffource, pour aller chercher ailleurs de quoi réparer les débris de leur fortune. Par-là, l'Inle Efpagnole, qui fut d'abord la plus maltraittée, parce qu'elle étoit la plus fréquentée \& la plus riche, fe trouva tout-à-coup prefque déferte.

Deux chofes empêchoient furtout qu'on ne remediât à Embarrass un fi criant défordre; la premiere, que les coupables n'é- du Préfident: toient pas aifés à connoître, ou trouvoient des aziles affûrés jufques dans les Navires, qui auroient dû leur donner la chaffe; la feconde étoit la mauvaife difpofition du Gouvernement. Depuis quelque têms les Jurifdictions indépendantes \& fupérieures, s'étoient fort multipliées; les Gouverneurs particuliers ne recevoient la Loy de perfonne, \& eux-mêmes n'étoient gueres en état de fe faire obéiri d'où il arrivoit que tout étoit plein de troubles $\&$ de défordres; que les Edits de la Cour n'étoient point refpectés; que les crimes demeuroient impunis, \& fe commettoient fans honte; que les biens, l'honneur, \& la vie des Habitans n'étoient point en fûreté ; que les Commandans, qui vouloient faire leur devoir, ne remportoient fouvent d'autre prix de leur zéle, qu'une mort violente; \& que chacun équipant en fraude des Navires, foit pour la chaffe des Efclaves, ou pour faire fon commerce, plufieurs, ou faute d'experience \& d'habileté, ou par la trahifon de leurs Facteurs, mettoient en Mer des Bâtimens mal armés, \& qui ne valoient rien; que la moindre tempête faifoit périr, ou qui devenoient la proye des Corfaires, d'où s'enfuivoit la ruine totale des Armateurs, \& une grande diminution du Commerce.

Tout cela fut repréfenté par le Prélat dans une affem- Remede Tom. $I$. $\mathrm{Mm} \mathrm{m}$ 


\section{HISTORR}

\$529. blée générale, de tous les Ordres de la Colonie, qưil quili propore convoqua exprès. Comme il parloit à gens, qui connoiffoient pour corriger toute l'étenduë du mal \& \& qui étoient intereffés à y cherces abis. cher un prompt remede; tous entrerent aifément dans fes vîës, \& après bien des déliberations, on convint des articles fuivans, qu'il fe chargea de propofer au Confeil des Indes au nom de l'Affemblée. $I^{\circ}$. Qu'il étoit abfolument néceffaire d'établir dans le Nouveau Monde un Pofte, qui fût comme le centre du Commerce; de ne rien négliger pour le fortifier, \& le mettre à l'abry de toute infulte, \& que pour cela il falloit choifir un Port, où il y eût une Audience Royale, avec une garnifon capable de faire refpecter fes Arrêts, \& les Ordonnances du Prince; que tous les $\mathrm{Na}$ vires, qui fortiroient d'Efpagne pour le Nouveau Monde, fuffent obligés de fe rendre en droiture dans ce Port, pour y recevoir leur deftination, \& qu'après qu'ils auroient chargé, ils retournaffent au même Port, pour y être vifités, \& pour y prendre un certificat de la bonne conduite des Equipages, \& qu'ils avoient payé les droits du Roi ; fans quoi les Capitaines feroient punis fuivant la qualité de leur dé* lit. Il y avoit touchant cet article plufieurs autres Reglemens, que je paffe, pour ne pas entrer dans un trop grand détail.

$2^{\circ}$. Qu'aucun lieu du Nouveau Monde ne convenoit mieux pour ce deffein, que San-Domingo, ou du moins quelqu'autre Port de l'Ine Efpagnole; qu'on trouvoit dans cet te Ifle toutes les chofes néceffaires à la Navigation; foit pour la conftruction des Vaiffeaux, foit pour les provifions de guerre \& de bouche; qu'elle feule étoit capable de four: air des vivres en abondance à tous les Navires, qui feroient le commerce des Indes, en quelque nombre, qu'ils fuffent. Que cela auroit encore un autre bon effet, qui feroit de peupler une Ifle, à laquelle il ne manquoir que des $\mathrm{Ha}$ bitans, pour être le Pays du monde le plus riche; \& que le Port, qui feroit deftiné à l'entrepôt général, deviendroi dans peu une Ville aufi célébre, que pouvoient l'être alors 


\section{DE S. DOMINGUE, LIV. VI. 459}

Londres \&. Palerme. Qu'il arriveroit de là que ce grand concours animant tous les Habitans à travailler, chacun fuivant la nature de fon terrein, \& les mettant en état de faire de grandes entreprifes; l'Or, l'Argent \& les autres Métaux; le Sucre, laCaffe, le Gingembre, \& les autres Marchandifes y entretiendroient un Commerce, qui feul fexoit capable denrichir l'Épagne. Que le Pays fe rempliffant d'Efpagnols, on y pourroit multiplier les Negres, fans craindre qu'ils prévalufent ; qu'il y auroit auffi beaucoup moins à craindre des autres défordres, quand tout feroit en regle, la Juftice bien adminiftrée, l'authorité armée, \& tout le monde utilement occupé ; qu'on fçauroit tout ce qui fortiroit chaque mois des Indes, \& jufqu'où monteroit le Commerce, qui s'y feroit, par confequent que les droits du Prince ne feroient pas fi fujets à être fraudés. Enfin que les mêmes raifons qui avoient porté les Rois Catho. liques à ordonner dès le commencement que tout ce qui entreroit des Indes en Efpagne feroit déchargé à Seville, étoient encore plus fortes, pour engager fa Majefté Imperiale à regler que tout ce qui fortiroit d'Efpagne, feroit débarqué dans un Port du Nouveau Monde.

Après avoir ainfi établi la nécefficé \& les avantages d'un pareil établiffement, l'Affemblée répondit par avances aux Objections, qu'on pourroit lui faire contre ce projet. La premiere regardoit l'Audience Royale du Mexique, dont on pouvoit craindre que l'authorité ne fût fort diminuée par le grand crédit, qu'on donneroit à celle de San-Domingo : à quoi on répondoit, qu'on ne fouftrayoit rien à la Jurifdiction de ce Tribunal, qu'un peu de cafuel, qui ne méritoit pas qu'on y fit attention; mais que quand il en devroit fouffrir, l'interêt général devoit l'emporter fur le particulier, \& que fi l'on préferoit l'Ine Efpagnole à la Nouvelle Efpagne, pour le deffein, que l'on formoit, c'eft que la fituation de l'une y étoit beaucoup plus propre, que celle de l'autre. On pouvoit encore objecter que, fi tous les $\mathrm{Na}$ $v$ ires des Indes fe trouvoient dans une erpece de nécelfité $M \mathrm{~mm}$ ij

Réponte aux objecctions contre ce projet. 


\section{$460 \quad H$ I s T O I R}

1529. de fe fournir de vivres dans une même Colonie, on leş y mettroit à quel prix on voudroit, ce qui feroit établir une Monopole extrêmement préjudiciable au Commerce; mais l'Affemblée s'attacha à faire voir qu'il en arriveroit tout le contraire, puifque les Habitans, fûrs du débit de leurs denrées, travailleroient à l'envie à cultiver les Terres, \& entretiendroient l'abondance dans l'Ifle. D'ailleurs que, quand on achetteroit un peu plus cher les provifions de bouche, on en feroit bien dédommagé par le prix du fret, que la fûreté de la Navigation authoriferoit les Armateurs à hauffer à proportion. Enfin on ajoûtoit que la Banque de Seville gagneroit beaucoup à cet établiffement, parce que les rifques de la Mer, des Corfaires, \& de la Cöntrebande, étant bien moins grands, il fe trouveroit un nombre bien plus confiderable de gens, qui armeroient, ou affûreroient des Navires.

Il eft fans Il eft certain que ce projet étoit parfaitement bien effet. imaginé, \& que les Rois Catholiques en euffent retiréde très-grands avantages; mais de tout têms l'interêt public a été facrifié à celui des Particuliers, \& quelquefois même à la jaloufie d'authorité, à l'indolence, \& à l'entêtement de ceux, qui ont le pouvoir en main. Dans tous les Etats il eft des chofes, dont tout le monde voit l'utilité , \& même la néceffité; \& qui demeurent néanmoins fans effet, fans qu’on puiffe trop fçavoir ni comment, ni pourquoi. Tel fut le fyfteme propofé dans l'Afremblée de San-Domingo; il échoüia; fans qu'on ait bien pầ en pénétrer la véritable raifon. C'eft dans ces occafions qu'il faut néceffairement recourir à une Providence dominante, fuperieure à toute fageffe \& à toute puiffance créée, laquelle,pour des raifons à elle feule connuës, met des bornes au progrès, comme à la durée des Etábliffemens humains.

Au commencement de l'année fuivante, le Préfident en-

I 530 . vouvelles voya l'Empereur 10000. Pefos d'Or, \& 50. Mefures de Mines décout-Perles pour fon Quint; il lui donna en même têms avis vertes. qu'on avoit découvert dans l'Ine Efpagnole une très-beł 


\section{De S. Domimgue, Liv. VI. 46 I}

le Mine d'Argent, \& plufieurs Mines de Fer ; illui envoya des monftres des unes \& des autres; \& l'on jugea en Efpagne que le Fer de l'Efpagnole vaudroit encore mieux que celui de Bifcaye. Il ne paroît pourtant pas qu'on ait jamais beaucoup travaillé à ces nouvelles Mines, \& il y a bien de l'apparence que la caufe de cette négligence fut le départ du Préfident; car quoique ce Prélat fût feul Evêque dans l'ifle Efpagnole, il fut envoyé à Mexico, en la même qualité, qu'il avoit dans l'Audience de San-Domingo, \& le Gouvernement des Antilles refta quelque têms entre les mains des Auditeurs. En Is 32. ces Magiftrats repréfenterent au Confeil des Indes, qu'on tiroit de grands fervices des Negres dans les Colonies de leur Reffort, \& qu'il étoit fort à fouhaitter que fa Majefté Imperiale en permit le tranfport fans aucune reftriction. Ils demanderent auffi des Laboureurs, \& la permiffion de recevoir les Portugais, qui fe préfenteroient pour s'établir parmi les Efpagnols. Ils propoferent d'envoyer dans leur Ine 500. jeunes bêtes tirées des Troupeaux de l'Empereur; d'y faire femer du Bled, \& planter de la Vigne; de permettre de porrer en Flandres fans paffer par Seville, des Sucres, des Cuirs, \& d'autres femblables Marchandifes; enfin d'exempter les Habitans de tous droits d'entrée pour leurs provifions de bouche, pour les chofes néceffaires à l'entretien de leurs Manufactures, \& pour les armes, dont ils ne pourroient point fe paffer. Charles-Quint étoit en Flandres, lorfque le Confeil reçut les lettres des Auditeurs, on attendit fon retour, pour lui communiquer leurs demandes, qui furent prefque toutes accordées, mais les affaires de l'Ine allerent fi fort en décadence dans cet intervalle, que les réponfes favorables du Prince, n'y purent pas avoir beaucoup de lieu.

La guerre avoit recommencé plus vivement que jamais la guerre avec le Cacique Henry, dont les Troupes étoient confi- recommence derablement groffies. Au mois d'Avril de l'année I532. diens. un de fes partis courut jufqu'à Puerto Réal, où il coupa la gorge à un Habitant, à fa femme, à fes deux enfans, $M m m$ iij 


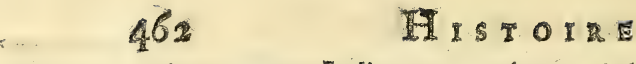

- \& à quatorze Indiens, qui étoient à leur fervice. Nul en-

y532. droit de l'Ifle n'étoit plus à l'abry de leurs hoftilités, \& les chofes allerent fi loin, que l'Empereur averti de la néceffité de finir cette guerre, ou d'abandonner l'Ifle Efpagno. le, prit enfin des mefures, qui furent efficaces, pour rétablir la paix. Il venoit de nommer pour Gouverneur de la Caftille d'Or un Officier d'un grand mérite, \& d'une experience confommée dans les affaires des Indes, nommé François de Barrio Nuevo. Il lui ordonna de paffer à SanDomingo avec 200. Hommes d'élite, de ne point fortir de l'Ine, qu'il ne l'eût entierement pacifiée, de quelque maniere que ce fût ; il lui donna pour cela un Plein-pouvoir abfolu, à condition feulement qu'il fauvât l'honneur de la Nation; il lui recommanda mêtre de commencer par tenter les voyes de la douceur, \& il lui remit une lettre pour Henry, par laquelle Sa Majefté Imperiale, convioit ce Cacique à rentrer dans l'obéiffance, lui offroit une Amniftie fans aucune referve pour lui \& pour les fiens, \& le menaçoit de tout le poids de fa puiffance $\&$ de fon indignarion, s'il refufoit ces offres, \& perfiftoit dans fa révolte.

Un Commiffaire arrive de la part de l'Empereur pour la fi nil:

Ce Prince avoit tellement à cour la confommation de cette affaire, que n'y ayant point d'autre Vaiffeau, qui fût prêt à mettre à la voile, que celui, qui l'avoit porté en Efpagne; il le donna à Barrio Nuevo, qui ne perdit pas un moment de têms, pour fe rendre à l'Ille Épagnole. Il préfenta en arrivant fes Provifions à l'Audience Royale, \& il rendit une lettre de l'Empereur à l'A miral. Ce jeune Seigneur étoit toûjours demeuré dans l'Ifle Efpagnole, \& quoiqu'il n'y eût aucune authorité, par rapport au Gouvernement, on ne laiffoit pas d'y avoir pour lui de fort grands égards, \& de lui rendre tous les honneurs dûs à fon fang , qui du côté maternel étoit uni à celui de l'Empereur même: aux fervices de fon Pere \& de fon Ayeul, \& à fa Dignité: Le Gouverneur de la Caftille d'Or voulut enfuite en homme fage 
de S. Domingue, Liv. VI. 463 qu’on déliberât fur le fujet de fa Commiffion, \& fur les moyens de l'exécuter; mais les Auditeurs refuferent de fe charger feuls d'une déliberation de cette confequence. Ils convoquerent une Affemblée générale, où fut appellé tout ce qui fe trouvoit alors dans la Capitale, ou dans les environs de Perfonnes diftinguées par leurs Emplois, \& par leur experience; \& comme les fentimens y furent extrêmement partagés, on chargea quatre des plus anciens Habitans des Indes de conferer entre eux, \& de donner par écrit leur avis commun, quand ils en feroient convenus.

Ces Députés furent François \& Alphonfe Davila ,Lopé On đélibes jà parlé. Ils eurent plufieurs conferences, \& le réfultat fut prendre. que les chofes n'étant plus dans la même fituation, où elles étoient, lorfque Sa Majefté Imperiale avoit été fuppliée d'y mettre ordre; les mefures qu'elle avoit prifes pour cela, n'étoient plus pour la plûpart d'aucune néceffité; que les 200 . Hommes de Troupes, que Barrio Nuevo avoit amenés, étoient furtout fort inutiles pour une guerre, qui demandoit des Soldats accoûtumés au Pays; qu'il falloit s'en tenir aux Milices, \& continuer la guerre fur le plan , qu’on avoit imaginé depuis quelque têms, \& dont on fe trouvoit bien. Ce Plan confiftoit à placer des bandes de 15 . ou 20. Soldats dans tous les endroits, où les Indiens avoient accoûtumé de paffer, pour venir piller le Pays, \& fe fournir des chofes, dont ils avoient befoin, \& où on pouvoit les furprendre, ou les combattre avec avantage; par-là on les affoibliffoit, ou dumoins on les obligeoit à refter dans leurs Montagnes. Les quatre Députés ajoûtoient qu'il n'y avoir néanmoins aucun inconvenient à ce que l'Officier envoyé par l'Empereur prît avec lui trois ou quatre de ces Troupes de Milices, fe fit accompagner de quelques Religieux, pénétrât le plus avant, qu'il feroit poffible dans jes Montagnes de Baoruco, \& tâchât de joindre le Cacique Henry, pour lui rendre la lettre de l'Empereur, fuppo* 


\section{$464 \quad H$ I s T O I R E}

1532. fé qu'il y fût encore, car il y avoit long-têms qu'on n'entendoit plus parler de lui, \& l'on ne fçavoit pas ce qu'il étoit devenu; enfin qu'il n'omît rien, s'il le rencontroit, pour l'engager à une paix folide \& durable.

Quel futle L'Audience Royale ayant reçû́ cet avis, le communiréfultat de cetre délibe- qua à Barrio Nuevo, qui l'approuva fort, déclara qu'il s'en हation. rapportoit fans peine au fentiment de ceux, qui devoient mieux fçavoir que lui ce qui convenoit, \& affûra qu'il exécuteroit avec plaifir tout ce qui lui feroit marqué. On lui donna donc 30 . Hommes, réfolus à le fuivre par tout, \& l'on y joignit un pareil nombre d'Indiens fideles, pour le fervir \& le guider dans les Montagnes. On nomma quel- ques Peres Francifquains pour l'accompagner, $\&$ on choifit ces Religieux préferablement aux autres, parce que Henry avoit été élevé chés eux, \& avoit toûjours témoigné beaucoup de vénération pour leur Robe. Enfin on arma une Caravelle à San-Domingo, pour porter le Général \& fa Troupe jufqu'à l'endroit, où l'on entre dans les Montagnes. Ces préparatifs occuperent tout le refte de l'année I 32 . \& les

1533. premiers mois de la fuivante. La Caravelle en mit enfuite deux entiers à ranger la Côte jufqu'au Port d'Yaquimo, parce que le Général envoyoit fouvent fa Chaloupe à terre, pour tâcher d’y avoir des nouvelles du Cacique Henry; mais il n'en apprit aucune.

Marche de Le Port d Yaquimo eft formé par une affés belle RivieBarrio Nuevo re, que le Général remonta le plus loin qu'il put. Il troule Cacique. va d'abord une Cafe Indienne, où il ne fe rencontra perfonne, \& un peu plus haut, un champ enfemencé ; mais il ne voulut pas qu'on touchât, ni à la Cale, ni au Champ. Peu de têms après, fur quelques indices, qu'il eut que Henry n'étoir pas loin, il lui écrivit, pour lui donner avis de fon arrivée, l'inftruire de fa Commiffion, \& l'informer qu'il avoit une lettre de l'Empereur à lui rendre. Il envoya la fienne par un Indien, qui s'offrit de lui-même à chercher le Cacique, \& qui fe fit fort de le trouver; mais cet homme n'a point paru depuis, \& l'on n'en a ja- 


\section{DE S. DOMingue, Liv. VI. 465}

mais pû fçavoir aucune nouvelle. Après qu'on l'eût attendu 20. jours, le Général entra dans les défilés des Montagnes, \& aprè's trois jours d'une marche, qu'il n'auroit jamais pû foutenir, s'il n'en avoit fait l'apprentiffage dans les Montagnes de Portoric, il apprit par des Indiens que le Cacique étoit dans une Lagune, que les Erpagnols appelloient la Lagune du Commandeur, \& qui a deux lieuës de circuit; c'eft apparemment une des deux parties du Lac Xaragua, dont nous avons parlé; mais il y avoit encore 8. lieuës à faire pour aller jufques-là, \& le chemin paroiffoit impraticable à tout autre, qu'à des Indiens. Les Ef pagnols obferverent auffi que fur toute la route, qu'ils avoient faite jufques-là, il n'y avoit pas une feule branche coupée aux Arbres, ni aucune trace, par ou l'on pût connoître qu'on y eût paffé : c'étoit une précaution du Cacique pour empêcher qu'on ne découvrît fa retraite.

Il falloit avoir autant de courage, qu'en avoit le Général Efpagnol, pour s'engager plus avant dans un Pays inconnu, $\&$ où à chaque pas, il trouvoit des difficultés capables d'effrayer les plus hardis : mais rien ne l'arrêta. Il arriva cultés. enfin à un Village, dont les maifons étoient âffés bien bâties, où il y avoit des vivres en abondance, \& toutes les commodités, dont ces Peuples pouvoient avoir l'idée. Il ne voulut pas encore permettre qu'on y prît rien, quoiqu'il n'y eût pas une ame dedans; il confentit feulement qu'on en emportât quelques Calebaffes, qu'il fit remplir d'eau, dont il avoit un extrême befoin. Au fortir de-là, il trouva un chemin fort large, qui avoit été coupé dans le bois, \& y étant entré, il fçut que le Cacique étoit à une demie lieuë de-là; mais que pour aller à lui, il falloit marcher dans la Lagune, ayant de l'eau jufquaux genoux, \& quelquefois jufqu'à la ceinture; puis traverfer un défilé de Montagnes très-difficile.

Il étoit trop avancé pour reculer, il s'approcha de la La- Il découvro gune, \& ayant apperçu des Indiens, qui étoient dans un le lieu dela Canot, il envoya leur demander s'ils n'avoient, point vû Cacique. 


\section{HIST I I E}

3533. un homme de leur Nation, qui portoit une Lettre à leute informé de l'arrivée d'un Officier, qui avoit une Lettre à lui remettre de la part de l'Empereur. Sur cette réponfe Barrio Nuevo ne fit plus aucune difficulté de s'approcher, \& pria ces Infulaires de vouloir bien prendre dans leur Ca. not une Femme Indienne, \& la conduire à leur Chef, chés qui elle avoit demeuré, \& qu'elle infruiroit du fujet de fa venuë. Ils lui répondirent que cela n’étoit pas néceffaire, que leur Seigneur étoit inftruit de tout, \& qu'ils n'oferoient prendre fur eux, de faire ce qu'il fouhaittoit. Ils fe rendirent pourtant à fes inftances; mais comme ils ne voulurent jamais s'approcher du bord, l'Indienne fut obligée pour s'embarquer, de fe mettre à l'eau jufqu'à la ceinture.

IeCacique Le lendemain de bon matin il partut deux Canots, dans envoye lui faite un compliment. l'un defquels étoit l'Indienne, avec un Parent du Cacique nommé Martin de Alfaro, fuivi d'une Troupe fort lefte de foldats Indiens, armés de Lances \& dEpées. Ce Canot vint débarquer auprès des Efpagnols : Barrio Nuevo s'avança feul, Alfaro en fit de même, \& ordonna à fes gens de s'éloigner, puis ayant falué le Général, il lui fit les excufes du Cacique, de ce qu'il n'étoit pas venu lus-même lui rendre fes devoirs, une incommodité, qui lui étoit furvenuë, en ayant été l'unique caufe, « Mais puifque vous avés s tant fait, ajoutra-t-il, que de venir jufqu'ici, Henry fe flatte » que vous voudrés bien vous tranfporter jufquau lieu, où » il eft arrêté. » Le Général reçut ce Compliment d'une ma. niere également noble \& affable, \& confentit d'aller trouver le Cacique. Ses gens firent en vain tous leurs efforts pour l'en détourner : il ne prit même avec lui que quinze Hommes, \& fans autres armes, qu'une maniere d'Efponton, qu'il: renuit a la main, \& fon Epée au côté, il s’abandonna à la conduite de Martin d'Alfaro. Cet Indien le mena par des. chemins fi rudes \& fi embaraffés, que fouvent il étoit obligé de marcher fur les mains, autant que fur les pieds. Ses gens fe lafierent bientôt, \& vouloient l'engager à retour: 
DE S. DOMINGUe, LIV́. VI. 467 ner fur fes pas, en lui repréfentant que le Cacique, ou fe mocquoit de lui, ou avoit deffein de le faire périr; mais il leur ferma la bouche, en leur difant : $\propto$ Je ne contrains s perfonne de me fuivre : quiconque a peur, peut s'en res tourner: pour moi, duffai-je demeurer feul, je fuis réfow lu d'aller jufqu'au bout : en acceptant la Commiffion, dont so l'Empereur mon Maître m'a honoré, j'en ai compris la s difficulté, \& je me fuis attendu à tout : fi j'y laiffe la vie, s je périrai content, puifque ce fera en faifant mon devoir. $\infty$ Au fonds, rien ne fait mieux fentir la fuperiorité, qu'avoit prife le Cacique fur les Efpagnols, que la conduite, que ceuxci tinrent en cette r£ncontre, \& où l'on ne reconnoît point la fierté de cette Nation.

Le courage ne foutint pourtant pas long-têms Barrio Nuevo, il fe trouva tout à coup fi épuifé de fatigues, qu'il fut obligé de s'arrêter pour prendre un peu de repos. Le bois réanmoins commençoit à s'éclaircir, \& l'on découvroit à travers les arbres la demeure de Henry. Alfaro prit alors les devants à la priere du Général, \& demanda de fa part au Cacique, où, \& comment il vouloit que l'entrevûe fe fit. Henry commença par gronder fort Alfaro, de n'avoir pas fait ouvrir un chemin, \& lui ordonna d'y travailler fur le champ, puis il envoya dire au Général qu'il pouvoit avancer en toute fûreté. Barrio Nuevo fe remit auffi-tôt en marche, \& Henry le voyant venir dans un état à faire peur, tout couvert de fange, \& pouvant à peine fe foûtenir, il courut au-devant de lui, \& fit paroître une très-grande confufion, de lui avoir caufé tant de fatigues. Le Général répondit à ces honnêtetés d'une maniere polie. mais qui ne laiffoit pas de faire fentir au Cacique, qu'il n'en avoit pas ufé avec lui, comme il convenoit à l'égard d'une perfonne de fon Rang, \& d'un Envoyé de l'Empereur. Henry s'excufa le mieux, qu'il lui fut poffible, \& prenant le Général par la main, il le conduifit fous un grand arbre, où ils s'affirent tous deux fur des Couvertures de Cotton, qu'on y avoit étenduës exprès. Dès qu'ils y furent, cinq Nnn ij

Il arrive chés le Cacique. 


\section{8}

3533. ou fix Capitaines Indiens vinrent embraffer Barrio Nuevo puis allerent fe mettre à la tête de foixante Soldats armés de Bouliers, depées, \& de Cafques. Les Capitaines étoient armés de même, mais ils avoient des Pennaches à leurs Cafques, \& tous s'étoient entouré le corps de groffes cordes teintes en rouge, \& qui leur faifoient comme une maniere de Cuiraffe. Les deux Chefs, après un court entretien, qui fe paffa en politeffes réciproques, firent éloigner un peu d’avantage leurs gens, \& le Général Ef́pagnol prenant la parole, dit :

Son difcours au $\mathrm{Ca}$ sique.
“ L'Empereur, mon très-redouté Seigneur, \& le vôtre, $\rightarrow$ le plus puiffant des Souverains du Monde, mais le meil» leur de tous les Maîtres, \& qui regarde tous fes Sujets > comme fes enfans, n'a pú apprendre la trifte fituation, où vous * êtes réduit avec un grand nombre de vos Compatriotes, » \& l'inquiétude, où vous tenés toute cette Ifle, fans en être s touché de la plus vive compaffion. Les maux, que vous » avés faits aux Cartillans, fes premiers, \& fes plus fidéles » Sujets, n'ont pourtant pas laiffé de l'irriter d'abord; mais * quand il a fçu que vous êtes Chrétien, \& les bonnes qua» lités, dont le Ciel vous a favorifé, toute fa colere s'eft » calmée, \& fon indignation s'eft changée en un défir ar» dent de vous voir prendre des fentimens plus raifonnaw bles. Il m'a donc envoyé, pour vous exhorter à mettre » bas les armes, \& vous offrir le pardon du paffé, pour vous, » \& pour tous ceux, qui vous ont fuivi; mais il y a ajouté $\infty$ un ordre de vous pourfuivre à toute outrance, fi vous ` perfiftés dans votre rebellion; \& il m'a donné des forces s fuffifantes pour cela. C'eft ce que vous verrés encore = mieux exprimé dans cette Lettre. Vous n'ignorés pas x combien il m'en a coûté pour vous la rendre moi-même; » je me fuis expofé à tout avec plaifir, pour obéir à mon » Souverain, \& par l'eftime que je fais de votre Perfonne * perfuadé d'ailleurs que je ne rifquois rien, en me livrant $\rightarrow$ entre les mains d'un Homme, en qui je fçavois qu'on avoit ^ remarqué des fentimens dignes de fa Naiffance \& de fa Re- 


\section{DE S. D Omingue, Liv. VI. 469}

* ligion, beaucoup de moderation, \& affés de difcerne$₫$ ment, pour faire la diftinction de ceux , qui viennent comm me amis, \& de ceux, qui cherchent à le furprendre. $\infty$

Henry écouta ce Difcours avec attention, \& reçut la La réponfe Lettre de l'Empereur avec une joye refpectueufe; mais du Cacique. comme il avoit mal aux yeux, il pria le Général de vouloir bien en faire la lecture. Barrio Nuevo y confentit avec plaifir, \& lut d'une voix affés haute pour être entendu des Soldats du Cacique. L'Empereur donnoit à Henry le titre de Dom; \& du refte, la Lettre contenoit en fubftance tout ce que le Général venoit de dire; elle finiffoit par affûrer aux Indiens qu'il envoyoit fes ordres à l'Audience Royale, afin que, s'ils fe foumettoient de bonne grace, elle leur affignât des Terres, où ils puffent vivre en liberté , \& ne manquaffent de rien. Cette Lecture finie, le Général rendit la Lettre au Cacique, qui la baifa de nouveau avec refpect, \& la mit fur fa tête. Il reçut auffi le fauf-conduit de l'Audience Royale, fcellé du Sceau de la Chancellerie, \& l'ayant examiné, il dit qu'il avoit toûjours aimé la Paix, \& n’avoit fait la Guerre, que par la néceffité de fe défendre; que fi jufqu'alors il avoit rejetté toutes les voyes d'accommodement, c'eft qu'il n'avoit point trouvé de fûreté à traitter avec les Caftillans, qui lui avoient fouvent manqué de parole. «A préfent que le Très-Augufte Empereur me donne la $\rightarrow$ fienne, ajoûta-t-il, je reffens, comme je le dois, l'hono neur, que me fait Sa Majefté Impériale, \& j'accepte avec w une très-humble reconnoiffance la grace, qu'elle veut bien $\infty$ miaccorder. $\infty$

En achevant ces mots, il sapprocha de fes Gens, leur Conditions montra la Lettre de lEmpereur, \& leur dit qu'il n'y avoit du Traité. plus moyen de refufer l'obéiffance à un fi puiffant Monarque, qui leur témoignoit une fi exceffive bonté. Ils répondirent tous par leurs acclamations ordinaires, c'eft-à-dire', par de grandes afpirations, qu'ils tirerent avec effor $\hat{\mathrm{da}} \mathrm{s}$ fond de leur poitrine; après quoi le Cacique ayant rejoint le Général Efpagnol, ils délibererent quelque têms enfem:

$$
N \cap \cap i i j
$$




\section{9 \\ H I 5 T O I R}

I533. ble, \& convinrent enfin des articles fuivans. $I^{\circ}$. Que le Cacique rappelleroit inceffamment tous ceux de fon parti, qui étoient répandus en differens quartiers de l'Ifle, \& qu'il les obligeroit à reconnoître à fon exemple l'Empereur pour leur Souverain Seigneur. $2^{\circ}$. quil mettroit deux de fes $\mathrm{Ca}$ pitaines aux trouffes des Negres fugitifs, pour les rendre à leurs Maîtres, moyennant une reconnoiffance, dont on conviendroit. $3^{\circ}$. Qu'il feroit toûjours dans l'obligation de re* tenir tous les Indıens dans le devoir, ou d'y faire rentrer ceux, qui s'en écarteroient dans la fuite. $4^{\circ}$. Que pour lever tout ombre de défiance, il quitteroit au plûtôt les Mon= ragnes, \& defcendroit dans la Plaine, ou on lui donneroit pour fon entretien un des Troupeaux de lEmpe reur.

Il eft ratifié Les Traités ne fe font jamais parmi ces Peuples, qu'au par les Indiens.

milieu des Feftins. On jugea que dans une occafion de cette importance il ne falloit pas s'éloigner de cette ancienne pratique. Les Efpagnols avoient apporté avec eux du Ris \& de l'Eau de Vie. Les Indiens fournirent le Gibier \& le Poiffon, on fe mit à table, \& le Général commença par boire à la fanté de l'Empereur, action, qu'il accompagna de grandes marques du plus profond refpect. Il but enfuite à celle du Cacique, que les Indiens, depuis qu'ils eurent vû. la lettre de Sa Majefté Imperiale, n’appelloient plus que, $D_{\bullet}$ Henry notre Seigneur. La joye fut grande parmi les Convives, \& l'on fe fit de part \& d'autres mille proteftations d'une amitié fincere \& durable. D. Henry \& Donna Mancia fon Epoufe, ne voulurent pourtant pas fe mettre à Table, \& ne gouterent de rien, fous prétexte qu'ils avoient dîné. Ce refus, qui avoit un air de défiance, fit quelque peine au Général, mais il la diflimula fagement : à cela près il eut tout lieu de fe loüer des bonnes manieres du Cacique, qui lui promit d'aller inceffamment à San-Domingo, pour $y$ varifier la paix. Il voulut même qu'un de fes Capitaines nommé Gonzalez, accompagnât le Général à cette $\mathrm{Ca}$ pitale, pour y faluer de fa part l'Amiral, les Audireurs \& 


\section{DES. DOMINGUE, LIV. VI. 47 I}

rous les Officiers Royaux. Il eft vrai quil recommanda en particulier à cet homme de bien obferver toutes chofes, \& de voir, s'il n'y avoit pas encore quelque trabiton cachée fous des démarches en apparence fi finceres. Enfin il fit reconduire les Efpagnols jufqu'à leur Navire par un Officier à la tête d'un détachement.

La Caravelle étoit moüillée dans un Port, qui eft aujourd'hui connu-fous le nom de Jacquemel. Dès que Bar- qui penfe ralo rio Nuevo y fut arrivé, il voulut régaler fon Eferorte, \& il re. donna à ces Indiens du Vin de Caftille, \& des Liqueurs à difcretion; la plûpart en burent avec excès, \& en furent: tellement incommodés, qu'on crut qu'ils alloient mourir. Cela inquieta fort le Général, \& il craignit avec raifon que, fi ce malheur arrivoit, le Cacique ne l'accufât d'avoir empoifonné fes Gens; mais fa crainte fut bientôt diflipée: un peu d'huile, qu'on fit avaler aux malades, les fit vomir, \& ils recouvrerent en peu d'heures une parfaite fanté. Barrio Nuevo leur fit à tous en les congediant, une gratification, \& envoya de fort beaux préfens au Cacique, \& à fon Epou$\mathrm{fe}$, après quoi il mit à la voile, pour fe rendre à la $\mathrm{Ca}$ pitale, qu'il remplit à fon arrivée de la plus grande joye, qu'elle eût reffentie depuis long-têms. On y donna à fon courage, à fon zéle \& à fa prudence les éloges, qui leur étoient dûs, \& la paix fut proclamée avec de grandes Cérémonies.

Le Député de D. Henry ne fe laiffa pas encore prendre à ces premieres démontrations; \& avant que de faire aucune démarche, qui pût engager fon maître, il voulut examiner à loifrr, fi tout ce qu'il voyoit, n'étoit pas un jeu concerté. Il alloit de maifon en maifon pour tâcher de découvrir ce qu'on y difoit, \& il n'omettoit rien pour fe bien inftruire de la difpofition, où l'on étoit à l'égard du Traité fait avec D. Henry. On s'apperçut bientôt de fes inquiétudes, on s'attacha à le bien régaler, \& fes foupçons s"évanoüirent enfin tout-à-fait. Il fe trouva même fi bien: de ce nouveau genre de vie, qu'il oublia de s'en retourner

Défiance diu Cacique, \&c furquoi elles étnient fon. dées. 


\section{H I T O R E}

1533. au têms, qui lui avoit été prefcrit. Ce retardement donna à penfer au Cacique; il attendit encore quelques jours, au bout defquels il voulut fçavoir ce qui empêchoit GonzaI z de revenir. Il s'approcha de la Ville d'Azua, \& fit dire aux Habitans, qu'il fouhaittoit de parler à quelqu'un d'entre eux. Il étoit prefque feul, mais il avoit placé so. Hommes dans un Bois qui étoit proche: il ne fut pas longtêms fans voir venir à lui une centaine d'Éfpagnols, qui l'aborderent avec toutes les marques d'une réconciliation fincere.

Elles font. Il leur demanda, s'ils n'avoient point des nouvelles de paix publiée. Gonzalez, \& ils répondirent qu'il étoit paffé par Azua, il y avoit quatre jours, dans une Caravelle, accompagné d'un Officier Caftillan, nommé Pierre Romero, lequel étoit chargé de préfens pour lui, \& d'un plein pouvoir pour ratifier le Traité de paix au nom de l'Audience Royale. On lui ajoûta que la Caravelle devoit être actuellement à Xaragua. Cette réponfe le réjoüit fort, il fit appeller fes gens, on s'embraffa, \& l'on célébra de nouveau la paix par un Feftin. D. Henry refufa encore de toucher à rien, s'excufant fur une indifpofition, qui lui étoit furvenuë. Le lendemain il prit la route de Xaragua; où il trouva la Caravelle. Il y a de l'apparence que ce qu'on appelloit encore Xaragua, étoit Leogane ou Yaguana, bâti affés près de l'endroit, où avoit été l'ancienne Xaragua, laquelle ne fubfiftoit plus. Le Cacique reçut avec beaucoup de reconnoiffance les préfens, que lui remit Romero; Gonzalez l'affûra qu'il ne devoit plus avoir aucun doure de la fincerité des Efpagnols, \& fur le champ il fit embarquer fur la Caravelle un bon nombre de Negres fugitifs, qu'il avoit déjà fait arrêter. Enfin tous les ombrages furent diffipés de part \& d'autre, \& l'on fit par tout de grandes réjoüiffances pour le retour d'une paix fi long-têms défirée.

Le P. de Las Cafas va trouver le Casique,
Mais perfonne n'y prit plus de part, que le Pere Barthélemy de Las Cafas. Ce Religieux vivoit depuis 12. ans.; dans une retraite auftere, \& y édifioit autant par la pratique des 


\section{DE S. Domingue, LIV. VI.}

des vertus propres de fon nouvel Etat, qu'il avoit fait auparavant par l'ardeur d'un zele infatigable. L'accomodement conclu avec fes chers Indiens réveilla ce zele, \& avec la permifion de fon Superieur, il alla trouver le Cacique, dont il étoit fort connu. 11 en fut parfaitement bien reçû, \& l'on célébra avec beaucoup d'alegreffe dans les Montagnes de Baoruco, l'arrivée du grand Protecteur des Indiens. Las Cafas profita de cette favorable réception pour décharger fon cour à fes chers Infulaires, \& il parla fur tout ce qui s'étoit paffé avec une liberté, qui dans la bouche d'un autre n'eût peut-être pas produit un trop bon effet. Il leur fit furtout extrêmement valoir la bonté de l'Empereur, qui avoit bien voulu s'abaiffer jưqu'à les rechercher, pour ne pas expofer le falut de leurs ames, foit en les pouffant à bout, foit en les laiffant plus long-têms dans une fituation, où tout leur manquoit pour vivre en véritables Chrétiens. Il les trouva fur ce point dans des fentimens très-raifonnables, \& le Cacique lui avoüa que fa plus grande peine avoit été de voir mourir quantité d'Enfans fans Baptême, \& d'Adultes fans Sacremens; \& que cette confideration avoit bien autant contribué, que tout autre chofe, à lui faire conclure un Traité, qu'il ne fçavoit pas encore trop, s'il ne feroit pas un jour fatal à ce qui reftoit des triftes débris de fa Nation. Il lui ajoûta en particulier qu'il n'avoit pas manqué un jour à dire fes prieres ordinaires, \& qu'il avoit exactement jeûné tous les Vendredis; on fçavoit d'ailleurs qu'il avoit veillé avec beaucoup de f́in fur la conduite \& les mœurs de fes Sujets, quil avoit furtout pris de bonnes mefures pour empêcher tout Commerce fulpect, entre les perfonnes de different fexe, \& qu'il avoit porté l'attention jufqu'à ne permettre à aucun des fiens de fe marier avant 25 . ans,

Le Pere de Las Cafas demeura quelque têms dans ces Montagnes, \& tâcha de raffûrer le Cacique fur ce qui lui Apoftoliques donnoit encore un peu d'inquiétude pour l'avenir. $\propto$ L'Em- parmi les In\$ pereur, lui dit-il, a engagé fa parole \& fon honneur, il 


\section{HIS TOIR}

1533. $\%$ n'y a point de fúceté au monde, s'il ne s'en trouve pass

» dans un Traité établi fur de tels fondemens. Enfin quand

` on a agi avec autant de prudence, que vous avés fait, il

2. faut abandonner le refteà la Divine Providence, qui fait

servir au bien de fes Elûs jufqu'à la malice de leurs propres

„Ennemis. „ D. Henry parut content, \& l'Homme de Dieu trouva la même docilité parmi tous fes Sujets. Il leur dit plufieurs fois la Meffe; baptifa tous ceux ,qui n'étoient point baptifés, \& adminiftra aux autres les Sacremens de Pénitence \& d'Euchariftie. Il eft étonnant que ces Infulaires, qui étoient tous Chrétiens, \& dont plufieurs avoient été inftruits dès l'enfance avec foin, ne fçuffent pas que dans un befoin ils pouvoient conferer le Baptême; car de leur aveu ils avoient laiffé mourir jufqu'à 300 . Enfans fans leur procurer l'adoption Divine, qui eft le fruit de ce Sacrement. Le Mifionnaire trouva encore bien de lignorance dans ces Neophites fur leurs plus effentiels devoirs, \& les principaux Articles du Chriftianifme, \& il y remedia autant, qu'il lui fut poffible dans le peu de têms, qu'il avoit à leur donner. D. Henry le reconduifit lui-même jufqu'à Azua, ou un $\mathrm{Ca}$ pitaine Indien nommé Tomaios, celui de tous, qui avoit fait le plus de peine aux Efpagnols, fut Baptifé. L'Audience Royale avoit témoigné beaucoup de refentiment de ce que le Pere de Las Cafas avoit entrepris ce Voyage fans fa participation, \& vouloit quil fût puni, mais elle s'appaifa. lorfqu'elle eut appris tout ce qui s'étoit paffé pendant for féjour parmi les Indiens. D'ailleurs ce Religieux fçut bien faire obferver à ces Magittrats, que la paix ayant été publiée dans les formes; rien n'empêchoit déformais d'aller vifiter des gens, qu'on ne regardoit plus comme Ennemis . \& $q$ quil étoit furprenant qu'on en fit furtour un crime à un homme de fon caractere, \& qui n'avoit jamais ufé de. fon crédit fur ces Peuples, que pour le bien de l'Etat. Nouvel éta- Vers le même têms, c'êt-à-dire, fur la fin du mois blifiement du d'Aốt, en vertu d'un Traité fait avec un Habitant de Sansôté de Monts-Chrifto,

Domingo nommé Boleños, foixante Laboureurs arriverent 


\section{DE S. Domingue, IIV. VI. 475}

d'Efpagne, la plâpart avec Femmes \& Enfans, pour s'aller établir du côté de Monte-Chrifto : cette Contrée eft une des plus fertiles de l'Ifle, \& le voifinage de Cibao auroit pu être un attrait dans un autre têms; mais, faute d'Indiens, les Mines étoient abandonnées, \& les nouveaux Habitans prirent le parti de fe borner à la Culture des Terres. Sur le même Vaiffeau, qui les avoit apportés, le Licencié Gilles Gonzalez Davila, étoit venu avec la qualité de Vifiteur Royal, pour gouverner l'Ine dans l'abfence du Préfident D. Sebaftien Ramirez, lequel étoit toûjours au Mexique.

Le Cacique D. Henry étoit encore dans fes Montagnes, \& il tardoit beaucoup aux Efpagnols qu'il en fortît. Il tint va à San Do. enfin la parole, quil en avoit donnée; mais ce ne fut qu'a- quelle manieprès qu'il eût comfommé les vivres, dont il avoit fait de te le Traité grandes provifions; il fe rendit enfuite à San-Domingo, où il eft executé figna le Traitté de Paix, quijufques-là n’avoit éré figné , que par fés Députés. Il fut reçû dans cette Capitale d'une maniere, qui eût été capable de le gagner, quand il auroit encore eu quelque doute de la drosture des Efpagnols: on lui laiffa choifir un lieu, pour s'y établir avec tous ceux de fa Nation, dont il fut déclaré Prince héréditaire, extempt de Tribut, \& obligé au feul hommage, qu'il feroit tenu de faire rendre en fon nom à l'Empereur, \& à fes Succeffeurs Rois de Caftille, toutes les fois, qu'il en feroit requis. Il fe retira peu de têms après, dans un lieu nommé Boya, à treize ou quatorze lieuës de la Capitale, vers le Nord-Eft. Tous les Indiens, qui purent prouver leur defcendance des premiers Habitans de l'Ine, eurent permiflion de le fuivre, \& leur pofterité fubfifte encore aujourd'hui au même lieu, \& joüit des mêmes Privileges. Leur Prince, qui s'intitule, Cacique de l'I le Hajti, juge \& condamne à mort; mais il y a appel à l'Audience Royale. Ils étoient environ quatre mille, lorfqu'ils furent ainfi réünis; mais ce nombre eft fort diminué depuis ce têms-là. Jai pourtant quelque peine à croire qu'ils fuffent réduits, il y a quinze ans, à trente Hommes, \& cinquante ou foixante Femmes, com-

$\mathrm{O}$ o o ij 


\section{HISTOIR}

I533. me je l'ai vû marqué dans un Mémoire, d'ailleurs trèsexact.

Decadence Quant anx autres Indiens, qui avoient êté amenés d'ailde la Colonie leurs, ils ne changerent pas de condition, \& comme on ne Erpagnole. les ménagea gueres plus, qu'on avoit fait jufqu'alors, on ne fut pas long-têms fans en voir la fin. La perte des.uns ne rendoit pas les autres plus moderés, chacun fongeoit à profiter du préfent, \& fe mettoit peu en peine, fi fes Succeffeurs auroient des Ef́claves, pourvû qu'il tirât de ceux, dont il étoit en poffeflion, toute l'utilité, qu'ils étoient capables de lui apporter. De cette forte les richefles, que l'inle Efpagnole renferme dans fon fein, font aujourd'hui fort inutiles à ceux de fes Habitans, qui font plus à portée de les en tirer, \& qui croyent faire beaucoup, que d'empêcher leurs voifins d'en profiter.

1538. Jai dit qu'on avoit découvert une Mine d'Argent dans

L'Audience cette Ifle; l'Empereur avoit donné la permiffion d'y fabriRoyals fait
monter la quer de la Monnoye de ce métal, \& l'on y faifoit des Reaux Monnoye, \& de la valeur intrinfeque de ceux d'Efpagne. La cherté des trempereur le denrées, \& la néceffité, où l'on étoit de fe fervir de rette yais. Monnoye, firent croire à l'Audience Royale, qu'elle pouvoit la mettre plus haut, \& elle avoit fait monter le Real à 24. Maravedis; ce qui s'étoit bientôt étendu à toutes les autres Provinces du Nouveau Monde, \& caufoit de grands défor: dres dans le Commerce. L'Empereurapprit avec étonnement cette entreprife, \& la regarda comme un attentât contre l'au* thorité du Souverain. II commença par remetrre les chofes fur l'ancien pied, puis il fit avertir les Auditeurs de n' $\hat{e ̂}_{*}$ tre pas une autrefois aftés hardis, pour rien ofer de pareil fans fon aveu. L'Amiral des Indes D. Loüis Colomb étoit alors à la Cour de Charles-Quint, où il pourfuivoit vivement le procès, que fon Ayeul avoit commencé contre le Fifc Royal, mais avec aufi peu de fuccès. Deux ans après, il fe fit un Traitté, dont le Cardinal de Loayfa, \& D. Fernand Colomb, Oncle de l'Amiral, furent les Arbitres. Par ce Traitté, D. Loüis fut déclaré Ca- 


\section{De S. Domingue, IIv. VI. 477}

pitaine Général de l'lle Efpagnole, mais avec de fi grandes limitations, qu'il ne lui en refta gueres que le Titre.

Il ne laiffa pas de faire le Voyage des Indes; mais il y a bien de l'apparence qu'il n'y refta pas long-têms. Il céda enfin tous fes droits, \& toutes fes prétentions fur la ViceRoyauté perpetuelle du Nouveau Monde, pour les Titres de Duc de Veragua, \& de Marquis de la Vega. C'éroit une grofle Bourgade de la Janiaique; \& l'on s'accoûtuma même dans la fuite, à fubftituer le nom de l'Ine à celui de cette Place. L'Amiral joüit peu du fruit de cet accommodement, $\&$ il y a de l'apparence que fes deux Freres étoient morts avant lui. Ce qui eft certain, c'eft qu'Ifabelle Colomb, fa Sour aînée, devenuë heritiere de cette Famille, en tranfporta tous les Titres dans une Branche de la Maifon de Bragance, qui eft établie en Efpagne, ayant époufé, ainfi que je lai dit plus haut, D. Georges de Portugal, Comte de Gelves, dont la pofterité s'intitule, de Portugal.Colomb, Duc deVeragua, Marquis de la famaïque \& Amiral des Indes.

En I 547 . l'Eglife de San-Domingo fut érigée en Métropole. Cette Ville avoit pourtant dès - lors beaucoup per-

du de fon luttre, \& l'Or \& l'Argent commençoient à y être érigée en Méfi rares, que peu d'années après, on n'y voyoit plus que tropole. de la Monnoye de Cuivre. Le Pere de Las Cafas avoit quitté l'Ifle Efpagnole, \& après avoir refufé l'Evêché de Cufco dans le Perou, avoit été contraint d'accepter celui de Chiappa, dans le Mexique. Il eut en ce têms-là de grandes difputes avec le Docteur Jean Ginés Sepulveda, au fujet de la maniere, dont on devoit traitter les Indiens, \& fur le droit, qu'on avoit eu de les affujettir par la force des armes; mais l'Ine Efpagnole ne pouvoit plus prendre aucun interêt à cette controverfe, dont il paroît que l'Evếque de Chiappa eut tout l'honneur; jufques - là, que les Ouvrages, que le Docteur compofa pour foutenir fon fentiment, furent cenfurés \& fupprimés par l'authorité du Prince; mais comme plufieurs étoient encore d'avis de laifo fer aux Habitans des Colonies Efpagnoles les Efclaves

$$
\text { Q o o iij }
$$

1540.

D. Louis

Colomb parfe à l'Efpagnolo en qualité de Capitain Général. Extinction de cette famille.

\section{7.}


I547. dont ils étoient actuellement les Maitres, en les mettant fur le pied de Domeftiques à gages, le Prélat entreprit de faire voir que la chofe étoit impratiquable, \& que laiffer ces malheureux entre les mains des Elpagnols, c'étoit les facrifier.

Quetle fut Ce fut alors \& à cette occafion, qu'il compofa ce faToccafion qui meux Traitié de la Tyrannie des Efpagnols dans les Indes, Calas à écrire qu'il fit imprimer plufieurs années après, \& qu'il dédia au fon Livre de Roy Philippe II. il y affüre que les Efpagnols avoient fait latyranniedes périr plus de quinze Millions d'Indiens. Mais il faut con-
Elpagiols. venir quil regne dans fon Ouvrage un air de vivacité \& d'exaggeration, qui prévient un peu contre lui, \& que les faits, qu'il rapporte, fans être alterés dans la fubft ance, ont fous fa plume, je ne fçai quoi d'odieux \& de criant, qu'il pouvoit peut-être adoucir. Il n'avoit apparemment pas affés fait réflexion, qu'il ne fuffit pas à un Hıftorien d'être veridique, pour ne pas manquer à la fitelité, que demande l'Hiftoire, qu'il faut encore être extrêmement en garde, contre ce que la prévention, la haine, l'interêt, l'amirié, l'engagement, un zéle ou trop amer, ou trop ardent peuvent donner de couleurs, ou étrangeres, ou trop vives aux faits d'ailleurs plus certains. Mais on peut bien affûrer que le Saint Evêque de Chiappa, dont, malgré fes défauts, ou, pour parler plus jufte, les excès de fes vertus, le nom eft demeuré très refpectable dans les Annales du Nouveau Monde, \& dans les Hiftoires d'Efpagne, ne prévoyoit pas les mauvais effers, que produifit fon Ouvrage peu d'années après, qu'il eut été rentu public, lorique traduit en François par un Hollandois, il fe fut répandu parmi les Révoltés des Pays-Bas. Car il eft vrai de dire, que rien n'anima davantage ces Peuples à perfifter dans leur rébellion, que la crainte qu'il ne leur arrivât, s'ils entroient en quelque accommodement avec l'Épagne, ce qui étoit arrivé dans la plûpart des Provinces de l'Amérique, où l'on n’avoit jamais exercé plus de cruautés contre les Indiens, que quand ils fe croyoient plus affurés fur la foy des 
'Traités, ou qu'ils faifoient paroître plus de refpect \& de foumiffion. Du moins, fut-on bien aife de pouvoir prétexter cette crainte, \& l'authorifer d'un tel exemple.

En I 564 . la Conception de la Vega fut prefque touto renverfée par un Tremblement de Terre. Cette Ville étoit bâtie au pied d'une Montagne, fur laquelle on avoit planté une Croix. Les Indiens, qui voyoient les Erpagnols fe profterner devant cette Croix, s'imaginerent apparemment que c'étoit là leur Dieu, \& pour fe venger de tous les maux, que ces Etrangers leur faifoient, réfolurent de la renverfer, ils commencerent par y attacher des cordes; mais ils eurent beau tirer, la Croix n'en fut pas même ébranlée. Ils amafferent enfuite quantité de bois tout autour, \& y mirent le feu. Cette feconde tentative ne réuffit pas mieux que la premiere : la Croix au milieudes flammes ne changea pas même de couleur, finon au pied, où il paroiffoit un peu. de noir, comme fi on en eût approché une chandelle allumée. Après cela,ils effayerent de la couper avec leurs pierres aiguifées, \& ils remarquerent qu'auffi-tôt qu'ils en avoient coupé un morceau, le vuide fe rempliffoit. Ils renoncerent enfin à un travail inutile, \& plufieurs ont même affûré, qu'ils avoient apperçu une Dame d'un port \& d'un regard pleins de majefté, affife fur un des Bras de la Croix, qui rendoit tous leurs efforts inutiles. Le bruit d'un fi grand prodige fe répandit bientôt partout, \& chacun voulut avoir un morceau de la Croix miraculeufe. Dieu fit pour authorifer \& pour montrer qu'il agréoit la pieté des Fidéles, ce qu'il avoit fait pour confondre la facrilege entreprife des Infideles; on eût beau couper la Croix pendant bien des années, elle ne diminua point. Enfin le Miracle ceffa, \& alors on tranfporta dans l'Eglife ce qui reftoit de ce précieux Bois, $\&$ on le conferva avec foin; les différens morceaux, qu'on en avoit coupés, furent les infrumens de plufieurs guérifons furnaturelles, \& dans le Tremblement de Terre, dont je viens de parler, aucun de ceux, qui en avoient, ne fut bleffé, quoique plufieurs fe fuffent trouvés fous les ruines des 


\section{$480 \quad$ HIS T O I R E}

1586. Edifices, comme les Religieux de Saint François, fous celles de leur Eglife. On affüre aufi que la Cathedrale, qui étoir de pierre de taille, ayant été abattuë, le feul endroit, ò̀ l'on gardoit la Croix miraculeufe, fut confervé. Il y a environ Is. ans, qu'on voyoit encore au milieu des mazures de cette Ville, un Monaftere tout entier, \& ce ne pouvoit être que celui des Religieux, dont je viens de parler, deux Fontaines, \& quelques reftes de Fortifications. Le Village de la Vega, dont j’ai parlé ailleurs, \& qui a été formé des débris de la Conception, n'en eft qu'à deux lieuës au Sud-Eft.

Grand Com- Cependant l'Ille Efpagnole ne laiffa pas de fe foûtenir merce de rifl encore affés long-têms, après qu'on eût ceffé d'en tirer de le Elpagnole. l'Or. Elle avoit de quoi réparer cette perte, qui étoit pourDomingo. tant pour les feuls droits du Roi, de cinq ou fix millions tous les ans, par le grand Commerce, qu'elle faifoit. de Sucre, de bois de Brefil, de Caffe, de Tabac, de Cotton, \& de Gingembre. Cette derniere Marchandife s'avilit enfin par fa trop grande abondance; les autres ont manqué peu à peu, faute d'Ouvriers. Acofta dit qu'en i 587 . on ap. porta en Caftille plus de 22000 . quintaux de Caffe de l'Ifle É́pagnole, \& 9000. Caiffes de Sucre. Néanmoins dès l'année précedente, fa Capitale avoit été prife, pillée. \& ruinée en partie par François Drak. Ce Capitaine Anglois fit fa defcente à l'Oueft de la Ville, \& mit environ 1200. Hommes à terre. S'érant enfuite avancé en ordre de Bataille, il fut attaqué par la Cavalerie Efpagnole, qu'il mit aifément en fuite. Après ce premier fuccès il partagea fa Troupe en deux bandes, \& attaqua en même têms deux Portes de la Ville. Il les emporta fi brufquiement malgré le Canon des Affiegés, que ceux-ci eurent à peine le loifir de fe fauver par une troifiéme, qui étoit à lautre extrêmité de la Ville. Le butin, que firent les Vainqueurs, ne répondit pas à la réputation de cette Métropole du Nouveau. Monde; ils y trouverent feulement quelques meubles précieux \& quelque Vaiffelle d'Argent; peu d'Or \& d'Argent monnoyé, 


\section{de S. Domingue, Liv. VI. 48 I}

monnoyé, \& beaucoup de monnoye decuivre. Drak, avant que de permettre le pillage, mit fes gens en Bataille dans la grande place; puis il envoya fommer le Gouverneur du Château de fe rendre, \& fur fon refus il fit donner un affaut, que les Efpagnols foûtinrent mal. Le Château fut forcé, \& Drak Maître de tout, mit fes Soldats à difcretion dans les plus belles Maifons. Ils y refterent un mois, enfuite ils commencerent à rafer la Ville; ils en avoient déjà abbattu une bonne partie, lorfque les Efpagnols accoururent, \& rachetterent le refte. Dans la rélátion, que les Anglois ont publiée de cette expédition, ils ont rapporté qu'ils trouverent fur une muraille un Globe peint, avec la figure d'un homme à Cheval, qui fortoit de plus de la moitié de la circonference du Globe, avec cette devife, Non fufficit orbis. Cinq ans après Yaguana eut un fort pareil ⿳亠㐅े celui de San-Domingo: Chriftophle Newport la prit \& la I591. ruina prefque entierement.

L'Ifle Efpagnole fe feroit pourtant encore relevée de ces pertes par le Commerce, lequel continuoit toûjours fur un affés bon pied, furtout avec les Hollandois; mais le Roi Carholique ôta aux Habitans cette unique reffource, qui leur reftoit, en leur défendant de trafiquer avec les Etrangers. Les Hollandois, à qui ce Commerce apportoit de grands profits, voulurent le foutenir par les Armes, \& envoyerent dans ces Mers une Flotte commandée par Abraham de Verne; mais celle d'Efpagne l'ayant rencontrée en 1606. vers les Côtes de Cuba, l'attaqua avec tant de réfolution, qu'après avoir pris \& coulé à fonds plufieurs $\mathrm{Na}$ 1606 vires, elle obligea les aurres à fe fauver. Le Commerce ne laiffa pas de continuer comme auparavant, malgré la vigilance des Gouverneurs, ou peut-être même par leur connivence; mais le Confeil prit pour fe faire obéir un moyen, qui fut efficace, ce fut de faire rafer les places Maritimes, qu'on ne pouvoit garder. On démolit Yaguana, qui étoit extrêmement déchû, Puerto-di-Plata, \& Bayaha, qui étoient les Rendés-vous les plus ordinaires des Interlopes: Tome I. Etrangers défondu aux Habitans de l'Ifle Efpagnole. 
482 HISt. DE S. Dom. LIV. VI.

\& les Habitans de ces trois Places, eurent ordre de fe retirer dans les Terres. Ceux d'Yaguana \& de Bayaha fe joignirent enfemble, \& allerent à l'Orient, où ils formerent une Ville, à laquelle ils donnerent le nom de Baysguana. Ceux de Puerto-di-Plata s'approcherent de la Capitale, \& bâtirent Monte-di-Plata, auprès de Boya, ou D. Henry s'étoit pofté. Les Villes de Salvatierra de la Savana, d'Yaquimo, de San-Juan de la Maguana, de Bonao, de Buenaventura, de Larez de Guahaba \& de Puerto-Real, avoient déjà été abandonnées. L'indigence \& le défaut dıs Commerce, avec l'efperance de faire ailleurs plus de fortune, en ayant difperfé les Habitans dans les nouvelles Colonies, furtout dans le Mexique.

Déperiffe- Enfin du moment que le Commerce eut entierement cefment entier fé avec les Etrangers dans l'Ille Efpagnole, elle ne fut delacolonie. plus reconnoiffable. Il n'y venoit qu'un Navire d'Efpagne tous les trois ans; le Préfident \& les principaux Officiers en achettoient d'abord la Carguaifon, \& la vendoient en détail aux Habitans, au prix qu'ils vouloient. Auffi la plûpare fe trouvoient réduits à aller prefque nuds, n’ayant pas de quoi avoir un morceau de toile pour fe couvrir, ce qui a donné lieu à une Coûtume affés finguliere, qui dure encore. Dans les Villes ou groffes Bourgades, on dit les Dimanches \& les Fêtes une Meffe avant le jour, afin que ceux , qui n'ont pas le moyen d'être décemment vêtus, puiffent fe couvrir des ténebres de la nuir, pour fatisfaire au précepte de l'Eglife. Telle étoit la fituation, où fe trouvoit la premiere, \& la Mere de toutes les Colonies Épagnoles de l'Amérique, lorfque les François entreprirent de paztager avec les Caftillans une Ine, dont ceux-ci laiffoient depuis long-têmps une fi grande partie en friche. C'eft ce qui va faire la matiere de la feconde partie de cet Ouvrage.

Fin du faxiéme livure of de la premiere Partie. 


\section{Dans ce premier Volume.}

A

A Bricot de $S$. Domingue,
Voyés Mamey. Abrojo, autrement appellé le Mouchoir quarré. Ecuieil dangereux au Nord de l'Ifle Efpagnole. Sa fituation, p. 6 . Acclamations. Maniere, dont les Infulaires de l'Efpagnole faifoient leurs acclamations , 469 . Acofta. Le Pere Foleph de Acofta, Jefuite. Son fentiment fur la nature du Vent alifé, ou de la Brife, 7. Es uiv. Acul. Port de l'Ifle Efpagnole, les premiers noms, qu'il a portés.

33. Acuña, Dom Alvare d'Acuña. Réception,qu'il fait à Chriftophle Colomb dans le Port de Lifbonne.

Adélantade. Ce que c'eft que cette Charge.

129.

Adrien Doyen de Louvain, depuis Cardinal \& enfin Pape, 335. Approuve le projet du
Licencié Barthélemy de Las Cafas, 347.456. Agama. Sorte de Cancre. Sa defcription, $2 \mathrm{I}$. Aguado. Dom fean Agnado, Maitre d'Hôtel dela Reine Ifa. belle de Caftille, eft envoyé Commiffaire à l'Ifle Efpagnole. Sa maniere d'agir avec D. Barthélemy Colomb , I 36.5 a conduite envers Chriftophle Colomb , 137. Son retour en Efpagne,

139. Aneynaba, Cacique de l'Irle de Portoric, reçoit bien les Efpagnols, les conduit aux Mines d'Or, les en rend les Maîtres. Se fait nommer Fean Ponce de Leon, 278. Aguila. D. Diegue del Aguila refure le Gouvernement de la Province du Darien, qui lui eft offert par le Roi Ferdinand, 433. Aguilard. Le Marquis d'AguiPpp ij 


\section{T A B L E}

lard, Grand Veneur \& Confeiller d'Etat, confulté fur la caufe des Indiens, $\quad 356$. Aguirre. Le Licencié Agnirre affifte à un Confeil tenu pour décider la caufe des Indiens, 360.

Aigrettes, ou, Pefcheurs, fortes d'Oifeaux, qu'on trouve dans l'Ifle Efpagnole, 30. Alaminos. Antoine de Alaminos premier Pilote fur l'Efcadre, qui fit la découverte de l'Yucatan, détermine le Commandant à tourner de ce côté-là , \& pourquoi, 367. Il eft bleffé dans la Floride, 370. Ne peut doubler une pointe fur la Côte de la Nouvelle Épagne, 382. Il eft nommé premier Pilote de la Flotte de Fernand Cortez, 389. Il eft envoyé en Efpagne par Cortez, arrive à l'Ifle de Cuba , échappe à la vigilance de $\mathrm{Ve}$ lafquez, \& paffe le premier de tous le Canal de Bahama, 390. Albe. Le Duc d'Albe Favori du Roi Ferdinend, \& fon Coufin Germain, follicite en faveur de D. Diegue Colomb, qui avoit Epoufé fa Niece, $27 \mathrm{r}$. Albitez. Diego de Albitez habitant de Sainte Marie l'Ancienne du Darien, trahit Diego de Nicuefla, 306. 307.

Albuquerque. Rodrigue d'Albuguerque. L'emploi de Dif- tributeur des Indiens eft créé en fa faveur. Son avarice. 330. On écrit contre lui en Cour, $\&$ il eft foutenu par la faveur de Zapata fon parent, 33 r. Il eft enfin dépoüillé de fon Emploi,

332.

Alcaïde. Ce que c'eft que cet Emploi, 152. Alexandre VI. Ferdinand \& Ifabelle donnent avis à ce Pape de la découverte du Nouveau Monde, \& lui en demandent la proprieté, 109. I 10. Il partage les nouvelles Découvertes entre les Efpagnols \& les Portugais parle moyen de la Ligne de Demarcation, I10. Alfaro. Martin de Alfaro Capitaine Indien, parent du Cacique D. Henry, eft envoyé à Barrio Nuevo pour le complimenter; il le conduit vers le Cacique, par des chemins très-rudes, 466. Il en eft reprimendé du Cacique, 467. Alfinger Capitaine Flamand, envoyé Gouverneur dansla Province du Venezuela. Cruautés inoüies, qu'il y exerce, 452 . 453. Sa mort, 453 . Algnazil. Ce que c'eft que cet Emploi:

314. Alis Alifé. Signification de ces deux mots, origine du dernier,

Allemands. Leurs cruautés dans la Province de Venezuela, $452.453^{\circ}$ 


\section{DE S M T I E R E .}

compagne Vafco-Nugnez de Balboa dans la guerre, que ce Capitaine fait aux Indiens, 427. Demande la Commition de découvrir le Perou, 439. L'engagement, qu'il prend avec Pizarre \& Fernand de Lucques,

Alvarado. Diego de Alvarado entreprend de défendre la Fortereffe de San-Domingocontre Bovadilla,

195.

Pierre de Alvarado Commandant d'un des Vaiffeaux de l'Efcadre, qui découvrit la NouvelEfpagne, 37I. Grijalva l'envoye à Velafquez pour recevoir fes ordres, 380. Il ne parle pas d'une maniere favorable à fon Général, 380. 38I. Cortez l'envoye par terre de la Trinité à la Havane avec une partie de fes Troupes, 388. Il commande un des Navires de la Flotte deftinée à la Conquête de la Nouvelle Efpagne, 389. Amanas, ou Ifles Turques, au Nord de l'Ifle Efpagnole recommandables par leurs Salines,

6. Ambre. On croit avoir trouvé une Carriere d'Ambre dans l'Ifle Efpagnole, 124 . Ambregris. On en trouve après une violente tempête fur une des Cayes, qui font au Nord de l'Ifle Efpagnole.

Americ Vefpuce s'embarque pour le nouveau Monde avec Ojeda, publie une fauffe relation de fon Voyage, laquelle fait donner fon nom à tout cet hemifphere, 187. I 88. Son fecond Voyage avec Ojeda, il fe brouillle avec lui, \& le fait mettre aux fers, 216. Ampuez. Fean d'Ampuez Facteur Royal, eft envoyé pour faire un Etabliffement dans la Province de Venezuela. Sa bonne conduite, il bâtit la Ville de Coro", 449. Il fe rend Maître de Curaçao, \& de quelques autres Ifles, 450. Il eft obligé de ceder la place aux Allemands, 452. Il fe retire dans les Inles, qu'il avoit conquifes, \& que l'Empereur lui avoit confervées, Anacoana Reine de Maguana; Sceur de Behechio Roi de Xaragua, fe retire après la mort de fon mari chés fon Frere, 62. Son caractere, fon affection pour les Efpagnols; 147. Elle détermine fon Frere à payer le Tribut à la Couronne de Caftille, 149. Elle vifite un Navire Efpagnol, I 5 I. Elle fuccede à fon Frere au Royaume de Xaragua, 231. Elle careffe fort les Efpagnols, qui ne la payent que d'ingratitude, \&l'accufent d'avoir de mauvais deffeins contre leur Nation, là-même. Réception, qu'elle fait au Gouverneur Général, 232. Elle eft menée prifonniere à San. Pp iij 


\section{T A B L E}

Domingo, \& elle y eft penduë,

Arcabay, quartier de la Côte

234.

Andagoya. Pafcal de Andagoya découvre le Royaume de Cuzco,

439. Andaloufie. Nouvelle Andalonfie. Limites de cette Province, 284. Voyé Ojeda.

Anges, forte de Poiffons, qui fe pêche fur les Côtes de l'Ifle Efpagnole, $2 \mathrm{r}$.

Anglois. Navire Anglois à Portoric. Ses avanteres, 404.405 . Anthropophages. Peuples déclarés Anthropophages, \& à quoi ils font condamnés, $4 \mathrm{I}$ o. Voyés Cannibales.

Antigoa. L'Ifle d'Antigoa eft découverte, d'où lui vient ce nom,

I I 4 . Antilles. Situation des Antilles,

I. Leur divifion, 2. Origine de ce nom, 2. \& 3. Ifle imaginaire de ce nom, 3 . Araignées. Araignées de l'Ifle Efpagnole,

Arana. Pierre de Arana Commandant d'un Vaiffeau, que Chriftophle Colomb envoye à l'Ifle Efpagnole, $\quad 162$. Rodrigue de Arana, proche parent du précédent, eft fait Gouverneur de la premiere Fortereffe bâtie dans l'Ifle Efpagnole, 98. Il y eft affiegé, I 16 . Sa mort, I 7 . Arbolancho. Pierre de Arbolancho, envoyé en Cour par Balboa, 432 . Il eft bien reçû, 433. Il arrive trop tard, làmême. Occidentale de l'Ifle Efpagnole, premierement appellé Cahay, 189. Arcs-en-Ciel, formé par la clarté de la Lune,

I 2. Arenal. Puntadel Arenal, découverte par Chriftophle $\mathrm{Co}-$ lomb, 164. Armes. Armes des Infulaires de l'Erpagnole, Armoiries, données par le Roi \& la Reine de Caftille, à Criftophle Colomb, 109. Armoiries, données par Ferdinand à l'Ifle Efpagnole \& à fes principales Villes, 236 . Arriaga. Lonis Arriaga, fon traité pour bâtir quatre Villes, 2 I 2 . Il eft fans effet, 213. Artibonite, ou Hartibonite, Riviere de l'Ifle Efpagnole. Sa fituation, 18. Arzilla, Fortereffe fur la Cô. te d'Afrique, attaquée par les Maures, qui levent le fiege,

214 . Atença. Pierre d'Atença porte les premieres Cannes de Sucres dans l'Ifle Efpagnole, Atlantide, Ifle imaginaire. $\mathrm{Ce}$ qu'en écrit Platon, 66. Audience Royale. Tribunal Superieur, établi à San-Domingo, 287. L'Audience Royale de SanDomingo envoye un Auditeur à Velafquez, pour lui défendre de faire la guerre à Cortez, 


\section{E S M A T I R E S.}

Audience Royale établie au Mexique, limites de celles de San-Domingo, 444 . Auditeurs, ou Confeillers de l'Audience Royale de SanDomingo, refufent de fairerendre des Indiens injuftement enlevés, \& font accufés de les avoir eux-mêmes achettés ; 338. Ils font interdits pour avoir abufé de leur pouvoir, 341. Ils font cités par Zuazo, 343. Ils font rétablis, 343. Ils refufent d'expedier le Licencié Las Cafas, 415 . Leurs appointemens font augmentés, \&x pourquoi , 424 . Ils demeurent chargés du Gouvernement en l'abfence du Préfident, $46 \mathrm{I}$. Avocats. Chriftophle Colomb les fait exclure des Indes, 142. Axi, ou Piment, forte de Poivre, qui croît dans l'Amerique, 5o. Les Efpagnols efperent en faire un grand commerce, 108. Merveilles arrivées fur des racines d'Axi, I 50.

Ayllon. Luc Vafquez d'Ayllon Auditeur Royal, eft nommé pour aller complimenter le Roi Charles fur fon avenement à la Couronne, 348. Il eft arrêté \& fes papiers faifis, làmême. Il eft envoyé à l'Ifle de Cuba, pour détourner Velafquez de mettre en Mer une Flotte contre Cortez , 393. Il n'y réüfit pas \& s'embarque fur la Flotte , 394. Il arme deux Vaiffeaux pour aller en Floride, 410. Il y enleve des Sauvages, \& n'en profite point, 411. It pale en Efpagne, \& obtient !e Gouvernement du Pays, qu'il a découvert, là-même. Sa mort dans une feconde expedition en Floride felon quelques Auteurs, là-même.

Ayora. Fean de Ayora, eft nommé Lieutenant au Gouvernement de la Province du $\mathrm{Da}$ rien,

434.

Azua de Compoftella. Port \& Ville de L'Ifle Efpagnole. $S a$ fondation, 256. Fertilité de fon Terroir, 406. Cequi fe paffe auprès de cette Ville, entre les Habitans \& le Cacique Henry, 472. Azur. On croit en avoir trouvé une Carriere dans l'Ifle Efpagnole,

I 24 .

\section{B}

$B$ Adajoz. Voyés Fonfeca \&
Mota. Badillo. Pierre de Badillo, Lieutenant de Roi de San-Juan, refufe de rendre juftice aus Cacique Henry, 397. Il perit malheureufement. 403 . Bahama. Ifle de Bahama, une des Lucayes, donne fon nom au Canal, 6. Qui l'a pafféle premier.

340.

Balboa. Vasco Nuñez de Balboa. Avis important, qu'il donne, premiere caufe de fa for- 


\section{T A B L E}

tune, 298. Soncaractere, làmême. Ce qu'on a dit de la maniere, dont il étoit forti de l'Ifle Efpagnole , 299. Vûës, qu'on lui attribuë, en confeillant de placer la Colonie d'O jeda dans la Caftille d'Or. Il eft fait Alcaïde Major de Sainte Marie l'Ancienne, zor. 11 refufe de recevoir Nicueffa dans cette Ville, 305. il s'en répent, \& fait punir un homme, qui avoit mal parlé de ce Gouverneur, auquel il fait donner un bon confeil, 306 . Il s'attire toute l'authorité dans $\mathrm{fa}$ Colonie, fait faire le procès à Encifo; envoye demander du fecours à l'Amiral ; engage fon Collegue à paffer en Efpagne, \& pourquoi, 427 . Il tâche en vain de fe racommoder avec Encifo. Il envoye un riche prefent au Tréforier Royal des Indes, pour s'affurrer de fa protection. Il fait de grandes Conquêtes, \& envaye 300 . Marcs d'Or au Roi d'ERpagne pour fonQuint, 428. Il apprend les premieres nouvelles de la Mer du Sud, 429. Il fait de nouvelles Conquêtes, veut paffer à l'Ifle Efpagnole, \&z de-là en Caftille, mais on s'y oppofe. Il reçoit du fecours de l'Amiral des Indes , \& de mauvaifes nouvelles d'Efpagne. II fe difpofe à la Découverte de la Mer du Sud, 430. Il la fait heureufement. Il eft fort aimé de fes gens, $43 \mathrm{r}$. Il prend poffeffion de la Mer du Sud d'une maniere fort finguliere. Il découvre les Inles des Perles, \& court rifque de faire naufrage. Il fait part à la Cour de fes Découvertes : \& y envoye beaucoup d'Or, \& de Perles, 432 . Le Roi Catholique veut qu'il foit récompenfé , 433 . Comment \& en quel équipage il reçoit la nouvelle de l'arrivée de Pedrarias, en qualité de Gouverneur de la Provin. ce du Darien, 434. 435. Il ne tient qu'à lui que toute la Province ne fe fouleve en fa faveur. On lui fait fon procès, 435. Il eft condamné à une groffe amende, 436 . Il eft fait A délantade de la Mer du Sud, \& des Provinces de $\mathrm{Pa}$ nama \& de Coiba, \& le Rai recommande à Pedrarias de le bien traiter, \& de fuivre fes confeils , 438 . Il fe broüille avec Pedrarias: on les réconcilie. Pedrarias lui fait couper la tête,

Baleine. Golphe de la Baleine Sa fituation, 166. Ballefter. Michel Ballefter Commandant à la Conception de la Vega, refufe d'y recevoir Roldan. Donne avis à Dom Barthélemy Colomb qu'il n'eft pas en fûreté à Ifabelle, I 55 . Il va trouver Roldan de la part de l'Amiral, pour l'engager à mettre bas les armes , I73. Il y retourne une feconde 


\section{E S I A T I E R ES.}

fois avec Carvajal, 175. Avis qu'il donne à l'Amiral de la difpofition où il a trouvé les Rebelles, 177. Il eft affiegé dans la Conception de la Vega , par Roldan, I8I. L'Amiral l'envoye en Efpagne, 184 .

$B$ ananier. Arbriffeau fruitier de l'Ifle Efpagnole, qui porte toûjours du fruit, $5 \mathrm{r}$. $B$ anderas. Rio de Banderas, origine de ce nom, 378. Baruco. Montagnes de Baoruco font les mêmes que les Montagnes de la Beata, I 7 *. Un Cacique, parent d'Anacoana, $s^{2} y$ retire après la prife de cette Reine, 285. Les Ancêtres du Cacique Henri avoient regné dans quelque canton de ces Ifles, 396. II s'y retire, 397 . Il y établit fa République, 400. Reception qu'on y fait au P. de Las Cafas,

473.

Baracoa. Port de l'Ifle de $\mathrm{Cu}-$ ba , 88.

Barba. Pierre de Barba, Commandant à la Havane. Reçoit ordre de Velafquez d'arrêter Cortez, 389. Bardeci. Lopé de Bardeci, Habitant de l'Ifle Efpagnole, eft confulté fur la maniere de finir la guerre avec le Cacique Henri, 463.

Barrantés. Garcias de Barrantés eft envoyé en Efpagne par Chriftophle Colomb, 184 . Barrientos. Etienne Barrientos, Tome $I$.
Habitant de Sainte Marie l'ancienne, veut tromper Nicueffa pour le perdre, $\quad 306$. Barrio Nuevo. Francois de Barrio Nuevo, nommé Gouverneur de la Caftille d'Or. Il reçoit ordre de finir la guerre du Cacique Henri, \& fe rend en diligence à l'Ifle Efpagnole, 462. Il confulte l'Audience Royale, 463. En conféquence de la délibération faite à San-Domingo, il va chercher le Cacique, 464. Difficultés qu'il rencontre dans fa màrche, \& fon courage à les furmonter, $465 \cdot 466$. Il joint le Cacique, \& ce qui fe paffa entr'eux, 467.468 .469 . II conclut le Traitté de Paix, 470. Ce qui lui arrive à fon retour au Port d'Yaquimo, 47r. De quelle maniere il eft reçu àSan-Domingo, là-même. Barros. Fean de Barros Hiftorien célébre, particularité qu'il raporte de l'Ifle de Corve, 68. Baftidas. Rodrigue de Baftidas, Capitaine Efpagnol, découvre le Port de Carthagene , arrive à Xaragua, où le Gouverneur General le fait arrêter. Il échape au naufrage, qui fait périr la Flotte Efpagnole. Il eft récompenfé à la Cour pour fa bonne conduite envers les Indiens , 216. Rodrigue de Baftidas obrient le Gouvernement de Sainte Marthe, avec le titre d'Adélantade. Ses propres gens fe Qq q 


\section{T A B I E}

révoltent contre lui. Sa mort, 44 I.

Bafrimentos. Puerto de Baftimen tos découvert par Colomb, 240.Comment il eft nommé par Nicueffa, 304. Bafurto. Fean de Bafurto fait de grands préparatifs pour peupler les environs du Lac Nicaragua; il trouve en arrivant à Panama, cqu'on y a envoyé un autre Commandant. On lui propofe la découverte du $\mathrm{Pe}-$

rou. Sa mort.
Batos, efpece de Balon, de quo compofé, 39. 40. Jeu de Batos, 40.

Bayaha. Ville Efpagnole détruite, \& pourquoi, $\quad 48 \mathrm{I}$ 。 Bayaguana. Bourgade. A quelle occafion elle eft bâtie. 482 .

Beata. Petite Ifle, fa fituation, 256. Montagnes de la Beata, $17 *$.

Begue. Bourgade Efpagnole. Sa fituation. Son origine. 480.

Bebechio., Roi de Xaragua avoit trente-deux femmes, 62. Il ne peut être rendu Tributaire de la Caftille parl'Amiral Chriftophle Colomb, I34. D. Barthelemy Colomb entreprend de le foumettre, 147. Il fe laiffe perfuader, 149. Il paye fon premier Tribut, I 5 r. Sa mort, 3 I.

Benitez. François Benitez parle mal de Nicueffa, \& en eft puni, 306. Berezillo. Fameux Chien. Son

Hiftoire, $28 \mathrm{I}, 282$
Velafquez fonge à lui, pous: le charger du commandemens. de fa Flotte,

Befchinchi. Ce que c'eft, fes proprietés,

52.

Betbléem. Riviere. Pourquoi elle eft ainfi nommée, fon premier nom, 242. Sa profondeur, elle fe déborde prodigieufement, \& pourquoi , 243. Bourgade bâtie fur fes bords, 244. brîlée \& abandonnée , là-même.

Bimini. Petite Ifle des Lucayes. Sa fituation, 322. Fontaine fabuleufe de Bimini, là-même. Blanc. Sorte de Monnoye. Sa valeur, 265.

Bohio. L'Ifle Efpagnole eft indiquée àChriftophle Colombfous ce nom. Sa fignification, 89. Boincar. Port de Cuba, 372 . Boletios. Habitant de San-Domingo. Son Traité pour un établiffement Efpagnol à MonteCrifto, 474.

Bonao. Bourgade. Sa fituation, 173. Ce qui s'y paffe à l'occafion de la révolte de Roldan, 173. \& fuiv. Ce que produit fon terrein,

406.

Bonayre. Petite Ifle proche de Curaçao. d'Ampuez s'en empare , 450. L'Empereur la lui conferve, la même. Il $s^{\prime} y$ retire,

$45 \mathrm{I}$.

Bonices. Ou Poiffons volans. chaffés par les Dorades, 23 . \& par des oifeaux,

Boriquen. Voyés Portoric.

Boto. Le Cap Boto. Sa fituation, 


\section{DES M A T E R E}

Bovadilla. Dom François de Bovadilla Commandeur de l'Ordre de Calatrava. Il eft envoyé aux Indes, en quelle qualité. Son caractere. Ses Inftructions. Il arrive à San-Domingo, 193 . II fomme D. Diegue Colomb de lui livrer la Citadelle, 194. Sur fon refus il s'en empare à force ouverte, 195 . Il délivre les Prifonniers qui y étoient, \& parle mal des Colombs, là-même. Ses violences à l'égard de Chriftophle Colomb, qu'il fait mettre en prifon les fers aux pieds dans la Fortereffe, 197. Il traitte de la même maniere les deux Freres de l'Amiral, 198. Il fait beaucoup d'amitié à Roldan, \& à fes Complices. Il fait inftruire le procès de trois Freres, 199. Son embarras. Il fe détermine à les envoyer en Efpagne, avec les pieces de leur procès, 200 . Il publie une amniftie en faveur de tous ceux, qui étoient coupables des dernieres Révoltes. Ordre qu'il donne à celui, qui conduifoit les Colombs en Efpagne, 20r. Indignation du Roi \& de la Reine contre lui, 202. Sa conduite dans le Gouvernement des Indes, 204.205 . Il rend les Infulaires efclaves, 205. 206. Il eft révoquẻ, 207. Sa furprife à cette nouvelle, 2ro. Il eft abandonné de tout le monde, 2II. Il périt en Mer, 215 .
Il maltraite Rodrigue Baftidas s 2I6. Il refufe de faire juftice d'un Efpagnol , qui avoit fait éventrer un Cacique par un Dogue, 220. Boutin. Le P. Pierre Bowtin Jefuite, Miffionnaire à Saint Domingue. Ses obfervations fur la longitude du Cap,

Boya. Bourgade Indienne. Sa fituation; à quelle occafion elle a été bâtie,

$475^{\circ}$

Boyl. Le P. Boyl Benedictin Catalan, nommé Superieur des premiers Miffionnaires envoyés àl'Ifle Efpagnole, I I 2. Il opine à arrêter le Roi de Marien , \$17. Ses démêlés avec l'Amiral, qui le choifit, pour être membre du Confeil établi à Ifabelle, I25. Il fe met: à la tête des Mécontens. Sa conduite imprudente, fon retour en Efpagne, \& quel en fut le motif, I28. Il déclame à la Cour contre Chrifophle Colomb, 136. Sẹs déclamations font fans effet, I 4 I . Elles font caufe d'un Reglement,qui exclut des Indes ceux, qui ne font pas Caftillans, 143 . Brayan. Cacique de l'Ifle de Portoric. Comment il s'affûre que les Efpagnols ne font pas immortels, 280.28I.

Brefil. Bois de Brefil fort commun auprès du Port d' $\mathrm{Ya}_{\mathrm{a}}$ quimo, 188. Il donne à ce Port le nom de Port du Brefil, 236. Reglement pour la coupe du Bois de Brefil :

Qq q ij 


\section{T A B L E}

209.

Brife. Vent qui fouffe de la partie de l'Eft. Origine de ce mot: caufes \& nature de ce Vent, 7. \& Juiv. Buenaventura. Ville Efpagnole, $\mathrm{fa}$ fondation \& fa fituation, 235. Fontes d'or, qui s'y faifoient, 266. En quel état elle étoit après que les Mines eurent été fermées,

Burgos. Voyés Fonfeca.

Burgot. Sorte de Coquillage, qui fe trouve fur les rivages de l'Ine Efpagnole,

$2 \mathrm{I}$. Butet. M. Butet Lieutenant de Roy, Commandant à Bayaha. Son Journal, ce qu'il rapporte de la fituation de l'Etang falé , \& de celui du Culde-Sac,

17. 18.

Butios. Prêtres \& Medecins de

l'Ifle Efpagnole, ce qui les diftinguoit des autres. Leur fourberie, 57. Rifques qu'ils couroient, quand un Malade mouroit entre leurs mains, 58. Leur maniere de traitter les Malades.

là-même.

\section{C}

Abanes. Port des Cabanes. Sa fituation, \& pourquoi il eft ainfi nommé, 166

Cabrera. Gabriel de Cabrera, ce que lui dit un Infulaire de $\mathrm{Cu}$ ba,

319.

Sacao. Fruit découvert la pre. miere fois par Chriftophle Colomb. Ufage qu'en faíoient les
Indiens,

238.

Cacique. Signification de ce mot, 39. Obfeques des Caciques . 45. Fourberie d'un Cacique pour fe faire payer un tribut 55. Fonctions des Caciques dans les Fêtes publiques. Secret, qu'avoient les Caciques , 56. Prefque tous les Caciques de l'Ifle Efpagnole fe liguent comme les Caftillans, $\mathbf{1} 27$. Ordre de la Reine If́abelle touchant les Enfans des Caciques, 396. Un jeune Cacique fcandalifé de voir les. Efpagnols prêts à fe battre pour de l'Or, renverfe la balance, ou on le pefoit,

Cadix Nomvelle Cadix Efpagnole. Sa fituation, 277 . En quel têms elle fut bâtie, 422 .

Cabay. voyés Arcahay.

Caïques. Ifles qui font au Nord de l'Ifle Efpagnole,

Calcadilia. Voyés Ortiz.

Campeche. Origine de ce nom. Situation de la Ville de Campeche, 368.

Canards. Efpece de Canards Sauvages dans l'Ine Efpagnole, 28.

Cancres. Trois efpeces de Cancres dans l'Ife Efpagnole, 21.22.

Cannibales. C'eit la même chofe qu'Antropophage, 2.38. Canots. Riviere des Canots. Sa fituation. Pourquoi elle eft ainfl nommée, $38 \mathrm{I}$. Caonabo. Prince Caraibe, Roi de Maguana, 6r. Aftiege la premiere Fortereffe des Efpa- 


\section{E S M A T I R E S.}

gnols, \& la brûle, I I6. II7. Eft défait par le Roi de Marien, là-même. Il fait mine d'affieger la Fortereffe de Saint Thomas, 127. Il eftime plus la Fonte \& le Cuivre que l'Or, 129. Eft enlevé par Ojeda, 330. Sa fierté à l'égard de Chriftophle Colomb, Iz I. Sa mort, la-même. Sa prife caufe un foulevement prefque général dans l'Ifle,

132.

Cap François. Sentimens divers fur fa longitude,

Vieux Cap François. Sa fituation,

$10 \mathrm{r}$.

Caracole. Baye de Caracole. Sa fituation. Les Efpagnols l'avoient nommé Puerto Real, 95 .

Caracoli. Ce que c'eft, 168.

Caraibes. Habitans des petites Antilles, Antropophages, 2. Il eft permis de les enlever comme tels pour les faire efclaves, 284. Ceux de la Guaw deloupe fe défendent bien, 287.

Caraque. Ville Efpagnole. Le Siege Epifcopal de Coro y eft transferé, 449.

Caret. Efpece de Tortuë, 23. Careta. Cacique Indien, allié de Balboa,

Cariari. Bourgade Indienne, 239.

Caroline. Province de l'Amerique Septentrionnale, $4 \mathrm{II}$.

Carrieres. Qui fe trouvent dans l'Ifle Efpagnole,

Carthagene. Voyés Baftidas, 216. Ce qui $s^{\prime} y$ pafle entre
Ojeda \& les Indiens, 289 . Heredia chargé d'y bâtir une Ville, 443.

Carthaginois. Ce qu'on rapporte d'un Navire Carthaginois, qui fut porté fur une terre inconnuë, 67. Conduite qu'on ajoûte que tint le Sénat de Carthage à cette occafion, 68 . Carvajal. Alonje Sanchez de Carvajal. Il eft choifi pour être du Confeil établi à Ifabelle, 125. Il commande un Vaiffeau que Chriftophle Colomb envoye à l'Ifle Efpagnole, I6I. Il fe rend par terre de Xaragua à San-Domingo, 17r. Il arrive à cette Capitale, 172. Les Rebelles ne veulent traitter qu'avec lui. Il eft fufpect à l'Amiral, 174. 175. L'Amiral fe détermine à fe fervir de lui, là-même. Il négocie avec fuccès avec Roldan, 176. 177. L'Amiral mande ars Roi \& à la Reine qu'il fouhaite qu'on s'en rapporte à lui, fur tout ce qui s'eft paffé à l'occafion de ces brouiilleries, I79. Il pourfuit les Rebelles, I8I. Il vient enfin à bout de les amener à un accommodement, I 82. L'accord fe rompt, \& Carvajal le renouë, 183 . II figne le Memoire que l'Amiral envoye à la Cour, 184 . Il reçoit ordre de la Cour de refter dans l'Ifle pour avoir foin des interềts des Colombs, 209. Fean de Carvajal eft envoyé Qg g iij 


\section{T A B L E}

par l'Audience Royale de San-Domingo, pour commander par interim dans la Province de Venezuela. Y exerce des cruautés inoüies, on lui fait fon procès, \& il a la tête coupée,

Le Docteur Carvajal, 454. feiller d'Etat, 335. reprimande que lui fait le Cardinal $\mathrm{Xi}_{\text {- }}$ menés,

Cafas. D. Bartbelemy de Las Cafas, Licencié. Le nombre deRivieres qu'il compte dansla Vega Real. Son fentiment fur l'état de l'Ifle Efpagnole au têms de fa découverte, $6 \mathbf{I}$. $\mathrm{Ce}$ qu'il penfoit du grand Commandeur Ovando, 265. Il fuit Velafquez dans l'Ifle de Cuba, les fervices qu'il y rendit à la Religion \& à l'Etat, 32 r. Son caractere , 333 . Il paffe en Efpagne pour y plaider la caufe des Indiens, 334. Les mouvemens qu'il fe donne à la Cour, là-même. Il demande au Cardinal Ximenés la permiffion d'aller trouver le Prince Charles en Flandre, elle lui eft refufée ; mais le Cardinal entre dans fes deffeins. Il forme un plan de conduite pour la maniere de traitter les Indiens, 335. En quoi confifte ce Plan, 336 . On fe récrie contre , 338. Il eft déclaré Protecteur des Indiens, 34r. Les PP. de faint Jérôme ne veulent point qu'il s'embargue avec eux, \& pourquoi,
342. Il fe broitille avec eux 343. Il fe retire chés les Do. miniquains, \& repaffe en Efpagne, 344. Il ne ménage point en Cour les PP. de S。 Jerôme, 345. Il intente un procès criminel aux Auditeurs Royaux, mais fans fuccès, 346. Il eft protegé par $M$. de Chiévres, \& propofe d'envoyer des Negres \& des Laboureurs à l'Ille Efpagnole, 346. Il a git efficacement contre les Départemens, pour faire mettre en liberté quantité d'Indiens, qu'on avoit enlevés fous prétexte qu'ils étoient Anthropophages. Les PP. de S. Jerôme en reviennent à fon fiftême, 349. Il envoye des Laboureurs à l'Ifle Efpagnole, $\&$ on les lui débauche en che. min, 353. Il propofe le Plan d'une Colonie fort finguliere, là-même. 354. Il engage les Predicateurs \& les Theologiens du Roi à une démarche hardie, 354. Il obtient une Junte par le crédit des Seigneurs Flamands, 356. La Junte approuve fon projet, contre lequel il s'éleve un crì public, 356.357 . Il répond à tout ce qu'on lui objecte, 357. Ce qui fe paffe entre lui \& l'Evêque de Darien, 358 . Son difcours en préfence de l'Empereur, 36r. Ce qu'il penfoit de Grijalva, 372. Et de Velafquez, 380 . Son projet eft approuvé en partie. II 


\section{ES M A T I E E S.}

paffe aux Indes avec 200. Laboureurs, 472. Il apprend en arrivant à l'Ifle de Portoric de fâcheufes nouvelles du lieu de fa Conceffion, 4I 3. I1 paffe à San-Domingo, où on lui fait de grandes difficultés touchant l'execution de fon projet, 4 I5. Il eft obligé de s'accommoder avec l'Audience Royale, 4i 6 . Il repaffe à Portoric, où il ne retrouve plus fes Laboureurs, là-même. Il arrive àla Côte de Cumana , \& il trouve partout des obftacles à fes deffeins, 417. Il retourne à l'Ifle Efpagnole, \& les ordres qu'il laiffe dans fa Conceffion font mal executés. Ce qui en arrive, 4 r 8.4 ig. Il apprend par hazard la cléroute de fes gens, 420. Il fe fait Dominiquain. Il fe plaint de Gomara \& d'Oviedo, $42 \mathrm{I}$. Ce qu'il a écrit contre Pedrarias, 438 . Il va trouver le $\mathrm{Ca}$ sique Henry, \& ce qui fe paffe à cette entrevîë, 472 . 473. L'Audience Royale le trouve mauvais, \& s'appaife, 474. Il refufe l'Evêché de Cufco, \& eft obligé d'accepter celui de Chiappa. Ses difputes contre le Docteur Sepulveda, 477. Son Traitté de la Tyrannie des Efpagnols. Et le mauvais effet qu'il produifit dans les Pays-Bas, 478.

Caffave. Nourriture des Infulaires de l'Efpagnole, so. caffier ou Caneficier. De quelle maniereil pouffe fes racines, $\mathrm{I} 6$. Ils meurent tous dans l'Ifle Efpagnole, dont ils faifoient le plus grand commerce, 350 . Caftañeda. Dom Fean de Caftañeda, Gouverneur de l'Ifle de Sainte-Marie, une des Açorres, manque Chriftophle Colomb , qu'il vouloit arrêter,

103.

Caftellon. Facques de Cafellon réduit les Indiens de Cumana , $42 \mathrm{x}$. Son fentiment fur la maniere de finir la guerre du $\mathrm{Ca}$ cique Henry, 463. Caftille. La feule Caftille fait tous les frais de la Découverte du Nouveau Monde, 79. Cafille d'Or. Limites de cette Province, 284. Voyés $\mathrm{Ni}$ cuefla.

Cafillo. Bernard Diaz de Caftillo Soldat Efpagnol, qui a été à la Découverte \& à la Conquête de la N. Efpagne. Auteur peu exact, 371.387 . Caftro. Micbel de Caftro Habitant de l'Ifle Efpagnole, apprend le défordre que les $\mathrm{Ne}$ gres révoltez ont fait dans fon habitation, 423. Il court après eux, eft bleffé, les défait, \& ramene les Efclaves, qu'on lui avoit enlevés, 424 . Catay. Sa fituation, 70. Colomb $s^{\prime} \in$ croit très-proche, 239. Catherine Cacique établie fur le fleuve Ozama, attire les Efpagnols dans fon Pays, I45. \& Juiv. Epoufe un jeune Lfpagnol, \& fe fait baptifer, $1 \& \sigma$. 


\section{T A B L E}

Caverne, d'où font fortis le Soleil \& la Lune, felon les Infulaires de l'Erpagnole. Sa fituation, \& fa defcription, 60.

Cayacoa Roi de Higuey, $6_{3}$. Agnez Cayacoa fa Veuve, fe fait Chrétienne, là-même. Caye Saint Loinis. Obfervations du Pere Feuillée en cet endroit,

5.

Caymans. Particularités touchant ces animaux, 26.

Cemaco. Cacique Indien, attaque les Efpagnols, 299. Il eft défait,

Cerron. Michel Cerran eft fait Gouverneur de Portoric par l'Amiral D. Diegue, 279. Jean Ponce de Leon l'envoye Prifonnier en Efpagne, làmême. Il eft rétabli dans fon Gouvernement,

Cervantez. Gonzalo Gomez deCervantez, parent du Commandeur François de Bovadilla, qui ordonne qu'on remette les Colombs entre fes mains, $20 \mathrm{I}$. Chanfons. Les Chanfons étoient les annales des Infulaires de l'Efpagnole', \& on les changeoit à chaque nouveau Regne , 38. Elles étoient toûjours accompagnées de danfes en rond, 39. à quelle occafion on les compofoit, 45 . Charles - Quint Roi d'Efpagne, arrive à Villaviciofa, 346. I1 accorde aux Seigneurs de la Cour des Départemens d'Indiens, là-même. Son attention au foulagement de ces mêmes
Indiens, 348. 349. II fait affembler un Confeil Extraordinaire, pour examiner de quelle maniere on les doit traitter, 359. Ce qui s'y paffe, 360 . o fuiv. Il eft pour la premiere fois traitté de Majefté dans cette affemblée, \& à quelle occafion, 360 . Il ne conclut rien, \& pourquoi, 365. Il reçoit les premieres nouvelles dela Conquête du Mexique, 392. II s'embarque pour aller prendre poffeffion de l'Empire, $40 \mathrm{I}$. Il renvoya aux Indes l'Amiral D. Diegue Colomb , 408. II limite fon authorité, 409. II fait de nouveau examiner la caufe des Indiens, 425. II renvoye cette affaire aux Superieurs des Dominiquains \& des Francifcains, 426. Il réfufe de rendre juftice à la famille des Colombs, 443. Nouvelle Junte affemblée par fon ordre, pour difcuter la caufe des Indiens, 454. Il fe trouve plus embarraffé que jamais, 456. Les mefures quil prend pour finir la guerre du Cacique Henri, 462. Charles VIII. Roi de France. Il apprend à Barthelemy Colomb les découvertes de fon Frere, \& lui fait un préfent, I 26.

Charpentier. Pic-vert de l'Ifle Efpagnole. Pourquoi il eft appellé Charpentier, 29. Chaffe. Différentes manieres de chaffer en ufage parmi les In- 


\section{E S M A T I E R E S.}

fulaires de l'Efpagnole, 46. Cibao. Province ou canton de Chats. Port des Chats. Sa fituation. Erreur, qui donne lieu à ce nom, 166. Chemis, Quadrupedes de l'Ifle Efpagnole. 35. Chemis ou Zemez. Voyés Zemez.

Chevanx. Surprife des Infulaires de l'ifle Efpagnole, à la vîë de ces Animaux, IIg. Chico. Françoïs Alvarez Chico eft fait Procureur General du Confeil établi à la VeraCruz, 390. Chico, Riviere de la Floride, préfentement de la $\mathrm{Ca}-$ roline, 405. Elle eft nommée le Fourdain, \& pourquoi, 411. Chicora, Province de la Floride, où eft la Riviere Chico, 4 II . Chiens employés dans les combats contre les Infulaires de l'Efpagnole, I33. Cacique éventré par un Chien, 2 19. Un Officier va à la chaffe des Infulaires, avec une meute deChiens, 329.

Chievres. M. de Chievres favorable à Las Cafas, 346.347 . Chilan Combal, Sacrificateur de l'Yucatan, fa prédiction, 374 . Chique, appellé Nigua par les Infulaires de l'Efpagnole, petit infecte fort incommode, 34 . 35.

Chiribichi, Port de la Province de Cumana, 412. Chowx Carailke, efpece d'Arum, ou de pied de Veau, . . . 5o. Ciba. Signification de ce mot I 2 I.

Tome $I I_{2}$ l'Ifle Efpagnole. Chriftophle Colomb s'imagine que c'eft le Cipango de Marc-Paul de Venife, 90. Qjeda y arrive, \& en rapporte quantité de Montres d'Or, 12 I. Chriftophle Colomb vifite auflice canton, x 23. On n'a point trouvé ailleurs d'or plus pur, ni de Mines plus abondantes que dans cette Province, 218.

Cibas, Pierres, ou Coquilles précieufes, 118. Cignayos, Peuple de l'Ine Efpagnole, 157 . Ils paroiffent vouloir remuer, , I8.4. Cipanga. Nom, que les premiers Habitans de l'Efpagnole lui donnerent, \& pourquoi, 4.

Cipangi, Nom, que portoit autrefois l'Ifle de la Martinique, 4 . Cipango. Inle abondante en Or, felon Marc-Paul deVenife, 70. Cifternes. San-Damingo, par la pareffe de fes Habitans, eft réduit à l'eau de Cifterne, qui n'eft pas bonne, 222 .

Climat. Varieté des Climats dans l'Ifle Efpagnole, I I. Incommodité de ces changemens, 14 . Cobos. D. Francicio de los Cobos du Confeil des Indes. 347.

Cochem. Ifle. Sa fituation, \& ce que fignifie ce mot, 169.

Cocbons. Voyés les pages 227. \& 35 r. lis:

Cochon Marin, 24.

Cobiba. Voyés Tabac.

Colibry, Oifeau fingulier, 31. 32. Colmenarez. Radrigne Henriques R 5 L 


\section{T A B L E}

de Colmenarez arrive à Sainte Marie l'Ancienne. Y négocie en faveur de Nicueffa, 302. Il va le trouver, 304. En quel état il le trouve, 305 . Il fuit Balboa à la Guerre contre les Indiens,

Colomb. Chriftophle Colomb. Il veut engager les Elpagnols à fe préparer à la recherche de l'Or, en recevant les Sacremens de Penitence \& d'Euchariftie, 47. Quel étoit Chriftophle Colomb, 64. 65. Ses premieres Navigations, 66. Ses conjectures fur l'exiftence de Nouveau Monde, 67. On prétend fauffement qu'il a profité des Memoires d'un autre, qui a voit été avant lui dans l'Amérique, 69. Il fait fon Plan, \& le propofe à plufieurs Puiffances, 70. Trahifon, qu'on lui fait en Portugal, 7 I . Il paffe en ESpagne, la même. Il s'adreffe au Roi Ferdinand, 72. Il effuye bien des contradictions \& des lenteurs de cette Cour , 73. Il s'adreffe aux Ducs de Medina Celi , \& de Medina Sidonia. Il veut paffer en France, 74. 75. Son projet eft approuvé, \& fes conditions acceptées, 76. 77. Il va s'embarquer, 79. 11 met à la voile, 80. Mutineries des Efpagnols, 81. 82. Sa conduite en cette occafion, la même. Propofition hardie, qu'il leur fait, 83 . Il découvrele premier la Terre, \& il eft falué Amiral \&
Vice-Roi des Indes, 84. II prend poffeffion de l'Ifle de $S$. Sauveur, 85. Suite de fes Découvertes, 87. \& fuiv. Un de fes Navires le quitte; il arrive à l'Ifle Efpagnole, 90. II découvre la Tortuë, 91 . Son Navire febrife, 94. Ce qui fe paffe entre lui \& le Roi de $\mathrm{Ma}$ rien, 95. Fo Juiv. Il bâtit une Fortereffe dans les Etats de ce Prince, 97. Il part pour l'Efpagne, 98. Il découvre toute la Côte du Nord, 99. Le Navire, qui l'avoit quitté , le rejoint, 100. Il entre dans la Baye de Samana, \&c ce qui s'y paffe, ror. Il effuye une violente Tempête, Mauvaife manœuvre, qu'il fait en cette occafion, 102 . Ce qui lui arrive aux Açorres, 103. Il re-lâche en Portugal, de quelle maniere il y eft reçû, 103. I04. IO5. Il arrive en EfPagne, reception, qu'on lui fait, I05. I06. Il reçoit des Lettres du Roi, ro6. Ses imaginations touchant le Pays, quilil a découvert 107. Son entrée à Barcelonne, la même. Ce qui fe paffe à l'Audience, que lui donnent le Roi \& la Reine, 108. Honneurs, qu'on lui rend. Graces, que la Cour lui fait, 109. r ro. On lui délivre des Patentes confirmatives d'Amiral \& de Vice-Roi des Indes. II I. Son Audience de congé, I 12. Il part pour retourner aux Indes, Ir3. Il découvre 


\section{DE S M T I E R E .}

les petites Antilles, II4. Et I'Ifle de Portoric, I I 4 . I I 5 . Il trouve fa Colonie ruinée, Ir5. Confeil violent, qu'on lui donne, \& qu'il rejette, 117. Sa conduite avec le Roi de Marien, I 8 . Il bâtit la Ville d'Ifabelle, II9. II envoye vifiter les Mines de Cibao, I 20 . Il découvre une fédition. Il va vifiter lui-même les Mines de Cibao, Sa marche bruyante, \& le mauvais effet, qu'elle produit, 122. Découvertes, qu'il fait dans fon Voyage de Cibao, 124. Il y bâtit une Citadelle, la même. Mutinerie contre lui, fa conduite avec le Superieur des Miffionnaires, I25. Il découvre les Ifles de Cuba \& de Sant-Yago, la même. Il tombe malade \& retourne à Ifabelle, 126. mécontentemens contre lui, 127 . Il crée fon Frere Adélantade des Indes, 128 . Il reçoit du fecours d'Efpagne, \& marche contre une Armée d'Indiens, 132. Il les défait, 133. Il rend la plûpart des Rois de l'Ifle Tributaires de la Couronne de Caftille, 134. Toute la Colonie fe déclare contre lui, \& contre fesFreres, 137. Sa conduite à l'égard d'un Commiffaire de la Cour, la même. Il fe difpofe à paffer en Efpagne, \& découvre les Mines de Saint Chriftophle, I38. Il s'embarque; ce qui lui arrive à la Guadeloupe, 139. Son arri- vée en $\mathrm{E} f$ agne, \& fa réception à la Cour, 140. Reglemens, qu'il fait pour l'Etabliffement des Indes, $\mathbf{1}_{1} \mathrm{~T}$. Avis pernicieux, qu'il donne pour les peupler, I42. Source de la haine, que lui porte Jean Rodrigue de Fonfeca. Il ordonne de placer la Colonie ailleurs qu'à Ifabelle, 144. Offres, que lui font le Roi \&la Reine d'Efpagne, \& pourquoi il les refufe; avis qu'on lui donne, 160. Il part pour fon troifiéme Voyage, 161 . Il fait un grand détour \& pourquoi, 162. Il découvrel'Ifle de la Trinité, 163 . $\&$ peu de têms après le Continent, I64. Diveries autres Découvertes, 165.166. Ses imaginations fur les diverfes Obfervations qu'il fait, 167 . Il découvre la Pêche des Perles, I 68. Calomnies inventées contre lui à ce fujet, 169 . II arrive pour la premiere fois à San-Domingo, 170 . Il y apprend de faccheufes nouvelles, la même, Sa conduite à l'égard des Révoltés, I7I, Ö fwiv. Il rend compte à la Cour de cette Révolte, 179. Son entrevîë avec le Chef des Révoltés, $18 \mathrm{r}$. Il concluë un Traité avec lui ; il balance s'il n'ira point en Efpagne, \& fe détermine mal à propos à n'y point aller, 183. Il écrit de nouveau à la Cour, au fujer de la Révolte, I 84 . C e qui fe paffe entre lui \& O jeda, r 88 ,

Rrr ij 


\section{T A B L E}

o suiv. Mouvement à Grenade contrelui, 190. La Reine fe détermineà le rappeller, 191 . Prétexte, qu'elle prend pour cela, 1 92. De quelle maniere il reçoit la nouvelle de l'arrivée de Bovadilla, 196. Il fe met à la difcretion de ce Gouverneur, qui le fait enfermer dans la Fortereffe les fers aux pieds, 197. Il engage Dom Barthelemi fon Frere à fe livrer auff, 198. Chefs d'accufations contre lui, 199. Ses réponfes, 200. Il eft envoyé en Efpagne, il ne veut point qu'on lui ôte les fers, $20 \mathrm{r}$. Ia réception, qu'on lui fait en Efpagne, 202. Son difcours à la Reine, 203. Propofition, qu'il lui fait pour de nouvelles découvertes, 204. II part pour fon quatriéme Voyage. On lui refufe l'entrée du Port de San-Domingo, 214. Il prédit une grofle Tempête, la même. Comment tout fon bien échape au naufrage, 215 . Il découvre la Province de Honduras, 237. Il manque la découverte du Mexique, nouvelles Découvertes, 239. \& s. Il effuye une violente Tempête,24I. Il découvre la Province de Veragua, 242. Il y fait bâtir une Bourgade, 244.Danger, où il fe trouve, la même. II arrive en mauvais état à la Jamaïque, 245. Ses Navires y demeurent échoüés. Sa conduite avec les Infulaires, 246.
Ses gens fe foulevent contre lui, 248. Stratagême, dont il s'avife pour avoir des vivres, 25 r. Il reçoit des nouvelles de l'Ifle Efpagnole, 252. Mauvaifes manieres d'Ovando à fon égard, 253. Il tente inutilement de ramener les $\mathrm{Nu}$ tins, la même. Il arrive à SanDomingo , 255. De quelle maniere il y eft reçû, 256 . II arrive en Efpagne, 257. Ses efforts inutiles pour rentrer dans fa Charge de Vice-Roi ; de quelle maniere il ferma la bouche à fes envieux, 258. Sa mort, 259. Son caractere, 260. Ce qui lui arrive dans l'Ifle du Cuba, 320 . D. Chrifiopble Colomb, petit-fils du precedent, $\quad 442$. D. Barthelemy Colomb, Frere du premier Amiral. Ses premieres Avantures; il paffe en Angleterre, 7I. II eft annobli, I09. Il arrive à Ifabelle, I28. Il eft fait Adélantade des Indes, 129. La maniere, dont il eft traité par le Commiffaire Royal, 136. Il vifite Puerto di Plata, I39. Il bâtit la ville de San-Domingo, I46. Il en part pour le Royaume de $\mathrm{Xa-}$ ragua, 147. De quelle maniere il y eft reçû, I 48 . Il engage le Roi à payer tribut à la Couronne de Caftille, 149. Il paffe fur le ventre à une $\mathrm{Ar}$ mée d'Infulaires, \& fait prifonnier le Roi Guarionex, I 50 . Il reçoit le premier tribut de 


\section{E S M A T I R E S.}

Behechio, I Ír. Défauts de fon Gouvernement, 152. Il tâche envain d'appaifer une Révolte excitée contre lui \& contre fes Freres, 155. Il reçoit du fecours d'Efpagne, i 56 . I! fait offrir fon amititié au Roi des Ciguayos, \& à quelies conditions, I 57 . Elles font rejettées, la même. Il le défait \& le prend, i 58 . Il le fait mourir, I59.Pourquoil'A miral fonFrere ne l'envoye point continuer fes découvertes, 180 . Il eft chargé de fers, I98. Il s'em. barque avec fon Frere pour de nouvelles découvertes, 214. Il fe rend Maître d'un grand Canot d'Indiens fur la Cốte de Honduras , 238 . Il découvre plufieurs Mines d'Or dans la Province de Veragua, 243. II eft chargé de faire un Etabliffement dans le Pays, enleve le Cacique du lieu, fa Bourgade eft brûlée, 244. Il défait les Rebelles dans la Jamaïque, 254. Il fe faifit de leur Chef, 255 . L'Amiral fon Frere l'envoye au Roi Philippe \& à la Reine Jeannefon Epoufe, 259. Le Roi Ferdinand l'envoye à l'Ifle Efpagnole, 320. Faveur, qu'il lui fait, $32 \mathrm{x}$. Sa mort, 33 r. Son Eloge, 332. D. Diegue Colomb, Frere del'Amiral Dom Chriftophle. Il eft annobli, ro9. Il eft fait Gouverneur d'Ifabelle, I22. Et Prefident du Confeil, I25. Ce qui fe paffe entre lui $\&$
D. Pedro Marguarit , $12 \%$ 。

De quelle maniere Roldan en ufe avec lui, 154. Il refufe de livrer les Prifonniers \& $\mathrm{la} \mathrm{Ci}$ tadelle de San-Domingo à Bovadilla, 194. 195. Il eft mis aux fers, 198. Il repaffe à SanDomingo, D. Diegue Colomb, Fils aîné du premier Amiral Dom Chriftophle Colomb, \& fon Succeffeur. Son Pere le laiffe Page auprès du Prince d'Efpagne, I I 3. Et demande à la Cour, qu'on le lui envoye pour le former, I 84 . Il époufe la Niece du Duc d'Albe, 270. Il obtient de repaffer aux Indes pour y commander; mais non pas en qualité de ViceRoi , 27r. Il arrive à SanDomingo, il ne s'y conduit pas avec affés de prudence, 274 . Il établit l'Ifle des Perles, 276. Il change de fon authorité le Gouverneur de Portoric nommé par la Cour, 279. Il établit la Jamaïque. Mortifications, qu'il reçoit de la Cour, 285. Sa conduite peu politique, 286. Nouvelle mortification, que lui donne le Roi , 287. Il eft accufé de plufieurs chofes fans fondement, 308 . Le Roi lui envoye fon Oncle D. Barthelemy, \& pourquoi, 320. Les droits de fa Charge diminués, 330. Il repaffe en Efpagne, 33 I. Son fentiment touchant la maniere de traiter des Indiens , 369. Conduite de Rr. $\mathrm{rij}$ 


\section{T A B L E}

Velafquez à fon égard ; il follicite fes droits, 407. L'Empereur reconnoit fon innocencence fur prefque tous les pointsd'accufation intentés contre lui, \& le renvoye aux Indes, 408. Son arrivée à SanDomingo, \& la conduite qu'il y tient, 409. Il marche contre les Negres révoltés, 423 . Nouvelles accufations contre lui, 424. Il eft encore rappellé, \& fait de nouveau connoître fon innocence, 425 . Secours, qu'il envoye à Balboa, 428. Sa mort, 44 I. 442 . D. Diegue Colomb , fecond Fils du precedent, $44^{2}$. Il eft reçû Page du Prince d'Efpagne,

443 .

Dominique Colomb, Pere du premier Amiral, pourquoi fe retire dans l'Etat de Genés, 65. Quelques - uns croyent que c'eft de fon nom que la Capitale de l'Ifle Efpagnole a été nommée San-Domingo, 146.

D. Ferdinand ou Fernand Colomb , fecond Fils du premier Amiral. Son peu d'exactitude dans la vie de fon Pere, 55. Son Pere le met Page auprès du Prince d'Efpagne, 1 17 . Il n'étoit point du troifiéme Voyage de fon Pere, I63. Il s'embarque avec fon Pere, 214 . Il paffe à SanDomingo, 274. Il conclut un Traité entre la Cour \& fon Neveu, 476.
Fean-Antoine Colomb, $\mathrm{Pa}$ rent des precedens. Commande un Navire, que le premier Amiral envoye à l'Ifle Efpagnole, 162. Ce qui lui arrive à Xaragua, $\quad 17 \mathrm{I}$. Colomb le jeune, fameux Armateur, fes Explois, 65. Ifabelle rolomb, Fille cadette de l'Amiral D. Diegue , 442. Son mariage, 445. D. Loüis Colomb, Fils a $\hat{1}$ né de l'Amiral D. Diegue, \& fon Succeffeur dans la Char ge d'Amiral des Indes, 442。 443. Ses revenus font augmentés, la même. L'Empereur lui écrit, 462. Son Traité avec la Cour, $\quad 476$. Pbilippine Colomb, Fille a $\hat{\imath}-$ née de l'Amiral D. Diegue, 442.

Colonie. Avis touchant la maniere de peupler les Colonies, I42. 143 .

Commiffaires. Voyés Aguado \&: Feronymites.

Conception de la Vega. Ville de l'Ifle Efpagnole. Sa premiere Fondation, 138 . Elle eft affiegée par les Rebelles, 155 , Le Chef des Rebelles fe préfente de nouveau pour l'attaquer, $18 \mathrm{I}$. Fontes d'Or, qui $s^{\prime} y$ font, 266. Elle eft érigée en Evêché , 309. Diligence del'Empereur pour la peupler, 426. Son Evêché eft réini à celui de San-Domingo, 444 。 Elle eft renverfée par un trem. blement de terre, 479. Bous? 


\section{E S M A T E R E S.}

gade bâtie de fes ruines, 480 .

Conception. Ifle, 88.

Conception. Port de l'Efpapagnole,

Conchillos. Le Commandeur Lopé de Conchillos,eft contraire au Licencié de Las Cafas, 334. Il perd fon département d'Indiens, 337. Il gouverne les affaires du Nouveau Monde avec Fonfeca,

433.

Concubines. Indiennes tenuës par les Efpagnols à titre de Concubines. On oblige ceux-ci de les renvoyer, ou de les époufer, 263. congres. Sortes de Poiffons, qui fe pêchent fur les Côtes de l'Ifle Efpagnole,

21 .

Confeil établi à Ifabelie, 125 . Et à la Vera-Cruz, 390.

Contraftés. La Cofta de los Contraftés, fa fituation. Origine de ce nom,

242.

Copal. Sorte de Gomme, 369.

Coquillages, qui fe trouvent fur les Côtes de l'Ifle Efpagnole, $2 \mathrm{I}$.

Coraçol. Voyés Curaçao.

Cordonë. Voyés Fonfeca.

Le P. François de Cordonë, Dominiquain, eft envoyé à la Côte de Cumana, 326. Danger où il re trouve, \& à quelle occafion, 327. Il eft maftacré par les Barbares , 328 .

François Fernandez de Cordoüë eft nommé Chef de l'entreprife faite pour la découverte du Continent, 366. Il découvre l'Yucatan, 367. Ce qui lui arrive à Campêche, 368. Il eft bleffé, 369. Il débarque en Floride, \& y eft -attaqué par les Sauvages . 370. Il arrive à l'Ifle de $\mathrm{Cu}-$ ba, \& y meurt, la même. François Fernandez de Cordonë, Capitaine des Gardes de Pedrarias, eft chargé de faire un Etabliffement vers le Lac Nicaragua, 439. Gonzalez de Cordonë, furnommé le Grand Capitaine, 373.

Le P. Pierre de Cordone", Superieur des Dominiquains de l'Ifle Efpagnole. Ce qu'il répond aux Officiers, qui fe plaignoient de la liberté avec laquelle un de fes Religieux avoit parlé en Chaire, 3I2. Il paffe en Efpagne, 324 . II retourne à l'Ifle Efpagnole, \& envoye des Miffionnaires à la Côte du Cumana, 325. Ses efforts inutiles pour fauver ces Religieux, 328.

Coris. Quadrupede de l'Ifle EFpagnole, Coriane. Canton de la Province de Venezuela.

Cornets. Sortes de Coquillage, $2 \mathrm{I}$.

Corneilles, 28.

Coro ou Venezuela, 326. Ville bâtie par Jean d'Ampuez, 449. Ses deux Ports, 450. Coronel. Pero Fernandez Coronel eft choifi pour êre du Confeil de la Ville d'Ifabeille, r25. Il amene du fecours à San- 


\section{T A B L E}

Domingo, il Negocie envain avec le Chef des Rebelles, I 56 . Il figne le Memoire de l'Amiral fur cette Révolte, I 84 .

Corfaires. Ils commencent à fréqquenter les Mers des Indes, 456.

Cortez. Fernand Cortez, eft choifi pour la conquête de la nouvelle Efpagne, fa naiffance; il paffe à l'Ifle Efpagnole, 383. Ses premieres A vantures, 384. Son caractere, 385 . Sa conduite à l'égard de Velarquez, 387. Il part de SantYago, la même. Ce quilui arrive à la Trinité de Cuba, 388. Ce qui lui arrive en allant à la Havane, la même. Ce qui lui arrive dans ce Port. 389. Il met à la voile, la mếme. Il fe démet du Generalat, quilui eft rendu par le Confeil de la Vera-Cruz, 39 r. II reçoit du fecours, \& apprend des nouvelles de l'Ifle de $\mathrm{Cu}$ $\mathrm{ba}$, la méme. La Cour, modere la trop grande authorité, qu'il fe donne, 444. Mariin Cortez de Moriroy, Pere du précédent, 383 . Corves, Ifle des Açorres. Ce qu'on y trouva, lorfqu'on la découvrit, 68. Cofa. Fean de la Cofa, Fameux Pilote, s'embarque avec Ojeda, \& Americ Vefpuce, 186. 187. Il s'affocie avec Rodrigue de Baftidas, pour de nouvelles Découvertes, 216 . Il s'offre à accompagnę Ojeda dans une nouvefle entreprife, 283. Il le va joindre à l'Ifle Efpagnole, 284. Il donne aus Capitaine un bon avis, qui n'eft pas fuivi, 289. Il eft tué,

Cotocbe. Pointe, ou Cap de Cotoche,

Cotton, 87.89.

Cotubanama, Roi du Higuey, $6_{3}$. Il fe foumet au Tribut, 134 . Il fait la guerre aux Efpagnols, 220. Il demande \& obtient la Paix, 22I. Il fe fait appeller Jean de Efquibel, 222, $11 \mathrm{re-}$ commence la guerre, 262. Sa prife, \& fon fupplice, 264 . Cotuy. El Cotuy Ville Efpagnole, 236.

Cozumel. Ifle de Cozumel. Nom, que lui donne Grijalva, \& ce qu'il y trouve, 273.274 .

Crabes. Trois fortes de Crabes dans l'Ifle Efpagnole, 22. 23.

Crapau de Mer,

Crocodiles ou Caymans, 2 r. Particularités de ceux de Cuba, 26. 27.

Croix. Voyés Oxi. Croix trout vée dans l'Yucatan, 368. Origine de fon culte dans cette Province, 373. Croix miraculeufe auprès de la Conception de la Vega , $\quad 479$. Cuba. Premiere découverte de cette Inle, 88. Chriftophle Colomb en fait le tour, 125 . Conquête de cette Ifle, 375 . \& $\int$. Créance des Infulaires, 318. Ses differens noms, la même 


\section{DES M A T I ER E S。}

même. La Religion y eft prêchée par Las Cafas, 321 . Credulité des Habitans de cette Ifle , 322. Etat floriffant de la Colonie Efpagnole, 365. En quel état elle étoit en 1520. $\&$ ce qu'on en tiroit, 407 . Cubagua. Découverte de cette Ifle, \& nom qu'on lui donne, 169. On y fait un Etabliffement, 276. Particularités de cette Ifle 277. Las Cafas n'y peut établir fon authorité, 418. La Garnifon Efpagnole s'en retire, 419. On y bâtit la nouvelle Cadix,

422.

Cubanacan, Canton de l'Ifle de Cuba,

89.

Cuivre, Mine de Cuivre trouvée dans l'Ifle Efpagnole, 267.

cul-de-Sac, Etang du Cul-deSac. Voyés Xaragua Quel côte de l'Ifle Efpagnole porte ce nom,

Culua. Voyés Tlua.

147.

Cumana, Province du Continent de l'Amérique, I88. Les PP. Dominiquains s'y établiffent . 325. 326. Trahifon qu'un Capitaine Efpagnol y fait aux Indiens, 326. Les fuites, qu'elle eut, 327. La même chofe arrive une feconde fois, \& elle a les mêmes fuites, 4r2. 413. Vengeance tirée des Habitans de cette Province, 414. Las Caías y va faire un Etabliffement, 4) 6 . Les Efpagnols en font chaffés, 418 . Ils y retournent; vengeance, qu'ils tirent des InTom. I. .

diens,
Curaçao, Ifle. Sa fituation, 422. Jean d'Ampuez s'en empare, $\&$ le Gouvernement lui en refte,

Cuzco, Las Cafas réfure l'Evêché de cette Ville,

439.

\section{D} Anfes des Infulaires de
l'Efpagnole 39.

Darien, Riviere, fa ficuation. Colonie établie fur fes bords, 299. Province du Darien, voyés la Caftille d'Or.

Davila. Voyés Pedrarias. Alphorise Davila, un des Capitaines de Grijalva, eft attaqué par les Indiens, $38 \mathrm{I}$. Il commande un Navire de la Flotte de Cortez, 389. Eft nommé Regidor du Confeil de la Vera-Cruz,

390. Alphonfe Davila, Habitant de l'ifle Efpagnole. Son fentiment fur les moyens de finir la guerre des Indiens, $\quad 463$.

Le Licencié Gilles Gonzalez Davila eft envoyé en qualité de Vifiteur Royal, pour gouverner l'Ifle Efpagnole, 475 .

N. Davila envoyé à SanDomingo Commiffaire, 270. Declinaifon de l'aiguille aimentée, premiere obfervation, qui en fut faite,

$8 \mathrm{I}$.

Demarcation. Ligne de Demarcation, ce que c'eft, Iro. Demoifelles qui accompagnent la Vice-Reine à l'Ifle Erpagnole。 Sfi 


\section{T A B L E}

274. Elles s'y marient, \& la policent,

275 .

Demon. Le Demon préfidoit d'une maniere fenfible aux fuperftitions des Infulaires de l'Ifle Efpagnole, 53. Il fe faifoit voir à eux, 54 .

Denys. Le Frere Denys Francifquain, tué par les Indiens, 419. 'Départemens, ce que c'eft, différens noms, qu'on leur a donnés, leur origine 185 . Ils font établis dans l'Ifle Efpagnole, 228. Les Seigneurs de la Cour en obtiennent, 266. Ils font infoutenables, 456. Voyés Las Cafas, Montefino, Indiens.

Defirade. La Defirade, une des petites Antilles, fa découverte, origine de ce nom,

I 14.

Deza. D. Diego de Deza, Archevêque de Seville eft d'avis qu'on tienne à Chriftophle Colomb tout ce qu'on lui a promis, 258. Il donne à Las Cafas des Lettres de recommandation pour le Roi , 314. Le Docteur Pierre de Deza, parent du precedent, eft défigné Archevêque de Xaragua 309. Eft nommé à l'Evêché de la Conception, 3 ro. Diaz. Michel Diaz découvre les Mines de S. Chriftophle, 138. 139. Son avanture avec une Dame Indienne, 144 . \& fuiv. Refufe de livrer à Bovadilla la Fortereffe de SanDomingo, I95. Eft fait Lieurenant du Gouverneur de Por\&oric, 279. Eft envoyé prifon- nier en Efpagne, la mêmic. Eft rétabli dans fa Charge, $32 \mathrm{I}$.

Dicux des Infulaires de l'Efpagnole,

Dienx des Efpagnols felon un Cacique Indien, 316.317 .

Dominique. La Dominique, une des petites Antilles, fa découverte, pourquoi elle eft ainfi nommée,

I 4 .

Dominiquains, les PP. Dominiquains arrivent à l'Ifle Efpagnole. Leur zéle \& l'aufterité de leurvie, 283.289. Ils fe récrient inutilement contre un Reglement défavantageux aux Indiens, . 31 I. 333. Ils s'établiffent à la Côte de Cumana, 409. Voyés le P. Pierre de Cordonë. L'Empereur Charles-Quint fe décharge duTraittement desIndiens fur leursSuperieurs ', 426. Voyés Francifquains.

Dorades, forte de Poiffon, qui donne la chaffe aux Bonites, $2 \mathbf{r}$.

Drago. Bocadel Drago, fa fituation, origine de ce nom, 167 . Drak, François Drak, Capitaine Anglois, prend \& pille San-Domingo, $480.48 \mathrm{I}$.

Duero. André Duero, Secretaire de Velafquez, l'engage à mettre Cortez à la tête de fon expedition de la nouvelle EFpagne,

383 .

$\mathrm{E}$

$25 \pi \%$
Clipse,
Ecosse, un Pere Francif- 


\section{DES M A T I E R E}

paffe aux Indes,

Ecreniffe de Mer,

342. Escovedo,
Ecu. Port de l'Ecu. Son premier nom,

Elephans, il n'y en a point dans le Nouveau Monde,

69. Encifo, un des Capitaines d'Ojeda, eft envoyé chercher du fecours à l'Ifle Efpagnole, 291. Il oblige Pizarre \& la Colonie d'Ojeda de retourner à S. Sebaftien, 297. Il gagne une bataille contre les Indiens de Darien, il y bâtit une ville, faute qu'il fit en cela, 300. Il défend mal à propos la Traitte de l'Or; il eft dépouiillé du Commandement, 3or. Balboa lui fait faire fon procès, 327. Il part pour l'Efpagne, 428. Il y agit efficacement contre Balboa, 430. Il eft fait Alguazil-Mayor de la Province du Darien, 434. Epinard Sauvage, Legume de l'Ifle Erpagnole, so. Efcalanté. Fean de Efcalanté, un des Commandans de Navire de la Flotte de Cortez , 389. Il eft fait Alguazil-Mayor de la nouvelle Efpagne,

Efcobar. Diego de Efcobar, Commandant du Fort de la Magdeleine fe range du parti des Rébelles, 155. 174. Il eft envoyé à la Jamaïque avec une Lettre \& un Préfent pour l'Amiral Chriftophle Colomb, 252. Il conduit à la guerre du Higuey les Milices de la Conception. 263.
Efcovedo. Rodrigue Efcovedo, Notaire Royale fur l'EFcadre, qui fit la découverte du Nouveau Monde, 86. Espagnols. Ils ont apporté dans l'Europe le mal de Naples, 43. 44. Leurs plaintes contre Americ Vefpuce, 187. Extrême averfion que les Indiens ont d'eux.-318. Voyés Caftillans. Ifle Espagnole. Ses differens noms, fa fituation, fa defcription, 4. \& fuiv. Origine de ce nom, 92. Sources de fa décadence, $395 \cdot 396$. Ce qui la fait déferter, $40 \mathrm{I} .44 \mathrm{I}$. 443. 457. Ce quil la fait entierement tomber, $48 \mathrm{I}$.

Nouvelle Efpagne, fa découverte, d'où vient cenom, 375 . Voyés Cortez.

Efpinar. Le P. Alphonfe de Efpinar, Francifquain, porte en Efpagne la Lettre des Offciers Royaux contre les Dominiquains ,

Efpinofa. Fean de Efpinofa eft fait Alcaïde Major de la Province de Darien, 434. Il fait le Procès à Balboa, 437. Il eff chargé de bâtir la Ville de $\mathrm{Pa}$ nama, 438 . Il eft envoyé Prefident à San-Domingo, 442.

Fean de Espinofa. Sergent. Bovadilla lui configne les Prifonniers, qu'il trouve dans la Fortereffe de San-Domingo, I95.

Efquibel. Fean de Efquibel eft chargé de la guerre du Higuey, Sff ij 


\section{T A B L E}

220. Il oblige les Ennemis à quitter la Campagne. Il accorde la Paix à leur Cacique.Il bâtit une Fortereffe dans le Pays, 22 r. Il eft de nouveau chargé de leur faire la guerre, $\&$ les défait, 263. Il eft envoyé à la Jamaique pour y faire un Etabliffement, 285 . Bravades d'Ojeda à fon occafion, la même. Comment il s'en venge,

295.

Evêchés. Fondation des Evêchés dans l'Ifle Efpagnole, 309.

\section{I}

If Aifans, dans l'Ine Efpagno-
29. Famine, 120. 124. 135.172. Eemmes, pluralité des Femmes dans l'Ifle Efpagnole, 45. Femmes enfevelies toutes vivantes avec leurs Maris. Elles heritent de leurs Freres , 49. Origine des Femmes fuivant les Infulaires de l'Efpagnole, 60 .

IEerdinand, Roi Catholique. Ses ombrages contre Chriftophle Colomb ; la populace de Grenade fe mutine contre lui, $\mathbf{I} 90$. Il eft peu favorable à Colomb, 202. 204. Lettres, qu'il lui écrit, 213. Les Indes lui reftent en propre. Il refufe de rendre juftice à Colomb, 258. Il accorde des. Départemens d'Indiens aux Seigneurs de la Cour, 266. Il s'oppofe aux pourfuites de l'Amiral Dom
Diegue, 270. Il fait des Reglemens pernicieux aux Indiens 3,II. Il reconnoît qu'on l'a trompé, $3 \mathrm{I}_{j}$. Sa mort, 334. Il envoye un Gouverneur à la Province de Darien, 433.

Ferdinand o I I abelle, leur Traitté avec Chriftophle Colomb, 77. 78. Honneurs, qu'ils lui font, 106. 108. 109. Ils demandent au Pape la proprieté des Indes, r09. I Io. Ils renouvellent les donations, qu'ils ont faites à Chriftophle Colomb, III. Reception, qu'ils lui font, lorfqu'il arrive enchaîné en Efpagne, 202. Les Inftructions qu'ils donnent à Ovando , 208. \& fuiv。 Ferdinandine, nom donné à l'Ifle de Cuba, $\quad 3.8$. Fernambouc, opinion fur la découverte de cette Côte, 69 . Eernandine:, Ifle des Lucayes; 88.

Fen. Maniere de faire le feu dans l'Ifle Efpagnole, 48. Eeüillée. Le.P. Feinillée, Minime. Ses Obfervations à la Caye $S$. Louiis,

Figneroa. Le P. Lonis de Figua roa, Jeronimite eft envoyé Commiffaire aux Indes, 336. Il eft nommé. Evêque de la Conception, \& Prefident de l'Audience Royale de SanDomingo, 425 . Sa mort, 426 。 Le Licencié Rodrigue de Figueroa envoyé Commandant à I'Ifle Efpagnole; il arrive 


\section{E S M A T I E R E.}

San-Domingo, 35 r. Son avarice, on lui fait fon Procès, 408.

Fiefchi. Barthelemi Fiefchi, Gentilhomme Genois, paffe en Canot de la Jamaïque à l'Inle Efpagnole, 246.

Elamand, forte de Fourmi de l'Inle Efpagnole, Flamand, Oifeau de l'ifle Efpagnole, Flamand, Naufrage d'un Capitaine Flamand, 296. Flamands, les Seigneurs Flamands obtiennent des Départemens d'Indiens, 346. Is font d'avis qu'on carfe les Départemens, 348. Ils favorifent Las Cafas, 357.358.

Fléches. Baye des Fléches. Sa fituation, origine de ce nom, Ior.

Flora. Antoine Flora, Alcaide Major de Cubagua, fa lâcheté, 419. Floride, fa découverte, 323 , $\mathrm{Ce}$ qui y arrive à François Fernandez de Cordouë, 370. Expedition de Luc Vafquez d'Ayllon dans la Floride, 410. Pamphille de Narvaés y va faire un Etabliffement, 443 . Floridiens font Anthropophages, 38. 411 .

Fonfeca. Antoine de Fonfeca, fon difcours à Ovando, 210 . Fonfeca. D. Fean Rodrigue de Fonjeca. Il eft chargé des Armemens des Indes, 144 . Il eft nommé à l'Evêché de Badajoz, il eft Rappelléàla Cour, $16 \mathbf{r}$.
Il eft foupçonné d'appuyer les Révoltés contre les Colombs, 180 . Infidelité, qu'il fait à Chriftophle Colomb, I 86. H eft fait Evêque de Cordouë, 20I. Il paffe à l'Evêché de Palencia, il fe broüille avec $\mathrm{O}$ vando, 272. Source de fa haine contre les Colombs, 285. 286. Il reçoit mal Las Cafas, 335 . Il paffe à l'Evêché de Burgos, on lui ôte fon Département d'Indiens, 337. II eft du Confeil des Indes, 347 . Las Cafas ne peut le gagner, 353. Sa réponfe aux Prédicateurs du Roy, 355 . Il eft recufé par Las Cafas, $35^{6}$. Il eft favorable à Velafquez, 386. 392. Il favorife $\mathrm{Las} \mathrm{Ca}$ fas, 412. Il fait nommer $\mathrm{Pe}$ drarias Gouverneur de la $\mathrm{Ca}$ tille d'Or,

Mayor de Fonfeca, Niece du précedent, deftinée en $\mathrm{ma}$ riage à Velafquez, $\quad 386$.

Fontaine de Cubagua, 277.

Eontaine de fouvence, 322.

Fontes d'Or dans l'Ine Efpagnole, 263 .

Fourmis, ravage, qu'elles font dansl'ifle Efpagnole, \& dans celle de Portoric, 350.

Fourmisblanches, autrement appellée Poux de Bois, ravage, qu'elles font dans les Ifles,

35.

Fraîcheur des nuits dans l'Ifle Efpagnole,

Francifquains, Chriftophle Colomb demande de ces Relis. SIf iij 


\section{T A B L E}

gieux pourles Indes, $14 \mathrm{r}$. Ils font les premiers Religieux établis dans le Nouveau monde, 210 . Ils font chargés d'élever de jeunes Indiens, 229. Ils font favorables aux Départemens, 313. Quatorze de ces Religieux venus de Picardie, paffent aux Indes, 342. Experience, qu'ils font pour faire mourir les Fourmis, 35r. Un P. Francifquain fe déclare à la Cour contre les Départemens, 360. Son difcours devant l'Empereur 363. Francifquains établis à la Côte de Cumana, 409. Leur Superieur eft chargé de ce qui regarde le traittement des Indiens, 426 .

Erançois. Des Corfaires François commencent à fréquenter les Mers des Indes, 407.

Erczier. M. Frezier Ingenieur du Roi, fes obfervations, 5 . Froid extraordinaire fous la Zone

Torride, 165 . Fronk. Ce que c'eft, $24 \mathrm{I}$. Fuente. Le Docteur de la Fuente, fon difcours aux Miniftres d'E. tat 2

355.

\section{G}

CAlera. Le Cap de la GaII lera, $\quad 164$. Galere, Infecte de Mer, Sa defcription, 29. Galleza, Nont de la Capitane, fur laquelle Chriftophle Co. lomb découvrit le Nouveau Monde , 80. Elle échouë \& fe brife, 24. Gamiz. Pierre de Gamiz, un des Chefs de la Révolte de l'Alcaide Major, 174. Il efcorte Carvajal à la Capitale, 175 .

Gange. Chriftophle Colomb fe croit près de ce Fleuve, 230. Garay. François de Garay découvre les. Mines de SaintChriftophle, I38. Il trouve un grain d'Or extraordinaire 206.

Garcez. Le P. Fean Garcez Dominiquain, eft envoyé à la Côte de Cumana, 326. Danger où il fe trouve, 327. I1 eft maffacré par les Indiens, 328.

Garnica. Gaspard de Garnica, il eft envoyé à la Havane, \& pourquoi, 389.

Gâteaux préfentés aux Idoles par les Infulaires de l'Efpagnole 。 56.

Gatinara. Le Grand Chancelier Gatinara. Las Cafas s'adreffe à lui, pour obtenir l'execution de fon projet, 353. Il affifte à un grand Confeil tenu devant l'Empereur pour la caufe des Indiens. Ce qu'il dit à l'Evêque de Terre-Ferme, 360 .

Gayac. Bois de Gayac, à quoi il eft bon,

Genes. La République de Genes refufe d'entrer dans le projet de Chriftophle Colomb, 70. Genois entreprennent la Traitte des Negres dans l'IfleEfpagnole, elle ne leur réuffit pas, 327 . 


\section{E S M A T I E R S.}

Gorges de Portugal, Comte de Gelves, époufe Ifabelle Colomb, heritiere de cette Maifon, les Titres, qu'il prend, 443 . Ginez, Capitaine Efpagnol, ce qui lui arrive à l'Ifle de Portoric,

44. 404 .

Globe peint trouvé à San-Domingo .

$48 \mathrm{r}$.

Goacanaric, Roi de Marien, 6r.

II invite Chriftophle Colomb à le venir voir, 94. Ses bons fervices dans le naufrage de la Gallega, 95. 96. Réception qu'il fait à l'Amiral , 97. Continuation de fes bonnes manieres, 98. 99. Il envoye fon Frere à l'Amiral, I 6 . Il eft fufpect aux Efpagnols, 117 . L'Amiral lui rend vifite, \& en eft bien reçû, II 8 . Il mene des Troupes aux fecours des Efpagnols : 132. Il fe rend Tributaire de la Couronne de Caftille. Mauvaifes manieres des Efpagnols à fon égard, fa mort. On l'accufe des plus honteux excès,

I34.

Gabava, Ville de l'Ifle Efpagnole,

$25^{6}$

Gomez. Alexis Gomez, fon combat contre un Indien, 264 . Gonaives, Etang des Gonaives, 25.

Gonzalez. Alphonse Gonzalez, Ecclefiaftique, ce qu'il trouve dans un Temple de l'Yucatan, 367.

Gonzalez, Capitaine Indien eft envoyé par D. Henri ̀̀ San-Domingo, 467.
De quelle maniere il s'y conduit, 468.

Gilles Gonzalez, Cacique Indien, il eft attiré par un $\mathrm{Na}$ vire Efpagnol, à quel deffein, \& pourquoi. Il eft tué en combattant,

415.

Gofchi, Quadrupede de lifle Efpagnole,

35.36 .

Gofier. Grands Gofiers forte d'Oifeaux, 30.

Gracia, Puerto di Gracia. Sa fituation. Origine de ce nom, 100.

Terre de Gracia, fa fituation,

166

Gracias à Dios, Cap, pourquoi il eft ainfi nommé,

Grain d'Or. Voyés Garay.

Grange. La Grange, Montagne, fa fituation,

99.

Grijalva. Fean de Grijalva eft nommé Commandant de l'EScadre deftinée à pourfuivre les Découverte de l'Yucatan: défenfe, quilui eft faite, $37 \mathrm{I}$. Son caractere, la même. Son départ \& fes Découvertes, 372. \& Suiv. Il eft bleflé, 274. Ce qui lui arrive dans la Riviere de Tabafco, 375. \& fuiv. Continuation de fes Découvertes, \& pourquoi il ne fait point d'Etabliffement dans la nouvelle Efpagne, 378 . \& $\int$. Il en prend polfeffion, 376 . 379. Il envoye demander permiffion à Velafquez de faire un Etabliffement, 380. Il retourne à l'Ifle de Cuba, Reception, que lui Velafquez, 382. La voix publique le de- 


\section{T A B L E}

mande pour Capitaine Gene- Guerra. Chriftophle Guerra mairal de la Flotte, deftinée à la conquête de la nouvelle Efpagne,

383.

Guadeloupe, une des petites Antilles, fa découverte. Origine de ce nom, I I 4. Ce qui y arrive à Chriftophle Colomb, I39. I40. Un Efpagnol, qui vouloit y enlever des Caraibes, y eft repouffé avec perte, 187.

Guababa. Larez de Guababa, Ville de l'inle Efpagnole, 236. Elle eft détruite, 309, Guanabani, la premiere découverte de Chriftophle Colomb, 87.

Guanaja, Ifie de la Province de Honduras,

Guanajos, Peuples de la Province de Honduras, 237. Guanin, forte de métal, $\quad 162$. Guaric, les Efpagnols nomment ainfi le Cap François, \& pourquoi,

$6 \mathrm{x}$.

Guarionex, Roi de Magua ; il fe défend quelque têms de payer Tribut à la Couronne de $\mathrm{Ca}$ ftille, \& s'y foumet enfin, 134. Ses Sujets l'obligent à prendre les armes de nouveau; il eft pris, \& mis en liberté à la priere de fes Sujets, I5O. Il fe retire chés les Cyguayos. La maniere dont il y eft reçû , I 57 . Il eft livré aux Épagnols, 160. Il eft embarqué pour 'Éfpagne, \& périt en chemin. Pourquoi il ne fe fit pas Chréien.

214.

289.

Guevara. D. Fernand de Gueva$r a$, un des Chefs de la confpiration contre l'Alcaïde Major, eft condamné à être pendu, \& délivré par Bovadilla, 195. Il eft bien traité par le même Bovadilla,

199.20r。

Guichardin, ce qu'il dit de l'origine du mal de Naples, 44.

Guzman. D. Gonzalez de Guz.man, eft envoyé en Efpagne par Velafquez, 386. Il eft Gouverneur de Cuba, \& donné pour Adjoint aux Evêques de San-Domingo \& de SantYago, pour ce qui regarde les Indiens,

445 .

Guttierez. Pierre Guttierez. Chriftophle Colomb lui montre la terre, qu'il venoit de découvrir,

84.

\section{H}

TI Acha. Rio de la Hacha: des Perles, 277. Hayti, Nom Indien de l'Ifle Efpagnole, 4. Les premieres connoiffances qu'en eût ChriAtophle Colomb,

Hamach, ce que c'eft. Origine de ce mot.

53.

Hanegua, mefure de Bled, I 4 r. Hatuey, Cacique de l'Ifle de Cuba, d'où il étoit originaire, 3 I6. A vis qu'il donne aux autres Caciques touchant le Dieu des Efpagnols, 316.317. Il s'oppole 


\section{DES MA T I R E S.}

's'oppofe à la defcente des Efpagnols, \& il eft pris \& condamné à être brûlé , 317. Pourquoi il ne veut pas être Chrétien,

3 I 8 .

Hattibonite. Voyés Artibonite. Havane. Ville \& Port de l'Ifle de Cuba, ce qui a donné occafion de l'établir, 324. Velafquez y envoye ordre d'arrêter Cortez , 388. Fertilité de fon terroir.

Hayna, Riviere de l'Ille Efpagnole, fa fituation, 223.

Henry de Portugal, Comte de Vifeo, conte qu'on fait à fon fujet, \& au fujet de l'Ifle Antille, 4. C'eft lui, à qui l'on doit les premiers efforts des Européens pour les nouvelles Découvertes, Henry. Cacique de l'Ifle Erpagnole. Elevé chés les PP. de $S$. François, puis réduit à l'efclavage, 396. Il eft maltraité de fon Maître, \& n'en peut avoir juftice, 397. Il fe cantonne dans les Montagnes du Baoruco, \& y remporte plufieurs avantages contre les Efpagnols , 397. 398. Sa moderation, 399. Sa bonne conduite, fa vigilance, 400 . Ce qui fe paffe entre lui $\&$ un Pere Francifquain, $40 \mathrm{I}$. 402. 403. Il n'eft pas tô̂jours obeíi de fes gens, 446 . Ce qui fe paffe entrelui \& le fieur de S. Michel, 447. Ses Troupes font confiderablement groffies, $46 x$. Il envoye faiTome $I$ 。 re des Complimens au Commiffaire de l'Empereur, 466. Son entrevûë avec ce Commiflaire, \& ce qui s'y paffe, 468. Il reçoit une Lettre de lEmpereur, 469. Son Traité avec les Efpagnols, 470. Ses défiances, 470. 47 $\mathrm{I}$. Elles font levées, \& la paix fe publie, 472. Ce qui fe paffe entre lui \& le P. Barthelemy de Las Cafas, 373. 474. II arrive à San-Domingo, \& y ratifie le Traité. Il eft déclaré Prince de fa Nation, \& s'établit à Boya avec ce qui refte d'Infulaires de l'Efpagnole , 475 .

Heredia, eft chargé de bâtir la Ville de Carthagene, 443 . Heriffons, Sorte de Poifron de Mer,qui fe trouve fur les Côtes del'Inle Efpagnole, 24 .

Fxerons. Voyés Aigrettes.

Herrera. Antoine Herrera, Hiftorien célébre. Son opinion fur l'origine du nom des Antilles, 3. Hiftoire qu'il raconte d'un Lamentin , 26. II s'efforce envain de juftifier le procedé d'Ovando envers Chriftophle Colomb, 253 . Et pour prouver que la petite Verole étoit naturelle aux Peuples de l'Amérique, 349. Son exaggeration fur la quantité de Sucre, qui fe faifoit dans la Vega Real, 450. Ce qu'il a écrit au fujet de la rupture, entre Velafquez \& Cortez, 387. Il rend juftice à D. Bar: It 


\section{T A B L E}

thelemy de Las Cafas, 421 : Herrera, Habitant de l'If. le Efpagnole. Engage Bafurto à un grand armement, pour un Etabliffement vers le Lac Nicaragua, 439. Hefperides. Oviedo croit que les Antilles font les Hefperides des Anciens, 68. Higuey, Province Orientale de I'Ifle Efpagnole, 62. Premiere guerre dans cette Province, 220. \& fuiv. Seconde guerre, 262. So fuiv.

Hirondelles, de l'Ifle Efpagnole, femblables aux nôtres, 28. Hifpaniola, Nom Latin de l'Ifle Efpagnole, 92. Hyguanama, Reine de l'Ifle Efpagnole,

63.

Honduras, découverte, \& $\mathrm{fi}_{1}$ tuation de cette Province, 258.

Hofpitalité. Jufqu'à quel point elle eft pratiquée par les Infulaires de l'Efpagnole, 49. 'Humidite', caufes de l'humidité dans l'Ifle Efpagnole, \& fes pernicieux effets,

IO.

\section{I}

T.

Amaïca ou famaïque, une des grandes Antilles. Sa découverte, I25. A quelle occafion les Efpagnols s'y font établis, 283.284 .285 . Femme de la Jamaïque, dans l'Ifle de Cozumel,

Zean. D. Fean II. Roi de Portugal, Chriftophle Colomb s'a- dreffe à-lui pour fon projet 70. Réception qu'il lui fait au retour de la découverte da Nouveau Monde, 104. ro5.

D. Fean d'Arragon, Prince hereditaire d'Efpagne, II2. Sa mort, 161 . Le P. Fean, Religieux de Saint François, prêche la Foi dans les Etats de Guarionex. I5O.

Feanne d'Arragon, fon mariage avec l'Archiduc d'Autriche, I4O. Elle arrive en Efpagne,

259.

Feronymites. Quatre Peres Jeronymites font envoyés Commiffaires aux Indes, 336. Leurs inftructions, $337^{\circ}$ o fuiv. Ils arrivent à San-Domingo, 342。 Las Cafas fe brouille avec eux, 343. Pourquoi ils ne touchent point aux Départemens, 344. Ce qu'on leur reprocheà cette occafion, $345^{\circ}$ Ils font rappellés, 347 . Ils changent de conduite 349 . Ils repaffent en Efpagne, \& ne peuvent obtenir une $\mathrm{Au}^{-}$ dience du Roi 352. Avantages, qu'ils procurent à l'Ifle Efpagnole par la fabrique du Sucre , 407. Avis qu'ils donnent à Pedrarias,

437. Igniame, forte de Plante, I5r. Iguana ou Ivana, Amphibie, fa defcription, 27.

Immortalité, ce qu'en penfoient les Infulaires de l'Épagnole , 59.

Indiens. Defcriptions, caracteres, 


\section{E S M A T E R E .}

M̋ours, Coûtumes, Gouvernement, Religion des Infulaires de l'Espagnole, 36. \& fuiv. Pourquoi ils font nommés Indiens, I 06. Des Infulaires de l'Épagnole ornent le Triomphe de Chriftophle Colomb, ro7. Bâtême des premiers Indiens, II 2. Ils font vexés par les Efpagnols, leur défefpoir, \& les fuites qu'il eut, 135. Ils ne veulent plus travailler pour nourrir les Efpagnols, r49. La Reine de Caftille trouve mauvais qu'on les faffe efclaves, I 6r. Ce qui re paffe entre les Efpagnols \& les Indiens de la Côte de $\mathrm{Pa}-$ ra, I65. Les Infulaires de l'Efpagnole font réduits en efclavage, 205. Attention de la Cour pour leur converfion, 209. Ils font déclarés libres, $\&$ ne veulent plus travailler aux Mines, 2 I r. On les y oblige en les payant, 217. Belle action d'un Indien, qui fe bat contre deux Efpagnols, 22I. Les Indiens du Higuey font défaits, 22I. 222. Mefures, que prend la Cour pour . les policer, 230. Horrible maffacre des Indiens de Xaragua, 254. Indiens du Continent, 240. Les Infulaires de la Jamaique croient les Efpagnols immortels, 255. Déferpoir des Indiens du Higuey, 263.264 . Les Infulaires font plus maltraitté que jamais, 265 . Comment ceux de Portoric s'affurrent que les Efpagnols ne font pas immortels, 280 . $28 \mathrm{r}$. Ce qui les porte à fe foûmetre à eux, 282. Les PP. Dominiquains entreprennent de convertir les Infulaires de I'Efpagnole, \& y réuffi fent, 288. Indiens de Carthagene. Voyés Ojeda, 289. Ils font défaits, 291. Indiens de Saint Sebaftien, la même. On examine au Confeil la maniere, dont on doit traitter les Indiens, 313.314 . Ordonnances en leur faveur fans effet, 3 I 5 . Indiens enlevés à la $\mathrm{Co}^{-}$ te de Cumana, 327. Les autres s'en vengent fur les Miffionnaires Dominiquains, 328 . On veut empêcher les Miffionnaires d'inftruire les Infulaires de l'Efpagnole, 329. Ils fe convertiffent, 330. On permet les mariages des Efpagnols avec les Indiennes, 333 . Sous quel prétexte on prétend qu'ils doivent demeurer dans l'Efclavage, 344. La petite Verole en fait mourir un grand nombre, 349. Leur Caufe eft plaidée de nouveau, 259. \& fuiv. Indiens de 1'Yucatan, 367. Indiens fujets à l'yvrognerie, 417. On examine de nouveau, s'il faut les rendre libres, ou les retenir efclaves, 454. Déliberation prife à ce fujet, fans effet, 456. Nouvelles difputes à leur fujet, Fourdain, Fleuve de la Floride T t t ij 


\section{T A B L E}

$S_{a}$ découverte, d'où vient ce nom, 408. Son premier nom, $4 \mathrm{IO}$.

Fouvence, Fontaine de Jouvence,

322. So fuiv. Ifabelle Reine de Caftille. Ce qu'elle dit au fujet du peu de profondeur des racines des arbres dans l'Ifle Efpagnole, I6. Elle accepte les conditions propofées par Chriftophle Colomb , 76. Les dépenfes qu'elle fait-pour les Indes, Ir3. Elle trouve mauvais qu'on réduife les Indiens en fervitude, 133. Elle veut que les feuls Sujets de la Couronne de Caftille paffent aux Indes, 143. Elle s'irrite contre Chriftophle Colomb, \& le rappelle, pourquoi, I9I. Elle lui donne une Audience particuliere, \& ce qu'elle lui dit, 202. \& fuiv. Elle fe confirme dans la penfée de n'envoyer aux Indes que fes propres Sujets, 208. Sa mort \& fon caractere, 257. \& fuiv. Ses ordres pour I'éducation des jeunes Caciques, 396. Voyés Ferdinand Jjabelle.

Ifabelle, une des Ifles Lucayes, 88. Ifabelle, premiere Ville bârie dans le Nouveau Monde. Sa fituation, I20. On y étaBlit un Confeil, 125. On la trouve mal placée, 144. Grande difette \& grande mortalité dans cette Ville, 149. Sa décadence,
Fuana, Nom donné à l'Tíle de Cuba, par Chriftophle Colomb,

Ivana. Voyés Iguana.

Incatan. Voyés Yucatan.

Inifs, Ils font exclus du Nouveau Monde, 209. 213 。

Fules II. Souverain. Pontife. Il confent à l'érection de quelques Evêchés dans le Nouveau Monde,

309.

fulien. Indien de l'Yucatan, $a$ mené à l'Ifle de Cuba, 368 . If fert d'Interprete à Grijalva 。 376.

Funte extraordinaire pour examiner la Caufe des Indiens 。 356.

T Impech. Voyés Campea I

T. Abat. Le P. Labat, Dominiquain, ce qu'il dit $d u$ grand gofier, 30. Du Colibry 32. Et de l'origine du mot de

Tabac,
Laboureurs. Voyés Las Cafas, 346.353.

Lachaux. $M$. de Lachaux, un des Protecteurs du Licencié de Las Cafas, qui lui communique fon projet d'Etabliffement à la Terre Ferme de l'Amérique, 354.364 . Lacs de l'Ifle Efpagnole, 18. or Juiv. 


\section{DES M A T I R E S.}

Eambis, forte de Coquillage, qui fe trouve fur les rivages de l'Ifle Efpagnole,

$2 \mathrm{I}$.

Zamentin, Defcription de cet animal, 24. 25. Hiftoire d'un Lamentin apprivoifé, 25:26. Chriftophle Colomb le prend pour la Syrene des Anciens, I08.

Langage des Infulaires de l'EFpagnols ,

53.

Lapa, Cap de Lapa. Sa fituation,

Larez. Voyés Guababa.

Lariz. Amador de Lariz, Thréforier Royal dans l'Ifle de Cuba; il engage Velafquez à nommer Cortez , Capitaine General de la Flotte, deftinée à la Conquête de la Nouvelle Efpagne,

Limaçon de Mer, dans les Mers des Antilles,

$2 \mathrm{r}$.

Lebron. Le Licencié Lebron, Diftributeur des Negres dans l'Ifle Efpagnole,

Ledefma. Pierre de Ledefma, Pilote Efpagnol, action hardie, qu'il fait pour fauver Chriftophle \& Barthelemy Colomb d'un grand danger, 245 .

Lemery, Erreur de M. de Lemery fur l'origine du mot de Petun,

$4 \mathrm{I}$.

Leogane, 235. Voyés

Leon. Fean Ponce de Leon, $\mathrm{Ca}_{\mathrm{a}}$ pitaine Efpagnol, mene les Milices de San-Domingo à la guerre du Higuey; 267. Il paffe dans l'Ifle de Portoric, il $y$ eft bien reçû, il en eft fait
Gouverneur, 278. 279. Il y fait la guerre avec fuccès, $28 \mathrm{r}$. Il court après la Fontaine de Jouvence, 321. 322. Il découvre la Floride , 323. Il retourne à l'Ine de Portoric , 324. Il ne fait aucun Etabliffement à la Floride, 410. Lepre, Maladie commune à SanDomingo ,

Linotte, Oifeau de l'Ifle Efpagnole, 30.

Lions, communs dans la Coriane; mais il n'y font point de mal,

Locuyos, ou, Mouches luifantes. Defcription de cet Ani$\mathrm{mal}$; 32. 33 .

Louy Je. La Baye du Can dé Louyfe, ou l'Acul,

Lucayes. Ifles Lucayes, leur fituation, 6. D'où vient ce nom 。 87.

Lucayes, Habitans des Lucayes, 87. On les enleve pour les mener à l'Ifle Efpagnole, comment, \& avec quel fuccès, 268.269 . On s'en fert avec fuccès pour la Pêche des Perles, 276.

Lucques. Fernand de Lucques . Ecolatre de l'Eglife de Sain. te Marie l'Ancienne. Sa fo cieté avec Pizarre \& Almagre, pour la découverte du Perou. Comment il la cimente, 440. Lumbreros. Pierre de Lumbreros, fon courage pour découvrir un Lac, 19. Lune, effet de fa clarté fous la T. t $\mathrm{iij}$ 


\section{TA B L E}

Zone Torride,
Luxan. Fean de Luxan, Con- Mameys, Abricots de S. Do.

Zone Torride, I2. M l'Ine Efpagnole,
Luxan. Fean de Luxan, Con- Mameys, Abricots de S. Do. feiller du Confeil d'Ifabeile, 125.

\section{M}

M Acana, forte d'Armes des Infulaires de l'Efpa-

gnole,
Macoris, Riviere de l'Inle Efpagnole, fa fituation, 17. Magdeleine. La Magdeleine, Forterefle, I 55 . Magua, Royaume de l'Ille Efpagnole, $6 \mathrm{x}$. Maguana, Royaume de l'Ifle Efpagnole, 6r. Voyés SanInan, 62. 406. 'Majefté, La premiere fois, que ce

Titre fut donné au Roi d'Efpagne,

Majorada, Ville de l'Íle Elpagnole, Maifons des Infulaires de l'Ine

Efpagnole, leur defcription, 51.52.

Maïz, forte de Legumes de l'Amérique, 50. 51 . Mal de Naples, fon origine, \&

les divers noms, qu'on lui donne, 43.44. Malaber eft envoyé à Roldan, pour le faire rentrer dans fon devoir,

I55. Maldonade. Alphone Maldonade, eft nommé Alcaïde Major de l'Ifle Efpagnole, 208. Il fait mettre en prifon Chriftophle de Tapia,

273. MLalfenis, Oifeau de proye de mingue, imagination des Infulaires de l'Efpagnole fur ce fruit,

Manati. Voyés Lamentin, 25. Manauré, Cacique Indien de la Province de Venezuala. 11 s'allie avec les Efpagnols , 449. Les Allemands le mettent à la Torture, pour fçavoir où eft fon Or,

Mancia, Femme du Cacique Henry, 470. Manicatex, General de l'armée des Infulaires de l'Efpagnole, 133. Il fe foûmet aux Efpagnols, 134. Roldan fe retire chés lui, \& reçoit fon Tribut 。

$155^{\circ}$

Manioc, plante des Indes, $5 \mathbf{I}$. Le jus de fa racine eft un poifon très-préfent, $\quad 329$. Manuel. D. Fean Manuel, 356. Manzanedo. Le P. Bernardin de Manzanedo, Jeronymite, eft envoyé Commiffaire aux Indes, 336 . Il paffe en Efpagne, 345. Il fe retire à fon Couvent,

347.

Maracapana, Village de la Cố te de Cumana, I88.4I2. Maraguey, Cacique Indien qui fait maffacrer deux Religieux de S. Dominique,

Maravedis, Monnoye d'Efpgne, Marc-Paul de Venife, 70. Marchena. Le P. Fean Perez de Marchena, Francifquain, rend fervice à Chriftophle 


\section{E S M A I E R E S.}

Colomb ,

74. 80 . Marée de l'Ifle Efpagnole, 7 . Margarit. Le Commandour D. Pedro Margarit, Seigneur Catalan. Eft fait Commandant du Fort de Saint Thomas, 124. Il eft envoyé - pour faire des courfes fur les Terres de Caonabo, 125. Il reçoit ordre de vifiter toutes les Provinces de l'Ifle Efpagnole, I26. Belle action, \& mauvaife conduite de ce Commandant, 127. Il repaffe en Efpagne, 128. Il y invective contre les Colombs, 136. Marguerite, Ifle. Sa découverte, I69. Les Efpagnols de Cubagua s'y retirent 277. Etabliffement fait dans cette Ifle, 490.

Marie, Femme Indienne de la Côte de Cumana, fert d'Interprete à Las Cafas, 417. Marien, Royaume de l'Ifle Efgnole, $6 \mathrm{r}$. Marigalante, l'une des Antilles, Pourquoi elle eft ainfi nommée, 1 I 4 .

Marin, Lowis Marin, Offlcier Efpagnol, va joindre Fernand Cortez à la nouvelle Efpagne,

Martin. Benoît Martin, Chapelain de Velafquez, qui l'envoye en Efpagne, Martinique. Voyés Matinino. Martyr. D. Pierre Martyr d' Anglerie. Seigneur Milanois. Ecrit peu exactement fur le fujet des Indes, 4. Ce qu'il dit du Lac Xaragua, 18. Ce qu'il dit de la naiffance de Chriftophle 'Colomb , 64. Ce qui fait que fon authorité n'eft pas grande au fujet des Indes, II7. Il donne toûjours le tort aux Indiens, I3 r. Il eft du Confeil des Indes, 347. Martyrs, Ifles de la Floride, 323.

Matance, Baye \& Bourgade de l'Ifle de Cuba, 372. Matienço. Le P. de Matienço, Dominiquain, Confeffeur du Roi Ferdinand, rend fervice à Las Cafas, 334 . Matinino, une des Antilles, aujourd'hui la Martinique. On prétend qu'elle a peuplé l'Ifle Efpagnole, 4.214. Matteos. Fernand Perez Matteos, Pilote fous Chriftophle Colomb, 163 . Maures, ils font exclus des Indes, 209. 213.

Mayci, La Pointe de Mayci, dans l'Ifle de Cuba.

Mayobanex, Cacique des $\mathrm{Cy}$ guayos retire chés lui Guarionex, I57. Refufe l'amitié de Barthelemy Colomb, \& de lui remettre Guarionex, la même. Réponfe généreufe, qu'il fait à fes Sujets, I 58 .Il'eft pris \& pendu à San-Domingo, I 59. I 60. Medecins. Quels ils étoient, \& comment on les traittoit parmi les Infulaires de l'Efpagnole, 57.58.

Medina Celi, Les Duos de Medina Celi, \& de.Medina Sidonia. 


\section{T A B L E}

refufent d'écouter Chriftophle Colomb , Melchior, Indien de 1'Yucatan, mené à l'Ifle de Cuba, 368. Il fert d'Interprete à Grijalva, 376.

Mendez. Diego Mendez paffe en Canot de la Jamaïque à l'Ifle Efpagnole, 246. 247. Il ne peut rien obtenir du grand Commandeur, \& paffe en Efpagne,

Mendoza. Le Cardinal de Mendoza, Archevêque de Tolede, donne une Audience favorable à Chriftophle Colomb , 75 . Comment il le fait fervir à table, ro9.

Mer, Nature de la Mer des Antilles,

20. 21 . Mer du Sud. Sa découverte, 429. voyés Balboa.

Mefara, ou Mexia. Rodrigue de Mefcia eft envoyé pour découvrir un Lac, \& ne peut aller jufqu'au bout, $\mathbf{r}$. Il eft envoyé contre les Indiens, \& les défait, 235. Il eft chargé de plufieurs Etabliffemens, 236.

Le P. Pierre Mexia, Superieur General des Francifquains eft donné pour Adjoint aux Evêques de San-Dorningo, \& de Sant-Yago, pour. regler la maniere de traitter les Indiens,

Mexique. Voyés Nouvelle Ef pagne, Grijalva, \& Cortez. Mires. Mine d'Or, à la fource de l'Yaqué, 19. Mines de Ci- bao. Voyés Cibaō. Décortvertes des Mines de Saint Chriftophle, I38. I39. Mines de Cuivre près de Puerto Real, 267. Mines d'Argent:\& de Fer dans l'Ifle Efpagnole, $46 \mathrm{I}$.

Mini, Bourgade de l'Yucatan, comment les Efpagnols y font reçûs, \& ce qu'ils y apprennent,

37.5 .

Minieres del'Ifle Efpagnole, 20. Miffionnaires, On les empêche d'inftruire les Infulaires de l'Erpagnole de nos Myfteres 。 329. Leurs bons exemples convertiffent ces mêmes Infulaires,

330.

Mobuis, forte de Quadrupede de l'Ifle Efpagnole,

Moluques. Chriftophle Colom propofe de chercher un paffage par l'Amérique, pour aller aux Moluques, 204. Mombins, forte de Fruits de l'Ifle Efpagnole,

Mona La Mona, petite Ifle entre Portoric \& l'Ifle Efpagnole, 5. Le Roi Catholique en cede la proprieté à D. Barthelemy Colomb pour fa vie, $32 \mathrm{I}$. Les Anglois y débarquent, 405 . Montferrat, une des Antilles. Sa découverte, \& d'où lui vient ce nom,

I 14.

Montagnes d'une hauteur extraordinaire dans l'Ifle Efpagnole. 15. Monte.Crifto, Montagne, Riviere, Bourgade, 17.99. 475 . 


\section{DES M A T I E R E .}

Monte di Plata, Montagne de l'Ifle Efpagnole, d'où lui vient ce nom, 100. Bourgade, à quelle occafion elle fut bâtie, 482.

Montejo. François de Montejo, un des Capitaines de l'Efcadre de Grijalva, 37ז. Comment il eft reçû dans l'Yucatan, 374. Il entre dans le Kio de Banderas, \& y eft bien reçî, , 378. Il n'eft pas du fentiment qu'on s'établiffe dans la nouvelle Efpagne, 382. II commande un des Navires de la Flotte de Cortez, 389 . Il eft nommé Alcaide de la VeraCruz, 390. Il eft envoyé en Elpagne par Cortez, \& bien reçû de l'Empereur, 392. Il eft chargé de peupler l'Yuca$\tan$,

443.

Montefino. Le P. Antoine Montefino, Dominiquain. Prêche contre les Départemens à SanDomingo, \& ce qui en arrive, 3II. 3 I 2. Son Superieur l'envoye en Efpagne, où il plaide fa Caure avec fuccès, 313. 3 I4. 3 I 5 . Il s'embarque pour la Côte de Cumana, 325 . Il tombe malade à Portoric , 326 . Moralez. André de Moralez, Pilote Efpagnol. Son Serment, 188.

Moralez, Thréforier fort puiffant à la Cour. Les Révoltés de la Jamaique comptent fur fa protection, \& pourquoi, 249. Morla. François de Morla, un des Capitaines de la Flotte de

Tome $I$.
Cortez , 389.

Morne ronge, dans la plaine du Cap, on croit qu'il renferme une Mine de Cuivre, 267.

Mota. Le Docteur Mota, Evêque de Badajoz, ce qui fe paffe chés lui, 358 .

Motezuma, Empereur du Mexique eft informé de l'approche des Efpagnols, \& les ordres qu'il donne, 370 .

Mouches luifantes. Voyés Locuyos.

Monchoir quarré. Eceüil , 5. Voyés Abrojo.

Moules, $2 \mathrm{r}$ 。 Monfiques, préfervatif contre ces lnfectes, 32.

Moxica. Adrien de Moxica, un des principaux Officiers de la confpiration de Roldan, I74. L'Amiral lui écrit, 183. Il eft pendu, 190.

Mulets, fortes de Poiffons, qu'on pêche fur les Côtes de l'Iíle Efpagnole ,

$2 \mathrm{I}$.

\section{N}

T Arvaez. Pamphile de Nar1 vaez va chercher Ojeda à l'Ifle de Cuba, 295. Il fait à la Cour d'Éfpagne les affaires de Velafquez , 386. Velafquez le nomme General de fa Flotte contre Cortez, fa conduite à l'égard de $\mathrm{Vafquez,}$ 393. Il eft chargé de faire un Etabliffement dans la Floride, 443.

Navedad. La Naveáad', nom de la premiere Fortereffe, qui $\mathrm{Vu} u$ 


\section{T A B L E}

fut bâtie dans l'Ine Efpagnole, 97. Chriftophle Colomb à fon fon retour la trouve brûlée \& démolie, 1 I 5 . Comment cela s'étoit paffé,

117. Naufrage d'une Flotte Efpagnole chargée d'Or, 215 。 Negres. Le Grand Commandeur Ovando s'oppofe à ce qu'on envoye des Negres aux Indes, \& pourquoi, 229. On les introduit dans l'Ifle Efpagnole, 287. A quelle occafion, 288 . Las Cafas propofed'en envoyer par toutes les Indes, 346 . Le premier envoy des Negres ne réüfit point, \& pourquoi, 347. Les Negres défertent \& fe rangent auprès du Cacique Henry, 40r. On en demande un grand nombre à l'Empereur, 407. Ils fe multiplient dans l'Ílle Efpagnole, \& s'y révoltent, 422. Ils font défaits \& punis,

423.

Newport. Chriftophle Newport, prend \& pille Yaguana, $48 \mathrm{r}$.

Neyva, une des grandes $\mathrm{Ri}-$ vieres de l'Ifle Efpagnole, I 7 .

Nicaragua, entreprife pour s'établir fur les bords du Lac $\mathrm{Ni}$ caragua, 439. Voyés Pedrarias.

Nicayagua, un des noms de la Riviere Yaqué, 122.

Nicot. M. Nicot, Ambafladeur de France à Lisbonne, envoye à la Reine Mere la premiere Plante de Tabac, qui foit venuë dans ce Royaume, $4^{I}$ 。
Nicotiane, nom, qui fut donné au Tabac à caufe de $\mathrm{M}$. Nicot.

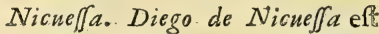
nommé Gouverneur de la $\mathrm{Caf}$ tille d'Or, 283.284 . Il enleve cent Caraibes à l'Ifle de Sainte Croix, 284. Réponfe qu'il fait à $\mathrm{O} j e d a$, qui lui propofoit de vuider leur différent par un Combat fingulier, la même. Il fecoure fort à propos le même Ojeda, 2.90。 29I. Il effuye une rude Tempête, \& les malheurs, dont elle fut fuivie, 302. \& Suiv。 On l'appelle pour gouverner la Colonie du Darien, \& fa mauvaife conduite, 305 . Il n'eft point reçî̀ à Sainte $\mathrm{Ma}$ rie, la même. On cherche à la tromper, \& on en vient à bout, 306. 307. Ce qu'il devint,

307.

Niña. La Niña, une des Caravelles, qui découvrirent le Nouveau Monde, 80 . Nizao, Riviere de l'Ifle Efpagnole, 19.

Nombre de Dios, Ville Efpagnole du Continent de l'Amérique. Découverte de l'endroit où elle $\mathrm{a}$ été bâtie, 215 Sa Fondation,

304.

Nords, nom qu'on donne à S. Domingue aux Vents forcés du Nords.

Norogna. D. Martin de Noro gna, reçoit ordre du Roi de Portugal de conduire Chriftophle Colomb jufqu'à Liso 


\section{E S M A T I E R E S.}

bonne,

I05.

Nortez. Ginez de Nortez, un des Capitaines de la Flotte de

Cortez,
Nourriture ordinaire des Infulaires de l'Épagnole, 50.5 I. Nugnez. Alphonfe Nugnez, un des Capitaines de Nicueffa, 303.

\section{O}

$\mathrm{O}$

$B$ feques des Infulaires de l'Épagnole, 45 . Ocampo. Gonzalez de Ocampo, eft chargé d'aller punir les Indiens de la Côte de Cumana, 4I3. De quelle maniere il s'y prend pour en venir à bout, $4 \mathrm{I} 4$. Il execute fes ordres, 415. Il commande l'Efcadre, qui porte Las Cafas au même endroit, $4 \mathrm{r} 6$. Il retourne, fans avoir rien fait, à l'Ifle Efpagnole, \& pourquoi, 117.

Ojeda. Alphonfe de Ojeda, Capitaine Efpagnol, fon caractere, I 20. 295. Il découvre les Mines de Cibao, 121. Il eft chargé de défendre la Fortereffe de Saint Thomas,

- 25. De quelle maniere il fe faifit de Caonabo, I30. I3 I. Il découvre l'impieté de quelques Indiens, I3 I. Il part d'Efpagne, pour faire des découvertes, 186. Succès de ce Voyage, 187. Il paffe à l'Ifle Efpagnole, fa conduite avec 'Amiral, I 88. \& $\int_{0}$ Il entre- prend un fecond Voyage avec Americ Vefpuce, qui fe brouiille avec lui, \& le fait mettre aux fers, 2i 6 . Rifque qu'il courre en fe fauvant, 217 . Il eft fait Gouverneur de la nouvelle Andaloufie, 283. Il fe broüille avec Nicueffa, \& le défie, 284. Il menace le Gouverneur de la Jamaïque, \& met à la voile, 185 . Ses avantures à la Côte de Carthagene ,289. Il bâtit la Ville de Saint Sebaftien, 29i. Il eft bleffé d'une Fléche empoifonnée, 292. Etrange maniere, dont il fe guérit, 293. II s'embarque pour l'Ifle Efpagnole, \& 11 eft mis aux fers dans fon Navire, la même. II eft dégradé dans l'Ifle de $\mathrm{Cu}$ ba, ce qu'il y eut à fouffrir. Sa dévotion envers la Mere de Dieu, 294. Il arrive à la Jamaïque, \& paffe à l'Ine Efpagnole, où il meurt miferable, 295.

Alphonse de Ojeda, différent du précedent, enleve des Indiens dans le Continent de Y'Amérique, 4I2. Il y périt dans une Embufcade, 413 . Olano. Lopé de Olano, Lieutenant de Nicueffa, l'abandonne, \& par-là eft caufe de prefque tous fes malheurs, 302 . Nicueffa lui fait grace de la vie, \& le retient prifonnier. 303.

Olid.'Chriftopble de Olid, eft envoyé pour fçavoir des nousV u u ij 


\section{T A B L E}

velles de la Flotte de Grijalva; un coup de. Vent l'oblige à retourner à l'Ifle de Cuba , 380. Il commande un des $\mathrm{Na}$ vires de la Flotte de Cortez, 389.

Ophir. Voyés Vatable.

Opinion, preuve fenfible que c'eft l'opinion des Hommes, qui met le prix aux choles, 95.

Or, comment les Indiens fe difpofoient à chercher de l'Or, 47.243.

oracles, les fauffes Divinités des Infulaires de $l^{2} E$ fpagnole rendoient des Oracles, 54. Fourberie à ce fujet, $\quad 55$. Ordaz. Diego de Ordaz. Veiafquez lui ordonne de prêter main forte à fon Envoyé contre Cortez, 389.

Pierre de Ordaz paffe en Canot de l'Ifle de Cuba à la Jamaiqque, pour y demander du fecours en faveur d'Ojeda. 295.

Orenoque, grand Fleuve du Continent de l'Amérique. Force de fon courant, 167.168 . Oriftan, Ville ou Bourgade de la Jamaique,

407.

Orozco. Francois de Orozco eft chargé de l'Artillerie, pour la Conquête de la nouvelle Efpagne,
Ortiz. Dom Diego Ortiz, Evêque de Ceuta. Autrement, Le Doctenr Calcadilla, fa mauvaife foi à l'égard de Chriftophle Colomb,
Ortolans de l'Ifle Efpagnole, 29 . Aruba, Ifle de la Côte de Venezuela, Jean d'Ampuez s'en empare, 450. Il s'y retire , $\&$ pourquoi, 452. Oüan. Voyés San-Ö̈an, 64 . Ovando. D. Nicolas Ovando. Commandeur de Larez, puis grand Commandeur d'Alcantara. Envoye découvrir un Lac de l'lifle Efpagnole, 19. Il eft nommé Gouverneur General des Indes, 207. Ses inftructions, 208. 209. 210 . Il arrive à San-Domingo, 210. Sa conduite en arrivant, $2 \mathrm{Ir}$ 。 Il fonge à bâtir des Villes \& des Bourgades, 212. Il refure de recevoir Chriftophle Colomb à San-Domingo, \& pourquoi, 214 . 219 . Il méprife un avis, que cet Amiral lui donne, 215. Il oblige les Infulaires à travailler aux Mines, en les payant, 317. Il envoye des Troupes pour réduire la Prow vince du Higuey, 220. Il rebâtit San-Domingo, \& le place $\mathrm{mal}, 222$. Il $\mathrm{y}$ fait conftruire une Citadelle, \& un Hôpital, 225. Il écrit en Cour au fujet des. Infulaires, 227. La réponfe, qu'on lui fait, 226. Il établit les Départemens d'Indiens, la même. Eloge de de fon Gouvernement. Il bâtit deux Monafteres de Saint François., 229. Nouveaux ordres, qu'il reçoit de la Cour: il trouve le moyen de les éluder, 230. Il reçoit des plain- 


\section{E S M T I ER E S.}

tes contre la Reine de Xaragua, \& prend la réfolution de fe tranfporter fur les lieux, $23 \mathrm{r}$. Réception, que lui fait la Reine: il fe perfuade qu'elle a effectivement de mauvais deffeins contre les Efpagnols, 232. Il fe faifit de fa perronne, 233. Il la fait pendre, Cruautés,qu'il exerce contreles Sujets de cette Princeffe, 234 . Il fonde plufieurs Villes, 235 . 236. Son infenfibilité, en apprenant que Chriftophle Colomb étoit dégradé à la Jamaique, 248. Il lui fait fçavoir de fes nouvelles d'une maniere, qui fent l'infulte, 252 . Il l'envoye chercher, 255 . Réception, qu'il lui fait, 256 . Il recommence la guerre dans le Higuey, 263. Ce qu'on difoit. de bien $\&$ de mal de fa maniere de gouverner, 265 . Il s'oppole envain à ce qu'on donne des Départemens aux Seigneurs de la Cour, 266. II remedie au concubinage, qui s'étoit introduit dans l'Ifle Efpagnole, \& propole d'y tranfporter les Habitans des $\mathrm{Lu}$ cayes; 268. De quelle manjere il garantit. Bernardin de Sainte Claire de fa ruine entiere, 270. Il eft rappellé , 271. Caufes de fon rappel, 272. Il eft regretté dans les Indes, 273 . Il eft bien reçû à la Cour, 274. Pourquoi il s'oppofe à ce qu'on introduife
desNegres dans les Indes, $28 \%$.

Oviedo. Gonzale-Fernandez d'Oviedo y Valdez, Autheur d'une Hiftoire des Indes, ce qu'il dit'du Lac Xaragua, 18. Ce qu'il dit des moeurs des Infulaires de l'Efpagnole, 42 。 Et de l'origine du mal de $\mathrm{Na}$. ples, 44 . Il croit que les Antilles font les $\mathrm{Hefperides,} \mathrm{\&} \mathrm{fes}$ imaginations à ce fujet, 68 . Comment il raconte la maniere, dont une des Caravelles de Chriftophle Colomb l'aban: donne, 100. Voyés 128. I 3 1. 138. 163. Ce qu'il dit à Charles-Quint de la Ville de San-Domingo, 225 . Ce qu'il dit au même Empereur au fujet de Chriftophle Colomb, 261. Il parle mal de Las $\mathrm{Ca}$ fas, 42 I. Il paffe dans la Caftille d'Or, \& en quelle qualité, 434 . Il fe brouille avec $\mathrm{Pe}$ drarias, \& repaffe en Caftille: 457. Il eft chargé de tranfporterles Habitans de Sainte Marie l'Ancienne à Panama, 439. Ce qu'il raconte de la mort de D. Diegue Colomb, 442 。 Ouragan, origine de ce terme, 53. Ce qui fait ceffer les Ouragans fur la Côte du Sud de l'ifle Efpagnole, $275^{\circ}$

Ozama, un des grands Fleuves de l'Ifle Efpagnole, 17. 225.

Oyes, particularités de ces Oifeaux dans l'Ifle Efpagnole, 29. 


\section{T A B L E}

\section{P}

1 Acheco. Catherine Suarez

1 Pacheco. Cortez l'époufe, malgré les Parens de la Demoifelle,

Zadilla. Le P. Garcias de Padilla, Francifquain, eft propofé pour l'Evêché de Larez, 309. 310. Eft nommé premier Evêque de San-Domingo, 310.347 .355$. Pagurus, efpece de Cancre, 22.

Paix. Le Port de Paix, fon premier nom, fa fituation, 5 . Palacios Rubios. Le Docteur Palacios Rubios, eft chargé de convenir avec Las Cafas d'un Reglement pour les Indiens, 335 .

Palencia. Voyés Fonfeca.

Palmier, particularités de cet arbre,

16.

Palos. Port de l'Eftramadoure,

79. Il avoit les meilleurs $\mathrm{Ma}$ -

telots de l'Efpagne du têms de Chriftophle Colomb, qui s'y embarque, pour la découverte du Nouveau Monde,

80 .

Panama, fondation de cette Ville,

438.

Province de Panama, $\quad 436$.

Pani, Riviere de l'Ifle Efpagnole,

19.

Panuco, Province de Panuco, $38 \mathrm{r}$.

Paon, où ces Oifeaux fe trouvent dans l'Ifle Efpagnole, 29.
Paradis. Paradis des Infulaires de l'Efpagnole, 59. Le $\mathrm{Pa}$ radis terreftre placé dans l'Ifle Efpagnole, 69. Idée de Chriftophle Colomb fur le $\mathrm{Pa}$ radis Terreftre, 168 .

Paria, Côte du Continent de l'Amérique, fa découverte, I66.

Paros, une forte de Monnoye Efpagnole, 3 II. Pafmo, forte de Maladie, 224. PafJamonté. D. Micbel de Pafsamonté, bâtit un Hôpital à SanDomingo, 225. Eft envoyé à.l'Ifle Efpagnole, a vec le titre de Thréforier General, \& pour y adminiftrer la juftice, 270. Il eft ennemi déclaré de l'Amiral D. Diegue , 330. II demande au Roy la permiffion de paffer en Efpagne, \& la réponfe qu'il en reçoit, $34 \mathrm{I}$. Les PP. Jeronimites font de grandes plaintes de lui , 352 . Ii protege Velafquez contre l'A miral, 366. Il contribuë à la difgrace de Figueroa, 408. Il rend de mauvais fervices à l'Amiral, 424. Balboa s'affùre de fa protection par des prefens, 428. Il figne des Provifions de Capitaine General en faveur du même Balboa, 430 . Sa mort, $44 \mathrm{r}$.

Patate. Racine, qui fait une des plus ordinaires nourritures dans 'Amérique, 5o. Diverfes efpeces de Patates, 5x.89. Pedrarias. D. Pedrarias Davila. plaintes de Las Cafas contre 


\section{DES M A T I E R E}

\üi, 357. \& de l'Evêque du Darien, 358. Il eft nommé Gouverneur de la Caftille d'Or, 433. Il arrive à Sainte Marie l'Ancienne, 434. De quelle maniere il eft reçû, 435. Il fait faire le Procès à Balboa, la même. Sa mauvaife foi à l'égard de Balboa', 436. Il lui fait couper la tête, 437. Avis, qu'il reçoit de la part des PP. de Saint Jérôme, la même. Cruautés, qu'il exerce contre les Indiens; il tranfporte la Ville de Sainte Marie l'Ancienne à Panama, 438 . Il fonge à la découverte du $\mathrm{Pe}-$ rou, \& à l'Etabliffemeut fur le Lac Nicaragua, 439. Rerdrix dans l'Ifle Efpagnole. 29.

Perez, Matelot Efpagnol, qui le premier découvre l'Ifle de la Trinité, 164 . Perez. Rodrigue Perez,, Sergent Major,

Perles, découverte de la Pêche desPerles, I 68. 169.277. 432.

Berou, premieres notions du $\mathrm{Pe}$ rou données aux Efpagnols, 429. Traitté pour la découverte de ce grand Pays. D'où vient le nom de Perou, 440.

Perroquets, font naturels aux Ifles de l'Amérique, 30. $\mathrm{Ma}$ nieres de les prendre, 46 . On en apporte un grand nombre aux Efpagnols,

Perroquets de mer,

87 Pers. Le P. Fean-B. le Pers Je- fuite. Voyés la Préface. Ce qu'il dit du Lac Xaragua, 1 8. Ce qu'il dit du Colibry, 32 . Pêcbeurs ou Aigrettes, Oifeaux, 30.

Petun. Voyés Tabac.

Philippes $I$. Roy d'Efpagne, arrive en Efpagne. L'Amiral lui envoye fon Frere, 259.

Pians, forte de Maladie, qui fait périr beaucoup de Volailles,

Picardie. Des PP. Francifquains de Picardie vont aux Indes, en qualité de Miffionnaires, 342 .

Pic-vert de l'Ifle Efpagnole, 29.

Pilote, forte de Poiffon, 2r.23.

Piment Voyés Axi.

Pinçon. François-Martin Pin çon, Pilote de la Pinta, une des Caravelles, qui firent la découverte du Nouveau Monde,

80.

Martin Alphonfe Pinçon, Commandant de la Pinta, 80 . Il s'imagine avoir vâ la Terre. 8I. Il quitte Chriftophle $\mathrm{Co}$ lomb, 9o. Il le rejoint, \& ce qu'il avoit fait pendant fa féparation, I00. Son arrivée en Efpagne, 105. 106, Sa mort, 106.

Vincent Yanez Pingon, Commandant de la Niña, $80^{\circ}$ II fecoure à propos Chriftophle Colomb,

pins. Ifle des pins, 95. 238.

Pinta. Voyés Pincon.

Pintades. Poules Pintades originaires de l'Ifle Efpagnole, 


\section{T A B L E}

leur différence de celles de Gainée,

29.

Pife. Bernard de Pife, confipire contre Chriftophle Colomb, qui l'envoye prifonnier en Efpagne,

122.

Pizarre. Francois Pizarre, Ojeda le laiffe Commandant à Saint Sebaftien, 293. Il s'embarque pour retourner à l'Ifle Erpagnole, 296. Encifo l'oblige à retourner à Saint Sebaftien, 297. Il accompagne Balboa dans fes Conquêtes, 428. Il s'offre pour. la Conquête du Perou, 439 . Son affociation avec Fernand de Lucques, \& Diego de Almagro, 440.

Catberine Pizarro Altamirano, Mere de Fernand Cortez.

383.

plata. Monte di Plata, 100. Platon, Ce qu'il dit de l'Ifle Allantide, 66. \& de ce qui étoit au-delà ,

67.

Playa. Puerto de la Playa, 164 .

Pluyes, particularités fur tes

Pluyes de l'Ifle Efpagnole, ro.

Poifon, effet extraordinaire d'un poifon,

Poiffons qui fe trouvent fur les

Côtes de l'Ifle Efpagnole, 21 .

Dommes de mer, forte de Coquillages,

$2 \pi$.

Pompes d'eau, ce que c'eft, $24 \mathrm{I}$.

Pontevedra, Cavalier Efpagnol, défarmé par un Indien, 22I.

Parcello. Vasco Porcello, prétend au Commandement de la Flot-

te deftinée à la Conquête de la nouvelle Efpagne, $\quad 382$. Porcelaine, forte de Coquillage, 2 I.

Porras. François de Porras, Capitaine d'un Navire de la derniere Efcadre de Chriftophle Colomb. Difcours infolent, qu'il tient à cet Amiral, 248. II fe révolte ouvertement, \& ce quile rendoit fi hardi, 249 . II $s^{\prime}$ embarque envain jufqu'à trois fois, pour paffer à l'Ifle Efpagnole, ce qu'il dit aux Infulaires contre l'Amiral. 250. Sa conduite à leur égard, 351. De quelle maniere if répond aux avances de l'Amiral pour le regagner, 253 . 154. Il eft défait \& pris par D. Barthelemy Colomb , 254 . Ovando le délivre malgrél'Amiral,

256 .

Port du Prince dans l'Ifle du Cuba,

Portobelo, fa fituation, origine de ce nom,

25.

Portocarrero. Alphonfe Fernand de Portocarrero, Commandanr d'un Vaiffeau de la Flotte de Cortez, 389. Il eft fait Alcaide de la Vera-Cruz, 390. II eft Député au Roi d'Efpagne, pour l'informer de tout ce qui s'étoit paffé, foit dans l'Ifle de Cuba, entre Velafquez \& Cortez, foit dans la nouvelle Efpagne, 392. Portoplatte, autrement Puerto di Plata, 100. IOI. Pertoric. Voyés Boriquen, $\mathrm{IOI}$. 


\section{E S M A T I R E S.}

Chriftophle Colomb découvre cette Ifle, r o r. Illa vifite, I I 4 . I I 5. Defcription de cette Ifle, 277. On y trouve des Mines d'Or, \& elle eft mife fous le joug, 278. Elle fe révolte, 279.280. 281. Elle eft affujettie de nouveau, 28 r. 282 . Potonchan, Bourgade de l'Yucatan, les Efpagnols y font battus, 369. Grijalva y' eft bleffé, 474 . Pourpier, Legume, 50. pourpre, forte de Coquillage, $2 \mathrm{r}$.

Poux de Bois. Voyés Chique, Nigua.

Predicateurs du Roi, démarche hardie, qu'ils font à l'inftigation de Las Cafas, 354. \& Juiv.

'Prêtres de l'Ifle Efpagnole, 57. $\&$ de l'Yucatan, $\quad 369$. Proceffion des anciens Infulaires de l'Efpagnole. Voyés la Vignette du premier Livre, \& la page 56.

Procureurs, ils font exclus des Indes, \& pourquoi, 142 . Providence, Ine de la Providence,

Puerto Bueno, Port de la Jamaique, mal nommé, 246 .

Puerto de los Hidalgos, ou Porta de los Cavalleros, I 23.

Puerto di Baftimentos, nommé depuis Nombre de Dios, 240.304.

Puerto di Plata, roo. ror. l'Amiral \& fon Frere le vifitent à deffein d'y faire un Etabliffement, I39. Ovando re: Tom. $I$ 。 prend ce deffein, 218. \& l'execute, 226. Etat floriffani de ce Port, 406. Il eft démoli, $48 \mathrm{r}$.

Puerto Real, autrement Baye de Caracole, Chriftophle Colomb y fait naufrage, 95. On y fait un Etabliflement, 236. On tire de l'Or des Mines voifines, 306.

\section{Q}

Vevedo. D. Fean de Que-
vedo, Francifquain, premier Evêque de la Terre-Ferme de l'Amérique, 358. La difpute s'échauffe entre lui \& Las Cafas, au fưjet de la maniere, dont il faut traitter les Indiens, 359. Son difcours en préfence de Charles-Quint, 360. 36r. Il veut parler de nouveau, \& on ne le lui permet pas, 364. Sa more, 365. Ò̀ étoit le fiege de fon Evêché,

433.

Quibia, Cacique du Veragua, 24r. D. Barthelemy Colomb lui rend vifite, \& ce Cacique le trompe, 243. D. Barthelemy le fait prifonnier, il fe fauve, \& brûle la Bourgade E[pagnole,

$244 \%$

Quint. Le Quint, droit du Roi d'Efpagne, 212 . Il eft réduit au Dixiéme, 409. Quirquey \& Quirqueya, fignification de ces termes. 


\section{T A B L E}

\section{R}

R Acines, de quelle maniere 1 les Arbres jettent leurs Racines dans l'Ifle Efpagnole, I5. C) fuiv.

Ramiers, 28. Ramirez. D. Sebaftien Ramirez de Fuente Leal eft nommé Evêque de San-Domingo , \& Prefident de l'Audience Royale, 444. Eloge de ce Prélat, 445. Son attention à remedier aux abus , 456. \& fuiv. Il envoye beaucoup d'Orà l'Empereur, 460. Il eft fait Prefident de l'Audience du Mexique, $46 \mathrm{I}$. Rancheria. La Rancheria, Bourgade du Continent de l'Amérique, auprès de laquelle on pêche des Perles,

277.

Ravet, forte de Hanneton de l'Ifle Efpagnole,

35 .

Rayes, Poiffons,

$2 \mathrm{I}$.

Religion des Infulaires de l'Efpagnole,

53. \& Suiv.

Remora, Poiffon, 23. Remy. Le P. Remy, Francifquain, va trouver le Cacique Henry, $\&$ ce qui lui arrive, 401 . \& fuiv. Hl y retourne, \& avec quel fuccès,

446. Retrete. el Retrete , Port du Continent del'Amérique, d'où vient ce nom, \& ce qui fe paffe en cet endroit, 240 .

Rbinoceros, forte d'Efcarbot. Sa defcription, 33.34 . Riquille, ou Etang falé, I8. Ig.
Riviere de l'Ifle Efpagnole, riz. $6 \mathrm{r}$.

Roche, Poifion de Roche, 24. Rocbefort. Le Miniftre Rochefort, fon fentiment fur l'origine dus. mot d'Antilles, 20. Voyés 42 . Rocon, les Infulaires de l'Efpagnole fe frottoient de Rocou, $\&$ l'effet que cela produifoit , 36.

Rodrigue, Cacique Indien, il va pour faire ceffer la guerre du Cacique Henri o \& les Révoltés le font pendre, 446 . Roldan. François Roldan Ximenez, il eft nommé Alcaide Major de l'Ifle Efpagnole. fon caractere, 153 . Il fe révolte $\&$ fait foulever les Indiens, 154. I5.5. Il tente de s'emparer de la Conception: fon entrevtië avec D. Barthelemy Colomb, 155. Son entrevîe avec Coronel, 156 . Il débauche des Efpagnols nouvellement débarqués, I 7 I. L'Amiral effaye de le gagner, 172 . \& Suiv. Il lui écrit, I 75 . Suite de la négociation, 177. II trouve de l'appuy à la Cour, 180. Son entrevûë avec l'Amiral; il attaque de nouveau la Conception; il concluë un accord avec Carvajal; ce quile fait rompre, 182. Nouvel accord executé, I83. Ce qui fe paffe entre lui \& Ojeda, I 88 . \& fuiv. Bovadilla le comble d'honnêtetés, I99. 20 r. 11 ef? rappellé, 208. Ovando informe contre lui, 2II. Sa 


\section{DES M A T E R ES.}

mort,

215. gée en Evêché,

Romain mite, prêche la Foi dans les Etats de Guarionex, 150.

Romero. Pierre Romero, Officier Caftillan, eft envoyé pour ratifier le Traitté fait avec le Cacique Henry,

Rofées, force des rofées dans

l'Ifle Efpagnole,

12.

Rolfignol, Oifeau de l'Ifle Efpagnole, affés peu femblable à notre Roffignol, 30.42 .

\section{$S$}

Acrifices, Ifle, ou Caye des

Sacrifices. D'où vient ce nom,

379.

Sailler. Barthelemy Sailler.

Lieutenant d'Alfinger, 452. 453.

Saint Blaife. Le Cap Saint Blaife, fa fituation, 245 . Saint Cbriftophle. Ifle de Saint Chriftophle, une des petitesAntilles. Découverte \& nommée par Chriftophle Colomb, I 14. Mines de Saint Chriftopble, $\mathbf{3} 39.265$.

Montagnes de Saint Chriftophle,

243.

Saint Dominique. Le P. Alphonje de Saint Dominique, Jeronymite, un des Commiffaires envoyés aux Indes,

Saint Efprit, Ville de l'Ine de Cuba, $38 \%$ Saint 7 ean de Ponoric, Ifle, I 14 . Voyés Portoric. La Ville de Saint Jean de Portoric eft éri-

Michel, Saint Michel, Genilhom2。 Saint Michel, Gentilhomme Efpagnol, eft envoyé contre le Cacique Henry, il convient avec lui d'une entrevîë, 447 . II la manque par fon imprudence,

Saint Nicolas. Port \& Mole Saint Nicolas,

Saint Romain. Le Cap Saint Romain,

450 .

Saint Sebaftien, fondation \& fituation de cette Ville, 29I. Elle eft brûlée par les Indiens, 297.

Saint Thomas, Port de l'Inle Efpagnole. Ses autres noms, 93 . Fort de Saint Thomas, bâti pour la fûreté des Mines de Cibao,

124.

Sainte Catherine, Port de l'Ifle de Cuba, 90. Sainte Claire. Bernardin de Sainte Claire Thréforier, amaffe des biens immenfes, fon luxe infenfé; on lui fait fon procès. Ses biens font vendus, $\&$ on trouve moyen de les lui conferver,

270.

Sainte Croix. Voyés Cozumel.

Sainte Helene. Cap Sainte Helene, fa fituation,

Sainte Marre. Port Sainte rie,

Sainte Marie, nom que Chriftophle Colomb donna à la Capitane, qu'il montoit , lorfqu'il découvrit le Nouveaus Monde,

So. 


\section{T A B L E}

Sainte Marie, une des Ifles Açorres, ce qui y arrive à Chriftophle Colomb, 103. Sainte Marie l'Ancienne, Ville bâtie furle Darien, ainfi nommée en vertu d'un Vœu, 300. Voyés Quevedo. Elle eft abandonnée, \& les Habitans tranfportés à Panama, 438.

Salfons, différence \& partage des Saifons dans l'Ille Efpagnole,

I3.

Salamanca. Diego de Salamanca, Maître d'Hôtel de Chriftophle Colomb, quil'envoye à Bonao,

I 8 r.

Salamanque. Le P. Micbelde Salamanque, Dominiquain. Son difcours hardi en préfence du Confeil des Indes, 355 . Salvaleon de Higney, fituation \& fondation de cette Ville, 264 . Ponce de Leon, Gouverneur de Salvaleon, 278. On commence à y faire du Sucre, 406.

Salvatierra de la Savana, Ville Efpagnole, fa fondation, 236 . Ses Armoiries. Voyés Ar. moiries, cette Ville eft le rendez-vous pour la Conquête de Cuba, Salzedo, Domeftique de Colomb.

84.

Salzedo, les Infulaires, de Portoric le noyent, \& pourquoi,

280.

Diego Lopez de Salzedo, neveu du grand Commandeur Qvando, eft pourvân du Gou- vernement de la Fortereffe de de San-Domingo,

Fean de Salzedo, eft envoyé par Velafquez aux PP. de Saint Jérôme, \& pourquos, 382.

Samana, prefqu'Ifle de l'Ifle Efpagnole, fa fituation, roI. Sancedo. François Sancedo, un des Capitaines de la Flotte de Cortez,

Sanchez. Rodrigue Sanchez, Contrôleur des Guerres dans l'Efcadre, qui découvrit le Nouveau Monde, 84. San-Domingo, Capitale de l'Ifle Efpagnole, fa fondation. Ori gine de ce nom, 146. Son autre nom, la même. Elle eft renverfée par un Ouragan, $217 \%$ Elle eft rebâtie magnifiquement, \& mal fituée, 222 . 223. Particularités de cett3 Ville, 224. 225. 226. Ouragans à cette Côte, 275. La Vilie eft érigée en Evêché , 276. Etat floriffant de cette Ville, 406. Elle eft propofée pour fervir d'entrepôt univerfel à toutes les Indes, 438. o fwiv. Elle eft érigée en Archevêché, 477. Elle eft prife \& pillée par les Anglois 480. 48r. Voyés. Audienco Royale.

San-Fuan de la Maguana, Ville Efpagnole, 62. 435 . 406 . Sandoval, Regidor, ou Confeiller de la Vera-Cruz, 390. San-Ö̈an, 62. Voyés San-Juar de la Maguana \& Maguea, 


\section{DES MA T I E R E.}

235.

San-Salvador, nom que donna Chriftophle Colomb à la premiere Ifle, qu'il découvrit, 85.

Santa. Ifa Santa,

165.

Santa-Cruz de Ycayagua, Ville Efpagnole, fa fituation, elle eft détruite, 264.

Santa Gloria, Port de la Jamaique, où les Vaiffeaux de Chriftophle Colomb échoiierent,

246.

Santa Maria de la Verapaz, fondation de cette Ville, 235 .

Santa Maria del Puerto, Ville Efpagnole, fa fituation, 235 .

Sant-Angel:Louis de Sant-Angel, fes bons offices auprès du Cardinal de Mendoza, \& de la Reine Ifabelle, en faveur de Chriftophle Colomb, 75. 76.

Santigliario. Alphonse de Santigliano, grand Commandeur, 212.

Sant-Yago, Ville Efpagnole: Sa fituation, 218.219.

Saomoto, Ifle des Lucayes, que Chriftophle Colomb nomma Ifabelle,

88.

Saona, petite Ifle à l'Eft de l'Erpagnole, 5. Elle fournit des vivres à San-Domingo. Le Cacique en eft dévoré par un chien, comment les Infulaires s'en vengent,

219.

Sargaffes, ce que c'eft, 23. Saturnin. Saint Saturnin eft invoqué pour faire ceffer: le fleau des Fourmis, $45 \mathrm{~T}$.

Saucedo. François de Saucedo va joindre Cortez,

Sauvages, étonnemetit des vages la premiere fois qu'ils virent les Européens , 86.87.

Scibo ou Zeïbo, Ville Efpagnole. Sa fondation, \& fa fituation, 264.

Sedition contre les Colombs à la Jamaïque, 24.8.

Seneque, prétenduë Prophetie du Poëte Seneque, fur la découverte d'un Nouveau Monde,

66.

Seneque le Pbilosophe, met en queftion, par maniere de difpute, fi l'Ocean n'eft pas infini,

73.

Serein, pourquoi le ferein incon-mode moins dans l'Ifle Épagnole qu'ailleurs, 13 . Serrano. Antoine Serrano, fon projet pour établir les petites Antilles. Ce quile fait échoiier, 4 I2.

Seville, Ville ou Bourgade de la Jamaique,

Seville, Ville d'Efpagne eft déclarée Métropolitaine des Indes, 3 ro. C'eft le feul Pors d'où l'on puiffe partir pour les Indes, 459. Sierpe. Canat de Sierpe, 167. Singes. Gros Singes dans le Continent de l'Amérique, I 66 . Sodomie, les Infulaires de 1'Epagnole étoient ils fujets à ce peché? $4 ? \cdot 43$. Il eft repréfenté dans l'Yucatan, 367 . Soldat, efpece d'Ecreviffe, $\mathfrak{f a}$ $\mathrm{X} \times \mathrm{x}$ iij 


\section{T A B L E}

defcription ,

23.

Solis. Antoine de Solis, Autheur

de l'Hiftoire de la Conquê-

te du Mexique, fe trom-

pe au fujet de la mort de

François Fernandez de Cordouë, 369 . Son fentiment fur le têms auquel Cortez $\mathrm{fe}$ broiille avez Velafquez, 387 . Songe, les Infulaires de l'Erpagnole voyoient fouvent en fonge les Démons,

Soto. Francois de Soto, Las Ca-

fas l'établit Commandant dans

fa Colonie, il n'execute pas les ordres, que le Licencié lui en avoit donnés, \& ce qui en arrive, 418 . Il meurt enragé, \& pourquoi,

419.

Soto Mayor. D. Chrifropble de Soto Mayor, eft nommé par leRoi Gouverneur dePortoric, \& ce qui l'empêche d'entrer en poffeffion de fon Gouvernement, 279. Il accepte la Charge d'Alcaide Major, \& fe dédit, la même. Sa Mort funefte, $28 \mathrm{I}$.

Succeffion, ordre des fucceffions dans l'Ifle Efpagnole, 49. Sucre, premieres Cannes de Sucre plantécs dans l'Ifle Efpagnole, 267. Toutes les Cannes de Sucre, dont la Vega Real furtout étoit pleine, meurent, 350. Endroits, où il fe fabriquoit du Sucre dans l'Ifle, 406. Grand Commerce de Sucre dans cette Ifle, \& ce qui en revenoit au Roi Catholique ,

Tabac, maniere de le fumer. 1 40. Origine de ce mot $4 \mathrm{I}$.

Tabaco, fignification de ce mot, $4 \mathrm{I}$.

Tabagie, origine de ce mot, $4^{\mathrm{T}}$. Tabafco. Voyés Labat.

Tabafco, Riviere, Grijalva y entre, \& ce qui s'y paffe, 375. \& Juiv.

Talavera. Bernardin de Talave$r a$ cherchant à fuir les pourfuites de la juftice, enleve un Bâtiment, fur lequel il arrive à Saint Sebaftien, 292. Il fait mettre Ojeda aux fers, 293. L'Amiral D. Diegue le fait pendre,

295.

Le P. Fernandez de Talavera, Jéronymite, Conferfeur de la Reine Ifabelle, fait une affemblée de Cofmographes, pour examiner le projet de Chriftophle Colomb, 73.

Tambour, defcription du Tambour des Infulaires de l'Efpagnole, 39.

Tapia. Chriftopble de Tapia eft nommé Gouverneur de la Fortereffe de San-Domingo, le Grand Commandeur refufe de le mettre en poffeffion, 273. Il eft mis en prifon, François de Tapia, Frere du précedent, eft nommé au même Gouvernement , 273 . L'Amiral refufe de lui ceder 


\section{DES M A T I E R E S.}

le logement, qui lui appartient, il repaffe en Efpagne, obtient la main-levée de fon logement, \& un département d'Indien, 274 . eft condamné à une amende par les PP. de S. Jérôme, 343. Tellez. Dom Alphonse Tellez, Confeiller d'Etat,

Iemple dans l'Yucatan, 367. 368. 373. \& dans la nouvelle Efpagne,

374.

T'erroir, diverfité étonnante du Terroir dans l'Ifle Efpagnole,

I5.

Tertre. Le $P$, du Tertre, Dominiquain, Auteur de l'Hiftoire des Antilles, fon fentiment fur l'origine du terme d'Antilles,

2. 42 .

Tiburon. Le Cap Tiburon, 69.

Tiburons, forte de Poiffons, 242.

Tigres font méchans, \& trèsforts dans la Coriane, 444 . Tlascala, Province de la nouvelle Efpagne, découverte par Grijalva, 382.

Tolede. D. Ferdinand de Tolede, Grand Commandeur de Leon, \& Grand Veneur de Caftille, donne fa fille en mariage à 1'Amiral D. Diegue Colomb, \& follicite auprès du Roi, en faveur de fon gendre, $27 \mathrm{I}$.

Doña Maria de Tolede", Fille du précedent, époufe l'Amiral D. Diegue Colomb, 271. Elle arrive à San-Domingo, 274. Elle paffe en Ef. pagne, 442. Elle marie une de Ses filles, 443 . Nowvelle Tolede, Ville de la Côte de Cumana, par qui elle fut bâtie, 415 . Elle eft abandonnée \& ruinée, 419 .

Tomaios, Capitaine Indien. II reçoit le Baptême,

Tominos. Voyés Colibry.

Torrez. Antoine de Torrez doit commander au retour la Elotte, qui conduit Chriftophle Colomb à l'Ifle Efpagnole, I I I. 11 eft chargé des Armemens pour les Indes, 161. Ovando laiffe une partie de fa Flotte fous fes ordres, 210 . Il fe perd dans un naufrage, 215.

Tortuë, Ifle, s. Chriftophle Colomb la découvre, \& pourquoi il la nomme ainfi, $9 \mathrm{I}$.

Tortuës, Ifles du côté de la Floride, par qui elles font découvertes, 324 . Tortuë, animal. Il y en a de deux efpeces, 23 .

Tourterelles, 28. Il y en a de différentes efpeces dans l'Efpagnole,

29.

Traditions des Infulaires de l'Erpagnole, 38. Traffierra, Le P. Fean de Traffierra, Francifquain rend à Chriftophle Colomb une Lettre du Roi Catholique, 197.

Tremblemens de Terre fréquens, \& peu dangereux aux environs du Fleuve Ozama,

Tribut impofé aux Caciques-de l'Ifle Efpagnole, I3 4 . Trinité. La Trinité, Ifle de l'Amérique, découverte par Chriftophle Colomb; pourquai cl- 


\section{T A B L E}

le fut ainfi nommée, 164 . Ses égard, $20 T_{\text {. }}$ Habitans font fort doux. Valparaï o, premier nom du Port Soins que fe donne Las Ca- de Paix, fas pour empêcher qu'on ne les enleve comme Cannibales, 349.

La Trinité, Ville de l'Ifle de Cuba. Ce qui s'y paffe à l'égard de Cortez, 387.388 . Trompes Marines, $24 \mathrm{I}$. Iruxillo, Ville de la Province de Honduras, 238.

Turques, Ifles Turques, leur fituation. Voyés Amanas.

Tufpa, Montagnes de la nouvelle Efpagne,

\section{V}

7 Aldenebro, Cavalier Efpagnol défarmé par un Indien, $22 \mathrm{I}$.

Taldivia. François Valdivia eft nommé Regidor de Sainte Marie l'Ancienne, 3०r. On l'envoye demander du fecours à l'Ifle Efpagnole, 427. fuccès de fon Voyage, 428. Il y retourne pour le même deffein, 423. Sa mort funefte, 430. $V$ alence. Plats de Valence, 169. Talençuele, Habitant de l'Ine Efpagnole ; il pouffe à bout le jeune Cacique Henry, qui étoit dans fon département, 396. 397. Il le pourfuit, \& il eft bleffé, 398. Tallejo. Alphon $\int e$ de Vallejo eft chargé de conduire en Efpagne les Colombs enchaînés, fes bonnes manieres à leur

Vargas. Le Licencié Vargas eft d'une Junte établie pour examiner la Caufe des Indiens, 456.

Vatable, ce qu'il dit de l'Ifle Efpagnole,

69.

Vega. La Vega Real, grande plaine de l'IIle Efpagnole. Son étenduë, fa fertilité, fa beauté, 6I. 124 .

$V$ ega, Bourgade de la Jamaique, 477 .

D. Fernand de Vega, Grand Commandeur de Caftille, eft du Confeil des Indes, 407. Nouvelle Vega. Sa fituation, 486.

Veginez. Fean de Veginez, $\mathrm{Ha}_{2}$ bitant de Sainte Marie l'Ancienne, trahit Nicueffa, 306. Vela. Cap de la Vela découvert par Ojeda, $\quad \quad \quad$ 88. Velafquez. Antoine \& Bernardin de Velafquez, parens de celui qui fuit, $\quad 382$. Diego de Velafquez eft chargé de pourfuivre les Indiens cantonnés dans les Montagnes de Baoruco, 235. Il eft envoyé à l'Ifle de Cuba, pour en faire la Conquête, 3 I5. Son caractere, 3 I6. Il fait fa defcente, \& acheve en trèspeu de têms la Conquête de toute l'inle, 317 . Etat floriffant de l'Inle de Cuba fous fon Gouvernement, 365. Il enwoye une Efcadre à la Découverte 


\section{DES M A T I E R E.}

couverte du Continent , 366 . Il arme une nouvelle Efcadre pour continuer les découvertes, ordre qu'il donne au Commandant, 37I. Il eft en peine de cette Efcadre, \& peu de têms après il en apprend des nouvelles; il s'emporte mal à propos contre le Commandant, 380 . Il le reçoit mal, fait un nouvel Armement, \& envoye demander aux PP. Jéronymites, la permiffion de faire des Etabliffemens dans la nouvelle Efpagne. Il a de la peine à fe déterminer pour le choix d'un Capitaine General de fa Flotte, 382. Quelles étoient fes prétentions; il choifit Fernand Cortez, 383. Ce qui s'étoit paffé auparavant entr'eux deux, 384. On lui prédit qu'il fe repentira de ce choix. Ce qui a voit le plus contribué à le tromper, 385 . L'Evêque de Burgos fe déclare fon protecteur, lui deftine fa Niéce en mariage, \& lui obtient la qualité d'Adélantade de l'Ifle de Cuba, \& $z$ des nouvelles découvertes, 386 . Il fe broüille avec Cortez, $\&$ fait envain plufieurs efforts, pour lui ôter l'emploi, qu'il lui avoit donné, 387.0 388. Il manque un Navire, que Cortez envoyoit en Efpagne, 390. Il reçoit avis que fes provifions font fignées ; mais que toute la Cour fe déclare pour Cortez, 392. Il arTome $I$. me une puiffante Flotte pour faire la guerre à Cortez , 393. l'Audience Royale de SanDomingo lui envoye faire défenfe de paffer outre, 393. 394. Il n'obéit pas, 394 . Il eft interdit, \& rétabli dans fon Gouvernement , 409 。 4Io. Il meurt de chagrin, 445 .

Fean Velasquez, Thréforier Royal, rend à Chriftophle Colomb une Lettre de Roi \& de la Reine d'Erpagne, 197. Fean Velafquez de Leon, parent de Diegue Velafquez, qui lui mande de prêter main forte à fon Envoyé contre Cortez. Il commande un des Navires de la Flotte de Cortez, 389 。

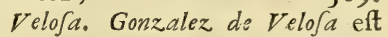
le premier qui fit bâtir un Moulin à Sucre dans l'Ifle Efpagnole, 267.

Velfers. Les Velfers, Bourgeois d'Ausbourg. L'Empereur Charles-Quint leur cede 12 Province de Venezuela pour les avances, qu'ils lui ont faites. Conditions de ce Traité,

Venezuela. Golphe de Venezucla, ou de la petite Venife, découvert par $O j$ jeda, d'où vient ce nom, 188. Voyés Coro, 326. Jean d'Ampuez fait un Etabliffement dans la Province de Venezuela, paricula. rités de ce Pays, 449. L'ErmY y y 


\section{T A B L E}

pereur le cede aux Velfers, 450. So juiv. Les Allemands y commettent de grandes cruautés, auffi bien qu'un Capitaine Efpagnol,

Vent de Terre, Cequi le produ $\&$ fes effets,

10.

Villa-Ricca de la Vera-Cruz, premiere Ville bâtie dans la nouvelle Efpagne, 3.79. Confeil de la Vera-Cruz, 390. Origine de ce nom, 39 I.

Veragua, Fleuve du Continent de l'Amérique, abondant en Or, 24r. Chriftophle Colomb y entre, 242. La pofterité de l'Amiral obtient le Titre de Duc de Veragua. 477.

Tera Paz. Voyés Santa Maria de la Vera-Paz.

Terdugo. François Verdugo reçoit ordre de dépofer Cortez de fa Charge de Capitaine General, 388. Velafquez eft fort irrité contre lui, parce qu'il n'avoit pas exécuté cet ordre, 389.

Verne. Abrabam de Verne, Commandant d'une Flotte Hollandoife, eft battu par les Efpagnols, $48 \mathrm{r}$. Terole. La petite Verole fait de grands ravages dans les Antilles, 349. Herrera prétend mal à propos, que cette Maladie étoit naturelle à ces Pays-là, 350. Verettes, plaine des Verretes. 18. 19. Vif-Argent. Mines de Vif-Ar- gent à San-Domingo, 224 Villalobos. Le Licencié Marcel de Villalobos. Auditeur Royat de San-Domingo, fait un Traité pour l'Etabliffement de l'Ine Marguerite, 44. Villaman. Martin de Villaman. Capitaine Efpagnol, eft établi Commandant d'une Fortereffe dans la Province de $\mathrm{Hi}$ guey, -22.2. Sa mauvaife conduite eft caufe du renouvellement de la guerre, \& il eft maffacré, 262.263 .

Vin. On fait de bon Vin à la $\mathrm{Ja}$ maique, 407. Les Indiens de Cumana font forts friands dés Vins d'Efpagne, 4i 15 . Ils en boivent avec excès, 417 Ulua ou Culna, Ifle de la nouvelle Efpagne, que Grijalva nomma Saint fean d'vlud. 379.

$V$ oleurs, fupplice, dontles Infulaires de l'Efpagnole les puniffoient, 48. Uraba. Golphe d'Uraba, 29 I. Vrira, Mines d'Urira, 243. Utias Quadrupede de l'Inle Erpagnole, 35. \& de l'Ifle de Cuba,

\section{$\mathrm{X}$}

89.

Y Anique, Riviere de la 1. Province de Cibao, 124. Xaragua. Lac de Xaragua, 18. 19. 465 . Royaume \& Ville de Xaragua, 62.170.231. On fonge à ériger en Archevêché la Ville de Xaragua, 309. Ximenés. Le Cardinal Frangois 


\section{E S M A T I E R E S.}

Ximenés de Cifneros, Francifquain, Archevêque de Tolede eft confulté fur les prétentions de Chriftophle Colomb, quel fut fon avis, 258. Il eft déclaré Régent du Royaume, \& fe détermine à envoyer des Commiffaires aux Indes, 335. \& Juiv. Il leur donne pour Adjoint un Adminiftrateur, \& fait Las $\mathrm{Ca}$ fas Protecteur General des Indiens, 341 . Sa mort, 346 。

\section{$\mathrm{Y}$}

$\checkmark$ Aguana, Ville Efpagnole 1 dans la Province de $\mathrm{Xa}_{\mathrm{a}}$ ragua, 235. Avantages de cette Ville, 406. Elle eft pillée par les Anglois, 48 $\mathrm{r}$. Les Efpagnols la démoliffent eux-mêmes, les Habitans fe tranfportent à l'Orient de l'Ifle, 48 I. 482.

Yaqué, grande Riviere de I'Ille Efpagnole, 17. Ses différens noms,

99. 123.

Yaquimo, ou le Port du Brefil, aujourd'hui Aquin, 188.236. Defcription de ce Port, 464. Ybarra. Le Licencié Ybarra arrive à San-Domingo, avec la qualité de Diftributeur des Indiens, \& meurt auffitôt, non fans foupçon de poifon, 332.

Ycayagua, canton du Higuey, 263.

Yebra, ou Riviere de Bethléem dans la Province de Veragua. 242.

rucatan, premieres notions de ce Pays-là , 238. Il eft découvert par François Fernandez de Cordouê., 37 . C fuiv. Variations fur ce nom, 370. Grijalva dans l'Yucatan, $\quad 372$. \& fuiv.

Yuna, une des grandes Rivieres de l'Ifle Efpagnole, $17 \%$ I 8 .

\section{Z}

7 Amudio. Fean de Zamu $\checkmark$ dio, Alcaide de Sainte $\mathrm{Ma}$ rie l'Ancienne, $30 \mathrm{I}$. Il eft fort animé contre Nicueffa, 306 . Il l'oblige à s'embarquer fur un méchant Bâtiment, 307. Balboa lui perfuade d'aller en Efpagne, \& pourquoi, 427 . Ce qu'il mande de la Cour à Balboa, 430. Zapata. Le Docteur Zapata, Confeiller d'Etat, fait nommer Albuquerque fon parent, Diftributeur des Indiens, 330. Il obtient en fa faveur un Brevet du Roi , 33r. Le Cardinal Ximenés le confulte fur les projets de Las Cafas . 335. Il soppofe aux intentions du Cardinal, qui lui en fait une verte reprimende, 341 .

Le Licencié Zapata, du Confeil des Indes, $347^{\circ}$ 


\section{TABLE DES MATIERES.}

Zemés ou Chemis, Idoles des Infulaires de l'Ifle Efpagnole, 54. 55. Oracles fur l'abolition de leur culte, $\quad 63$. Znazo. Le Licencié Alphonse Zuazo, eft envoyé Adminiftrateur aux Indes, 34r. Il arrive à San-Domingo, \& ce qu'il y fait, 343. Il a du deffous dans une occafion, 346 . Il arrête les papiers de l'Auditeur Luc Vafquez d'Ayllon; $\&$ il eft révoqué, 348 . Son

fucceffeur, 351 . Il eft calome nié, 352. Bon effet de fes foins pendant fon adminiftration, 407. Son fucceffeur veut lui faire fon Procès, \& il démontre fon innocence, 408. Il eft envoyé pour gouverner l'Ifle de Cuba, où il fe comporte avec la même droiture \& la même integrité qu’à San-Domingo, \& avec le même fuccès .

409.410.

Fin de la Table des Matieres du Premier Volume. 


\section{F A U T E S}

\section{A CORRIGER DANS LE PREMIER VOLUME。}

P Age 21. Ligne 25. Coral, lifés, Corail.
Page 27. Ligne 28. pates, lifés, pattes.

Page 32. Ligne I6. un peu plus petit, lifés, une fois plus petits.

Ligne 20. aux Efpagnols, lifés, aux Infulaires.

Page 6o. Ligne 9. de Dondon, lifés, du Dondon.

Page 62. Ligne 10. nous parlerons, lifés, nous avons parlé.

Page 107. Ligne Ix. grand Empire, life's, vafte Empire.

Page 109. Ligne 25. en-deftous, lifés, au-deffous.

Page 167. Ligne 1. de ce Cap, lifés, entre ce Cap.

Page 225. Ligne 21. y fit conftruire, lifés, fit conftruire à SamDomingo.

Page 234. Ligne 28. pieté, lifés, pitié.

Page 236. Ligne 11. 13. 20. Guahana, lifes, Guahaba.

Page 242. Ligne 20. la mauvaife, lifés, \& la mauvaife.

Page 262. Ligne 33. Villeman, lifés, Villaman.

page 271. Ligne 35. qui l'uniffoit, lifés, qui les uniffoit.

Ligne 31 . Donna, lifés, Doña.

Page 305. Ligne 22. de fon arrivée, ajoûtés prochaine.

Page 326. Ligne 11. Caro, lifés, Coro.

Page 372. Ligne 3. fi on ne l'eût arrêté, lifés, fî on ne l'eût pas arrêté.

Page 405. Ligne 17. de Mona, lifés, de la Mona.

Page 408. Ligne is. rappelle, lifés, rappella.

Page 415. Ligne 8. Gauzalés, lifés, Gonzalés.

Page 42 I. Ligne 20. vicieux, lifés, défectueux.

page 437. Ligme 11. le reconcilia, lifés, les reconcilia.

Page 440. Ligne 32. Villalabos, lifés, Villalobos.

Page 47. Ligne 27. Donna, lijés, Dořa. 







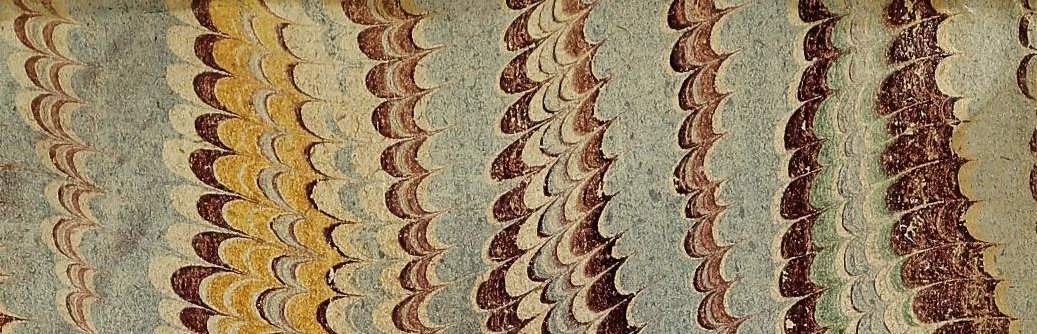

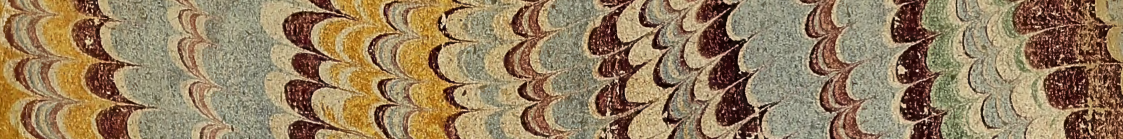
f(c) 10 f(a)

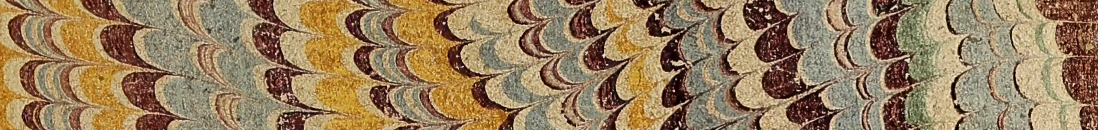

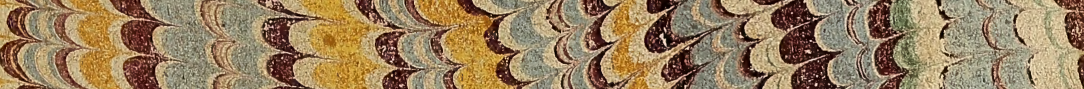

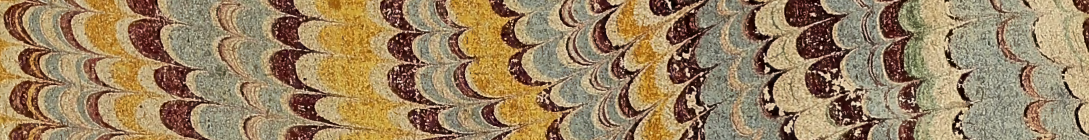
अ H.

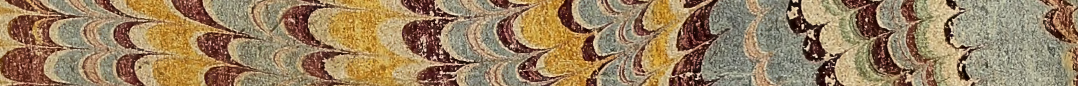

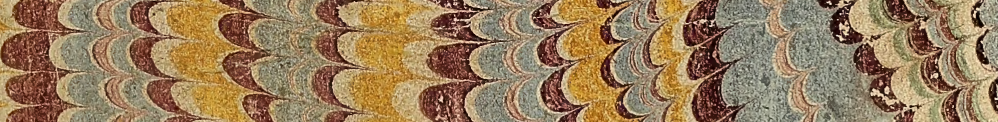

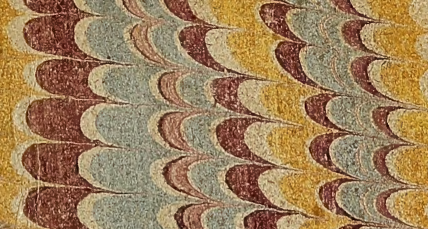

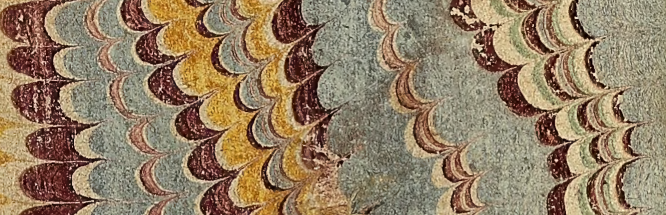
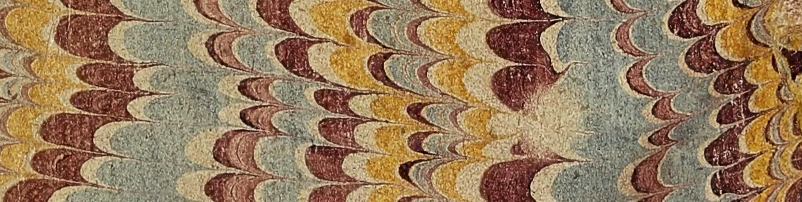

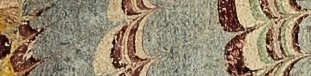

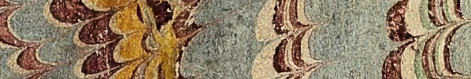

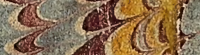

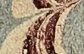

ix.
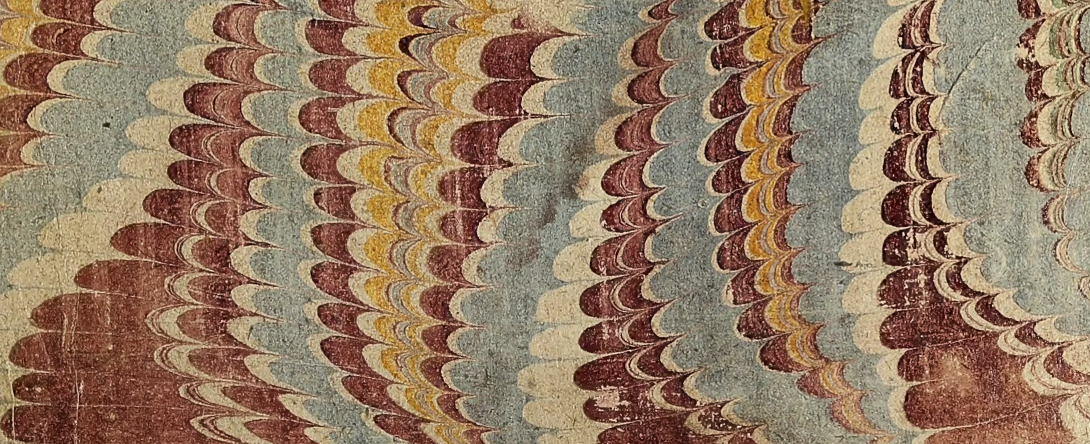
of 10

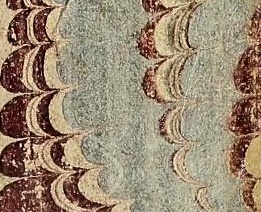
is 1 


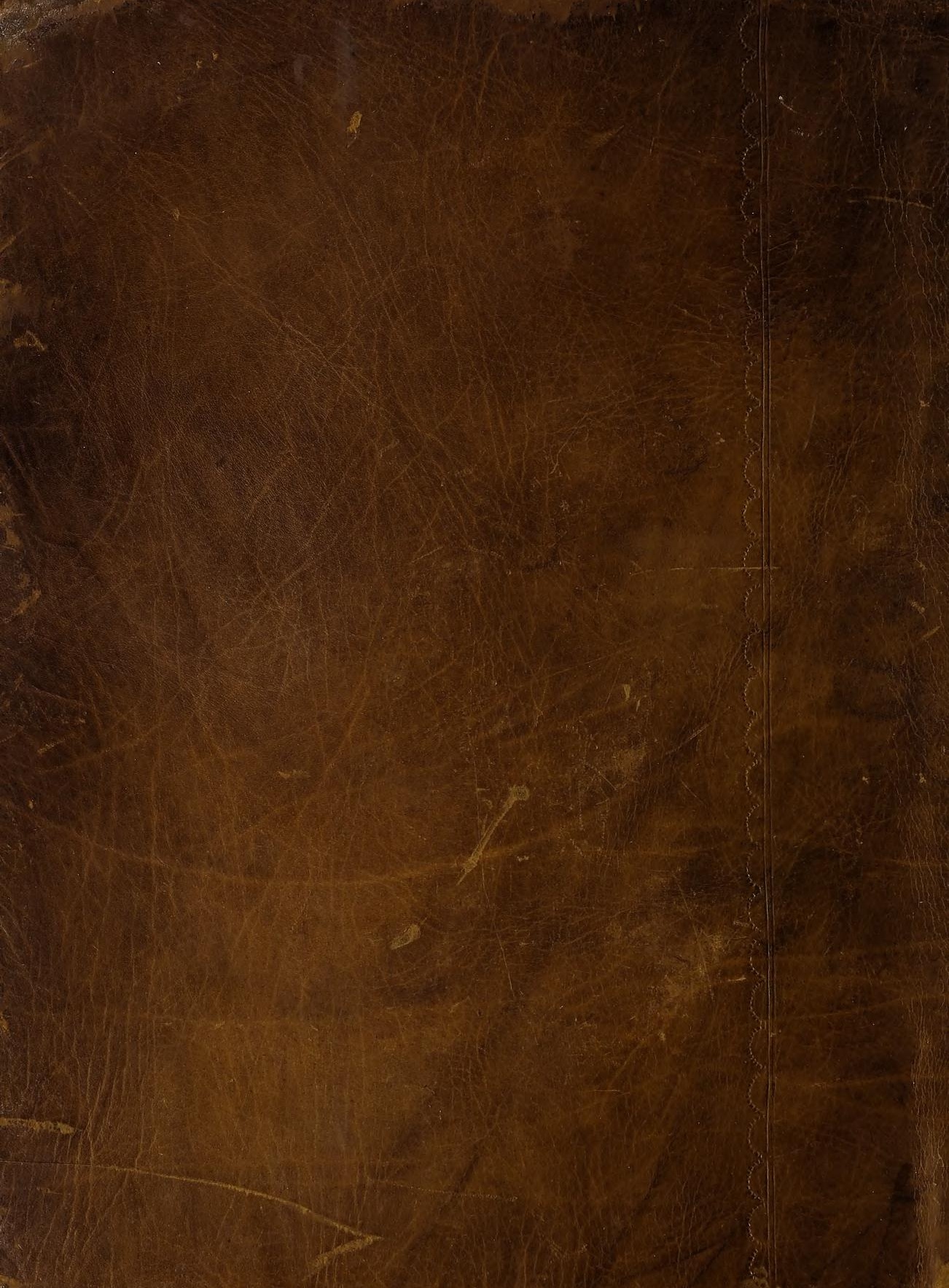

